
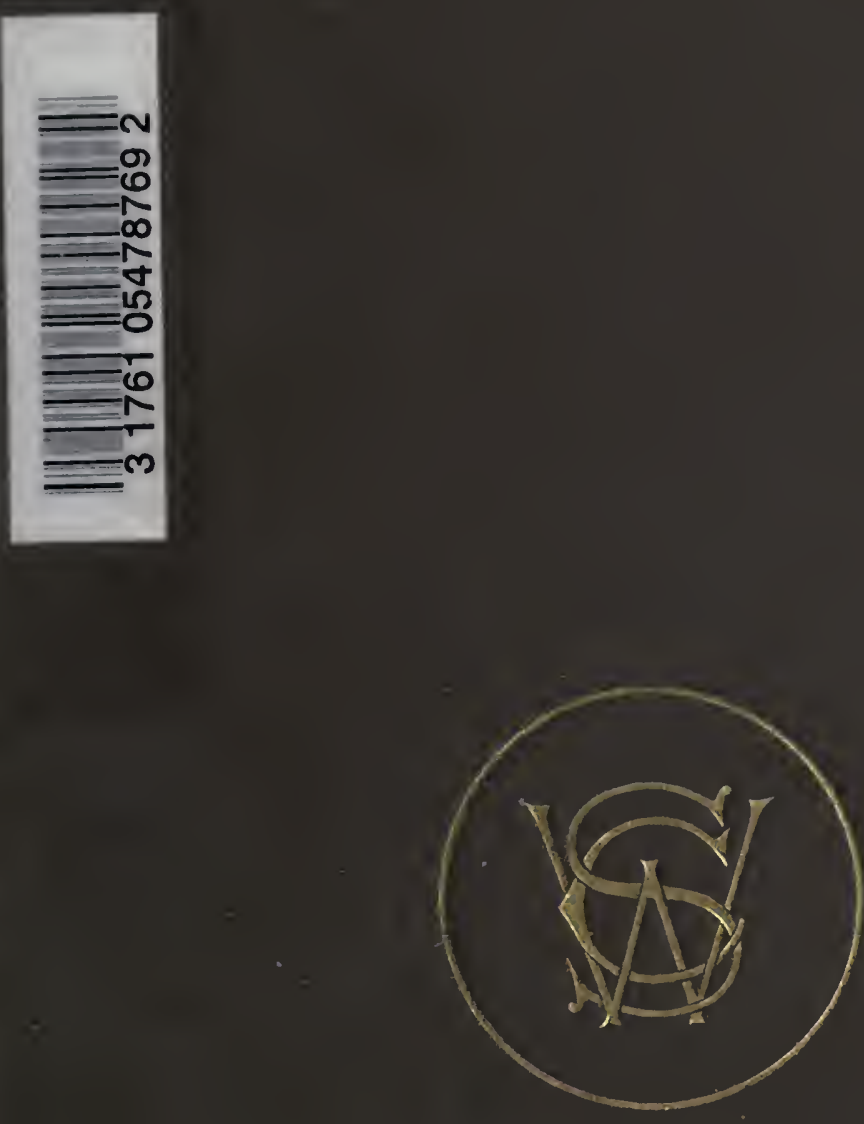
$(1,0)=$

ser

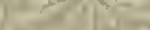

82

N.

$8 x^{2}$

政

\section{(5)}

ristion

(6)

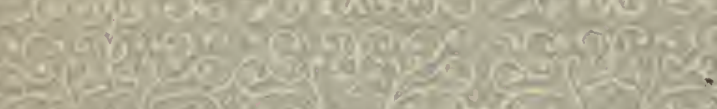

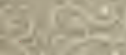

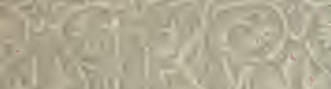

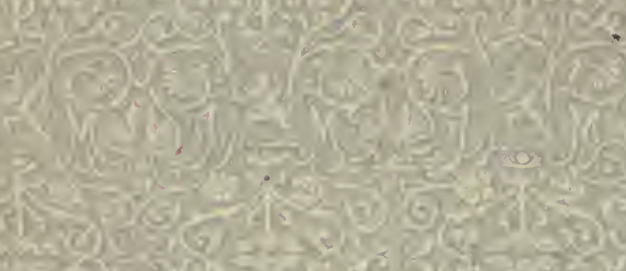

Q

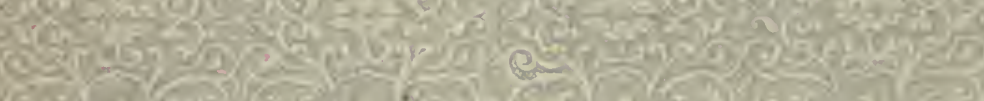

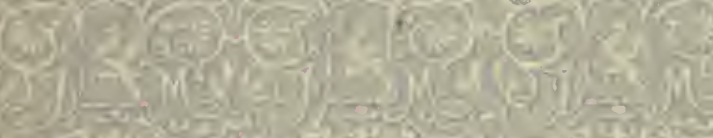

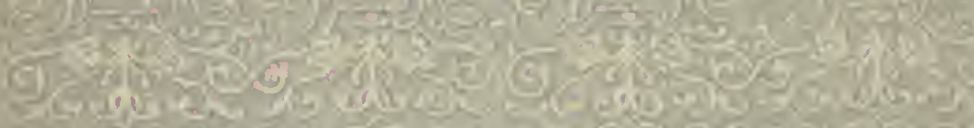

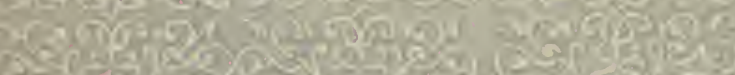

E. (2)

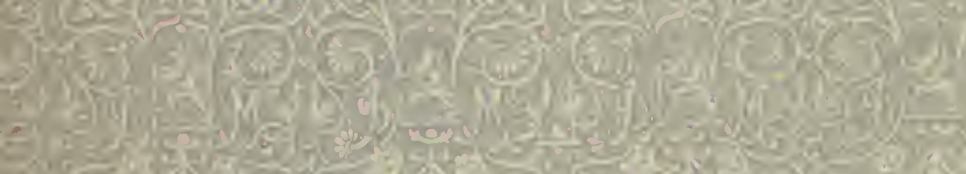

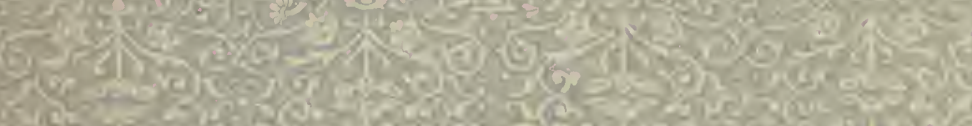

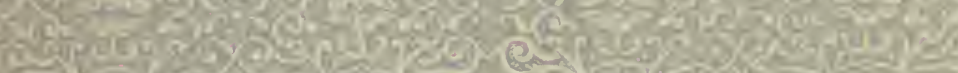

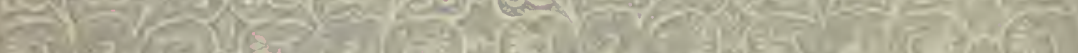

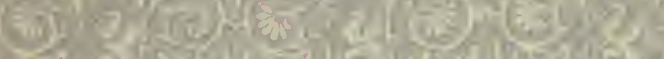

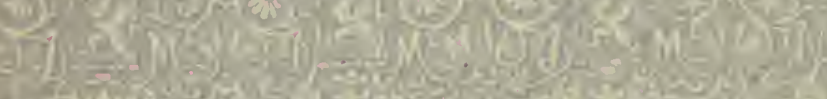

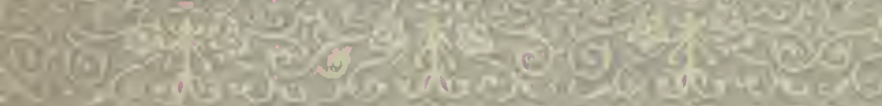

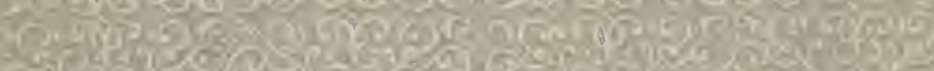

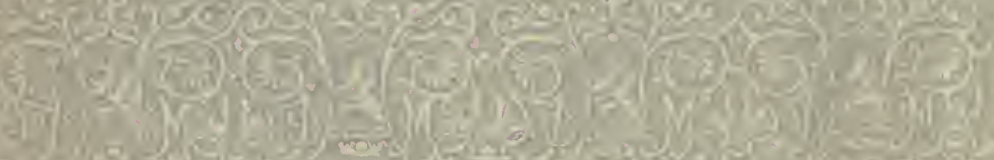

Nisile

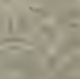

\section{.}





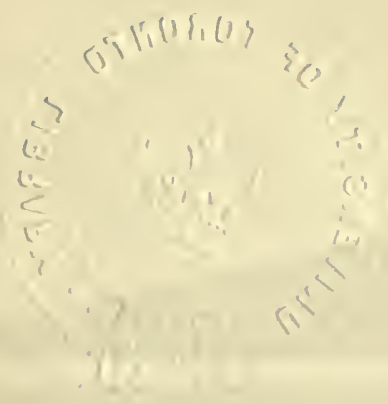

Digitized by the Internet Archive in 2007 with funding from Microsoft Corporation 

THE

\title{
SCIENTIFIC WORKS
}

\author{
OF \\ C. WILLIAM SIEMENS, KT. \\ F.R.S., D.C.L., LL.D. \\ CIVIL FNGINEER.
}




\title{
UNIFORM WITH THE PRESENT WORK.
}

\author{
With Portroits and Illustrations, 8vo, $16 s$.
}

\section{LIFE OF SIR WILLIAM SIEMENS, F.R.S.,}

D.C.L., LL.D., Nember of Council of the Institution of Civil Engineers. lyy WILLIAM POLE, F.R.S., Honorary Secretary of the Institution of Civil Engineers.

"For many yenrs Sir W. Siemens has been a regular attendant at our meetings, and to few, indeeil, lave they been nore indebted for suceess. Whatever the occasion, he had always new and interesting idens, punt forth in longuage whieh a child cullel mulerstand. It is 110 exaggeration to say that the life of such a man was spent in the pullit: serviee."-lonn Ra) Leigh at british Association, 1854.

"Mr. Pole had a straightforwand story to tell, and has told it in a way likely to interest anl instıuet a wide eirele of realcr's. Sir Williams bingraphy slows him to have been a man of high talent, which under effective discipline and the teachings of cxperienee, was stecessfully and profitably apjlicel in devising and carrying out undertakings which forne unarked features in the history of the period with which this biugraphy deals."-Times.

"So inseprarably comected is the career of this remaliable man with snme of the niost wonderful inventions of the past half-century, that the narrative of his life is in fact a listory of the progress, in this country, of applied science in the two great dejartments of heat and electricity. As Nir. Pole justly observes, he was a civil engineer according to the most comprehensive definition of that profession-the art of direeting the great powers in Nature for the use and convenience of Man."-Sicutsman.

"The most interesting book of the kind that we lave read since Nasmyth's delightful autobiography."-Saturtuy leviev.

"His suecess in life was doubtless due in no small degree to his inuate genius, but this would have been unavailing without the energy and determination which accompunied it. The recoril of his life and work should be read hy every stulent, and should be in the hibrary of every Mechanies' Institute in the country."-Builder.

"It is of much more than merely techuical or scientific interest . . . . his biographer with ahmirable skill maintains the personal interest of the uarrative throughout."-Manchester Gurdian.

"A story of great interest, one sure to become fimiliar in Englisl1-speak ing louseholds, as well as in those of Germany."-Liverpool Mercury.

"The book will be found full of instruction and interest."-Nuture. 


\section{5 \\ 557155}

THE

\section{SCIENTIFIC WORKS}

\section{WILLIAM SIEMENS, KT.} F.R.S., D.C.L., LL.D.

CIVII ENGINEER.

A COLLECTION OF

\section{·PAPERS AND DISCUSSIONS.}

EDITED BY

E. F. BAMBER, C.E.

VOL. I.

HEA'I AND METALLURGY.

WITH 47 PLATES.

LONDON :

JOHN MURRAY, ALBEMARLE STREET.

1889.

[All Rights reserved.] 


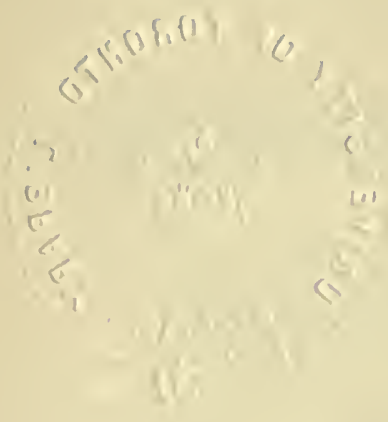

LONDUN :

BRADBURY, AGNEW, \& CO., PRINTERS, WHTTFFRIARS,

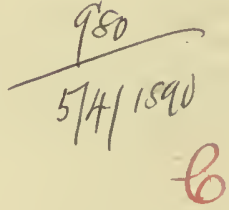




\section{PREFACE.}

Sin Willinm Simmess in his will expressed the wish that his scientific papers should be published in a collected form, and his Executors entrusted the task of editing them to Mr. E. F. Bamber, who had been the private secretary to Sir William Siemens for the last ten years of his life.

With a view of showing more fully what a variety of subjects Sir. William had thoroughly grasped, extracts from the discussions of learned Societies have been added, which show in many cases the independent and individual point of view from which Sir Willian Siemens regarded even familiar subjects.

The papers have been divided, according to their subjects, into three volumes, dealing with-

Heat and Metallurgy (Vol. I.),

Electricity and Miscellaneous Subjects (Vol. II.), AdDiesists Axp Lectures (Vol. III.),

being arranged in each volume in chronological order, and much care has been bestowed upon making the index really useful. 
A perusal of these volumes will show that, like other inventors, Sir William Siemens was not uniformly fortunate enough to attain the results he anticipated from his inventions; the faithful record of his attempts to overcome difficulties, and of his uniform practice to investigate thoroughly the scientific basis of the various problems, will, it is hoped, be of use to those who are following similar lines of research.

These volumes may be regarded as complementary to "The Life of Sir William Siemens," by Dr. William Pole, F.R.S.; and the Executors take this opportunity of publicly expressing their thanks for the admirable mannel in which Dr. Pole has accomplished his arduous task, and for the kindness with which Messrs. Mácmillan have permitted the use, as frontispiece, of the portrait of Sir Willian Siemens published in Nature shortly after Sir William Siemens's death.

The Executors desire to express their appreciation of the careful manner in which these volumes have been edited by Mr. Bamber; and for the valuable assistance rendered in their compilation, the special thanks of the Executors are due to Mr. J. Head, who for many years lield the responsible and important position of manager of Sir William's metallurgical business, and who, since Sir William Siemens's death, has continued to act in the same capacity for $\mathrm{Mr}$. Frederick Siemens.

It has, moreover, been possible to present the papers in their present complete form only through the kindness and 
courtesy of the Royal Society, Institution of Civil Engrineers, Institution of Mechanical Engineers, Society of Arts, British Association, Society of Telegrapl Engineers, Iron and Steel Institute, Royal Institution of British Architects, Institute of Naval Architects, Physical Society, Royal United Service Institution, Royal Institution, Chemical Society, Society of Chemical Industry, who most generously placed their transactions and blocks at the disposal of the Executors, for which they beg also to express their cordial thanks.

THE EXECUTORS. 



\section{CONTENTS OF VOLUME I.}

\section{PAPERS.}

\section{HEAT.}

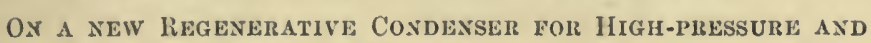
Low-Pressute Steam Exgines . . . . . . . . . 3

ON THE EXIPANSION OF loLATED STEAM AND THE TOTAL Heat OF StEal . . . . . . . . . . . 17

ON the Conversion of Heat into MeChanical Effect • . 29

ON a Regenerative Steam Exgixe . • • • . • . 50

OF A NEW CONSTRUCTION OF FURNACE, PARTICULARLY APPLICABLE WHERE INTENSE HEAT IS IREQUIRED . . . • • . 62

ON a Regeinerative Gas FurNace as aplied to Glasshouses, PUddlix, HEATING, ETC. . . . . . . . . . 81

ON UNIFORM ROTATION . . . . . . . . . . . . . . 107

Sec also ON AN IMproved Goversor for Stend ExgINes, Mech. Eng. Inst. Proc. 1853, pp. 75-83.

and DESCIIPTION OF AX IMPROVED CHRONOMETRIC GoverNor For Steam ENGINes, Mech. Eng. Inst, Proc, 1866, pp. 19-31.

ON A STEAM JET FOR EXHAUSTING AIR, ETC., AND SOME RESULTS OE ITS APPLICATION . . . . . . . . 141 Sec also ON the SteAd BLAST, Brit. Assoe. Rep. 1871 (Sect.) pl). 210-211.

ON TUE USE ON COAL GAS AS A FUEL . . . . . 177 Sec also ON GAS SUPPLY bOTII hOR HEATING AND ILLUaINATING PURPosks, Brit. Assoc. of Gas Managers, 1881.

\section{METALLURGY.}

ON the Regexerative Gas Furnace as applied to the MaNufacture of Cast Stell . . . . . . . 209 ON PUdDling IroN . . . . . . . . . . 237 
ON SMeltixg Irox AND Steel

See also ON THE MANUFACTURe OF IRON AND STTEEL BY A Direct Process, I. \& S. Inst. Jour. 1873, p. 253.

SOME FURTher REMARKS REgardiNg THE PRODUCTION OF IRON ANd Steel By Direct Process . . . . . . . 340

ON the Production of Steel aNd its APplication to MiliTARY PURPOSES

\section{DISCUSSION OF PAPERS, ETC.}

\section{HEAT.}

ON Heated-air lingines . . . . . . . . 2 26, 161

ON Horizontal Pumping Engines . . . . . . . 68

ON A CoMined VApour ENGine . . . . . . . . 69

ON THE APPLICATION UF SÜPERHEATED STEAM . . . . 72

ON Combined Steam . . . . . . . . . 76

ON GiFHARD's INJECTOK . . . . . . . . 78, 79, 101

ON Coke Maỵufacture . . . . . . . . . . 99

ON the SteaM-steering ENGiNe iN the "Great EasterN" . 124

ON Liquid Fuel . . . . . . . . . . 12.;, 130

ON Coal Getting . . . . . . . . . . . . 128

ON Regenerative Hot Blast Stoves . . . . . . 132

ON the AERo-Stean ENGINe . . . . . . . . 136

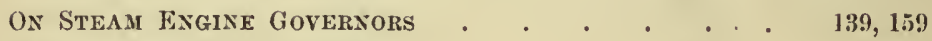

ON THE EJECTOR CONDENSER . . . . . . . . . 157

ON MODER Locomotives . . . . . . . . . . $16 \pi$

ON Peat-fuel Machinery . • . • • . . . 166

ON Steam-ENgiNe CONDENSERS . . . . . . . . . 167

ON Combustion of Refuse Vegetable Substances . . . 168

ON EXPeriments on Steam Bollers . . . . . . 170 
ON A NEW REVERSING AND GXPANSIVE VALVE GEAR • . 173

ON Gas Producers . . . . . . . . . . . 157

ON SteaA-ILATING Fol 'I'OWNS . . . . . . 190

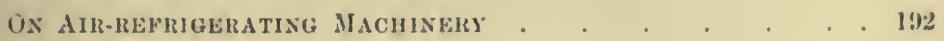

ON THE GAS ENGINE . . . . . . . . . 203

\section{ME'TALLURGY.}

ON Blast Furnaces . . . . . . 25i, 26i4, 273, 276

ON tile Strexgth of Irox axd Stell. . . . . . 269

ON TESTING RAIls . . . . . . . . . . 271

ON Puddixg Furxaces . . . . . . . . 280, 353

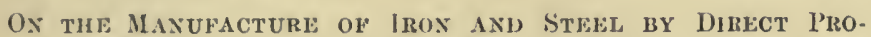

CESSES . . . . . . . . . . . 303, 328

'T'Fe l'residext's (Mr. I. Lothilax 13Ello's) AdDhess . . . 309

ON SPIEgELEISEN . . . . . . . . . . . 311

ON IRON AND STEEL FOR SHIP-BUILDING . . . . . 313

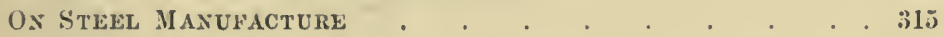

ON Fluid Compressed Steel aNd GuNs . . . . . 320

ON a letort fursace . . . . . . . . . . 324

ON ANTHRACITE COKE . . . . . . . . . 325

ON Recext Metaldurgical l'rochesses . . . . . . 330

Ox csixg Moltex Metal diRect from the Blast fursace a 331

On Castixg Arraxglants . . . . . . . . 335

Ox the Permanext Way of Rallways . . . . . 338

ON The Separation OF Carbox aND JMPURITIEs from IRON AND STEEL . . . . . . . . . . . . 353

ON the Presentation of the Bessemer Medal to l'rofessor TunNer . . . . . . . . . . . . 360

ON the Separation of phosphorus from Pig-iron . . . 362

ON ReCExt IMPRovements IN THE MANUMACtURE OF IroN SPONGE . . . . . . . . . . . . 365

ON STEEL For SHIPBUildiNg _ . . . . $\quad 367,409,426,448$

ON Stell for Mairine Botlers . . . . . . . 369

ON tile Mechanical and other Properties of Iron and MiLD STEEL, AND THEIR Use in CoNstructioN - . $\quad 373.409419$ 
On Iron AND Steel yor Architectural Construction

On the Elimination of Phosphorus .

402

ON Iron and Steel at Low Temperatures . . . . . 422

ON STEel Compression . . . . . . . . . . . 429

On Hardening IroN and Steel: its Causes and Effects • 433

ON SteEl-MAKiNg MAChinery . . . . . . . . . 437

ON THE Corrosion OF IroN AND Steel . . . . . . 440

ON Steel Plates . . . . . . . . . . . 444

ON a Mechanical Agitator for Steel Manufacture, and the Distribution of Elements ix Steel INgots . . 450

On the Metaldurgy and Maxufacture of Modern British ORDNANCE . . . . . . . . . . 452

ON STEEL For Structures . . . . . . . . . 458

ON the INFluence of the Board of Trade Rulzs for Boilers UPON THE COMMERCial MAIINe . . . • . . . 462

ON THE Use of Steel Castings in LieU of IroN aNd Steel ForgINGS 


\section{LIST OF ILLUSTRATIONS.}

\section{HEAT.}

R EGENerative CONDEXser .

Gixpansion of SteaM . . . . . . . . . 3-4

Conversion of Heat into Dynameal Hefeet * . . 5

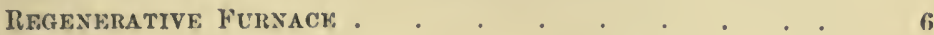

Regenerative Gas Furnace: . . . . . . . 7-18

Gas Producer . . . . . . . . . . 7-8

Plate Glass Melting Furnner . . . . . . . . 9-13

Round Flint Glass Furuser . . . . . . . 14-15

Pudlling Furnace . . . . . . . . . 16-17

Steel Melting Furnace . . . . . . . . . . 18

UxIFORM ROTATION . . . . . . . . . 19-22

Gyrometric Gorernm . . . . . . . . . 20-21

Flective Cluck . . . . . . . . . . . 22

STEAM JET . . . . . . . . . . . . 23-30

As Exhauster or Blower . . . . . . . . 23-24

Applied to Pneumatic Despateh Tube . . . . . . 25-27

Applied to Raisc Water . . . . . . . . 28

Fur Sugar Bvaporating Pan . . . . . . . . 29

Applied to Gas Producer . . . . . . . . 30

HeAted Air ExgiNe . . . . . . . . . 31-32

Coal Gas as Fuel . . . . . . . . . . 33-35

Circular Gas Producer . . . . . . . . . . 33

Diagram of Gas Proluction . . . . . . . . 34

IRegenerative Gas Fire and Gas Lamp . . . . . 35

REFRigRatiNg APPARATUS . . . . . . . . 36

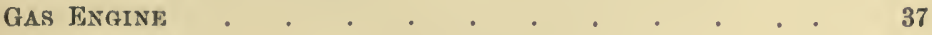




\section{METALLURGY.}

Regherative Gas Furnace Applien to Manufacture of CAST STEET.

PLATES

. $38-40$

Gas Producer . . . . . . . . . . 38

Strel Nelting Furmare . . . . . . . . . 39-40

ON Puddling . . . . . . . . . . . $41-42$

Gas Producer. . . . . . . . . . . 41

Puldling Furnace . . . . . . . . . 42

ON SMelting IroN AND Steel . . . . . . . 43-45

Stepl Melting Fumace . . . . . . . . . $43-44$

Hlast Furnuef Diaguram . . . . . . . . . t5

ON the Production of SteEl axd its Application to Military I'Urposes . . . . . . . . $\mathrm{Hi-17}$

Section of Steel Melting Furnapr . . . . . . . 46

Section of Rotator. . . . . . . . . . . . 47 
HEAT. 

THE

\section{SCIENTIFIC PAPERS}

OF

\section{SIR WM. SIEMENS, F.R.S.}

\section{H EAT.}

CONDENSER FOR IAND AND OTHER STEAM-ENGINES.

Br C. W. Siemens.*

Mr. Srexers submitted and explained his condenser for land and other steam engines.

The action of the condenser is as follows : as the jet of steam passes over the top of the condenser, water is forced through a series of plates, and passes out at the top in a spray at the rate of 3 feet per second. When the water lerel falls below the bottom of the plates, a jet of water is then thrown across the end of the plates into the water well.

The water level falls to its lowest point during about $\frac{1}{8}$ th part of the stroke of the piston; during the last $\frac{1}{8}$ th stroke the water is driven upwards.

The lower end of the plates of the condensers are about $150^{\circ}$ of heat, the upper portion are about $212^{\circ}$. The ascending water rushes out at a temperature nearly equal to the temperature of the plates themselres.

The gases are then carried into the hot well by the succeeding jet of steam.

* Copy Extract from Minutes of Committee of Mechanics of the Society of Arts, May, 1850.

VOL. I. 
The ejection pipe at the base of the condenser is furnished with an air vessel for the purpose of obtaining a greater force during the time the vacuum is greatest.

The whole condenser bears but a small proportion to the size of the cylinder, and there would frequently be room for it within the cylinder.

By Mr. Siemens's condenser, about 6 times the quantity of water to condense the steam, about 20 are required by the ordinary process.

The principal application of this condenser is looked for in high-pressure engines. One of his condensers at work on 16 horse-power engine made by Cappel.

In low-pressure engines there would not be power to force it into the atmosphere. In this engine three condensations take place : one at $180^{\circ}$, this condenses the steam $200^{\circ}$, and the remaining $\frac{1}{5}$ in. is steam first cooled by jet; two, by contact surfaces ; and third, condensed at its maximum pressure.

Mr. Crampton sees nothing opposed to the condenser but the cleaning, and that may easily be managed by simply having a duplicate set of plates.

Mr. Glynn quite convinced that the principle involved is one likely to be highly useful.

Resolved:-It is the opinion of this Committee that $\mathrm{Mr}$. Siemens's Regenerative Condenser is new, highly ingenious, and appears to be highly valuable in its application to steam engines, and is therefore well entitled to the Society's reward of their Gold Medal.

$$
\begin{array}{ll}
\text { Signed, } & \text { C. VARLey. } \\
& \text { T. R. Crajipton. }
\end{array}
$$




\section{ON A NEW REGENERATIVE CONDENSER FOR HIGH-}

\section{PRESSURE AND LOW-PRESSURE STEAM-ENGINES.}

\section{By Mr. C. Widuiasr Siemens."*}

Trie condenser of a steam engine has for its object the complete discharge of steam from within the working cylinder after it has served to propel the piston. This is effected by conducting the expended steam into a closed chamber, containing an extended surface of comparatively cool substance, which absorbs the latent heat of the steam and thereby reduces it to its liquid state. Cold water is generally employed for this purpose, which is either brought into immediate contact with the steam, as is the case in Watt's injection condenser; or through the medium of metallic walls, as in the surface condenser by Hornblower, improved upon by Hall and others. The more or less perfect condensation of the steam depends, first, on the absence of air from the condenser, and secondly, on the temperature at which condensation takes place.

The accompanying table shows the elastic force of steam in

TABLE OF THE PRESSURE OF THE VAPOUR OF WATER, FROM THE FREEZING TO THE BOILING POINT.

\begin{tabular}{|c|c||c|c|}
\hline $\begin{array}{c}\text { Temperature. } \\
\text { Fahr. }\end{array}$ & $\begin{array}{c}\text { Pressure. } \\
\text { Inches of Mercury. }\end{array}$ & $\begin{array}{c}\text { Temperature. } \\
\text { Fahr. }\end{array}$ & $\begin{array}{c}\text { Pressure. } \\
\text { Inches of Mercury. }\end{array}$ \\
\cline { 2 - 3 } 32 & $0 \cdot 20$ & 130 & $4 \cdot 34$ \\
40 & $0 \cdot 26$ & 140 & $5 \cdot 74$ \\
50 & $0 \cdot 37$ & 150 & $7 \cdot 42$ \\
60 & 0.52 & 160 & $9 \cdot 46$ \\
70 & $0 \cdot 72$ & 170 & $12 \cdot 13$ \\
80 & $1 \cdot 00$ & 180 & $15 \cdot 15$ \\
90 & $1 \cdot 36$ & 190 & $19 \cdot 00$ \\
100 & $1 \cdot 86$ & 200 & $23 \cdot 64$ \\
110 & $2 \cdot 53$ & 210 & $28 \cdot 34$ \\
120 & $3 \cdot 33$ & 212 & $30 \cdot 00$ \\
\hline
\end{tabular}

vapour, at various temperatures. It will be observed that, in order to produce a perfect vacuum, the water should leave the condenser at about $32^{\circ}$ Fahr., or be introduced in the form of ice.

* Excerpt Minutes of Procedings of the Institution of Mechanical Engineers, 1851, pp. 18-34. 
Condensing water, however, is generally obtained at the temperature of about $60^{\circ} \mathrm{Fahr}$., and it leaves the condenser at about $110^{\circ}$ Fahr., which latter temperature implies a remaining atmosphere of vapour equal to 2.5 inches of mercury, or in other words a vacuum of 27.5 inches below the atmospheric pressure at $30^{\circ} 0$ inches. If a smaller quantity of condensing water be used, it will be raised to a proportionately higher temperature, and a less perfect condensation will be effected. At $212^{\circ} \mathrm{Fahr}$. the pressure of the uncondensed vapour would be equal to that of the atmosphere, and the object of the condenser would be entirely frustrated.

In all cases where an abundant supply of condensing water cannot be obtained, or where the heat of the steam employed by the engine is reclaimed for other purposes, steam engines are worked without a condensing apparatus, or at high pressure, at the sacrifice of an effective pressure nearly equal to that of the atmosphere upon the working piston. The regenerative condenser, forming the subject of the present paper, redeems the engine from this waste of heat in the one case and loss of mechanical effect in the other case, being possessed of the peculiar property of returning the condensing and condensed water at the initial temperature of the steam previous to its discharge from the working cylinder, commonly speaking at $212^{\circ}$ Fahr. ; producing nevertheless an efficient vacuum.

Fig. 1, Plate 1, shows a sectional elevation of the regenerative condenser, as applied to a 10-horse-power high-pressure engine. It consists of an upright rectangular trunk of cast iron $\mathrm{A}$, the lower end $\mathrm{B}$ of which is cylindrical, and contains a working piston C. The trunk A is filled with metallic plates D, which are placed upright and parallel to each other, with intervening spaces of not less than 1-16th inch in breadth. The upper extremity of the condenser communicates on one side $\mathrm{E}$ to the exhaust port of the engine; and on the other to the hot well $\mathrm{F}$ through a valre $\mathrm{G}$. A stop $\mathrm{H}$ prevents the opening of the valve beyond a certain distance, in order that it may shut again more instantaneously. The metallic plates $\mathrm{D}$ are fastened together by five or more thin bolts, with small washers between the adjacent plates, which keep them the required distance apart. They can easily be removed from the condenser for the purpose of cleaning, by taking off the 
cover I and drawing out the whole of the plates. An injection pipe $\mathrm{K}$ enters the condenser immediately below the plates; it is provided with a small air ressel $I_{\text {, }}$, and a regulating cock. Various inodes have been provided to give motion to the displacing piston $\mathrm{C}$, among which a knee motion worked directly from the beam or crosshead of the engine is generally found the most convenient, as shown at M M in Fig. 1.

The action of the condenser is as follows. Motion is given to the displacing piston $\mathrm{C}$ by the engine, causing it to accomplish two strokes for every one of the engine. At the moment when the exhanst purt of the engine opens, the plates D are completely immersed in water, a small portion of which has entered the passage above the plates at $A$, and is, together with the air present, carried off, by the rush of steam, through the valve $G$ into the hot well $\mathrm{F}$, where the water remains, while the excess of steam escapes at $\mathrm{J}$ into the atmosphere. An instant after the partial discharge of the steam cylinder has commenced, the water recedes between the plates $\mathrm{D}$, and exposes thein gradually to the steam, which condenses on them in the manner following. The upper edges of the plates, emerging first from the receding water, are enveloped in steam of atmospheric pressure, and in condensing a portion thereof they become rapidly heated to nearly the temperature of the steam, or about $210^{\circ} \mathrm{Fahr}$. 'The partial condensation diminishes the density and temperature of the remaining steam, which requires additional and cooler surfaces for its further condensation. This is provided for by the continual emerging of additional portions of the metallic surfaces from the receding water. By the time the water level leaves the bottom of the plates, the far greater portion of the steam is condensed. The condensation of the remaining portion of steam could not so readily be accomplished by means of metallic surfaces; but the piston $\mathrm{C}$, continuing to descend, causes it to come into immediate contact with the jet of cold water from the pipe $K$, which completes the vacuum in the manner of a common injection condenser. The air vessel $\mathrm{L}$, connected with the injection pipe, has the effect of accumulating the injection water at the time when the water has ascended between the plates, and of forcing it into the condenser with increased intensity at the time when it is required to complete the vacuum. 
Although the action of this condenser is strictly consecutive, yet it does not check the continuous flow of steam from the cylinder; and it completes the vacuum when the working piston of the engine has accomplished only one-tenth part of its stroke. Both the engine crank and the crank driving the condenser are on the top centre at the same moment, but the latter completes its revolution in the time of half a revolution of the engine crank; consequently when the engine piston has passed through only onetenth of the whole stroke, the condenser crank will have travelled through nearly half its stroke, by which time the whole process of condensation will have been completed.

The principal part of the latent heat of the steam is stored up in the plates $\mathrm{D}$, the upper extremities of which are heated to $210^{\circ}$ Fahr., and the lower to about $150^{\circ}$ Fahr. The water, in ascending again between the plates during the last tenth part of the engine's stroke, absorbs heat from them in a similar successive manner, passing first the coolest and by degrees the hottest portions of their surfaces; and it issues finally into the upper steam passage A at a temperature approaching the boiling point, at which moment a fresh discharge of steam from the engine takes place, which carries it off into the hot well, as above described, and raises its temperature fully to the boiling point.

Fig. 3, Plate 2, represents an actual indicator diagram, showing the time occupied in completing the vacuum; but it will be observed that the loss of time and power may be diminished by increasing the capacity of the displacing cylinder. As it is however, this loss does not amount to one-seventh part of a uniform vacuum, an equivalent for which is obtained in the saving of the power hitherto absorbed by the air pump ; for it will be observed that the displacing piston works between two vacuums, and therefore meets with no resisting load.

The quantity of condensing water required with this condenser to condense $1 \mathrm{lb}$. of steam of atmospheric pressure-taking the initial temperature of the condensing water at $60^{\circ} \mathrm{Fahr}$., the fina? temperature at $210^{\circ} \mathrm{Fahr}$., and the latent heat of steam of $212^{\circ}$ Fahr. at 960 units-is $\frac{960}{210-60}=6.4$ lbs. of water to condense $1 \mathrm{lb}$. of steam. The common injection condenser, supposing the condensing and condensed water to issue at $110^{\circ}$ Fahr., requires 
$\frac{960+(212-110)}{110-60}=21.2$ lbs. of water to condense $1 \mathrm{lb}$. of steam, in place of the $6.4 \mathrm{lbs}$. which the regenerative condenser requires. In the case of a locomotive or other high-pressure engine, where the steam is released from the cylinder at a pressure of say $30 \mathrm{lbs}$. above the atmosphere, two-thirds would be allowed to escape uncondensed, and the vacuum would be obtained with only $6 \cdot 4 \div 3=2 \cdot 13 \mathrm{lbs}$. of condensing water for every $1 \mathrm{lb}$. of steam pussed through the cylinders. The small quantity of condensing water required renders the regenerative condenser applicable to engines in nearly every locality; and pains have been taken to render the apparatus itself equally light and compact.

The advantages resulting from the application of the regenerative condenser to high-pressure engines are as follow.

1. Additional effective power, gained on account of the vacuum. The indicator diagram, Fig. 3, Plate 2, illustrates this gain, which, supposing the average steam pressure to be 40 lbs. above the atmosphere and the vacuum within the cylinder to be $10 \mathrm{lbs}$, amounts to 20 per cent. irrespective of expansion. If both the steam pressure and the work on the engine remain unchanged after the condenser is applied, it is evident that the steam may be worked expansively to a large extent without diminishing the absolute driving power of the engine.

2. Heat saved in generating the steam, by the use of boiling-hot feed water ; and the remaining portion of the hot water may be advantageously used for heating buildings, dyeing, \&c. Highpressure engines are frequently provided with heating apparatus for the feed water, which heats it on the arerage to about the temperature of the condensing water from low-pressure engines, or $110^{\circ} \mathrm{Fahr}$. The regenerative condenser heats it to $210^{\circ} \mathrm{Fahr}$., which constitutes a saving of $\frac{210-110}{960}=$ about 10 per cent. When such heating apparatus is not provided, the saving amounts to $\frac{210-60}{960}=$ about 15 per cent.

3. The steam which is not condensed may be used to cause a draught in the chimney, or for other purposes.

4. The displacing cylinder, unlike the air pump of the injection condenser, abstracts no motive power from the engine. 
5. The condenser may be started and stopped at any time, by turning the supply of injection water either on or off. If turned on, it at once forms the vacuum, without involving the necessity of blowing through; and if turned off, it allows the engine to proceed in the same manner as though no condenser had been applied.

6. The air contained in the condenser is at the commencement of each stroke bodily expelled, which is of great advantage to the formation of a good vacuum, instead of the ordinary air pump removing only a portion of the air at each stroke, and consequently leaving a portion always in the condenser.

7. The regenerative condenser is more compact and even less expensive than the ordinary injection condenser, being less than one quarter of the size and having only one valve instead of three. Its proportionate dimensions are as follows:-Area of platechamber, three times the area of exhaust pipe ; length of plates, one-quarter to one-third of stroke of engine ; thickness of plates, 1-292nd part of their length; spaces between plates, the same, but never less than 1-16th inch, it having been found that the alternate rush of water and condensiug steam prevents the settlement of grease and earthy matter between the plates, if they are not less than 1-16th inch apart : capacity of displacing cylinder, one and a half times the capacity of the plate-chamber. The total capacity of the condenser is equal to only about one-tenth of the capacity of the working cylinder.

In applying the regenerative condenser to existing high-pressure engines, a saving of fuel of from 30 to 35 per cent. has been effected, or an increase of power to that amount with the same expenditure of fuel as previously. This saving may however be still augmented considerably, if advantage be taken of the increased effective pressure to work the engine expansively. In most cases this may be easily effected, by merely adding to the lap of the slide valve and increasing the lead of the eccentric proportionately, whereby the additional advantage of a more early discharge of the steam is obtained.

The first regenerative condenser was attached to a 16-horsepower high-pressure engine at Saltley Works near Birmingham in September, 1849, where it has been found to answer, although it is not perfect in its proportions, and could not be kept constantly 
in operation in consequence of a deficiency of injection water. The actual indicator diagram, shown in Fig. 3, Plate 2, was taken from this engine; since then several more of the regenerative condensers lave been erected, and the results above referred to hare been obtained. The dotted line in Fig. 3 shows the indicator diagram taken from the engine before the condenser was applied; and the full line shows the dingram from the engine working with the condeuser, and exerting exactly the same power ns in the former case. The shaded portion of the diagram shors the power gained or saved by the use of the condenser.

The advantages attending the application of the regenerative condenser to stationary engines being practically proved, the author is desirous to extend it also to that important class the locomotive engine. In inviting the attention of railway engineers to this enquiry, he is prepared for practical objections being raised on account of the great rapidity of motion, the necessity for the greatest possible simplicity and lightness, the deficiency of condensing water, \&c.; but he thinks that the condenser under consideration is peculiarly well adapted to meet these objections.

The peculiarities of the regenerative condenser in this respect are as follow. ' It may be accommodated to any speed of piston, by reducing the length and increasing the breadth of the condensing plates, thus reducing the velocity of the displacing piston proportionately. Its dimensions are proportionate to the capacity of cylinder only, and not, as in other condensers, to the horsepower of the engine. The total weight of a pair of condensers, as applied to a locomotive engine with cylinders of 13 inches diameter and 20 inches stroke, is about $3 \frac{1}{2} \mathrm{cwts}$. The power of the blast remains nearly undiminished. The condenser requires no attention in working the engine, and in case it should fail to act from any accidental cause the engine will continue to work high pressure as usual. Moreover it does not interfere with the working parts of the engine.

'The advantages which would result from a vacuum in the cylinder of a locomotive engine have been ably set forth by Mr. Edward Woods in his "Observations on the consumption of fuel and evaporation of water in locomotive and other steam engines." The present paper may therefore be limited to the means proposed for that purpose. 
The two condensers are cast in one piece, and placed immediately in front of the cylinders of the engine. Each of them closely resembles the condensers above described; only the length of the condensing plates and the stroke of the displacing pistons are much reduced in proportion to the steam cylinder stroke, in order that the velocity of the water between the plates may not exceed certain limits. The two displacing pistons are connected to opposite ends of a short vibrating beam, which receives its motion from the engine.

In addition to the exhaust valres leading into the hot well, these condensers are provided with a second set of discharge valves, of a somewhat peculiar construction, which with rery limited motion combine the advantage of opening a perfectly clear passage for the exhaust steam of the engine into the chimney, where its remaining expansive force is required to produce the draught. Each of these valves consists of a longitudinal rectangular slot, in the upper wall of the steam passage which leads from the cylinder to the condenser. At the ends of the slot are triangular pieces, supporting the sides of two longitudinal lips which cover the aperture, except at times when a higher pressure from within forces them open : the extent of their motion is limited by dead stops. The escape of steam, together with the hot water, into the hot well is regulated by a blow-off valve from the hot well into the atmosphere; by this means a pressure above the atmosphere is obtained in the hot well, which acts favourably in forcing the boiling-hot condensing water into the feed pump of the boiler.

It has been shown previously that the ordinary supply of feed water in locomotive engines, where two-thirds of the steam is allowed to escape uncondensed, is of itself not quite half-sufficient to maintain a vacuum within the condenser, and an additional supply of water must be provided for. But considering how small the excess of condensing water will be, especially if the diameters of the working cylinders are reduced in proportion to the additional effective power gained, and considering that boiling-hot water will readily part with the principal portion of its heat, it is proposed to take the excess of condensing water back to the tender through a simple refrigerator, in which advantage is taken of the rapid motion of the engine through the air for 
cooling the water. The refrigerator may be placed conveniently on the back of the tender.

The application of the regenerative condenser to low-pressure engines, as shown in Fig. 2, Plate 1, requires but a short notice after what has been said already; the letters refer to the same parts as in the former description of the high-pressure condenser slown in Fig. 1. In the low-pressure condenser the steam at the time when it is released from the cylinder has not sufficient force to expel the air and heated water from-the condenser into the atinosphere, and a partially vacuous space must be provided for their reception. For this purpose the side B of the displacing cylinder, which in the arrangement hitherto described is always empty, is put in communication with the exhaust valre $G$ of the condenser, and receives the charge of water and air at the time when the piston $\mathrm{C}$ is at the opposite end; a second valve $\mathrm{O}$ is provided, through which the water is expelled into the hot well $\mathrm{F}$ during the return of the piston C. For the convenience of arrangement, the displacing cylinder is reversed in this case.

The chief advantages obtained by the application of this condenser to the low-pressure engine are :-

1. The requisite amount of injection water is reduced in the proportion of 3 to 1 .

2. The feed water of the boiler is obtained nearly boiling hot, which constitutes a saving in fuel of $\frac{210-110}{960}=$ about 10 per cent.

3. The whole amount of heat generated under the boiler is given off by the engine in the form of water at $210^{\circ} \mathrm{Fahr}$., which in most cases may be advantageously employed for heating buildings, washing, dyeing, and other purposes.

4. A large proportion of the power required for working the air pump is saved.

The author proposes to conclude this paper with a short historic sketch of the steam engine condenser, to illustrate the distinct features of this regeneratire system.

In Newcomen's engine the condensation of the steam was effected by the alternate introduction of a jet of cold water into the steam cylinder itself. The cold water naturally cooled the walls of the cylinder, which in their turn condensed a large portion 
of the succeeding charge of steam before it had forced the piston upwards.

James Watt, in seeking a remedy against this loss of heat, conceived the possibility of condensing the steam in a separate closed ressel; and in carrying his idea into effect, he not only realised his immediate object, but at the same time rendered the steam engine susceptible of that degree of perfection and general application which it now possesses. The injection condenser of Watt is the most effectual of its kind, and has maintained its exclusive dominion to the present day. It consists of a closed vessel, which communicates periodically with the steam cylinder. The injection water, together with the condensed steam and the air, which last is partly evolved from the injection water and partly leaks in through the joints of the cylinder and exhaust pipe, are continually discharged from it by means of the air pump.

Shortly after the introduction of Watt's condenser, a surface condenser was proposed by Hornblower, which consisted of a close annular ressel of thin metal plate, on the inner surfaces of which the waste steam of the engine was condensed; its latent heat being continually carried off by a stream of cold water which surrounded the vessel. A comparatively small air pump was provided, which served to discharge the condensed water (to be again forced into the boiler) and any air that might leak in through the joints. This condenser failed in practice, for want of sufficient extent of cooling surface.

An effective surface condenser would possess considerable advantages over the injection condenser, especially in the case of marine engines. Allowing the condensed steam to be continually returned into the boiler, it prevents incrustation of the boiler, and moreover dispenses with the necessity of blowing off. Its air pump absorbs a much smaller proportion of the power of the engine, and its functions require less personal, attention. Stimulated by these considerations, several attempts were made to improve on Hornblower's invention; but since all these improvements partake very much of the same character, it is thought sufficient for the present purpose to mention only Hall's condenser, which has obtained the greatest amount of notoriety. It consists of two flat chests or closed chambers, connected together by means of a large number of brass tubes, through which the condensing steam 
circulates. 'These tubes are surrounded by cold water, which fills up the space between the flat chests. A small air pump removes the condensed water and air from the lower chest. The great weight and cost of this condenser, its liability to derangement, and the inipossibility of removing the calcareous deposit of the water from the tubes without taking the whole fabric to pieces, are found to be serious practical objections.

In the year 1847 the author had occasion to apply a surface condenser in a situation where economy of space and inaterial were essential. In considering the most rational distribution of surfaces, he happened to find an arrangement which, with less than one half the amount of material used in Hall's condenser, produced a very satisfactory result, and which paved the way to the more important improrement that forms the principal subject of this paper.

The surface. condenser referred to, shown in Figs. 4 and 5 , Plate 2, consists of a number of copper plates A A, of $\frac{3}{32}$ nds inch thickness and about $4 \frac{1}{2}$ inches broad by 2 feet long, which are fixed together by two longitudinal flattenea wires of the same metal between the adjacent plates ; and the whole pile is screwed up tight together between the sides of a rectangular cast iron vessel, which constitutes the body of the condenser. The ends of the plates project through the top and bottom of the condenser, and are planed flush with its exterior surfaces. The joints at top and bottom are secured by means of india-rubber rings, which are screwed down under small cast iron frames, and yield to the difference of expansion between the two metals. The flattened wires are laid parallel, about 3 inches apart from each other, and form with the plates a large number of narrow passages, through which the cold condensing water flows in a vertical direction, without entering the vacuons space of the condenser, into which the edges of the plates outside the flattened wires project, forming the condensing surfaces.

The rationale of this condenser is as follows. The transmission of heat in a surface condenser is threefold : first, from the condensing steam to the internal metal surfaces; secondly, from the internal surfaces through the body of the metal to its external surfaces ; and thirdly, from the external surfaces to the surrounding water by which it is carried off. The first operation (condensa- 
tion) would, it is presumed, proceed with undefined rapidity, if it were not retarded by the second and third, or by the presence of some permanent gases, which accumulate on the condensing surfaces and prevent their immediate contact with the steam. The second (conduction) varies in direct proportion with the conducting power of the metal, and with its thickness; but the conducting power of copper is so great that its thickness seems to exercise no appreciable influence on the amount of heat transmitted in a given time. This interesting fact is proved by Dr. Ure's experiment with two copper pans, of the same internal area, but very unequal thickness of bottom, the thicknesses being in the proportion of 1 to 12 ; which were both filled with water, and dipped into a hot solution of muriate of lime. It was found that the water in the thick pan evaporated the quickest, which may be accounted for by its slightly increased external surface in contact with the heating solution; and this affords additional evidence that the limit of transmission does not lie within the metal, but rather between the metal surface and the liquid. That the absorption of the heat by the water is a slow process may be inferred from the circumstance that water, although possessing a large capacity for heat, is a very bad conductor, and depends for its power to absorb heat on the slow circulation over the heating surface caused by the lower specific gravity of the heated particles of water. A strong artificial current along the heating surfaces greatly accelerates the process.

The surface condenser above described was arranged in accordance with these observations. It contains :- heat-absorbing surfaces (by the water), 18 square feet per horse porrer ; condensing surfaces, 9 square feet per horse power ; computed mean thickness of metal through which the heat is transmitted, $1 \frac{1}{4}$ inch ; weight of copper, $60 \mathrm{lbs}$. per horse power ; space occupied by plates, 0.4 cubic foot per horse power, or about one-tenth of the space occupied by the tubes in the tubular condenser.

The essential features of this condenser are its comparative cheapness of construction, and the easy access which it affords to the water channels between the plates. It also requires less condensing water than previous surface condensers, in consequence of the repeated and close contact in which each particle is brought with the heating surfaces, before it can reach the upper reservoir or hot well. The author considers that the surface condenser just 
described may be advantageonsly applied to marine engines; and not being subject to a patent, he hopes it will receive a sufficient trial.

Being required to sare the waste steam of a low-pressure engine in the form of slightly heated water, for Mr. John Graham of Manchester, the author in the spring of 1847 conceived the idea of a regenerative condenser. Figs. 4 and 5, Plate 2, show his first arrangement as already described, which may be termed a regenerative surface condenser. It consists of a revolving ralve $B$, which admits the waste stean of the engine first to the atmosphere at $\mathrm{C}$, and then successively into the separate compartments, D, E, F, G, where it is condensed at various densities. The cold water enters at $\mathrm{H}$, and first passes between the plates within the last compartment $\mathrm{G}$, and by degrees through those within the first compartment $\mathrm{D}$, where the steam is of nearly atmospheric pressure, and consequently heats the water to nearly $212^{\circ}$ Fahr., when it passes out at I.

The next step was a regencrative injection condenser on the same principle, as represented by Fig. 6, Plate 2. The revolving valve $B$ admits the waste steam of the engine first to the atmosphere at $\mathrm{C}$, and then successively into the separate compartments, D, E, F, G, where it is condensed at various densities. The cold water is injected at $\mathrm{H}$, and is passed down through the steam in each compartment in succession by uneans of the displacing pistons $\mathrm{K} K$, which work all on the same piston rod through each of the divisions between the compartments ; and the heated water passes out at the bottom at I. L I are overflowing distributing trays, for the purpose of bringing the water more rapidly and completely into contact with the steam. $\mathrm{M}$ is a small pump to extract the air that is mixed with the steam and water.

The regenerative condenser in its present form partakes of the nature of both the surface and the injection condensers.

Attempts have been made from time to time to condense the steam of a high-pressure engine without the aid of an air pump, by blowing the steam into a small injection condenser which is provided with a large exhaust valve. It is clear that the steam of high pressure will at first partially blow through the condenser, and rid it of its air and condensing water ; and that by degrees the jet of cold water will overpower the influx of steam, and consequently 
produce a vacuum. An arrangement of this description, although simple, is at least very imperfect; because it is a matter of considerable difficulty so to proportion the injection of cold water that the first rush of steam may not forthwith be condensed, but may exert its expansive force in a cold vessel, and yet that an instant afterwards a complete condensation of the remaining steam may be effected. If too much water be used, the air and water will not be expelled, and consequently no vacuum will be formed; if too little, no final condensation will take place. The quantity of injection water must be very large, because the whole of the steam has to be condensed; and having to complete the condensation in the same vessel, the water must leare it at a low temperature.

The principle of the regenerative condenser has been carried still further in the regenerative engine, which has been executed on a large scale by Messrs. Fox, Henderson \& Co., under the superintendence of the author. In this engine the steam, after it has served to propel the working piston to the end of its stroke, is received into a series of consecutive chambers, from which it returns to the working cylinder an indefinite number of times. On a future occasion the author will be glad to bring the particuIars of this engine before the Institution.

Mr. Sifmens, in answer to enquiries, replied that the experiment at the Saltley Works, had been tried ,with one week's working with the condenser, and then one week without it ; and the saving of fuel with the condenser was at the rate of 18 per cent. The apparatus with which the condenser worked was however too light, and had not been made for the purpose; also that condenser was the first that had been made, and the proportions had been improved in the subsequent ones.

There was a deficiency in the supply of condensing water, which sometimes interfered with the regular working of the condenser, as well as the defects arising from the gearing being too light for working it, and these had caused irregularities in the working of the engine; there was also a difficulty in regulating the engine as a condensing engine with the present governor. The steam pressure was 30 lbs. per inch; but a smaller supply of condensing water would be sufficient if a higher pressure of steam were employed.

As regarded its use in locomotive engines, Mr. Siemens replied 
that it would only be necessary for the condenser to work quick enough to condense one cylinder-full of steam before the next cylinder-full was discharged; and this he thought would easily be effected by widening the plates of the condenser to a proportionate size, and shortening the stroke of the condenser piston, so as to reduce its velocity as far as might be required. The condensed steam would then return to the tender in pipes, between which air was caused to circulate by means of the rapid motion of the engine. He expected the condensing water would be cooled down to about $100^{\circ}$ before it was returned to the tender, by the process of passing through the pipes of the refrigerator, from the rapid motion of the engine through the air ; and the water was not required to be so cold as in the ordinary condenser, since only the last portion of the steam was condensed by injection.

Mr. Siemens showed by a comparative indicator diagram that with the application of the condenser to a locomotive engine the steam might be cut off at about one-third of the stroke, instead of at two-thirds as usual, and thereby a saving of one-half the steam would be effected with the same power.

\section{ON THE EXPANSION OF ISOLATED STEAM, AND THE TOTAL HEAT OF STEAM.}

By Mr. Charles W. Siemens, of London.*

THE object of this paper is to lay before the members the results of certain experiments on steam, purporting, in the first place, to corroborate Regnault's disproval of Watt's law, "that the sum of latent and sensible heat in steam of various pressures is the same ;" in the second place, to prove the rate of expansion by heat of isolated steam; and, in the third place, to illustrate the immediate practical results of those experiments in working steam engines expansively.

* Excerpt Mlinutes of Proceedings of the Institution of Mechanical Engineers, 1852, pp. 131-141.

VoL. I. 
The author pursued these experiments at long intervals since the year 1847 , with no other object in view than to extend his own information; and, consequently, without pretence to generalisation or extreme accuracy. The question, however, is one of great practical importance to engineers, and with the advantage of valuable suggestions and the co-operation of his friends, Mr. Edward A. Cowper and Mr. William P. Marshall, the author has again taken up the experiments, which, having been referred to at the previous meeting by Mr. Cowper, he feels himself called upon to lay before this Institution in their present state, though incomplete.

The amount of heat required to convert one pound of water into steam of different pressures has occupicd the attention of natural philosophers from the earliest periods of the modern steam engine.

Dr. Black observed, about a century ago, that a large quantity of heat was absorbed by water in its conversion into steam (not accompanied by an increase of temperature), which he termed "the latent heat of steam." His apparatus consisted siniply of a metallic vessel containing water, which he exposed to a very regular fire; and from the comparative time which was occupied, first in raising the temperature of the water to the boiling point, and, secondly, in effecting the evaporation, he approximately determined the amount of latent heat. Resuming the experiment, in conjunction with Dr. Irvine, he employed a different apparatus, consisting of a steam generator, and of a surface condenser, or a serpentine tube, surrounded by a large body of cold water.

The steam which condensed in the serpentine tube was carefully collected and weighed, and the rise of temperature of the surrounding water was observed, which, multiplied by its known quantity, represented the total quantity of heat which the steam had yiclded.

The quantity of heat requisite to raise the temperature of one pound of water through $1^{\circ}$ Fahr. being taken for the unit of heat, Black and Irvine obtained for the lotal quantity of heat in

Steam of atmospheric pressure, the number . . $\quad 854$

Southern . 


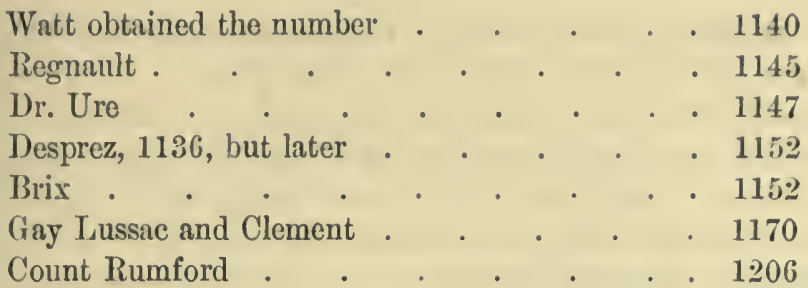

All of these eminent experimentalists employed essentially the same apparatus, and the differences between their results proves its great liability to error. Brix, of Berlin, was the first to investigate those errors, and to calculate approximately their effect upon the results obtained.

While such a large amount of labour and talent has been expended to determine the latent heat in steam of atmospheric pressure, a far more important question seems to have been passed over with neglect, namely, What is the relative amount of heat in steam of various densities?

The celebrated Watt justly perceived the importance of this question, but contented himself with one experiment upon which he based his law, "that the sum of latent and sensible heat in steam is the same under all pressures."

Southern repeated the experiment, and found that steam of greater density contained absolutely more heat than steam of lower pressure, which induced him to adopt the hypothesis that "the latent heat of steam was the same at all pressures."

Subsequent experiments and general reasoning seemed to be in favour of Watt's law, which enjoyed the general confidence until it was attacked, only a few years since, by Rognault, of Paris, who proved by a series of exceedingly elaborate and carefully conducted experiments, that neither the law of Watt nor that of Southern was correct, but that the truth lay between the two. The apparatus employed by M. Regnault may be said to be a refinement upon those previously employed, and with the advantage of Brix's labours to determine the amount of errors, he seems to have succeeded in measuring the absolute amount of heat in steam of various pressures with surprising accuracy.

The costly and complicated nature of the apparatus employed by M. Regnault has hitherto prevented other experimentalists 
from repeating the experiment, and in the meantime practical engineers still continue to adhere to Watt's law.

Shortly after the publication of Regnault's experiments by the Cavendish Society, in 1848, the idea occurred to the author of the present paper that their results might be brought to a positive test by a simple apparatus, which he places before the Meeting in operation, shown in Fig. 1, Plate 3. It consists of an upright cylindrical vessel of tin-plate $A$, which is surrounded by an outer vessel filled with charcoal B B, or other non-conducting material. A steam-pipe $\mathrm{C}$, with a contracted glass vein $\mathrm{D}$, enters the inner vessel in a slanting position, in order that the water of priming from the boiler, and of condensation within the pipe, may return to the former, allowing only a small jet of pure steam to enter the vessel, where it suddenly expands and communicates its temperature to the bulb of a thermometer $\mathrm{E}$, which is inserted through a stuffing-box from above. The lower extremity of the inner vessel $A$ is connected on the one hand to a mercury gauge $G$, and on the other to a condenser, by means of a stopcock to regulate the pressure. The pressure and temperature of the steam within the boiler being known, and the temperature of the expanded steam observed, it will be seen whether that temperature coincides with the temperature which is due to pressure indicated by the mercury gauge. If it did, then Watt's law would be confirmed, but since the temperature rises higher than is due to the pressure, it follows that the high-pressure steam contains an excess of heat, which serves to super-heat the expanded steam. All losses of heat from the apparatus would tend to reduce the temperature, and be in favour of Watt's law ; but it will be shown that those losses may be entirely eliminated, and a true quantitative result be obtained. For this purpose the pressure in the boiler should first be raised to its highest point, and the indicating apparatus be well penetrated by the heat; the fire under the boiler should thereupon be reduced, and observations made simultaneously, and at regular intervals, of the declining pressure within the boiler, and temperature of the expanded steam of constant pressure. The pressures being nearly equal, the fire under the boiler is again increased, and the observations continued until the maximum pressure is once more obtained; and the loss of heat by radiation, \&c., may be cor- 
rectly estimated, by a comparison of the two series of obserrations.

The second portion of this paper relates to the rate of expansion of isolated steam by heat, that is, steam isolated from the water from which it is generated.

The author has not been able to meet with ally direct experiments on this subject, except some at a recent period by Mr. Frost, of America, which, however, do not seem entitled to much confidence. The rate of expansion of air and other permanent gases by heat was first determined by Daltoll and Gay Lussac simultaneously, who determined that all gases expanded uniformly, and at the same absolute rate, amounting to an increase of bulk equal to $\frac{1}{480}$ th part of the total bulk at $32^{\circ}$ Falnr. for every one degree Fahr., or $\frac{1}{60}$ th part of the total bulk at $212^{\circ}$. Dulong and Petit confirmed the law of Dalton and Gay-Lussac, but it appears that these philosophers confined their labours to the permanent gases and atmospheric pressure, and merely supposed the general applicability of their discovery.

Being interested in the application of "super-heated" steam, the author tried some direct experiments on its rate of expansion, in the year 1847 , which confirmed his view, that vapours expand more rapidly than permanent gases, or in other words, that the rate of expansion of different gases and vapours is equal, not at the same absolute temperature, but at points equally removed from their points of generation.

The apparatus employed in these experiments has been placed before the meeting, and its simplicity, when seen in operation, is such that the result, it is hoped, can hardly be doubted.

It is shown in Fig. 2, Plate 3, and consists of a metallic trough $A \mathrm{~A}$, containing oil, which is placed upon a furnace $B \mathrm{~B}$, heated by gas flames. One end of the trough is provided with a stuffingbox, through which a glass tube $\mathrm{C}$, of about $\frac{1}{16}$ th inch diameter, and sealed at one end, may be slipped, which will rest horizontally upon a scale below the surface of the oil. The mouth of the glass tube is connected to an open mercury syphon $G$, with either the one or the other leg filled with mercury, to produce the desired pressure within the horizontal glass tube. A small drop of water and a piston of mercury $P$ being introduced into the bottom of the tube, it is placed in the oil bath, and connected 
to the syphon. The oil bath is then gradually heated, and the temperature observed. As soon as the boiling point of water under the pressure in question is reached, the mercury piston will move rapidly forward, until all the water is converted into steam. The temperature continuing to increase, the piston will continue its course more slowly upon the scale, where its progress is noted from time to time, together with the temperature.

The experiment is continued until the temperature reaches about $400^{\circ}$, when the oil begins to boil. The gas flame is then withdrawn, and the bath allowed to cool gradually. The observations of the temperature and the position of the mercury piston are continued until the steam contained behind it is recondensed. A comparison between the two series of observations gives the correct mean of the experiment, by which the effects of the friction of the mercury piston, any possible slight leakage of steam past it, and faults consequent on the slow transmission of heat, are completely neutralized.

The curve A on Fig. 3, Plate 4, has been drawn, expressing the rate of expansion of isolated steam according to these experiments. The results of nine separate experiments very nearly coincide (as shown by the dotted lines, which give the extreme variation in the experiments), except at the starting point, where the rate of expansion is so very great that it is difficult to obtain correct observations ; changes in the barometer, moreover, affect the curve in the vicinity of the boiling point. To obviate the effect of these inaccuracies, the unit of volume in laying dorm the curres from each of the nine experiments was taken, not at the absolute boiling point, but at $250^{\circ}$, where the expansion had already assumed a definite course.

The diagram also shows a straight line $\mathrm{B}$, expressing the rate of expansion of common air, which at first diverges greatly from the hyperbolic curve of expansion of steam, although the asymptote of the latter seems to run parallel to the former. The author considers it therefore highly probable, "that the rate of expansion of all gases may be expressed by one hyperbola, which starts from the condensing point of the gas," and that the apparently uniform rate of expansion of the permanent gases may be accounted for by their great elevation, at the ordinary temperature, above their supposed boiling point, in consequence whereof the true curve 
approaches so nearly to its asymptote that the difference cannot be detected by experiments.

The general result obtained from the above experiments may be stated as follows : that steam generated at $212^{\circ}$, and maintained at a constant pressure of one atmosphere, when heated out of contact with water to

$230^{\circ}$ is expanded 5 times more than air would be.

$\begin{array}{lllll}240^{\circ} & , & 4 & , & " \\ 260^{\circ} & " & 3 & , & " \\ 370^{\circ} & " & 2 & , & ,\end{array}$

The anthor intends to extend the range of his experiments upon gases and vapours under high pressure, and will be glad to communicate the further results to the Institution.

The diagram contains another curve, $\mathrm{C}$, showing the results of Ir. Frost's experiments, alluded to before, which, from the very sudden and iriegular rise at the commencement, appears to be affected by some serious source of error.

The two curres of pressure and density, $\mathrm{P}$ and $\mathrm{D}$, show the rate at which saturated steam increases in pressure and in density, witl the rise of temperature marked at the bottom of the diagram. It will be observed that the pressure increases at a rather greater rate than the density; and it is a remarkable circumstance, that the difference, or the rate at which the pressure increases faster than the density, which is in effect the rate of expansion of saturated steam with the increase of sensible temperature, exactly coincides with the line $\mathrm{B}$, representing the rate of expansion of atmospheric air.

An extension of our knowledge on the properties of steam is a matter of such evident importance to engineers, that it would be useless to dwell upon its practical importance. Snffice it to say, that it has been theoretically demonstrated that a perfect Boulton and Watt Condensing Engine (abstracting friction and all losses of heat in the furnace and through radiation) would only yield about seven per cent. of the mechanical force which would be equivalent to the expended heat. It may be argued from this, that the steam engine is destined to undergo another great modification in principle, and in the author's humble opinion this crisis will be accelerated by inquiries into those properties of gaseons fluids which have hitherto excited but little attention, and especially into the properties of dry steam, or isolatcd steam. 
The present paper will be confined to showing the effect of the above experiments upon the rate of expansion of steam within the steam cylinder of an engine. It was demonstrated by the firstnamed experiments, that expanded steam is super-heated steam; and, by the second, it is shown what is the expansion of bulk due to an increase of temperature.

Supposing the results of the experiments to be correct, the expansion curve as laid down by Pambour, and which is based upon Watt's law, requires a modification due to the excess of temperature in expanded steam ; and it will be observed that this correction in the curve of expansion is in farour of working engines expansively, as a greater average pressure is obtained during expansion than would be the case if the expanded steam were not thus super-heated. Its correctness is corroborated by some actual observations by Mr. Edward A. Cowper in taking diagrams of expansive engines, previous to his acquaintance with the above experimients. It moreover appears that in Cornwall, engineers have been practically acquainted with the fact, that expanded steam is super-heated steam, and more economic in its use than saturated steam; for it is a practice with them to generate the steam at very high pressure, and to expand it down to the required pressure previous to its reaching the steam cylinder.

Another remarkable practical observation is, that a jet of highpressure steam does not scald the naked hand, while a jet of lowpressure steam does, although the high-pressure steam is the hotter substance. The cooling effect of a jet of high-pressure steam is so powerful, that, as the author has been informed, ice has been actually produced in the heat of summer in America, by blowing a powerful jet of steam of $400 \mathrm{lbs}$. pressure per square inch against a damp cloth. This phenomenon may be explained by the perfectly dry and under-saturated state of expanded steam, which, with a strong tendency to re-saturate itself, produces a powerful evaporation on moist surfaces with which it comes in contact.

The rapid rate of expansion of steam by heat, when still near its boiling point, proves the economy of heating the steam cylinder either by a steam jacket, or by the application of fire. It is, however, important to observe, that the specific heat of steam seems to diminish, the more the temperature exceeds the boiling point. The annexed table of observations gives the data from which the curve A in Fig. 3 has been drawn. 
TABLE OF EXPERIMENTS ON THE EXPAXSION OF ISOLATED АTMOSPHFIC ВTЕAM.

\begin{tabular}{|c|c|c|c|c|c|c|c|c|c|}
\hline $\begin{array}{c}\text { Teupera. } \\
\text { ture. } \\
\text { Degrees } \\
\text { Falir. }\end{array}$ & 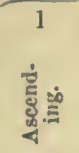 & 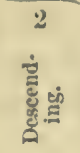 & 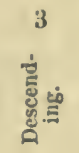 & 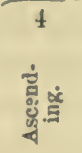 & 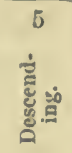 & 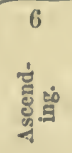 & 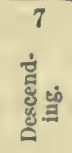 & 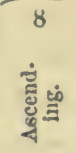 & 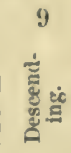 \\
\hline $20 y$ & $05 \cdot 0$ & $\ldots$ & $\ldots$ & ... & $\cdots$ & ... & ... & $\cdots$ & $\ldots$ \\
\hline 210 & $5 \cdot 00$ & & ... & & & ... & & $\ldots$ & $\cdots$ \\
\hline 212 & 8.00 & $8 \cdot 00$ & & $10 \cdot 00$ & $9 \cdot 70$ & $\ldots$ & $8 \cdot 00$ & $\ldots$ & $9 \cdot 04$ \\
\hline 213 & $\ldots$ & & $10 \cdot 00$ & $\ldots$ & & ... & & $\ldots$ & ... \\
\hline 214 & $\ldots$ & $8 \cdot 40$ & $10 \cdot 40$ & 10 & $10 \cdot 05$ & $\ldots$ & $9 \div 0$ & $\ldots$ & ... \\
\hline 215 & $8 \cdot 80$ & 8.68 & $10 \cdot 52$ & $10 \cdot 12$ & $10 \cdot 16$ & ... & $9 \cdot 90$ & $\dddot{0}$ & $9 \cdot 30$ \\
\hline $217 \frac{1}{2}$ & $\begin{array}{l}9 \cdot 00 \\
9 \cdot 10\end{array}$ & $8 \cdot 90$ & $10 \cdot 66$ & $10 \cdot 20$ & 1032 & $\cdots$ & $\ddot{0} 0$ & $\begin{array}{l}9 \cdot 30 \\
9 \cdot 50\end{array}$ & $9 \cdot 45$ \\
\hline $222 \frac{1}{2}$ & $9 \cdot 22$ & & $\begin{array}{l}10.8 t \\
10.94\end{array}$ & $10 \cdot 48$ & $10 \cdot 61$ & ... & & $9 \cdot 60$ & 9.65 \\
\hline $225^{\circ}$ & 9) 32 & $9 \cdot 34$ & $11 \cdot 01$ & $10 \div 3$ & $10 \cdot 70$ & ... & $10 \cdot 70$ & $9 \cdot 68$ & $9 \cdot 74$ \\
\hline $227 \frac{1}{2}$ & & & $11 \cdot 11$ & $10 \cdot 60$ & & ... & & $9 \cdot 75$ & \\
\hline $230^{\circ}$ & 954 & $9 \cdot 58$ & 11.21 & $10 \cdot 68$ & $10 \cdot 86$ & $\ldots$ & 11.00 & $9 \cdot 81$ & $9 \cdot 91$ \\
\hline - $232 \frac{1}{2}$ & & & $11 \cdot 29$ & & & $\ldots$ & & & \\
\hline 235 & $9 \cdot 68$ & $9 \cdot 70$ & $11 \cdot 34$ & $10 \cdot 84$ & $11 \cdot 00$ & $\ldots$ & $11 \cdot 16$ & $9 \cdot 95$ & 10.02 \\
\hline 240 & $9 \cdot 80$ & $9 \cdot 85$ & $11 \cdot \$ 6$ & $10 \cdot 94$ & $11 \cdot 12$ & ... & $11 \cdot 34$ & 10.06 & $10 \cdot 13$ \\
\hline 245 & 9.94 & $9 \cdot 96$ & $11 \cdot 58$ & $11 \cdot 04$ & $11 \cdot 23$ & $\ldots$ & $11 \cdot 49$ & $10 \cdot 19$ & $10 \cdot 23$ \\
\hline 2.50 & $10 \cdot 10$ & $10 \cdot 05$ & $11 \cdot 70$ & $11 \cdot 18$ & $11 \cdot 35$ & $\ldots$ & $11 \cdot 60$ & $10 \cdot 29$ & $10 \cdot 33$ \\
\hline 255 & $10 \cdot 21$ & $10 \cdot 15$ & $11 \cdot 80$ & $11 \cdot 30$ & $11 \cdot 47$ & $\ldots$ & $11 \cdot 71$ & $10 \cdot 40$ & $10 \cdot 44$ \\
\hline 260 & $10 \cdot 31$ & $10 \cdot 25$ & $11 \cdot 90$ & $11 \cdot 40$ & $11 \% 9$ & & $11 \cdot 83$ & $10 \cdot 50$ & 10.54 \\
\hline 261 & & & & & & $11 \cdot 90$ & & & \\
\hline $\begin{array}{l}265 \\
268\end{array}$ & 10.41 & $10 \cdot 35$ & $12 \cdot 00$ & 11.51 & $11 \cdot 70$ & & 11.94 & $10 \cdot 60$ & $10 \cdot 64$ \\
\hline 270 & $10 \div 1$ & $10 \div 4$ & ... & $11 \bullet 61$ & $11 \ddot{8}_{0}$ & $\begin{array}{l}12 \cdot 10 \\
12 \cdot 18\end{array}$ & $12 \ddot{0} 8$ & $10 \ddot{7} 0$ & $10 \div \overline{7}$ \\
\hline 275 & $10^{\circ} 60$ & 10.53 & ... & $11 \cdot 73$ & $11 \cdot 91$ & & $12 \cdot 16$ & 10.80 & 10.85 \\
\hline 278 & & $\because \cdots$ & $\cdots$ & 1) & & $12 \cdot 30$ & $\because \cdots 0$ & 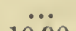 & $\cdots$ \\
\hline $\begin{array}{l}280 \\
284\end{array}$ & $10 \cdot 70$ & $10 \cdot 62$ & ... & 11.85 & $12 \cdot 02$ & 12.35 & $12 \cdot 28$ & $10 \cdot 90$ & $10 \cdot 96$ \\
\hline 285 & $10 \cdot 80$ & $10 \cdot 72$ & ... & 11.98 & $12 \cdot 14$ & & $12 \ddot{4} 0$ & $11 \cdot 00$ & 1006 \\
\hline 290 & $10 \cdot 90$ & $10 \cdot 81$ & ... & $12 \cdot 10$ & $12 \cdot 26$ & 12.55 & $12 \div 0$ & $11 \cdot 10$ & $11 \cdot 17$ \\
\hline 294 & (1) & . & $\ldots$ & & $\cdots$ & $12 \cdot 64$ & & & \\
\hline $\begin{array}{l}295 \\
298\end{array}$ & $10 \cdot 98$ & $10 \cdot 91$ & $\ldots$ & $12 \cdot 20$ & $12 \cdot 39$ & 10.75 & $12 \cdot 60$ & $11 \cdot 20$ & $11 \cdot 27$ \\
\hline 300 & $11 \cdot 08$ & 11.01 & ... & $12 \cdot 30$ & $1 \ddot{2} \ddot{0} 0$ & $12 \cdot 79$ & $1 \ddot{2} \ddot{7} 0$ & $11 \ddot{3} 0$ & 11038 \\
\hline $30 \overline{5}$ & $11 \cdot 18$ & $11 \cdot 11$ & $\ldots$ & $12 \cdot 40$ & 12.58 & 12.88 & 12.80 & $11 \cdot 40$ & $11 \cdot 48$ \\
\hline 310 & $11 \cdot 26$ & $11 \cdot 21$ & $\ldots$ & $12 \div 51$ & $12 \cdot 69$ & $13 \cdot 00$ & $12 \cdot 95$ & $11 \cdot 50$ & 11.58 \\
\hline 315 & $11 \cdot 36$ & $11 \cdot 31$ & $\ldots$ & $12 \cdot 62$ & $12 \cdot 80$ & $13 \cdot 10$ & $13 \cdot 08$ & $11 \cdot 60$ & $11 \cdot 69$ \\
\hline 320 & $11 \cdot 46$ & $11 \cdot 42$ & $\ldots$ & $12 \cdot 73$ & $12 \cdot 90$ & $\ldots$ & $\ldots$ & $11 \cdot 71$ & $11 \cdot 79$ \\
\hline 325 & $11 \cdot 56$ & $11 \cdot 52$ & $\ldots$ & $12 \cdot 85$ & $13 \cdot 02$ & ... & $\ldots$ & $11 \cdot 81$ & 11.89 \\
\hline 330 & $11 \cdot 63$ & $11 \cdot 64$ & $\ldots$ & $12 \cdot 98$ & $13 \cdot 15$ & $\ldots$ & $\ldots$ & $11 \cdot 91$ & 11.99 \\
\hline 335 & $11 \cdot 73$ & $11 \cdot 7 \bar{\hbar}$ & $\ldots$ & $13 \cdot 10$ & $13 \cdot 25$ & ... & $\ldots$ & $12 \cdot 02$ & $12 \cdot 08$ \\
\hline 340 & $11 \cdot 83$ & 11.85 & $\ldots$ & $13 \cdot 21$ & $13 \cdot 36$ & $\ldots$ & $\ldots$ & $\ldots$ & ... \\
\hline 345 & 11.93 & $11 \cdot 95$ & $\ldots$ & $13 \cdot 33$ & $13 \cdot 41$ & $\ldots$ & .. & ... & ... \\
\hline 350 & $12 \cdot 02$ & 12.05 & $\ldots$ & $13 \cdot 48$ & $13 \cdot 50$ & ... & ... & .. & ... \\
\hline $35 \%$ & $12 \cdot 11$ & $12 \cdot 15$ & $\ldots$ & $\cdots$ & $\cdots$ & $\ldots$ & $\cdots$ & ... & ... \\
\hline 360 & $12 \cdot 20$ & $12 \cdot 26$ & $\ldots$ & $\ldots$ & ... & $\ldots$ & $\cdots$ & $\cdots$ & \\
\hline 365 & $12 \cdot 30$ & $12 \cdot 40$ & ... & ... & $\cdots$ & $\cdots$ & $\cdots$ & $\cdots$ & ... \\
\hline 370 & $12 \cdot 40$ & $12: 50$ & ... & $\cdots$ & $\cdots$ & $\cdots$ & $\cdots$ & ... & ... \\
\hline 375 & $12 \cdot 50$ & $12 \cdot 55$ & $\cdots$ & $\ldots$ & ... & $\ldots$ & $\ldots$ & $\ldots$ & \\
\hline 380 & $12 \cdot 60$ & $12 \cdot 60$ & ... & & $\ldots$ & ... & ... & $\cdots$ & ... \\
\hline
\end{tabular}


Mr. Siemens explained the action of the two instruments, and showed their process in operation.

Mr. Crampton inquired whether the charcoal in the casing of the instrument would not get heated by the tube of high-pressure steam passing through it during the experiment, and so superheat the steam in the internal cylinder?

$\mathrm{Mr}$. Siemens explained, that it was not possible for such an effect to take place, as the end of the steam-pipe was exceedingly small, and was protected by a thick non-conducting.casing. He had also observed several times during the experiments, that whenever any priming took place in the boiler, and a drop of water came out with the steam, and fell on the bulb of the internal thermometer, the mercury fell immediately to $212^{\circ}$, or the boiling point of water, and remained steadily there for four or five minutes, until the whole of the priming water was converted into steam, when the mercury again gradually rose to its former temperature. This showed that the increased temperature above $212^{\circ}$ in the internal cylinder was entirely due to the extra heat in the expanded high-pressure steam, and not to any heat derived from the cliarcoal casing. As a check on the accuracy of the observations, he had tried them successively in an ascending and descending series, when an error from the source alluded to would have been apparent, and been doubled in effect, but he could not detect more than one degree difference in the observations.

In the discussion of the Paper

\section{"ON THE USE OF HEATED AIR AS A MOTIVE POWER," by Mr. B. Cheverton,}

Mr. C. W. Simurexs, ; after sketching a diagram explanatory of the action of Ericsson's engine, stated that he had not seen the machine, but he believed the description which had been given of

* Excerpt Minutes of Proceedings of the Institution of Civil Engineers, Tol. XII. Session 1852-1853, p. 345 et seq. 
the arrangement was substantially correct. He had followed its progress with considerable interest, having himself been engaged, for a number of years, in maturing an engine, in which steam was employed in a highly heated state.

The pistons being on their bottom stroke, the air from the reservoirs was admitted below, urging the working piston upward. Being heated, in its passage through the regenerator to $400^{\circ} \mathrm{Fahr}$., the volume of the air was increased in the proportion of 2 to 3 , and hence the reservoirs were deprived of only two-thirds the contents of a working cylinder of compressed air. An additional means of economising the supply of compressed air was, by shutting off the admission, before the upward stroke was completed, allowing it to act expansively.

The pumping cylinder had, in the meautime, discharged its contents of fresh atmospheric air into the reservoir, to make up for the supply of the working cylinder, so that the pressure of $10 \mathrm{lbs}$. per square inch was always maintained. The position of the slide-valve being then reversed, the air from beneath the working piston was free to escape into the atmosphere, but having to pass through the regenerator, the free and sensible heat contained in it was restored to the metallic wire gauze, in the inverse order to that in which it was taken up, issuing finally at a little above the temperature at which it entered from the reservoir.

The descending stroke was effected by the mere weight of the pistons. When completed, the position of the slide-valve was again altered, and the air from the reservoir entered and forced the piston upward. In its passage through the regenerator it absorbed the heat which had been deposited there, and with an additional supply from the fire, its rolume was again doubled, in filling the working cylinder.

Supposing the action of the regenerator could be made perfect. so that the air left the regenerator at exactly the same temperature at which it had entered, it might seem at first sight, that the engine would work without any expenditure of heat, beyond the mere losses from radiation, \&c.

This view had indeed been maintained by Captain Ericsson and others ; but upon consideration it became apparent, that there was a theoretical consumption of heat, which might be very accurately calculated, from the fact that the air entered the regenerator 
in a compressed state and returned through it, after expansion to atmospheric pressure had taken place. This expansion was accompanied by a diminution of temperature of some $70^{\circ}$ or $80^{\circ} \mathrm{Fahr}$., which became latent and had to be replaced by the fire.

The theoretical consumption of a perfect caloric engine, amounted to only one-fourteenth part of the theoretical consumption of a Boulton and Watt condensing engine. The practical arrangement of Ericsson's engine, however, rendered the attainment of such a result impossible, for the following reasons :-

Fully two-thirds of the power of the engine must be expended in working the air pump independent of the resisting pressure of the atmosphere, which was equal to three-fifths of the total working pressure. The consequence was, that to produce the effective displacement of the piston, for one single volume of air at its full pressure, from 7 to 8 volumes had to be cooled and heated alternately.

The working piston of Ericsson's engine had, moreover, to work air-tight in a heated cylinder, which $\mathrm{Mr}$. Siemens had practically found to be a matter of great difficulty. The lubricating material would become rapidly carbonized, and would fill up the meshes of the regenerator.

The extent of heating surface provided, also appeared to be too small for the quantity of heat required to be transmitted. It was understood, from good authority, that the present working cylinders of 14 feet diameter, were now being replaced by others of 16 feet, which was the greatest size the breadth of beam of the vessel would permit.

Mr. Armstrong's views required correction, owing to the evolution of heat in compressing the air in the pumps which would produce expansion and increased resistance. A corresponding cooling effect was, moreover, produced through its expansion in the working cylinder, which would diminish the power shown by him to be obtainable. These objections would, he expected, mar the anticipated results of this interesting experiment. 


\title{
ON THE CONVERSION OF HEAT INTO MECHANICAL
}

\section{EFFECT.}

\author{
By Charles Widuiam Siemexs," Assoc. Tnst. C.E.
}

Turs subject may be considered under three heads.

First, an inquiry into general qualitative and quantitative relations between heat and mechanical effect.

Second, the theoretical and practical consideration of actual engines, including those of Stirling and Ericsson.

Third, the definition of the characteristics of a perfect engine.

The first portion relates to a purely theoretical question, and would, separately considered, fall beyond the usual limits of discussion at this Institution; but the author is obliged to ask for an exception in his farour, finding it would be impossible to establish the ultimate object in view, without having proved his premises, which are based upon evidence of recent discoreries.

In discussing the succeeding heads he will have to rely, to a considerable extent, on his indiridual judgment and experimental researches.

First. On the relations between "Heat and Mechanical Effect."

The power obtained from a steam-engine depends upon the increase of volume given to the water in its transformation into steam, by the action of the fire under the boiler. Dr. Black observed, in 1763 , that the effect of the fire was, for the most part, required to effect the conversion, after the water had been raised to the temperature of the steam itself; and, moreover, that it made no difference whether the evaporation took place in the open air, or in a closed vessel under pressure. Upon these facts he grounded his theory, that steam was a compound of water and heat, which heat, on entering into combination with the water, lost its individual properties, or became latent.

This "material theory" of heat has been generally adopted, in preference to the "theory of undulation," according to which heat

* Fxcerpt Minutes of Procecdings of the Institution of Civil Engineers, Vol. XII. 1852-1853, pp. 571-590. 
is regarded as the undulatory motion of a supposed ætherial fluid pervading all nature.

The supporters of the material theory explain the different phenomena of sensible, radiant, and latent heat, by the free or combined state of their supposed fluids; the "specific heat of bodies by their different degrees of affinity for that fluid." The affinity of materials for heat is supposed to be invariably increased by increase of volume, and the evolution of heat, by friction between solids, is supposed to arise from permanent compression of their particles.

The latter supposition has been disprored by Sir Humphry Davy, who showed, that heat was evolved by friction between two pieces of ice, which caused them to melt, and could not, therefore, arise from permanent compression of the solid particles.

Dulong proved, moreover, that the specific heat of gases is the same before and after compression, showing that the heat lost in their expansion is not absorbed into the gas, and cannot be accounted for according to the " material theory." Joule, of Manchester, produced heat by agitating water in a closed vessel, and also by an electric current, which, in its turn, was produced by power, in turning the handle of a magneto-electric machine.

The latter experiments are not only proofs against the supposition that heat is material; but their greater value consists in showing an intimate connection between heat and the mechanical force by which it was produced, and they are the foundation of the "dynamical theory of heat."

According to this theory, in its general form, heat, mechanical force, electricity, chemical affinity, light, and sound, are but different manifestations of one great and infinite cause "motion."

Recent discoveries and experimental researches all accord with this great principle, which seems destined to open a new era of natural sciences.* Dulong and Gay-Lussac have proved, by their experiments on sound, that the greater the specific heat of a gas the more rapid are its atomic vibrations. Elevation of temperature does not alter the rapidity, but increases the length of those vibrations, and in consequence produces "expansion" of the bods.

* Vide Grove "On the Co-relation of Physical Forces," 1842 and 1850. 
The specific heat and temperature of a body determine the vibrating velocity of the material particles, the square of which multiplied by the weight of the particles, gives their inherent force, or " vis riva."

In solids the "vis viva" is least remarkable, in fluids it is greater, and in gaseous fluids it predominates so strongly over the gravitation, that the latter force becomes practically inappreciable.

Joule explains the elastic pressure of a gas by the rebound of its particles against the side of the vessel containing it, ${ }^{*}$ and proves the correctness of his views by calculation. If one side of a ressel gradually yields to the pressure, as is the case with a working piston, then the rebound of the particles will be less than their impact, and consequently the length of their vibrations must diminish, in proportion to the outward motion produced.

It is thus shown, that vibratory motion, or heat, is conrerted into its equivalent of on ward motion, or dynamical effect.

To express this equivalent by number, it is necessary to agree, in the first place, on an arbitrary unit of heat, which is usually the heat required to raise the temperature of $1 \mathrm{lb}$. of water through $1^{\circ}$ Centigrade, or Fahrenheit, and also, on a unit of mechanical effect, which is usually the "foot-pound," or the poiver required to lift $1 \mathrm{jb}$. through 1 foot. The data for these calculations may be taken from any materials, the specific heat and density of which are well known.

The nature of the material cannot affect the result, for if one should be more farourable to the production of mechanical force by heat than another, and the second be more favourable to the reverse process, it would follow that by a judicious selection of materials, a machine might be devised, which would reproduce more than its own cause of motion. This would be "to ascribe creative power to matter," in contradiction to the laws of nature.

The limits of this paper do not permit of the train of reasoning, by which the numerical equivalent of power for heat has been ascertained, in different ways, by English, French, and German natural philosophers, within the last ten years; the author must, therefore, content himself with merely mentioning their names and

*Vide Transactions of Philosophical Society of Manchester, 1848. 
publications. Carnot and Clapeyron produced the first general formulæ, which contained, however, an uncertain function, and were still based upon the supposition that heat was material.* Holtzman, of Manheim, in pursuing the views of Carnot and Clapeyron, obtained a complete mathematical solution in $1845 . \dagger$ Joule, of Manchester, solved the problem experimentally about the same time. $\neq$

The "dynamical theory" was 'more fully developed by Helmholtz in $1847, \S$ and Mayer.\| Mr. W. J. M. Rankine, C.E., and Professor Thomson, of Edinburgh, have much extended the dynamical theory of heat, and applied the same to calculate the power of steam and air engines. T

II. Regnault, of Paris, has, by careful experimental researches on the total heat of steam, \&c., ** provided some important data for the development of the dynamical theory of heat.

The following are the results obtained in units of power, or foot lbs., for one unit of heat, by different authors :-

\begin{tabular}{|c|c|c|}
\hline & $\begin{array}{c}\text { Centigrade } \\
\text { Thernometer. }\end{array}$ & $\begin{array}{l}\text { Fahrenheit's } \\
\text { Thermometer. }\end{array}$ \\
\hline $\begin{array}{l}\text { By Holtzman's formula. } \\
\text { By Joule's experiments } \\
\text { By Rankine's formula } \\
\text { By Thomson's formula } \\
\text { For the best Cornish engine, by M. de } \\
\quad \text { Pambour } \\
\left.\begin{array}{l}\text { For a perfect low-pressure condensing } \\
\text { engine . } \\
\text { For an actual Boulton and Watt's engine }\end{array}\right\}\end{array}$ & $\begin{array}{l}1227 \text { foot lbs. } \\
1386 \quad " \\
1252 \quad " \\
1390 \quad " \\
148 \text { ", } \\
90 \cdot 8 \quad, \\
46 \quad,\end{array}$ & $\begin{array}{l}682 \text { foot lbs. } \\
770 \quad " \\
695 \quad " \\
772 \quad: \\
82 \quad " \\
50.4 \quad, \\
25.5 \quad "\end{array}$ \\
\hline
\end{tabular}

The comparatively small effect produced by the steam-engine of the present day would seem to indicate that there is still much room for improvement.

Practical engineers will probably receive with incredulity, and

* Vide Annales de Chimie et Physique, XXIII.

+ Vide his pamphlet "Ueber die Waerme und Elasticitaet der Gase und Daempfe."

$\ddagger$ Vide Transactions of the Philosophical Society of Manchester, Vol. XVIII.

$\$$ Vide Ueber die Erhaltung der Kraft.

II Vide Mechanische Aequivalent der Waerme, 1851.

T. Vide Transactions of Royal Society of Edinburgh, 1849-1850 and 1850-1851.

** Vide Comptes Rendus. 
certrinly derive but little advantage from, the preceding numerical statement, the result of abstract calculation, unless it can be proved by simple demonstration, and in such a manner that the essential difference between the actually and the theoretically perfect engine is clearly pointed out.

The author proposes to accomplish this by means of a diagram (Fig. 1, Plate 5), which is, in effect, the expansion curve of saturated steam indefinitely prolonged.

The vertical lines and figures at the bottom signify the pressures of saturated steam in lbs. per square inch; the horizontal lines and figures on the sides denote the volume of steam compared with the volume of water from which it is prodnced; and the horizontal lines, with figures on the curve, express the temperatures of the steam corresponding to the pressure and volume of the same.

The outer curre, $a$ a $a$, is that usually employed in calculating the power of expansion engines, being the expression of Watt's law "that the total heat in steam is the same at all pressures."

The inner curve, $b b q$, is the corrected one, in accordance with the recent discoveries of Regnault, "on the total heat of steam," * and may be termed "the curve of equal heat."

The fields between the horizontal dotted lines represent the power giren out by the steam, in losing equal decrements of $10^{\circ}$ of temperature in its expansion, and it is important to obserre, that the areas of these fields are nearly alike, between the limits to which the pressure and temperature of steam are experimentally known, increasing only slightly, and in a uniform ratio inrersely as the temperatures.

This gradual increase may be ascribed to the fact, that the curve in question is one of equal heat, whereas it has been shown, that in expanding behind a working piston, the steam must lose heat in the dynamical proportion to the power giren out.

Messrs. Rankine and Clausius have first drawn attention to this circumstance, and proved that the expansion of steam, behind a piston, must be attended by partial condensation.

* Vide the Publications of the Carendish Society, Vol. I.

voL. I. 
On the other hand, experiments made by the author* prove that steam, when expanded spontaneously, is superheated steam, being a verification of Regnault's discovery, that the total heat of steam increases with its pressure.

When steam is expanded behind a working piston the excess of free heat is first absorbed, or changed into dynamical effect, and if that does not suffice, partial condensation must take place. It appears, however, to the author, that Messrs. Rankine and Clausius undervalue the amount of free heat, and, therefore, overestimate the amount of condensation during expansion, by taking the specific heat of steam at 0.305 (Regnault's co-efficient of increasing heat), which there seem good reasons to believe is far too low, because :-

1st. The specific heat of an elastic fluid must be proportionate to its rate of expansion by heat. It has been shown, however, in experiments instituted by the author above referred to, that the rate of expansion of steam near its point of saturation is about three times greater than that of air at the same temperature, which would make its specific heat $3 \times \cdot 267=\cdot 801$, diminishing howerer rapidly with the increase of temperature.

2nd. The actual forms of diagrams, taken from the best expansive steam engines, do not show the effect of condensation : the ordinates of the lower portion of the curve are indeed higher than those given by Watt's law, starting from the same point. This is shown by Fig. 2, Plate 5, which is a diagram taken from the Old Ford Engine, by Mr. W. Pole, $\dagger$ in which $a a a$ is the actual curve, $b \quad b \quad b$ the curre representing Watt's law, and $c c c$ the curve of equal heat. The rise of the actual curve towards the end may in part be owing to the generation of steam from the heated sides of the cylinder's ; but it could not be supposed that the effect of such generation would equal that of spontaneous condensation throughout the body of the steam. Moreover the actual curve proves to be almost the perfect dynamical curve, as is proved by the equal areas, or fields of power, obtained by drawing lines from points of the curve of equal progression of temperature. If the limits of the sheet of diagrams had admitted of a con-

* Vide Proceedings of the Institution of Mechanical Engineers, for June 1, 1852 , p. 24, ante.

$\dagger$ Vide Treatise on the Cornish Engine, by W. Pole, Part III. 
tinuation of the curve horizontally (Fig. 1, Plate 5), it wonld luve exhibited continually decreasing volumes, and increasing temperatures, until finally a point would have been reached, where the volume of the steam was equal only to the water producing it. It may be assumed, that the temperature would, at that point, be $640^{\circ}$ Centigrade $\left(1180^{\circ} \mathrm{Fahr}\right.$.), or in other words, that the entire heat of the stean wonld be sensible. Supposing this steam (which would hare at least 2,000 lbs. pressure per square inch) could be introduced below a piston, and in giving out its power be expanded, until its temperature was reduced to zero, then the entire 640 degrees of heat would have been converted into their equivalent of power, of which the field of the diagram would represent the integral. The theoretical equivalent of mechanical force for heat is thus represented to the eye; and in computing the area of the entire figure, it is found to coincide nearly with, but somewhat to exceed, the results of abstract calculation and of Mr. Joule's experiments. That portion of the diagram (Fig. 1) which is shaded darker than the rest, represents the power of a perfect low-pressure condensing engine ; it covers only about 1-14th part of the entire area.

The diagram shows that the expansive steam-engine would be theoretically a perfect engine, if the water was heated in a close boiler to $1180^{\circ}$ Fahr., and being then introduced below the working piston, under a pressure of at least 2,000 lbs., would resolve itself entirely into steam, and was allowed to expand 2000 times before it was discharged into a vacuous space, which, in this case, would not necessarily be a condenser. The impracticable nature of such an engine is manifest, and it becomes necessary to seek for other means of obtaining from heat its full value of power.

It may not be considered out of place to mention here, the wellknown experiments on steam-guns by Mr. Perkins, which went far to prove the actual possibility of charging water with sufficient heat, in close vessels, that, upon liberation, it would resolve itself entirely into steam.

Before leaving this part of the paper, it will be necessary to show the effect produced by the expansion of air, or any other permanently elastic fluid, under a working piston. In the diagram (Fig. 3, Plate 5), the figures on the base and vertical 
lines denote the pressure in lbs. per square inch, and the figures un the side denote volumes of air, as compared with the volume of the same weight of water. The curve $a$ a $a$ represents Marriotte's law, and is a curve of equal heat. The curve $b b b$ is the dynamical curve, representing the real rate of expansion of air, behind a working piston. The difference between the two curves arises from the loss of sensible heat, which is converted into effect. The figures upon the curve show the rate of progression of temperature, in compressing air of atmospheric pressure at $60^{\circ} \mathrm{Fahr}$.

In constructing this curve, the specific heat of air at constant volume has been taken at 267 as determined by Delaroche and Bernard. It furnishes itself at least an approximate proof of the correctness of this number, because the curve agrees with the observed fact, that in compressing air, to donble its original pressure, its temperature is raised $70^{\circ} \mathrm{Fahr}$. The dotted horizontal lines limit the uniform fields of power obtained for every $10^{\circ}$ decrease of temperature. This curve is directly applicable to air, which when reduced to atmospheric pressure has a temperature of $60^{\circ} \mathrm{Fahr}$. It can, howerer, easily be corrected, for any degree of temperature, by adding the difference of temperature at a corresponding pressure throughout, and by adding to each volume the same difference of temperature, divided by 508 (the ratio of expansion of air at $60^{\circ} \mathrm{Fahr}$.) *

Secondly. - " On the performance of actual engines, including the air-engines of Stirling and Ericsson."

* The dynamical theory of heat must not be considered the creation of the last few years, but, like all abstract truths in nature, it seems to have presented itself to the ninds of the greatest philosophers in all ages, to be, after them, again superseded by theories moulded, as it were to order, to explain some isolated phenomenon, such as the radiation of the sun, the leating flame of a fire, or the latent heat in steam; until at length the means of observation were sufficicntly perfected to cover with absolute proof, what could before be reached only by the imagination. it may here be mentioned, as instances, a quotation by Barn Humboldt from Aristotle, "who considered the first principle in nature to be a unity in all its manifestations, and the manifestations themselves he reduced always to motion as their foundation." Again, in Lord Bacon's Aphorisms, the chapter on "The first Vintages of the Force of Heat," occurs the following remarkable passage :- "From the instances taken collectively, as well as singly, the nature whose limit is heat, appears to be motion." And further on, - "But that the very essence of heat, or the substantial self of heat, is motion, and nothing else limited," \&c., \&c. Bacon fails, however, in his attempts to prove his philosophy, in confounding the visible motion of heating water, or of fire, with the intrinsic motion of the particles that manifests itself as heat. 
In accordance with the principles put forth, the power of an engine is expressed by a simple formula :

$$
\text { Ind. H.P. }=\frac{a c}{38,000}\left\{r p-p^{\prime}+\frac{r A\left(t-t^{\prime}\right)}{v}\right\}
$$

in which $c$ is the relocity of the piston in feet per minute; $a$ the area of the same in square inches; $t$ the temperature of the steam, or air, on entering the cylinder; $t^{\prime}$ its temperature on leaving the same; $v$ expresses the volumes of the steam, or air, on entering the cylinder, as compared to one volume of water; $r$ the ratio of expansion, or fraction of stroke at which the supply is shut off; A a constant, denoting the mechanical equivalent, per unit of heat, being (as shown by the diagrams) for steam = 400 , and for air $=0.267 \times 400=106 ; p$ the pressure of the fluid on entering the cylinder (pressure in boiler) in lbs. per square inch; and $p^{\prime}$ the pressure against the working piston (back pressure) in lbs. per square inch.

The power required to work air, or feed pumps, has to be deducted froin the result of this formula.

Take, for example, an expansive and condensing steam-engine of 16 inches diameter and 200 feet velocity of piston; the total pressure of steam in the boiler $60 \mathrm{lbs}$, cut off at one-fourth part of the stroke; the racuum in the cylinder averaging $11 \mathrm{lbs}$. (having $4 \mathrm{lbs}$. resisting pressure); the initial temperature of the steam $=295^{\circ}$; and the final temperature $t^{\prime}=207^{\circ}$ Fabr.; the volume at $60 \mathrm{lbs}$. pressure would be $=460$ (see diagram, or any table on the pressure, temperature, and volume of steam).

The indicated horse-power of this engine will be $\left.=\frac{201 \times 200}{33,000}\left(0.25 \times 60-4+\frac{0.25 \times 400(295-207}{460}\right)\right)=36.75$.

The eraporation in the boiler is $2 \frac{r a c}{2 \cdot 4 v}=9 \cdot 1$ cubic feet of water per hour.

The result agrees with that obtained by the usual method of computing the contents of the expansion curve, and is certainly more accurate and more expeditiously arriced at.

For non-expansire engines, the factor: $\frac{r\left(t-t^{\prime}\right)}{v}$ has no ralue, because $t=t^{\prime}$, and $r=1$. 
In applying this formula, to ascertain the porrer of an airengine, the value of the constant $A$ is $=106$, as shown by the diagram, Fig. 3, Plate 5.

If the object is to ascertain merely the relative economy of an engine, as compared with a perfect engine, it suffices to determine-

1st. The total units of heat which are imparted to the working fluid, and, 2nd, the units of heat which disappear in producing useful effect; and inasmuch as the former exceed the latter, so the engine falls short of producing a full equivalent of mechanical effect for the heat expanded.

Take the example of an air-engine consisting of a working cylinder, $A$, an air-pump $B$, and a reservoir $D$ between them (Fig. 4, Plate 5). To obtain the greatest effect, the admission of air into the working cylinder should, under all circumstances, be so regulated, that it may expand down to atmospheric pressure before it is discharged.

Supposing that nothing was known of the proportion between the cylinders, of the working pressure, or of the rate of expansion, but that the temperature of the air was known to be,-

$60^{\circ}$ Fahr. On entering the pump at $m$.

$130^{\circ} \quad$, On entering the ressel $\mathrm{D}$, which would be the case if compressed to half its original volume.

$710^{\circ}, \quad$ On entering the working cylinder, which would be the heat required to double its volume at constant pressure, and

$570^{\circ}, \quad$ On being discharged, having lost $140^{\circ}$ in its expansion down to the atmospheric pressure.

Then the heat supplied by the fire would be $=710-130=$ $580^{\circ}$ Fahr: and the difference of temperature of the air, on entering and on leaving the en gine, would be $=570-60=$ $510^{\circ}$ Fahr. It follows, that $580-510=70^{\circ}$. of heat have been converted into their equivalent of mechanical effect, and the duty performed by the engine, for every one unit (Fahr.) of heat employed, is $=\frac{70}{580} 770=91 \cdot 2 \mathrm{lbs}$. lifted 1 foot high.

The expansive air-engine is, therefore, theoretically superior to Boulton and Watt's condensing engine, but inferior to a good 
expansive engine. Practically considered it is certainly inferior to both, because one-lialf of the gross power of the working piston is absorbed by the pump, and the losses by friction and leakage are trebled in consequence. Moreorer, it has been found by its earliest promoter, Mr. Stirling, of Dundee, that the working of a tight piston, in a highly-heated cyliuder, is attended with almost insurmountable difficulty.

The most essential difference between the steam-engine and the air-engine is, that in the former, the unproductive heat is expended in the boiler, where it becomes latent, in effecting increase of volume without displacement of the piston, whereas, in the latter, it presents itself as free heat at the exhaust port.

Mr. Stirling, and after him Captain Ericsson, in taking advantage of this circumstance in favour of the air-engine, employed the free lost heat to warm the fresh air on entering the reservoir from the pump.

Ericsson constructed an engine on this plan, in 1833, which, according to received accounts, worked with considerable economy of fuel, but failed, in consequence of a defective heating apparatus, and the continual derangement of the working piston in a heated cylinder.

The apparatus he employed for recovering the lost heat rcsembled a locomotive boiler, through the tubes of which the co!d air passed, while the heated and expanded air circulated in the opposite direction, through the intervening spaces. He termed this apparatus the "legenerator," because he supposed, that by its means the same heat might be used perpetually over and over again, to produce motive power.

Stirling, of Dundee, patented an air-engine in 1816, and improrements in 1827 and in 1840. He constructed one of these machines, an account of which he brought before the Institution in 1845.* In it he had combined several importau advantages over former attempts, namely-

1st. The hot working piston was dispensed with.

2nd. The working pressure was increased, by using the same body of highly-compressed air over and over again.

* Vide Minutes of Proceedings of the Institation of Civil Engincers for 1845, Vol. IV. p. 348 . 
3rd. The reabsorption of the waste heat was carried out to greater perfection, by means of a series of thin iron plates, presenting a very large aggregate surface, which were held a small distance apart by fillets, to allow of the passage of air between them.

The lower extremities of these plates were heated by the fire to about $650^{\circ}$ Fahr., while the upper extremities were maintained at the lowest possible temperature, by coils of cold-water pipes. The air was made to pass to and fro between the same surfaces, for every stroke of the engine, by means of a large displacing plunger, which was not required to work tight in its cylinder. In descending, the air absorbed heat, in the gradual proportion of the increasing temperature of the plates, and in consequence its elastic pressure was increased during the ascending stroke. By the reverse process, a fall to the former temperature and a decrease of pressure, inversely proportionate to the temperature and the space occupied, was effected, which space was, in the meantime, increased by the amount of the capacity of the working cylinder.

The opposite ends of the working cylinder communicated with two distinct heating apparatuses, the displacing plungers of which were attached to the opposite ends of a beam and made stroke, while the working piston was on its dead centres.

The excessive pressure of the heated air, beneath the one, over the cold air above the other displacing plunger, constituted the working pressure ; and the capacities of the displacing cylinders had to be so proportioned to the working cylinder, that the working pressure was not exceeded by the resisting pressures at the end of each stroke; or supposing the rolume of the air was doubled by the heat, it follows, that the net capacity of each displacing cylinder had to be equal to at least twice the capacity of the working cylinder.

Fig. 5, Plate 5, is a theoretical diagram of Stirling's engine; the curve $a$ a $a$ represents the entire expansion of the air, from the time when it is all confined in the heated space, below the displacing plunger, to the moment when it occupies the cold extended space, above the displacing plunger, and the working cylinder. The power due to this expansion is measured by the field $a$ a $a x y z$, and is equivalent to 123 units of heat, as shown 
by Fig. 8 , Plate 5 ; whereas the power actually imparted to the working piston is represented by the portion of the diagram marked $b b b$, the corners of which are rounded off, in the ratio produeed by the two cranks working over right angles, and is equivalent to 27.5 units, being about $\frac{2}{6}$ th parts of the entire area. The field $\begin{aligned} & b \\ & b\end{aligned} \quad b \quad y \quad z$, immediately below the sectioned portion, represents the back pressure on the working piston, or the power required to force the air from the working cylinders baek into the displacing ressels.

The theoretical effect produeed by a Stirling's engine, is to that of a perfect engine, as the units of heat expended in the entire expansion to the units producing useful effeet, or as 123 to $27 \cdot 5$.

There remains to be eonsidered the necessary meehanical loss of heat, owing to the differenee of temperature between the air on entering the eool ends of the metallie plates (the regenerators), and on returning from the same, which loss has been proved, by experiments hereafter to be explained, to amount to about $25^{\circ}$ Fahr., or to $\frac{3}{4} \times 25=19^{\circ} \mathrm{Fahr}$. if distributed upon the entire quantity of air employed, beenuse only three-quarters of the same are actually heated each time.

The real effect of a Stirling's engine, as eompared with a perfect engine, is therefore as $123+19: 27 \cdot 5=5 \cdot 16: 1$, or it yields the power of $\frac{770}{5 \cdot 16}=149 \mathrm{lbs}$. lifted 1 foot high, for every water unit of heat expended.

It follows from the abore, that the Stirling's engine converts into dynamical effect about one-fifth of the heat supplied, which is about equal to the performance of the best Cornish engines.

For calculating the aetual power of a Stirling's engine of given proportions; the formula assumes the following more simple form :-

Ind. H.P. $=\frac{a c}{33,000} \times \frac{A\left(t-t^{\prime}\right)}{5 \cdot 16 v}$ in which $A=106$ and $t-t^{\prime}$ the deerease of temperature, by the expansion of the air from the greatest to the lowest pressure.

The cause of the failure of $\mathrm{Mr}$. Stirling's engine in practice may apparently be traced, chielly to insuffieieney of heating 
surface, occasioned apparently from misapprehension of the principle involved, it having been thought that the same heat would serve over and over again to produce power, and that the necessary expenditure of heat consisted only in the mechanical loss by imperfect action of the respirative plates, which were approached to each other to the utmost limits, consistent with an unobstructed passage of the air.

By the aid of the dynamical theory of heat it has been shown, that there is another and far more important expenditure of heat which should have been provided for.

Another great practical defect in Stirling's engine, arises from the necessity of providing a reservoir of highly-compressed air to start with, and from the difficulty of preventing the escape of that stock of air, through the stuffing-boxes, \&c.

Ericsson patented in 1851 another form of engine, which has lately been executed on a gigantic scale and continues to excite public attention.

This engine, of which Fig. 6, Plate 5, represents the theoretical diagram, differs from the expansive air-engine (Fig. 4, Plate 5), only in the application to it of Stirling's respirator, or regenerator, and in the proportion between the capacities of the working and pumping cylinder, which in his engine are as three to two. $A$ is the working cylinder, the bottom of which is made of wrought iron, and exposed to the fire ; $B$ is the pumping cylinder, which draws in atmospheric air through the ralse $u$ and delivers it into the air reservoir $C$ through the valve $v ; D$ is a slide valve, regulating the admission of air to and from the working cylinders ; $E$ is the respirator, or regenerator (a box filled with wire gauze), which is heated at the bottom by the fire, but is maintained cool towards the upper end, by the alternate rush of cold air downwards: The top of the working cylinder and the bottom of the pumping cylinder are left open to the atmosphere, and the two pistons are attached to the same rod by which motion is imparted to the crank.

The pressure in the air reservoir $C^{\gamma}$ is said to be maintained at $10 \mathrm{lbs}$. per superficial inch $(=25 \mathrm{lbs}$. total pressure). In the diagram, the figure $a b c d_{\text {s }} e$ represents the entire pressure below the working piston amolnting to $28 \mathrm{lbs}$. pressure per inch, up to the point $c$, where the admission is supposed to be cut off, in order 
to expand the air down to atmospheric pressure, before it is discharged, whereby the maximum eflect will be obtained. From this gross effect has to be deducted, first the resisting pressure of the atmosphere against the working piston, which is represented by the field $a b f e$, and secondly the power absorbed by the pumping cylinder. $B$, as represented by the field $b g h f$. By laying this field of resistance upon the field of power $b c d f$ of the working cylinder, there remains the field $b c d h g$ representing the entire effective pressure upon the working piston. This pressure amounts, on the average, to nearly 3 lbs. per square inch on the working piston.

In order to estimate the comparative economy of Ericsson's engine, it is necessary to consider the total quantity of heat absorbed for one revolution, the proportion of it which is transferred into useful effect, and the difference between the two, which of necessity escapes in the form of sensible heat.

If the atmospheric air enters the pumping cylinder at a temperature of $60^{\circ}$ Fahr., it will be raised, by compression, to $10 \mathrm{lbs}$. additional pressure and to a temperature of $111^{\circ} \mathrm{Fahr}$., as is shown in the dynamical diagram (Fig. 3, Plate 5).

This air has to be heated on its passage to the working cylinder, so that its volume is increased in the proportion of two to three, in order that the air delivered by the pumping cylinder may each time suffice to fill the working cylinder. To effect this it must be heated to $391^{\circ} \mathrm{Fahr}$.

The expansion that takes place in the working cylinder will reduce that temperature to $314^{\circ}$, which is the temperature at which the pumping cylinder full of air at $60^{\circ}$ will fill the working cylinder of one-half greater capacity (for $\frac{508}{2}+60=314$ ).

The temperature lost, during expansion in the working cylinder, is $391-314=77^{\circ}$, which must be supplied to it again by the fire, before it reaches the respirator, in order not to cool down its lower extremity, and $25^{\circ}$ in addition, to make up for the loss, on account of the imperfect action of the same.

The air issues into the atmosphere at a temperature $25^{\circ}$ above that of the upper extremity of the respirator, or at $111+25=136^{\circ}$ Fahr., being $136-60=76^{\circ}$ hotte; than when it entered. 
- Therefore-

The total heat supplied to the air $=77+25=102^{\circ} \mathrm{Fahr}$.

The sensible heat carried off $\quad=136-60=76$ "

There remains the heat absorbed by being converted into effect . . . . . . $26^{\circ}$ Fahr.

Or the Ericsson engine produces the effect of $\frac{26}{102} 770=196 \mathrm{lbs}$. lifted 1 foot high, for every (water) unit of heat expended.

This proves, that the Ericsson engine realises, theoretically, nearly one-fourth the effect of a perfect engine, and would possess a considerable advantage over any of those before considered, but for the following serious imperfections :-

1st. Its gross working pressure has been demonstrated to be 3 lbs. per square inch, but the engine being single-acting, the true avernge pressure is only $1 \frac{1}{2} \mathrm{lb}$. per inch, and supposing the engine will move with $\frac{1}{2} \mathrm{lb}$. pressure per inch upon the working piston, its mere friction will absorb one-third of the whole porrer.

2nd. The working piston has to move air-tight in a heated cylinder, which by former attempts has been proved to be attended with great practical difficulties. These are no doubt reduced, by the air being heated in a smaller degree than had been attempted before; but the temperature still remains sufficient to carbonise the lubricating material, and by affecting the shape of the cylinder, to cause leakage.

3rd. The available heating surface of the engine is confined to the bottom surface of the working cylinder, and to the passage leading to the regenerator.

Taking into account the intermittent action and slow heatabsorbing power of the air, the heating surface of an air-engine should, in the opinion of the author, not be less than 6 superficial feet for $1 \mathrm{lb}$. of coal consumed per hour, or about seven times larger than in the engines of the "Ericsson."

4th. The weight, bulk, and first cost of Ericsson's engine are inversely proportionate to its low working pressure and slow speed.

5th. Incidental losses of heat, by radiation from the large exposed surface of the heated cylinder, necessitate a very considerable addition to the expenditure of fuel. 
The engines of the "Ericsson" are said to consist of four working cylinders of 14 feet diameter and 6 feet stroke, making upwards of 14 strokes per minute.

Their collective indicated H.P. is $\frac{4 \times 21168 \times 84 \times 3}{33,000}=676$, from which must be deducted 33 per cent. for friction of pistons alone, and say 27 per cent. for friction of general machinery and of the air in rushing through the regenerator ; in all 60 per cent., learing 271 actual horse power.

There still remains one distinct class of engine for consideration, namely, the combined steam and ether engine. This consists of an ordinary steam engine with a tubular condenser. Instead of the cold water, which is usually admitted into the chamber surrounding the tubes, ether, or chloroform, is substituted, which, it is well known, boil at a temperature far below the boiling-point of water, and therefore will generate their own rapours, under a considerable pressure, by the heat giren off by the steam in the act of ccndensation. The vapours of ether, or chloroform, are made to give motion to a second engine, and are in their turn condensed by very cold water.

It would seem, at first sight, that by this ingenious arrangement the power obtained for a given quantity of fuel was doubled, if compared with the performance of the steam engine alone; but the preceding investigations will have proved, that the heat imparted to the ether must fall short of that giren out under the steam boiler, in proportion as the heat is changed into the dynamic effect obtained from the steam engine. The additional effect of the ether engine might indeed be obtained at once from the steam, if the expansive action of the steam was sufficiently extended; considering, however, that an engine, in which the steam is expanded at one-third part of the stroke, absorbs only about oneeighth portion of the entire heat of the steam, and considering also that it is rery inconvenient to extend the rate of expansion much further, in rotary engines, there remains, at present, a considerable advantage in favour of the combined steam and ether engine, if the practical difficulties inrolved, such as the tightness of the joints, are not taken into account. Supposing the dynamic equivalent, per unit of heat obtained by the cngine, to be 90 foot-lbs., that of the ether engine may be taken at two-thirds, 
or 60 foot-lbs., making a total of 150 foot-lbs.,-which nearly equals the performance of the best Cornish engines.

The following table is intended to convey a more distinct idea of the comparative merits of the different steam and air engines referred to.

\begin{tabular}{|c|c|c|c|}
\hline Description of Engine. & $\begin{array}{l}\text { Theoretical } \\
\text { Performance } \\
\text { in Foot-lbs. }\end{array}$ & $\begin{array}{l}\text { Actual } \\
\text { Performance } \\
\text { in Foot-lbs. }\end{array}$ & $\begin{array}{c}\text { Actual } \\
\text { Perfornuance } \\
\text { in lbs, of Coal } \\
\text { per H. P. } \\
\text { per hour. }\end{array}$ \\
\hline $\begin{array}{l}\text { A Boulton and Watt condens- } \\
\text { ing engine, low pressure }\end{array}$ & $51 \cdot 8$ & $2 y^{*}$ & $8 \cdot 00$ \\
\hline The best Cornish engine & $158 \cdot 8$ & 82 & $2 \cdot 38$ \\
\hline $\begin{array}{l}\text { Combined steam and expan- } \\
\text { sive ether engine }\end{array}$ & $150 \cdot 0$ & $75^{\circ}$ & $3 \cdot 09$ \\
\hline The expansive air-engine . . & $91 \cdot 0$ & $3 \%$ & $6 \cdot 63$ \\
\hline Stirling's engine . . & $130^{\cdot} 0$ & $65 \cdot$ & $3 \cdot 57$ \\
\hline Eriesson's engine. & $1960^{\circ}$ & 65 & $3 \cdot 57$ \\
\hline A perfect engine & $770 \cdot 0$ & $385^{\circ}$ & $0 \cdot 60$ \\
\hline
\end{tabular}

The statements of the actual performance of air-engines must be considered as only rough approximations, as it is not possible to calculate losses of heat, with any degree of precision. The actual performance of the "Ericsson" engine may be deemed too low, considering its theoretical superiority; but the author considers the disproportion to be fully accounted for, by the extraordinary losses of useful effect, arising from the exposure of the heated cylinder, and the low working pressure.

In Stirling's engine, the heated cylinder is closed and surrounded by flues and brickwork, in consequence of which, its economical effect is thought to be equal to that of Ericsson's engine, although it is in theory inferior.

Thirdly. "On the necessary characteristics of a perfect engine."

In the first part of this paper it has been shown, that an engine would be theoretically perfect, if all the heat applied to the elastic medium was consumed in its expansion behind a working piston (or its substitutes, such as a disc, a flexible bag, \&c.) leaving no portion of it to be thrown into a condenser, or into the atmosphere. In the second part, several actual engines have been examined, with a view to test their degree of theoretical and practical perfection. Such an inquiry should have for its end, 
the attainment of some moro perfect result than could hitherto be obtained. The author will therefore attempt to state his views of the characteristics of a perfect engine.

1st. All the elastic material employed should actually enter the working cylinder (or its substitute), and produce its full value of effective displacement of piston, without deduction for the resisting pressure, or the working of pumps.

2 nd. The production of the elastic material, previous to its entering the working cylinder, should not require a continuous expenditure of heat, or in the case of the steam-engine, the latent heat expended in the boiler should be recovered.

3rd. That working material is the best which is capable of receiving the largest possible quantity of heat in a giren space. Its temperature and pressure should be raised to the highest point which the vessel containing it will admit of, but on leaving the working cylinder, the temperature should be reduced to a minimum. This may be accomplished, either by infinite expansion, or practically by the application of a regenerator.

4th. Losses of heat by radiation and leakage, should be reduced to the smallest possible amount, by working at high pressure and relocity, and by corering all heated surfaces with non-conducting materials. These losses being, proportionally, more to be apprehended in a perfect, than in an imperfect engine.

5th. Large and compact heating surface and considerable body of material are essential, to attain a high temperature, without rapid destruction of the vessels.

6th. No working part of the engine should be brought into contact with highly-heated material.

The respirator, or regenerator, is undoubtedly a useful agent, for recovering the free, or otherwise unprodnctive heat of a caloric engine, and the following experimental investigations on its action, by the author, may not be thought deroid of interest.

The annular space between two concentric cylinders was fitted with 750 brass strips, each 5 feet 9 inches long, and held $\frac{1}{16}$ th of an inch apart from each other, by projecting ribs upon erery alternate strip. The internal cylinder contained a piston, with an enlarged hollow piston rod, passing through a stuffing-box, and was worked to and fro by an engine. The lower extremity of the 
external cylinder was heated by a fire to $650^{\circ}$ Fahr., as indicated by the pyrometer, and was maintained at that temperature.

A second, or charging cylinder was provided, which by the motion of its working piston, alternately withdrew and returned the same air to the first cylinder. The capacity of the charging cylinder was 24 cubic feet, and its piston made 18 strokes per minute : about two-thirds of its contents, or 16 cubic feet of air of atmospheric pressure, passed with each stroke, to and fro through the respirator, and all the heat carried away was absorbed by the sides of the cylinder. 'After $2 \frac{1}{2}$ hours' working, the temperature of the charging cylinder was raised from $60^{\circ}$ to $110^{\circ} \mathrm{Fahr}$. $\left(50^{\circ}\right)$. Its capacity for heat had been previously ascertained, by suddenly admitting steam, and weighing the condensed water obtained (in heating it from $60^{\circ}$ to $210^{\circ}$ Fahr.) $\left(150^{\circ}\right)$, which amounted to about $54 \mathrm{lbs}$. The quantity of air which passed from the respirator into the cylinder was 43,200 cubic feet, and its weight $3860 \mathrm{lbs}$ : this, if multiplied by its specific heat 0.267 , is equal to $897 \mathrm{lbs}$. of water-power of absorbing heat. The heat given off was $\frac{50}{150} 1000=18000$ units, and consequently the air left the respirator, each time, at a temperature of $\frac{18000}{897}=20^{\circ} 01^{\circ}$ nigher than that at which it entered. Adding to this, for loss of heat by radiation during the experiment, which according to established rules may be taken at $5^{\circ}$, the entire loss of heat by the respirator amounts to $25^{\circ} \mathrm{Fahr}$. when air is employed. In using steam it does not exceed $10^{\circ} \mathrm{Fahr}$, owing to the greater conducting power of that fluid.

The regenerator condenser, which was designed and executed some years ago by the author, is an illustration that water may be also subjected to respirative action.

The paper is illustrated by a series of diagrams from whence Plate 5 is compiled.

Mr. Siemexs explained, that the diagrams were chiefly intended to illustrate the peculiar functions of the "respirator," or as Mr. Ericsson had termed it, the "regenerator." Very conflicting opinions had been expressed regarding this most essential element in Ericsson's engine. Some thought that, by its agency, the heat 
used to effect a stroke of the engine could be wholly recovered, except accidental losses, and that, theoretically, it involred the accomplishment of a perpetual motion. Others, on the contrary, contended that the regenerator was only an obstruction to the passage of the air, and of no ntility whatever. He had endeavoured to prove in his paper, that neither the one extreme view, nor the other was correct; that, indeed, the respirator might be usefully employed, to recover that portion of heat which presented itself at the exhaust part of the engine, in the form of free, or sensible heat, but that neither the respirator, nor any other possible contrivance, could recover the heat that was lost in the expansion of the air behind the working piston. He had adopted the new "dynamical theory of heat" for his argument, because that theory enabled him to calculate the absolute quantities of heat, that must inevitably be sacrificed, to produce a given mechanical effect, and to separate the same from the other and much larger quantity, that served only to form the elastic nedium behind the working piston, and which might be recovered, by means of a respirator, unless, as he had shown in the paper, it was all converted into power, by the expansive action being carried to its last (but impracticable) limits. Ericsson himself seemed to incline to the idea, that he could recover the whole of the heat by means of his " regencrator," for" it would be difficult otherwise to account for the extraordinary insufficiency of heating surface he had provided. Mr. Siemens could speak confidently as to the mechanical efficiency of action of the respirator, having applied a precisely similar contrivance to a steam-engine of his design, some years previously.

Mr. Siemens agreed with Mr. Hawksley's proposition, that an engine of his proportions could not give out any power. The valve between the two cylinders in Ericsson's engine was as necessary as it was between the boiler and cylinder of an ordinary steam-engine, and could not be replaced by the regenerator, which had a very different office to fulfil. Ericsson's engine might indeed be compared to a steam-engine, in which the boiler was represented by the air-chamber between the two cylinders, and the feed-pump by Ericsson's pumping cylinder. Ericsson had the disadvantage of sacrificing two-thirds of his power to move the pump, but had the advantage of expending no latent 
heat to form his elastic medium. But it must be borne in mind, that Ericsson had to add to his air a larger amount of sensible heat, of which only a smali proportion was really expended in expansion, and the remainder would go to waste, unless it was recovered by the regenerator. Nevertheless, the drawbacks to Ericsson's engine, on account of the great resistance of the pump, the small working pressure, the insufficiency of heating surface, and the working of a piston in a heated cylinder, were so great, that he thought no beneficial results could be expected from it.

\title{
ON A REGENERATIVE STEAM-ENGINE.
}

\author{
By C. W. Siemens, Esq., C.E.*
}

THE application of the steam-engine to our various purposes of manufacture and locomotion is of very recent date, although the elastic force of steam was known even by the ancients; for we read in Hero of Alexandria, on Pneumatics (translation by Woodcroft) that the Egyptian priesthood made use of it for the somewhat undignified purpose of performing pretended miracles before an ignorant population. The first suggestion of its useful application for raising water is due to the Marquis of Worcester, and dwelt upon in his "Century of Inventions."

The idea was taken up by Papin, Savory, and Newcomen, who added important elements towards its practical realization ; but to James Watt belongs the merit of having laid down a comprehensive principle of the steam-engine, and of having devised means to render the same capable of performing the rudest as well as the most delicate operations.

If any proof were wanting of the great genius of Watt, it would be sufficient to observe that the steam-engine of the present day is, in point of principle, still the same as it left his hands half a century ago, and that our age of material progress could only affect.

* Excerpt Minutes of Proceedings of the Royal Institution of Great Britain, Vol. II. 1856, pp. 227-236. 
its form. Great honour, however, is due to Fulton, Stephenson, Nasmytl, and others, for having adapted the same to the most important purposes.

The steam-engine of Watt was composed of four organic parts, which were pointed out on a working model before the meeting, namely:-1. The furnace, or chamber of combustion, with its flues and chimney. 2. The boiler, or steam generator. 3. The steam-ressel, or cylinder, wherein the elastic force of the steam is imparted to the piston, or other first moving parts of the machinery. 4. The condenser, where the elastic force of the steam is destroyed by abstracting its latent heat, by injection of cold water, or by exposure of cooled metallic surfaces. In the case of high-pressure engines, it would seem that the condenser was suppressed; but it might be said, that this class of engines makes use of one great common condenser, namely, the atmosphere; the separate condenser possessing only the advantage of relieving the working piston of the opposing atmospheric pressure. The only essential improvement of the steam-engine that has been introduced since the time of Watt consists in working the steam expansively, whereby a considerable economy has been attained; but it is well known that Watt foresaw the advantages that would be realized in this direction, and was prerented only by insufficiency of the mechanical means at his disposal from realising the same.

The lofty superstructure proved the soundness of the foundation Watt had laid; and it would seem hopeless to change the same, unless it could be proved that the very principle regarding the nature of heat, whereon Watt had built, had given way to another more comprehensive principle. The engine of Watt was based upon the material theory of heat that prevailed at his time, and almost to the present day. According to this theory, steam was regarded as a chemical compound of water and the supposed imponderable fluid " heat," which possessed amongst others the property of occupying under atmospheric pressure nearly 1700 times the bulk of the water contained in it. The Boulton and Watt condensing engine took the full adrantage of this angmentation of volume, which effected a proportionate displacement of piston, and the condensation of the steam obviated all resisting pressure to the piston. 
In the course of the last few years our views of the nature of heat had however undergone a complete change ; and, according to the new "dynamic theory," heat, as well as electricity, light, sound, and chemical action, are regarded as different manifestations of motion between the intimate particles of matter, and can be expressed in equivalent values of palpable motion and dynamic effect. In support of this theory, he (Mr. Siemens) could not do better than refer to the able discourses, recently delivered in the Royal Institution, by Mr. Grove and Professor Thomson.

Viewed from the position of the new theory, the heat given out in the condenser of a steam-engine, represented a loss of mechanical effect, amounting to $\frac{13}{14}$ part of the total heat imparted to the boiler ; and the remaining $\frac{1}{14}$ part was all the heat really converted into mechanical effect. The greater proportion of the lost heat might be utilized by a perfect dynamic engine. A vast field for practical discovery was thus opened out; but it might yet be asked whether it was worth while to leave our present tried and approved forms of engines, to seek for economy, however great, in a new direction, considering the vast extent of our coal fields. The reply to this objection was, that the coal in its transit from the pit to the furnace acquired a considerable value, which, for this country, might be estimated at $£ 8$ per horse-power per annum (taking a consumption of $13 \frac{1}{2}$ tons of coal, at an average expenditure of 12 shillings per ton).

Estimating the total force of the stationary and locomotive engines employed in this country at one million nominal horsepower; it followed that the total expenditure for steam coal amounted to eight million pounds sterling per annum, of which at least two-thirds might be saved. In other countries, where coal is scarce, the importance of economy becomes still more apparent; but it is of the highest importance for marine engines, the coals whereof had to be purchased at transatlantic stations, at a cost of several pounds per ton, to which must still be added the indirect cost of its carriage by the steamer itself in place of merchandise.

These observations, Mr. Siemens thought, might justify him in bringing before the Institution an engine, the result of nearly ten years' experimental researches, which he thought to be the first practical application of the dynamic theory of heat, of which he was proud to call himself an early disciple. Others, more able than 
himself, might probably have arrived sooner at a practically useful result, but he might claim for himself at least that strong conriction, approaching enthusiasm, which alone could have given lim strength to combat successfully the general discouragement and the serious disappointments he had met with.

The following illustrations, proving the imperishable nature of physical forces and their mutual convertibility, were made use of to indicate more clearly the principles his engine was based upon.

A weight falling over a pulley, to which it was attached by a string, would impart rotary motion to a fly wheel, fixed upon the same axis with the pulley, and the relocity imparted to the wheel would cause the string to wind itself upon the pulley, till the weight had reached nearly its original elevation. If the friction of the spindle and the resistance of the atmosphere could be dispensed with, the weight would be lifted to precisely the same point from whence it fell, before the motion of the wheel was arrested. In descending again, it would impart motion to the wheel as before, and this operation of the weight, of alternately falling and rising, could contime ad infinitum. If the string were cut at the instant when the weight had descended, the rotation of the wheel would continue uniformly, but it might soon be brought to a stop by immersing it in a basin filled with water. In this case the water was the recipient of the force due to the falling weight, residing in the wheel; and by repeating the same experiment a sufficient number of times, we could find an increase of temperature in the rater, a fact discovered by Jonle, in 1843, which first proved the identity of heat and dynamic effect, and established their numerieal relation. If the weight falling over a pulley were one pound, aud the distance through whicl it fell one foot, then each impulse given to the wheel would represent one foot pound, the commonly adopted unit of force ; and if the water contained in the basin weighed also one pound, it would require 770 repetitions of the experiment of arresting the wheel in the water, before the temperature of that water was increased by one degree Fahrenheit.

Another illustration made use of, was that of a hammer falling in vacuo upon a perfectly elastic anvil. The hammer would, under these circumstances, rebound to precisely its original eleration, and granting the perfect elasticity of both hammer and anvil, neither 
sound nor heat would be produced at the point of concussion. If a piece of copper were suddenly introduced between anvil and hammer, the latter would not rebound, but would make the copper the recipient of the expended force. If the hammer were now lifted again and again by an engine, and the piece of copper were turned about on the anvil, so that at the end of the operation it had precisely the same form as at the commencement, then no outward effect would be produced by the force expended, but the piece of copper would be heated perhaps to redness; and if the engine employed to lift the hammer were perfect, then the heat produced within the copper should be sufficient to sustain its motion.

A familiar instrument for converting force into heat was the fire-syringe. The force expended in compressing the air imparted a sufficient temperature (about $600^{\circ} \mathrm{Fahr}$.) to the same to ignite a piece of German tinder. When the plunger of the syringe was drawn back, it might be observed that the temperature of the enclosed air was again reduced to its original degree, because the heat developed in compression of the air had been spent again in its expansion behind the piston. If the expansion of the heated and compressed air had been without resistance, no reduction of its temperature could have taken place, because no force would be obtained; a fact which had been recently proved by Regnault, and which was perhaps the strongest point in farour of the dynamic theory of heat that could be brought forward. If the heated and compressed air in the fire-syringe could be produced by some external canse and be introduced behind the plunger after it had descended freely to the bottom, then the force imparted to the plunger in the expansion might be turned to some useful purpose, and a dynamically perfect engine might be obtained. But although the elevated temperature might be readily supplied by means of a fire, it would not be possible to give a sufficient density to the air, except by an expenditure of force in its compression. If, however, heat were applied to a drop of water confined below the plunger till its temperature was raised sufficiently to effect its conversion into steam of the density of the water itself (Gaignard de la Tour's state of vapours), and then allowed to expand below the plunger till its temperature was reduced to zero, a dynamically perfect engine would be obtained. The impracticable nature of 
such an engine was however manifest, if it was considered that steam of the density of the water producing it, would exert a pressure of probably several hundred atmospheres, which pressure the moving part of the engine must be made strong enough to bear at a temperature of more than $1000^{\circ}$ Fahr., and that the capacity of the working cylinder must be sufficient to allow of an expansion of the steam to sereral thousand times its original rolume. It was therefore necessary to look for other means of obtaining from heat its equiralent value of force, which means, it was contended, were furnished by the "regenerative steam-engine."

This engine, of which several diagrams and a model were exhibited, consisted of three essential parts, namely, the furnace ; the working cylinder, with its respirator and heating ressel ; and the regenerative cylinder. It consisted also of a boiler and condenser, (unless the steam were discharged into the atmosphere,) but these were not essential to the working of the engine, although of great practical utility. The regenerative cylinder had for its object alternately to charge and discharge two working cylinders, and the action of its piston might be compared to that of a hammer oscillating between two elastic anvils. The regenerative cylinder communicated at its one extremity with one working cylinder, and at the other extremity with another and similar working cylinder, and these communications were not intercepted by valves. The working cylinders were so constituted that their capacity for steam of constant pressure was the same, no matter where the working piston stood. Each consisted of a cylinder of cast iron, open at both ends, which was completely enclosed in another cylinder or heating vessel, one end of which was exposed to the action of a fire. Within the inner cylinder was a large hollow piston, filled with non-conducting material, to which was attached a long trunk or enlarged hollow piston rod of nearly half the sectional area of the piston itself. This trunk was attached to the working crank of the engine in the usual manner. The trunk of the second working cylinder stood precisely opposite, and was connected with the same crank. The piston of the regenerative cylinder was also connected with the same crank; but stood at right angles to the two working cylinders. The consequence of this arrangement was, that while the two working trunks made their strokcs (the one inward and the other out- 
ward) the piston of the regenerative cylinder remained comparatively quiescent upon its turning or dead point, and vice versâ. Around the two heating vessels boilers were disposed, which received the heat of the fire, after it had acted upon the former. The steam generated within the boilers was introduced into the engine by means of an ordinary slide valve (of comparatively very small dimensions) at short intervals, and when the piston of the regenerative cylinder was in its extreme position. The admission of the steam, which was of high pressure, took place on that side of the regenerative cylinder where compression by the motion of its piston had already taken place, and at the same instant a corresponding escape of expanded steam on the other side of the regenerative piston was allowed to take place into the atmosphere. The quantity of steam freshly admitted at each stroke did, however, not exceed one-tenth part of the steam contained in the working cylinders of the engine, and served to renew the same by degrees, while it added its own expansive force to the effect of the engine. The compression of the steam into either of the working cylinders took place when its hollow piston stood at the bottom. While in this position the steam occupied the annular chamber between the working trunk and the cylinder, besides the narrow space between the cylinder and the surrounding heating vessel. The pressure of the steam being the same above and below the hollow piston, but the effective area below being equal to twice the area above, the working trunk, attached to the piston, would be forced outward through the stuffing box, while the steam of the annular chamber above the piston passed through the narrow space intervening, into a space of twice the capacity of the annular chamber below the hollow piston. During its passage the steam had to traverse a mass of metallic wire gauze or plates, the respirator, presenting a large aggregate surface, which reached at one end sufficiently downward into the heating ressel that its temperature was raised from $600^{\circ}$ to $700^{\circ} \mathrm{Fahr}$., while its other extremity remained at the temperature of saturated steam, or about $250^{\circ}$ Fahr. In consequence of the addition of temperature the steam received on its passage through the respirator, its elastic force was doubled, and it therefore filled the larger capacity below the hollow piston or displacer without 
loss of pressure. When the effective stroke of the working trunk was nearly completed, the regenerative piston commenced to recede, and the steam below the hollow piston expanded into the regenerative cylinder, depositing on its regress through the respirator the heat it had received on its egress through the same, less only the quantity that had been lost in its expansion below the working piston, which was converted into dynamic effect or engine-power, and had to be supplied by the fire. The expansion and simultaneous reduction of temperature of the steam caused a diminution of its pressure from four to nearly one atmosphere ; and the working trunk could now effect its return stroke without opposing pressure, and while the second working trunk made its effective or outward stroke impelled by a pressure of four atmospheres.

The respirator, which was invented by the Rev. Mr. Stirling, of Dundee, in 1816, fulfilled its ofice with surprising rapidity and perfection, if it were made of suitable proportions. Its action was proved at the end of the lecture by a working model. It had been applied without success to hot-air engines by Stirling and Ericsson, but failed for want of proper application ; for it had been assumed (in accordance with the material theory of heat) that it was capable of recovering all heat imparted to the air, and, in consequence, no sufficient provision of heating apparatus had been made. It having been found impossible to produce, what in effect would have been a perpetual motion, the respirator had been discarded entirely, and was even now looked upon with great suspicion by engineers and men of science. Mr. Siemens had, however, no doubt that its real merits to recover heat that could not practically be converted by one single operation into mechanical effect, would be better appreciated. The rapidity with which the temperature of a volume of steam was raised from $250^{\circ}$ to $650^{\circ}$ Fahr. by means of a respirator, was indicated 'by the fact that he had obtained with his engines a velocity of 150 revolutions per minute. The single action of heating the steam occupied only a quarter the time of the entire revolution of the engine, and it followed that it was accomplished in one-tenth part of a second. But, in explanation of this phenomenon, it was contended, that the transmitting of a given amount of heat from a hotter to a cooler body, was proportionate to the heating surface multiplied 
by the time occupied, and that the latter factor might be reduced ad libitum, by increasing the former proportionately. The airengines of Stirling and Ericsson had failed also, because their heated cylinders had been rapidly destroyed by the fire; but the cause of this was, that an insufficient extent of heating surface had been provided, and it was well known that even a steamboiler would be rapidly destroyed under such circumstances. Mr. Siemens was led by his own experience to believe that his heating vessels would last certainly from three to five years, and being only a piece of rough casting, that could be replaced in a few hours, and at a cost below that of a slight boiler repair, he considered that he had practically solved the difficulty arising from high temperature. It was however important to add, that all the working parts of his engine were at the temperature of saturated steam, and therefore in the condition of ordinary steam-engines ; whereas in Ericsson's engine, the hot air had entered the working cylinder. In surrounding the heating vessel with the boiler, an excessive accumulation of heat was prevented from taking place, and the pressure of the steam in the boiler became the true index to the engine-driver of the temperature of the heating vessel. Another essential property of the heating ressel was, that all its parts should be free to expand by heat without straining other parts, which was accomplished by a free suspension, and by undulating its surface. Lastly, it should be massive, to withstand the fire with impunity, for iron was, strictly speaking, a combustible material. The pyropherus, or finely-divided metallic iron, took fire spontaneously on exposure to the atmosphere, a chip of iron was ignited in flying through the flame of a candle ; an iron tea-kettle was destroyed by exposing it (unfilled with water) to a kitchen fire ; whereas, in forging a crank shaft, the solid mass of iron withstands the white heat of the forge fire for several weeks without deteriorating. A heating vessel, properly constructed and protected, might be heated with safety to $700^{\circ} \mathrm{Fahr}$., at which temperature it would be almost as able to resist pressure, as at the ordinary temperature of the atmosphere, the point of maximum strength of iron being at $550^{\circ}$ Fahr., as had been proved by experiments made for the Franklin Institution. The construction of a heating vessel combining these desiderata was of paramount importance for the success of Mr. Siemens's engine, and had not 
been accomplished without combating against considerable practical difficulty.

Although heat may be entirely converted into mechanical effect, it would nevertheless be impossible to construct an engine capable of fulfilling this condition without causing at the same time a portion of heat to be transferred from a hotter to a cooler body, and which must ultimately be discharged. This necessity has been generally proved, and in a very elegant manner, by Professor Clausius, of Zürich, and implies at least the partial truth of "Carnot's theory." In the "regenerative steam-engine," prorision had been made for absorbing this quantity of heat, arising in this case from the circumstance, that the saturated steam enters the respirator in a state of greatest density or compression, and returns through it (expanding into the regenerative cylinder) at a gradually diminishing density, although the temperature of the extreme edges of the respirator remains proportionate to the condensing point of the steam of greatest density, by providing water chambers about the cover of the working cylinder, and around the regenerative cylinder, which are in communication with the steam-boiler. The heat absorbed from the slightly superheated steam is thus rendered useful to generate fresh steam.

Objection had been raised by casual observers against the regenerative steam-engine, on account of its apparent similarity in principle to the "air-engines" of Stirling and Ericsson, implying similar sources of failure. The apparent similarity in principle arose from the circumstance that both Stirling and Ericsson, as well as himself, had employed the respirator and high temperatures; but these were but subordinate means or appliances, that might be resorted to in carrying out a correct as well as an erroneous principle.

In the winter of 1852-53, when Ericsson was engaged upon his gigantic experiment in America, the speaker had had occasion to read a paper to the Institution of Civil Engineers, entitled "On the conversion of heat into mechanical effect," wherein he had endearoured to set forth the causes of probable failure of that experiment, and to guard against a sweeping condemnation on that account of some of the means Ericsson had employed.

According, to the dynamic theory of heat, the elastic medium employed in a perfect caloric engine was a matter of indiffer- 
ence, and air had been resorted to, because it was perfectly elastic, and always at hand. In practice, however, the elastic medium employed was a matter of very great importance, and he (Mr. Siemens) had given the decided preference to steam, and for the following reasons :-

1. The co-efficient of expansion of saturated steam by heat exceeded that of air in the proportion of about $3: 2$, but decreased with an increase of temperature. This was not in accordance with the established rule by Gay-Lussac and Dalton, but was the result of his own experiments (described in a paper, "On the expansion of isolated steam, and the total heat of steam," communicated to the Institution of Mechanical Engineers, in 1852), ${ }^{*}$ and had been borne out by his practical experience on a large scale. Mr. Siemens had been first induced to undertake these experiments in consequence of an observation by Faraday, that the elastic force of the more permanent vapours gave way rapidly, when by abstraction of heat their points of condensation were nearly attained. $\mathrm{He}$ conceived that gases and vapours would expand equally by heat, when compared, not indeed at the same temperature, but at temperatures equally removed from their points of condensation.

2. When saturated steam was compressed (within the regenerative cylinder), its temperature would not rise considerably (as the fire-syringe evinced in respect of air), because, as Regnault had proved, the total heat of steam increased with its density, and consequently the heat generated in compression was required by the denser steam to prevent its actual condensation. Without this fortunate circumstance, the steam would be heated already by compression to such an extent, that it would be difficult indeed to double its elastic force by the further addition of heat in the respirator.

3. Steam exercised no chemical action upon the metal of the heating vessel and respirator, because the oxygen it contained was engaged by hydrogen, which latter had the stronger affinity for it until a white heat was reached; whereas the free oxygen of atmospheric air attacked iron and brass at much lower temperatures.

4. The specific gravity of steam was only about one-half that 
of atmospheric air at equal temperature and pressure; moreover it was a far better conductor of heat, and both circumstances qualified it for rapid respirative action.

5. The fresh steam required for starting and sustaining the power of the engine was generated by heat that would otherwise be lost. No air-pumps, \&c., were required, and the management of the engine beeame as simple as that of an ordinary highpressure steam-engine.

In conclusion, it was stated that at present therc were several regenerative engines in constant practical operation, in this country (at the works of Messrs. Newall \& Co., at Gateshead), in France, and in Germany, varying from five to forty horse-power, which had proved the practicability of the principle involved, although they were still capable of improvement. Sereral other engines were now in course of construction at establishments celebrated for precision of execution, and with the advantage of Mr. Siemens's increased experience in designing them. He had been fortunate to meet with men of intelligence and enterprise, lately joined together in a public company, whose co-operation insured a more rapid development of his invention than indi. vidual effort could produce. The benefit he had hoped to derive from his discourse, incomplete as it necessarily was, would be realized, if those men, eminent in science, whom he saw around him, would accept his labours as an earnest towards the practical realization of the dynamical theory of heat, and hasten its triumphs by their own researches. It was impossible to overestimate the benefits that mankind would derive from a motive forcc at one-third or one-fourth part the cost and incumbrance of the present steam-engine. The total consumption of coal would certainly not diminish; but our powers of locomotion and production would be increased to an extent difficult to conceive, tending to relieve men from every kind of bodily toil, and hasten the advent of the hoped for period-of general enlightenment and comfort. 


\section{ON A NEW CONSTRUCTION OF FURNACE, PARTICULARLY APPLICABLE WHERE INTENSE HEAT IS REQUIRED.}

By Mr. C. Williay Sremens, Mem. Inst. M.E.*

THE high importance of the stores of combustible material which are distributed upon the surface of the earth renders their wasteful expenditure and rapid diminution in quantity in many parts a serious subject for consideration; and in the writer's opinion there is no object more worthy of the earnest attention of engineers and men of science generally than that of causing the generation and application of heat to be conducted upon scientific and economical principles. Our knowledge of the nature of heat has been greatly adranced of late years by the investigations of Mr. J. P. Joule, of Manchester, and others; which have enabled us to appreciate correctly the theoretical equivalent of mechanical effect or power for a given expenditure of heat. We are enabled by this new dynamic theory of heat to tell, for instance, that in working an engine of the most approved description we utilise at most only one-sixth to one-eighth part of the heat that is actually communicated to the boiler, allowing the remainder to be washed away by a flood of cold water in the condenser. If we investigate the operations of melting and heating metals, and indeed any operation where intense heat is required, we find that a still larger proportion of heat is lost, amounting in some cases to more than 90 per cent. of the total heat produced.

Impressed by these riews the writer has for many years devoted much attention to carrying out some conceptions of his own for obtaining the proper equivalent of effect from heat : some of the results he has obtained are known to the members of the Institution, amongst which are the regenerative steam-engine and condenser, the regenerative evaporator, and an apparatus for the economic production of ice. The regenerative principle appears to be of rery great importance and capable of almost universal

* Excerpt Minutes of Proceedings of the Institution of Mechanical Engincers, 1857, pp. 103-111. 
application ; and the object of the present paper is to describe an application of this principle to furnaces of every description.

'The invention of the regenerative furnace is due to the writer's brother, Mr. Frederick Siemens; and it has been matured and rariously applied by the writer within the last few months. The resnlt has in all cases been a large saving in fuel over the plans in common use, amounting to from 70 to 80 per cent. of the total quantity of fuel hitherto consumed. The apparatus employed is moreover of a rery simple and permanent description, and combines economy of fuel with other advantages, amongst which are the total prevention of smoke and a general improvement in the quality of the work produced.

Figs. 1 to 4, Plate 6, represent the new furnace in the form applicable to piling iron, or heating iron, steel, or other substances.

Fig. 1 is a longitudinal section of the furnace, and Fig. 2 a sectional plan ; Figs. 3 and 4 are transverse sections.

The furnace consists of the heated chamber $A$, and of two fireplaces or solid hearths $B$ and $C$, communicating respectively with the two regenerators $D$ and $E$. Each regenerator consists of a serics of walls of firebrick, laid in open Flemish bond, in such a manner that the pigeon-holes of each wall are opposite the solid parts of the succeeding wall, the object being to form a number of zigzag or tortuous passages through the regenerators, lcading to opposite sides of the valre F, shown dotted in Fig. 1, at the bottom of the chimney $\mathrm{G}$. The valve $\mathrm{F}$ consists of a rectangnlar box of iron open at the two sides to the two regenerators $\mathrm{D}$ and $\mathrm{E}$, at the bottom to the atmosphere, and at the top to the chimney G. A spindle passes through the centre of the two remaining close sides of the box, and carrics a rectangular flap or moveable plate, fitting the box sideways and bearing against one of its upper and one of its lower edges, according to the position of the tumbling lever and weight $\mathrm{H}$ which are fixed upon the spindle outside.

When the valre is in the position shown dotted in Fig. 1, the atmospheric air entering from below proceeds in the direction indicated by the arrows, passing through the regenerator $\mathrm{D}$, orer the fireplacc $B$, through the heated chamber $A$, over the fireplace $\mathrm{C}$, through the regenerator $\mathrm{E}$, and by the valre $\mathrm{F}$ into the chimney G. 
A fire having been lighted upon the hearth B through the side opening $\mathrm{K}$, the flame passes through the furnace and through the regenerator $\mathrm{E}$ to the chimney $\mathrm{G}$. In its passage through the regenerator $\mathrm{E}$, the first perforated wall that the flame strikes against will be heated to a considerable degree, the second wall to a lower degree, and so on in succession, the heat of the current being thoroughly exhausted by the time it reaches the chimney.

After about one hour's work the position of the valve $F$ is reversed and fuel is supplied through the opening $\mathrm{L}$ to the second fireplace $\mathrm{C}$, which is then acted upon by a current proceeding in the opposite direction to that indicated by the arrows. The cold atmospheric air comes in contact first with the least heated wall of the regenerator $\mathrm{E}$, and then with the more heated walls successively, acquiring thereby a degree of temperature approaching the temperature of the heated current which previously entered the same regenerator. The heat thus imparted to the fresh air greatly increases the temperature of the flame which is now being produced upon the hearth $\mathrm{C}$, and consequently the nearest end of the regenerator $\mathrm{D}$ will be heated also to an increased degree, the current reaching the chimney comparatively cool.

When the valve $\mathrm{F}$ is again reversed, the fresh air will be heated nearly to the increased temperature of the hot end of the regenerator D, and will produce a still hotter flame with the fuel supplied to the hearth B. It is evident that by a continuation of this process an accumulation of heat to any degree may be produced within the furnace, provided only the heat produced in combustion is greater than the heat lost by radiation and the heat absorbed by the metal or other substances in the heating chamber.

In the regenerative furnace now described, the temperature at which the heat is communicated to the materials does not affect the quantity of fuel requisite, except so far as increased radiation is concerned ; for the products of combustion pass away in all cases at a temperature not above $200^{\circ}$ or $300^{\circ} \mathrm{Fahr}$. This new principle of furnace is therefore applicable with the greatest advantage in cases where intense heat is required. It has been applied to furnaces for reheating steel and iron, at the works of Messrs. Marriott and Atkinson at Sheffield. One of these furnaces has now been in constant work for nearly three months; and according to a statement received from Mr. Atkinson it has worked 
quite satisfactorily, and the result of a careful comparison has shown a saving of 79 per cent. to have been effected orer the old furnace in heating the same quantity of metal. Mr. Atkinson las also applied this principle of furnace for melting cast steel, and has obtained a still larger saving, although the new melting furuace has not yet been rendered entirely satisfactory for the workman.

The regenerative furnace has also been applied to the purpose of puddling iron; and though the new puddling furnace has been completed and worked only for a few days at the works of Messrs. Rushton and Eckersley at Bolton, the writer is able to state that it converts a charge of $480 \mathrm{lbs}$. of pig metal into wrought iron with an expenditure of only $160 \mathrm{lbs}$. of common coal, as compared with 6 cwt. required in the ordinary furnaces : the net yield of wrought iron is higher than that of the ordinary puddling furnace, and the quality of the iron produced seems also to be superior. It is also worth mentioning that the chimney of this puddling furnace may be watched for hours, and no trace of smoke be seen issuing from it. Several other applications of this principle of furnace are contemplated by the writer, which it would be premature to enter upon on the present occasion.

\section{In the discussion of the Paper,}

Mr. Sicurexs said he considered the durability of the brickwork might be fully accounted for by the circumstance that, on attaining the very high degree of temperature, the air had first to heat the ends of the first wall of bricks that it met with to a very intense degree, but the next wall to a less degree, and so on gradually diminishing towards the chimney. It might be expected at first that the cold air entering would have a tendency to crack the hot bricks ; but it should be remembered that the air became gradually heated as it advanced, coming in contact at first witl a comparatively cool wall, and afterwards by degrees with hotter and hotter walls, taking up only $100^{\circ}$ or $200^{\circ}$ of temperature from each successive wall, each one being only a little hotter than the air on reaching it. There was consequently no sudden difference of temperature at any point between the air and the brickwork with which it came in contact, and all risk of sudden chilling and 
cracking of the brickwork was thus avoided. The alternating principle of the furnace gave a remarkable result in the extremely high degree of temperature that could be ultimately attained, as each repetition of the process added something to the previous temperature of the furnace, the heat continually accumulating; and if the surface were sufficiently covered to prevent loss of heat by radiation, it would be possible by continuing the alternation to attain a temperature far higher than in any existing furnace, and limited only by the materials employed.

Mr. Siemens had not yet had any long experience of the application of the plan to puddling, but from the results already obtained he thought there was full reason to anticipate its entire success. This case was a peculiar one from the necessity of keeping the puddling door open during the process, the furnace being consequently exposed to the open air ; and some modifications were therefore required in the details, which only the experience of further trials could enable them to get fully matured; there were also difficulties to be overcome in the working on the part of the men, from the great contrast to the accustomed working of puddling furnaces, so much smaller quantity of fuel and so much less draught being required. Besides the saving in fuel, he expected a decided advantage both in the quantity and the quality of the iron made, by removing the violent draught produced by the intense heat of the chimney in the ordinary puddling furnaces; the comparatively cold chimney in the new furnace, with the damper lowered to within two inches of the top of the chimney, gave so small a draught that the flame did not cut the iron and waste it as in the ordinary furnace, a higher temperature being obtained with a more quiescent atmosphere. There was also the advantage that no flame or particles of fuel were carried over the surface of the iron, bringing sulphur and other impurities from the firegrate.

Ashes had to be cleared out frequently from the regenerators, but they were readily removed through the holes provided for the purpose at the back of the furnace, and the puddler simply raked them out on putting a fresh charge into the furnace. The new furnace was found to puddle the iron in about the same time as the ordinary ones, a charge being brought out about every two hours if the fires were sufficiently attended to. It took rather longer to 
get up the heat at first, but the furnace retained the heat longer aud a higher temperature was obtained; one night's stoppage required about the same time as the ordinary furnace to get up tho heat again in the morning, but a longer stoppage would cause a somewhat longer time to be required. The principal difficulty experienced in working was from the men putting on too much coal at once, being accustomed to the necessities of the old furnace, and thus choking the fire and retarding instead of accelerating the working of the furnace.

The experience with the new puddling furnace was too limited at present to determine fully the difference in the time of the process ; in the furnace now working at Bolton it was found that the iron was about 10 minutes longer in melting down, but was rather quicker in coming to nature than in the ordinary puddling furnaces; and there was no decided difference in the whole time of working. Sorne difference in management from the ordinary furnace was of course required, which caused a difficulty at first in carrying out the new plan; but the principle of the furnace was quite simple, and no more skill and care was needed than was to be looked for in the men concerned. The quantity of fuel consumed and amount of firing required were much less ; and by keeping the fire low a large proportion of oxygenated air was allowed to enter during the puddling process, which was supplied at a very high temperature, preventing fluctuations in the temperature of the furnace; and the very low draught of the chimney was an important point in greatly reducing the quantity of cold air unavoidably diawn in at the puddling door whilst open during the process.

Mr. Siemens said he had not attempted the application of the principle at present to steam-engine furnaces, the trials haring been first made in those kinds of furnaces where the highest temperature was employed, and where consequently the greatest economy could be effected by the regenerative plan; but even in the case of steam boilers, a considerable portion of the fuel was generally wasted, by the air being allowed to escape into the chimney at a higher temperature than was required for the purpose of maintaining the draught. 


\section{In the discussion of the Paper}

\section{"DESCRIPTION OF TIO PAIR OF HORIZONTAL PUMPING ENGINES," by Mr. E. A. CowPER,}

Mr. C. W. Siemens * said he was acquainted with the pumping-engines at the Berlin Waterworks, where there were twelve powerful beam-engines, coupled in pairs at right angles with fly-wheels, and working vertical pumps under a pressure of 160 feet head of water. The present double ring valves allowed an easy and unrestricted motion of the water, as the joint circumferences of the four openings gave a large area of passage with a little lift of the valves.

With regard to the employment of the crank and fly-wheel for pumping-engines, in place of the Cornish system of lifting the water by the weight of the plungers, it was true that a large fly-wheel with a great weight in the rim, running at a considerably higher speed than the weight in the Cornish engine, had the advantage of more vis inertice; but only a limited fluctuation in its speed was available, and the weight was never stopped as in the Cornish engine, where the whole weight of the pumprods was stopped and started again at each stroke. It was therefore to be expected that a greater economy could be obtained by the latter plan, in case of very great lifts, a larger proportion of moving power being absorbed at the commencement of the stroke, allowing the expansion to be carried to a higher degree by admitting of greater extremes of pressure in the stroke. $\mathrm{He}$ accordingly thought there were cases, such as pumping from deep pits, where the Cornish plan would prove the most economical, the pump rods falling gradually by their own weight, and being then lifted by the free action of the steam in the cylinder; but in many cases, such as low lift pumps, the horizontal direct construction was preferable. He observed that the engines described had not been designed for such a high degree of economy as was attained in the Cornish engines, since the steam was cut off only

* Excerpt Minutes of Proceedings of the Institution of Mechanical Engineers, 1858, p. 57. 
at one-third the stroke; and there did not appear to be a steam-jacket to the cylinders. He had found a great advantage in employing a jacket not only round the sides of the cylinders, but also at the ends, and it was more important to have a jacket at the ends than round the sides; for on the steam first entering the cylinder, a much larger extent of surface was offered to it by the end than by the small portion of the sides then exposed. When the cylinder was not protected by a jacket, the end of the cylinder being cooler than the steam on first entering, caused a portion to be condensed, which was partly evaporated again in the latter part of the stroke, when the pressure and consequent temperature of the steam was lowered by expansion. The effect of this generation of steam in the cylinder was to increase the pressure at the end of the stroke beyond that due to the expansion; and the line of the indicator diagram was thus raised in the latter part of the figure above the regular curve of expansion. But this did not appear to be the case in the indicator diagram from the Crystal Palace engines, which showed the steam entering the cylinder at a total pressure of about $34 \mathrm{lbs}$. per square inch, cut off at one-third of the stroke, and expanded down to a final pressure of $11 \mathrm{lbs}$. due to the expansion.

In the discussion of the Paper

"ON THE PERFORMANCES OF THE SCREW STEAM SHIP 'SAHEL;' fitted with Du Trembloy's combined-vapour engine, AND OF THE SISTER SHIP 'OASIS, fitted with steam-engines worked expansively, and provided with partial surface condensation," by JAMES WARDROP JAMESON,

Mr. Siemexs * said, when treating of air-engines, in a paper which had been read at the Institution in the Session 1852-53, † he

- Excerpt Minutes of Proceedings of the Institution of Civil Engineers, Vol. XVIII. Session 1858-59. pp. 256-259.

+ Vide Mlinutes of Proceedings of the Institution of Civil Engincers, Yol. XII. p. 571 , and p. 29 , ante. 
had adverted to the combined-vapour engine. The results then arrived at, from calculation, were very similar to those now recorded by the author. The comparison of the performances of the combined engine and of the ordinary expansive steam-engine, as shown by the diagrams, was very remarkable. There was a difference in the consumption of fuel, per indicated H. P. per hour, as between $3 \cdot 1 \mathrm{lbs}$. in the combined engine, and $7 \cdot 4 \mathrm{lbs}$. in a direct acting engine, of nearly the same power, working steam expansively. That would naturally seem to indicate the vast superiority of the ether engine. But before accepting such a fact, which was the result of experiment, as a proof of the superiority of the principle involved, he thought the conditions under which the experiments were made should be carefully inquired into, and an estimate be formed of the causes, either in construction or in working, which might have influenced the result. For instance, it was well known, that an unprotected cylinder condensed a large quantity of steam, if worked expansively. He had known cases, where the result was modified to the extent of 50 per cent., by that cause alone. On the other hand, the ether-engine seemed to have been under some disadvantage. There was a bad vacuum, of $5 \mathrm{lbs}$. only, in the ether cylinder, which was, no doubt, in a great measure, to be attributed to the difficulty of condensing ether, the condensing point being very low ; but he thought it might also be due, partly, to the exhaust ports being of insufficient area, for ether steam being five times heavier than water steam, the ports for its discharge should be more than twice the usual area. To judge of the merits of the invention now brought forward, it would be necessary to revert to broader principles, instead of limiting the inquiry simply to the facts stated. Perhaps he might be allowed, shortly, to develop the relative merits, in a theoretical point of view, of the combined ether-engine, and of a well arranged expansive steam-engine. He believed he was the first to adrocate, in the Institution, the dynamic theory of heat. According to that theory, heat and power were identical. The particles of a heated body were in a more agitated condition than in a cooler body, the motion of the particles being greatest in elastic fluids, and their pressure upon the sides of the ressel such, that if one side yielded to the impact, or pressure, as was the case with a working piston, the reaction 
would be less than the impact. Hence the motion of the particles would be diminished, in proportion as the piston was urged forward, and the result would be a reduction of temperature. Expansion might be carried to a point, where the elastic force was entirely exhnusted, at which point the elastic fluid must have ussumed the liquid, or solid state. Commencing with steam of the density of water, and expanding it down, until a perfect vacuum was obtained, would form, in point of principle, a perfect engine, which nothing could supersede. But the practical difficulty of carrying expansion to its utmost limits, was the great strength and size of the cylinders required to withstand the enormous pressure of steam of that density, and to be at the same time of sufficient dimensious to allow of the expansion of the steam down to that extraordinary degree. All the various air and other engines, designed to supersede the steam-engine, might be said to aim at one point, that of carrying the expansive action to a farther degree than could be done with the steam-engine, without having to resort to cylinders of great size and strength. In the combined ether-engine, the analogy was evident. Instead of expanding the steam down to a minimum pressure, the expansive action in the steam cylinder was stopped at a certain point, and the stcam was made to impart its remaining heat to another liquid, which evaporated at a lower temperature, and the vapour of which occupied less room than steam at a given temperature, and could consequently continue the expansive action in a cylinder of smaller dimensions than would otherwise be required. This was all the advantage that could be claimed in farour of the combined ether engine. It was a matter of calculation, whether that advantage was sufficient to balance the disadvantages of a necessarily imperfect vacuum, in both the steam and the ether cylinders, of the complication of parts, and of other drawbacks which had been mentioned in the paper. There was an omission of one fact in the paper, which perhaps the author could supply, - that was, the quantity of ether evaporated, for a given amount of steam condensed. No mention had been made of this; nor was he acquainted with any experiments on the subject. It was a wellascertained fact, that the vapour of ether was about four times heavier than steam at the same pressure, and the question was, how much of that ether vapour would be produced for a given 
amount of condensed steam. In the absence of direct experiments on that point, he thought it might be assumed, that a given volume of steam would produce an equal rolume of ether vapour of the same pressure. That would appear to be the result of general theory. The practical question was, how far the extra power obtained by the ether-engine might be realised, by working steam to a very high degree of expansion. The unprotected cylinder of a marine engine would not give a favourable result, because the steam generated in the boiler could not be dealt with as a permanently elastic fluid, as had been too much the practice, but would lose much of its elastic force through condensation in the cylinder. The old engines of Watt were not simply lined with a conducting material, as was now thought sufficient by many Fngineers, but were supplied with a steam-jacket kept filled with steam of higher tension than the working pressure, to make up for the loss of heat sustained in expansion. By properly protecting the cylinder, by means of a complete steam-jacket, against the enormous loss sustained by condensation of the high-pressure steam upon the sides of the cylinder, and re-evaporation from the same surfaces, after expansion had taken place, he thought results might be obtained, equal to those claimed for the etherengine. There was no doubt, however, that the combined etherengine might, in its turn, be still greatly improved, if the practical disadrantages of the greater complication, and of the danger arising from the leakage of the ether rapour, should not prevent its extended application.

\section{In the discussion of the Paper}

\section{"ON THE APPLICATION OF SUPERHEATED} STEAM," by Mr. JoHn N. RyDER,

Mr. C. W. Siemens * said he had seen the trial of superheated steam that had been referred to at Messrs. Hoyle's works; and

* Excerpt Minutes of Proceedings of the Institution of Mechanical Engineers, 1860, pp. 30-33. 
though the result had not proved farourable in that case, le thought that the failure might be fully accounted for by the imperfect way in which the experiment had been tried : any single cases however of want of success could not be admitted, he considered, as permanent objections to the introduction of a system. There was much difficulty in making an experiment complete and arriving at the correct result, and the value of the result depended upon the mode in which it had been conducted and a perfect knowledge of all the circumstances involved. Amongst the circumstances to be considered in any experiments on superheated steam were the actual size and construction of the engine, whether the cylinders had steam jackets or were well or imperfectly clothed, the degree of exposure and length of the steam pipes, and the construction, form, and size of the boilers : the particulars of all these circumstances should be carefully noted in any experiments to determine the practical value of superheating the steam.

The advantages to be attained by superheating, most of which were referred to in the paper, were-firstly, entirely preventing the passage of priming water with the steam, by completely evaporating this water in passing the steam through the superheating apparatus; secondly, obtaining a greater bulk of steam from the same water, by its expansion with the increase of temperature ; and thirdly, prerenting any condensation of the steam by contact with the cooler sides of the cylinder, whereby the steam could be kept in a perfectly dry state throughout the entire strole. The evaporation of the priming water was a clear gain, as it was difficult if not impossible to prevent priming altogether, and in many cases the amount of priming was rery considerable, causing serious risk of injury to the engine as well as waste of heat. In regard to the advantage to be obtained by adding heat to the steam to increase its bulk, this involved the theoretical question of the rate of expansion of steam by heat. It had been generally assumed that isolated steam expanded under all circumstances at the same rate us air, namely 1-490th of its bulk at $32^{\circ}$ for eacl degree Fahr. : but he had shown by the results of experiments given in a paper at a former meeting * (Proceedings Inst. MI.E. 1852, page 131) that its rate of expansion was considerably greater when near the con- 
densing or boiling point, being in the case of atmospheric steam an average of 5 times the rate of air up to $230^{\circ}$ and 3 times up to $260^{\circ}$; diminishing in fact in a ratio that could be represented by a hyperbolic curve, approaching gradually at higher temperatures to the same uniform rate of expansion as air which would be represented by the asymptote to the curve. On this assumption it followed that there would be a certain advantage gained in applying heat direct to expand the bulk of steam, instead of employing the same heat to generate an additional quantity of ordinary steam; but the extent of gain that could be attained was not large, since the rise of temperature was practically limited to a moderate range, and the specific heat of steam near the point of saturation was proportionately great.

The most important source of economy in superheating steam was no doubt to be found in preventing condensation in the cylinder ; for the consequence of condensation of any portion of the steam on entering the cylinder was the total loss of the power of that steam during the remainder of the stroke. But in order to effect this object completely he considered that it was not enough to supply extra heat sufficient to heat the metal of the cylinder up to the temperature of saturated steam of the maximum pressure, whether by superheating the steam or by a steam-jacket round the cylinder; for although this were done, there must still be condensation in the cylinder during the expansion of the steam. on account of the loss of heat accompanying the development of moving power from the pressure of the steam on the piston; since there would be as much heat lost from the steam (or so to speak rendered latent in the form of power) as was equivalent to the total work done by the steam, according to the accepted theory of the mutual convertibility of heat and power, by which according to Joule's results one unit of heat (the quantity of heat requirer to raise the temperature of $1 \mathrm{lb}$. of water $1^{\circ} \mathrm{Fahr}$.) was equivalent to or became converted into a power of $770 \mathrm{ft}$.-lbs. (770 lbs. lifted 1 foot). This amount of heat lost during the expansion of the steam must consequently be supplied by superheating the steam originally admitted to the cylinder in order entirely to prevent condensation ; and this appeared about the point to which superheating could be carried advantageously, and generally speaking required an addition of about $100^{\circ}$ to the natural temperature of 
the steam, varying of course with the degree to which the steam was worked expansirely. The circumstance that this amount of heat was got rid of during the expansion of the steam in the cylinder went far to account for the statement given in the paper, that the quantity of injection water required to condense the steam was found to be proportionate to the total weight of steam, or of water evaporated, whether the steam were superheated or not: for the heat added to the steam by superheating had probably been hardly sufficient to replace the loss arising from expansion and from the cooling by conduction and radiation from the metal of the cylinder. He believed that by superheating the steam judiciously a saving of from 15 to even 20 per cent. of fuel might be effected, eren upon a properly constructed engine; but he was equally satisfied that superheated steam must eventually gire way to regenerated steam, by whicl alone the full equivalent of motive power could be obtained from heat, diminished only by the unaroidable losses from radiation, \&c.

In the use of high temperatures there was much difficulty in getting the joints to stand steam-tight, which he had experienced in superheating steam in his regenerative steam-engine; and after the failure of various cements and copper rings, he had succeeded. in making a joint that stood even a red heat and remained quite steam-tight. The cement he used was composed of red lead and oil mixed with as much dust of cast iron as could be worked into it. He showed a specimen of the joint fresh made, and one that had been exposed to a red heat in which the cement had become nearly as hard as iron itself. 
In the discussion of the Paper

\section{"ON COMBINED STEAM," \\ By John Withered, United States,}

Mr. C. W. Siemers * said that he had, for nearly the last fifteen years, occupied himself with this question. When he first turned his attention to the subject, he endearoured to ascertain the advantage of superheating steam, and he made some rather elaborate experiments to determine the rate of expansion. He found, that Gay-Lussac's law of an uniform rate of expansion of elastic fluids by heat, was not applicable, but that steam, near its point of saturation, expanded in a greater ratio than afterwards. A curve representing the rate of expansion was rounded at the beginning, but gradually approached a straight line ; it was, in fact, a hyperbola, the asymptote of which ran parallel to a line representing the uniform progression of expansion of air. So that at a temperature considerably removed from the boiling point, air and steam expanded, practically, at the same rate; whereas at first, steam expanded four times, or fire times more than air, for the same increase of temperature. $\mathrm{He}$ also found, that steam near its point of saturation, possessed great capacity for heat; and therefore, by simply superheating steam, no great economy could be produced. The results of recent practice showed, however, in many instances, a very large saring, which might be ascribed to a secondary cause. Steam, in expanding behind a working piston, lost a portion of its heat, which was converted into mechanical effect. This heat was entirely lost, and a portion of the steam must condense, or form water. This water re-evaporated when the pressure had become reduced by expansion, and cooled the sides of the cylinder, thereby producing condensation in the fresh steam from the boiler; and thus an action was established on the sides of the cylinder, (resembling that of a sponge, which, under the influence of an alternating pressure, absorbed and emitted water,) by which a certain amount of steam passed, at each stroke,

* Txcerpt Minutes of Proceedings of the Institution of Civil Engineers, Vol. XIX. Session 1859-60, pp. 479-480. 
through the cylinder, without exerting its elastic force upon the piston. To prevent this action, it was necessary to sufficiently increase the temperature of the steam, that it might be expanded through the stroke, without condensation. According to the present well-established law, expressing mechanical force by the quantity of heat, he found, that an increase of temperature of $100^{\circ} \mathrm{Fahr}$. would suffice to prevent condensation in an ordinary expansive engine. Increasing the heat beyond that point would not be aecompanied with any marked economy, and would engender many diffieulties; lubrication would become difficult, and friction would be produced. Great stress had been laid upon the peculiar properties of mixed steam, and the advantages which it possessed over superheated steam, but he had never seen any remarkable results from its use. In an engine which he designed, he virtually used the two steams together, inasmuch as, at each stroke, he added to a volume of superheated steam, a certain proportion of saturated steam ; but he never observed any spontaneous inerease in the bulk. There was, however, one adrantage in the author's system,-by mixing ordinary saturated steam with superheated steam, he had the means of regulating the temperature. If, then, a compensating rod was introduced into the steam pipe, so as to limit the admission of steam in proportion to the temperature, beneficial results might be obtained. He was convinced, however, that in simply superheating stenm, the ultimate degree of economy would not be reached. The chief advantage of superheating was to prevent condensation in the working cylinder, whereas Mr. Siemens's object had been, and still was, to prevent the loss of the latent heat of the steam, by means of the regenerative system. Although he had advanced but slowly, owing to the difficulties and expense attending experiments of this description, he had two engines at work, which gare him every confidence of ultimate and complete success. 
In the discussion of the Paper

\section{"ON GIFFARD INJECTOR FOR FEEDING STEAM- BOILERS," by Mr. John RoBINson,}

Mr. C. W. Sremens * said he had made some calculations as to the rise of temperature in the feed-water by its passage through the injector, on the assumption that the steam supply carried the water along with it by impact, taking no account of the friction of the water ; that is, that if $1 \mathrm{lb}$. of steam in motion were mixed with $2 \mathrm{lbs}$. of water at rest, the result produced would be 3 lbs. put in motion at one-third the original velocity of the steam.

Now since the velocity of water or steam issuing into the atmosphere from the same boiler was equal to that acquired by a falling body in falling through the height of a column of the same water or steam giving the same effective pressure, and since the velocity acquired by a falling body was proportional to the square root of the height through which it fell, it followed that the relocity of the water and of the steam would be proportional to the square roots of the relative rolumes; and as the volume of steam with one atmosphere effective pressure was 860 times that of water, it would issue with $\sqrt{860}$ or 29 times the velocity of the water from the same boiler. Hence the steam issuing would just balance 29 times its own weight of water trying to issue from the boiler ; and, therefore, assuming the total heat of the steam to be $1200^{\circ}$, and the original temperature of the feed $100^{\circ}$, the rise of temperature of the feed would be $\frac{1200-100}{29+1}=37^{\circ}$. And calculating the rise of temperature in the same way for the ligher pressure of steam there would be

with 1 atmosphere effective pressure $37^{\circ}$ rise of temperature

\begin{tabular}{|c|c|c|c|c|c|c|}
\hline , & 2 & " & " & ", & $44^{\circ}$ & ," \\
\hline " & 3 & " & " & ", & $50^{\circ}$ & " \\
\hline " & 4 & " & , & " & $55^{\circ}$ & ", \\
\hline , & 10 & ", & ", & , & $80^{\circ}$ & ", \\
\hline
\end{tabular}

* Excerpt Minutes of Proceedings of the Institution of Mechanical Engineers, 1860, p. 78 . 
Comparing these theoretical results with the experiments given in Table V., it appeared that in practice with steain of $51 \mathrm{lbs}$., or about 3 atmospheres effective pressure, the rise of temperature was $74^{\circ}$, while the calculation gare only a little more than $50^{\circ}$; but then it was assumed that there had been no loss of power by friction, and the quantity of feed-water propelled into the boiler had been supposed to be the maximum amount theoretically possible. The calculation accordingly gare the minimum rise of temperature when the steam was only just able to balance the pressure of the water tending to escape from the boiler; and consequently in practice the actual rise of temperature must always be greater than that obtained by the calculation; but the two results differed not more, he thought, than might be expected, if all losses of effect were taken into account. The table agreed moreorer with the calculation in giving a greater rise of temperature at higher pressures of steam; although the losses of effect must necessarily increase with the pressure, or rather with the increase of relocity of the jet. Much must also depend upon the proper adjustment of the instrument to make the quantity of water injected a maximum.

In the discussion of the Paper

"ON AN APPLICATION OF GIFFARD'S INJECTOR AS AN ELEVATOR FOR THE DRAINAGE OF COLLIERY WORKINGS," by Mr. C. W. WaRdle,

Mr. C. W. Sicurexs * said, that although the injector was rery beautiful and economical in action where water had to be raised and also to be heated, as in feeding a boiler, it was remarkably deficient in respect of economy when employed simply as an elevator for raising water, where the water was not required to be

* Excerpt Minutes of Proceedings of the Instituticn of Mechanical Engineers, 1861, p. 227. 
heated. This was shown in the experiment which had been mentioned, where the water was raised only 36 feet high in being heated $26^{\circ}$; but the perfect equivalent of heat as established definitely by Joule's investigations and others subsequent, was that the heat required to raise $1 \mathrm{lb}$. of water $1^{\circ}$ in temperature would raise $1 \mathrm{lb}$. a height of $772 \mathrm{feet}$, and $1 \mathrm{lb}$. heated $26^{\circ}$ would raise $1 \mathrm{lb}$. a height of $772 \times 26$ or 20,072 feet ; hence the economy of the elevator was as 36 to 20,072 , or only $\frac{1}{500}$ th of the theoretical perfect duty of the heat. A rery good pumping-engine realized $\frac{1}{6}$ th of the theoretical effect, and ordinary steam-engines realized $\frac{1}{16}$ th to $\frac{1}{1+}$ th, and werc consequently 40 to 56 times superior in duty to the elevator. The clevator was therefore economically applicable only where fuel was no object, or as an injector wherc the heat came in again usefully, as in feeding a steam boiler.

The injector, indeed, although inferior to a pump in mere propelling power, he considercd the most perfect instrument for feeding boilers, so long as the supply-water was cool enough to allow it to work; for then all the heat imparted to the water was returned into the boiler without any waste, whereas in using steam to work a pump the larger part of the heat was wasted by being thrown away with the exhaust steam. The injector, however, would not be economical if the supply water could be heated by other means free of expense, sincc its action required the supply water to be kept cool.

The amount of condensation in the long steam pipe mentioned in the paper seemed small for such a length of pipe, alld he thought a good deal of water must be carried across the depositing box by the current of steam and pass through into the clevator. He had seen lately in France a simplc and efficient contrivance by M. Le Chatelier, for freeing the steam from water, by making the steam pipe from the boiler descend vertically into the depositing box, surrounded by a cylindrical and concentric casing, from the top of which the steam was taken off for the cngine; the wet steam rushing into the depositing box in a vertical current, carried forward all the water it contained down to the bottom of the box by the velocity imparted to it, while the steam itself turned sharp round the bottom of the steam pipe and ascended through the annular space, passing off dry, and the water was allowed to drain 
back into the boiler. This apparatus was applied to a boiler which previously consumed $8 \mathrm{lbs}$. of water per lb. of fuel, and the result was that the consumption was reduced afterwards to only 6 or $6 \frac{1}{2}$ lbs. of water real evaporation per lb. of fuel, while the engine went much faster in consequence of having drier steam. But where the steam simply shot across the top of the depositing ressel, as in the apparatus that had been described, he was satisfied that a considerable quantity of water must be lost by being carried across with it.

\section{ON A REGENERATIVE GAS FURNACE, AS APPLIED} TO GLASSHOUSES, PUDDLING, HEATING, Etc.

\section{By Mr. C. William Sifarexs.*}

THE arrangement of furnaces about to be described is applicable with the greatest advantage in cases where great heat has to be maintained : as in melting and refining glass, steel, and metallic ores, in puddling and welding iron, and in heating gas and zinc retorts, \&c. The fuel employed, which may be of very inferior description, is separately converted into a crude gas, which in being conducted to the furnace has its naturally low heating power greatly increased by being heated to nearly the high temperature of the furnace itself, ranging to above $3000^{\circ}$ Fahr.; undergoing at the same time certain chemical changes whereby the heat developed in its subsequent combustion is increased. The heating effect produced is still further angmented by the air necessary for combustion being also heated separately to the same high degree of temperature, before mixing with the heated gas in the combustion chamber or furnace; and the latter is thus filled with a pure and gentle flame of equal intensity throughout the whole chamber. The heat imparted to the gas and air before mixing is obtained from the products of combustion, which after leaving the furnace are reduced to a temperature frequently not

* Excerpt Minutes of Proceedings of the Institution of Mechanical Engineers, 1862, pp. 21-36, and 40-44.

voL. I. 
exceeding $250^{\circ}$ Fahr. on reaching the chimney, whereby great economy in fuel is produced, with other advantages.

The transfer of heat from the products of combustion to the air and gas entering the furnace is effected by means of regenerators, the principle of which has been recognised to some extent since the early part of the present century, but has not hitherto been carried out in any useful application in the arts, unless the respirator invented by Dr. Jeffreys be so considered. The discovery of this principle is ascribed to Rev. Mr. Stirling of Dundee, who in conjunction with his brother, James Stirling, attempted as early as the year 1817 to apply it to the construction of a hot-air engine : their engine did not however succed, nor did Captain Ericsson's later attempts in the same direction lead to more satisfactory results. The economical principle of the regenerator having attracted the writer's attention in 1846, he constructed in the following year an engine in which superheated steam was used in conjunction with the regenerator: many practical difficulties however prevented a realisation of the success which thcory and experiments appeared to promise ; but it is gratifying to find that one principle then adopted, that of superheating the steam, has since receired the sanction of an extended application.

The employment of regenerators for getting up a high degree of heat in furnaces was suggested in 1857 by the writer's brother, Mr. Frederick Siemens, and has since been worked out by them conjointly through the several stages of progressive improvement. The results obtained by the earlier applications of the principle were communicated by the writer in a paper read at a former meeting of this Institution (see Proceedings Inst. MI.E., 1857, page 103) * : and two or thrce of the furnaces then described, employed for heating bars of steel, remain still in operation. In attempting however to apply the principle to puddling and other larger furnaces, serious practical difficulties arose, which for a considerable time frustrated all efforts ; until by adopting the plan of volatilising the solid fuel in the first instance, and employing it entirely in a gaseous form for heating purposes, practical results were at length attained surpassing even the sanguine expectations previously formed. 
In the early form of the regenerative heating furnace, which has been in continuous work during the last three years for heating bars of steel at Messrs. Marriott and Atkinson's Steel Works, Sheflield, and also at the Broughton Copper Works, Manchester, there is a single fireplace containing a ridge of fuel fed from the top; and two heating chambers, in which the bars of metal to be heated are laid, with a regenerator at the end of each chamber, by which the waste heat passing off from the furnace is intercepted oul its way to the chimney, and transferred to the air entering the furnace. Each regenerator is composed of a mass of open firebricks, exposing a large surface for the absorption of heat, through which the products of combustion are made to pass from the furnace, and are thus gradually deprived of nearly all their heat previous to escaping into the chimney : the end of the regenerator nearest the furnace becomes gradually heated to nearly the temperature of the furnace itself, while the other end next the chimney remains comparatively cool. The direction of the draught being now reversed by means of a valve, the air entering the furnace is made to pass through the heated regenerator in the contrary direction, encountering first the cooler portions of the brickwork, and acquiring successire additions of heat in passing through the regenerator, until it issues into the first chamber of the furnace at a very high temperature, and traversing the ridge of fuel produces a flame which fills the second heating chamber; whence the products of combustion passing through the second cold regenerator deposit their heat successively in the inverse manner, reaching the chimney comparatively cool. By thus alternating the current through the two regenerators, a high degree of temperature is maintained constantly in the furnace. This arrangement of furnace is evidently applicable only in exceptional cases where two chambers are to be heated alternately, nor does it admit of being carried out upon a large scale.

In heating a single chamber the expedient was resorted to of providing two fireplaces to be traversed in succession by the heated air, with the heating chamber placed between, as in the furnace shown in the drawings accompanying the previous paper (Proceedings Inst. M.E., 1857, Plate 118). Here the difficulty arose that the air, the oxygen of which was already combined with carbon (forming carbonic acid) in traversing the first fireplace, 
took up a second equivalent of carbon (forming carbonic oxide) in traversing the second, so that the fuel of the second fire was consumed to no purpose. In order to diminish this loss and also avoid impairing the draught by a double resistance, the ridges of fuel were discontinued and the coal was fed into the furnace from the sides, resting on a solid hearth, to be there volatilised by the heated air passing over it. By frequently stirring the first fire its combustion was favoured until the current was reversed, when it was left undisturbed until the next change, and so on alternately. It was found very difficult however to maintain an active and uniform combustion and to burn the purely carbonaceous substance that was left in the fireplace after the gaseous portion of the fuel had been volatilised; and it had frequently to be raked out in order to make room for fresh gaseous fuel. This circumstance led to the first step towards the employment of fuel in the form of gas, by providing a small grate below the heap of fuel, through which a gentle current of air was allowed to enter, forming carbonic oxide, which afterwards further combined with oxygen on meeting with the hot current of air entering the furnace from the regenerator. The two fireplaces of alternating activity were however attended with considerable practical inconvenience: the furnacemen in particular disliked the idea of attending two fireplaces instead of one, and being little interested in the saving of fuel, took no pains to work the furnace in a satisfactory manner.

It therefore became necessary to devise a plan of heating a single chamber continuously by one fireplace, in combination with the alternate reversal of currents through the regenerators, but without reversing the direction of the flame. This was accomplished by means of double reversing valves, and was practically carried out in a puddling furnace that worked for a considerable length of time at the ironworks of Messrs. R. and W. Johnson near Manchester. The two regenerators were placed longitudinally side by side, with a flue between, underneath the puddling chamber, and the fireplace was put at one end of the puddling chamber, as in an ordinary puddling furnace, and fed with fuel from above. The heated air from the first regenerator was brought up at the back of the fireplace, and meeting there with the fuel produced the required flame in the puddling chamber; whence the products of combustion passed down at the end of the chamber, and were 
carried back along the flue below to the hot end of the second regenerator, through which they made their way to the chimney. For recersing the currents through the regenerators two valves were needed, commected by a lever, one at the hot end of the regenerators near the fire, and the other at the cool end next the chinnney; whereby the heated air was made to enter the fireplace by the same passage as previously, and the direction of the flame through the puddling chamber was not changed. By this arrangement the regenerative furnace was assimilated as nearly as could be to an ordinary puddling furnace in form and mode of working. The few furnaces constructed in this manner produced a great heat with little mole than one-half the consumption of fuel of ordinary furnaces in doing the same amount of work. A considerable saving of iron was also effected in puddling, owing to the absence of strong cutting draughts, a mild draught being found sufficient to produce the necessary heat. There still remained drawbacks however which prevented an extensire application of this form of furnace : the fire required frequent attention, and it was difficult to maintain a uniform volume of flame in the furnace; the reversing ralve at the hot end of the regenerators was moreorer liable to get out of order, and the furnace was costly to erect.

The most important step in the development of the regenerative furnace has been the complete separation of the fireplace or gas producer from the heating chamber or furnace itself. When a uniform and sufficient supply of combustible gas is ensured, it can evidently be heated just like the air, by being passed through a separate regenerator before reaching the furnace, whereby its heating power is greatly increased. The difficulty of maintaining a uniform flame in the furnace is thereby certainly remored, and there is no longer any necessity for keeping the flame alirays in the same direction through the furnace, since the gas can be introduced with equal facility at each end of the heating chamber in turn, and the periodical change of direction of the flame through the furnace tends only to make the heat more uniform throughout: whereas in the previous plan of employing solid fuel for heating in the furnace, the relative position of the fireplace and heating chamber being fixed and unchangeable required the direction of the flame to be kept always the same, unaltered by the 
reversal of currents through the regenerators. The new plan of a separate gas producer has now been successfully carried out in practice, and there are already a considerable number of the regenerative gas furnaces in satisfactory operation in this country and on the continent, applied to glasshouses, iron furnaces, \&c. In the neighbourhood of Birmingham, at Messrs. Lloyd and Summerfield's Glass Works, a flint glass furnace constructed upon this plan has now been in continuous operation for nearly twelve months, and affords a good opportunity for ascertaining the consumption of fuel of the regenerative furnace as compared with the previous furnace performing the same work. At the Glass Works of Messrs. Chance Brothers and Co. near Birmingham, the regenerative gas furnace has been under trial for the same length of time, and has latterly been adopted for the various purposes in crown and sheet glass making upon a very large scale. Messrs. James Russell and Sons, Crown Tube Works, Wednesbury, are also applying the furnace to the delicate operation of welding iron tubes, and in a short time will probably employ no solid fuel for any furnaces at their works. Another flint glass furnace erected by Messrs. Osler in Birmingham, and several puddling furnaces erected by Messrs. Gibbs Brothers at Deepfields, and by Mr. Richard Smith at the Round Oak Iron Works, are amongst the latest applications of the regenerative gas furnace, the designs having in all cases been furnished by the writer and carried out under his brother's immediate superintendence.

The gas producer is shown in Figs. 1, 2, and 3, Plates 7 and 8 : Fig. 1 is a longitudinal section, Fig. 2 a front elevation and transverse section at the front, and Fig. 3 a transverse section at the back. The producers are entirely separate from the furnace where the heat is required, and are made sufficient in number and capacity to supply several furnaces. The fuel, which may be of the poorest description, such as slack, coke dust, lignite, or peat, is supplied at intervals of from 6 to 8 hours through the covered holes A, Figs. 1 and 2, and descends gradually on the inclined plane $\mathrm{B}$, which is set at an inclination of from $45^{\circ}$ to $60^{\circ}$ according to the nature of the fuel used. The upper portion of the incline $\mathrm{B}$ is made solid, being formed of iron plates covered with firebrick; but the lower portion $\mathrm{C}$ is an open grate formed of horizontal flat steps. At the foot of the grate $\mathrm{C}$ is a covered 
water trough $\mathrm{D}$, filled with water up to a constant lerel from the small feeding cistern E, supplied by a water pipe with a ball tap. 'The large opening under the water trough is convenient for drawing out clinkers, which generally collect at that point. The small stoppered holes F F at the front and G G at the top of the producer are provided to allow of putting in an iron bar occasionally to break up the mass of fuel and detach clinkers from the side walls. Each producer is made large enough to hold abont 10 tons of fuel in a low incandescent state, and is capable of converting about 2 tons of it daily into a combustible gas, which passes off through the opening $\mathrm{H}$ into the main gas flue leading to the furnaces.

The action of the gas producer in working is as follows: the fuel descending slowly on the solid portion B of the inclined plane, Plate 7 , becomes heated and parts with its volatile constituents, the hydro-carbon gases, water, ammonia, and some carbonic acid, which are the same as would be evolved from it in a gas retort. There now remains from 60 to 70 per cent. of purely carbonaceous matter to be disposed of, which is accomplished by the slow current of air entering through the grate $\mathrm{C}$, producing regular combustion immediately upon the grate; but the carbonic acid thereby produced, having to pass slowly on through a layer of incandescent fuel from 3 to 4 feet thick, takes up another equiralent of carbon, and the carbonic oxide thus formed passes off with the other combustible gases to the furnace. For every cubic foot of combustible carbonic oxide thus produced, taking the atmosphere to consist of $\frac{1}{5}$ th part by volume of oxygen and $\frac{4}{5}$ ths of nitrogen, two cubic feet of incombustible nitrogen pass also through the grate, tending greatly to diminish the richness or heating power of the gas. All the carbonaceous portion of the fuel is not howerer volatilised on such disadvantageous terms : for the water trough $\mathrm{D}$ at the foot of the grate, absorbing the spare heat from the fire, emits steam through the small holes I under the lid; and each cubic foot of steam in traversing the layer of from 3 to 4 feet of incandescent fuel is decomposed into a mixture consisting of one cubic foot of hydrogen and nearly an equal rolume of carbonic oxide, with a variable small proportion of carbonic acid. Thus one cubic foot of steam yields as much inflammable gas as five cubic feet of atmospheric air ; but the one operation is dependent 
upon the other, inasmuch as the passage of air through the fire is attended with the generation of heat, whereas the production of the water gases, as well as the erolution of the hydro-carbons, is carried on at the expense of heat. The generation of steam in the water trough being dependent on the amount of heat in the fire, regulates itself naturally to the requirements; and the total production of combustible gases varies with the admission of air. And since the admission of air into the grate depends in its turn upon the withdrawal of the gases evolved in the producer, the production of the gases is entirely regulated by the demand for them. The production of gas may eren be arrested entirely for 12 hours without deranging the producer, which will begin work again as soon as the gas valve of the furnace is reopened; since the mass of fuel and brickwork retain sufficient heat to keep up a dull red heat in the producer during that interval. The gas is however of a more uniform quality when there is a continuous demand for it, and for this reason it is best to supply several furnaces from one set of producers, so as to keep the producers constantly at work. The opening $H$ leading from each producer into the main gas flue can be closed by inserting a damper from above, as shown in Fig. 7 , in case any one of the producers is required to be stopped for repairs or because part of the furnaces supplied are out of work.

It is important that the main gas flue leading to the furnaces should contain an excess of pressure however slight above the atmosphere, in order to prevent any inward draughts of air through crevices, which would produce a partial combustion of the gas and diminish its heating power in the furnace, besides causing a deposit of soot in the flues. It is therefore necessary to deliver the gas into the furnace without depending upon a chimney draught for that purpose. This could easily be accomplished if the gas producers were placed at a lower level than the furnaces, but as that is generally impossible, the following plan has been adopted. The mixture of gases on leaving the producers has a temperature ranging between $300^{\circ}$ and $400^{\circ}$ Fahr., which must under all circumstances be sacrificed, since it makes no difference to the result at what temperature the gas to be heated enters the regenerators, the final temperature being in all cases very nearly that of the heated chamber of the furnace or say $2500^{\circ} \mathrm{Fahr}$. 
The initial heat of the gas is therefore made available for producing a plenum of pressure by making the gas rise about 20 feet above the producers, then carrying it horizontally 20 or 30 feet through the wrought iron tube J, Plate 7, and letting it again descend to the furnace, as shown by the arrows in Fig. 1. The horizontal tube $J$ being exposed to the atmosphere causes the gas to lose from $100^{\circ}$ to $150^{\circ}$ of temperature, which increases its density from 15 to 20 per cent. and gives a preponderating weight to that extent to the descending column, urging it forwards into the furnace.

The application of the regenerative gas furnace as a plate glass melting furnace is shown in Plates 9 to 12 , which represent a melting furnace now in course of erection at the British Plate Glass Works near St. Helen's. This furnace does not differ materially from the regenerative gas furnaces previously erected and at work at Messrs. Chance's and Messrs. Lloyd and Summerfield's, but is selected in preference because it is the most improved in details of construction. Plate 9 shows a longitudinal section of the furnace, Plate 10 a transrerse section, and Plate 11 a sectional plan above and below the bed or "siege" as it is termed of the furnace. Figs. 7, 8, and 9, Plate 12, show the detail of the gas and air valves.

The heating chamber $\mathrm{A}$ of the furnace, Figs. 4 and 5 , contains twelve glass pots $B$, which are got out through the side doors when the glass is ready for casting upon the moulding table. Underneath are placed transversely the four regenerators C C, composed of open firebricks built up on a grating, which are arched over at the top and support the bed or siege D of the furnace. The regenerators work in pairs, the two under the right hand end of the siege communicating with that end of the heating chamber, while the other two communicate with the opposite end, as shown in Fig. 4. The gas enters the chamber through the three passages E, Figs. 5 and 6 , and the air through the two intermediate passages $\mathrm{F}$, whereby they are kept entirely separate up to the moment of entering the furnace, but are then able immediately to mingle intimately, producing at once an intense and uniform flame in the heating chamber. The siege $D$ is built of firebrick, with a number of transverse channels, shown black in Figs. 4 and 8 , through which the cold entering air is made to 
pass on its way into the air flue $G$, as shown by the arrows in Fig. 5 ; by this means the siege is kept comparatively cool, so that no fluid glass can pass through crevices into the regenerators. Any melted glass that may fall from the heating chamber through the apertures at the ends of the siege does not get into the regenerators, but falls into the pockets M, Fig. 4, whence it can be removed through the opening at the bottom. The passage $\mathrm{N}$, Fig. 5, by which the air enters, affords the means of getting at the regenerators through an opening at the end of each.

From the air flue G, Fig. 8, the entering air is directed by the reversing valve $H$ into the air regenerator, as shown by the arrows, and there becomes heated ready for entering the furnace; at the same time the gas entering from the gas flue I, Fig. 7, is directed by the reversing valve $J$ into the gas regenerator, where it becomes heated to the same temperature as the air. Similarly the products of combustion on leaving the opposite end of the furnace pass down through the second pair of regenerators, as shown by the arrows in Fig. 4, and after being here deprived of their heat are directed by the reversing valves $I I$ and $J$ into the chimney flue $K$. When the second pair of regenerators have become considerably heated by the passage of the hot products of combustion, and the first pair correspondingly cooled by the entering air and gas, the valves $H$ and $J$ are reversed by the hand levers, as shown dotted in Figs. 7 and 8, causing the currents to pass through the regenerators and the heating chamber in the contrary direction, whereby the hot pair of regenerators are now made use of for heating the gas and air entering the furnace, while the cool pair abstract the heat from the products of combustion escaping from the furnace. The supply of air and gas to the furnace is regulated by the adjustable stop valves $\mathrm{L}$, whereby the nature and volume of the flame in the furnace may be varied at pleasure ; whilst the chimney damper is used to regulate the amount of pressure in the furnace in relation to the atmosphere, so as to allow the opening of working holes.

The construction of furnace above described may be varied in many ways to suit local circumstances. The regenerators are in some instances not placed immediately under but at the side of the furnace; but it is important that they should always be placed at a lower level than the furnace, in order that the air and gas 
may rise naturally into the heating chamber, forming there a plenum of pressure.

Plates 13, 14, and 15 show the application of the regenerative gas furnace as a round flint glass furnace. Plates 13 and 14 show vertical sections of the furnace taken at right angles to each other, and Plate 15 a sectional plan above and below the siege. The round form of furnace is found convenient in flint glass-houses, affording the greatest amount of accommodation to the glassblowers. The four regenerators $\mathrm{C}$ are here arranged below the siege as before, and the air and gas from the hot regenerators enter the annular heating chamber $\Lambda$ at one side of the furnace, as shown by the arrows in Fig. 10, and pass all round it, the products of combustion escaping at the opposite side into the cold regenerators. The direction of the current is reversed at intervals exactly as in the plate glass furnace already described, by means of the reversing valves $H$ and $J$ in the air and gas passages, Figs. 11 and 12. Furnaces of this construction have lately been got to work at Namur in Belgium and at Montluçon in France, and several others of the same description are in course of erection at the present time. The furnace just started by Messrs. Osler in Birmingham also partakes of this form, being made semicircular.

In setting out each individual furnace, the heating effect required, the quality of the fuel employed, and the particular nature of the process to be performed, have to be considered. The amount of heat required determines the capacity of the regenerators; and the gas regenerators require fully as large a capacity as the regenerators, and sometimes even a greater. This would perhaps hardly be expected, but will be seen to be the case from the following considerations. The gases proceeding from the gas producers are a mixture of olefiant gas, marsh gas, vapour of tar, water and animoniacal compounds, hydrogen gas and carbonic oxide; besides nitrogen, carbonic acid, some sulphuretted hydrogen, and some bisulphuret of carbon. The specific gravity of this mixture averages 0.78 , that of air being 1.00 ; and a ton of fuel, not including the earthy remnants, produces according to calculation nearly 64,000 cubic feet of gas. By heating these gases to $3000^{\circ} \mathrm{Fahr}$. their volume would be fully six times increased, but in reality a much larger increase of volume ensues, in consequence of some important chemical changes effected at the same time. 
The olefiant gas and tar vapour are well known to deposit carbon on being heated to redness, which is immediately taken up by the carbonic acid and vapour of water, the former being converted into carbonic oxide and the latter into carbonic oxide and pure hydrogen. The ammoniacal vapours and sulphuretted hydrogen are also decomposed, and permanently elastic gases with a preponderance of hydrogen are formed. The specific gravity of the mixture is reduced in consequence of these transformations to $0 \cdot 70$, showing an increase of volume from 64,000 to nearly 72,000 cubic feet per ton of fuel, taken at the same temperature. This chemical change represents a large absorption of heat from the regenerator, but the heat is given out again by combustion in the furnace, enhancing the heating power of the fuel beyond the increase due to elevation of temperature alone.

The chemical transformation is also of importance in preventing "sulphuring ;" for it is believed that the sulphur in separating from its hydrogen takes up oxygen supplied by the carbonic acid and water, forming sulphurous acid, a firm compound, which is not decomposed on meeting with metallic oxides in the furnace. This view is so far borne out by experience that glass containing a moderate proportion of lead in its composition may be melted in open crucibles without injury, instead of requiring covered pots for the purpose as in ordinary furnaces. In dealing with the highest quality of flint glass, however, it is found necessary to retain covered pots; but every other description of glass is melted in open pots. In all branches of glass manufacture, saving of fuel is of relatively small moment as compared with the improvement effected in the colour and general quality of the glass by the use of the regenerative gas furnace, owing to the absence of dust and cinders and the high degree of temperature which may with safety be maintained throughout the heating chamber.

These advantages of the regenerative gas furnace are of equal value in the case of puddling and welding iron. Plates 16 and 17 represent a puddling furnace constructed on this plan. Fig. 13 is a longitudinal section of the furnace, Fig. 14 a sectional plan of the puddling chamber, and Fig. 15 a sectional plan of the regenerators; Fig. 16 is a transverse section at the end of the furnace, and Figs. 17 and 18 are vertical sections through the gas and air passages. 
The four regenerators $\mathrm{C}$ are in this cense arranged longitudinally underneath the puddling chamber $A$, which may be of the usual form. In order to complete the combustion of the gas and air in passing through the comparatively short length of the puddling chamber, it is necessary to mix them more intimately than is requisite in the large glass furnaces previously described. For this purpose a mixing chamber $0, \mathrm{Fig} .13$, is provided at each end of the puddling chamber, and the gas and air from the regenerators are made to enter the mixing chamber from opposite sides, as shown in Fig. 16 ; the gas aperture $\mathrm{E}$ is moreover placed several inches lower than the air aperture F, so that the lighter stream of gas rises through the stream of air while both are urged forward intu the puddling chamber, and an intense and perfect. combustion is produced. The mixing chambers $\mathrm{O}$ are sloped towards the furnace, as shown in Fig. 13, in order to drain them of any cinders which may get over the bridge. The reversal of the current through the furnace is effected about every hour by the reversing valves $H$ and $J$ in the air and gas flues, the arrangement of which is exactly similar to that already described in the glass furnace : the supply of gas and air is regulated by the throttle valves $\mathrm{L}$, and the draught through the furnace by the ordinary chimneydamper.

This same arrangement, with obvious modifications, may be applied also to blooming and heating furnaces, the advantages in both cases being a decided saving of iron, besides an important saving in the quantity and quality of the fucl employed. The space sared near the hammer and rolls by doing away with fireplaces, separate chimney-stacks, and stores of fucl, is also a considerable advantage in favour of the regenerative gas furnace in ironworks. The facility which it affords for either concentrating the heating effect or diffusing it equally over a long chamber, by effecting a more or less rapid mixture of the air and gas, renders the furnace particularly applicable for heating large and irregular forgings or long strips or tubes which have to be brought to a welding heat throughout. It has already been applied to a considerable extent in Germany for heating iron, having been worked out there under the direction of the miter's eldest brother, Dr. Werner Siemens, who has also coutributed essentially to the development of the system. The furnaces at the extensire iron and 
engine works of M. Borsig of Berlin are being remodelled for the adoption of this system of heating, as hare also been those at the imperial factories at Warsaw.

Another important application of the regenerative gas furnace is as a steel melting furnace, in which the highest degree of heat known in the arts is required, presenting consequently the greatest margin for saving of fuel. Plate 18 represents a regenerative steel furnace which has been in satisfactory operation in Germany for a considerable length of time, being worked with lignite, a fuel little superior to peat in heating power. This application of the regenerative gas furnace is indeed rapidly extending in Germany, but has not yet practically succeeded in Sheffield where it was also tried : it is however in course of application at the Brades Steel works near Birmingham. Fig. 19 is a longitudinal section of the furnace, Fig. 20 a transrerse section, and Fig. 21 a sectional plan.

The two pairs of regenerators C C, Figs. 19 and 21, are situated at the ends of the long melting chamber $A$, in which the steel melting pots B B are arranged in a double row. The chamber is covered with iron cramped arch-pieces $\mathrm{P}$, any of which can be readily removed for getting at the pots. The arrangement of the reversing valves and the air and gas flues is similar to that in the glass furnace previously described.

Other applications of the regenerative gas furnace are being carried out at the present time : among which may be mentioned one to brick and pottery kilns for Mr. Humphrey Chamberlain near Southampton, for Messrs. Cliff of Wortley near Leeds, and for Mr. Cliff of the Imperial Potteries, Lambeth; also to the heating of gas retorts at the Paris General Gas Works, and at the Chartered Gas Co.'s Works, London. The description already given however is sufficient to show the facility with which this mode of heating may be adapted to the various circumstances under which furnaces are employed. The important application of the regenerative system to hot-blast stoves for blast furnaces by Mr. E. A. Cowper has already been separately communicated to this Institution (see Proceedings Inst. M. E., 1860, page 54).

The experience hitherto obtained with the regenerative mode of heating shows that it is attended with the greatest proportionate advantage in localities where good coal is scarce but where an 
inferior fuel abounds. This applies most forcibly to the South Staffordshire district, where the best coal in lumps is worth 12s. $6 d$. per ton, whereas good slack can be had at $3 s$. or $4 s$. per ton. The question gains moreover in importance when it is considered that, according to the best authorities, the thick coal of the district is coming to an end, while millions of tons of coal-dust have accumulated, of no present commercial value, which on being converted into gas in the manner described by means of the gas producers would acquire a heating value equal at any rate to the same weight of the best coal in the manner in which it is at present used. Considering also the proximity of the pits to the ironworks in this district, it may be suggested whether the gas producers being of very simple construction might not with advantage be placed near the banks of fuel above or eren under ground, the gas being conveyed to the works by a culvert so as to supersede carting of the fuel. Such an arrangement might notably contribute to perpetuate the high position which South Staffordshire has so long maintained as an iron producing district.

\section{In the discussion of the Paper}

Mr. Sizurexs observed that the essential features of the regenerative gas furnace described in the paper, as now matured and carried out in practice, were the separate gas producers, in which the solid fucl was converted into a gaseous form for use in the furnace, and the regenerators, in which the gas and air were each raised to a high degree of temperature previous to their mixture and combustion in the furnace, whereby the heat produced by the combustion was rery greatly increased. In the gas produccrs the fuel underwent a slow digestion, and the whole of the combustible constituents were drawn off into the furnace in the form of gas: while the incombustible ash or valueless portion of the fuel was left behind. The gas produced was of a crude nature in its original state, and much inferior to common gas for illuminating or heating purposes, and if burnt only with ordinary air would give very poor results : but it underwent a further change in the regencrator where it was heated up to about $3000^{\circ}$ Fahr., at which temperature the sereral gaseous compounds contained in it became decomposed, the rich carburetted hydrogen depositing 
carbon which was at once taken up by the vapour of water present, producing carbonic oxide and hydrogen; so that there was then present the greatest amount of free hydrogen, which had three or four times the heating power of any other gas. The air used for burning the gas was also heated by the regenerator up to about $3000^{\circ}$ and then mixed with the gas at the same temperature, producing perfect and most intense combustion : the regenerative system thus presented the means of attaining an almost unlimited degree of temperature. At the same time there was no great current or draught through the furnace, since the chimney draught was not required in this furnace to urge the combustion as in ordinary furnaces heated by solid fuel, and the cutting draughts destructive of ordinary furnaces were therefore entirely avoided. There was no difficulty in keeping up an abundant supply of gas if there were enough gas-producers and if the passages to the furnace were large enough ; the puddling chamber could then be completely filled with flame at any moment, or the flame could be as instantly stopped, by means of the regulating valves and chimney damper. By having separate air and gas valves the chemical nature or heating power of the flame could also be regulated to any desired degree, by altering the proportion of air admitted with the gas, so as to produce any required effect from a smoky flame to a pure bright flame. In the furnace for flattening the cylinders of sheet glass a quantity of bright clean flame was required for softening the glass without melting it; but in the melting furnace, on the contrary, an intense soaking heat was wanted, with rery little variation : and both sorts of heat were obtained in the new furnace from the same gas main, by simply regulating the quantities of air and gas admitted. Of the puddling furnaces two were now just being started in the South Staffordshire district, but about twenty puddling and heating furnaces had been at work in Germany for some months already with complete success. They had not yet obtained any absolute results with the regenerative puddling furnaces in this country, but at present the time of working a heat was about the same as in the ordinary puddling furnaces. The puddling furnaces working on this plan near Wolverhampton were not jet in a complete state for operation as they had been expected to be before this time, on account of a defect in the chimney flue and 
in the drainage of the premises. No permanent difficulty could be anticipated in carrying out the new puddling furnace in practice, on account of the large amount of experience gained in the application of the regenerative furnace for other purposes. There was only one chimney to a number of furnaces, and the draught was simpiy regulated by $a$ separate damper to each furnace. The chimney was not required to be lined with firebrick, but was built of red bricks, as the heat passed off from the puddling chamber was all arrested in the regenerators and the chimney was always cool. The chimney damper regulatcd only the force of draught in each furnace, but the quantity and quality of flame were regulated by the gas valve. No furringup had taken place in the regenerators, because the steam mixed with the gas would volatilise any carbon that might otherwise be deposited on the walls of the regenerator: it was for this purpose that care was taken to supply an excess of vapour of water from the water trough in the grate of the gas producer A regenerative heating furnace had been three years in constant work at Messrs. Marriott and Atkinson's Steel Works, Sheffield, heating the steel for the rolling mill, and no inconvenience had been experienced from vitrification of the materials of the furnace. MIr. Atkinson was prevented from being present at the meeting himself as he had wished, but had sent'a letter expressing his satisfaction with the furnace, as especially adrantageous for hcating steel on account of the uniformity of the heat obtained in it. The glass-melting furnace at Messrs. Illoyd and Summerfield's had also been in constant work for nearly a year without sustaining any injury from the great heat employed in it. The temperature in the furnace was at least a full welding heat of iron, as a bar of iron held in it dropped melted in half a minute; the hot end of the regenerator had a temperature of about $3000^{\circ} \mathrm{Fahr}$., and the heat in the furnace must of course be greater. For measuring such high temperatures he made use of the pyrometer described at a previous meeting," consisting of a well protected ressel containing a measured quantity of water, and a piece of copper or platinum of definite size, which was exposed for a sufficient length of time to the heat to be measured and was then dropped

* See Proceedings of the Institution of Mechanical Fngineers, 1860, p. 59. vol. I. 
into the water; the rise of temperature produced in the water showed the degree of heat upon a thermometer scale graduated in the proper proportion, and the results thus obtained must certainly be correct within $10^{\circ}$ or $15^{\circ} \mathrm{Fahr}$. Rather larger yields were obtained with the regenerative puddling furnace, but it had not been long enough at work yet to give any definite results. The puddling furnaces at work in Germany however showed at least 4 or 5 per cent. increase in the yield of iron, and this result was indeed to be expected, because the new furnace was free from the cutting action of the flame produced by a strong draught, and the ball was surrounded on all sides by an equally hot flame. As regarded cost, Mr. Siemens said that the alteration of present furnaces would be attended with a considerable expense, as there was all the extra bottom brickwork of the regenerators, besides the separate gas producers and the valves and mains; but the separate chimneys for each furnace were saved, and the cost of maintenance was greatly reduced, judging from the condition of the glass furnaces that had been twelve months at work. In new works however the cost of construction of the regenerative puddling furnaces would not much exceed the total cost of the present furnaces complete; and the new furnaces had the advantage of occupying only their own space, without requiring room for a coal pen to each furnace; they could thus be built closer together and consequently more could be brought within reach of one hammer.

Mr. Siemens thought a pair of the new puddling furnaces would cost about $£ 300$ complete. The regenerative glass furnaces hitherto erected had been very expensive in construction, having heavy iron plates in the sieges and a great deal of ironwork in the fittings of the furnace and in the gas producers, much of which had been greatly reduced or dispensed with in the furnaces subsequently put up. In starting the new plan of furnace he had thought it best to keep all the work very substantial, to be on the safe side for strength and durability; and the gas producers had also been provided each with a separate gas tube and valve, so that each could be shut off from the furnace if desired, to avoid risk of the furnace being interfered with in its working by a defect at any particular point. 


\section{In the discussion of the Paper}

\section{"ON THE DISTILLATION OF COAL, THE UTILIZA-} TION OF THE RESULTING PRODUCTS, AND THE manufacture of COKE," by M. Pernolet,*

Mr. C. W. Sremexs said he had lately paid considerable attention to the subject of coke-making; and he believed that the coke-orens generally used, especially in the north of England, were very primitive. The admission of air into them caused a portion of the coke to burn, and the gases from the remaining coal, being driven out, went to waste. He thought it hardly possible to conceive anything more rude than that system, because those gases, possessing heating powers of nearly equal value to the remaining coke, were allowed to escape freely into the atmosphere, involving not only a great loss of fuel in the most valuable form, but also a serious nuisance in populous districts. As regarded the quality of the coke produced in the ordinary oven, it had been satisfactorily proved to be inferior to that produced in the close oven when properly arranged, although it was, perlaps, more lustrous in appearance. The reason of its real inferiority was, that the coke first acted upon by atmospheric air was partially burned; but the carbonic acid formed by this combustion passed through the remaining mass in the oven, and robbed it of such an amount of carbon as was necessary to reduce the carbonic acid to carbonic oxide. Hence the earthy constituent of the coke was relatively increased, and, as was stated in the paper, the coke produced in close ovens contained, for the same amount of earthy matter present, 15 per cent. pure carbon. This, with a poor description of coal, was a most important feature, irrespective of the value of the additional yield, both of coke and of the secondary products.

As regarded the conversion of the ordinary coke-oven into a close oven-which he understood to be the subject of this paperhe considered that it was practicable, and that the kind of oren now brought before the notice of the Institution, had many ex-

* Excerpt Mlinutes of Proceedings of the Institution of Civil Engineers, Fol XXIII., Sessioh 1863-64, pp. 452-3. 
cellent qualities, but, that it was not the only one possessing important improvements. The plan had been tried, indeed, at Lambeth, with this difference, that coal was burnt to effect the carbonization, the gases being used for illuminating purposes. Those orens were being pulled down, because the gas produced in them was found to be deficient in brilliancy. Those most in use on the Continent were of two different descriptions. The first.was a semi-cylindrical horizontal oven, closed at the ends with movable doors, and provided with a covering arch forming an annular chamber, through which the gases generated in the oven circulated, and were consumed there by the admission of atmospheric air, in order to continue the distillation of the coal inside. That was an improvement, inasmuch as the gases did not go to waste; and he believed ovens of that description were used at the Ebbw Vale works, with great effect. In South Wales excellent coke was formed by mixing anthracite with bituminous substances, and by exposing the mixture to great heat in close ovens.

Another description of coke-oven which he had seen in France, and which seemed to be a favourite in many establishments; was in the form of a number of upright retorts, and was known as the "Four Appold." Each retort was slightly conical, and was filled by shooting the coal from carts at the top. The gases erolved, passed through the sides of the retort, and were burnt there by the admission of atmospheric air. After a distillation of 24 hours or 40 hours, a trap-door at the bottom was opened, and the whole of the coke, amounting to several tons, was dropped into railway trucks, or carts, and carried away. That was another instance where the full value of the carbonaceous material was obtained. He might mention, also, an oven he had lately tried, which was based upon the same principle, as regarded the general arrangement. It was an upright retort, but, instead of being simply heated by the gas issuing from the coal, a poorer kind of gas was used, which had been previously heated by passing through a regenerator; the air necessary to combustion being also passed through a regenerator placed at the side of the retorts, so that only a portion of the gases evolved was required to heat the coal, the rest being applied to other uses, either for illuminating purposes or for the heating of working furnaces, \&c. He had noticed the remarkable fact, that when the gas was drawn from the bottom of the retort, 
instead of from the top, a much higher illuminating power was obtained.

Operating on Staffordshire coal, which, in the ordinary way, yielded gas of about 10 candle-power, he had obtained, by this method, an illuminating power of eighteen candles, or twenty candles. Very little tar, or other secondary products were formed because, in passing over the heated surfaces, they were decomposed and turned into gas, or combined with the coke, which latter was thereby increased in hardness. It might be considered a drawback that there were no secondary products, but it was in reality not so ; for in most places the tar and ammoniacal liquor were difficult to dispose of, and if used to improve the coke they were applied to the best advantage.

He thought the question of coke making had oeen treated too lightly. The present tendency of engineers was to burn coal in locomotive engines, because coking, as generally performed, was a wasteful process, in which the most raluable part of the fuel was lost. But by improving the coke ovens, and by making judicious use of the gases, both for jlluminating and heating purposes, coke might be produced at a reduced rate, to be used for locomotive engines and blast-furnaces, and a larger aggregate saving of coal might be effected.

In the discussion of the Paper

"ON GIFFARD'S INJECTOR,"

$$
\text { By John Exglayd, M. Inst. C.E., }
$$

Mr. C. W. Siemexs* said he thought that the cause of action of this instrument should be better understood than it appeared to be, on account of the physical principles involved, which were, without necessity, at present invested with mystery. He could not agree in the view, expressed by Mr. Phipps, that the action of the Injector was due to the circumstance, that the impact produced

- Excerpt Minutes of Proceedings of the Institution of Civil Engineers, Vul. XXIV. Session, 1861-65, pp. 222-225, and 236-238. 
by a jet on a solid surface was equal to double the pressure due to the area which produced it; but he thought it might be shown, that the jet produced by the steam possessed a rery much higher velocity than a jet of water produced by the same pressure which would come out to meet it from the boiler. Thus the steam from the boiler issued with a velocity $v=8 \sqrt{h}$, or nearly so, neglecting the error arising from the circumstance of its being an elastic fluid ; while the water of the boiler would issue with a velocity represented also by the formula $v^{\prime}=8 \sqrt{h^{\prime}}$; but the pressure being the same in the two cases, it followed that the height of the column $h$ was superior to $h^{\prime}$ in the proportion of the relative densities of steam and water. Hence the relocity $v$ of the steam would exceed the velocity $v^{\prime}$ of the water in the proportion of $\sqrt{h}: \sqrt{h}$, or in the case of steam of four atmospheres' pressure, $v: v^{\prime}=\sqrt{1}: \sqrt{477}$, water being 477 times denser than steam of that pressure, or $v: v^{\prime}=1: 21 \cdot 8$.

It was therefore evident, that every particle of steam rushed forward with a velocity ncarly twenty-two times greater than that with which the water could meet it, only if it were to rush forward in its elastic state, it was evident that each particle of steam would hare to encounter 477 particles of water within the same volume, and must be forced back notwithstanding its superior velocity.

But if the steam were imagined to be condensed between the point of issue and that of its meeting with the jet of water, if, for instance, its elastic force could be destroyed by making it pass through an infinitcly cold space, then the result would be a very contracted jet of watcr passing forward with the extraordinary velocity of $v^{\prime}=8 \sqrt{h^{\prime}}=8 \sqrt{477 \times 3 \times 32}=1712$ feet per second, meeting a column of $v=8 \sqrt{h}=8 \sqrt{3 \times 32}=78$ feet per second.

The effect would be, that the column of water resulting from the condensation of the steam would pierce the comparatively sluggish jet of water meeting it, as though it were a steel wire forcing its way into the boiler. This was, however, an impossible position, for the steam could not be condensed by itself spontaneously. But the injector effected the spontaneous condensation of the jet of steam by incorporating with it a sufficient quantity of cold water, which was so regulated, that the mean velocity of the united jet of steam and water still exceeded the velocity of 78 feet per second with which the opposing jet from 
the boiler would meet it. Supposing the initial temperature of the water to be about $70^{\circ} \mathrm{Fahr}$, the weight of the condensing water should exceed the weight of the condensed steam about ten times to effect perfect condensation ; the velocity of the united jet or sheaf would be in this case $=\frac{1,712}{10+1}=155$ feet per second, or nearly doubly sufficient to force its way into the boiler.

It might here be remarked, that the author of the paper was clearly in error when he stated that the steam was only partially condensed in the sheaf. Uncondensed steam encountering water could not drive it back; but a column of water encountering another column of inferior velocity must drive it back. It was essential that water of sufficiently low temperature should be brought into contact with the jet of steam to effect its entire condensation, without reducing its velocity below the limit indicated by the imaginary velocity of the opposing column. In the case assumed, the weight of condensing water, or of the water injected into the builer, must not exceed the reight of condensed steam by $\frac{1,712}{78}$ $=22$ times, or making allowance for losses of effect, say by 18 times. Taking the total heat of steam at 1,150 units, it followed that the rise of temperature of the injected water would be $=\frac{1,150}{18}=64^{\circ} \mathrm{Fahr}$, and assuming that the final temperature of the sheaf must not exceed $190^{\circ}$, in order to effect entire condensation, it followed that the initial temperature of the injected water must_not exceed $190-64=126^{\circ} \mathrm{Fahr}$. If it should be attempted, under the circumstances, to inject water of a temperature exceeding $126^{\circ} \mathrm{Fahr}$., the sheaf must break up, and the action of the instrument be paralyzed. On the other hand, the greatest quantity of water which each pound of steam would be able to take depended upon the relative velocity of steam and water when acted upon by the same pressure, and might be expressed by $\frac{1,712}{78}=22 \mathrm{lbs}$. That would be the greatest quantity of water which each pound of steam could urge forward into the boiler, or could urge forward if there were no loss from friction or by the vortices formed. In reality it would probably not deliver much abore half that quantity into the boiler. 
The subject had been considered irrespective of the question of heat, but that, in his opinion, was a fallacious method, for, it would be seen, that without complete condensation the instrument could not act ; neither could its effect, nor the limits of its action, be determined, without taking into account the amount of heat contained in the steam and in the water, as well as their proper velocities when acted upon by pressure.

Mr. Siemens thought the injector could only be advantagenusly applied as a motor, in cases where the water had not only to be raised but also to be heated, and its legitimate application would probably remain confined to the feeding of steam boilers. Its practical advantages were not overstated in the paper, where feedwater of sufficiently low temperature was used. The minimum temperature, to obtain an advantageous result, would be about $100^{\circ} \mathrm{Fahr}$. In the case of a high-pressure engine, it was a question whether a heater and a pump would not be more advantageous than this instrument. The author had stated that $2 \cdot 3$ cubic feet of steam would be expended to pump one cubic foot of water into the boiler. But even this calculation, unfavourable as it might seem, still left a great margin in farour of the pump, inasmuch as the water could be raised by waste heat to nearly $212^{\circ}$. He beliered that the injector would be found applicable with the greatest advantage in the case of marine engines, or of condensing engines in general, where there were no means of heating the feed-water to above $100^{\circ}$. Under such circumstances the power expended to work the feed-pump could be entirely saved, because although the injector would expend heat on the water, it would return the same to the boiler; whereas the pump used the steam to work it, and gare nothing in return.

Mr. Siemens said, the areas of the different jets of water and steam, which had been stated to be adopted in practice, agreed very well with his own calculations. * The areas were determined by the quantity of steam necessary to condense in order to impel the water. Taking the case of a pressure of $60 \mathrm{lbs}$, , or an effective pressure of three atmospheres, the steam was 477 times lighter than water, while its velocity was only in the ratio of $\sqrt{477}$, or nearly 22 times greater than that of the water; the

* Vide Minutes of Proceedings of the Institution of Mechanical Engineers, 1860, pp. $48-78$. 
consequence was, that the area must be larger to allow a given weight of steam to issue from an orifice, than if water issued under the same pressure, in the proportion of $\sqrt{477}: \sqrt{1}$, or about 21 times the area. But, inasmuch as the quantity of water had to be increased ten-fold, it followed that $\frac{1}{1}$ th of 21 times, or $2 \cdot 1$ times, ought to be the area of the steam orifice as compared with the orifice in the boiler. This calculation agreed accurately with the proportions it had been found expedient to adopt; but he was surprised to learn that the same proportions of area were given to the injector, although the conditions of its application, especially as regarded the pressure in the boiler, might be very different. Witl a pressure of twenty atmospheres, for instance, the density of the steam was 110 times less than that of the water ; therefore, the relative velocity would be as $\sqrt{110}: \sqrt{1}$, or as $10.5: 1$, and about double the area of steam would be required to supply the necessary quantity to impel the water forward into the boiler.

He felt convinced many of the partial failures they had heard of might be due to this, - that the injector had been calculated, or determined experimentally, for ordinary high-pressure engines, but if applied to low-pressure, or very high-pressure engines, it failed to work satisfactorily. It could even be shown, that the injector was not applicable at all if the pressure exceeded certain limits. As, with a pressure of twenty atmospheres, the velocity of the steam was only $10^{\circ} 5$ times greater than that of the water, and as the steam. must take up about 10 times its own weight of water in order to condense, it would consequently possess only just power sufficient to impart to that amount of water the requisite velocity, when that point would be reached, where the injector would no longer work with water of ordinary temperature.

The author had referred to the dynamical theory of heat, and had said, that a sudden change in the sheaf took place, when there was an instantaneous conrersion of heat into work, a rortex being found in the sheaf, producing this result. Mr. Siemens had been one of the earliest disciples of this new theory of heat ; and in the year $1853, *$ a paper by him was read at the Institution in which the caloric engines were passed in review by the light of that theory. 'Taking the case of a pressure of $60 \mathrm{lbs}$., the force repre-

* Vide Minutes of Proseclings of the Institntion of Civil Engineers, Vol. XII, 1. 571, and p. 29 , ante. 
sented by a jet of steam issuing out into the atmosphere was simply the product of the column in feet representing that pressure, multiplied by the weight of steam in lbs. issuing in a given time. The column representing the pressure of steam of four atmospheres total pressure was, according to the table, 45,792 feet; - that was, steam of a pressure of $60 \mathrm{lbs}$. would be produced by a column of its own weight 45,792 feet high. 'Therefore, 45,792 foot-lbs. was the mechanical work due to $1 \mathrm{lb}$. of that column of steam. Now the quantity of heat contained in $1 \mathrm{lb}$. of steam was 1,150 units. These 1,150 units of heat produced in the injector 45,792 foot-lbs. of work, or for every unit of heat $\frac{45,792}{1,150}=39.8$ foot-lbs. The full mechanical equivalent of a unit of heat was however $=772$ foot-lbs., or units of force, and therefore the maximum useful effect of the injector did not exceed $\frac{39 \cdot 8}{772}$, or about the twentieth part of the theoretical effect due to the heat in the steam. A good expansive steam-engine would gire as much as one-sixth part of the full theoretical effect due to the heat expended, and supposing that there was 33 per cent. loss in an ordinary pump, it followed that water could be raised with an expenditure of $6+\frac{33}{100}=8$ times the theoretical expenditure of heat, instead of 20 times that quantity which the injector required. Consequently, the injector could only be advantageously applied, when the water was required to be both heated and raised; and it could never compete with an engine and pump for simply raising and propelling water. 


\section{ON UNIFORM ROTATION.}

By C. W. Siemens, F.R.S.," Mem. Inst. C.E.

Asoxgst the means at our disposal for obtaining uniform rotation, there is none for which the same degree of accuracy can be claimed as that which distinguishes the vibrating pendulum, or the oscillating spring-wheel of the common watch ; yet there are many purposes, both in physical science and in the mechanical arts, for which smaller subdivisions of time than the period of one oscillation are matter of considerable importance, and which can only be measured by uniform rotation.

Conical Pexduluar. - The apparatus by which continuous rotation of the greatest regularity has hitherto been obtained, is the conical pendulum, which was first applied by James Watt to regulate the speed of his engines, and which has since receired further development in the instrument known as the Chronometric Governor.

On examining into the principle involved in the conical pendulum, it will be found that the time $t$ of its rotation is dependent upon its length $l$, and on the angle $a$ which it makes with its vertical axis of rotation, which dependence is expressed by the formula $t=\phi \sqrt{l \cos a}$, the coefficient $\phi$ being a function due to gravitation. The value of $t$ being dependent upon $a$, it follows that "uniform rotation of a conical pendulum cannot be obtained except on condition that the angle of its rotation remains constant."

WATT's Goverxor.- - In the case of Watt's centrifugal governor, the angle of rotation of the pendulum varies with every change in the relative condition of power and load on the engine, and the change of angle is, indeed, taken advantage of to close or open the steam-supply valre. In order to close the steam-(or throttle-) valve the angle of rotation has to be increased, which necessitates a corresponding increase of the engine's velocity; on the other hand, an increase of the valve-orifice must be consequent on a reduction of the speed of the engine.

Considering this dependence of the action of the instrument

* Excerpt Philosophical Transactions of the Royal Society, 1866, pp. 657-670. 
upon permanent change of speed of the engine, the name of "governor" seems inappropriate, the instrument being, in fact, only a "moderator" of the amount of fluctuation to which the engine would be subjected without its agency. The amount of these fluctuations depends, in a great measure, upon the mechanical construction of the instrument, which is, generally speaking, very objectionable, inasmuch as the pendulous arms are mostly suspended at points beside the common axis of rotation, giving rise to an increased variation of time for a given change of angle; the reason being that the true pendulous length has to be measured from the point of intersection of the pendulums or rods with the axis of rotation, which point descends as the angle increases, causing the pendulous length to diminish at both extremities. A better result would be obtained if each pendulous rod were suspended from the point past the axis of rotation (as slown by dotted lines in Plate 19, Fig. 1), causing the two rods to cross in the line of the axis at a point which would rise with increase of angle, and render the true pendulous length approximately uniform between certain limits.

The governor of Watt is, however, subject to another defect which does not admit of an easy rectification, and which consists in its want of power to operate on the steam-valve at the moment when the equilibrium between the power and load on the engine is disturbed. It will be seen that while the engine proceeds uniformly, gravitation and centrifugal force must be in equilibrium as regards the governor-balls, but at the moment when, for instance, a portion of the load on the engine is removed, steam-power will be set at liberty for accelerating the fly-wheel. This acceleration proceeds in accordance with the well-known gravitation laws until the increase of centrifugal force imparted to the governor-balls suffices to overcome the friction of the valve and its mechanical connexions, which are not inconsiderable. In the mean time the speed of the engine will have been increased to an extent considerably beyond what is required in order to maintain the valve in its new adjustment; the action of the governor, when it does take place, will therefore be excessive, and a series of fluctuations in the speed of the engine must follow before the proper readjustment of its valve can be effected.

Chrovometric Goveryor.-Impressed with these inperfections 
in Watt's centrifugal governor, I proposed, twenty-three years ago, in connexion with my brother, Werner Siemens, a gorernor based also on the conical pendulum, which in this case was to be independent in its action of change in its angular rotation, and, moreover, was to be provided always with a store of power ready to orercome the resistance of the valve at the first moment when the balance between the power and load of the engine was disturbed. This instrument (the chronometric governor) has been applied with success in many cases where engines were required to work with great regularity under varying conditions of load; it has also received an interesting application by the Astronomer Royal for regulating astronomical and chronographical instruments, proving the high degree of precision of which it is capable.

The leading idea involved in this gorernor consisted in providing a conical pendulum in uniform rotation, and in establishing a differential motion between it and the wheel driven by the engine, which differential motion was made to act upon the source of power of the latter. If this idea could be carried out, it was evident that the engine, or machine to be governed, must suit its motion closely to that of the independent rotating pendulum, because the least retardation on its part must immediately result in an enlargement of the valve-orifice (it being understood that an increase of available power is always obtainable), and the least motion in advance of the pendulum must automatically reduce the source of power. This action would be effected instantly, notwithstanding a considerable resistance in the valve, because the weight of the pendulum in rotation represents, in this case, a store of power, inasmuch as its angular velocity would have to be suddenly checked or increased as the case may be, unless the valve obeyed to the first appearance of a differential motion. In order to realize these conditions, it was necessary to maintain the conical pendulum in question at a uniform angle of rotation, notwithstanding the changes of driving- or sustaining-power which must necessarily arise through its action upon the regulating ralve of the engine; and this could only be accomplished by providing the means of destroying or absorbing any excess of driving-power beyond what was necessary to overcome the friction of the instrument, and which must tend otherwise to increase its angle of rotation. On the other hand, a surplus of driving-power had to be provided to 
prevent an occasional collapse of the pendulum in opening the valve. The sustaining- or driving-power of the pendulum was obtained in taking advantage of the differential motion, a weight being attached to a horizontal lever upon the throttle-valve spindle, which, in exerting a pressure of the differential wheel against the two principal wheels, caused an impulse to be given to the one connected with the pendulum, whereas the third wheel was driven by the engine in the direction proper to raise the weight continually. The excess of driving-power imparted to the pendulum was destroyed by calling into action a friction between two solid substances at the moment when the angle of rotation had reached its intended maximum ; or a liquid resistance was introduced, such as a fan, rotating with the pendulum, being dipped into a bath of mercury or other liquid, at the moment when the extension of the pendulum was attained (see Plate 19, Fig. 2).

The governors constructed on this principle are remarkable for their instantaneous action upon the supply-valre of the engine, when a sudden disturbance of the balance between load and power takes place; and they possess also, to the fullest extent, the power of maintaining the regulated macline at the same speed, when the load reaches its maximum, as when it is at its minimum. In the hands of the Astronomer Royal the uniformity of motion obtained by the use of this governor approaches indeed that of an ordinary chronometer, yet it is not free from objections resulting from the delicate adjustment and frequent attention requisite to maintain it in good working condition. In its application to the regulating of physical apparatus it has, moreover, been found that the conical pendulum is apt to fall into elliptical rotation, whereby the subdivisions of time below the half second become inaccurate.

Foucault's Governor.-Monsieur Foucault, of Paris, has treated the same question in a different manner, substituting for the friction between solids, or of solids against fluids which we employed to fix the angle of rotation of the conical pendulum, the varying resistance of an air-propeller, according to the amount of area for the escape of air, which area he regulates by means of the angular elevation of his conical pendulum. The conical pendulum he employs is mounted in the manner of a Watt's governor of the best construction, which renders his apparatus portable, and therefore convenient for general purposes, while, on 
the other hand, it appears to depend for its correct aotion upon the perfect condition of many mechanical details.

Some months since an idea suggested itself to me which, while it furnishes the elements of a very general and complete solution of the problem under consideration, appears to possess also a separate scientific interest, which chiefly induces me to bring the subject before the Royal Society.

LIQUid IA Rotation.-If an open cylindrical glass vessel or tumbler containing some liquid be made to rotate upon its vertical axis, the liquid will be observed to rise from the centre towards the sides to a height depending on the angular velocity and the diameter of the ressel. As soon as the velocity has reached a certain limit the liquid will commence to overflow the upper edge of the ressel, being thrown from it in the form of a fluid sheet in a tangential direction. If the relocity remain constant from this moment, the overflow of the liquid will be observed to cease, although the liquid remaining in the ressel will continue to touch the extreme edge or brim. Supposing that the relocity of the vessel be now diminished, the liquid will be observed to sink, but will rise again immediately to its former position when the rotation returns to its previous limit of angular velocity. This velocity is the result of the balance of two forces acting on the liquid particles, namely, gravity and centrifugal force.

It is a well-known fact that the curvilinear surface produced by a liquid in rotation is that of a paraboloid, the parameter of which is expressed by $\frac{g}{w^{2}}$, and the curve itself therefore by the formula

$$
y^{2}=\frac{2 g}{w^{2}} x, \quad . \quad \cdot \quad \cdot \quad \cdot .
$$

$x$ signifying vertical distance from the apex, $y$ the corresponding horizontal distance from the axis of rotation, $w$ the angular velocity of rotation, and $g$ acceleration by gravity in one second.

In this formula there is no factor denoting the density of the liquid, which prores that the point to which the liquid is raised by a given angular velocity is independent of the specific gravity of the liquid employed.

By substituting for $y$ the radius $r$ of the rotating cup at the brim, and for $x$ the height $h$ of the brim above the lowest level 
of the liquid, we may write the foregoing general formula as follows :-

and

$$
h=\frac{r^{2} w^{2}}{2 g}, \text {. . . . . . }
$$

$$
v=\frac{\sqrt{2 g h}}{r} ; . . . . .
$$

two convenient formulæ for determining the height to which liquid will rise when the diameter of the rotating vessel and its angular velocity are given, or for determining the angular velocity due to a given height and diameter, it being understood that the values of $g, r$, and $h$, must be expressed in the same unit of length.

If it is desired to determine the number of revolutions per second $n$, instead of the angular velocity $w$, we may put $n=\frac{w}{2 \pi}$, and in putting this value for $v(=2 \pi n)$ into the last formula, we have

$$
n=\frac{\sqrt{2 g h}}{2 r_{\pi}} \text {. }
$$

These formulæ are applicable to vessels of every possible external form rotating upon their vertical axis, and to every possible liquid, but they are based upon the supposition that the liquid is raised by rotation to the upper edge or brim of the vessel, a condition which it may appear at first sight difficult to realize for practical purposes.

If the production of uniform rotation be the object in view, it is necessary that the liquid in the rotating vessel should always be at the point of overflow, although the driving-power might vary considerably, and that all surplus driving-power should be absorbed by other work than that of accelerating the rotating vessel, also that the stock of liquid within the vessel should never diminish. I hope to prove by the following demonstration that these various conditions can be fulfilled by suitable mechanical arrangements resulting in the construction of a simple and efficient instrument, which is represented by Plate 20, Fig. 1, and which has survived the ordeal of experimental proof.

Liquid Grometer.-The rotating vessel consists, in this case, of a cup $\mathrm{C}$ open both at the top and bottom, but widest at the top, the sides being made to close in towards the bottom in a parabolic curve analogous to that formed by the liquid in rotation. 
This cup contains upon its inner surface tliree or four radial ribs which unite in a central boss, by which the cup is supported upon the spindle $\mathrm{S}$. This support is not an absolute one, but the spindle is armed with a screw-tliread of rapidly ascending path, into which the screw-threads upon the inner surface of the boss are made to fit ; a fixed connection between the driving-spindle and the cup $\mathrm{C}$ is established by means of a spiral spring $\mathrm{E}$, one end of which is fastened to the projecting end of the spindle $\mathrm{S}$, and the other to the cup. Before this spring is fixed, it is drawn out longitudinally to sucl an extent as to balance the weight of the cup, which latter may therefore be snid to float upon the screw-threads without exercising any pressure upon the same. The upper support of the spindle $\mathrm{S}$ is a boss projecting from the bottom of a cylindrical vessel $B$ of glass sides and glass-domed top, which completely enclose the cup $C$, while it renders its action visible: this outer ressel is filled with liquid to such a height as to submerge the lower edge of the cup. Rotation of the liquid in the outer ressel is prevented by radial ribs upon its bottom surface; and upon the external surface of the rotating cup $\mathrm{C}$ two concentric projections are provided, one at the upper edge, and the second near the surface of the outer liquid, for the purpose of throwing off some liquid which would otherwise be apt to adhere to the external surface of the cup, in defiance of centrifugal force, and interfere slightly with its proper action.

Rotation being imparted to the shaft $\mathrm{S}$ and the cup $\mathrm{C}$ by clockwork or from any otlier source, the liquid at the bottom of the cup will be acted upon by centrifugal force and rise upon its inner sides, while additional liquid will enter from without and maintain the apex of the liquid curve nearly on a level with the surrounding lake. At the moment when the liquid in rotation touches the upper edge of the cup, the speed should be such as is determined by the formula $n=\frac{\sqrt{2 g h}}{2 r \pi}$, in which $h$ may be taken for the height of the brim of the cup above the lake surface; but considering that the power necessary to maintain the cup at its velocity, after the liquid has been raised to its upper edge, is exceedingly small, because no fresh material has to be put into motion, it would be practically impossible to prevent further acceleration. In order to make sure that the liquid will not fall 
below the brim of the rotating cup, an excess of driving-power must be applied, and that excess must be disposed of otherwise than in producing further acceleration of the cup. This is accomplished by means of a continual overflow of a thin sheet of liquid, which is projected against the sides of the outer vessel and falls back into the lake at the bottom, whence a similar quantity of liquid penetrates into the cup, to be also raised by its rotation and projected over its edge.

The power absorbed in raising and projecting the liquid must be strictly proportionate to the quantity of liquid so acted on in a given time, or to the thickness of overflow, provided the condition of uniform velocity be realized; but the velocity of the cup depends upon the height to which the liquid has to be raised, and must therefore be increased in order to raise the liquid column above the brim of the cup. The necessary increase of velocity to produce such an overflow is not great, considering that the height of the liquid column increases in the square ratio of the velocity, and may be neglected in all cases where only approximate results are required, or where variations in the driving-power are comparatively small; but no high degree of accuracy could have been claimed for this instrument unless the following compensation action had suggested itself :-

Automatic DIP of CUP.-We have assumed hitherto a rigid connexion between the cup and its driving-spindle, and unless the cup does overflow, we are, indeed, justified in this assumption, the spring $\mathrm{E}$ being too rigid to yield to the resistance of the cup in motion when no work is performed. With an increase of power the resistance of the cup also increases, and an overflow of liquid proportionate to the power is produced; the connecting spring $\mathrm{E}$ must yield, at the same time, proportionately to the torsional resistance thus created, and in the same ratio the cup will descend upon the helical surface which serves for its guide. While, therefore, on the one hand, the $h$ of our formula increases with the overflow, it is diminished, in the same ratio, by the descent of the cup, both depending directly upon the driving-power. In so adjusting the stiffness and length of the spring that the one action equals the other for any given increase of power, it must equal it also for other amounts of increase within reasonable limits, and strictly uniform rotation must be the result. The 
"rensonable limits" to this antomatic adjustment are imposed by the restricted orifice through which the liquid has to penetrate into the cup, and also by the range of action of the spring, for which the law of Mariotte is applicable. Experiments, to be hereafter described, have shown that the driving-power may be varied between wide limits without producing any sensible variation of speed. The final adjustment of the instrument to the normal relocity required is, moreorer, easily effected by raising or lowering the cup while it is runuing, for which purpose the lower end of the upright spindle $S$ is supported in the axis of an adjusting screw $\mathrm{E}$, as will be seen by inspection of Plate 20, Fig. 1.

RANGE OF POWER INCREASED.-The range of power through which uniform rotation can be obtained, may be further increased by an arrangement which is represented in Plate 20, Fig. 2, and Plate 21, Fig. 6, and which consists in arresting the liquid projected over the edge of the cup by a belt of fixed vanes $M$, whence it drops through the zone of rotating radial vanes $L$, which again impart tangential motion to it at the expense of the superfluous drivingpower of the cup of which they form part. It is hardly necessary to add that these fixed and rotating vanes only increase the range of pover of the instrument, without in any way affecting its rate of rotation, and that a second set of fixed and rotating vanes might be added with the same effect as the first. Although the rotating cup represented in Plate 20, Fig. 2, and Plate 21, Fig. 6, is not provided with the automatic dip, it is equally evident that the fixed and moveable vanes do not preclude that arrangement, which is only dispensed with in such cases where great uniformity of motion is not required.

An interesting application of such a "Liquid Gyrometer," as this instrument may appropriately be called, would be that of obtaining synchronous motion at different places connected by a telegraphic wire, for philosophical or telegraphic purposes; but in order to test its fitness for such purposes, I have constructed a clock of which it constitutes the regulating principle, the moving power being obtained by electro-magnetism.

Clock regulated BY LIQUid in ROTATION.--This clock is represented by Plate 22, Figs. 7 and 8 , and consists of three principal parts :- 
1. The pedestal containing a battery of two "Marie Davy's elements" suitably arranged.

2. The body of the clock, with sides formed of plate glass, containing an electro-magnet, by which rotatory motion is imparted to an iron bar or keeper fixed upon the vertical main axis which passes into

3 , the regulating chamber, consisting of a close cylindrical glass vessel with domed glass top containing the rotating cup and a certain quantity of paraffin oil, which fluid is particularly applicable on account of its perfect fluidity and non-affinity for the materials composing the regulator.

The regulating cup is in this instance formed of vulcanite, and is suspended from the top of the vertical axis by means of a spiral spring, which, being fixed at both ends, not only supports the weight of the cup but acts also as a torsional spring, enabling the cup to descend upon its helical central guide whenever an increase of driving-power calls into existence its equivalent of torsional resistance.

The rings of stationary and rotating vanes are dispensed with in this instance, because no great variations in the driving-power are contemplated. The electro-magnet acts by attraction of the armature during a small portion of its rotation, and one contact only is required, which is so arranged that no destruction of the metallic surfaces can arise through the discharge of extra-current sparks, which latter are received by an elastic point of platinum slightly in advance of the proper contact surface and moved by the same eccentric. By this simple arrangement the usual difficulty attending dry contacts is avoided, and a continued action of the instrument ensured. A train of reducing-wheels communicates the motion of the cup-spindle to hands upon the face of the clock, which record hours and minutes in the usual manner.

The diameter of the rotating cup being $=0.040$ metre, and the height of its edge over the surface of the liquid $=0.034$ metre, the number $n$ of its rotations per second in accordance with our formula

$$
n=\frac{\sqrt{19 \cdot 6 \text { metre } \times \cdot 038 \text { metre }}}{\cdot 040 \text { metre } \pi}=6 \cdot 9 \text { revolutions per second. }
$$

Experiment gave, on the contrary, a speed of $7 \cdot 5$ revolutions 
per second, or $\cdot 6$ revolution per second more than was indicated by theory, a result which seemed to stamp the action of the instruunent with uncertainty, when it was recollected that no allowance had been made for the aperture at the bottom of the cup, leaving a portion of the rotating liquid withont an external support.

CORRECTION FOR roller ORIFICE OF CUr.-If we assume, for instance, that the sides of the cup were cylindrical and merely descended below the surface of the liquid without closing in at the bottom, we should find that by rotation of this cylinder, supposing the inner surface to be rough or armed with radial projections, the liquid would rise on the circumference above the external level of surface, but would also form a depression or vortex in the centre of rotation. The surface of the rotating liquid would be that produced by the rotation of a vertical parabola, as represented in the diagram (Plate 19, Fig. 3). In order to maintain the hydrostatic equilibrium between the rotating column with the external liquid, it is necessary that its nean height of column must remain the same, or that the plane of external liquid level must divide the solid figure comprised between the cylinder and the curve of rotation into equal parts. In order to realise these conditions experimentally, it would be necessary to provide the lower portion of the rotating cylinder with an easy fitting and balanced piston, without which circular currents would be produced within the rotating liquid (descending by force of gravity at the sides, and rising again in the centre) and mar the result.

The body comprised between a paraboloid of the height $h^{\prime}$ and a cylinder is, however, divided equally by a horizontal plane cutting it at the distance of $\frac{h^{\prime}}{\sqrt{2}}$ from the edge, or at $h^{\prime}-\frac{h^{\prime}}{\sqrt{2}}=\cdot 293 h^{\prime}$ from the apex. The form of the curve depends upon the angular velocity alone, and would remain the same if the upper diameter of the tube were to be increased, only the curve would in that case have to be continued until it met the sides (as shown by dotted lines), and to the extent of these prolongations the liquid would be raised higher above the external level without producing a corresponding depression in the centre of rotation.

It follows that the aperture at the bottom of the rotating cup causes a vortex or depression of the apex of the curve of rotation below the external liquid to the extent of $\cdot 293$ part of the height 
due to its own diameter, and to the correct number of rotations $n^{\prime}$ per second.

It is

$$
n^{\prime}=\frac{\sqrt{2 g\left(h+\cdot 293 h^{\prime}\right)}}{2 r \pi},
$$

and also

$$
n^{\prime}=\frac{\sqrt{2 g h^{\prime}}}{2 \rho \pi}
$$

if $\rho$ is the radius of lower aperture of cup; therefore

or

$$
\begin{aligned}
& \frac{\sqrt{2 g\left(h+\cdot 293 h^{\prime}\right)}}{2 r \pi}=\frac{\sqrt{2 g h^{\prime}}}{2 \rho \pi}, \\
& h^{\prime}=h \frac{\rho^{2}}{r^{2}-\cdot 293 \rho^{2}} ;
\end{aligned}
$$

and in substituting this value for $h^{\prime}$ into the first formula, we have

or

$$
n^{\prime}=\frac{\sqrt{2 g h+2 g h \frac{\rho^{2}}{r^{2}-\cdot 293 \rho^{2}}}}{2 r \pi}
$$

$$
n^{\prime}=\frac{\sqrt{2 g h\left(1+\frac{\rho^{2}}{r^{2}-.293 \rho^{2}}\right)}}{2 r \pi}, \ldots .
$$

for our corrected formula to determine the velocity of cup with continuous overflow.

In applying this formula to the clock, taking for $\rho$ its value of 8 millimetres and the other values also in millimetres in order to avoid fractions, we find

$$
n^{\prime}=\frac{19600 \times 38\left(1+\frac{64}{400-16 \cdot 05}\right)}{40 \pi}=7 \cdot 4 \text { revolutions per second, }
$$

or 1 revolution per second less than the actual speed. This remaining excess of the actual over the calculated velocity of the cup is rather more than what may be fairly attributed to error of measurements, and appears to be due to adhesion of a film of liquid (which may be estimated at nearly 25 millimetre thickness) to the inner sides and edge of the cup, whereby its effectual dimensions are proportionately reduced. For a uniform speed this error must be a constant quantity, which cannot affect the working of the instrument injuriously, so long as the other conditions are such as to produce uniform rotation. The discrepancy is diminished by increasing the dimensions of the cup, and its amount is such 
that the compensation is effected, under all circumstances, by one or two turns of the regulating screw supporting the vertical spindle.

When the regulation of the cup is once effected, it continues to rotate at a remarkably uniform rate. Change of temperature affects the density of the liquid considerably, but does not influence the rate of the cup otherwise than inasmuch as it affects the level in the cup-chamber; which will rise with increase of temperature proportionately to the depth of liquid it contains, and which is inconsiderable. The lineal dimensions of the cup, and the length of the suspending spring, will also increase, all tending to lower the rate with increase of temperature; but, on the other hand, the length of the upright cup-spindle increases with increase of temperature, and in regulating the length and composition of that spindle properly, entire compensation for change of temperature is effected. The cup-chamber being entirely closed against the atmosphere, no fault can arise through eraporation or dispersion of the liquid within moderate periods of time.

In the case of the clock under consideration, no compensation for change of temperature was provided, nor is the cup entirely balanced by the spring, yet its rate is as uniform as that of the common clock with which it has been compared; but in order to test the regulating-power of the instrument, the driving-power was varied by the introduction of artificial resistances into the galvanic circuit, when the following results were observed :-

\begin{tabular}{|c|c|c|c|c|c|}
\hline $\begin{array}{c}\text { Time of } \\
\text { Common } \\
\text { Clock, } \\
\text { in Seconds. }\end{array}$ & $\begin{array}{l}\text { Mercury units } \\
\text { of Resistance } \\
\text { of Clock } \\
\text { and Battery. }\end{array}$ & $\begin{array}{l}\text { Units of } \\
\text { Resistance } \\
\text { put luto } \\
\text { Circuit. }\end{array}$ & $\begin{array}{l}\text { Relative } \\
\text { Value of } \\
\text { Driving. } \\
\text { power. }\end{array}$ & $\begin{array}{l}\text { Time of } \\
\text { Liquid Gyro- } \\
\text { meter Clock, } \\
\text { in Seconds. }\end{array}$ & $\begin{array}{l}\text { Variations } \\
\text { in Time } \\
\text { produced, } \\
\text { in Seconds. }\end{array}$ \\
\hline 720 & 110 & 0 & 100 & 736 & 16 slow \\
\hline 720 & 110 & 10 & 92 & 734 & $14 "$ \\
\hline 720 & 110 & 20 & 85 & 734 & $14 "$ \\
\hline 720 & 110 & 30 & 78 & 733 & 13 \\
\hline 720 & 110 & 40 & 73 & 732 & $12 "$ \\
\hline 720 & 110 & 50 & 69 & 731 & $11 "$ \\
\hline 720 & 110 & 60 & 64 & 729 & 9 \\
\hline 720 & 110 & 70 & 61 & 726 & $6 "$ \\
\hline 720 & 110 & 80 & 58 & 723 & 3 \\
\hline 720 & 110 & 90 & 55 & 720 & correct \\
\hline 720 & 110 & 100 & 52 & 723 & 3 fast \\
\hline 720 & 110 & 110 & 50 & 726 & $6 "$ \\
\hline 720 & 110 & 120 & 48 & 725 & $5 \%$ \\
\hline 720 & 110 & 130 & 46 & 724 & $4 \%$ \\
\hline 720 & 110 & 140 & 44 & 722 & $2 "$ \\
\hline 720 & 110 & 150 & 42 & 729 & 9 slow \\
\hline \multicolumn{6}{|c|}{ when the overflow had ceased. } \\
\hline
\end{tabular}


This result shows that the spring employed was decidedly too weak, producing a decrease of speed with increase of power.

A more careful adjustment of the spring would improve these results, which suffice, however, to prove the capabilities of the instrument.

It appears at first sight as though the friction of the cup upon the threads of the screw must interfere with its automatic adjustment; but this is practically not the case, owing to the circumstance that small fluctuations in the resistance continually occur, causing torsional oscillations of the cup, the mean of which must be its true position notwithstanding friction, which friction moreover is reduced to a minimum, owing to the suspension of the weight by the spring.

Another interesting quality of the gyrometric cup is its comparative indifference to a vertical position; it may, indeed, be tipped very considerably without interfering with the uniform overflow all round, and the time of its rotations is diminished only in the ratio of the square roots of the vertical mean heights, or it is $n^{\prime}: n=\sqrt{h:} \sqrt{h \cos \beta}$, or for a tipping angle $\beta=3^{\circ}$, $n^{\prime}: n=1: 1.0007$, showing that no particular care is requisite to place the instrument upon a horizontal foundation.

Grrometric Governor. - The most useful practical application of this instrument is that of regulating the power and velocity of steam-engines. A cup of very large dimensions, provided with several belts of check-vanes and with the automatic dip arrangement, might be conceived which, in being connected by gearing with the main shaft of an engine, would limit its velocity by absorbing directly all its surplus power. This surplus power would appear in the cup-chamber in the form of molecular motion or heat, and would have to be got rid of by the application of cooling agents, if the natural dispersion of heat by radiation would no longer suffice to keep down the temperature. This would, however, be a wasteful proceeding, and it becomes necessary to operate, not upon the power produced, but rather upon the source of power, by rendering it always equal to the accidental resistance or load in order to maintain uniform velocity. The arrangement adapted for this purpose is represented by Plate 20, Fig. 2, and Plate 21, Figs. 3, 4, 5 and 6.

$\mathrm{S}$ is the main shaft of the engine, which imparts motion to the 
upright spindle $\mathrm{H}$ carrying an inverted wheel $\mathrm{E}$. The axis $\mathrm{A}$ of the regulating cup, being concentric with the spindle $H$, carries a pinion $\mathrm{F}$, and both the wheel and the pinion gear into two interinediate or planet-wheels $G$ and $G^{\prime}$, which latter are loose upon studs and are suspended from a rocking-frame $I$, the latter being free to turn upon its central support. The rocking-frame $I$ is connected by a rod $\mathrm{R}$ to a bell-crank lever $\mathrm{O}$, which is fastened upon the spindle of the steam-regulating or throttle-valve $\mathrm{V}$; but the horizontal arm of the lever $O$ carries a weight $P$ which, being acted upon by gravity, tends to open the valve and at the same time to force the rocking-frame $I$, with its planet-wheels $G$ and $G^{\prime}$, round the vertical axis. This pressure is resisted, on the one hand, by the teeth of the pinion $\mathrm{F}$, which can only yield in the ratio imposed by the rotating cup $\mathrm{C}$, and on the other hand, by the teeth of the inverted wheel $\mathbf{E}$, which latter, being driven round by the engine in the direction contrary to the effort produced by the weight $P$, causes the latter to be continually raised. If the engine should succeed in raising the weight $P$, say 100 millims., while the regulating cup yields also to the extent of 100 millims., then the lever 0 , and with it the regulating valve $V$, will retain their relative position; but if the engine should raise it, say 95 or 105 millims., while the cup yields 100 millims., then the valve will be either opened or closed by 5 millims., and the engine will be urged or checked, as the case may be, to such an extent as to make its revolutions coincide again absolutely with those of the regulating cup.

The driving-power of the cup is limited by the weight B, and may be considered as a constant regulated quantity (although it is derived indirectly from the engine); but whenever the ralve has to be opened or closed, a resistance arises which goes either in diminution of or in addition to the weight $P$, and the power of the cup must be such that its speed remains sufficiently uniform under the influence of these occasional variations.

By means of the automatic dip arrangement it would not be difficult to obtain perfect uniformity, notwithstanding these irregularities in the driving power; but in the case of steam-engine governors this arrangement is dispensed with for the sake of a more immediate action upon the valve at the moment when a differential velocity arises. Supposing that the greatest amount of 
occasional variation of speed is to be 1 per cent., and that the dimensions of the cup are as follows,

Diameter at upper $\operatorname{rim}$. . . = 200 millims.

Diameter of rim above the liquid . . = 200 millims.

Diameter of orifice at bottom of cup.$=90$ millims. we find the available power of the instrument in the following manner :-

The normal speed of a cup of these dimensions is, according to our formula.

$$
n=\frac{\sqrt{19600 \times 200\left(1+\frac{45^{2}}{100^{2}-\cdot 293 \times 45^{2}}\right)}}{200 \pi}=3.31 \text { revolutions per }
$$

second.

The height to which the liquid is raised by rotation increases in the square ratio of the speed of rotation, the increase of height due to 1 per cent. increase of speed would therefore result from the following proportion, $100 v: 101 v=\sqrt{h}: \sqrt{h^{\prime}}$, or the height due to the increased speed, $h^{\prime}=204$ millims., that is to say, the liquid would be raised 4 millims. above the brim of the cup, which, being an unbalanced column, will produce an upward flow of the liquid in the cup, as expressed by the well-known formula, $v=\sqrt{2 g h}$; or $h$ being in this case $=4$ millims., we have $v=\cdot 280$ metre flow per second, which, if multiplied by the least sectional area at the entrance into the $\operatorname{cup}=\cdot 0057$ square metre, gives the quantity of liquid $\cdot 280$ metre $\times \cdot 0057$ square metre $=\cdot 0016$ cubic metre, or 1:6 litre of liquid raised 204 millims. high and projected with a velocity of $\frac{102}{100} \times 3.31 \times 2 \pi r=2.1$ metres per second over the brim of the cup, to be stopped by the stationary wings and once more accelerated by the rotating wings, which, being one-fifth more in diameter than the cup itself, impart to the liquid a velocity of $\frac{6}{5} \times 2 \cdot 1=2 \cdot 5$ metres per second. These accelerations represent a power which, according to the formula $h=\frac{v^{2}}{2 g^{\prime}}$, is equal to the same liquid being lifted

for $v=2 \cdot 1$ metres . to $\cdot 225$ metre height, and for $v=2.5$. . to 320 metre height. In the cup it was lifted to $\cdot 200$ metre height, making a total lift . to $\overline{745}$ metre height. 
If the liquid employed is water, the 1.6 litre represents 1.6 kilogram., and the resistance produced by 1 per cent. increase of velocity is $1.6 \times \cdot 745=1 \cdot 2$ kilogrammetres per second, which is equivalent to forcing a valve rod or lever through one decimetre space in ten seconds against a resistance of 120 kilograms.

This force exceeds by far what is usually required of a governor, and fits the new instrument for the accomplishment of objects which could hitherto not be attempted, such for instance as regulating the power of engines by the link motion or other variable expansion gear (whereby a considerable saving of fuel may be effected), or moving the gate of a water-wheel.

The most striking feature of this governor is, however, the rapidity with which a readjustment between power and load of an engine is effected; experiment has proved that two-thirds of the total load upon an engine may be suddenly thrown off without producing any visible change in its rotation. It must be borne in mind that the variation of 1 per cent., which was assumed in calculating the power of the instrument, applies only to the short period of ten seconds, when the readjustment of the valve is effected, after which the cup and, with it, the engine returns to its normal rate of rotation ; but an increase or decrease of speed of 1 per cent. during ten seconds is so small a total amount that it is not perceptible to the eye, and may be regarded as non-existing for practical purposes.

A uniform velocity of engines, such as is secured by this instrument, is of considerable practical importance in spinning, grinding corn, and other manufacturing operations, because it not only prevents breakages and irregularities in the quality of the work produced, but it enables manufacturers to attain to the maximum speed at which their work can be produced.

It has been shown that the rotating cup is not sensitive to tipping, a circumstance rendering the gyrometric governor also applicable to marine engines, which are much in need of a means for maintaining a uniform speed, particularly where the screw propeller is used, which, in being raised by waves above the water, allows the engine to fly off at a dangerous speed.

The gyrometric cup appears therefore to be equally applicable for maintaining powerful machinery at a nearly uniform velocity, and for obtaining the higher uniformity of rotation requisite for philosophical and telegraphic instruments. 
In the discussion of the Paper entitled

"DESCRIPTION OF THE STEAM STEERING ENGINE IN THE 'GREAT EASTERN' STEAMSHIP," By Mr. J. McFindane GraY,

Mr. C. W. Siemexs * observed that the present paper was the first they had had upon a subject which he thought was a very important one ; for to see a large number of men at the helm of a big ship, trying to bear her round, certainly showed great imperfection in the present mechanical arrangements for steering. The apparatus now described as applied to the steering of the "Great Eastern" gare evidence of a great deal of thought; and the details of the arrangement for starting the steering engine, and making it obey signals given from a distant part of the ship, were highly ingenious, and the results of the working in practice showed, that all the requirements of the case had been duly considered beforehand. He inquired whether any difficulty had ever been experienced in starting the engine after it had been standing for a time, owing to accumulation of water in the cylinders; and whether a difficulty did not arise from the same cause whenever the rudder had to be held by the engine for any length of time in the same position; and he asked what provision was made for getting rid of water in the steam cylinders.

Another question that had occurred to him, though somewhat beyond the immediate subject of the paper, was whether the steering engine during the time it was standing might not be made serviceable for aiding in the propulsion of the ship by means of a Ruthven re-action propeller, discharging a jet of water from the stern in the opposite direction to the ship's motion. He did not adrocate such a plan of propulsion in substitution for the screw and paddles; but he thought it might be advantageously applied in conjunction with these, for utilizing a moderate auxiliary power from a separate engine like that employed for the steering-

* Excerpt Minutes of Proceedings of the Institution of Mechanical Engineers, 1867 , pp. $279-281$. 
gear, which was not required to be constantly at work for steering. 'The stream of water projected backwards from the stern might either be discharged in a line parallel to the keel of the vessel, or by means of deflectors it might readily be diverted to either side for changing the ship's course. Such an arrangement, he thought, would have several advantages over any plan of steering by a rudder, becuuse the action of a rudder depended upon the onrard motion of the ship, and without onward motion a rudder could produce no effect; whereas by a jet of water issuing laterally from the stern the ship could be steered round while she was not moving forwards or moving very slowly, which in some circumstances was an important consideration. In managing a ship for the purpose of picking up submarine telegraph cables, he had himself found rery great difficulty in turning the ship round by means of the rudder, while obliged to remain stationary upon the same spot for the performance of the necessary operations. Moreover, if such a plan of steering by a water jet were thoroughly carried out, the rudder, which was the most vulnerable portion of a ship, might be dispensed with.

\section{In the discussion of the Paper}

\section{"ON LIQUID FUEL," by Bexjamin H. Paul,}

The Chairman * (Mr. C. W. Siemens) said that the discussion had elicited quite a conflict of opinions, while those held on each side were apparently based on independent facts ; but he believed it was not impossible to reconcile many of the statements which were apparently contradictory, by properly discriminating between theoretical and practical results. These two ought to be kept distinctly apart. The practical result would ultimately approach to the theoretical, if all the conditions of the various operations were perfect, but it could never quite attain it; and, unfortunately, in the consumption of solid fuel, the practical results did

"Excerpt Journal of the Society of Arts, Vol. XVI. 1867-1868, pp. 409-410. 
not nearly approximate to the theoretical ones. He believed that some years hence any engineer who looked at the furnace of one of our present marine boilers would be ashamed of it. The mode of throwing the fuel on a kind of volcano, giving off a large proportion of valuable substance in the form of thick smoke, was very objectionable. As far as he could follow the calculations given, he thought Dr. Paul had rather overstated than otherwise the theoretical evaporating power of liquid fuel as compared with coal. He gave the evaporating power of hydrogen at $64 \mathrm{lbs}$., which agreed with the statement laid before the United Service Institution by Professor Macquorn Rankine, but there was a correction to be made in that. Professor Rankine gave the evaporating power of hydrogen at 64.2 , and of carbon at 16.05 , but he considered, in this calculation, the hydrogen as existing in a gaseous state, and the carbon in that of a solid. He made an allowance for the chemical affinity between the hydrogen and carbon when in the form of marsh gas, but he did not allow for the hydrocarbon as being in a liquid condition, in which state it was when in the form of oil. There must be a correction made on that account, though he could not precisely say what it should be. There was another correction to be made with regard to the latent heat of the steam resulting from the combustion of hydrogen, by which, no doubt, the results would be very sensibly modified. However, if they went from theory to practice, they had certainly great allowances to make in favour of the oil. For instance, coal contained not only alkaline matters, but also a great deal of water, which oil did not; then, a certain portion of oxygen was already absorbed by the coal, and there was a great waste by smoke. Further, it was impossible, whilst burning fuel upon a grate, to obtain that regularity of proportion between the air and the material consumed, which was necessary to produce an economical result. All these points were arguments in favour of the liquid fuel. He must say, that he quite agreed with several of the speakers, that volatile liquid fuel was totally inapplicable, and would be one of the most dangerous things imaginable on board ship ; they must, therefore, consider the question as confined to the use of heavy oils, which might, no doubt, be employed with advantage. They admitted of better stowage than coal, occupied much less bulk, and would save on board ship a great deal of 
labour, which meant space, of course, as less men would be required. Then there was another great advantage - there was no smoke. This, in the caso of men-of-war, was rery important, because a fleet of steam ressels at present could be seen while they were many miles below the horizon. For the mercantile marine, however, the question would reduce itself to one of price; and if the oil were $£ 5$ a ton; and the coal $£ 1$, no doubt the advantage would be in favour of the latter.

Captain Selwyn said he was now using oil at $1 d$. a gallon, or not quite $£ 1$ s. a ton.

The Chairman said, that so long as the oil could be obtained at anything like the price now mentioned, no doubt it would be a most valuable fuel; but the question was, would the price remain so favourable to the consumer if the demand should increase? Of that he must say he had considerable doubt. If they had to distil the oil specially for the purpose from coal it must be expensive, and they must therefore fall back upon the natural supplies, or those which were incidental to other manufactures, which supplies must necessarily be limited. As to the use of water for burning, he was quite sure that no one acquainted with the subject would attribute any special evaporating power to water itself. . Water might be usefully applied sometimes in conreying heat from one place to another, as, for instance, the introduction of a jet of steam under a grate on which anthracite coal was burning produced a gaseous fuel, the heat from which might be readily conveyed to a considerable distance, but as to getting heat out of water it was absolutely impossible. He would conclude by moring a vote of thanks to Dr. Paul, to which he was sure they would feel he was fully entitled for his able and carefully written paper. 
In the discussion of the Papers

" ON MACHINES EMPLOYED IN WORKING AND BREAKING DOWN COAL, SO AS TO AVOID THE USE of Gunpowder," by Samuel Parker Bidder, Jun. Assoc. Inst. C.E. ; and

"ON COAL GETTING MACHINERY, AS A SUBSTITUTE for the USE of GunPowder," by Charlies John Chubb,

Mr. C. W. Simarexs * remarked that it was of the greatest interest to all that coal should not only be got economically, but without involving human suffering. Although it had been asserted that the casualties caused by the explosion of powder were not so numerous as might have been supposed, nevertheless it was acknowledged that there was a serious loss of life every year. Independently, however, of that, there was the question of annoyance and injury to health that might be produced by noxious vapours arising from the explosion of powder in confined spaces. Moreover, it had been shown that coal could be got more economically by wedging than by blasting. The quantity of coal released by wedge action must be greater than that released by explosions, inasmuch as powder threw out the cone of least resistance, whereas a wedge would exert its power upon a larger range of coal. The question of undercutting the coal was no doubt important. He had been endeavouring to calculate what force would be expended in each case, but he had not been able to obtain a satisfactory result. If the coal was holed, or undercut, a disc of it had to be dealt with, and with the wedge the line of cleavage would be contained in that disc. He expected that the force expended would increase with the depth at which the force was applied; so that if the machine was inserted into a hole 4 feet deep, it would expend four times the force that it would if the machine was put in only 2 feet deep. But the question became much involved if the coal was to be torn out of the face, because

* Excerpt Minutes of Proceedings of the Institution of Civil Engineers, Vol. XXVIII. Session 1868-1869, pp. 141-142. 
then the top and bottom rocks formed an element which he thought no calculation could reach. If the working was carried out in a mass of coal of infinite extent, then one might be disposed to consider the resistance to the circumference of the semicircular or shallow cylinder and the sphere which would have to be separated if the force were applied in a mass ; but inasmuch as the layer was confined between sides of rock, and that rock was pressed by a superincumbent weight of untold amount, the question was incapable of solution. On general grounds he believed it would be impossible for the Institution to arrive at any definite conclusion with regard to the best machine. The nachines of Mr. Chubb and of Mr. Jones were similar in principle, and were both no doubt powerful though limited in range of expansion; but, while such limited range was sufficient to separate the coal, he believed that the largest quantity of coal could be got with a minimum expenditure of force, because all the force of that short range was directly applied. It was, however, necessary that the coal should be sufficiently hard to allow of a perfectly cylindrical hole being drilled or bored, and that it should not yield more than the length of the stroke of the pistons. Mr. Bidder's machine, on the other hand, was capable of greater range, and by it greater force could be brought to bear upon one point. It seemed also to have the advantage that a smaller hole sufficed for its action; but, on the other hand, that hole must be deeper than was necessary in the case of Mr. Chubb's machine. He subscribed to the objection urged by Mr. Mallet, that a proportion, not easily ascertained, of the force expended must be lost by pressing the front of the wedge against the mass of dead coal. The wedges pressed not against the coal that was going to be loosened, but against the dead mass of coal further on ; and it was a question, which would puzzle a mathematician to determine, what proportion of force was expended in compressing the coal, and what proportion in cracking it away from its position. With Mr. Bidder's machine the loss of a portion of the pressure by the compression of the coal suggested to Mr. Siemens a modification which was this:- where coal was naturally tender, and where it wns advisable to work it in comparatively thin layers, there might be applied a machine composed of three strong steel bars, arranged like a pair of scissors, with a hydraulic ram driving at the ends vol. I. 
into gudgeons, so as to press out the ends of the scissors; the ends of the bars being provided with little surface-plates to distribute the pressure orer a certain extent of surface. Such a machine, in coal sufficiently tender, would work rapidly, because with one piston in operation a range of at least 9 inches could be obtained, and the fissure in that case would be in aid of the separation of the mass.

\section{In the discussion of the Paper}

\section{"ON THE PROGRESS OF LIQUID FUEL," *}

\section{By Captain J. H. SELwYx,}

Mr. Charles W. Simmexs said, as the Chairman has called upon me, I may say I go so far with the author of the paper, in the able manner in which he bas put it forward, that in burning a fuel, a hydro-carbon, such as oil is, we may expect rery superior results to those which we obtain from eraporating water by carbon or ordinary coal. No doubt, the calculation which Captain Selwyn has put before us is the correct one, according to the best facts with which we are acquainted. Only I would observe that if the 6.46 per cent. of non-combustible matter in the oil is oxygen there should be a tare allowed on account of it.

Captain Selwyn. I think I gave that.

Mr. Siemens. It appeared to me that Captain Selwyn did not make any distincticn between oxygen and mere foreign inatter.

Captain Selwyn. I took both cases and gave you the result of both cases.

IIr. Siemens. Well, in the case of oxygen, of course combustion takes place without generation of heat, inasmuch as the fixed oxygen in combining with fixed carbon produces a gaseous compound, carbonic acid. without generating heat at all. Therefore, for the equivalent of the oxygen, carbon ought to be taken off the result. It may be asked, why should oil give such a superior result

* Excerpt Transactions of the Institute of Naval Architects, Vol. X. 1869, p. 37. 
to coal, which, if you analyze it, contains very often not more than (6 per cent. of foreign matter. I think an explanation may be attempted in this way, that in burning coal we feed the furnace in an exceedingly irregular manner, charging the grate at one time with an excess of hydro-carbon, which flies off and finds an insufficient amount of oxygen in the atmospheric air that enters the grate to burn it; and at other times the air that rushes through the grate has not time to take up its equivalent of carbon to produce carbonic acid. The result is, that in examining the products of combustion of an ordinary furnace, we find as much as 25 or 30 per cent. of pure oxygen on one hand, and we find a considerable amount of unconsumed carbonaceous matter going into the chimney along with it. This must be attributed not only to the unequal feeding of the coal into the grate, but it must also be attributed to the cooling effect exercised by the boiler, in checking combustion before the chemical action is completed. The first consideration in constructing a suitable grate ought to be to maintain the temperature of the flame for a sufficient length of time to complete the chemical action between the oxygen and carbonaceous matter. That, no doubt, can be obtained in a much more perfect manner in dealing with a liquid fuel like oil. This liquid in itself would be rather difficult to deal with, inasmuch as the surface it presents in the liquid state to the oxygen of the atmosphere would be very limited ; but in blowing in it, as Captain Selwyn does, by a jet, you get an extreme subdivision of the oil, and in consequence you may obtain a perfect combustion. From the results brought before us by Captain Selwyn that seems to be the case ; we get an extremely perfect combustion, and, therefore, we get an extremely great duty performed. The practical question then arises, what are the sources of supply of this oil ? I do not know whether the author of the paper has gone into that point, but it is a question of very great practical importance. As long as we have liquid fuel, there can be no doubt that, weight for weight, it is superior to solid fuel. These heavy oils are free from the great objections that apply to light hydro-carbons, on account of their volatile qualities. But the question with me is, whether we can obtain such a supply of heavy oils at a moderate cost as will justify their employment upon a large scale; for instance, will justify their application to our marine boilers. 
In the discussion of the Paper

"ON RECENT IMPROVEMENTS IN REGENERATIVE HOT BLAST STOVES FOR BLAST FURNACES,"

By Edward Alfred Cowper, M. Inst. C.E.,

Mr. C. W. Siemens * said, the apparatus described by Mr. Cowper for heating the blast differed from the ordinary hot blast stove in this essential respect,-that the same surface of refractory material that absorbed the heat from the products of combustion served also to impart heat to the incoming blast. It was necessary, under these circumstances, that there should be two stoves, or air-tight receivers, filled with the refractory materials : the one to give off its heat to the incoming blast on its way to the furnace, and the other to be heated up for continuing the operation when the heat of the first-named stove was exhausted, valves being provided for reversing the currents from time to time, as described in the paper. By these means the same surface of refractory materials was made to take up the heat from the burning gas and to impart it to the blast; and as a consequence it followed, that the degree of heat that might be imparted to the blast was not limited by the point of safety of the iron tubes composing the ordinary stoves, but was limited only by the point of fusion of the refractory materials composing the regenerator of the new stoves. For heating blast to a moderate degree only, this stove passessed some advantages over the ordinary tube-stove, as the use of regenerators was always attended with a saving of fuel : but whenever a high degree of heat was desired exceeding $1,000^{\circ} \mathrm{Fahr}$, then the tubular stove altogether failed, and the regenerative stove must be used.

The question of importance connected with this subject was, whether it was desirable to use blast of such very high temperature. Some jears ago it was the opinion of practical ironmasters, that the quality of the pig metal produced was deteriorated when

* Excerpt Minutes of Proceedings of the Institution of Civil Engineers, Vol. XXX. Session 1869-70, pp. 315-317. 
the temperature of the blast exceeded $500^{\circ}$ or $600^{\circ}$. Now, however, ironmasters saw the advantage of raising the temperature of the blast from $600^{\circ}$ to $800^{\circ}$ or $1,000^{\circ}$; and in using this regenerative stove, the temperature had been raised as high as $1,400^{\circ}$, without any deterioration of the quality having been observed. At the same time, there were ironmasters of high intelligence who asserted, that though the quality of the metal was maintained, yet that there was very little or no economy whatever in increasing the temperature of the blast above $1,000^{\circ}$; but although this view had been gravely adranced lately, in discussions that had taken place before another Institution, he felt convinced that the conclusion in question was based upon a misapprehension, and would share the fate of the former objections to the introduction of hot blast generally.

In inquiring into the chemistry of the blast furnace, it would be difficult to separate carefully the operations going on at each stage within the vast mass of incandescent matter; but if the problem was to decide upon the goodness or the efficiency of a mechanical contrivance for transmitting power, consisting of a number of wheels, cams, and differential pulleys, there would be no very minute inspection of the effect produced by each crank, wheel, or pulley; but the conditions of power applied to the machine would be taken, and the power judged by the motion of the load at the other end, taking it for granted that, according to the law of the conservation of force, nothing could be added or taken away except by friction. In the same way he looked upon blast furnaces. It was known that carbon, fluxing material, and ore, consisting for the most part of sesqui-oxide of iron and of silica, were put into the furnace, and atmospheric air was blown in at bottom. It was known that atmospheric, air on coming into contact with carbon in a state of incandescence formed one of two combinations-viz., carbonic acid if the combustion was perfect, and carbonic oxide if the combustion was imperfect. It was known that when a pound of carbon was burned into carbonic acid 14,000 units of heat were liberated; whereas if carbonic acid was formed, only 4,000 units of heat were liberated. It depended, therefore, entirely upon the composition of the gases resulting from the combustion in the blast furnace what would be the effective duty performed. Analyses of the gases issuing from the top of the furnace proved 
them to consist of about $\frac{4}{5}$ ths of carbonic oxide and $\frac{1}{3}$ th of carbonic acid, and if this proportion was invariable, it would be possible to say with great precision what would be the amount of heat developed by a given amount of blast of a given temperature. There were several duties to be performed by the heat thus developed. The iron oxide had to be deoxidized or reduced, and the iron had to be melted. The "gang" and flux had to be combined and melted; and the products of combustion themselves escaped at the top at a certain temperature, which implied a loss of heat. But, without going into à priori calculations of these separate duties, he found that the necessary consumption of coke to smelt a ton of iron from Cleveland iron-stone, containing 40 per cent. of iron, could not be less than $19 \cdot 6$ cwt. This limit of economy could not be surpassed, however much the capacity of the furnace might be increased; it was the limitation which could be approached but never exceeded, except by raising the temperature of the blast to a higher point. In doing that there was heat imparted from without the furnace, which necessarily saved a similar amount of heat that had to be developed inside the furnace, by combustion of coke by means of the blast. In continuing this argument it might be thought, at first sight, that the burning of 1 pound of fuel in the stoves would save 1 pound of coke in the blast furnace; and this would really be the case, if the products of combustion of the blast furnace were carbonic acid, as in the stove; but inasmuch as the escaping gases were a mixture of carbonic acid with carbonic oxide, in the proportion of 1 to 4 , the number of units of heat produced within the furnace per $\mathrm{lb}$. of fuel would be reduced in the proportion of $14,000: \frac{4}{5} 4,000+\frac{1}{5} 14,000$ or of $14,000: 6,000$; that was to say, the number of units of heat produced by each pound of carbon consumed in the blast furnace did not exceed 6,000 ; whereas each pound of carbon burned in the stove would produce 14,000 units. It was evidently, therefore, important to raise as much heat in the stove as possible, in order to save more than double the amount in the blast furnace; and when it was borne in mind, that the fuel in the stoves was obtained for nothing by burning the waste gases from the top of the blast furnace, it was obvious that there was the strongest argument for getting as much heat as possible in that way. The argument insisted upon by some ironmasters, that it would be no use to go 
beyond $1,000^{\circ}$, was based upon a misconception. They showed that each degree of extra heat in the blast produced a diminishing anount of saring in coke per ton of iron ; but they lost sight of this circumstance, that the quantity of blast used per ton of iron was greatly reduced when raised to a high temperature,the quantity of blast used being proportionate to the amount of carbon burnt in the blast furnace. In effecting, therefore, a reduction of the coke from 24 cwt. to 20 cwt., the amount of blast used per ton of iron was diminished in the same proportion, and $1^{\circ}$ of temperature added to the blast did not represent the same amount of heat as $1^{\circ}$ of heat communicated to blast of a lower temperature, when relatively a larger quantity was used; but if the effect of 1 unit of heat added to the blast in the stove at various degrees was taken into account, it would be found that as much saving of coke was effected in the blast furnace by adding to the blast above $1,000^{\circ}$ as there was by adding 1 unit of heat below that limit. There was the further important saving of fuel and engine-power, in effecting an increased duty with a given amount of blast, which had been neglected in these calculations.

It would take up too much time to go further into this somewhat complex question, as it would be necessary to take into account the increased proportions of the carbonic acid gas and the lower temperature of the waste gases which resulted from high temperature of blast; but the question resolved itself into a simple one if it was looked at from a general point of view-that each unit of heat given to the blast before entering the furnace must sare fuel equivalent to between 2 and 3 units of heat in the furnace, and moreover, that a much cheaper fuel was available in the stoves than within the blast furnaces. 


\title{
In the discussion of the Paper
}

\section{"ON THE WARSOP AERO-STEAM ENGINE,"}

\author{
By Mr. Richard Eaton,
}

The Chatrman (Mr. C. Wilitam Sibmens) * remarked that the subject of the paper was a very interesting one, both on account of the theoretical questions involved, and also in consequence of the practical results that had been arrived at, which seemed to be of a decidedly favourable character.

The main question that presented itself in regard to the use of the air injection was, what was the cause of the advantages ascribed to it. These advantages were of two kinds :--first, the adrantage in the boiler of preventing sediment and preventing priming by the injection of heated air into the water ; and secondly the advantage in the engine of getting more work done by a given volume of the mixed steam and air than would be performed by an equal rolume of steam alone at the sume pressure.

With regard to the advantage in the boiler, consequent upon the injection of divided currents of heated air into the water, he thought there was reason $t a$ anticipate a marked effect from such a process; for each bubble of heated air rising through the mass of hot water would naturally become saturated with steam by its contact with the water, increasing in volume many times, and would thus relieve the evaporating surface of the boiler of part of the work it would otherwise have to perform. Moreover in ordinary boilers, the steam being generated only in contact with the evaporating surfaces of the boiler-plates and tubes, each bubble of steam at the moment of its generation left behind it a liberated particle of solid matter, which had previously been contained in the water ; and this being liberated in immediate contact with the boiler surface, it was natural and probable that it should attach itself at once to that surface in the form of a solid incrustation. If however the required evaporation in a boiler could be produced otherwise than in contact with the

* Excerpt Minutes of Proceedings of the Institution of Mechanical Engineers, 1870, pp. 245-248. 
plates, it appeared likely that the sediment in the water would form itself into mud composed of an aggregation of separate small particles; and from the facts brought forward in the paper this seemed to be the action that really took place with the injection of the heated air. With regard to priming, an interesting point to ascertain in a boiler working with the air injection would be the temperature of the water with reference to the working pressure of the mixed steam and air : because when two gases co-existed in the same space, each exerted its pressure independently of the other, and therefore it seemed reasonable to infer that the temperature of the water would be lower than the temperuture corresponding to the pressure in the boiler, in the proportion of the original pressure of the steam alone to the actual pressure of the combined steam and air in the boiler. Thus supposing that the steam in the boiler were at a total pressure of three atmospheres, the water being at the corresponding temperature of $275^{\circ} \mathrm{Fahr}$., and that an equal volume of air at atmospheric pressure were compressed and forced into the boiler, the compressed air would expand again to atmospheric pressure in the boiler during the transit of the air-bubbles through the heated water, and each bubble of air would take up steam by vaporisation until the point of saturation was reached. The pressure of the mixed steam and air in the boiler would then be four atmospheres, while the temperature of the water would correspond to the density of the steam irrespective of the air present, and would consequently remain that corresponding to a pressure of only three atmospheres, the atmosphere of air permeating the whole steam space in equilibrium, in accordance with the law of the mutual diffusion of gases. It would be interesting to observe whether this were really the fact; and if it were so, he thought it would explain the circumstance which had been mentioned in the paper, that the moment the air was turned off violent ebullition and priming took place. For as soon as the air was turned off, the mixture of air and steam over the water in the boiler would no longer be replenished by a similar mixture of gases; and the temperature of the water being below that corresponding to the pressure of the mixed air and steam, a sudden collapse of the steam would necessarily take place; and as a consequence the engine would require more steam, the throttle valve would open wide, and the larger volume of steam suddenly called for would of itself 
naturally induce priming, independently of the further circumstance that the liberation of the steam from the water would no longer be facilitated by the passage of bubbles of heated air through the mass of the water.

In reference to the other question-why the mixture of steam and air should do more duty in the engine than an equal,volume of steam alone at the same pressure-he did not think this could be because the air-compressing engine which was united with the steam-engine was more economical than the steam-engine itself. On the contrary, mere air-engines, wherever they had been tried, had not giren such faronrable results as good steam-engines; and there were theoretical reasons why they could not give better results than a proper steam-engine. It had however occurred to him as an explanation which might be suggested of the economy found to result from the use of mixed steam and air in the engine, that the presence of air in the steam cylinder would certainly prevent the condensation of steam against the sides of the cylinder : and the loss from this cause he believed to be much greater than was usually supposed. If the cylinder was uncovered, the loss by condensation was very great, and was shown by the form of the indicator diagrams taken from such engines; and even when the cylinder was carefully clothed, there was a considerable condensation from the high-pressure steam coming in contact with surfaces that had been cooled by previous exposure to the condenser or to the exhaust steam at atmospheric pressure. This condensation he beliered took place even when the steam cylinder was thoroughly steam-jacketed all round and at the ends, although to a much less extent, and in that case it arose from the slow conducting power of the thick metal sides of the cylinder allowing the inner surface to continue considerably cooler than the outer surface heated by the steam in the jacket; and though the steam thus condensed in the cylinder was afterwards evaporated ac in in the latter part of the stroke, yet its mechanical effect was aln sot entirely lost. The presence of air mixed with the steam, it appeared to him, would hare the effect of preventing this condensation from taking place after the first moment of contact of the steam with the cool metal, because at that moment the condensation of the particles of steam which first touched the cool metal would leare a lining of air in contact with the metal, consisting of the portion of air that had been mixed with the steam before 
its condensation; and a veil composed of the non-condensible and nor-conducting portion of the mixed gases would thus remain to protect the rest of the stenm in the cylinder from contact with the cool metal surfaces, and wonld thereby prevent further loss from condensation. He believed this was a point of considerable importance in favour of the use of the combined steam and air in an engine with unprotected cylinders. The application of the same plan to a condensing engine was one that he had not been acquainted with previously; and from the statements which had been given it appeared that the introduction of so large a quantity of air with the steam had not been found to prevent the formation of a tolerable vacuum.

The use of the air injection was a subject which he hoped would be more fully investigated; and from the perseverance which had been shown in working it out thus far there was reason to expect the plan would be developed to a still further extent. He mored a rote of thanks to Mr. Eaton and Mr. Warsop for the paper, which was passed.

In the discussion of the Paper

"ON A SIMPLE CONSTRUCTION OF STEAM-ENGINE GOVERNOR HAVING A CLOSE APPROXIMATION

TO PERFECT ACTION," by Mr. JlRemiah HEAD,

Mr. C. W. Sienexs * remarked there could be no doubt that by the plan of crossing the suspending arms of the governor, so as to cause the balls to expand in a parabolic curve within certain limits, as described in the paper, a real chronometric action was obtained; but such an action would not be practically applicable to regulate the speed of a steam-engine, because, as had been ex-

* Exeerpt Minutes of Proeeedings of the Institution of Meehanical Engineers, 1871, p. 226. 
plained, there would be no tendency for the balls to stop in their movement if the governor was perfectly chronometric, but they would fly at once from one extremity of their range to the other under the slightest alternations of speed. The common governor was the one that was least affected by change. of speed, and required the greatest amount of change to bring it into action; but it had the advantage of not allowing the engine to "hunt" or beat about between the extremes of speed before settling down to the proper rate; it was thus a safe governor in this respect, though a bad one in others. The original invention of Watt, which had also this advantage, and, moreorer, allowed of only a slight variation in speed, occupied a sort of mean position between the common governor and a parabolic one, and was therefore the best practical governor hitherto applied; and the same might now be said of the modified construction of the crossed-arm governor, in which the spiral spring was added as described in the paper. The addition of the spiral spring, however, did away with the true chronometric character of the governor, because the spring acted in conjunction with gravity to depress the balls, without being influenced by the cross-suspension ; and therefore a great increase of speed was still required to raise the balls, and the governor was thus rendered a practical one, instead of being a mere theoretical abstraction, as would be the case without the spring. A farther advantage of the spring, when aiding gravity to depress the balls, was that the centrifugal force on the balls was thereby increased; if, for instance, a speed of 40 revolutions per minute was sufficient to maintain the balls at their mean angle when no spring was used, and if with the spring 60 revolutions per minute were requisite to keep them in the same position, the centrifugal force residing in the balls in these trro cases would be in the proportion of the square of 40 to the square of 60 , or as 4 to 9 , and the regulating power for a given variation of speed would be increased in the same proportion. A smaller relative variation in speed therefore, in the governor provided with the spring, would be sufficient for enabling the balls to overcome the constant resistance of the valve-levers and valve; and this he believed to be one of the reasons why the crossed-arm governor described in the paper acted so well. The only kind of governor that was capable of acting instantly upon the throttle-ralve at the moment of the 
change of speed was the differential governor; but short of the differential governor the arrangement of the crossed-arm governor with spiral spring appeared to him a very useful and valuable one.

\title{
ON A STEAM JET FOR EXHAUSTING AIR, \&C., AND SOMF RESULTS OF ITS APPLICATION,*
}

\author{
By C. Wruliam Siemexs, Esq., D.C.L., F.R.S., Pres. Inst. M.E.
}

THE steam jet, althongh it has long been used with such remarkable success for producing a current of air to form an artificial draught in locomotive and portable engine boilers, has hitherto been extremely limited in its application to other purposes; for though its simplicity for the propulsion of air is a great recommendation, the effect realised from a given expenditure of steam has been extremely unsatisfactory, in comparison with the results of the same steam in working an engine and air pump; nor has sufficient pressure of air been obtained from the steam jet to render it applicable for pneumatic propulsion or the production of furnace blast. The form and application of the steam jet having remained hitherto essentially the same as in the original steam blast of the locomotive in 1829 , it occurred 'to the writer that much might be done to improve its effect by a judicious arrangement of the parts, so as to aroid eddies in the combined current of steam and air, and also to utilise more completely the initial momentum of the steam. In carrying out this idea, the first results obtained about a year ago were sufficiently encouraging ; and by gradually recognising more fully the points of essential importance, the writer succeeded in constructing a steam jet exhausting apparatus capable of producing a vacuum of as much as 24 inches of mercury, with steam of only three atmospheres effective pressure; and a useful effect has been obtained from the

* Excerpt Minutes of Proceedings of the Institution of Mechanical Enginecrs, 1872, pp. $97-116$. 
steam, equal to that of the ordinary fan blast, and even of the steam engine and pump.

This improved steam jet is shown half full size in the longitudinal and transverse sections, Figs. 2 to 5, Plates 23 and 24. A very thin annular jet of steam is employed, in the form of a hollow cylindrical column, discharged from the annular orifice between the two conical nozzles $\mathrm{A}$ and $\mathrm{B}$, the steam being supplied from the pipe $\mathrm{C}$ into the space between the two nozzles. The inner nozzle $\mathrm{A}$ can be adjusted up or down by the hand screw $\mathrm{D}$, so as to diminish or increase the area of the annular orifice between the two nozzles, for regulating the quantity of steam issuing. The air to be propelled by the steam jet is admitted from the pipe $\mathrm{E}$ through an exterior annular orifice surrounding the steam jet, and also through the centre of the hollow jet. The tube $G$, into which the steam jet issues, is made of conical shape at the bottom, so as to form with the outer nozzle $B$ a rapidly converging annular passage for the entrance of the air ; and the width of this air passage is regulated by adjusting the nozzle $B$ by means of the nut $\mathrm{H}$ at bottom. The tube $\mathrm{G}$ continues to converge very gradually for some distance above the jet orifice, the length of the convergent portion increasing with the width of the outer annular air orifice, and also with the steam pressure employed; the most advantageous length varies from 12 to 20 times the width of the annular air orifice, the object being to ensure the complete commingling of the steam and air within the length of the mixing chamber $\mathrm{G}$, beyond which the tube gradually increases in diameter in a parabolic curve to the upper end, as shown in Fig. 1. A tapering spindle $I$ is sometimes fixed in the centre of the inner nozzle $A$, and carried up through the mixing chamber $G$, for the purpose of preventing reflux through the centre of the combined current.

The rationale of this arrangement is as follows. First, by gradually contracting the area of the air passages on approaching the jet, the velocity of motion of the entering air is so much accelerated before it is brought into contact with the steam, that the difference in the velocity of the two currents at the point where they come together is much reduced, and in consequence the eddies which previously impaired the efficiency of the steam jet are to a great extent obviated, and a higher useful result is 
realised. Secondly, by the annular form of the steam jet the extent of surface contact between the air and the steam is greatly increased, and the quantity of air delivered is by this means very much augmented in proportion to the quantity of steam employed ; also the great extent of surface contact tends to diminish eddies. 'Thirdly, by discharging the combined current of steam and air through the expanding parabolic delivery funnel of considerable length, in which its velocity is gradually reduced and its momentum accordingly utilised by being converted into pressure, the degree of exhanstion or compression produced by the steam jet is very materially increased under otherwise similar circumstances.

The results of a long series of experiments with this form of steam jet, both for exhausting and compressing air, have led to the following conclusions :-

First, that the quantity of air delivered per minute by a steam jet depends upon the extent of surface contact between the air and the steam, irrespective of the steam pressure, up to the limit of exhaustion or compression that the jet is capable of producing.

Second, that the maximum degree of vacuum or of pressure attainable increases in direct proportion to the steam pressure employed, other circumstances being similar.

Third, that the quantity of air delivered per minute, within the limits of effective action of the apparatus, is in inverse relation to the weight of air acted upon; and that a better result is therefore realised in exhausting air than in compressing it.

Fourth, that the limits of air pressure attainable with a given pressure of steam are the same in compressing and in exhausting, within the limit of a perfect vacuum in the latter case.

The principle of action of the steam jet had received but little attention until the time of the interesting question raised in 1858 by the invention of the Giffard injector, by means of which water cau be forced into a high-pressure boiler by a jet of steam of the same pressure, or even of greatly inferior pressure. The physical explunation of this remarkable fact, which was first attempted the writer believes in a discussion of the subject in this Institution,* p. 39 .

* See Proceedings of the Institution of Mechanical Engineers, January, 1860, 
is based on the principle of conservation of momentum in the combined jet of steam and water; but although the source of power in both cases is a steam jet, the mode of action in the water injector differs essentially from that of the steam jet applied to propulsion of air, as in the former case the steam is condensed by contact with the water, and ceases to be an elastic fluid at the moment of issue, while in the latter the steam forms with the air a combined elastic stream.

A very elaborate investigation of the ordinary steam jet applied to propulsion of air was given by Professor Zeuner of Zurich in 1863, showing the effects produced by varying the relative areas of inflow of the air and steam, and varying the steam pressure employed. These theoretical enquiries, which were supported by elaborate experiments, have since been considerably advanced by Professor Rankine, who has shown that in the combined stream a considerable portion of the total momentum is lost, and that the relative proportion of this loss increases with the difference of relocity between the component streams.

The form of steam jet employed in Zeuner's experiments consisted of a contracted steam orifice, directed upwards in the line of the axis of a vertical delivery tube, but terminating a little below the base of the tube; the length of the tube relatively to its diameter was found to be only of minor importance. Exhaustion of air was effected at the lower end of this delivery tube, or compression of air at the upper end. The greatest extent of exhaustion or compression that was maintained with steam of two atmosplieres effective pressure amounted to 7 inches of mercury ; and 100 volumes of steam measured at atmospheric pressure were expended in compressing only 7 volumes of air to the abore pressure of about $\frac{1}{4}$ atmosphere. With a reduced orifice for the steam jet, a compression of $3 \frac{1}{4}$ inches of mercury was maintained, and 37 volumes of air were compressed by the expenditure of 100 volumes of steam measured at atmospheric pressure.

In a corresponding experiment made with the improved steam jet shown in Plate 23, maintaining a vacuum of $3 \frac{1}{4}$ inches of mercury, 137 volumes of air were removed by the expenditure of 100 volumes of steam, both measured at atmospheric pressure; 
which gives a result of nearly four times the useful effect that was obtained in 'zeuner's apparatus.

The following Table I. gives the results obtained with the steam jet arrmged as an exhauster for drawing air out of a closed vessel having a capacity of 225 cubic feet. The four last columns show the racuum produced in the vessel, measured in inches of mercury, when the exhauster had continued in action for the length of time indicated in the first column. The pressure of stean in the boiler was $45 \mathrm{lbs}$. per square inch, and the sectional area of the annular steam orifics of the jet was varied from 0.05 to 0.20 square inch.

TABLE I.

ETPERIMENTS WTTI STEAM-JET EXHAUSTER EXHAUSTIXg AIR FRoM A CLOSED VESSEL.

\begin{tabular}{|c|c|c|c|c|}
\hline \multirow{2}{*}{$\begin{array}{l}\text { Time of } \\
\text { action. }\end{array}$} & \multicolumn{4}{|c|}{ ARIA OF ANNITAAR ORIFLEE OE STEAM JET } \\
\hline & $0.05 \mathrm{sq} . \mathrm{ill}$. & $0.10 \mathrm{sil.} \mathrm{ill}$. & $0.1 ;$ sq. In. & $0 \cdot 2) \mathrm{sc}$. in. \\
\hline Minutes. & $\begin{array}{l}\text { Yacumun. } \\
\text { Inches of }\end{array}$ & $\begin{array}{l}\text { Yacuum. } \\
\text { Inches of }\end{array}$ & $\begin{array}{l}\text { Vacnum. } \\
\text { luches of }\end{array}$ & $\begin{array}{l}\text { Vacmumi } \\
\text { lnches of }\end{array}$ \\
\hline & Mereury. & Mercury. & Mercury. & Mercury. \\
\hline 1 & !) & 10 & $9 t$ & $8 \frac{1}{2}$ \\
\hline$\ddot{2}$ & 13 & $13 \frac{1}{2}$ & $13 \frac{1}{2}$ & 13 \\
\hline 3 & $14 \frac{1}{2}$ & 15 & $16 \frac{9}{4}$ & 159 \\
\hline 4 & $1.5 \frac{\pi}{2}$ & $15 \frac{1}{2}$ & 17 & $17^{\circ}$ \\
\hline 5 & 154 & $15 \frac{7}{8}$ & 18 & $17 \frac{3}{4}$ \\
\hline 6 & $\cdots$ & ... & $18 \frac{1}{2}$ & 181 \\
\hline 7 & $\cdots$ & $\cdots$ & $18 \frac{3}{4}$ & $1 S_{2}^{2}$ \\
\hline
\end{tabular}

Another set of experiments has been tried with the steam jet used as a blower for compressing air into the same closed vessel of 225 cubic feet capacity. For this purpose the conical delivery funuel of the steam jet was connected with the vessel by means of a 3-inch pipe containing a stop-cock; and into this pipe was delivered a small jet of cold water through a pipe of $\frac{1}{2}$ inch diameter under a pressure of $40 \mathrm{lbs}$. per square inch, with the object of condensing the steam from the blower, the water being turned on simultaneously with the starting of the steam jet. The sectional area of the outer annular air passage in the blower was 0.20 square inch, and of the inner air passage in the centre of the jet 0.16 square inch, making a total of 0.36 square inch of air section. The sectional area of the anumlar steam jet was 0.07 and 0.12 square 
inch in the different experiments, the results of which are given in the following Table II. :-

TABLE II.

EXPERIMENTS WITH STEAM-JET BLOWER COMPRESSING AIR INTO

A CLOSED VESSEL.

\begin{tabular}{|c|c|c|c|}
\hline \multirow{3}{*}{$\begin{array}{l}\text { Time of } \\
\text { action. }\end{array}$} & \multicolumn{3}{|c|}{ AREA OF ANNULAR ORIFICE OF STEAM JET. } \\
\hline & $0.07 \mathrm{sq}$. in. & $0.12 \mathrm{sq.} \mathrm{in.}$ & 0.07 sq. in. \\
\hline & $\begin{array}{l}\text { With } \\
\text { Conclensing } \\
\text { Water. }\end{array}$ & $\begin{array}{l}\text { With } \\
\text { Condensing } \\
\text { Water. }\end{array}$ & $\begin{array}{l}\text { Withont } \\
\text { Condensing } \\
\text { Water. }\end{array}$ \\
\hline 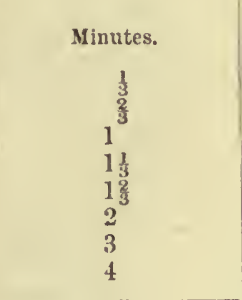 & $\begin{array}{c}\text { Pressure. } \\
\text { Inehes of } \\
\text { Mercury. } \\
6 \\
10 \\
12 \\
13 \\
13 \frac{1}{2} \\
14 \\
15 \\
15 \frac{1}{2}\end{array}$ & $\begin{array}{c}\text { Pressure. } \\
\text { Inches of } \\
\text { Mercury. } \\
5 \\
9 \\
12 \\
16 \\
19 \\
21 \frac{1}{2} \\
24 \\
25\end{array}$ & $\begin{array}{c}\text { Pressure. } \\
\text { lnches of } \\
\text { Mercury. } \\
9 \\
11 \\
14 \\
15 \\
154 \\
16 \\
163 \\
164\end{array}$ \\
\hline $\begin{array}{l}5 \\
6 \\
7 \\
8\end{array}$ & $\begin{array}{l}15 \\
14 \frac{3}{7} \\
14 \frac{3}{4} \\
14 \frac{3}{4}\end{array}$ & $\begin{array}{l}24 \frac{1}{3} \\
24 \frac{1}{4} \\
23 \frac{3}{4} \\
23 \frac{1}{2}\end{array}$ & $\begin{array}{l}12 \\
11 \\
10 \frac{1}{4} \\
10\end{array}$ \\
\hline $\begin{array}{l}\text { Final temperature } \\
\text { of air in vessel. }\end{array}$ & $113^{\circ}$ Fahr. & $\cdots$ & $15 \mathrm{~S}^{\circ} \mathrm{Fahr}$. \\
\hline
\end{tabular}

At the end of the fourth minute the stop-cock was closed, shutting off the steam-jet blower, and at the same time the condensing water was shut off; it will be seen that the pressure in the vessel then fell slightly, owing to the condensation of the small residue of the steam from the jet. In the third experiment, in which no condensing water was used, the fall of pressure was more considerable, and the final temperature of the air in the vessel was higher. The steam pressure in the boiler was 50 lbs. per square inch.

The following are some of the applications which have already been made or are in course of being made of this improved form of steam jet.

Pneumatic Despatch Tubes.-First, to the working of pnenmatic despatch tubes. For this purpose the steam jet has a great 
advantage over an ordinary steam-engine and air-pump in first cost and simplicity, and also in taking up much less space: the latter advantage being of the greatest value when it is required to work puenmatic despatch tubes in crowded localities where it is difficult to obtain room for steam machinery. A pneumatic tube 3 inches in diameter, to be worked on the circuit system arranged by the writer, has been laid down by the postal authorities in Iondon, from the Central Telegraph Station in Telegraph Street to Charing Cross and back, with intermediate stations at the General Post Office and near 'Temple Bar. The length of tube forming the whole of this circuit is 6,890 yards, or nearly four miles. This line was designed to be, and is, as a rule, worked by means of an air-pump $A$, driven by a steam-engine, as indicated in the diagram, Fig. 6, Plate 25. The pump draws air out of a vacuum vessel $\mathrm{V}$, and forces it into a pressure vessel $\mathrm{P}$, both vessels being in connection with the pnenmatic tube $T$, as indicated by the arrows. These ressels are introduced in order to prevent the pulsations of the engine from being felt in the working of the tube, and are of course unnecessary when the tube is worked by means of the steam jet. The piston carriers, which are propelled through the tube by the vacuum produced, are of the cylindrical form shown in Figs. 7 to 9 , Plate 26 ; they consist of a gutta-percha case covered with drugget or felt, and are made an easy fit in the tube, so as to slide freely through it.

This line has been experimentally worked by means of three steam-jet exhausters, similar to the one shown in Fig. 2, arranged in the manner shown at $\mathrm{E} \mathrm{E} \mathrm{E,} \mathrm{Fig.} \mathrm{6,} \mathrm{so} \mathrm{that} \mathrm{all} \mathrm{three} \mathrm{draw} \mathrm{air}$ out of the same tube F, the steam being supplied to them by the steam pipe $G$. When working with these three exhausters, the mean speed of a piston carrier trarelling through the tube from Charing Cross to Telegraph Street was $14 \frac{1}{3}$ miles per hour. The racuum maintained in the tube was equivalent to 10 inches of mercury, the steam pressure being $40 \mathrm{lbs}$. per square inch ; and the quantity of coal consumed under the boiler was 56 lbs. per hour. In the case of long lines of pneumatic tubes, it will be better to work them witl an exhauster at each end.

For placing the piston carriers into the tube or taking them out of it at the different stations S S, Fig. 6, without interrupting the current of air, the intercepting apparatus shown in Figs. 10 to 12, 
Plates 26 and 27 , is employed. This consists of two short tubes $B$ and $\mathrm{C}$, fixed side by side in a rocking frame, each of which can be brought into line with the circuit tube $\mathrm{T}$ at pleasure. Each end of the rocking frame is faced, and works against the faced side of a boss on the end of the circuit tube. Three annular grooves are turned in the faced side of the boss round the end of the circuit tube, for the purpose of preventing the leakage of air between the ends of the rocking frame and the bosses. One of the tubes B in the rocking frame is used as the sending or "through" tube, and is simply a hollow cylinder of the same internal diameter as the circuit tube $\mathrm{T}$; when this is in line with the circuit tube, a carrier can pass through the instrument without being stopped, and this tube is also used for putting carriers into the circuit. The other or receiving tube $\mathrm{C}$ has a perforated diaphragm at its down-stream end, so as to arrest the carriers when it is placed in line with the circuit tube, as in Figs. 11 and 12. This receiving tube is Dshaped in section, with a flat cover, which can be taken off if required; as for instance, to remore carriers, in the event of two arriving at once and so preventing the rocking frame from being moved. The flat corer is furnished with a pane of glass, to enable the attendant to see when a carrier has arrived. In order to prevent the continuous flow of air in the whole circuit of tube from being impeded by the receiving tube being left in the circuit after it has caught a carrier, a by-pass $\mathrm{F}$ for the air is provided, which communicates with the circuit tube $T$ at both ends of the instrument. A sliding rod H, Fig. 10, held on suitable supports, is supplied for pushing the carriers out of the receiving tube, when intercepted and brought ont of the circuit. The manipulation for sending and receiving the carriers is cxceedingly simple ; and a treadle is provided for moving the rocking frame with the foot.

RAISING OF WATER.-A second application of the improved steam jet is to the raising of water. For lifts not exceeding 20 feet a steam-jet exhauster could be used with advantage in situations where the erection of an engine and pumps would be attended with considerable cost and inconrenience, or where the work to be done was of short duration or of an occasional character, such as in draining lands, \&c. When employed for this purpose the exhauster would be applied in the manner shown in Fig. 13, 
Plate 28 , where $A$ and $B$ are two closed air-tight chambers fixed at a lieight of from 16 to 20 feet above the level of the water to be raised; inlet valves $\mathrm{C}$ are provided in the bottom of the chambers for the water to enter from the suction pipe $\mathrm{D}$, and outlet valves $\mathrm{fr}$ for the discharge of the water raised. The exhauster E, supplied with steam by the pipe $H$, exhausts the air from the chambers $A$ and $B$ through the pipe $F$, which is provided with a reversing valve I, for placing the exhauster in communication with each of the two chambers alteruately; and the delivery end of the exlianster, which may be closed by a valve, also communicates with the chambers through the pipe $K$ and the same reversing valve $L$. The chamber $A$ is provided with a float M, the rod of which works by tappets the tumbling lever $\mathrm{N}$, and this throws orer the weighted lever of the reversing valve L by means of the looped rod $R$.

'The action of the apparatus is as follows. While the exhauster is drawing the air out of the chamber $B$ through the pipe $F$, as shown in Fig. 13, thus causing the water to rise into the chamber through the suction pipe $\mathrm{D}$ under the pressure of the atmosphere, the discharged jet of combined steam and air from the exhauster passes through the pipe $K$ into the top of the other chamber A, which is full of water. The water in this chamber will consequently flow out through the bottom outlet valve $G$, its discharge being aided by the forcing action of the entering current of steam and air from the exhauster ; and this forcing action may be regulated by closing the top of the delivery funnel of the exhauster, in which case the discharge pipe for the water from the outlet valre $G$ may be raised abore the level of the chamber A. As the water descends in the chamber A, the float II sinking with it mores over the tumbling lever $\mathrm{N}$ into the vertical position, from which when the chamber is emptied the lever will fall into the reversed position, thereby throwing over the reversing valve $\mathrm{L}$. The action of the exhauster upon the two chambers is now reversed, the air being exhausted from the emptied chamber $A$, and the combined jet discharged into the chamber $\mathrm{B}$, which during this time has become filled with water; in this way the two chambers become alternately filled and emptied, and a continuous delivery of water is thus obtained. As the steam contained in the combined jet entering either chamber from the exhauster becomes 
gradually condensed by contact with the water, a partial vacuum will be already formed in the chamber as soon as emptied, whereby the work to be done by the exhauster in then exhausting the chamber will be diminished. In order to prevent the noise which would be caused by the combined jet of steam and air issuing from the open top of the delivery funnel of the exhauster, a "sound killer" S may be placed on the top of the funnel, consisting of a cylindrical metal ressel containing a series of perforated wooden diaphragms; this contrivance has been found by experiment to be very efficient in preventing noise.

The following are the results of a preliminary experiment made with a rougli apparatus for raising water, arranged as shown in the diagram, Fig. 14, Plate 28. The exhauster $\mathrm{E}$ was connected by a 2 -inch pipe $\mathbf{F}$ to a closed vessel A capable of holding $10^{\circ} 3$ cubic feet, into which the water was raised from varying depths through the suction pipe $\mathrm{D}$ of 2 inches diameter. The sectional area of the outer annular air passage in the exhauster used in this experiment was 0.35 square inch, and of the inner air passage in the centre of the jet 0.16 square inch, giving a total of 0.51 square inch of air section. With the sectional area of the annular steam orifice adjusted to 0.09 square inch, and with a steam pressure of $60 \mathrm{lbs}$. per square inch in the boiler, the exhauster raised 10.3 cubic feet of water 12 feet high in 40 seconds, and the same quantity $17 \frac{1}{2}$ feet high in 75 seconds. With the same area of air section, but with the area of the steam orifice adjusted to 0.08 square incli, and with $50 \mathrm{lbs}$. steam in the boiler, 10.3 cubic feet of water were raised 15 feet high in 40 seconds. The height of lift attainable depends upon the pressure of steam employed; and the quantity of water raised depends within certain limits upon the magnitude of the jet.

Evaporation of Sugar.-A third application of the improved steam jet is to the eraporation of sugar. In consequence of the remarkable results obtained with this stean-jet exhauster, it is proposed by Mr. R. A. Robertson of London to apply it to sugarboiling in the West Indies; and he has communicated to the writer the following notes on the subject.

The steam-jet exhauster has been employed experimentally with considerable success in exhausting vessels for evaporating liquids in vacuo, and its application for this purpose promises to 
becone of great value in the colonies for eraporating cane juice, principally on account of the simplicity of the arrangement. The great loss and deterioration consequent on the high temperature to which cane juice must be exposed for evaporating it on the old system in open pans are well known, and many ingenious plans have been invented and to some extent worked for evaporating at low temperatures; but, on account of the improved plans being either very much more costly or requiring much more skilled attention to work them, the greater part of the sugar produced is still made on the old and wasteful plan. Of all the contrivances for eraporating at low temperatures the ordinary vacuum pan exhausted by pumps is at present the best, when carefully designed ; and in it under favourable circumstances very rapid eraporation can be produced at low temperatures. In the sugar-growing colonies however alınost every circumstance is unfavourable for this mode of working; the water required for condensing the vapour from the evaporating pan is warm, and consequently must be used in large quantities, thereby necessitating large pumps for its remoral, and for exhausting the pan ; the pumps and motive power thus form together with the pan a very costly apparatus, which requires a considerable amount of skilled attention, often not obtainable, and frequent repairs.

On the contrary, a vacuum pan exhausted by the steam jet exhauster in the manner shown in Figs. 15 and 16, Plate 29, becomes a rery simple apparatus, only requiring a supply of steam at a moderate pressure for the jet $A$, which exhausts the vapour given off by the boiling solution of sugar or other liquid in the pan $B$; and the steam and vapour together are then passed through the heating tubes $\mathrm{D}$ of the pan, thereby producing evaporation. The area of the steam jet is regulated by the hand-wheel $\mathrm{C}$, the steam being supplied by the pipe $\mathrm{E}$; and the course of the current of steam and vapour is indicated by the arrows. By this arrangement the costly vacuum pumps and the steam-engine or other motive power are dispensed with, as well as the condenser and its supply of condensing water, the latter being in many places a consideration of vital importance; and in their stead is substituted the steam-jet exhauster, a comparatively cheap and simple apparntus, requiring little or no attention, and not liable to get out of order. 
Experiments on this mode of evaporating hare been so successful that a vacuum pan is now being constructed as above described, capable of evaporating 50 cubic feet of water per hour, in which it is estimated that a racuum of from 18 to 20 inches of mercury will be maintained. The form of pan shown in Fig. 16 is the simplest arrangement in which the steam jet exhauster can be applied for the purpose; but the exhauster can with equal adrantage be applied in those cases where racuum pans are worked on the systems known as double and triple effect. It has been successfully employed to exhaust a vacuum pan having a condenser placed high enough above the ground to discharge by gravitation against the vacuum the condensing water in which the vapour from the pan was condensed; there was thus left only the air and a very small quantity of vapour to be removed by the exhauster, which in this case was a very small one, not using sufficient steam to produce evaporation.

The steam-jet exhauster is further expected, on account of its cheapness and siniplicity, to prove very useful in the colonies for draining the molasses from the sugar, by exhausting the air from below the perforated bottom of a strainer containing the undrained sugar, the pressure of the atmosphere then driving the syrup or molasses through the sugar and perforated bottom. By this means the crude and imperfect mode of draining by gravitation, and also the more elaborate but costly and tronblesome centrifugal strainers, can be superseded with advantage.

Blower for Gas-Producers.-A further application of the improved steam jet is to gas-producers for heating purposes. The author has had occasion to make numerous applications of the steam jet arranged as a blower for accelerating the distillation of fuel in his gas-producers, as shown in Figs. 17 and 18, Plate 30.

The blower B is built into the side wall of the producer, and the combined current of air and steam delivered by it issues through an opening $\mathrm{A}$ into the space $\mathrm{C}$ underneath the fire-grate, which is closed by doors 1 . The small proportion of steam that enters together with the air is just sufficient to assist beneficially in the production of the combustible gas, inasmuch as in passing through the incandescent fuel the steam becomes converted into hydrogen and carbonic oxide. The steam is admitted to the blower through the branch pipe $\mathrm{E}$ from the main steam pipe $\mathrm{F}$, which supplies a 
number of blowers in a series of gas-producers. $\Lambda$ valve $G$ is provided in the branch pipe E, for shutting off the steam from the blower when not in nse; and a small tap.J serves for discharging any water that may collect in the pipe by condensation of the steam.

The advantages found to result from applying these blowers to gras-prodncers are, that coal dust of the most inferior description can be nsed, and that the gas production of eacl prodncer in consuming small fuel is raised from $1 \frac{1}{2}$ tons to :3 tons of gas per 24 hours; while at the same time the quality of the gas is improved, owing to the generation of hydrogen from the steam which enters intermingled with the air.

These applications of the improved steam jet suffice to illustrate its scope and value. Other useful applications will readily suggest themselves, where work may be accomplished by exhausting or compressing air or gases.

In conclnsion the author would remark that although the steam jet is not a new mechanical agent, and has been applied before for various purposes and in a variety of forms, yet the mechanical conditions under which it is capable of developing the greatest amount of nseful effect have not previously been laid down or practically realised in such a way as to produce results at all comparable with those obtained from a steam-engine working an air-pump ; but this it is maintained a steam jet may do, if care be taken that the available elastic force is changed into onward motion of the combined jet, and again into onward pressure, without undue loss of effect by eddies or by development of sound or heat, which have constituted the principal results in the case of an ordinary steam jet.

The President said he had beeu led to investigate the subject of the steam jet in consequence of having been engaged in constructing a circuit of pneumatic despatch tube for the Central telegraph oftice in London; the tube itself had cost $£ 3000$, and fully as much had been spent on the engine and air pump. As there was moreover great difficulty in finding room for this machinery in so crowded a locality, it had occurred to him that a more direct means of propelling the piston carriers through the tube would be a matter of some importance; and in considering 
the conditions of a steam jet he had been led to the conclusion that, if the elastic force of the steam could be all employed for giving velocity to its particles, and if each particle of steam so accelerated could be brought into direct and immediate contact with the air to be impelled, an average speed of the combined current could be obtained, which should represent nearly the whole of the elastic force originally existing in the steam. If this combined current were then sent through a long expanding mouthpiece or tube, enlarging gradually in a parabolic curve, so that the velocity of the current should be gradually converted into pressure by bringing the particles nearly to rest, it had appeared to him that very favourable results might be obtained; and the experiments he had made had proved that these anticipations had been correct.

There were some remarkable results connected with this steam jet. The quantity of work done by it, measured by the weight of air delivered per minute, was proportionate absolutely to the amount of surface contact between the steam jet and the air to be impelled, irrespective of the pressure of steam employed. Thus in discharging the combined current into the atmosphere, the same weight of air per minute would be thrown out with a steam pressure of $5 \mathrm{lbs}$. as with $60 \mathrm{lbs}$, the only difference being that with the lower pressure of steam the limit of exhaustion or compression would be sooner reached than with the higher. The experiments also showed that the degree of exhaustion or compression capable of being produced by the steam jet, that is the difference of pressure between the air at the jet and that in the vessel from which the jet was exhausting or into which it was compressing the air, was exactly proportionate to the steam pressure ; so that with 100 lbs. steam above the atmosphere the degree of exhaustion or compression attainable was double what it was with 50 lbs. steam. A third result was that, in exhausting the air from any vessel by the steam jet, it took as long a period of time to exhaust the first $1 \mathrm{lb}$. of pressure, from the atmospheric pressure of say $15 \mathrm{lbs}$. down to $14 \mathrm{lbs}$., as it did to reduce the pressure $1 \mathrm{lb}$. in any lower part of the scale, say from $8 \mathrm{lbs}$. to $7 \mathrm{lbs}$; this was explained by the consideration that the weight of air, which had to be put into motion with such a velocity as would force it through the contracted opening at the base of the expanding 
delivery tube, was the measure of the working capacity of the instrument. These were very distinctly marked characteristics of ฉ good steam jet; and if they were attended to in the construction of the jet apparatus for any particular application, it would be found that very economical results could be realised for the steam expended.

He exhibited a full-size specimen of one of the steam-jet exhausters employed to exhaust the pneumatic tube connecting the telecrraph oflices in London, so as to maintain a current of air flowing continuously through the tube in the same direction. 'The tube formed a complete circuit, and the piston carriers, whether put in at the commencing station of the circuit or at any intermediate station, all travelled in the same direction; the result was that a tube of only 3 inches diameter was sufficient for a great amount of work, because there might be ten or more carriers in the tube at a time, all flowing towards the end station, but capable of being intercepted and taken out at any intermediate station.

\section{In ansicer to various Speakers-}

The Presidext replied that the expanding form of the delivery tube from the steam jet was of considerable importance, though not so much so in the case of air as where a denser fluid had to be dealt with, as in the water jet of the Giffard injector. From experiments that he had made with a parallel delivery tube, in comparison with the expanding form, he had found that, in exhausting a vessel to the extent of producing a vacuum of 20 inches of mercury, the expanding tube rendered the jet about 10 per cent. more effective than it was with the parallel tube; but in exhausting to only a small extent, the greater density of the fluid would cause the expanding tube to be as much as 20 per cent. more effective than a parallel one. The form which he had adopted for the expanding delivery tube of the steam jet was a parabolic curre; but the difference in effect between this and an ordinary straight cone, with the same areas of passage at the two extremities, would be immaterial. The mixing chamber, which had to be of a definite length in proportion to the breadth of the annular air passage, was made to diminish gradually in area, 
somewhat in the form of a "vena contracta," the rate and extent of contraction being determined in each individual case according: to the velocity of the combined issuing current. But the point of chief importance in the instrument was the mode of bringing the entering air into contact with the steam jet. As the working power of the jet was proportionate to the extent of surface contact between the steam and the air, the annular form of jet suggested itself as the most suitable ; and the thickness of the annular film of steam should be very small, about $\frac{1}{5}$ th inch having been found by experiment to be the maximum thickness of film that was consistent with economical results. If the thickness of the jet were increased beyond this amount, the particles of steam inside the thickness of the jet would flow on at a greater rate than the outer particles forming the skin of the jet, the latter being retarded by contact with the air ; and eddies within the atmosphere of the steam itself would be the result. Again, if the steam jet were simply made to issue into a plain open tube, through which the air had to be propelled, the result would be very inconsiderable, because the eddies formed between the air and the steam would then attain their maximum amount; the steam issuing with great velocity and the air being nearly stationary, the latter would not be so much impelled in a steady current as set in rotation and rolled forwards by the power represented hy the difference of velocity between the two fluids. It was consequently requisite that the air should be accolerated as nearly to the full velocity as practicable before coming into actual contact with the stcam ; and this was the most important point connected witl the apparatus. 'The area of the air passages was therefore gradually contracted for some distance as thcy approached the issuing orifices ; and the combined areas of the central air aperture inside the steam jet and of the annular aperture outside the jet were made to be together rather less than the area of the issuing orifice at the outer extremity of the mixing chamber, through which the combined current issued; this arrangement ensured the air attaining the full relocity of the combined jet, whereby the amount of eddies and the consequent loss of power were reduced to a minimum.

The President considered that the suggested application of the 
stean jet for remoring dust from the casing of millstones during the grinding might be attended with good results; but it must be observed that the jet acted at a disadvantage when producing only a small degree of exhaustion or compression, though this disadrantage might to a certain extent be olsviated by reducing the area of the jet orifice when the work was below the capabilities of the full jet. For as the surface of contact between the stean and air determined the work done, and the quantity of steam of a giveu pressure in the jet in proportion to the air determined the degree of vacumm or compression produced, it followed that, in order to work economically, the area of the steam orifice ought to increase gradually as the vacuum or compression increased. Under any circumstances howerer the jet would be to some extent less advantageous when producing only a small degree of vacuum, because the difference of relocity between the steam and the air, which was produetive of eddies, was then greater than when an equal weight of air was discharged from a higher degree of vacuum, a larger proportion of the velocity of the steam being utilised in the latter case for overcoming the greater excess of pressure of the external atmosphere. The steam jet had not yet been applied for producing the air blast for millstones, but no doubt it might be employed advantageously for that purpose.

\title{
In the discussion of the Paper
}

"ON THE EJECTOR CONDENSER FOR STEAM-ENGINES

\section{DISPENSING WITH AN AIR-PUMP,"}

\author{
By Mr. Alexander Morton,
}

The President (Mr. C. Wruliam Sremexs) * considered that, ingenious as the ejector condenser was, its efficiency might be materially augmented by increasing the extent of surface of the water jet for condensing the steam. The condensing surface was

* Excerpt Minutes of Proceedings of the Iustitution of Mechanical Engineers, 1872 , p. 270. 
at present limited to the small cylindrical surface exposed to the steam by the short length of central jet intervening between the water nozzle and the receive nozzle of the discharge pipe. This seemed to him an extremely small surface for absorbing such a large amount of heat as had to be taken up by the steam; and he thought that better results in condensation of the steam, together with some economy of condensing water, would be obtained, if the surface of the water jet could be largely increased, without altering the apparatus in other respects. Such an increase of surface he suggested might be obtained by making the water jet annular, and introducing the exhaust steam by a central jet inside the annular water jet, as well as outside it as at present. The steam would then be condensed both by the internal and external surface of the annular water jet, instead of only by the external surface of the present solid jet; and judging from the experiments he liad made with an annular steam jet for the propulsion of air, he beliered the condensing action of the annular water jet would be inuch more efficacious and prompt. He inquired whether any trial had been made of the annular water jet.

The President observed that in the experiment which had been described with a small tube inserted up the centre of the discharged jet, it was to be expected that, if the height of the top of the tube were such that it encountered the water of the jet after this had had its motion accelerated by the propelling action of the steam, the great momentum of the water moving at so high a velocity would produce a high pressure by impact upon the orifice of the tube; but if the tube orifice were raised a little higher, it would be clear of the water, and would be exposed only to the central jet of boiler steam, at the point where that steam was itself undergoing condensation by the water jet, and where consequently there would be more or less of a vacuum, as had been mentioned to be the case. He did not think, however, that there could be any piercing of the water jet by the steam in the condenser, but only an interchange of particles between the colder water in the centre of the jet, and the hotter external portion, which was essentially a gradual process; and the larger the diameter of the solid jet, the greater would be the difference of temperature between the internal and external portions, and the greater would be the loss of condensing water. 
In the discussion of the Paper

"ON THL ALLEN GOVERNOR AND THROTTLEVALVE FOR STEAM-ENGINES,"

\author{
By Mr. Frederick W. Kitson,
}

The Prisidext (Mr. C. W. Simmexs) * said he considered the guiernor described in the paper was remarkable chiefly for its simplicity, and it appeared to have been found to answer well in practice. Reference having been made to his own liquid governor in connection with that now described, it was to be observed that, though both of them dealt with liquid resistance, they did so in a different manner.

In the governor now described the power to act upon the throttle. valve was obtained in an indirect way; the rotating paddle-wheel did not act directly upon the valve, but impelled the oil against the corrugations in the casing containing it, and the impact tended to make the casing rotate in the same direction; the casing howerer was held back either by a dead weight, or, as had been suggested, by a spring, or really by a combination of a dead weight and a spring, because a weight alone would overrun itself if acting at a constant leverage. When therefore the velocity of the rotating paddle-wheel was so proportioned to the weight as just to hold the latter suspended, a balance was established; but as soon as the engine exceeded its normal speed, an additional amount of impact was created in the oil casing, which accumulated until it had sufficient power to orercome the resistance of the throttleralre and of the stuffing-box on the valve spindle. This power however to move the valve was not large, in comparison with the total force acting to support the governor weight at the normal speed; if for instance 100 revolutions of the paddle-wheel per minute sufficed to balance a weight of $10 \mathrm{lbs}$., then a variation in speed of two or three revolutions per minute would affect the weight to the extent of only a small fraction of a pound, which would

* Excerpt Minutes of Proceedings of the Institution of Mechanical Engineers, 1873, pp. 60-62. 
accordingly be the limit of the force available for moving the valve. It was therefore an object of primary importance that the frictional resistance in the valve and stuffing-box should be reduced as much as possible; and this appeared to have been accomplished successfully by the construction of throttle-valve now described. If this delicacy of action could be maintained, the governor would be applicable no doubt to engines subjected to frequent and sudden alterations of load. His orm liquid goremor, described at a former meeting some years ago, ${ }^{*}$ consisted of a cup of parabolic section revolving upon a vertical spindle within a vessel partly filled with oil or water ; and by the rotation of the cup, which was open at top and bottom, the liquid was caused to rise up the sides of the cup, but did not overflow the edge until the speed of rotation had reached a certain limit. Up to the moment of the cup overflowing, it acted only as a flywheel, but at the moment it overflowed it became a pump, drawing in liquid through the central aperture at the bottom and discharging it over the top edge; the external surface of the cup and the interior of the vessel in which it revolred were provided with a series of radial ranes, and the overflowing stream of liquid from the cup impinged successively upon the stationary vanes and upon those on the revolving cup, thus presenting a practically uniform resistance to its rotation. The cup was driven by the engine through differential gearing, with which was also connected the weighted lever of the throttle-valve, this constant weight acting always to mailltain the uniform rotation of the cup. Although a weight was thus employed both in his own and in the Allen governor, there was an essential difference of action between the two, inasmuch as in the Allen governor the throttle-valve had to be moved by only a fractional portion of the suspended weight; whereas in his own governor the difference between the uniform rotation of the cup and the varying speed of the engine acted direct upon the valve through the differential gearing, the uniformly rotating cup serving as a fulcrum or abutment, while the actual amount of the weight upon the throttle-valve lever was immaterial, except as regarded the original determination of the frictional resistance for the cup. It would thus be seen that there was indeed more simi-

* See Proceedings of the Institution of Mechanical Engineers, 1866, p. 19 and p. 112 ante. 
larity in appearance between the two governors than really existed in their modes of aetion; and it was clear that the throttle-valve now described in conneetion with the Allen governor must be looked upon as an essential part of the governor, the prompt action of the governor depending upon the ease with which the valve could be moved with a slight amount of foree. Owing to the great simplicity of this governor, and the eareful manner in which the mechanical details had been worked out, he had no donbt it would meet with sueess in its application.

He proposed a vote of thanks for the paper, which was passed, to MIr. Kitson, who he regretted was prevented by illness fro:n being present at the meeting.

\section{In the discussion of the Paper}

\section{"ON WENHAM'S HEATED-AIR ENGINE,"}

By Mr. Conrad W. Cooke,

The President (Mr. C. Willialy Siemexs) * said that many years ago he had given much attention to the question of obtaining from heat a larger proportion of mechanical effeet than had previously been realised.

With regard to the best medium to be employed for the purpose, although on theoretical grounds this was immaterial so long as no heat was thrown away, there were many important considerations in favour of steam, which had a higher rate of expansion by heat than air, and did not involve the employment of an air-pump for producing a supply under pressure. By the applieation of the regenerative prineiple he had obtained in small steam engines satisfactory results upon the whole ; fifteen or sixteen engines altogether had been made on that plan, of from 5 to 10 horse power, and had worked for a series of years with very fair results. One of them

* Excerpt Minutes of Proccedings of the Institution of Mechanical Engineers, 1873, pp. 82-85.

FOL. I. 
had been put to work in Paris, and had been examined by Gen. Morin and Mr. Tresca, and in a whole day's working the consumption of coal had been found to be 1.67 kilos. or $3.68 \mathrm{lbs}$. per break horse power per hour. But on attempting to carry out the same plan in engines of larger size, of 20 horse power or more, difficulties had arisen in every direction, which had compelled him to relinquish the endearour. One difficulty had been that mentioned in the paper with regard to the joints; and he had found that the best joint to resist a high heat was made by turning a number of concentric grooves in the faces of the flanges, and filling them with a cement composed of fine dust of cast iron mixed with white and red lead previously mixed up with linseed oil, and worked into a very stiff cement that set as hard as iron when exposed to heat; by that means he had succeeded in making tight joints. But what had discouraged him at that time was the result he had arrived at in preparing a paper* to which reference had been made, "On the conversion of heat into mechanical effect." In considering what would give a proper conception of a really perfect engine, he came to the conclusion that if steam were generated at such a pressure as to occupy only the same bulk as the water itself, and were then expanded down until it was all condensed through expansion, the utmost effect theoretically possible would thereby be obtained, because the whole of the heat would have been converted into mechanical effect. In Fig. 2, Plate 32 , the diagram of a portion of the dynamical expansion curre of steam, the shaded rectangle showed the utmost power that could be obtained in a condensing engine with perfect vacuum using

* (See Proceedings of the Institution of Civil Engineers, 1852-53, p. 571). In the Steam expansion curve shown in Fig. 2, Plate 32, the horizontal scale gives the volumes of stcam compared with the volume of the water from which it is produced; this is the correct dynamical expansion curve of saturated stram allowing for the loss of the heat that is converted into mechanical effect when the steam is expanded behind a working piston; the shadel area, or any other rectangle drawn to the curve, represents the power obtained from a condensing engine with perfect vacuum but without expansion. In the Air expansion curve shown in Fig. 1, llate 31, the horizontal scale gives the volumes of air compared with the volume of an equal weight of water; the dotted curve is the hyperbolic expansion curve of constant heat, representing Marriotte's law that the pressure and volume are inversely proportionate to each other; and the full curve represents the actual rate of expansion, showing the reduction of temperature during expansion, and the consequent contraction of volume ; this curve is in accordance with the observed fact that, when air at any pressure and at the temperature of $32^{\circ}$ Fahr. is compressed to double its original pressure, its temperature is raised $70^{\circ}$ Fahr. 
steam without expansion, and the result was found to be that wherever this rectangle was taken its area amounted to only $\frac{3}{y^{2}}$ th of the area of the curre expressing the power due to the ultimate expansion of the same steam ; but a good high-pressure expansive engine using steam of four or five atmospheres total pressure, cutting off at about one tenth of the stroke and working down to a good vacuum, realised a very considerable proportion, something like one fourth or one fifth of the theoretical maximum which could ever be obtained. The theoretical minimum consumption of ficl in a perfect steam engine he had calculated would be (taking 14,000 as the total units of heat developed by the complete combustion of $1 \mathrm{lb}$. of carbon) $\frac{33,000 \mathrm{ft} \text {.- } 1 \mathrm{lbs} . \times 60 \mathrm{mins} \text {. }}{14,000 \mathrm{units} \text { heat } \times 772 \mathrm{ft} \text {. }-1 \mathrm{bs} .}=0.2 \mathrm{lb}$. or one fifth of a pound of carbon per hoise power per hour ; or one fourth of a pound of coal, taking into account impurities.

In the case of the air engine, it was apparent that both Stirling and Ericsson had over-estimated the real value of the regenerator under a misconception of its true action; they had imagined that it was possible to absorb and give back the whole of the heat originally put into the air, with the exception only of accidental losses, and had overlooked the fact that a portion of the heat became entirely used up by being changed into mechanical effect; both their engines had accordingly been deficient in heating power, and had failed to give permanently. satisfactory results. : Even supposing perfect re-absorption of heat from the exhaust air, theoretical considerations showed that an air engine was necessarily rery imperfect as a means of developing power from heat ; because although a volume of highly compressed and highly heated air, if expanded down to atmospheric pressure and discharged at no ligher temperature than that of the external atmosphere, would yield the full result for the heat absorbed in expansion, yet an equal weight of air would then have to be taken up again and compressed to the original pressure, thereby generating a great amount of heat, which would all be wasted because it was generated in the air before its expansion by heat took place and when it should occupy the least volume, the power of the engine being dependent upon the increase of volume. In the best air engines, therefore, eren supposing perfect absorption of the escaping heat, it would not be possible to realise anything like so much as 
one fourth or one fifth of the theoretical maximum of mechanical effect due to the heat put into the air. Another drawback was that in most air engines, and particularly in Stirling's, owing to the low conducting power of air and insufficient amount of heating surlace, the cylinder or vessel in which the air was heated by the fire was found to get fully red-hot, so that the products of combustion reached the chimney at that elevated temperature. This source of loss was obviated in the engine described in the present paper, by causing the products of combustion to pass through the working cylinder, the air being heated by direct contact with them ; and if the expansion in the cylinder could be carried far enough, no doubt the wholc of the heat in the products of combustion might in this case be utilised; but it was clearly impossible to carry expansive action very far in this engine, owing to its low working pressure, and moreover the working of the airpump constituted a very heavy loss of useful effect. The loss of sensible heat escaping at the exhaust might be remedied by the application of a regenerator; but this could not be done except at a sacrifice of the simplicity of construction which appeared to him to constitute the chief recommendation of the enginc. It was impracticable he believed to carry out the principle of the hot-air engine on a scale sufficient to give any large amount of power; but a question of much practical importance was to produce a safe engine of small power, which could be put up anywhere, in any room, because requiring no boiler, and therefore necessitating no increased rate of insurance against fire. This object had been already accomplished by various constructions of gas engines, and was also effected by the hot-air engine now described, which he hoped would be so far perfected in its details as to give an effective power of as much as 4 or 5 horse power; and even though the consumption of coal were not reduced below 8 lbs. per horse power per hour, there were no doubt many cases in which such a source of motive power could be advantageously employed.

He moved a vote of thanks, which was passed, to Mr. Cooke for his paper, and also to Mr. Wenham for the additional information he had kindly given. 


\section{In the discussion of the Paper}

" ON MODERN LOCOMOTIVES, designed wilh a view to ECONOMY, DURABILITY, and FACILITY OF REPAIR, together with some particulars of the DUTY Peirormed, and of the Cost of Repairs," by Jolis Rorrsson, M. Inst. C. E.,

Mr. Siemess * said he was one of the members of the jury in Vienna, where the subject of the contre-vapeur was discussed, and the exceptional reward of a Diploma of Honour was awarded to M. Le Chatelier for that remarkable inrention, which was fully appreciated throughout the Continent. It was a contrivance that should always be used; otherwise the result would be a failure. He imagined that on the London and North-Western line it had not been adopted as a system, but had been put into the hands of the engine driver to be employed occasionally; sometimes it inight liave been used properly, whereas at other times probably the water was not put on when reversing. In M. Le Chatelier not only France but Europe had lost one of her ablest engineers. He ras a man of very extensive information, of a genial nature, and a truc-hearted friend; and he had never known any one more ready to investigate and to appreciate any new idea. M. Le Chatelier had suggested sereral important improvements in stean economy. He was the first to draw attention to the great adrantages of perfect balancing and also of perfect jacketing in using steam expansirely. He had, with his friend M. Deville, devised a practical process for the production of aluminium, and had made many raluable suggestions in regard to metallurgical processes. The earnest activity of his mind was such that he could give attention to these matters, and to the ligh education of his children, while holding the responsible appointments of engineerin-chief to many large undertakings.

* Excerpt Minutes of Proceedings of the Institution of Civil Engineers, Yol. XXXVII. Session 1873-74, p. 27. 


\section{In the discussion of the Paper}

\section{" ON PEAT FUEL MACHINERY," by JOSEPH MuCarthy Meadows,}

Mr. Simmens * said, in the course of the discussion, the use to which the peat was to be applied appeared to have been left out of sight. If it was to be worked into peat charcoal, it was of course necessary that it should be thoroughly masticated and compressed, in order to make it of great density. Such peat charcoal was of considerable value, and in blast furnaces he thought it would be better than the best coke that could be obtained, because it was generally free from sulphur. This, however, was not always the case, for at Swansea he had analysed peat, and had found it to contain fully $\frac{1}{2}$ per cent. of sulphur, owing, no doubt, to the presence of the Copper Smelting Works. Again, if peat was required for locomotive work it must be rendered dense, or it would fly out in large quantities from the chimney; in which case a machine like the Messrs. Clayton's might be extremely useful. If, however, peat was only to be used for the production of heat, in stationary steam boilers or in furnaces, it would be entirely useless to subject it to manufacturing operations such as hád been described. He agreed with $\mathrm{Mr}$. Cowper in thinking that it was desirable to separate each piece as much as possible from its neighbour, so as to let the wind act upon it, rather than to dry it in sheds by artificial heat, because in the latter case a large proportion of it had to be burnt to produce the heat, and the operation was actually retarded because only a limited quantity of air could be brought in contact with each piece. Air-dried peat, containing 40 or 50 per cent. of water, was capable of producing any degree of heat if properly burnt; and he considered the proper way of burning such fuel was to convert it into a gaseous fuel. The gas was as rich if the peat contained 50 per cent. of moisture as if it contained none;

* Excerpt Minutes of Proceedings of the Institntion of Civil Engineers, Vol. XXXVIII. Dession 1873-74, pp. 265-66. 
but care should be taken to condense the water out of it before the gaseous fuel was used. He liad employed peat so treated for forging furnaces and steel melting furnaces, and found it the best fuel that could be used. He should prefer it even to the best coal for leating purposes, and he believed the time would come when the stores of peat in Ireland, in Scotland, and in the north of England would form a valuable addition to the stock of fuel for all operations for which coal was at present used. Such employment would tend more than anything else to the development of iron industry in Ireland.

\section{In the discussion of the Paper}

\section{" ON THE MCCARTER CONDENSER WITHOU'T AIR}

\section{PUMP FOR STEAM-ENGINES," by Mr. F. Preston,}

Mr. C. W. Srkmexs* , enquired about the amount of steam in the jet necessary to work the auxiliary condenser. A calculation had been given of the quantity of water which this condenser required as compared with the ordinary condenser, and he supposed there would not be any material difference in the quantity, but he had considerable doubt as to the economy of working this plan. This condenser worked upon the Newcomen principle, boiler-steam being admitted in the lower part of the condenser, which stood in lieu of a cylinder in the Newcomen engine; and the hot steam was brought into contact with the cold surface, in order to expel the water and air accumulated there. Now the quantity of steam so accumulated must be considerably more than the steam that would be necessary to work the air-pump, because the air-pump was worked on as economical a principle as was involved in the engine itself. Therefore the expulsion of a certain amount of water and a certain amount of air from the upper part of the condenser was accomplished in this condenser not in an economical manner. There was a compensating advantage in doing away

* Excerpt Minutes of Proceedings of the Institution of Mechanical Engineers, 1876, pp. 311-12. 
with one complication of the condensing engine, namely, the airpump; but whether that advantage was not purchased at too great a price was a question which he should like to see more fully elucidated than was done in the paper at present.

He should also like to know what vacuum could be regularly maintained by this condenser ; there seemed to him a difficulty in that respect. When the vacuum was produced in the auxiliary condenser no doubt the water in the upper chamber by its own gravity fell readily into the lower chamber; but only a small portion of the air that was accumulated in the upper chamber would follow it; and in proportion as the lower chamber was small or reduced in comparison with the upper chamber, or main condenser, in the same ratio the vacuum would be reduced in the upper chamber. It would be interesting to know, therefore, what was the vacuum that could be usually obtained with this condenser, and what was the amount of steam necessary to work it.

\section{In the discussion of the Paper}

"ON THE COMBUSTION OF REFUSE VEGETABLE SUBSTANCES, such as Straw, ReEds, Cotton Stalks, BRushwood, MEgass, \&c., UNDER STEAM BOILERS," By JoHn Head, Assoc. Inst. C. E.,

Dr. Siemens * said his experience of the form of engine under discussion was confined to what he had seen, as one of the jury, at the Vienna Exhibition a few years ago. Messrs. Ransome, Sims, and Head's apparatus was then worked very satisfactorily, as was also Mr. Garrett's. 'The jury, he believed, decided that both makers were entitled to an award, not only for their strawburning engines, but for their exhibits generally. With regard to the relative merits of the two methods, he thought Mr. Head's

* Excerpt Minutes of Proceedings of the Institution of Civil Engineers, Vol. XLVIII. Session 1876-1877, pp. 99-100. 
apparatus deserved the first place, because it contained all the elements of continuous, equal, and systematic feeding; whereas in Mr. Garrett's much depended upon the skill with which the operation was carried on. Mr. Garrett had stated that each timc the dried straw was introduced into the furnace an explosion took place. That surely meant that, at the moment when the straw entered the furnace, the combustible matter met an cxcessive amount of oxygen which had previously accumulated there. No doubt, however, a skilled workman could produce cxcellent results with Mr. Garrett's apparatus. With refcrence to the figures brought forward by Mr. Head, which had been contested by Mr. Garrett, he had just made a calculation which might throw some light on the subject. Mr. Head had stated that $1 \mathrm{lb}$. of coal was cqual in heating power to $3 \frac{1}{2} \mathrm{lbs}$. of dried straw ; and he had given analyses of the coal and of the straw. From this it appeared that the combustible constituents of Newcastle coal were, carbon 80 , and hydrogen 5 ; and of straw, carbon 35 , and hydrogen 5 ; making a total of combustible matter in the one case of 85 , and in the other 40 : but the hydrogen had a greater calorific power than the carbon, and for comparison might be doubled; so that the figures would be 90 and 45 . According to that analysis, straw ought to possess, roughly speaking, half the calorific effect of coal, and it would have that effect if the cumbustion of both materials were perfect. In the case of straw there was one deduction to be made which did not apply cqually to coal ; it contained a greater amount of ash in the form of silica; and that ash was the real difficulty to be contended with. There was also a greater amount of water in the straw than in the coal, but that was a matter of less difficulty. In the case of straw 15 per cent. of water had to be evaporated, and in the case of coal only 1.3 per cent. Taking those clements at their utmost value, he considered that Mr. Head's estimate, that $3 \frac{1}{2} \mathrm{lbs}$. of straw were equal in calorific cflect to $1 \mathrm{lb}$. of coal, was not excessive ; it appeared to him a reasonable amount, provided that something like perfect combustion were obtained. The apparatus, so admirably explained and illustrated, shorred that the question had been thoroughly gone into, and the assumption that complete combustion was obtained had been rerified. When straw and other similar vegetable matter were consumed, the important point was 
to remove the ash so as to continue the combustion under favourable circumstances, and this difficulty has apparently been successfully overcome. He thought the thanks of the Institution were due to Mr. Head for the admirable manner in which he had investigated the subject and brought it before the members.

In the discussion of the Paper

\section{"ON EXPERIMENTS RELATIVE TO STEAM} BOILERS," by Mr. Williay Boyd,

DR. C. W. Siemexs* remarked that the paper was exceedingly gratifying to himself, inasmuch as it contained results arrived at by an engineer who had evidently gone very systematically to work in testing material, and had not refrained from bringing the results he had obtained before that Institution. The first news he had had of this application of Landore steel was unfortunate. $\mathrm{He}$ was told that the steel had in one instance at least entirely failed to stand the test. Mr. Boyd had now brought before the meeting the particular circumstances under which his apparent failure arose. A test plate had been fastened between two plates of iron ; and when the tensile strain was applied, the steel, instead of elongating 20 or 25 per cent. as was expected, and of breaking, as was also expected, across the rivets, took its own course and broke through the fastening, along a line of fracture some 20 per cent. stronger than the line of least resistance. It was inferred from that experiment that such steel after all must be an unreliable material; but when he saw the details of the experiments he immediately suggested that the cause of failure would probably be found to lie in the mode in which the fastening had been made. Mild steel or homogeneous iron was a material that yielded very much before rupture, provided the tensile strain was applied fairly

* Excerpt Minutes of Proceedings of the Institution of Mechunical Engineers, 1878, pp. 233-236. 
over the whole section. 'This very property of yielding before breaking made it necessary that it should be fastened along the whole line of its section. In the particular fastening referred to, two larger rivets stood forward, and naturally would take nearly the whole of the strain that fell upon the plate. The other four rivets stood back to such an extent that, before they would receive any considerable portion of the strain, the two forward rivets would be loaded to such an extent as to cause a partial yielding of the metal, and, as they were near the edge, tearing action would set in. Now a material, however strong it might be, could be torn without much effort. Thus if a strip of india-rubber were nicked, it tore with little stress; whereas if there was no nick, it would bear almost any amount of elongation. In like manner the mild steel had to be treated differently from iron; and experiments like the present gave better information than any learned essays on the subject could possibly supply. When the strips of the same plate "were tested in the usual way, they stood the test as well as every other portion of the material supplied.

The use of iron rivets had been advocated, and was still advocated by many, for riveting these mild steel plates together. $\mathrm{He}$ could not too strongly protest against that practice. It was utterly against nature to stick together material like this mild steel with another material, iron, which behared quite differently as to elongation and yielding. Again, when iron rivets were used, the rivet-holes must necessarily be larger than they would need to be for steel rivets; being larger they would be put a greater distance apart, and the distance practically chosen was the same as was in ordinary use for iron plates of 20 per cent. greater thickness. 'Thus the thinner plate was held together at points relatively further apart; and the result was that the metal between hole and hole could not be so securely held as it should be, and tearing action set in. He was very glad to see that Mr. Boyd had resisted the temptation of using iron rivets, and had adopted steel riveting in these boilers.

He did not quite agree with the author that punching necessarily diminished the strength of a steel plate something like 33 per cent. No doubt his experiments had been very carefully made, but there was a great difference between punching and punching. His belief was that on punching a cylindrical piece or "burr" out 
of that plate it would be found that this piece was not as thick as the plate, but on the contrary considerably thinner. What then had become of this metal? It had not gone to increase the diameter of the burr, although its lower part might be a little bulged out in that way; but while the punch was being driven into it that metal had accumulated somewhere in the plate. There was thus a ring of highly compressed material formed round the hole, and this compression caused the surrounding portion of the plate to be under high tension. The result must be that, if pressure was applied, the portion already under high tension received additional tension, and tearing action began. Hence the great loss of strength in punching. He held in his hands the results of some experiments, made with great care by Mr. James Riley at the Landore works, which proved precisely what he had stated. There however plates, which before punching bore 29.33 tons per sq. in., bore after punching 30.7 tons per sq. in. without annealing. The reason of this anomaly was, the die in these cases was made considerably larger than the punch, and thereby the compression was practically avoided.* Another kind of punch had lately been introduced from Anierica, which was well worth the attention of the meeting. It was a helical punch, which, instead of driving out the metal before it, cut it out in a spiral form. This mode of punching he thought very promising, and he believed by adopting such a method the weakening effect that liad been experienced in punching thick plates would be entirely got over, without unduly increasing the size of the die. In punching thin plates the author found there was but very slight reduction of strength, and that the punched plate when annealed resumed its former strength exactly. It had also been found that by riming ont a punched hole the strength of the metal was entirely restored : showing that the cause of weakness was in

* Mr. J. G. Mair has since communicated to the Secretary the results of some experiments made on this point by Mr. Henry Sharp, of Bolton. Four pieces of $\frac{1}{2}$ in. steel plate, $2 \frac{7}{16}$ in. wide, were punched with an $\frac{11}{16}$ in. punch, but with a die $\frac{7}{8}$ in. in two cases and $\frac{3}{4}$ in. bare in the other two. The results were as uncler, showing 25 per cent. more strength for the greater clearance :-

$\begin{array}{lcc} & \frac{7}{8} \text { in. die. } & \frac{3}{4} \text { in. bare die. } \\ \text { 1st experiment } . \quad \cdot 32 \cdot 30 & 25 \cdot 92 \\ \text { 2nd experiment. } & \cdot 32 \cdot 85 & 26.08\end{array}$

Mean . . . 32.5 tons per sq. in. 26.0 tons per. sq. in. 
the immediate vicinity of the hole, and did not extend to any distance through the metal, which was in accordance with the explanation he had suggested.

The author had added an important item of information with regard to the staying of flat surfaces. The addition of the nuts to the stays showed a remarkable increase of strength, and he hoped that mode of staying would be generally adopted. It was a question howerer whetler for flat stay-plates this very mild steel should be used; it would probably be more advantageous to use for flat surfaces steel containing perhaps 0.4 per cent. of carbon; they would then get a material of great stiffness as well as great strength, and still of sufficient ductility. Steel with about 0.4 per cent. of carbon would not indeed elongate 25 per cent. before breaking, but it would elongate probably 12 per cent. ; and in the case of a flat plate that ought to be sufficient.

He might mention that lately he had witnessed two experiments made with a riew of bursting a steel boiler. These were made at Swindon by Mr. Dean of the Great Western Railway; and Mr. Parker, the Chief Surveyor at Lloyd's for the boiler department, was present at the second experiment. Both experiments failed, i.e., they could not burst the boiler; and he believed it was impossible to burst a steel boiler. It might be expanded and the joints racked to the extent of introducing an amount of leakage that would prevent further accumulation of pressure; but it would never be burst. That condition of things was certainly a satisfactory one.

\section{In the discussion of the Paper}

\section{"ON A NEW REVERSING AND EXPANSIVE} VALVE-GEAR," by Mr. DAVID Joy,

1R. C. W. Sremens * said that, listening to the rery excellent paper which had been brought before them, and to the observa-

* Excerpt Minutes of Proceedings of the Institution of Mechanical Engineers, 1880, pp. 444-445. 
tions of the speakers who had taken part in the discussion, one result seemed to his mind to be quite certain, namely, that the link-motion was doomed. He must say he did not feel the same regret on that score which appeared to animate Mr. Head. The link-motion had no doubt been a way out of a difficulty; but it was correct only within very narrow limits, and the moment those limits were exceeded it did not produce the expansire action desired. A motion had now been brought before them which challenged comparison with the best expansive gear that could be mentioned. There was a clean cut-off ; the steam was put on at once in ample quantity, and the exhaust also was opened promptly at the right time. There was also the means of adjusting the action so as to make the up-stroke and the down-stroke perfectly alike, which, as they all knew, was not the case with the linkmotion. And, as Mr. Webb had beautifully illustrated by his locomotive, the new gear had the advantage of giving a large useful space on the main shaft for increasing the length of the bearings. These were very important adrantages, which Mr. Joy might claim for his motion. But they had also been put in possession of two other motions, which seemed to be as perfect as Mr. Joy's. Still they need not regret that result. There were points of difference between the gears, though they all aimed at the same result, a very perfect cut-off and a perfect mode of reversing the engine. The object was achieved by different mechanical details, all of which he considered were superior, both theoretically and practically, to the old link-motion.

With the criticism offered by Mr. Boyd, in regard to a portion of Mr. Joy's motion, he thoroughly agreed. The slotted disc, which was turned into a different angular position, with the slide-block grinding up and down in the slot, was not, he thought, a desirable detail ; and he would recommend Mr. Joy to do away with it. He observed it had actually been done away with in one arrangement shown. All the friction was there reduced to the friction on the pins, which must be preferable to friction of sliding surfaces. With that exception Mr. Joy's motion appeared to him perfect, and one that would no doubt receive the most earnest attention of mechanical engineers. 


\section{In the discussion of the Paper}

\section{"ON GAS-GENERATING FURNACES,"}

\section{By Mr. F. Lü̈ruavx,}

Dr. Stemexs * said, Mr. Lü̈rmann was so well known as a gentleman who had originated practical ideas which had been largely used, that anything coming from him deserved much consideration. The gas-producer now advocated by Mr. Liirmann was based, as might be supposed, upon a sound philosophical principle-that of concentrating heat as much as possible in the operation of conrerting the solid fuel into gas. He had, however, two criticisms to make on Mr. Lürmann's paper, the one regarding the historical record with which he prefaced his arguments, and the other as to the technical value of the particular arrangements proposed by lim. It was now more than thirty years since he had constructed the first gas-producer applied to the regenerative gas furnace, and he might add, that the subject of fuel conrersion liad engaged his attention ever since. Under these circumstances he should have expected to find in the historical record of the author some allusion to his labours in this direction. In the years 1863 and 1864 he patented several varieties of gas-producers, in which the coal passed towards the fire-grate through retorts, in a rertical or inclined direction, which retorts were heated either by the gas resulting from the operation itself or from extraneous sources. Indeed, the hopper arrangement, described in the papel as Price's gas-producer, might, amongst others, have been taken from one of his specifications of that early date. He might further mention that in the year 1863 he brought a bill before Parliament to supply Birmingham with heating gas, and that the gas-producer then put forward comprised both the principle of retort-heating and that of the open grate for the final conversion of coke into carbonic oxide, whilst by another arrangement the coke was withdrawn from the apparatus to be used separately as breeze. This arrangement, he believed, was still in operation at Messrs.

- Excerpt Journal of the Iron and Steel Institute, 1880, p. 583-585. 
Russell \& Co.'s tube works near Birmingham. He held in his hand the specifications of the two patents alluded to, and it might not be without interest to the Institute to learn exactly what was known and claimed regarding the proposed method of producing gas as early as 1863 and 1864 . In the patent of 1863 it is said: "Thus, although we much prefer to make use of regenerators for producing the intense heat required, yet heating apparatus of different construction may be applied, and the form and construction of the heated chambers, as well as the means adopted for charging and discharging them, may be greatly modified; also the cliambers or retorts may be arranged in a somewhat inclined position instead of being placed vertical," \&c. ; and he claimed "constructing furnaces in which coal or other carbonaceous material is subjected, whilst descending gradually in upright recipients or retorts, to the action of intense heat resulting from the application of regenerators with reversal of currents, the result being either the total conversion of the carbonaceous matter into combustible gases when a grate is applied at the bottom of such recipients, or the production of both combustible gases and colke of superior quality, when admission of atmospheric air to the bottom of the recipient is prevented." And in 1864 the first two claims run as follows : "First, constructing apparatus for converting carbonaceous matter into combustible gases, in which such carbonaceous matter is first caused to descend gradually through one or more vertical or inclined retorts, from the lower end of which it passes in a thick layer upon a fire-grate, the heated combustible gases resulting from the imperfect combustion of the fuel upon the latter being made to pass around or against the outer surface of the said retort or retorts. Second, constructing gas-producers (which are chiefly applicable for the conversion of binding coal into combustible gas) in such a manner that the fuel descends through an inverted funnel, acting more or less as a retort, upon a solid moderately-inclined plane supporting the column of fuel, such inclined plane having one or more openings at the top for the admission of atmospheric air, as well as for the introduction of bars to break up the masses of coke, whilst one or more other openings are provided at bottom for the removal of clinkers or ashes, and for the introduction of a further quantity of air or steam or both, in order to complete the conversion of the car- 
bonaceous matter, substantially as hereinbefore described." $\mathrm{He}$ male these quotations simply by way of addendum to the historical record bronght before them by the author, his personal interest in the matter having ceased with the expiry of the patent through lapse of time. The reason for not perserering in the direction here indicated was due to the retort action being found too slow for the prodnction of combustible gas in such quantities as were required for working large furnaces, and he expected that Mr. Liurmann would be met with the same kind of difficulty when he attempted to give his gas-producers an extended application. His endeavours had since been directed to concentrate as much latent heat in the gas as possible, in order that it might travel, and therefore he had always used the spare heat for drawing up vapour, and to convert the water in this form into its two elements. In the form of producer now put forward, the enrichment of the gas was simply in the direction of obtaining a higher temperature, and this higher temperature could be utilized if the gas-producer was put into close connection with the furnace. But in the regenerative system that high heat was secured through the regenerators, and therefore was not required previously. In one form of the gas-producer, which was also largely used, a steam blast was employed, with a closed grate. He had since gone a step further in that direction, and he had obtained certainly a rery remarkable result.

\section{ON THE USE OF COAL GAS AS A FUEL.}

By Dr, C. Willitadi Siemexs.

Dr. C. Wrluiam Siemexs : * Mr. President, among the subjects suitable for discussion before this Society there is, perhaps, none more so than that of combustion, or rather that of the production of chemical energy, and its application. It has derolved upon me to bring this subject before you, and although I shonld have

* Excerpt Journal of the Society of Chemical Industry, 1881, pp. 39-46. vol. $x$. 
preferred that the choice had fallen on a gentleman who could have given inore time to the actual preparation of such a paper than I have been able to bestow upon it, yet having for nearly thirty years gircn much attention to the subject of combustion, and the utilization of gaseons fuel, it was perhaps natural that your President called upon me to open out the subject before this new Society.

The fuel at our disposal, generally speaking, is coal, and in most applications coal, in its raw condition, is still used for the production of heat. I hare put a table before you, showing the amount of heat energy residing in a pound of fuel. If that fuel is pure carbon, 14,544 units of heat are producible. If coke were used, and burnt entirely to carbonic acid, 12,500 heat units would be produccd. If coal of the average quality is employed, 11,000 heat units may be obtained. But, if instead of using solid fuel we should einploy gaseous fuel, wc immediately jump to much higher figures. Olefiant gas gires in its combustion 21,844 heat units ; marsh gas, 23,500 ; and hydrogen, 62,000 units, or rery nearly six times as much as raw coal. Then carbonic oxide, not counting the oxygen already taken up, but simply the carbon in the carbonic oxide, gives 10,100 . These figures may serve to show the grcat advantage in the use of gascous fuel; and if by some means or other we could impart to the fuel as it is consumed the greatest possible power for the production of heat energy, it wonld be clearly to the advantage of the user, because not only does this better fuel produce for the same weight of material in greatcr result, but it produces that result with a smaller expenditure of oxygen, that is, with less draught.

The principal reason why gaseous fuel, especially hydrogen, produces such a large amount of heat energy, consists in the heat energy already expended in expanding it to its volume, and the ultimate result, therefore, depends less upon combustion than it would do in the case of coal where a large proportion of the leat produced is expended in conrerting the solid into gaseous fuel to begin with. But gaseous fuel, when used instead of solid fuel, possesses several other advantages. It is much easier to produce perfect combustion in using gaseous than in using solid fuel. Solid fuel, when first heated, flies off to a great extent into products of distillation, and the supply of oxygen can hardly keep 
pace witl such a sudden increase of production of gas. The result is smoke, and smoke is waste, whichever way it is viewed. Moreover, it is a public nuisance, and as such it should be done away witl.

Then, in using gaseous fuel, the supply can be kept constant, and when the supply of air is once regulated, it can be employed in the exact proportion to produce the maximum result. This is :In important argument in favour of gaseons fuel. Then in graseous fuel we liave already a product of manufacture, and we have it free of ashes, and those drawbacks which attach to solid fuel, making disturbance and dirt not only in the atmosphere, but in works or dwellings where it is employed. Again, by the use of gaseous fuel, labour is saved to a very great extent. We have not to carry coal, but the fuel is supplied through tubes to the place where it is used, and the labour of producing the gas being concentrated labour, involves very much less expense than it would if solid fuel had to be dealt with.

Lastly, gaseous fuel admits of the attainment of results such as canuot possibly be produced with solid fuel. Yon can heat gas to any degree almost within ordinary furnace temperatures before it enters into combustion, and I have shown by means of furnaces which I have been constructing for the last twenty years, that ail can be heated to a very high temperature before entering into combustion with gas, and there is thus produced a compound, regenerative, cumulative action, which enables us to obtain by ineans of gaseous fuel the highest temperature which can be attained by combustion at all. You are all aware that the temperature attainable by combustion is limited by the point of dissociation, as Bunsen and St. Claire Deville have shown in their heautiful researches. I may mention that in applying a gas furnace for the fusion of steel on the open hearth, the point of dissociation is practically very nearly attained.

Although this furnace is sufficiently well known by this time, I may just shortly refer to its leading details. It comprises : gas-producer which is presented in a somewhat novel form; I shall refer to it again presently.

The furnace itself consists of a furnace bed, and of brick chambers filled with refractory material piled up loosely so as to admit the circulation of air or gas through the same; gas 
from the gas-producer is directed upwards through one of these chambers, and cold air is directed upwards tbrough the adjoining chamber. Both air and gas meet at the entrance of the combustion chamber, and if the brickwork contained in the two chambers is heated by any process, the air and gas flowing through it will also be heated to very nearly the temperature of the materials which impart that heat. They will therefore meet in combustion at a high platform, so to speak. If the temperature of the brickwork be at the upper surface, say $1000^{\circ}$, the air and gas will be heated practically to $1000^{\circ}$ before they combine, and the result of that combustion must be a temperature of at least $1000^{\circ}$ higher than it would have been if the gas had not been so heater. The products of combustion flow away at the other side through passages, every alternate passage leading into one or other of the two remaining chambers, and in flowing downwards over the surfaces of the brickwork they impart heat to those surfaces, raising their upper layers to nearly the temperature of the products of combustion, which after depositing their heat, reach the chimney comparatively cool. By reversing the direction of the gases, say every hour, or every half-hour, as the case may be, and admitting gas fuel at the place where one portion of the products of combustion left, and air at the point where the other portion of the products of combustion left, the currents of coal gas and air will pick up, so to speak, the heat which was kept there in deposit, and reach the point where they enter into combustion heated to a higher degree by another $1000^{\circ}$; and the consequence of this combustion will be the attainment of a still higher degree of heat than was obtained in the previous operation ; and so on, and on, until either there is an equilibrium produced by the fusion of the materials to be heated, at which point, of course, the excess of heat will be absorbed in work done, or it will go on accumulating until combustion itself will cease. Such a point will be reached at about $2500^{\circ}$ Cent., the temperature of dissociation, and in heating one of these furnaces up to the highest point which it would be safe to attain in them, the flame, which at one portion of the operation is a short white flame, becomes gradually extended into a long attenuated flame of somewhat bluish appearance, clearly showing that combustion is carried on under great difficulties. For any temperature exceeding these limits we should have to resort to 
different means altogether, such as the electric arc, because combustion, however carried on, would not give us a higher temperature, even if we found materials that would resist the heat. These, then, are some of the advantages which may be claimed in favour of gaseous fuel.

Fuel may be dealt with in two ways in order to produce gaseous fuel ; it may be placed in a retort, and the retort heated by the external application of heat in order to drive out the volatile constituents. 'This is the process, as you are aware, generally followed in gas-works. The use of gas for illuminating purposes dates from the end of the last century. It was in the year 1792 that Murdoch, of Soho, erected his gas-retort. After him Lampadius published, in 1801, his investigation, very crude according to our present ideas, on the subject of gas, and gas illumination, but it was not until 1815 that gas illumination came to be practically used, and it was applied first of all, I believe, in London. This mode of producing gas by heating a retort, gives rise to two principal products, the gas or gaseous fuel, and the residue, the carbonaceous matter, or coke. Both these constituents are rery suitable for heating purposes. Coke has this advantage over raw coal, that it burns without developing smoke, and it is, therefore, applicable for many purposes where this rapid development, or change of the solid fuel into gaseous constituents, would absolutely impede the operations to be performed, such as blast furnaces, or locomotive engines. The gaseous fuel produced in the retort is also applicable for heating purposes, but has hitherto been used chiefly as an illuminating agent. I shall presently refer to the working of a gas retort, with a view of showing that, although we treat the gas coming from the retort as illuminating gas, as an entity, it really consists of many constituents, and that the quality of the mixture of gas coming from such a retort at one portion of the process is very different from that which comes from it at other portions. If the purpose before us is the heating of a furnace, and our object is to obtain from the solid coal as much gaseous fuel as possible, then it would not be desirable to have resort to a retort. The retort process is a slow one, and the coke produced, although it can be used also as fuel, would be undesirable at works where no such fuel is required, where the only object is to heat furnaces for melting glass, for making steel, for heating 
iron, or whatever it may be. For such purposes the whole of the solid coal ought to be converted into gaseous fuel, and that has been accomplished for many years. It is accomplished in the blast furnace, where the combustion of coke under the influence of an insufficient amount of blast gives rise to a product at the top, consisting, in a great measure, of carbonic oxide gas mixed with a large proportion of nitrogen, which necessarily comes in with the air at the bottom. It is due chiefly to Mr. Ebelmen, a French physicist of some distinction, that attention was called to these gases in the early part of the century, but no practical application was made of gas for a number of years, nor were the gases coming from the blast furnace practically utilized until within the last twenty-five years.

In the year 1861, I, in connection with my brother Frederick, succeeded in the construction of a regenerative gas furnace in which gas is used resulting from the total destructive distillation of coal, and I now wish to place before you an apparatus of an improved character for effecting that purpose. The gas-producer which we have hitherto used was effective, so far as it goes, in producing a combustible gas, but it did not fulfil all the conditions necessary to produce this chemical operation to the best advantage. One of the essential conditions for the total conversion of coal into combustible gas is a maximum degree of heat at one portion of the process. Where air enters, or is forced into a mass of incandescent fuel, the temperature of that fuel is raised, and the result of perfect combustion is carbonic acid. In order to produce carbonic oxide, which is the gas fuel producible from the carbonaceous constituent of the coal, it is absolutely necessary that carbonic acid, or the result of perfect combustion, should be produced in the first instance, and only by passing this intensely heated carbonic acid over an additional mass of incandescent carbon will it take up another constituent of carbon, and constitute itself carbonic oxide; unless the temperature is high enough, this reconversion, or backward conversion from carbonic acid into carbonic oxide, will be effected only partially and imperfectly.

The apparatus, Plate 33, which I have lately tried, and which promises to ie a great improvement on the former arrangement, consists of a cylindrical chamber truncated towards the bottom, which is 
filled with coal through a large liopper at the top ; this iron casing is corered on the interior with a lining of refractory material, and in this lining passages are arranged all round for the exit of the gnses; a large opening at the bottom admits of the removal of aslies and clinkers that may be formed in the combustion of the fuel, and a blast, which by preference should be heated, is directed right into the very heart of the mass of fuel. The result is a rery high temperature in the centre of the mass, and no heat is lost at that point, which loss would interfere with the due conversio: back into carbonic oxide. At the same time, water, which is admitted by a continual streamlet into a pan near the bottom, is eraporated, and currents of steam are directed or drawn into the apparatus, passing through the zone of highest temperature towards the centre of the mass. They there become conrerted by contact with the incaudescent fuel into carbonic oxide, and liydrogen gas, which add greatly to the calorific eflect of the gas produced.

Much has been said of late years of water-gas, and one has seen statements in the papers calling attention to the enormous store of fuel we possess in the ocean; but a rery little consideration will show the utter fallacy of such a proposition, as getting actual heat energy from water, which is already the product of complete combustion. Water can only usefully assist in the operation of gas production if you have spare heat to expend. If in the gas-producer no water at all were admitted, you would obtain a current of carbonic oxide, mixed with the other products of distillation of the raw fuel that enters the apparatus; and the licat that would result from this combustion, even after a portion of it had been expended in the backward reconversion of the carbonic acid into carbonic oxide, and in the work of distillation of the raw coal into hydro-carbons, would be sufficient to impart to the gas at the point of exit a temperature of about $1,000^{\circ}$ I., or a little more. This heat must be considered as a loss, because if the gas had to be carried to any reasonable distance, this free heat would be dispersed before it reached the furnace, and it is with the view of utilising this heat, which rould otherwise be lost, that water can be had recourse to adrantageously. But it must be administered in judicious proportions. If too much water is admitted the chemical action which is intended to 
be carried into effect in the gas-producer would cease, and the temperature would never attain the degree necessary to convert carbonic acid back into carbonic oxide. There would result a poor vapoury gas, which on analysis would show a very large proportion of carbonic acid still present, and probably free oxygen, which never had combined at all. This is a point to which I have wished particularly to call the attention of this Society (which has for its object to combine strictly scientific investigation with its practical applications), viz., the degree to which water can be advantageously used for effecting this decomposition, and its re-combustion.

When this process is properly conducted in the old form of producer, the result of the total combustion is a gas of moderate temperature, perhaps $400^{\circ} \mathrm{F}$., found on analysis to contain of carbonic oxide 24 per cent., hydrogen 8 per cent., carburetted hydrogen 2 per cent., carbonic acid 4 per cent., nitrogen 61 per cent.; whereas in a well-organised gas-producer of the new form, the proportions of hydrogen and carbonic oxide could be materially increased, and the amount of nitrogen diminished proportionately. I may also mention with regard to this form of producer, that the earthy constituents of the coal are fused, or brought into a semifused condition, and are carried down in that condition by the weight of the fuel itself; the object bcing to produce this scmifused mass of clinkers within the mass of the fuel without giving them the opportunity of attaching themselres to the furnace, and thus to sare labour.

Another matter I wish to call attention to is the supply of gas that can be carried to a distance. After all, gas produced by total distillation in the gas-producer can only serve at works where it can be used at once, but for the multifarious purposes of daily life, for small works, and for domestic purposes where heating gas will become from day to day used to a larger extent, there it is necessary to send through pipes a gas of a much richer character than that coming from a gas-producer. It must be a pure combustible gas, such as marsh gas, or hydro-carbons, or hydrogen. This may be produced in retorts of the ordinary kind, or, as I proposed eighteen years ago, when I suggested the supply of heating gas to the Town Council of Birmingham, by the use of large vertical retorts heated by a regenerative furnace, and furnished with a supply of 
water at the lower extremity, in order to get a very active distillation, irrespective of the illuminating quality of the gas produced. But the difficulty which presented itself was one rather of establishment. It was proposed to build works simply for the purpose of supplying heating gas; and although the Town Council of Birmingham went to Parliament for a Bill to empower them to carry out this suggestion, they lost their Bill in the Committee of the House of Iuords. Since then the public desire for the use of heating gas has been gradually increasing, and another mode of supplying it has suggested itself to me. It may have been thought of by others, and it is one that recommends itself, I think, by its simplicity to your consideration. It consists in separating the produce of the distillation of coal in the gas retorts into two parts : one to be set aside for heating, and the other for illuminating purposes. The result of such a separation is illustrated by the diagram, Plate 34 , which is based on some experiments made many years ago by M. Ellissen, the Chemist of the Paris Gas Works, working in connection with M. Regnault, the great physicist. They wanted to determine by accurate observation and experiment what was the least time to be allowed for each distillation. Instead of carrying on the operation through six hours, they came to the conclusion that it should be hastened, and completed in four hours, and for this purpose the Paris Gas Works first adopted the regenerative gas furnace as a means of heating retorts, and they have used it very largely ever since. Through the kindness of M. Ellissen I hare been able to construct this diagram, showing the quantity and the illuminating quality of the gas leaving the retorts at each portion of the four hours during which the operation is carried on. The cross, line slows the illuminating power of the gas at the different portions. 'The abscissæ give the time, and each line represents a quarter of an hour, and the ordinates give the illuminating power on the curve and the quantity on the other curve. The diagram shows at once that during the first twenty-five minutes or half-an-hour, the gas coming from the retorts has a very low illuminating power. They are chiefly occluded gases, consisting in a great measure of marsh gas. At the end of the first half-hour, the maximum illuminating porer is reached, and for about an hour and a half this high illuminating power is pretty well maintained. It then gradually diminishes, 
until at the end of the fourth hour it is less than half what it was at the earlier portion of the process.

Now, if the gas produced in the retort could be dirceted by a simple reversing valve into one main or the other the illuminating power would rise from $13 \frac{1}{2}$ to 18 candle-power, and produce thus all the advantages which the public now desire, a gas of increased illuminating power; whereas the heating gas constituting the other half, or even two-thirds, of the total produce, would be all the better qualified for heating purposes than the gas which is now sent into our mains. It is well known that marsh gas produces a higher calorific effect weight for weight than olefiant gas. Therefore, if the marsh gas, and the hydrogen, which has still higher calorific power, could be supplicd separately, we should get a bettcr illuminating gas, and a better heating gas. It may be objected that this would involve the laying down of a separate set of mains ; but in answer to that, I contend that in many towns we have already two sets of mains, because at one time or another we hare had opposing Gas Companies, each with their set of mains ; but eren if they do not exist, the question of the supply of heating gas is such a large onc, that the laying down of additional mains should not stand in the way. If gas heating is to comc into general use, we shall soon require perhaps three or four times the amount of gas which can possibly be supplied through the existing mains. If at the same time such a great advantage can be realised as the production of a gas of a higher illuminating power, and with it a heating gas at lower cost, we should have an advantage every way. But with regard to the question of cost, of course, the public would be willing to pay a somewhat increased price for a gas of 40 or 50 per cent. increased illuminating power, whilst the heating gas, on the other hand, would not requirc the same amount of care and expense in purifying as is necessary for illuminating gas.

Then for this Society the question has another important aspect. If by the supply of heating gas the total consumption can be vastly increased the bye-products would be increased in the same proportion, and these bye-products have now attained an importance only second to that of the value of the gas itself. Therefore, if by the carrying out of such a plan the total production of gas can bc very greatly incrcased, an impulse rould 
be given to chemical manufactures such as I need not specify to this Society.

'I'here are other questions which I should like to have touched upon, regarding certain applicntions of heating gas, and certain means of intensifying illuminating gas, so as to bring it more nearly up to the standard of brilliancy of its great rival, the electric light ; but this would, I fear, be travelling outside my subject, which was to bring betore, the Society the question of gas as a heating agent.

The President (Professor Roscoe): We have all listened with great interest to this suggestive communication which Dr. Siemens has made to the Society.

I feel sure that it is a subject in which every one takes an interest, and it has been treated in his masterly manner. I am sure it will not fail to please all the members who are present. The suggestions he makes are certainly bold enough, and let us hope they may receive that attention from corporations, and from the gas companies, which their importance and the originality of the suggestions warrant. I am sure all the members of the Society would wish to hear, if Dr. Siemens will consent to give us in a few words, the mode of application, which I see from some models he has here, he has already thought out. I think it does form a very important part of his communication-the method in which he proposes to use the gases of low illuminating power for heating purposes, and with your cousent, gentlemen, I would ask him to give us an account of the method which he proposes to employ before we begin the discussion.

Dr. Siemens: I did not wish to extend my subject too much, but willingly comply with the desire expressed by the President, and will describe shortly two applications, one of heating gas, and the other of illuminating gas, I have had occasion to make lately, and which have given very encouraging results. In using gaseous fuel in an ordinary tire-place, it becomes necessary to introduce some substance which shall become incandescent in order to radiate the heat into the apartment. We have substance of this description in use in the ordinary gas-grates, such as pumicestone, or otlier purely refractory material, but coke or anthracite uaturally suggests itself also as a suituble substance for taking up heat and radiating it out; it joins in the incaudescence, and 
through its own slow combustion aids the gas, which per se is at the present time at all events the more expensire fuel. If gas could be supplied at 18 . a thousand feet, it would no longer be more expensive than coal, and the time will come; I believe, when we shall have good heating gas supplied to us at that price. Wherever gas fuel is used, there ought to be some means of accumulating the effect of heat-some mode of regeneration, and the question occupied my mind in my leisure hours, how could the regenerative principle be applied to an ordinary open fire-grate? After some time the idea occurred to me, that in taking advantage of the conducting power for heat of some metals, I might be able to pick up heat at the back of the fire-grate, and bring it down to a system of surfaces below the fire-grate, in order there to communicate it to currents of air supporting combustion in front of the grate.

Such an action is carried out in the grate of which I have a model here, Plate 35. It has the ordinary fire-bars, to the bottommost one of which an inclined plate is attached, but instead of the ordinary horizontal grate, an angular casting of iron with ribs projecting from its lower surface supports the fuel. In front of this casting, and behind the lower grate-bar, a gas-pipe is fixed, having a limited number (from 8 to 12) of gas orifices, of about one-sixteenth of an inch diameter. The gas issuing from these openings towards the back of the pipe, gives rise to flames percolating through the coke or anthracite, or other similar substances which fill the grate. Each gas flame in percolating up through the coke produces very much the appearance, of an ordinary coal fire in its best condition, and the coke in front of the grate soon becomes incandescent, giving out a very considerable amount of radiant heat. When this point has been reached, the gas may be nearly altogether turned off, as the glow of heat will be maintained almost entirely by the hot air currents which by this time set in, and produce intense combustion in front of the grate. I have, I think, fourteen such grates in my office and house, including all the principal rooms, and I have succeeded gradually in winning the lady portion of the household over in favour of the improvement. At first they said it was a dead fire, and you could not poke it, but gradually even the housemaids, who at first thought it was an abomination, have come round. They see that it gives them less 
trouble; that in lighting it is very agreeable to turn the gas on or ofl' as needful, and to be able to keep up the fire for half a day withont touching it. Many friends when they have come into the room hare said, "What a magnificent fire."

The cost also I have been able to ascertain by this time. For the first quarter of the present year, in the five large grates, including the drawing-room, my own stndy, and the dining-room, where a fire is maintained nearly the whole day, the consumption of gas amounted per grate to 6,800 cubic feet, being of the value of one guinea, or of one ton of coal when at its cheapest in London. I am quite sure I have saved more than a ton of coal in each grate, even after debiting myself with the consumption of coke, which amounts to about one-third the consumption of coal. 'l'aking it all in all, it is a cheap fire, and certainly it is perfectly smokeless. I am glad to say that several of the leading gratebuilders have taken up the construction of this grate, and I believe at this present moment there are several hundreds of them in actual use.

I have adopted the same principle for intensifying the light of an ordinary argand gas-burner, Plate 35 . Through the centre of the burner a stem of copper projects, which is bulged out cup-like, at its upper extremity, and is connected at its lower extremity with a cylindrical box of copper, of high conductive power. The cylindrical vessel is perforated all over, and round it ten layers of copper-wire gauze are wound. The bottom also is closed by ten dises of wire gauze. The burner is mounted in the ordinary way with a glass chimney, but at the point of the flame the lulged portion of the rod, filled up witl fire-clay, gathers up leat, and conducts it downwards to the wire gauze, whilst the current of air is drawn in by the flame itself, and is heated in its transit through the wire gauze, to a temperature of from about $500^{\circ}$ to $700^{\circ}$ Fahr. By this simple arrangement the intensity of the gas flame can be very nearly doubled. In fact, according to one experiment, it was rather more than doubled, measured photometrically; and at the same time a flame of much whiter character is obtained.

The President: Do you remember what is the illuminating power of sucli a burner?

Dr. Siemens: In using ordinary gas we get from this burner 
about 25 candles. I should mention that my brother, Frederick Siemens, has worked independently on this same subject, and produced a burner which has been tried lately by some of the gas authorities, and has given an economy superior even to what I have stated. But the construction of my brother's burner is essentially different, the gas flame being drawn downward through heating apparatus.

The President: Like Faraday's ? Faraday arranged gas-burners of that kind.

$D r$. Siemens : I am not acquainted with Faraday's arrangement, but although my brother has obtained very excellent results, I think that the plan I described is certainly a more simple arrangement, and for ordinary applications commends itself on that account. I should have mentioned that, in order to prevent the oxidation of the copper conductor, and also in order to hare a reflecting surface, I have covered the copper conductor with a rery thin coating of enamel or platinum.

In the discussion of the Paper

\section{"ON THE COMBINATION SYSTEM OF STEAM} HEATING FOR TOWNS AND VILLAGES,"

By Capt. Douglas Galton,

The Chairman (Dr. C. W. Siemens), ${ }^{*}$ in proposing a rote of thanks to Capt. Douglas Galton, said this question was not a new one in the abstract, for heating by steam had been carried out to his knowledge forty years ago. But there was a novelty in the proposal to generate steam in large volumes, at high pressure, at certain centres; and to send it at that high pressure for miles under the streets. It was also perhaps a novelty to divide steam by regulating and stopping valres, and supply it to indiridual

* Excerpt Journal of the Society of Arts, Vol. XXX. 1881-1882, pp. 93-94. 
houses, so that it might bo used for the various purposes mentioned. The great question which presented itself ras, would such a pipe be trustrorthy ; could it be laid and maintained for this purpose without danger and without trouble. The paper described an elaborate method of insulating the pipe to prerent excessive loss by radiation, and from the figures giren it seemed to have been rery successful; but it appeared to him doubtfnl whether, in our streets, a pipe so swelled out by insulators, and $\operatorname{logs}$ of wood, and planks, could be laid. The space below our streets was already so fully occupied, that the establishment of such pipes would present very great difficulties. As Sir Frederick Bramwell remarked, if they wanted to bring heat into houses, there was another means already established, and in full operation; and from a little calculation he had just made, he found that a cubic foot of coal-gas brought with it about 750 heat units, which would be about the same amount as would be supplied by $3 \frac{3}{4}$ cubic feet of steam, at a pressure of 6 atmospheres. The question, therefore, would reduce itself to this, whether the one pipe or the other could be maintained with the least expense. He, for one, must adhere, for the present, to the opinion that it would be ensier to supply gas than steam. The paper spoke of various moles in which steam heat could be used, and the radiator was alluded to, but he did not think that apparatus was very happily named. A steam-heated surface in a room no doubt radiated heat, but not under the same conditions as a fire-place. Probably, ninetenths of the heat given off from that hot surface would be given off to circulating currents of air, which would pass again and again through this radiator, and a very small portion would pass by radiation into the room. The rays from such a low source of heat would hardly be felt, as radiant heat, at any sensible distance from the source. Now, he looked upon an open fire-place not only as a thing endeared to them by long habit, but he attributed to it very high sanitary qualities. The open fire-place communicated absolutely no heat to the air of the room, because air being a perfectly transparent medium, the rays of heat passed clean through it. It gave heat only by heating the walls, ceiling, and furniture; and here was the great advantage of the open fire. If the air in the room were hotter than the walls, condensation would take place on them, and mildew and fermentation of rarious kinds 
would be engendered; whereas if the air were cooler than the walls, the latter must be absolutely dry. That was the great advantage of the open fire, and it endeared it to them, though many did not know exactly where and how the comfort arose. The Americans were very ingenious, but he would not take their word with regard to the comfort of their rooms; when he was there he suffered severely from the closeness of the atmosphere of the dwellings, and when he travelled at night in the sleeping-cars he was obliged to get up four or five times and step out on the foot-board to get thoroughly cool. The only explanation he could offer was that the attendants were black men, whose standard seemed to be the interior of Africa. But although he could not agree absolutely with the proposal, yet the question of doing away with the smoke and nuisance which now resulted from open fire-places was so important, that any suggestion, backed by a considerable amount of experience was welcome; and Captain Galton well deserved their thanks for the able manner in which he had brought the subject forward.

In the discussion of the Paper

\section{"ON AIR REFRIGERATING MACHINERY AND - ITS APPIICATIONS,"}

By Joseph James Colieman, F.I.C., F.C.S., \&c.,

Dr. Siemens* said the question that had been brought before the Institution was one of considerable engineering and public importance, and he was glad to see it brought forward in such a clear and efficient manner. The subject was not one of recent date, but had occupied the minds of many men for a considerable number of years. The author had been good enough to mention his name in connection with a proposal which he had made twenty-

* Excerpt Minutes of Proceedings of the Institution of Civil Engineers, Vol. LXVIII. 1882, pp. 176-186. 
five years ago to the effect of superadding to the simple play of the two pumps-the compressing and the re-expanding pumpan interchanger of temperature. 'That suggestion, as it presented itself to him, was published only in a provisional specification of a patent which had never been specified finally; but more than that had been accomplished, and perhaps it might interest the members to know exactly what had been done. Dr. Gorrie, an American, had patented and brought to England a certain scheme, which had been taken up by Mr. Wollaston Blake and a few other gentlemen in London, who erected plant which was perfect in all its details. The engine had a 25 -inch cylinder and 5 feet stroke; the compressing and re-expanding pumps were made by James Watt \& Co., and had been erected somewhere in the north of London; but when it came to be tried it was impossible to get a depression of temperature exceeding $20^{\circ}$ Fahrenheit. That being the case, after several ineffectual attempts to improve the result, he was asked to examine the machine and report to the proprietors. He had lost sight of the report, but Mr. Wollaston Blake had sent him a copy with the drawings, and suggestions which he had made for improving the efficiency of the engine, and these would be appended to his remarks (see p. 195 et seq.) The report was of some interest, as it went rery fully into the principles underlying the question of refrigeration, and the causes of the non-realisation of those results which should have been effected. It seemed curions that, from the à priori examination and calculations which he made, he had come to the conclusion that the temperature could not be depressed more than $20^{\circ}$ by the machine, that when that reduction of temperature was reached the loss of effect would exactly balance the beneficial result; and the actual trial corroborated that statement. The author had, perhaps, hardly given him credit for the labour which he had spent upon the subject. He had not only devised the temperature interchangers, which was the most essential feature in the whole process, and withont which no efficient results could be obtained, but he had fully recognised the antagonistic effect of aqueous vapour in the air dealt with. 'The loss of effect "by throttled passages" he had given at 10.08 HP. That required some explanation. Dr. Gorrie evidently wished to avail himself of the expansive force of the compressed and cooled gases before they were discharged ag in ; but he did vol. I. 
not conceive that the whole effect of the machine depended upon the heat (utilized negatively) in that final expansion; and in order to be sure, as he thought, doling out as it were the compressed air to the expanding cylinder, he introduced a throttlevalve into the compressed and cooled air ; and instructions were given to wiredraw that valve as much as possible on the supposition that after all the safe plan of gaining refrigeration would be to expand air through the throttle-valve, that was through a contracted orifice. Dr. Siemens showed that contraction was the worst thing that could happen-that by merely expanding air without exacting work from it, no depression of temperature would ensue. By friction and useless agitation of the fluid, the loss was $3 \mathrm{HP}$, by condensation of vapour, 1.90 HP. That, of course, was a fruitful source of loss. If the air was compressed and then not sufficiently refrigerated, the vapour which it contained would, on re-expansion and final cooling in the expansive cylinder, not only condense, but be converted into ice. The vapour which went in as steam would come out as ice, and the whole of the latent heat taken up in that double process of conversion was entirely lost. That loss in some of the earlier attempts was fully equal to the whole useful effects that could be expected. But the greatest loss of all was incurred in allowing the cold air to leave the apparatus at the minimum temperature. Dr. Siemens suggested that a current exchanger should be supplied; that the cold air, after it had done its negative work, so to speak, should pass up through spaces surrounding a number of vertical tubes, and that the compressed air should pass through the tubes themselves in the opposite direction, and exchange temperatures. In that way $7 \frac{1}{4} \mathrm{HP}$. could be saved. It was shown in the report that a very economical result might be obtained by observing these precautions. Attached to the report were diagrams taken from the three cylinders, and a sketch showing the kind of apparatus which was then proposed, and which, he thought, in all material points was similar to the machine brought before the members by the author of the paper. There was, however, one point in which he still dissented from the knowledge and experience of the present day. He had stated in the report that as ice-making was really negative work, there could be no absolute limit to the effect to be produced by heat in that direction. It was true that 
grent men like Dr. Clausius, Sir William Thomson, and Dr. Joule, had established a certain equivalent, an eqnivalent which was perfectly true if the neat generated in the mechanical process of compression were treated as waste. But by means of the regenerator it was possible to recover, at any rate, a large proportion of the heat so produced at the minimum temperature attained in compressing the air. The ice produced was, therefore, only eridence of a transfer of heat from the fresh water to air or water rnised to a high temperature. And in this respect the operation of freezing differed very essentially from that of power-producing, when $a$ given amount of heat must absolutely disappear. The report might perhaps be interesting, as it gave the particulars of the views which he then entertained, and of the theoretical conclusion at which he arrived - a conclusion which, he had little doubt, though it was not now fully admitted, would be admitted before the subject was done with. The paper dealt with the question as it stood at the present day in a very able and proper manner, and the applications which would flow from a cheap and ready mode of reducing temperature to any desirable point could not be easily overrated.

Report on the Performance of Newton's Patext Refrigerating Apparatus, with Suggestions for Improving THE SANE.

Having examined your apparatus for the artificial production of ice on your premises at Camden Town on the 8th inst., and having examined carefully into the principles involred, and into the canses of its present lack of success, I have to report thereon as follows :-

"Description.-The apparatus consists of a horizontal condensing steam-engine of 32 inches diameter of cylinder, of 5 feet length of stroke, in excellent condition, by Messrs. James Watt and Co., which imparts motion to a crank-shaft with two additional cranks, which are connected with the pistons of two air cylinders of 4 feet 6 inches stroke, and of 21 inches and 19 inches diameter respectively. 'The piston rods of the air cylinders are carried horizontally throngh the cylinder bottoms, and are each of 
them attached to a second piston 4 inches in diameter, working in the barrels of double-acting pumps, which inject at each stroke their fluid contents into one extremity and the other of their respective air cylinders. The larger air cylinder (of 21 inches diameter) compresses atmospheric air into an upright receiver, where it is allowed to separate from the injected water, the water issuing from the bottom through a ball-tap, and the comparatively dry air proceeding through a pipe leading from the tap into a larger horizontal receiver or reservoir, which is provided with a mercurial pressure-gauge indicating $55 \mathrm{lbs}$. effective pressure per square inch when the apparatus is at work.

"A copper pipe (of 3 inches diameter, and provided with a stopvalve) leads from the receiver to the second air cylinder of 19 inches diameter, wherein the compressed and cooled air is allowed to expand again down to atmospheric pressure, and being mixed in the expanding cylinder with a spray of injected brine (by means of the second injection pump) it is expelled into a large cistern containing about 500 gallons of brine. The injected brine here subsides, and the expanded air escapes freely into the atmosphere. It appears from records of experiments made on the 28th and 29th of April, and on the 13th of May last, that the water injected into the compressing cylinder was raised uniformly from $2 \frac{1}{2}^{\circ}$ to $3^{\circ}$ Fahr. in temperature, whereas the brine in the cistern (500 gallons) fell gradually in temperature from $2^{\circ}$ to $3^{\circ}$ per hour at first, but diminishing gradually, as the temperature descended gradually below that of the atmosphere, until it reached the temperature of $18.5^{\circ}$, which appears to be the lowest degree ever attained. The speed of the main shaft was, during the first-named experiment, twenty revolutions per minute, when the injected water was raiscd $3^{\circ}$, and the brine in the cistern reduced only $2^{\circ}$ per hour at the commencement of operations, and during the second experiment the speed varied from fourteen to sixteen revolutions per minute, when the injection water was raised only $2 \frac{1}{2}^{\circ}$, whereas the brine in the cistern was lowered $3^{\circ}$ Fahr. per hour, until it descended correspondingly below atmospheric temperature. The water to be frozen had been filled into cans of copper and dipped into the brine, after the greatest depression of temperature had been attained, which caused a rise of temperature from $18.5^{\circ}$ to $22^{\circ}$ or $23^{\circ}$. 
"When I examined the apparatus I found the speed to average fifteen revolutions per minute, and the following are the mean pressures and lorse-power indicated upon the three cylinders, viz.:-

\section{MEAN HORSE \\ PRESSURE, POWER.}

'T'lie steam cylinder according to data obtained from Mr. Blake . $\quad 8.8 \mathrm{lbs} . \quad 32$ Compressing cylinder . . . . $26 \cdot 75, \quad 37 \cdot 85$ Expanding cylinder with injection $.18 \cdot 25,, \quad 21 \cdot 1$ Expanding cylinder without injection . . . . $14 \cdot 22, \quad 16 \cdot 5$

"Theory-Before entering into a consideration of the merits and defects of the apparatus in its actual condition, it will be of advantage to establish gencrally the principles whereon its effect depends. The heat which it is purposed to abstract from the water is communicated to expanding air, or, in the language of modern science, is converted into mechanical effect, and it can be proved philosophically that a caloric engine may be devised which derives its power from the latent heat of water in catusing it to congeal. In fact, the heat communicated by the injected solution to the expanding air is a source of power to the machine, which would yicld both effective power and ice but for the compressing cylinder, which in the arrangement described has to be worked by an engine. The power expended in compressing the air produces, however, its equivalent of heat, which heat would be sufficient, in a philosophically perfect arrangement, to reproduce the power necessarily expended by the engine, and a surplus of effective power proportionate to the heat abstracted from the water would be realised.

"This view of the principle involved in your machine is novel, I believe, and somewhat startling; but I am confident it will be acquiesced in by those conversant with the dynamic theory of heat, and although the conditions of the ideal machine will probably nerer be realised, it is important for our purpose to know that the production of ice does not necessarily involve an expenditure of porrer.

"Starting, then, with the admission that the heat produced in 
the compressing cylinder is practically unavoidable, the question arises,-how great is the necessary expenditure of engine-power, or, in other words, the difference between the power absorbed in the compressing cylinder and the power obtained in the expanding cylinder? The difference of power arises in consequence of the abstraction of heat from the compressed air, and is directly proportionate to the number of degrees of heat abstracted or generated in compression and afterwards lost in expansion. The quantity of heat lost in the expanding cylinder is, however, proportionate to the power produced in expansion, and is entirely independent of the limits of expansion which, as has just been shown, determines the degree or quality of cold produced. It follows that low rates of compression and expansion of the air are favourable to the production of cold with the least expenditure of engine-power, and I find by calculation that the power value of a given amount of heat abstracted (or cold produced) increases in the ratios of the squares of the number of degrees of reduction of temperature required.

"It is therefore highly advantageous to compress and expand large volumes of air to a moderate extent, consistent with the requisite energy of action of the machine.

"Adhering for" the present to the rate of compression obtained in working your apparatus, namely 55 lbs. per square inch effective pressure, the following result might be obtained if no incidental losses of any kind were obtained, and taking the speed at 15 rerolutions per minute.

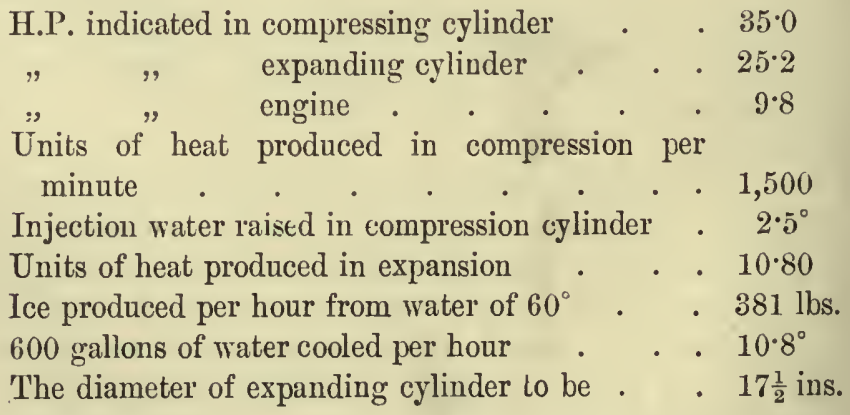

In comparing these results with those actually obtained, it will 
be observed the compressing cylinder did its work remarkably well, whereas the duty obtained from the expanding cylinder falls manifestly short of the results indicated by theory. It was necessary then to inquire carefully into the causes operating agrainst the performance of the expanding or freezing npparatus, and the following are the results of that enquiry :-

"1. The power developed in the expanding cylinder should be 25.2 H.P., whereas only 16.5 H.P. was actually indicated (when no solution was injected) owing to-

" $a$. A great loss of pressure between the cylinder and the receiver.

" $b$. Excessive expansion beneath the atmospheric line, which involves a loss of power on the return stroke.

"c. Imperfect adjustment of the admission valves.

"2. When solution was injected the indicated power rose to 21.15 H.P., or 6.93 H.P. higher than before, which excess of power may to a great extent be fictitious, being caused by the penetration of the solution into the indicator, but it proves that considerable force must be expended in forcing and agitating the solution, and all the power so spent will produce its equivalent of heat and must be deducted, besides the power lost in friction of piston, from the indicated 16.5 H.P. in estimating the refrigerating effect to be produced.

" 3 . The compressed air being cooled by injection of cold water, it will certainly be saturated with vapour, which vapour will be condensed and converted into ice during expansion, and produce a white fog pervading the expanded air.

"The quantity of vapour so condensed and congealed, supposing the temperature of the compressed air in the reservoir to be $68^{\circ}$ Fahrenheit, amounts to $0.06 \mathrm{lb}$. per minute, yielding about 1330 units of heat, which represents a loss $=1.9$ H.P.

" 4 . The expanded air leaves the apparatus at the temperature of the cistern, or say at $20^{\circ}$, which is $68^{\circ}-20^{\circ}=48^{\circ}$ below the temperature at which it entered the compressing cylinder, which represents a loss of effect $=312$ units $=7 \cdot 25$ H.P. at least.

" 5 . The cistern containing the solution, the expanding cylinder, the pump and the connecting pipes, present an aggregate surface 
of about 200 superficial feet of heat-absorbing surface $65^{\circ}-20^{\circ}=$ $45^{\circ}$ cooler than the surrounding atmosphere on an ordinary summer's day. The machinery especially being ill-protected, and of a dark colour, I estimate the loss of effect from this source at about 3.6 H.P., assuming that the covering prevents two-thirds of the radiation which would take place if the surface were unprotected. Assuming that the solution in the cylinder has been reduced to $20^{\circ}$ Fahrenheit, the total losses are as follows :-

", agitation and friction

$10 \cdot 08$

", condensation of vapour

, cold air leaving cistern .

,, absorption of heat from the atmusphere

\begin{tabular}{|c|c|c|c|c|}
\hline see & $g r$ & & & 10.08 \\
\hline , & , & 2 & say & $3 \cdot 00$ \\
\hline , & .. & 3 & & $1 \cdot 90$ \\
\hline ." & , & 4 & & $7 \cdot 25$ \\
\hline ". & "9 & 5 & & $3 \cdot 60$ \\
\hline & & & & $25 \cdot 83$ \\
\hline & & 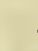 & & $25 \cdot 2$ \\
\hline
\end{tabular}

It follows that when the temperature of the cistern is reduced to $20^{\circ}$, the losses of cold produced equal or actually exceed the power of the apparatus of producing the same, which result is corroborated sufficiently well by the experience obtained, although it has been the result of independent calculation as regards paragraphs 1, 3 and 4, but only assumed as regards paragraphs 2 and 5, which, however, are the less important.

"The next question is whether, and to what extent, these different sources of loss can be obviated; and I will at once proceed to describe the fresh arrangements I propose for your adoption, and which are illustrated by the sketch shown on Plate 36.

"The proposed expanding and freezing apparatus consist of a cylinder of cast iron of 17 inches diameter, instead of 19 inches, and 4 feet 6 inches stroke. The pipes and valves connected with this cylinder to have a sectional area of not less than 15 square inches (instead of 7 square inches), and no stop-ralve to be introduced. The admission valves to cut off at one-fourth part of the stroke. The expanding cylinder is immersed in the cistern containing the freezing solution, and the expanded air issues from 
the cylinder into chambers $a, a$, forming the inner sides of the cistern, which clambers are perforated towards the bottom to allow the air to bribble through the solution. The cistern to be about 10 feet long, by 5 feet broad, by 2 feet 6 inches deep. The expanded air issues from the cistern into the atmosphere through a series of vertical tubes contained in a cylindrical air-tight chamber (C) through which the compressed air circulates on its way to the cylinder. The compressed air enters the annular chamber through a pipe $b$, and issues into the tube chamber $(C)$, through a number of holes in order to distribute it uniformly. It then descends gradually, and effects an interchange of temperature with the expanded air within the tubes, which latter issues at the top at nearly the temperature of the compressed air on entering, whereas the compressed air reaches the expanding cylinder nearly at the temperature of the cold cistern, or below the freezing point. The amular chamber $d$, serves to collect the cold compressed air at the bottom, and to supply it to the admission valves $e$ and $f$, by mealls of pipes not shown. The tube in the centre of the chamber $\mathrm{C}$ is of about 9 inches diameter, and contains a cylindrical ressel, $g$, filled with water, which enters the same from above, and is withdrawn at the bottom in a cooled condition to fill the former for the production of ice. The tube surface required is about 200 superficial feet.

"The advantages obtained by this exchange of temperatures are rery important. The compressed air is reduced below freezing point before it reaches the expanding cylinder, and the aqueous vapour it contained is at the same time condensed upon the tubes. Indeed the lower the temperature of the cistern descends, the more will the compressed air be reduced in temperature, and the cold produced will accumulate in intensity to any desired degree. Both injection pumps and one of the large air receivers will be dispensed with, for it makes no difference at what temperature the compressed air enters the exchanging apparatus. I should recommend, howerer, to retain the injection pump of the compressing cylinder till the efficacy of the new apparatus has been proved by experiment.

"This new apparatus would reduce the different losses of refrigerating effect in the following proportions, according to my estimation, viz. :- 
Probable loss expressed in H.P.

1. By throttled air passages . . . . say 2.5

2. ", agitation and friction of piston . . . . 1.5

3. " condensation of vapour in expanding cylinder . $0 \cdot 5$

4. ", cold air escaping . . . . . . . 2.5

5. ", heat absorbed by radiation . . . . $2 \cdot 0$

Gross power of expansion . . . . . . $25 \cdot 2$

Leaves effective refrigerating power . . . $16 \cdot 2$ which is capable of producing $258 \mathrm{lbs}$. of ice per hour.

"The production of ice may, however, be increased 25 per cent. in working the apparatus at the rate of twenty revolutions per minute, which the increased passages, \&c., admit of. It is hardly necessary to draw your attention to the gain of engine power which the proposed alterations are calculated to effect. In order to reduce the engine power required to its proper limit, I should propose considerable modifications in the general arrangement of the apparatus, consisting chiefly in attaching the three pistons upon one rod, in accelerating the speed of the pistons, and in compressing the air to only about $30 \mathrm{lbs}$. per square inch.

"Cost. An apparatus so constructed would be considerably less complicated and costly than our present apparatus. The expanding cylinder might be made of cast iron, the two injection pumps and one air reservoir would be suppressed, and in their stead the comparatively cheap exchanger of temperatures or reciprocator be added. The engine and moving gear would, moreover, be greatly diminished. The proposed alterations in the existing apparatus would not cost above $£ 200$ (I consider), taking into account the value of materials of the present expanding cylinder and injection pumps. London, 28th July, 1857.

To Wollaston Blake, Esq., F.R.S. \&c.

Signed, C. W. Siemens.

Mr. David Thomson said he had been much interested in the paper, the theoretical part of which he thought was quite correct. Dr. Siemens had thrown some doubt upon the formula as given in 
the paper, p. 147 ; Mr. Thomson had the honour of laying this formula before the Institution some years ago, when Mr. Kirk's paper on the Mechanical Production of Cold was read and discussed. At that time Dr. Siemens mentioned that the formula was due to Clausius, but Mr. Thomson had deduced it from Rankine's works.

Dr. Siemens observed that Clausius and Rankine worked independently and simultaneously at the same question, and arrived at the same conclusion. He did not doubt the correctness of the formula put forward by those eminent mathematicians and physicists, but he doubted its applicability under all conceivable circumstances to the question under consideration.

\section{In the discussion of the Paper}

\section{"ON THE THEORY OF THE GAS-ENGINE,"}

\section{By Dugatid CrerkK,}

Dr. Sievexs * said that one part of the paper dealt with matters regarding the mechanical arrangement of gas-engines, and the other with a theoretical question, that of the law of combustion. He would refer to the theoretical part first, because the author appeared to attach great importance to it, and as Dr. Siemens had from time to time given a great amount of consideration to the action of negative combustion or dissociation, it might be of some interest to the members to see how far his ricws fell in with those set forth by the author. It was well known that by combustion no unlimited degree of temperature could be attained. Thus, in a furnace worked at very high temperature the fuel was not completely burned when it came in contact with the oxygen of the heated or non-heated air. The moment a certain comparatively high temperature was reached

- Fxcerpt Minutes of Proceedings of the Institution of Civil Engineers, Vol. LXIX. Session 1881-82, pp. 251-4. 
the carbon refused to take up oxygen, or the hydrogen refused to take oxygen, and what had been called by Bunsen, and shortly after him, by St. Claire Deville, dissociation, arose. The point of dissociation was not a fixed one; partial dissociation came into play at a comparativcly low temperature, and went on increasing at a higher temperature in very much the same ratio as vapour density increased with temperature. Thus, if aqueous vapour were passed through a tube at a sufficient temperature the whole of the vapour would be dissociated, and the oxygen and the hydrogen would be separated. It was true if these gases were left to themselves they would, the moment the temperature lowered, again associate or burn; but if precautions were taken to cool them rapidly after they had attained that high temperature they would be found as a mixture of oxygen and hydrogen simply. The author had stated that the law which governed these actions was not well known and required research, but $\mathrm{Dr}$. Siemens would like to know whether he was aware of the researches of St. Claire Deville on the subject. It might be that the determinations of St. Claire Deville werc not quite correct, but in the meantime they might be regarded as being so. He found that at atmospheric pressure the point of half dissociation of aqueous vapour arose at a temperature of $2,800^{\circ}$ Centigrade, and that of complete dissociation at a much higher temperature. Taking that law as determined by the French philosopher, it did seem reasonable to suppose that when a mixture of hydrogen and oxygen, with or without a mixture of nitrogen, exploded, the point was reached beyond which the temperature did not increase, and, according to the author, that point was $1,500^{\circ}$ Centigrade. If such a temperature was reached in the working cylinder completc combustion would not take placc immediately, but only partial combustion would occur, which would go on as the temperature diminished by absorption into the cylinder or by expansion, and that combustion would be completed only in the course of the stroke. In that way the action which had been described with reference to the diagrams was reasonable enough. With regard to the mechanical arrangement of gas-engines, the author distinguished between three types. In the first, the mixture of gas and air drawn in at atmospheric pressure was exploded. In the second, with which the author had connected Dr. Siemens's name 
as chat of the first proposer, the combustion was produced gradually ; the gases were ignited as they flowed into the heating cylinder. In the third type, the gases, after being compressed and mixed, were admitted into the working cylinder, and suddenly exploded. With reference to the early engine which Dr. Siemens constructed iu 1860, Plate 37 , the author had stated that it combined other elements, which were entirely wanting in the gas-engines of the present day. The gas-engine of the present day, taking either of the three types, was, in his opinion, in the condition of the steam-engine at the time of Nercomen. The fuel was burnt in a cylinder which it was attempted to keep cold by passing water orer it, and it was easy to conceive that the heat so generated, was only partly utilised for maintaining the state of expansion of the heated gases, the cold sides of the cylinder taking a good half of it away at once, thus causing a great loss. Then there was another palpable loss in these engines. After expansion had taken place, after half the heat had been wasted in heating a cylinder which was intended to be kept cool in order to allow the piston to move, the gases were discharged at a temperature of $1,000^{\circ}$, or in the best types about $700^{\circ}$. That amount of heat, representing in one case one-half and in the other two-thirds of the total heat generated, was thrown away. This was heat which could be saved and made useful. Instead of commencing the combustion at a temperature of $60^{\circ}$, if the heat of the outgoing gases were transferred to the incoming gases, combustion might commence at a temperature of nearly $1,000^{\circ}$, and the result would be a very great economy. In the engine which he constructed in 1860 all those points were fully taken into account. The combustion of the gases took place in a cylinder without working a piston, and in a cylinder that could be maintained hot, and the gases, after haring complete expansive action, communicated their heat by means of a regenerator to the incoming gases before explosion took place. Although the engine was not worked with ordinary gas used for illumination, but by a cheaper kind made in a gas-producer, he then thought that a gas-engine constructed on that principle would prove to be the nearest approach to the theoretical limits which could never be exceeded, but which might exceed the limits of the steam-engine four or five fold. The engine promised to give very good results, but about the same time he began to give his 
attention to the production of intense heat in furnaces, and having to make his choice between the two subjects, he selected the furnace and the metallurgic process leading out of it; and that was why the engine had remained where it was for so long a time. But now the time had come when there was a greater demand for engines of a smaller kind to do their best in houses and in small works, and when marine engineers especially had become fully alive to the importance of more economical arrangements. He therefore looked upon the question before the Institution as one of first importance to engineers, and he hoped that it would be well discussed. 
ME'TALLURGY.

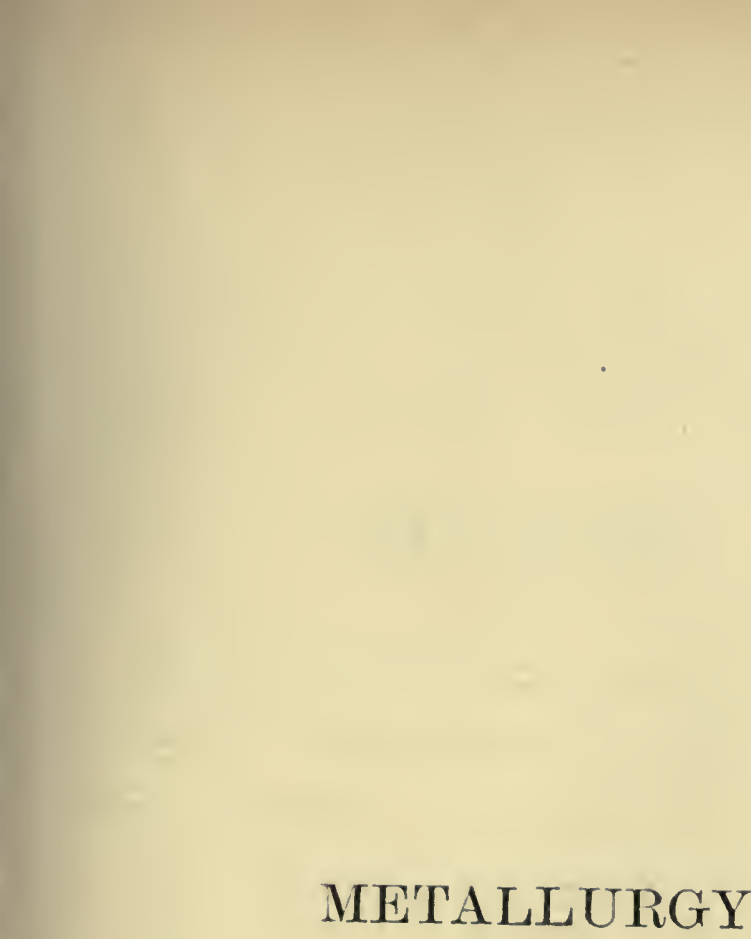





\section{METALLURGY.}

\section{"ON THE REGENERATIVE GAS FURNACE AS APPLIED TO THE MANUFACTURE OF CAST STEEL."}

[A Lecture delivered beforc the Fellows of the Chemical Socicty, May Tth, 1868.]

$$
\text { By C. W. Siemens, * F.R.S., Mem. Inst. C.E. }
$$

Is responding to your call to deliver a lecture to your Society, on a subject of applied chemistry, I feel that I have undertaken a very responsible task, a responsibility which is only balanced by the honorary distinction conferred by your call.

It is a hopeful sign of the adrancement of science that your Society puts itself into intellectual communication with engineers and others, whose mission it is to apply and practise that pure science cultivated within your body. It would be presumptuous on my part to reason with you upon a purely chemical subject, for although many years ago I had the advantage of receiving instruction fromWöller and Himly, I can in no way lay claim to be a chemist of the present day. Yet I ean safely affirm that of all the instructions I received in early life, there is none that has been a more useful guide to me in my professional pursuits.

The subject to which I wish to call your attention this erening is one that has occupied my mind for many years, and which I hope may engage your interest, involving as it does the generation of intense heat by means essentially differing from those in general use, and the application of that heat to the production of cast stcel in large masses, and directly from the ore or scrap metal.

- Excerpt Journal of the Chemical Society, 1868, pp. 279-310. 
The regenerative gas furnace, which is the joint production of my brother, Frederick Siemens, and myself, is already known through its application to nearly all those branches of industry in which furnace heat is employed. It was described by Faraday, to the members of the Royal Institution, in the last public lecture delirered by that great philosopher in 1862 , and has since been the subject of several publications. I need not, therefore, bring before you all the features of this mode of producing intense heat for the various purposes to which it has been applied, but shall confine myself to its description as applied only to the production of cast steel in large masses, which is the principal subject of my present communication.

NATURE of STEEL.-Before proceeding with this description I shall briefly remark upon the nature of steel and the methods by which it has hitherto been produced.

STEEL.-Dteel is generally regarded as a compound of iron and carbon, possessing the remarkable quality of becoming exceedingly hard when heated and suddenly cooled. The proportion of carbon determines the degree of hardness of which the steel is capable, or what is termed its temper.

The following table of the percentage of carbon in steel suited to different purposes, is prepared from analyses made in my laboratory by Mr. A. Willis, unless another authority is mentioned.

Description.

Wootz

Steel for flat files . . . .

" for turning tools. .

,. (Huntsman's) for cutters

.. for cutters .

, for chisels

Die steel (welding) . . .

Double shear steel . . . . . .

Welding steel . . . .

Quarry drills . . . . .

Mason's tools . . . . .

Ramrods

Common steel for stamping .
Carbon per cent.

Authority.

$1 \cdot 34$

$1 \cdot 2$

T. H. Henry

$1 \cdot 0$

$1 \cdot 0$

$\cdot 9$

.75

$\cdot 74$

7

$\cdot 68$

$\cdot 64$

$\cdot 6$

$\cdot 6$
A. Willis

,

,

,

,9

,

,

,

,

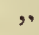

,9

, 
Description.
Steel for magnets containing

Carbon per cent. Authority. tungstell .

", $\quad$ hades . $\quad \cdot$.

Bessemer steel for rails . .

Homogeneous metal armour plates

Very mild steel from open hearth furnace

$\begin{array}{cc}\cdot 4 & \text { A. Willis } \\ \cdot 32 & , \\ \cdot 3 & , \\ .25 \text { to } \cdot 3 & \text { various } \\ \cdot 23 & \text { Percy } \\ \cdot 18 & \text { A. Willis } \\ \cdot 05 & \text { " } \\ \text { trace } & \text { Abel }\end{array}$

Sample before Spiegel was applied Bessemer iron (pure) .

A. Willis

A. Willis

Abel

Cast-steel containing less than 0.3 per cent. of carbon is no longer capable of being hardened, and should be classed rather as homogeneous or melted iron than as steel, while on the other hand an excess of carbon above 1.4 per cent. again deprives the metal of the quality of taking a temper, and it must then be regarded as approaching in character rather to white cast-iron.

It is, however, a contested question between chemists whether the presence of a third substance may not be necessary to produce steel. Frémy, in his celebrated controversy with M. Caron before the French Academy, maintains that nitrogen or cyanogen is a necessary constituent of steel ; the investigations of other chemists appear to confirm this theory, and the old Sheffield practice of mixing leather and other animal substances with the charcoal used in the converting furnace would also seem to corroborate it. M. Frémy's theory probably admits of great extension, and it may be that we should regard steel as a triple combination of iron with carbon and with another substance, taken from a series comprising nitrogen, sulphur, phosphorus, silicon, manganese, tungsten, titanium, tin, silver, and probably many other elementary bodies, each of which entering, in an exceedingly small proportion, into combination with the iron and carbon is capable of imparting to the steel distinctive physical properties.

Nitrogex. - Nitrogen has been found invariably in the stee produced by the ordinary processes.

Sulphur AND Phosphorus.-Sulphur and phosphorus are commonly regarded as the worst enemies to steel, the one rendering it "red-short," or incapable of being forged, and the other 
"cold-short," or brittle at ordinary temperatures. It is owing to the presence of these impurities in nearly all British irons, that the highest qualities of tool steel are still made entirely from Swedish or other charcoal-iron of high quality, produced from the purest ores. If phosphorus exists in steel in quantities exceeding 0.1 per cent., its presence is indicated on breaking the sample, by peculiarly bright and distinct faces of crystallisation on the fractured surface, but the steel admits of being forged and welded, and though somewhat brittle when cold, it is remarkable for hardness. It would, therefore, not be safe to maintain that phosphorus in small quantities is objectionable in steel under all circumstances. Steel containing above 0.2 per cent. of sulphur breaks under the hammer at a low red heat, and is, therefore, only applicable to the production of steel castings: for this purpose the presence of a small amount of sulphur is unquestionably a positive advantage, imparting increased fluidity to the molten metal and toughness to the casting when cold. This effect is so well understood in Sweden as regards cast-iron, that in casting ordnance sulphur is added to the metal.

Maxgaxese.-Manganese possesses the remarkable property of counteracting to a great extent the effect of sulphur (or redshortness) in steel. Its application for this purpose is due to Josiah Marshall Heath (1839), and must be classed among. the most important discoveries in modern times ; for it is only in consequence of the addition of manganese (in the form of oxide, mixed with carbon) to the steel melted in pots, that the Sheffield melters have been enabled to use English puddled iron for the commoner qualities of steel in place of the purer and more costly Swedish iron ; and again it is only in consequence of the addition (by Mushet) of manganese in the form of ferro-manganese or spiegeleisen to the liquid bath produced in the Bessemer converter that the better qualities of English pig-iron have been made available for the production of malleable Bessemer metal. It is distressing to think that the author of this invaluable discovery was deprived of the fruits of his labour by an unjust combination among the manufacturers chiefly benefited by him, who contested the validity of Heath's patents upon trivial grounds, relying for their success upon their financial power to crush his unquestionable claims. The specific chemical action of manganese has never 
been clearly demonstrated. It is certain that only traces of metallic manganese are ever found in cast-steel, and that the bulk of the manganese added is found combined with oxygen, silica, and alumina, in the form of slag ; yet it follows, from experiments which I have had occasion to make, that on adding manganese to a bath of liquid steel in an open reverberatory furnace, its beneficia. action ceases if the metal is retained in the furnace, exposed to the flame for any length of time, say more than half an hour. This is the caso quite independently of any sensible reduction in the proportion of carbon in the steel, and indicates that the effect of manganese is not due to the removal of sulphur or other substances with which it may enter into combination, but it is inseparable from the presence of metallic manganese in the steel, in however small a quantity. A further confirmation of the view, that the addition of manganese removes no impurity from the steel, is supplied by the fact, that if cast-steel from English iron which has been rendered perfectly malleable at a red-heat, by the addition of manganese, is re-melted without adding manganese, it becomes as red-short as ever. According to Parry, the presence of manganese in sensible quantity in steel tends to render it brittle when cold.

Silicon.-Silicon in small quantity seems to increase the hardness of steel without taking away from its malleability or toughness when cold, and the presence of a trace of silicon appears to have the singular effect of preventing that violent evolution of gas from fluid steel at the moment of solidification, which renders the ingot so frequently unsound. Steel containing above 0.5 per cent. of silicon breaks up under the hammer if heated above low redness.

Titavium, \&c.-The effect of titanium, tin, arsenic, silver, and other metals upon steel, is stated to produce increased hardness, but I have not myself made any experiments upon this subject, nor been able to find very reliable observations of othérs.

TUNGSTEN has a very remarkable effect upon steel, first observed by. Dr. Werner Siemens, in 1853, in increasing its power of retaining magnetism when hardened. Being specially interested in this question, I have determined, by careful experiments, the extent of the increase; and the practical result is, that whereas a horse-shoe magnet of ordinary steel, weighing 2 lbs., is con- 
sidered of good quality when it bears seven times its own weight, and the famous Haarlein magnet of the same weight, supports about 13 times its weight, I am now able to produce a similar horse-shoe magnet carrying 20 times its weight, suspended from its armature.

The chief difficulty besetting experiments on the effects of these various admixtures upon the quality of steel, consists in the unavoidable presence of other substances in variable proportions; but the effects of these other substances could be eliminated if the experiments were accompanied by exhaustive analyses, and it is impossible to over-estimate the advantages that would result from such a course.

Processes.-Dr. Percy, in his truly invaluable metallurgical work, has made us acquainted with the various known processes for obtaining steel which have been followed from the earliest times; but no method of producing steel can be considered admissible at the present day which does not pass the metal through the condition of entire liquefaction, for it is only by fusion that foreign admixtures can be thoroughly separated, and that flaws and fissures can be avoided; inasmuch, horrever, as the steel obtained by them may be subsequently fused, I shall briefly refer to them. The principal processes of this class are :-

1. The direct process of making steel, or steely iron, from the ore in the Catalan forge, by employing a large excess of charcoal. The steel is obtained without fusion in the form of a ball of spongy metal, and'is drawn out into bars.

2. The cementation process, in which bar-iron is converted into steel by prolonged contact at a comparatively low temperature either with liquid cast-iron, as formerly practised in Styria and elsewhere, ${ }^{*}$ or with crushed charcoal-a method extensively employed in Sheffield at the present day for the manufacture of steel for railway and carriage springs, and for the production of bar-steel from Swedish iron, which, when subsequently melted in pots, makes the finest quality of steel for tools and cutlery.

3. The decarburization process, in which steel is made from cust-iron by the removal of part of the carbon in the puddling 
furuace, or by the partial application of any of the older methods of decarburetting cast iron in an open hearth in direct contact with the fuel. A modified form of the decarburization process has been recently introduced to some extent by Messis. Heaton and Hargreaves. They remove the carbon of the pig-iron by the action of oxydizing salts, principally nitrate of soda, and either fuse the crude metal obtained, producing cast steel, or work it up into blooms under the hammer.

The Bessemer process, now so well known, is also a method of producing steel by the decarbonization of cast iron: but it presents a vast advantage over those just named, in the fact that the steel is obtained in the liquid state, and may be cast, free from flaws, into homogeneous ingots of any size. As Bessemer steel is produced much more cheaply than the cast steel obtained by any other process yet extensively in use, its introduction has opened out a vast field for the application of steel where iron alone could formerly be thought of. Thus many parts of steam and other machinery, railway plant, boiler-plates, and even rails, are now made of Bessemer steel, and are found to be cheaper in the end when made of that material rather than when made of iron, although their absolute cost is fully twice as great.

CAST STEEL.-The remaining methods of producing cast steel, are those in which it is obtained by the fusion either of steel already made by other processes, or of its component materials, iron or iron-ore, on the one hand, and carbon, either as charcoal or already combined in the form of cast iron, on the other.

The oldest known steel of high quality, the Indian Wootz, is obtained by the fusion of compact iron and carbonaceous substances in small crucibles, but it is only in the course of the last century that the manufacture of cast-steel was first introduced in Europe.

Réaumur states, in his work on the conversion of forged iron into steel, published in 1722 , that he had succeded in producing steel by the fusion together of cast and wrought iron in a common forge; but steel melting was first practically carried out in the latter half of the century by Huntsman, of Sheffield; the process he employed, consisting in "the fusion in closed crucibles of steel already madle by cementation in charcoal," is still universally in use for the production of the finest qualities of steel for tools and 
cutlery. The Hindoo process has, however, been revived within the last twenty years, by Heath, Price and Nicholson, Gentle Brown, Attwood, and others, and large quantities of steel are now made in Sheffield and elsewhere, by the fusion of puddled iron or puddled steel with charcoal, or with pure pig-iron (Acadian or Spiegeleisen), in such proportions as to form steel of the required quality. The Uchatius process is somewhat similar to these in principle; it consists in effecting the partial decarburization of granulated pig-iron by fusing it in contact with iron-ore, but the temper obtained is said to be irregular, and, together with the process just mentioned, it labours under the disadvantage of involving the expensive operation of fusion in pots.

Open Hearth.--Some method of effecting the fusion of steel more cheaply than in crucibles, as well as in larger masses, has long been a desideratum. Heath, the discoverer of the beneficial action of manganese, was the first (in 1845) to conceive that caststeel might be produced in large quantities by fusing wrought and cast-iron together upon the open hearth of a reverberatory furnace. The modus operandi he proposed, consisted in melting pig-metal in a cupola, and running it into the heated furnace. The wrought-iron was introduced into another part of the furnace, forming a bank between the bath of fluid metal and the chimney, to be there heated by the waste heat of the flame, previously to its being pushed forward into the liquid in order to be dissolved. Fearing the effect of the ashes from a common fire-place, Heath proposed to heat his furnace by jets of gas, and there is every probability that his experiments would have been crowned with success, if he had possessed the means of imparting to his flame the intensity of heat and, at the same time, the absence of cutting draught, which are essentially necessary. Since the date of Heath's patent, the fusion of steel in an open furnace has formed the subject of an extensive series of experiments, by Sudre, in France. The experiments of M. Sudre were made at the Montataire Iron Works, at the expense of the Emperor of the Frencl, and were superintended, on his behalf, by three members of the French Institute; MM. Sainte-Claire Deville, Treuille de Beaulieu, Colonel of Artillery, and Caron, Captain of Artillery, who have made an able report on the subject, showing that it is just possible to raise the heat of an ordinary furnace by means of a 
fan-blast, sufliciently to effect the fusion of tool-steel upon the open hearth in protecting the metal by a layer of glass, but that the rapid destruction of the furnace, the cost of fuel, and other difficnlties attending the operation, were such as to render the process, commercially, of doubtful value.

Regenerative Gas Furnacb.-The regenerative gas furnace is so manifestly suitable for the operation of melting steel, both in pots and on the open hearth, that iny attention was directed from the first towards this object. The early experinents conducted by iny brother and myself at Sheffield failed, however, partly on account of certain irregularities, arising from defects in the furnace which hare since been removed, but chiefly in consequence of the want of determination on the part of the manufacturers and their workmen to persevere with us to the attainment of the proposed results.

ATTw00D.-In 1862, Mr. Charles Attwood took a licence to apply the regenerative gas furnace to the melting of steel upon the open hearth in connection with certain chemical processes or mixtures of his own. I supplied the design of a furnace which answcred the purpose, except that the quality of steel produced was not such as Mr. Attwood desired. This circumstance decided him to carry out his process in closed pots heated in the same furnace.

Le Chatelier.-In 1863, my friend, M. Le Chatelier, Ingénieur en Chef des Mines, elaborated a process for producing steel from cast-iron by puddling, and melting the hot puddled blooms in a bath of cast-iron prepared in a regenerative gas furnace, upon a bed of bauxite of the following composition :-

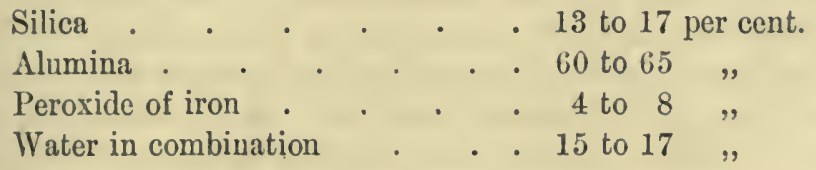

This material presents the adrantage of being exceedingly infusible and of containing no materials that could impart hurtful ingredients to the steel. A furnace of great heating power was constructed by Messrs. Boigue, Rambour and Co., at their works near Montluçon, in France, under my superintendence, and would 
certainly have accomplished the desired object if the company had displayed the least determination to succeed. The furnace-bottom of bauxite did not succeed, as it was not solidified by the heat, and rose to the surface of the liquid bath,-but this defect was soon rectified by the substitution of a white sand bottom. Through some carelessness, however, the covering arch of the furnace was damaged by excess of heat ; and this slight accident, which proved nothing except an ample sufficiency of heating power, sufficed to deter the company from pressing on to the attainment of that success which was so nearly within their reach. In the meantime I had granted a licence to Messis. Emile and Pierre Martin, of the Sireuil Works, to melt steel, both in pots and on the open hearth, and a furnace was erected by them in 1864 which was chiefly intended for a heating furnace, but was at the same time constructed of such materials (Dinas brick) and in such a form as to be also applicable for melting steel.

With this furnace, which was really less suitable than those previously erected, MM. Martin have succeeded in producing cast-steel of good quality and of various tempers, and their produce was awarded a gold medal at the great French Exhibition of last year. MM. Martin have since patented various arrangements of their own, such as the employment of particular fluxes to cover the surface of the molten metal, the application of a separate furnace for heating the iron before charging it into the melting furnace, and the employment of particular brands of cast and wrought-iron, which may be useful under special circumstances but which form no essential part of the general solution of the problem.

Having been so often disappointed by the indifference of manufacturers and the antagonism of their workmen, I determined, in 1865 , to erect experimental or "Sample Steel Works" of my own at Birmingham, for the purpose of maturing the details of these processes, before inviting manufacturers to adopt them. The first furnace erected at these works, is one for melting the higher qualities of steel in closed pots, and contains 16 pots of the usual capacity. The second, erected in 1867, is an open bath furnace, capable of melting a charge of 24 cwt. of steel every 6 hours. Although these works have been carried on under every disadvantage, inasmuch as I had to educate a set of men 
capable of managing steel furnaces, the result has been most beneficial, in affording me an opportunity of working out the details of processes for producing cast-steel from scrap-iron of ordinary quality and also directly from the ore, and in proving these results to others.

I shall now proceed to describe the construction and working of the regenerative gas furnaces (similar to those at Birmingham) which are now at work, or in course of erection, in this country and abroad for the production of cast-steel, both by the old method of fusion in pots, and by the new system of making cast-steel on a large scale and on an open furnace bed, from scrap-iron and from the ore.

The regenerative gas furnace consists of two essential parts :

The gas producer, in which the coal or other fuel used is converted into a combustible gas; and

The furnace, with its "regenerators" or chambers for storing the waste heat of the flame, and giving it up to the in-coming air and gas.

Any combustible gas might be burned in the regenerative furnace; I have used ordinary lighting gas very successfully on a small laboratory scale, but it is far too costly to be employed in larger furnaces, and the only gas generally available is that generated by the complete volatilisation of coal, wood, or other fuel, with admission of air in a special "gas producer." Any descrip. tion of carbonaceous matter may be worked in a suitable gas producer, and will afford gas sufficiently good for the supply of eren those furnaces in which the highest heat is required. Coal is the fuel chiefly used for gas furnaces in England; small coke has been employed in some cases, as in gas-works, where it is to be had at a cheap rate; wood is used in France, Bohemia, and Spain ; sawdust in Sweden, furnishing gas for welding and other high-heat furnaces; lignite in various parts of Germany ; and peat in Italy and elsewhere; this last being applicable with the greatest relative advantage.

Plate 38 represents a gas producer suitable for burning noncaking slack.

In form it is a rectangular fire-brick chamber, one side of which, $\mathrm{B}$, is inclined at an angle of from $45^{\circ}$ to $60^{\circ}$, and is provided with a grate, $\mathrm{C}$, at its foot. The fuel is filled in at the top 
of the incline at A, and falls in a thick bed upon the grate. Air is admitted at the grate, and as it rises slowly through the ignited mass, the carbonic acid, first formed by the combination of the oxygen with the carbon of the fuel, takes up an additional equivalent of carbon, forming carbonic oxide, which diluted by the inert nitrogen of the air and by a little unreduced carbonic acid, and mixed with the gases and vapours distilled from the raw fuel during its gradual descent towards the grate, is led off by the gas flue to the furnace. The ashes and clinkers that accumulate on the grate are removed at intervals of one or two days.

The composition of the gas varies with the nature of the fuel used, and the management of the gas producer. That of the gas from the producers at the Plate Glass Works, St. Gobain, France, burning a mixture of $\frac{3}{4}$ caking coal and $\frac{1}{4}$ non-caking coal, is as follows, by an analysis dated July, 1865 :-

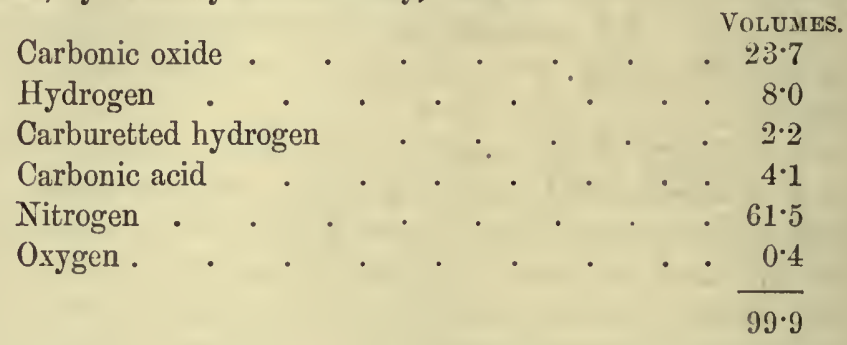

The trace of oxygen present is no doubt due to carelessness in collecting the gas, or to the leakage of air into the flue, and allowing for this, the corrected analysis will stand as under :-

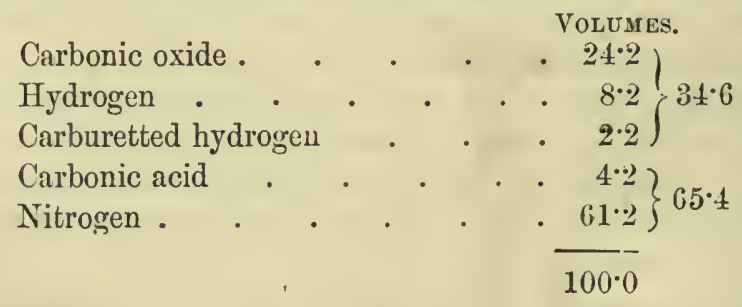

Only the first three of these constituents, say 35 per cent. of the whole, are of any use as fuel, the nitrogen and carbonic acid present only diluting the gas. It is the presence of this large proportion of inert gases, which must be heated to the full 
temperature of the flame, that renders it so difficult to maintain a high heat by gas of this description burned in tle ordinary way. In using such gas in a regenerative furnace the presence of so large an amount of nitrogen is not objectionable, as the heat it carries off is given up again to the air and gas coming in.

The gas as it passes off from the fuel contains also more or less aqneons vapour, which is got rid of by cooling it, witl some tar and other impurities, and a small quantity of suspended soot and dust.

Any air drawing in unburned through a hole in the mass of fuel, reduces the value of the gas, by burning the carbonic oxide again to carbonic acid. To prevent the indraught of air in this way at the side of the grate, I have found it very advantageous to set the side walls of the gas producer back, forming a broad step, about nine or ten inches above the grate; any air creeping up along the wall is thus thrown into the mass of fuel and completely burned. The effect of this feature in the form of the producer on the quality of the gas has been very striking.

Three-tenths of the total heat of combustion of solid carbon are evolved in burning it to carbonic oxide ; but in the gas producer, a small portion only of this heat is really lost, because it is in a great measure taken up and utilized in distilling the tar and hydrocarbon gases from the raw fuel ; and it may be still further economised, especially in burning a fuel, such as coke or anthracite, which contains little or no volatile matter, by introducing a regulated supply of steam with the air entering at the grate. This is effected very simply by keeping the ash-pit always wet. The steam is decomposed by the ignited coke, and its constituents, hydrogen and oxygen, are rearranged as a mixture of hydrogen and carbonic oxide, with a small variable proportion of carbonic acid. Each cubic foot of steam produces nearly two cubic feet of the mixed gases, which, being free from nitrogen have great heating power and form a valuable addition to the gas. The proportion of steam that can be advantageously introduced into the gas producer, is, however, limited, as it tends to cool the fire, and if this is at too low a heat, much carbonic acid is produced instead of carbonic oxide, causing waste of fuel.

From the high temperature of the gas, as it rises from the fuel $\left(1,000^{\circ} \mathrm{F}\right.$. to $1,300^{\circ} \mathrm{F}$.), and from its comparatively low specific gravity, it is considerably lighter than atmospheric air, and 
ascends into the upper part of the producer with a slight outward pressure. It is necessary to maintain this pressure through the whole length of the gas flue, in order to ensure a free supply of gas to the furnaces, and to prevent its deterioration in the flue, through the indraught of air at crevices in the brickwork. The slight loss of gas by leakage, which results from a pressure in the flue, is of no moment, as it ceases entirely in the course of a day or two, when the crevices become closed by tar and soot.

Where the furnace stands so much higher than the gas producer, that the flue may be made to rise considerably, the required plenum of pressure is at once obtained; but more frequently the furnaces and gas producers are placed nearly on the same level, and some special arrangement is necessary to maintain the pressure in the flue. The most simple contrivance for this purpose is the "elevated cooling tube." The hot gas is carried up by a brick stack to a height of eight or ten feet above the top of the gas producer, and is led through a horizontal sheet-iron cooling tube, $J$, of not less than 60 square feet of surface per gas producer, from which it passes down either directly to the furnace, or into an underground brick flue.

The gas rising from the producer at a temperature of about $1100^{\circ} \mathrm{F}$., is cooled as it passes along the overhead tube, and the descending column is consequently denser and heavier than the ascending column of the same length, and continually over-balances it. The system forms, in fact, a syphon in which the two limbs are of equal length, but the one is filled with a heavier fluid than the other. The height of cooling tube required to produce as great a pressure in the flue as would be obtained by placing the gas producers, say ten feet deeper in the ground, may be readily calculated. The temperature of the gas as it rises from the producers has been taken as $1,100^{\circ} \mathrm{F}$., and we may assume that it is cooled in the overhead tube to $100^{\circ} \mathrm{F}$., an extent of cooling very easily attained. The calculated specific gravity, referred to hydrogen, of the gas of which I have quoted the analysis, being $13 \cdot 14$, we obtain the following data :-

Weight of the gas per cube foot at $1,100^{\circ} \mathrm{F}$.

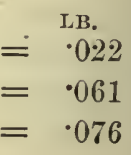

Weight of atmospheric air per cube foot at $60^{\circ} \mathrm{F}$ = $\quad 076$ 
and from these we have, on the one hand, the increase of pressure per foot of height, in a flue rising directly from the gas producer, $=076-0.22=\cdot 054 \mathrm{lb}$. per square foot; and on the other hand, the excess of pressure at the foot of the downtake from the cooling tube, over that at the same level in the flue, leading up from the gas producer (for each foot in height of the cooling tube $)=\cdot 061-\cdot 022=\cdot 039 \mathrm{lb}$. per square foot. The height of the cooling tube above the level of the flue that will be sufficient to produce the required pressure, equal to 10 feet of heated gas column, is therefore $\frac{\cdot 054}{.039} \cdot 10 \mathrm{ft}$. $=13^{\prime} 10^{\prime \prime}$, or say 14 feet.

This method of obtaining a pressure in the gas-flue by cooling the gas, has been objected to as throwing away heat that might be cmployed to more advantage in the furnace, but this is not the case, because the action of a regenerator is such, that the initial temperature of the gases to be heated has no effect on the final temperature, and only renders the cooling of the hotter fluid more or less complete. The only result, therefore, of working the furnace with gas of high temperature is to increase the heat of the waste gases passing off by the chimncy flue. The complete cooling of the gas results, on the other hand, in the great adrantage of condensing the steam that it always carries with it from the gas producer ; and in the case of iron and steel furnaces, in burning wet fuel, it is absolutely necessary to cool the gas very thoroughly, in order to get rid of the large amount of steam that it contains which, if allowed to pass on to the furnace would oxidise the metal.

There is, undoubtedly, a certain waste of heat, which might be utilized by surrounding the cooling tube with a boiler, or by otherwise cconomising the heat it gives off, as, for instance, in drying the fuel ; but the saving to be effected is not very great, for as 100 volumes of the gas require for combustion about 130 volumes of air, including 20 per cent. above that theoretically required, the heat given off in cooling the gas $1,000^{\circ}$ is no more than would be lost in discharging the products of the complete combustion of the fuel, at a temperature $435^{\circ}$ in excess of the actual temperature of $200^{\circ}$, and this loss is greatly diminished if a richer gas is obtained.

In crecting a number of gas producers and furnaces, I generally 
prefer to group the producers together, leading the gas from all into one main flue, from which the several furnaces draw their supplies. The advantages of this are saving of labour and convenience of management, from the gas producers being all close together, and greater regularity in working, as the furnaces are seldom all shut off at once; nor is it likely that all will require at the same time an exceptional amount of gas.

From the fact that the gas producers may be at any distance from the furnaces that they supply, if they are only at a lower level, it would be perfectly practicable to erect them in the very coal mine itself, burning the slack and waste coal in situ (in place of leaving it in the workings as is now often done), and distributing the gas by culverts to the works in the neighbourhood, instead of carrying the coal to the different works and establishing special gas producers at each. In rising to the mouth of the pit, the gas would acquire sufficient pressure to send it through several miles of culvert.

In the regenerative furnace the gas and air employed are separately heated by the waste heat of the flame, by means of what are termed "regenerators," placed beneath the furnace. These are four chambers, filled with fire-bricks, stacked loosely together, so as to expose as much surface as possible ; the waste gases from the flame are drawn down through two of the regenerators, and heating the upper rows of bricks to a temperature little short of that in the furnace itself, pass successively over cooler and cooler surfaces and escape, at length, to the chimney flue nearly cold. The current of hot gases is continued down through these two regenerators until a considerable depth of brickwork, near the top, is uniformly heated to a temperature nearly equal to that of the entering gas, the heat of the lower portion decreasing gradually downwards, at a rate depending on the velocity of the current, and the size and arrangement of the bricks. The direction of the draught is then reversed; the current of flame or hot waste gases is employed to heat up the second pair of regenerators ; and the gas and air entering the furnace are passed in the opposite direction through the first pair, and coming into contact, in the first instance, with the cooler brickwork below, are gradually heated as they ascend, until, at some distance from the top, they attain a temperature nearly equal to the initial heat of the waste gases, 
and, passing up into the furnace, meet and at once ignite, producing a strong flame, which, after passing through the heatingchamber, is drawn down through the second pair of regenerators to the climney-flue. The temperature attained by the ascending gas and air remains nearly constant, until the uppermost courses of the regenerator brickwork begin sensibly to cool ; but by this time the other two regenerators are sufficiently heated, and the draught is again reversed, the stream of waste gases being turned down through the first pair of regenerators, re-heating them in turn, and the gas and air which enter the furnace being passed up the second.

By thus reversing the direction of the draught at regular intervals, nearly all the heat is retained in the furnace that would otherwise be carried off by the products of combustion, the temperature in the chimney-flue rarely exceeding $300^{\circ} \mathrm{Fahr}$, whatever may be the heat in the furnace. The proportion of heat carried off in an ordinary furnace by the products of combustion is generally far greater than that which can be utilized, as all the heat of the flame below the temperature of the work to be heated is absolutely lost. The economy of fuel effected in the regenerative gas furnace, by removing this source of loss, and making all the heat of the waste gases, however low its intensity, contribute to raise the temperature of the flame, amounts in average practice to fully 50 per cent. on the quantity used in an ordinary furnace, and the saving is greater the higher the heat at which the furnace is worked. In addition to this economy in the amount of fuel used, a much cheaper quality may generally be burned in the gas producer than could be used in a furnace working at the same heat, and in which the fuel is barned directly upon the grate in the ordinary way.

When the heat of the furnace is not abstracted continually by cold materials charged into it, the temperature necessarily increases after each reversal, as only a very small fraction of the heat generated is carried off by the waste gases. The gas and air, in rising through the regenerators, are heated to a temperature nearly equal to that at which the flame liad been passing down, and when they meet and burn in the furnace the heat of combustion is added to that carried up from the regenerators, and the flame is necessarily hotter than before, and raises the second pair of regenerators to 
a higher heat. On again reversing, this higher heat is communicated to the gas and air passing in, and a still hotter flame is the result.

The temperature that may be attained in this way by the gradual accumulation of heat in the furnace and in the upper part of the regenerators appears to be quite unlimited, and the reat at which a suitably designed furnace can be worked is limited in practice only by the difficulty of finding a material sufficiently refractory of which it can be built.

Welsh Dinas brick, consisting of nearly pure silica, ${ }^{*}$ is the only material, of those practically available on a large scale, that I have found to resist the intense heat at which steel-melting furnaces are worked; but though it withstands perfectly the temperature required for the fusion of the mildest steel, even this is melted easily if the furnace is pushed to a still higher heat.

As the gas flame is quite free from the suspended dust which is always carried over from the fuel by the keen draught of an ordinary furnace, the brickwork exposed to it is not fluxed on the surface and gradually cut away, but fails, if at all, only from absolute softening and fusion throughout its mass. A Stourbridge brick, for example, exposed for a few hours to the heat of the steel-melting furnace, remains quite sharp on the edges, and is little altered even in colour; but it is so thoroughly softened by the intense heat, that on attempting to take it out, the tongs press into it and almost meet, and it is often pulled in two, the half-fused material drawing out in long strings. It results from this perfect purity of the flame, that where the heat is not sufficient to effect the absolute fusion of the bricks employed, the length of time is almost unlimited during which a gas furnace will work without repairs.

* Analysis of Dinas "clay" from Pont-Neath, Vaughan, Vale of Neath(Percy's Metallurgy, Vol. I. p. 237).

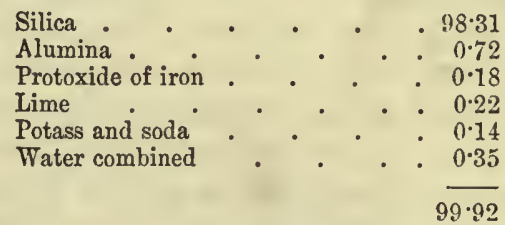

The "clay" is mixed with 1 per cen". of lime in making the bricks. 
Another advantage in employing the fuel in the manageable form of gas is that the rate of combustion may be regulated at plensure to produce an active heating flame of any length, from little more than two feet, as in the pot steel-melting furnaces, to thirty feet in the largest furnaces for the fusion of plate glass ; and the most intense heat may be thrown exactly upon the charge, the ends of the furnace and the apertures through which the gas and air are introduced being actually protected from the heat by the currents of unburned and comparatively cool gases flowing through them, and only mixing and burning at the very point at which the heat is required, and where it is taken up at once by the materials to be fused or heated. This is of especial importance in the case of those furnaces in which a very intense heat is employed.

The amount of brickwork required in the regenerators to absorb the waste heat of a given furnace is a matter of simple calculation. The products of the complete combustion of one pound of coal have a capacity for heat equal to that of nearly 17 pounds of firebrick," and (in reversing every hour) 17 pounds of regenerator

* Taking the analysis by Vaux of the celebrated ten-yard coal of South Staffordshire (Watts' Dictionary of Chemistry, i. 1081), the exact calculation is as follows :-

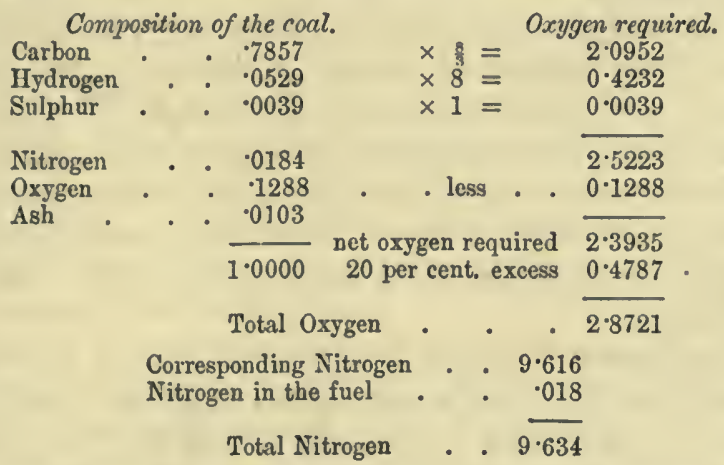

\begin{tabular}{lccc}
\multicolumn{1}{c}{$\begin{array}{c}\text { Gases produced from } 1 \text { llb. } \\
\text { of coal. }\end{array}$} & Specific heats. & $\begin{array}{c}\text { Equivalent weight } \\
\text { of water. }\end{array}$ \\
Carbonic acid & $=2.881$ & $\cdot 217$ & $\cdot 625$ \\
Water (Steam) & $=0.476$ & $\cdot 480$ & $\cdot 228$ \\
Sulphurous acid & $=0.004$ & $\cdot 154$ & $\cdot 001$ \\
Oxygen in excess & $=0.479$ & $\cdot 218$ & $\cdot 104$ \\
Nitrogen & $=9.634$ & $\cdot 244$ & $2 \cdot 350$
\end{tabular}

Total equivalent weight of water . . . $\overline{3 \cdot 308}$ 
brickwork at each end of the furnace per pound of coal burned in the gas-producer per hour would be theoretically sufficient to absorb the waste heat, if the whole mass of the regenerator were uniformly heated at each reversal to the full temperature of the flame, and then completely cooled by the gases coming in; but in practice by far the larger part of the depth of regenerator chequer-work is required to effect the gradual cooling of the products of combustion, and only a small portion near the top, perhaps a fourth of the whole mass, is heated uniformly to the full temperature of the flame; the heat of the lower portion decreasing gradually downwards nearly to the bottom. Three or four times as much brickwork is thus required in the regenerators, as is equal in capacity for heat to the products of combustion.

The best size and arrangement of the bricks is determined by the consideration of the extent of opening required between them to give a free passage to the air and gas, and by the rule, deduced from my experiments on the action of regenerators in 1851-2,* that a surface of six square feet is necessary in the regenerator to take up the heat of the products of combustion of one pound of coal in an hour.

By placing the regenerators vertically and heating them from the top, the heating and cooling actions are made much more uniform throughout than when the draught is in any other direction, as the hot descending current on the one hand passes down most freely through the coolest part of the mass, while the ascending current of air or gas to be heated, rises chiefly through that part which happens to be hottest, and cools it to an equality with the rest.

The regenerators should be always at a lower level than the heating chamber; as the gas and air are then forced into the furnace by the draught of the heated regenerators, and it may be worked to its full power, either with an outward pressure in the heating chamber, so that the flame blows out on opening the doors or with the pressure in the chamber just balanced, the flame sometimes blowing out a little, and sometimes drawing in. The outward pressure of the flame prevents that chilling of the furnace,

* Proceedings of the Institution of Civil Engineers, 1852-3, page 571, "On the Conversion of Heat into Mechanical Effect." 
and injury to the briekwork, from the in-draught of cold air tlirough crevices, which is otherwise unavoidable in any furnace worked without blast.

The action of the furnace is regulated by the chimney damper, and by valves governing the supply of gas and air, and the draught is reversed by cast-iron reversing valves, on the principle of the common four-way cock.

Fusiox of Steel IN Crucibles.-In the application of the system to the fusion of steel in elosed pots or crucibles, the melting-chamber, containing generally 24 pots, is eonstructed in the form of a long trench, 3 feet 6 inches wide at the bottom, and gathered in to under 2 feet at the top. The sides of the meltingchamber are arched both horizontally and rertically, to keep them from sinking together in working, and the work is strengthened by cross walls at intervals. The pots are set in a double row along the centre of the melting-chamber, and the flame passes from side to side, the gas and air from the regenerators being intro: duced alternately from one side and from the other, opposite to eacl pair of pots. The melting-chamber is closed above by loose firebrick covers, which are drawn partly off in succession by means of a lever suspended from a pulley above the furnace, when the pots are to be charged or drawn out. The pots stand in a bed of finely-ground coke-dust, resting on iron plates. The coke-dust burus away only very slowly, if it is made of hard coke and finely ground, and it presents the great advantage of remaining always in the form of a loose dry powder, in which the pots stand firmly, while every other material that I have tried either softens at the intense heat, ol sets after a time into a hard, uneven mass, in which the pots do not stand well.

The process of melting carried out in this form of gas furnace is the same in all respects as that in the small air furnaces or melting-holes fired with coke which are commonly employed, but a great saving is effected in the cost of fuel, and in the number of crucibles required.

The ordinary consumption of hard coke, costing 22s. per ton in Sheffield, is between three and four tons per ton of steel fused, while in the gas furnace the same work may be done by the expenditure of 15 to $20 \mathrm{crt}$. of common coal slack (worth only 5s. to $8 s$. per ton), at a cost that is of only $5 s$. against $75 s$. per ton 
of steel melted. There is a further saving in the number of crucibles required, as they may be used in the gas furnace four or five, and sometimes even ten times, while in furnaces heated by coke, two or three casts are as much as are erer obtained. The lining of the furnace lasts at least 15 to 20 weeks without repair (in working day and night), while 4 to 5 weeks is the longest duration of the ordinary coke-fired holes.

Fusion of Steel on THe Open Bed.-The furnace employed for the fusion of steel on the open bed is similar in shape to a reheating or puddling furnace; the direction of the flame is from end to end; and the regenerators are placed transversely below the bed, which is supported on iron plates, kept cool by a current of air. The air enters beneath the bed plates in front, and escapes by two ventilating shafts at the back of the furnace near the ends. This cooling of the bed is very necessary to keep the slag $\rho^{r}$ melted metal from finding its way through into the regenerator chambers. The upper part of the furnace is built entirely of Dinas brick.

There are three doors in the front of the furnace, one in the centre immediately over the tap-hole, and two near the bridges, through which the bed can be repaired when necessary, and ingot ends or other heavy scraps may be charged in. Sloping shoots are provided at the back of the furnace, through which long bars, such as old rails, may be conveniently charged, and beneath these are openings for charging the pig-iron. The upper end of the shoots is on a level with an elevated charging platform behind the furnace.

The bottom of the furnace is formed of silicious sand, which answers exceedingly well if properly selected and treated.

Instead of putting moist sand into the cold furnace, as is usually done in preparing the bottoms of furnaces for heating or melting iron or copper, I dry the sand, and introduce it into the hot furnace, in layers of about $1^{\prime \prime}$ thickness. The heat of the furnace must be sufficient to fuse the surface of each layer, that is to say, it must rather exceed a welding heat to begin with, and rise to a full steel-melting heat at the end of the operation, in order to impart additional solidity to the uppermost layers. Care must be taken that the surface of the bath assumes the form of a shallow basin, being deepest-near the tap-hole. Some white sands, such as 
that from Gormal, near Birmingham, will set under these circumstances into a hard impervious crust, capable of surviving from 20 to 30 charges of liquid steel, without requiring material repairs. If no natural sand of proper quality is available, white sand, such as Fontainebleau sand, may be mixed intimately. with about 25 per cent. of common red sand, to obtain the same results.

In tapping the furnace, the loose sand near the tapping-hole is removed, when the lower surface of the hard crust will be reached. The lowest point of this surface is thereupon pierced by means of a pointed bar, upon the withdrawal of which the fluid metal runs out from the hottest and deepest portion of the bath into the ladle in front of the furnace.

M. Le Chatelier now proposes to mix the natural Bauxite, of which the bottom of the experimental furnace at the works of MM. Boignes, Rambourg and Co., near Montluçon was first made, with about 1 per cent. of chloride of calcium dissolved in water, to calcine the mixture, and to form it into moulded masses of highly refractory matcrial.

A hard bottom being thus prepared, and the heat of the furnace being raised to whiteness, it is ready to receive the materials to be molted.

If these materials consist of bar iron, or of old iron and stecl rails, they are cut into lengths of about six feet, and are introduced into the furnace through slanting hoppers from the elevated platform at the back, so that their ends rest upon the sand bottom forming the bath.

If the capacity of the furnace is such, that charges of 3 tons can be formed, about 6 cwt. of grey pig-iron is introduced through the ports or short hoppers, below the main charging-hoppers before-mentioned. As soon as a bath of pig metal is formed, the heated ends of the rails or bars begin to dissolve, causing the bars gradually to descend. By partially closing the mouths of the charging-hoppers, a regulated quantity of flame is allowed to escape from the furnace, in order to heat the descending bars of metal previous to their entry into the melting-chamber, the object being to maintain the high temperature of the furnace, notwithstanding the constant introduction of cold metal. The escaping products of combustion, which are thus withdrawn from 
the regenerators, are a positive gain to the heat of the furnace, because, having been in contact with comparatively cold metal, they would be at a heat inferior to that of the upper portions of the regenerators, and would therefore only lower their temperatures.

As the bars sink in the hoppers by their gravity, they are followed up by additional bars until the metal charged amounts to about three tons, all of which will be rendered fluid within about four hours from the time of commencing the charge. The metallic bath is tested from time to time by the introduction of a bar through one of the front doors of the furnace, and if the bath should become thick before the end of the operation, although the heat has been maintained, it will be necessary to introduce an additional quantity of pig-metal. All the metal being liquid, a sample is taken out by means of a small iron ladle, and plunged into cold water while still red-hot. In breaking this sample upon an anvil, the temper and quality of the metal may be fairly judged. Its fracture should be bright and crystalline, betokening a very small proportion of carbon (not exceeding ' 1 per cent.), and the metal should be tough and malleable, notwithstanding its sudden refrigeration. From 5 to 8 per cent. of Spiegeleisen (containing not less than 9 per cent. of manganese) is thereupon charged through the side openings upon the bank of the furnace, and allowed to melt down into the bath, which is then stirred and made ready for tapping in the manner before described.

The amount of 'carbon introduced with the Spiegeleisen determines the temper of the steel produced, the manganese being necessary to prevent redshortness, unless Swedish or Styrian iron is used.

When old iron rails or scrap of inferior quality are charged, the addition of manganese does not suffice to effect the necessary purification of the steel produced; but the perfectly liquid condition of the bath, together with the unlimited time available for chemical reaction, offer extraordinary advantages for the introduction of such materials as may be found to combine with sulphur, phosphorus, silicon, or arsenic, which are the usual antagonists to be dealt with.

The experiments which I have been able to institute in this 
direction, are by no means complete;-nevertheless, I hare obtained most beneficial results from the introduction into the bath of litharge, in conjunction with oxidising salts containing strong bases, such as the alkaline nitrates, chromates, chlorates, stannates, titanates, \&c.

The choice of the reagents and the quantity to be employed depend, naturally, upon the quality and quantity of objectionable matter to be removed.

By the aid of the process just described, it will be possible to convert old iron rails into steel rails of sufficiently good quality at a cost scarcely exceeding that of re-rolling them into fresh iron rails. The non-expensive nature of the process may be judged by the fact that extremely little labour is required in conducting it ; that the loss of metal does not exceed from 5 to 6 per cent., and that from 10 to $12 \mathrm{cwt}$. of coal suffices to produce a ton of cast steel.

Ore.-Although I have succeeded in producing malleable steel from ordinary English iron by this process, it would be unreasonable to expect steel of really high quality, in using those materials which are already contaminated in the blast-furnace; and I am sanguine in the expectation of producing cast steel superior in quality, and at a low cost, directly from the better description of ores, such as the hematites, magnetic oxides, and the spathic carbonates. My experiments in this direction extend over several years; and last year I sent a few bars of steel produced from hematite ore, to the French Exhibition, which had stood a high test in Kirkcaldy's machine. A "grand prix" was awarded for this and other applications of the regenerative gas furnaces.

Haring tried various modifications of the furnace, I hare arrived at a form of apparatus (Plates 39 and 40) not dissimilar to the one just described.

The furnace and tapping arrangements are, indeed, the same, except that for the slanting hoppers, vertical hoppers over the middle of the bath are substituted, in which the ore gradually descends. Each hopper is formed of a cast-iron pipe, supporting a clay-pipe which is attached to it by means of a bayonet-joint, and reaches down into the furnace, while the cast-iron pipe rests with its flange on the charging platform. 
A fire space is provided surrounding each hopper, through which flame ascends from the furnace, and is allowed to escape in. regulated quantities near the upper extremity of the retort, the object being to heat the latter and the ore contained in it to a red heat. A wrought-iron pipe descends into each hopper from a general gas-tube above, through which a current of ordinary producer gas is forced in amongst the heated ore. The propulsion of the gas is effected most conveniently by means of a steam-jet in the gas-tube leading from the main gas-channel to the top of the furnace, care being taken to effect a total condensation of the steam by passing the gas finally through a small scrubber, in which water trickles orer pieces of coke. In this way the gas is at the same time purified from sulphurous acid, the sulphur of which might otherwise combine with the reduced ore.

The furnace is charged in the following manner :-

The hoppers and gas-pipes being placed in position, about $\frac{1}{4}$ cwt. of charcoal is charged through each hopper to form a basis for the ore with which these are afterwards filled.

About 10 cwt. of pig-metal is charged through the ports at the back or front of the furnace, which, upon being melted, forms a metallic bath below the hoppers. In the meantime, the ore in the lower parts of the hoppers, being heated in an atmosphere of reducing gas, has become partially reduced into metal sponge, which, in reaching the metallic bath, is readily dissolved in it, making room for the descent of the superincumbent ore, which is likewise reduced in its descent and dissolved in due course, fresh ore being continually supplied on the charging platform. The dissolution of the reduced ore proceeds with extraordinary rapidity, but is practically limited by the time necessary to effect the reduction of the ore in the hopper which occupies several hours. It is, however, not essential that the ore should be thoroughly reduced before reaching the bath, because the carbon contained in the cast metal serves also to complete the operation.

I prefer to employ a mixture of hematite and spathic ore, containing the elements for forming a fusible slag, which will accumulate on the surface of the metallic bath, and may be from time to time removed through the centre door. If the ore con- 
tains any silica, it is necessary to add some lime or other fluxing materials, but it is desirable to employ ores containing little gangue, in order not to encumber the furmace with slag, reserving the poorer' ores for the blast furnace. The ore should, moreover, be in pieces ranging from the size of a pea to that of a walnut, in order to be pervious to the reducing gases. If ores in the form of powder are employed, it is necessary to mix them with about 10 per cent. by weight of light carbonaceous materials, such as dry peat, wood, or charcoal.

The metallic bath having sufficiently increased in the course of from three to four hours, the supply of ore is stopped, and that contained in the hoppers is allowed to sink. Before the hoppers are einpty, a false cover of cast iron, lined with clay at its under side, is introduced, being suspended from above by a strong wire, in order to prevent the access of flame to the interior of the empty hoppers. Charcoal and ore are filled in upon the top of this false cover, and, on cutting the wire, afterwards form the commencement of the succeeding charge.

When all the ore has disappeared, the metallic bath is tested as before described in reference to the melting of scrap. If it should be partially solidified, cast iron is added to re-establish complete liquefaction; but if, on the other hand, the bath contains an excess of carbon, oxidising agents may be added as before described, in requisite proportion. From 5 to 8 per cent. of spiegeleisen is then added, and the furnace is tapped as already described.

The quality of the steel produced is chiefly dependent upon the quality of the ore, but considering that ores of great freedom from sulphur, phosphorus, or arsenic can be had in large quantities, this process contains all the elements for producing steel of high quality.

Having tried a variety of ores, I do not attach much importance to their precise composition, so long as they are comparatively free from gangue, and from sulphur and phosphorus, the heat being sufficient to reduce the most refractory. My experience is, however, as yet limited to experimental working.

I hoped to have been in a position to have given you the temperature of this furnace, as determined by an electric resistance 
pyrometer, which I have constructed for this purpose, but have not yet been able to obtain satisfactory results, owing to the destruction of the coil of platinum wire, which has to be exposed to the heat. My efforts were baffled moreover by the fact, interesting in itself, that platinum wire produced by fusion in Deville's furnace, does not increase in electrical resistance with increase of temperature in the same ratio as that produced by the old process, owing probably to the presence of carbon or other alloy in fractional quantities.

Avoiding the use of fused platinum wire, I have measured temperatures by electrical resistance up to a full welding heat, which I estimate at $1,600^{\circ} \mathrm{C} .=2,900^{\circ} \mathrm{F}$.; and in judging the heat of the steel-melting furnace by comparison of effects, I should put it at not less than $2,200^{\circ} \mathrm{C} .=4,000^{\circ} \mathrm{F}$. The effect of this degree of heat may be judged by the following :-

An ingot of rather hard cast-steel, weighing 6 cwt., was introduced into the furnace to be incorporated with the bath of steel. The ingot was nearly cold, and was allowed to remain fifteen minutes upon the bank before it was pushed into the bath, where it was completely dissolved in fifteen minutes, the time occupied in heating and melting the ingot being thirty minutes. A cube of wrought metal of nearly 8 inches, weighing $130 \mathrm{lbs}$., was also introduced cold into the furnace, and allowed to remain upon the bank during ten minutes to be heated externally to whiteness, before being pushed into the metallic bath, when twelve minutes sufficed to render it completely liquid. It must be borne in mind that these results are produced without a strong draught, the flame being indeed so mild, as not to oxidise the unprotected metal, which can be maintained for several hours as liquid steel in the furnace without adding carbon in any form.

It may be matter for surprise, that the material composing the furnace can be made to resist such a heat, and it must be admitted that best Dinas brick is the only brick capable of resisting for four to five weeks, by which time the thickness of the arch is reduced to about 2 inches, by the absolute fusion of the inner surface; but this excessive heat is confined to the heated chamber only, the regenerators being at such a moderate heat, that the 
chequerwork will stand for months, and the arches for years, of constant working.

In conclusion, I wish to express to you my sense of the disproportion that exists between the magnitude of the task I have bronght before you, and my ability to accomplish it in all its ramifications. It may be granted that the regeneratire gas furnace itself has passed beyond its experimental stage, but much has yet to be done in working out the applications of the system to the useful arts, and the modifications and improvements in processes which it frequently involves.

Much, also, has yet to be done before the method of producing cast steel, in one direct process from the ore, can take its place as the recognised system of making steel on a large scale from the purer iron ores, a position that I firmly believe it will assume, sooner or later. It is my earnest hope that, in bringing the subject before your Society, I may induce some of its members to forward this result, by taking up particular branches of the scientific inquiries upon which I have only been able to touch lightly in my present communication. I have much pleasure in acknowledging the assistance $\mathrm{I}$ have received in working out this subject from Mr. William Hackney, my principal superintendent, and Mr. Willis, the chemist in charge at my experimental works.

\section{ON PUDDIING IRON,}

\section{BY C. W. Siemens, F.R.S.}

[Paper read before the Chemical and Mechanical Sections of the British Association at Norwich, 1868, and ordered to be printed in extenso among the Reports.] *

NotwITHSTANDIXg the recent introduction of cast steel for structural purposes, the production of wrought iron (and puddled steel) by the puddling prosess ranks among the most important branches of British manufacture, representing an annual produc-

* Excerpt Journal of the British Association, 1868, pp. 58-71. 
tion exceeding one and a half millions of tons, and a money value of about nine millions sterling.

Notwithstanding its great national importance and the interesting chemical problems involved, the puddling process has received less scientific attention than other processes of more recent origin and inferior importance, owing probably to the mistaken sentiment that a time-honoured practice implies perfect adaptation of the best means to the end and leaves little scope for improrement.

The scanty scientific literature on the subject will be found in Dr. Percy's important work on iron and steel. Messis. Crace, Calvert and Richard Johnson, of Manchester,* have supplied most valuable information by a series of analyses of the contents of a puddling furnace, during the different stages of the process. These prove that the molten pig metal is mixed intimately, in the first place, either with a molten portion of the oxides (or Fettling) which form the lining or protecting covering to the cast-iron tray of the puddling chamber, or with a proportion of oxide of iron in the form of hammer slag or red ore thrown in expressly with the charge ; that the silicon is first separated from the iron; that the carbon only leaves the iron during the "boil" or period of ebullition; and that the sulphur and phosphorus separate last of all while the metal is " coming to nature."

The investigations by Price and Nicholson, and by M. Lan, confirm these results, from which Dr. Percy draws some important general conclusions, which have only to be followed up and supple-

* "Phil. Mag.," Sept. 1857. The following Table, from Messrs. Calvert and Johnson's Paper, includes the chief results of their investigations :-

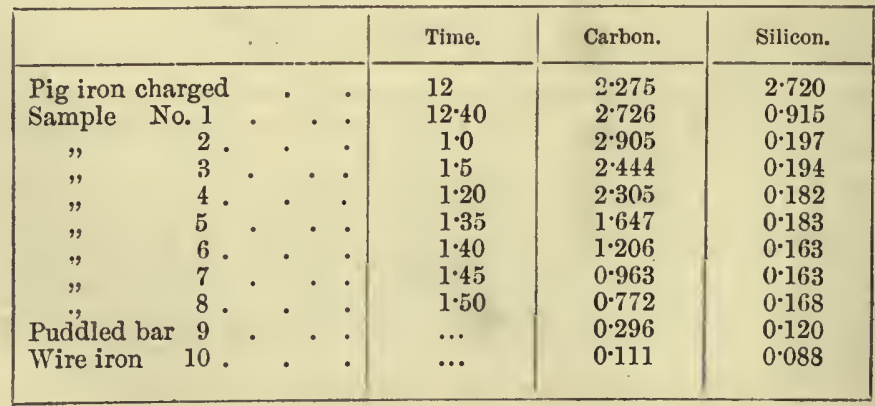


mented by some additional chemical facts and observations, in order to render the puddling process perfectly intelligible, and to bring into relief the defective manner in which it is at present put into practice, involving, as it does, great loss of metal, waste of fuel, and of human labour, and an imperfect separation of the two hurtful ingredients, sulphur and phosphorus.

Sirucos.-In forming (by means of the rabble) an intimate mechanical mixture between the fluid cast metal and the cinder, the silicon contained in the iron is brought into intimate contact with metallic oxide, and is rapidly attacked, being found afterwards in the cinder in the form of silicic acid (combined with oxide of iron). The heat of the furnace is always kept low during this stage of the process, and the flame is maintained as reducing as possible.

Carbon.-The disappearance of the carbon from the metal is accompanied by the appearance of violent ebullition and the evolution of carbonic oxide, which rises in innumerable bubbles to the surface of the bath, and burns (in an ordinary puddling furnace) with the blue flame peculiar to that gas. In puddling in a regenerative gas furnace this blue flame cannot be observed, because the flame of this furnace is strictly neutral, and there is no free oxygen present to burn the carbonic oxide rising from the fluid mass, a circumstance which by itself explains the superior results obtained from the gas furnace.

It is popularly believed that the oxygen acting upon the silicon and carbon of the metal is derived directly from the flame, which should, on that account, be made to contain an excess of oxygen, but the very appearance of the process proves that the combination between the carbon and oxygen does not take place on the surface, but throughout the body of the fluid mass, and must be attributed to reaction of the carbon upon the fluid cinder in separating from it metallio iron; while as the remoral of the silicon is still more rapid, and is effected under a reducing flame, there is strong evidence that it also is oxidized rather by the oxygen of the cinder than by the flame.*

But it has been argued that, although the reaction takes place below the surface, the oxygen may, nevertheless, be derived from

* At page 253 is appended a Table showing the comparative quantities of carbon in various kinds of iron and steel. 
the flame, which may oxidize the iron on the surface, forming an oxide or cinder, which is then transferred to the carbon at the bottom, in consequence of the general agitation of the mass.

This view I am, however, in a position to disprove by my recent experience in melting cast steel upon the open flame bed of a furnace, having invariably observed that no oxidation of the unprotected fluid metal takes place so long as it contains carbon in however slight a proportion.

But being desirous to ascertain by positive proof, what is the behaviour of silicon, and carboll, in fluid cast iron, when contact with the atmosphere, or the flame of the furnace, is strictly prevented; I instituted the following experiment at my Sample Steel Works, at Birmingham :-

Ten cwts. of Acadian pig metal, and one cwt. of broken glass, were charged upon the bed of a regenerative gas furnace (usually employed for melting steel upon the open hearth).

The bed of this furnace was formed of pure silicious sand, and one object in view was to ascertain whether any reaction takes place between silica and fluid cast metal, it being generally supposed that metallic silicon is produced under such circumstances by the reducing action of the carbon in the metal upon the silica or silicates present. The cast metal employed in this experiment was Acadian pig, containing silicon, 1.5 per cent. ; carbon, $4^{\circ} 0$ per cent.

In the course of an hour, the metal and glass were completely melted. A sample was taken out, containing silicon, $1 \cdot 08$ per cent. ; carbon, 2.90 per cent. $\left\{\begin{array}{l}0.6 \text { per cent. combined carbon. } \\ 2.3 \Rightarrow \text { graphite. }\end{array}\right.$

At the end of the second hour, another sample was taken out and tested, the result being silicon, $\cdot 96$ per cent.; carbon, $2 \cdot 40$ per cent., combined.

The physical condition of the metal had now undergone a decided change. The carbon having wholly combined with the iron, rendered it extremely hard.

The amount of silicon having steadily diminished, these results prove that no silicon is taken up by fluid cast metal in contact with silica or silicates.

The reduction of the amount of silicon in the metal might be accounted for by the presence of minute quantities of oxides of 
iron, produced in melting the pig metnl, which oxides were now incrensed by the addition of hematite ore in small doses.

At the end of the third hour, another sample was taken, containing silicon, $\cdot 76$ per cent. ; carbon, $2 \cdot 4$ per cent. combined, the metal being extremely hard, as before.

Additional doses of red ore were added gradually without agitating the bath, and the effect upon the fluid metal was observed from time to time.

At the end of the fifth hour, the samples taken from the fluid bath assumed a decidedly mild temper ; when the addition of ore was stopped, and exactly six hours after being charged, the metal was tapped and run into ingots; it now contained silicon, 0.046 per cent.; carbon, 25 per cent., thus both the silicon and the carbon had been almost entirely removed from the pig metal by mere contact with metallic oxide under a protecting glass covering.

The quantity of red ore added to the bath amounted to two hundredweight, and the weight of metal tapped to ten hundredweight, five pounds, being slightly in excess of the weight of pig metal charged.

But the pig metal had contained 1.5 per cent. of silicon, and 4 per cent. of carbon, or a combined total of 5.5 per cent., whereas the final metal contained collectively only 296 of silicon and carbon, showing a gain of metal of $5 \cdot 5-\cdot 296=5 \cdot 204$ per cent., or including the five pounds of increased weight, a total gain of $5 \cdot 7$ per cent. of metallic iron.

Supported by these observations, I venture to assert that the removal of the silicon and carbon from the pig iron in the ordinary muddling or "boiling" process is due entirely to the action of the fluid oxide of iron present, and that an equivalent amount of metallic iron is reduced and added to the bath, which gain, howerer, is generally and unnecessarily lost again in the subsequent stages of the process. The relative quantity of metal thus produced from the fluid cinder admits of being accurately determined.

The cinder may be taken to consist of $\mathrm{Fe}^{3} \mathrm{O}^{4}$ (this being the fusible combination of peroxide and protoxide), together with more or less tribasic silicate $\left(3 \mathrm{FeO}, \mathrm{SiO}^{3}\right)$, which may be regarded as a neutral admixture, not affecting the argument, and silicic acid or silica is represented by $\mathrm{Si}^{3}$, from which it follows that for every four atoms of silicon leaving the metal, nine atoms of 
metallic iron are set free, and taking the atomic weights of iron $=28$, and of silicon 22.5 , it follows that for every $4 \times 22.5=$ 90.0 grains of silicon abstracted from the metal, $9 \times 28=252$ grains of metallic iron are liberated from the cinder.

Carbonic oxide, again, being represented by $\mathrm{C} \mathrm{O}$, and the cinder by $\mathrm{Fe}^{3} \mathrm{O}^{4}$, it follows that for every four atoms of carbon removed from the metal, three atoms of iron are liberated; and taking into account the atomic weights of carbon $=6$ and of iron $=28$, it follows that for every $6 \times 4=24$ grains of carbon oxidized, $28 \times 3=84$ grains of metallic iron are added to the bath.

Assuming ordinary forge pig, after being remelted in the puddling furnace, to contain about 3 per cent. of carbon and 2 per cent. of silicon, it fullows from the foregoing that in removing this silicon $\frac{2.52}{90} \times 2=5.6$ per cent., and in removing the carbon $\frac{84}{2 *} \times 3=10^{\circ} 5$ per cent. of metallic iron is added to the bath, making a total increase of $5 \cdot 6+10 \cdot 5-5=11 \cdot 1$ per cent., or a charge of $420 \mathrm{lbs}$. of forge pig metal, ought to yield 466 lbs. of wrought metal, whereas from an ordinary puddling furnace the actual yield would generally amount to only $370 \mathrm{lbs}$. (or 12 per cent. less than the charge), showing a difference of $96 \mathrm{lbs}$. between the theoretical and actual yield in each charge.

This difference, amounting to fully 20 per cent., is due to the enormous waste by oxidation to which the iron is exposed after it has been "brought to nature" (by the removal of the carbon); when it is in the form of a granular or spongy metallic mass and during the process of forming it into balls. So great a waste of metal by oxidation seems at first sight almost incredible, but considering the extent of surface exposed in the finely divided puddled mass, it is not at all exceptional, and is in fact almost unavoidable in a furnace of the ordinary construction, maintained as a puddling furnace is, at a relding heat. Many attempts have been made, for example by Chenot, Clav, Renton, and others, to produce iron directly from the purer ores, by reducing the ore in the first instance to a metallic sponge, and balling up this sponge, which is a loose porous mass, somewhat similar to spongy puddled iron, on the bed of a furnace, but all these attempts have fuiled, simply on account of the great waste of iron, a waste amounting to from 25 to 50 per cent., in balling up the sponge. Indeed, the loss in an ordinary puddling furnace would probably be greater 
than 20 per cent. if the metal were not partly protected from the flame by the batl of cinder in which it lies; for in one instance in which the cinder accidentally ran out of a puddling furnace during the balling up of the charge, leaving the iron exposed to the flame, I found the yield reduced from the average of $413 \mathrm{lbs}$. down to $370 \mathrm{lbs}$., showing an increased waste of $43 \mathrm{lbs}$., or over 10 per cent., due to the more complete exposure of the metal to the oxidizing action of the flame.

In order to realize the theoretical result, a sufficient amount of oxides inust have been supplied to effect the oxidation of the silicon and carbon of the pig iron, and to form a tribasic silicate of iron ( $\left.3 \mathrm{Fe} \mathrm{O}, \mathrm{Si} \mathrm{O}^{3}\right)$ with the silicic acid produced.

The amount of oxide required may be readily ascertained.

In taking the expression, $\mathrm{Fe}^{3} \mathrm{O}^{4}$, the atomic weight of which is $3 \times 28+4 \times 8=116$, while that of the three atoms of iron alone is $3 \times 28=81$, it follows that $\frac{116}{84} \times 46=63.5 \mathrm{lbs}$. of cinder or oxide of iron are requisite to produce the $46 \mathrm{lbs}$. of reduced iron which were added to the bath. There must, however, remain a sufficient quantity of fluid cinder in the bath to form, with the silicon (extracted from the iron), a tribasic silicate of iroll, or about $60 \mathrm{lbs}$, making in all $124 \mathrm{lbs}$. of fettling which would have to be added for each charge, a quantity which is generally exceeded in practice notwithstanding the inferior results universally obtained.

There remain for our consideration the sulphur and phosphorus, which being generally contained in English forge pig in the proportion of from 2 to $^{\circ} 6$ per cent. each, can hardly affect the foregoing quantitative results, although they are of great importance as affecting the quality of the metal produced.

It has been suggested by Percy that the separation of these ingredients may be due to liquation. This I understand to mean that the crystals of metallic iron, which form throughout the boiling mass when the metal "comes to nature," exclude foreign substances in the same way that the ice formed upon sea water excludes the salt, and yields sweet water when re-melted.

According to this view, pig metal of inferior quality will really yield iron almost chemically pure, to which foreign ingredients are again added by mechanical admixture with the surrounding cinder, or semi-reduced metal.

It may be safely inferred that the freedom of the metal from 
impurities thus taken up will mainly depend upon the temperature, which should be high, in order to ensure the perfect fluidity and complete separation of the cinder.

The following was the result of an analysis of an inferior English pig iron before and after being puddled :-

\begin{tabular}{|c|c|c|c|}
\hline \multirow{6}{*}{$\begin{array}{l}\text { PIG AIETAL. } \\
\text { Sulphur } \\
\text { Phosphorus } \\
\text { Silicon } \\
\text { Iron and Carbon (by } \\
\text { difference). }\end{array}$} & & PUDDLED B & R. \\
\hline & .08 & Sulphur & $\cdot 017$ \\
\hline & $1 \cdot 16$ & Phosphorus & $\cdot 237$ \\
\hline & 1.97 & Silicon . & $\cdot 200$ \\
\hline & & Iron (by difference) & . $99 \cdot 5546$ \\
\hline & $96 \cdot 79$ & & \\
\hline & $100 \cdot 0$ & & $100 \cdot 000$ \\
\hline
\end{tabular}

showing the extent to which foreign matters are actually removed by the process of puddling.

These analyses were made a few days since by Mr. A. Willis in my laboratory at Birmingham.

Led by these chemical considerations, and by practical attention to the subject, extending over several years, I am brought to the conclusion that the process of puddling, as practised at present, is extremely "wasteful in iron and fuel, immensely laborious, and yielding a metal only imperfectly separated from its impurities."

How nearly we shall be able to approach the results indicated by the chemical reasoning here adopted, I am not prepared to say, but that much can be accomplished by the means actually at our doors is proved by the result of the working of a puddling furnace erected eighteen months since to my designs by the Bolton Steel and Iron Company in Lancashire.

This furnace consists of a puddling chamber of very nearly the ordinary form, which is heated however by means of a regenerative gas furnace, a system of which the principle is now sufficiently well established to render a very detailed description here unnecessary.

The general arrangement of the furnace is shown in the accompanying illustrations. It consists of two essential parts :

The gas-producer, in which the coal or' other fuel is converted into a combustible gas ; and

The furnace, with its "regenerators" or chambers for storing 
the wasto heat of the flame, and giving it up to the in-coming air or gas.

'The gas-producer is shown in Plate 41, Fig. 1 ; it is a rectangular fire-brick chamber, one side of which, $B$, is inclined at an angle of from $45^{\circ}$ to $60^{\circ}$, and is provided with a grate, $\mathrm{C}$, at its foot. The fuel, which may be of any description, such as coal, coke, lignite, peat, or even sawdust, is filled in through a hopper, $A$, at the top of the incline, and falls in a thick bed upon the grate. Air is admitted at the grate, and in burning, its oxygen unites with the earbon of the fucl, forming earbonic acid gas, which rises slowly through the ignited mass, taking up an additional equivalent of carbon, and thus forming carbonic oxide. The heat thus produeed distils off carburetted hydrogen and other gases and rapours from the fuel as it descends gradually towards the grate, and the carbonic oxide alleady named diluted by the inert nitrogen of the air and by any small quantity of unreduced carbonic acid, and mixed with these gases and vapours distilled from the raw fuel, is finally led off by the gas flue to the furnace. The ashes and elinkers that aecumulate in the grate are removed at intervals of one or two days.

$\mathrm{E}$ is a pipe for the purpose of supplying a little water to the ash pit, to be decomposed as it evaporates and comes in contact with the incandeseent fucl, thus forming some hydrogen and earbonie oxide, which serve to enrich the gas ; $G$ is a small plug hole by which the state of the fire may be inspected, and the fuel mored by a bar if neeessary ; and D is a sliding damper by which the gas-producer may be shut off at any time from the flue.

It is neeessary to maintain a slight outward pressure through the whole length of the gas flue leading to the furnaces, in order to prevent the burning of the gas in the flue through the indraught of air at creviees in the brickwork.

Where the furnaces stand much higher than the gas-producers, the required pressure is at once obtained; but more frequently the furnaees and gas-produeers are placed nearly on the same level, and some special arrangement is necessary to maintain the pressure in the flue. The most simple contrivance for this purpose is the "elevated cooling tube." The hot gas is carried up by a brick staek, H, to a height of eight or ten feet abore the top of the gasproducer, and is led through a horizontal sheet-iron cooling tube, 
J, (Fig. 1), from which it passes down either directly to the furnace, or into an underground brick flue.

The gas rising from the producer at a temperature of about $1000^{\circ}$ Fahr., is cooled as it passes along the overhead tube, and the descending column is consequently denser and heavier than the ascending column of the same length, and continually overbalances it. The system forms, in fact, a syphon in which the two limbs are of equal length, but the one is filled with a heavier gaseous fluid than the other.

In erecting a number of gas-producers and furnaces I generally prefer to group the producers together, leading the gas from all into one main flue, from which the several furnaces draw their supplies.

The puddling furnace, proper, is shown in Plate 41, Fig. 2, and Plate 42, Figs. 3 and 4.

Fig. 2 is a sectional plan, and Fig. 3 is a front elevation of the furnace, showing the gas reversing valve and flues in section.

Fig. 4, is a longitudinal section.

The peculiarity of the regenerative gas furnace, as applied either to puddling, or to any other process in which a high heat is required, consists in the utilization in the furnace of nearly the whole of the heat of combustion of the fuel, by heating the entering gas and air by means of the waste heat of the products of combustion, after they have left the furnace, and are of no further use for the operation being carried on. The waste heat is, so to speak, intercepted on its passage to the chimney, by means of masses of fire-brick stacked in an open or loose manner in certain chambers, called "Regenerator chambers," C, E, E1, Cl, (Fig. 3).

On first lighting the furnace the gas pisses in through the gas regulating valve, $\mathrm{B}$, (Fig. 2), and the gas reversing valve, $\mathrm{B}^{1}$, and is led into the flue, M, and thence into the bottom of the regenerator chamber, C, (Fig. 3) ; while the air enters through a corresponding "air reversing valve," behind the valve $\mathrm{B}^{1}$, and passes thence through the flue, $\mathrm{N}$, into the regenerator chamber, E. The currents of gas and air, both quite cold, rise separately through the regenerator chambers, $\mathrm{C}$ and $\mathrm{E}$, and pass up through the gas and air flues respectively, into the furnace above, where they meet and are lighted, burning and producing a 
moderate heat. The produets of combustion pass away through a similar set of flues at the other end of the furnace into the regenerator chambers, $\mathrm{C}^{\mathrm{l}}, \mathrm{E}^{1}$, and thence through the flues, $\mathrm{M}^{1}$, $\mathrm{N}^{1}$, and through the gas and air reversing valves, into the chimney flue, 0 . The waste heat is thus deposited in the upper courses of open fire-brick work filling the ehambers, $\mathrm{C}^{\mathrm{l}}, \mathrm{E}^{\mathrm{I}}$, so heating them up, while the lower portion, and the chimuey flue, are still quite cool ; then after about an hour, the reversing ralves, $\mathrm{B}^{1}$, (through whieh the air and gas are admitted to the furnace) are lerersed, by means of the levers, $\mathrm{P}$, and the air and gas enter through those regenerator ehambers, $\mathrm{E}^{\mathrm{l}}, \mathrm{C}^{\mathrm{l}}$, that liave just been heated by the waste products of combustion, and in passing up through the open briekwork they beeome heated, and then on meeting and entering into combustion in the furnaee, D, D, they produce a rery high temperature, probably $500^{\circ}$ Fahr. higher than when admitted eold; the waste heat from such higher temperature of combustion heating up the previously cold regenerator chambers, C, E, to a eorrespondingly higher heat. After about an hour's work the rerersing ralres, $\mathrm{B}^{1}$, are again rerersed, and the air and gas enter the first pair of regenerator chambers, C, E, but whieh are now very hot, and therefore the air and gas become very hot, and enter the furnaee in this state, meeting and entering into eombustion, and thus produeing a still higher temperature, probably $500^{\circ}$ higher still, and again heating the seeond pair of regenerator chambers, $\mathrm{C}^{1}, \mathrm{E}^{1}$, so much higher, which enables them to again leat the air and gas to a still higher degree, when the ralves, $\mathrm{B}$, are again reversed. Thus an accumulation of heat and an aeession of temperature is obtained, step by step, so to speak, until the furnace is as hot as is required; for unless eold materials are put in to be heated, and thus abstract heat, the temperature rises as long as the furnaee holds together, and the supply of gas and air is continued. The heat is at the same time so thoroughly abstraeted from the products of eombustion by the regenerators that the chimney flue remains always quite cool. The command of the temperature of the furnace and of the quality of the flame is rendered eomplete by means of the gas and air regulating ralres shown at B in Fig. 2, and by the ehimney damper. These are adjusted to any required extent of opening by the notched rods, $Q, \mathrm{R}$, and $\mathrm{S}$, (Fig. 2,) respectirely, so that having the power of 
producing as high a temperature as can be desired, there is also the power of varying it according to the requirements in each case.

The bed of the furnace, D, D, is of the ordinary construction, formed of iron plates, and is provided with water bridges at the ends, as shown, to protect the "fettling," (or oxide of iron used for lining the furnace) from being melted away. The overflow from one of the water bridges is led into a sheet-iron tank below the bed, and then away. The eraporation from this tank keeps the bottom plates cool and preserves the cinder covering then from melting off, and the steam is carried away by a draught of air entering through two holes I, I, (Fig. 3), below the tap hole, and passing off by small rentilating shafts at the back of the furnace.

A heating chamber, $H$, is arranged at cach end of the furnace, in which the charge of pig iron may be heated to redness before it is introduced into the puddling chamber, D, D.

The advantages of this furnace, for puddling, are that the heat can be raised to an almost unlimited degree; that the flame can be made at will oxidizing, neutral, or reducing, without interforing with the temperature; that in-draughts of air and cutting flames are avoided; and that the gas fuel is free from ashes, dust, and other impurities, which are carried into an ordinary puddling furnace from the grate. In this last respect the new furnace presents the same advantages as puddling with wood.

The following tables give the working results which werc obtained from this furnace, as compared with the results obtained at the same time in an ordinary furnace from the same pig (the ordinary forge mixture) : 
TABLE I.

Regexerative Gas furvace.

\begin{tabular}{|c|c|c|c|c|c|}
\hline Date. & $\begin{array}{l}\text { Nos of } \\
\text { Ileats. }\end{array}$ & $\begin{array}{c}\text { Time } \\
\text { clianged. }\end{array}$ & $\begin{array}{l}\text { First Ball } \\
\text { out. }\end{array}$ & $\begin{array}{c}\text { Metal } \\
\text { charged. }\end{array}$ & Yield. \\
\hline $\begin{array}{c}1567 . \\
\text { Мay } 27\end{array}$ & $\begin{array}{l}1 \\
2 \\
3 \\
4 \\
5 \\
6\end{array}$ & $\begin{array}{c}5 \cdot 25 \\
6 \cdot+5 \\
8 \cdot 8 \\
9 \cdot 15 \\
10 \cdot 20 \\
11 \cdot 40\end{array}$ & $\begin{array}{c}6 \cdot 32 \\
7 \cdot 50 \\
9 \cdot 9 \\
10 \cdot 7 \\
11 \cdot 22 \\
12 \cdot 46\end{array}$ & $\begin{array}{l}\text { lbs. } \\
410 \\
433 \\
430 \\
425 \\
426 \\
412\end{array}$ & $\begin{array}{l}\text { lbs. } \\
392 \\
396 \\
410 \\
426 \\
430 \\
412\end{array}$ \\
\hline May 27 & $\begin{array}{l}1 \\
2 \\
3 \\
4 \\
5 \\
6\end{array}$ & $\begin{array}{c}\text { SECOND } \\
1 \cdot 48 \\
2 \cdot 50 \\
3 \cdot 56 \\
5 \cdot 0 \\
6 \cdot 5 \\
7 \cdot 20\end{array}$ & $\begin{array}{l}\text { IIFT. } \\
\begin{array}{l}2 \cdot 47 \\
3 \cdot 47 \\
4 \cdot 53 \\
6 \cdot 3 \\
7 \cdot 12 \\
8 \cdot 15\end{array}\end{array}$ & $\begin{array}{l}428 \\
420 \\
426 \\
432 \\
423 \\
420\end{array}$ & $\begin{array}{l}410 \\
414 \\
418 \\
417 \\
407 \\
422\end{array}$ \\
\hline May 27 & $\begin{array}{l}1 \\
2 \\
3 \\
4 \\
5 \\
6\end{array}$ & $\begin{array}{c}\text { THIRD } \\
9 \cdot 10 \\
10 \cdot 2.5 \\
11 \cdot 35 \\
12 \cdot 45 \\
2 \cdot 10 \\
3 \cdot 16\end{array}$ & $\begin{array}{l}\text { IFT. } \\
11 \cdot 30 \\
12 \cdot 40 \\
2 \cdot 0 \\
3 \cdot 10 \\
4 \cdot 20\end{array}$ & $\begin{array}{l}423 \\
422 \\
420 \\
430 \\
424 \\
420\end{array}$ & $\begin{array}{l}414 \\
412 \\
420 \\
410 \\
418 \\
400\end{array}$ \\
\hline May 28 & $\begin{array}{l}1 \\
2 \\
3 \\
4 \\
5 \\
6\end{array}$ & $\begin{array}{c}\text { FIRST } \\
5 \cdot 38 \\
6 \cdot 50 \\
8 \cdot 6 \\
9 \cdot 15 \\
10 \cdot 35 \\
11 \cdot 55\end{array}$ & $\begin{array}{l}\text { IFT. } \\
6.45 \\
8.0 \\
9.8 \\
10.25 \\
11.45 \\
1.8\end{array}$ & $\begin{array}{l}423 \\
422 \\
430 \\
426 \\
426 \\
430\end{array}$ & $\begin{array}{l}402 \\
400 \\
390 \\
407 \\
420 \\
416\end{array}$ \\
\hline MIay 28 & $\begin{array}{l}1 \\
2 \\
3 \\
4 \\
5 \\
6\end{array}$ & $\begin{array}{l}\text { SECOND } \\
2 \cdot 0 \\
3 \cdot 6 \\
4 \cdot 5 \\
5 \cdot 23 \\
6 \cdot 33 \\
7 \cdot 49\end{array}$ & $\begin{array}{l}\text { HIFT. } \\
\begin{array}{l}3 \cdot 1 \\
4 \cdot 0 \\
5 \cdot 18 \\
6 \cdot 27 \\
7 \cdot 46 \\
8 \cdot 50\end{array}\end{array}$ & $\begin{array}{l}422 \\
424 \\
423 \\
423 \\
427 \\
420\end{array}$ & $\begin{array}{l}422 \\
415 \\
424 \\
415 \\
420 \\
406\end{array}$ \\
\hline May 28 & $\begin{array}{l}1 \\
2 \\
3 \\
4 \\
5 \\
6\end{array}$ & $\begin{array}{l}\text { THIRD } \\
10.0 \\
11 \cdot 25 \\
12 \cdot 40 \\
1 \cdot 50 \\
3 \cdot 13 \\
4 \cdot 30\end{array}$ & $\begin{array}{l}\text { IIFT. } \\
\begin{array}{r}11 \cdot 20 \\
11 \cdot 33 \\
1 \cdot 45 \\
2 \cdot 58 \\
4 \cdot 20 \\
5 \cdot 35\end{array}\end{array}$ & $\begin{array}{l}420 \\
420 \\
423 \\
425 \\
430 \\
422\end{array}$ & $\begin{array}{l}424 \\
410 \\
412 \\
420 \\
418 \\
426\end{array}$ \\
\hline & $\begin{array}{l}\text { harge . } \\
\text { ield. } \\
\text { at the ra } \\
\text { pig iron }\end{array}$ & of ton of & ddled bar. & $\begin{array}{rl}\text { Cwt. } & \text { qrs. } \\
136 & 1 \\
132 & 3 \\
20 & 2\end{array}$ & \\
\hline
\end{tabular}


TABLE II.

ORDINARY FuRNACE.

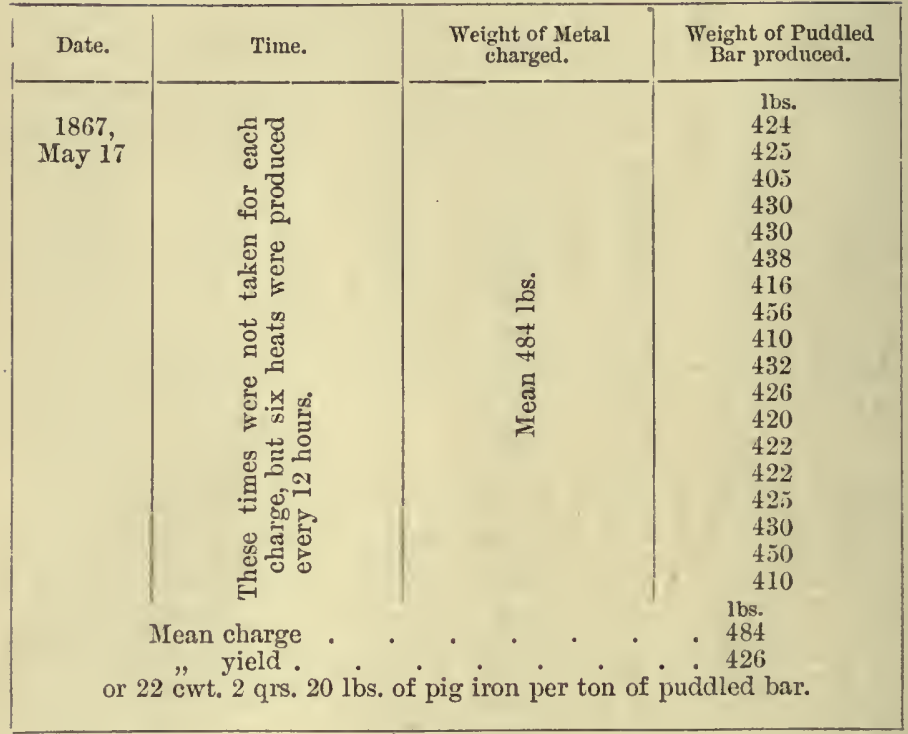

It will be observed that the ordinary furnace received charges of $484 \mathrm{lbs}$. each, and yielded on an average $426 \mathrm{lbs}$., representing a loss of 12 per cent., whereas the gas furnace received charges averaging $424 \mathrm{lbs}$., and yielded $413 \mathrm{lbs}$., representing a loss of less than $2 \cdot 6$ per cent.

It is important to observe, moreover, that the gas furnace turned. out eighteen heats in three shifts per twenty-four hours, instead of only twelve heats per twenty-four hours, which was the limit of production in the ordinary furnace.

This rate of working was attained without the employment of any arrangement for heating the pig iron before charging it into the furnace, the heating chambers at the ends not having been used. The adoption of the plan of heating the metal beforehand, a system already extensively in use both in this country and on the Continent, effects a further saving of ten to fifteen minutes in the time required for working each charge, as well as a considerable economy in fuel.

The quality of the iron produced frum the gas furnace was 
proved decidedly superior to that from the ordinary furnace, being what is technically called "best best" in the one, and "best" in the other case, from the same pig.

The economy of fuel was also greatly in favour of the gas furnace, but could not be accurately ascertained because some mill furnaces were worked from the same set of producers. Still, judging from the experience of several years, in the working of regenerative gas furnaces as re-heating or mill furnaces, and as glass furnaces, the saving of fuel in puddling cannot be less than 40 to 50 per cent. in quantity, while a much clieaper quality may be used.

The consumption of "fettling" was, however, greater in the gas furnace, and the superior yield was naturally attributed by the forge managers to that cause, although the writer beld a different opinion.

'The gas furnace, however, had not been provided with water bridges, these were subsequently added, and the furnace put to work again in February last, since which time it has been worked continuously.

The result of the water bridges has been that the amount of "fettling" required is reduced to an ordinary proportion, the average quantity of red ore used being $92 \cdot 6 \mathrm{lbs}$. per charge, besides the usual allowance of bull dog, while the yield per charge of 483.3 lbs. of grey forge pig has been increased to $485 \mathrm{lbs}$. of puddled bar, as shown by the following return of a series of eighty consecutive charges in June last :

TABLE III.

Regeverative Gas Fursace.

\begin{tabular}{|c|c|c|c|}
\hline Date. & $\begin{array}{c}\text { No, of } \\
\text { lleats. }\end{array}$ & Total Charges and Yields. & $\begin{array}{c}\text { A verage } \\
\text { per Heat. }\end{array}$ \\
\hline June, 1868 & so & $\begin{array}{lccc}\text { lbs. } & \text { cwt. } & \text { qrs. lbs. } \\
\text { Pig iron charged } & 38,668=345 & 1 & 0 \\
\text { Puddled bar returned } & 38,808=346 & 1 & 2.5 \\
\text { lied ore for "fettling" } & 3,406=66 & 0 & 14\end{array}$ & $\begin{array}{l}\text { Ibs. } \\
483 \cdot 3 \\
48.5 \\
92 \cdot 6\end{array}$ \\
\hline
\end{tabular}

proving that the yield of puddled bar slightly exceeds the charge of pig metal (representing a saving of fully 12 per cent. orer the ordinary furnace), while the superiority of quality in favour of the gas furnace is fully maintained.

It is also worthy of remark that these results are obtained regu- 
larly by the ordinary puddlers of the works, and that no repairs have been necessary to the gas puddling furnace since November last, the roof being reported to be still in excellent condition.

In these investigations I have confined myself to the puddling of ordinary English forge pig in order to avoid confusion, but it is self-evident that the same reasoning also applies in a modified degree to white pig metal or refined metal, the use of which I should not, however, advocate.

WATER BRIDGES.--Regarding the water bridges, I was desirous to ascertain the expenditure of heat at which the saving of "fettling" and greater ease of working was effected. The water passing through the bridges was accordingly measured by Mr. W. Hackney (who has also furnished me with the other working data) and found to amount to $25 \mathrm{lbs}$. per minute, heated $40^{\circ} \mathrm{Fahr}$. This represents 60,000 units of heat per hour, or a consumption not exceeding $8 \mathrm{lbs}$. to 10 lbs. of solid fuel per hour, an expenditure rery much exceeded by the advantages obtained where water or cooling cisterns are available.

The labour of the puddler and of his underhand being very much shortened and facilitated by means of the furnace, I should strongly recommend the introduction of three working shifts of 8 hours each per 24 hours, each shift representing the usual number of heats, by which arrangement botll the employer and the employed would be materially benefited. The labour of the puddler may be further reduced with advantage by the introduction of the mechanical "Rabble" which has already made considerable progress on the Continent.

By working in this manner, a regenerative gas puddling furnace of ordinary dimensions would produce an annual yield of about 940 tons of bar iron, of superior quality, from the same weight of grey pig metal and the ordinary proportion of "fettling."

In conclusion, I may state that a considerable number of these puddling furnaces have been erected by me abroad, and that, in this country, they are also being taken up by the Monkbridge Iron Co., Leeds, and a few other enterprising firms.

The construction of these furnaces has been still further improved lately by the application of horizontal regenerators, to save deep excavations, and by other arrangements whereby the first cost is diminished and the working of the furnace facilitated. 
TABLE IV.

l'ercentage of Carmon and Silicon contained iN various kisds of Cast and Wrovgit Iron aNd Steel.

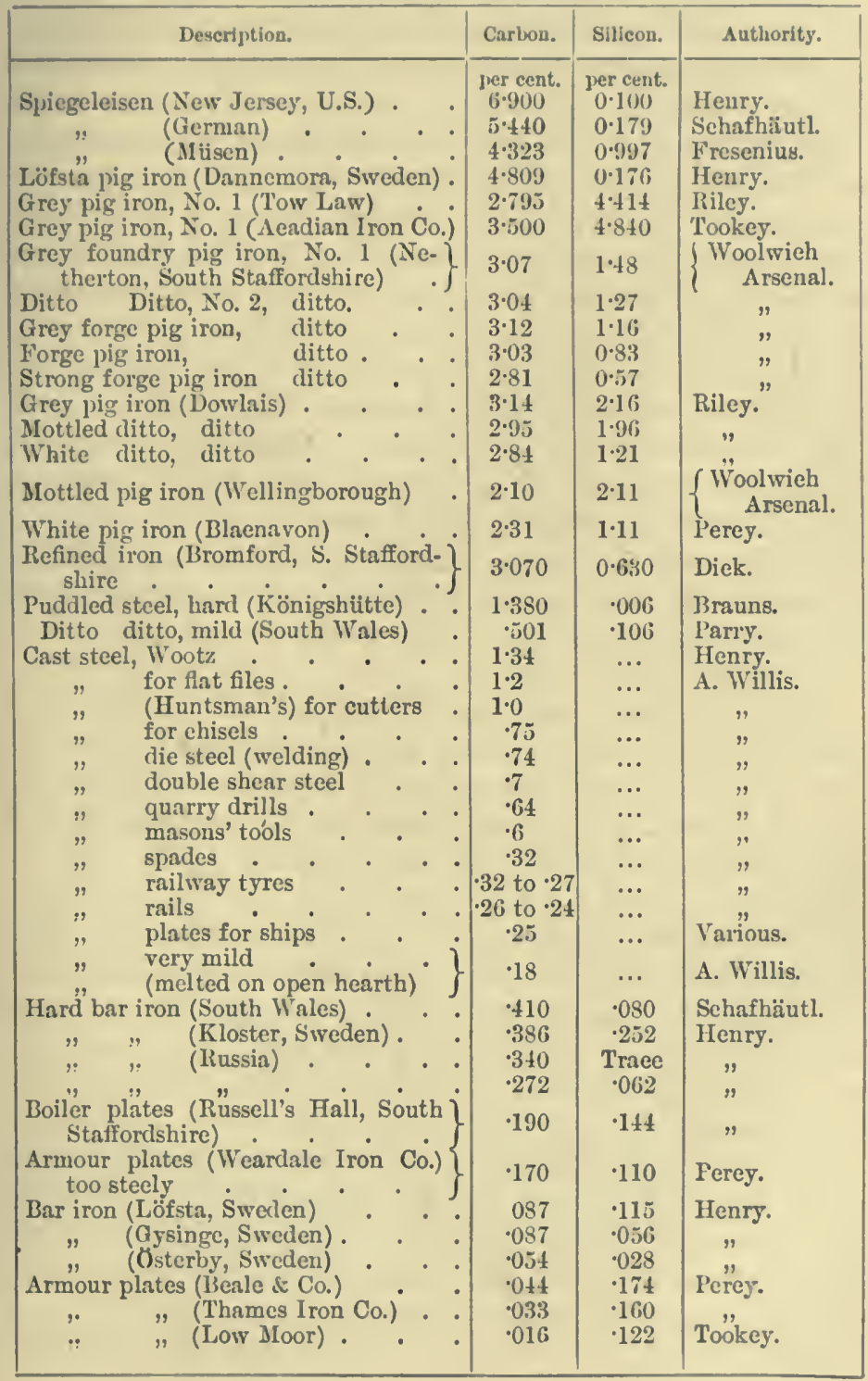


Mr. Siemexs said he quite agreed with most of the remarks that had been made.

Mr. Bramwell's way of putting the loss of iron was quite correct, and if ever the puddling process was brought to an absolute state of perfection the saving would in some cases be 20 per cent. instead of only 12 per cent. as at present. Undoubtedly what was saved in weight, was due to the improved chemical action, as named by Mr. Hawksley and Mr. Mallet, and he was glad to find that his explanation of the theory of puddling was so readily appreciated. both by chemists, in Section B, where his paper had also been read, and by engineers. In working it out he admitted at once that he had had the benefit of special advantages, by being able to exclude nearly all free oxygen whilst he was working with a very high temperature, much higher indeed than usual.

In answer to Mr. Mallet's remark as to the use of the new furnace for other metals, he might say it was now being used for zinc, lead, and other ores, with great success.

He was happy to be able to relieve Mr. Jones's mind of the impression that the furnace cost $£ 3,000$; the cost of a pair of puddling furnaces and their gas producers was $£ 450$, or $£ 225$ per puddling furnace complete.

Caking coal, brown coal, free burning coal, and peat, \&c., \&c., had been in daily use for years in the gas producers with excellent effect, indeed the arrangement offered a means of utilising for operations requiring high temperatures, several descriptions of fuel that had never been used for the purpose before.

He certainly did not heat the boilers in a mill with the waste heat from the puddling furnaces, simply because he had no "waste heat" to throw away; all he made he used, and for the highest or best paying purposes. With regard to the last objection that had been raised, he was happy to say he had not found any difficulty with the workmen, they had, in fact, after a few days' work at the furnace, taken to it very well indeed; he was sorry to say that it was with the masters only that he had any trouble, and he simply mentioned it as the contrary had been stated, but without the intention of finding fault with ironmasters, who would no doubt soon see that what was chemically right, and practicable, must also prove remunerative to themselves.

He would only add one word in explanation of the quality 
obtained, in reference to the remarks made by Mr. Cowper, Mr. Kolnn, and Mr. Hackney; Mr. Kolnn said the silicon might burn out on the surface of the melted metal, but he thought that the experiments he had produced clearly indicated that both the silicon and the carbon in the cast metal were oxidized by the oxygen contained in the fettling. He begged to say that he had not the slightest idea of suggesting that pig iron containing large quantities of silicon was preferable; he preferred the best, as every ironmaster did, but had given the effects of a furnace on a bad sample of iron as a severe test of its powers. There was no doubt that the practical improvement in the quality of the iron produced in his furnace was due, as Mr. Cowper had stated, partly to a mechanical cause and partly to a chemical one, for the purer flame of the furnace did far less injury to the iron, and the higher temperature at which the metal was balled up without being bumed, caused the cinder to be so much more fluid, as to run out better from the iron when squeezed, hammered, or rolled, thus excluding more thoroughly those bad welds, "blacks" and "greys," so plentiful in ordinary iron.

In the discussion of the Paper, and the Supplementary Paper,

"ON THE FURTHER UTILISATION OF THE WASTE

GAS FROM BLAST FURNACES, AND THE ECONOMIY OF COKE DUE TO INCREASED CAPACITY OF iURNACE," by Mr. Charles Cocirane, of Dudley,

Mr. C. W. Siemexs * said he had listened with great pleasure to the paper, combining as it did practical experience with theoretical considerations; and as regarded the chemical part of the question the argunents advanced secmed to be based upon correct

* Excerpt Minutes of Proceedings of the Institution of Mechanical Engineers, 1869 , pp. $33-36,39,42-43,62-68$. 
chemical proportions, although there was one of the conclusions arrived at that he could not agree with.

In reference to the plan of closing in the charging hopper at the furnace top with the additional covering now described, there could be no doubt that a saving of gas must be thereby effected; and although at first glance it might be thought that the amount of this saving would not be anything material, as the time that the furnace top was open on each occasion of charging seemed only momentary, it appeared from actual observation that this time of opening really amounted altogether to as much as 1-16th of the whole time of working of the furnace, representing a loss of 1.16th of all the gas evolved from the furnace. At the same time this loss was attended with the additional objection of interruption in the flow of gas to the boiler fires and hot-blast stoves where it was employed for heating purposes; and it was a decided advantage that these interruptions were now entirely obviated by the double closing of the furnace top.

With regard to the theoretical minimum consumption of $7 \frac{1}{2} \mathrm{cwt}$. of coke in the blast furnace for the reduction of 1 ton of iron from the ore, it was certainly true that, with an ironstone containing 40 per cent. of iron, $6 \frac{1}{2}$ cwt. of carbon would suffice to reduce 1 ton of iron from the ore by combining with the oxygen contained in the ore, and $1 \mathrm{cwt}$. of carbon in addition would be more than sufficient for the carbonisation of the iron, making the $7 \frac{1}{2}$ cwt. of carbon per ton of iron; but he did not see that sufficient heat could then be produced by the combustion of that reduced quantity of carbon in the furnace. Moreover he did not consider that it would be possible in practice to attain to this theoretical minimum consumption of coke by any addition to the height of the blast furnace. A small additional amount of heat might indeed be absorbed from the waste gas by raising the furnaces still higher than at present, but this process could not go on indefinitely, and there would still be a certain surplus of heat that would escape; because the combustion of coke by atmospheric oxygen that was necessary to effect the fusion of a given quantity of reduced ore at a high temperature must always leave a certain margin of heat available for reducing and heating the incoming ore. Moreover as the incoming ore was limited in quantity and possessed only a limited capacity for heat, it followed 
that eren if it were a perfect conductor of heat and presented an unlimited exient of surface for absorbing the heat from the gas, there would still be a certain amount of heat that would escape at the furnace top; and in increasing the height of the furnace, a neutral point would speedily be reached, beyond which no further increase of height would produce any further absorption of heat, for the reason that the quantity of ore charged could not on the arerage exceed the quantity of ore smelted during the same interval of time, and its relative capacity for heat could not be increased by an augmentation of heat-absorbing surface. The saving consequent upon increased capacity of the blast furnace rould continue to increase until a certain minimum consumption of fuel was reached, but this would not be the theoretical minimum assigned by chemical calculations. The ore could not do more than take up a certain amount of heat from the gas; and supposing that its capacity for heat were sufficient to reduce the temperature of the gas down to $500^{\circ}$ or $400^{\circ}$, that would be the temperature at which the gas must then escape, and no further saring would be possible. If the relative quantity of ore that could be charged into the furnace were indefinitely great, then indeed the escaping gas could be cooled down as low as the temperature of the external atmosphere; but inasmuch as the quantity of ore charged into the furnace top was the same as the quantity smelted in the lower part of the furnace, this ore could not absorb more than a certain maximum quantity of heat, and all the surplus heat in the waste gas must escape. 'There was also the further question whether with anything like such a small proportion of coke a sufficient temperature could be obtained in the furnace to ensure the perfect fusion of the ore : for this purpose an infinitely high temperature of blast would be requisite, but with a blast at only $1000^{\circ}$ temperature it would certainly be impossible to attain to anything like the theoretical minimum consumption, which left no margin at all of extra carbon for producing the heat required for smelting the ore; and it must be borne in mind that the mere transfer of oxygen from the ore to the carbon was not attended by any erolution of leat, but by an absolute absorption of heat.

Mr. C. W. Siemens did not understand how the temperature of rol. 1. 
the escaping gas could be independent of the rate of driving of the furnace, unless an excess of heat-absorbing surface had been provided; because with a greater rate of driving, a given extent of surface would then be called upon to absorb a greater quantity of heat in the same time. When the extent of cooling surface of the materials was so proportioned as to reduce the temperature of the escaping gas to a certain degree, short of the ultimate attainable point, only a small further quantity of waste heat would be absorbed by passing a greater quantity of gas over the same amount of surface in the samc time, and the consequence would be that the gas would escape hotter; just as, in the case of a steam boiler, a small extent of boiler surface caused a hot chimney. This question however was independent of the chemical advantages that might be obtained by hard driving.

Mr. C. W. Siemens thought the illustration suggested of the firebrick regenerator in the hot-blast stoves was not a parallel case, because the area of cooling surface of the firebrick in the regenerator was practically unlimited, on account of the means afforded of reversing the direction of the current through the regenerator as often as desired, whereby the points of maximum and minimum heat might virtually be separated by any distancc required. There was no means of taking up a greater quantity of heat from the escaping gas in the blast furnace, because there was only a limited quantity of material, which was heated by a fixed quantity of gas; for although in any particular quartcr of an hour it might be possible to fill in more material than corresponded to the average rate of smelting, yet in the course of a week the total quantity of ore put in was exactly the quantity smelted; and for absorbing the extra heat generated in smelting 1 cwt. of ore at the bottom of the furnace it was not possible by any means whatever to add more than 1 cwt. of fresh ore at the furnace top, with the proportionate quantity of the other materials.

Mr. C. W. Siemens remarked that at the previous meeting, while appreciating the value of the facts brought forward in the paper then read, he had been unable to agree with the conclusion 
arrived at as to the quantity of coke that should be sufficient for smelting a ton of iron in a blast furnace having a capacity carried to the ultimate limits then indicated. The $7 \frac{1}{2}$ crts. of coke per ton of iron, which had been originally named as the theoretical minimum consumption, represented no more than the carbon necessary for combining chemically with the peroxide of iron or calcined ore, and for carbonising the reduced metal so as to bring it into the state of ordinary pig iron; and the idea that it would be theoretically possible, by any increase in the capacity of the blast furnace, to bring down the consumption of coke to that amount, arose from the error of taking a simple arithmetical progression to represent the saving of coke consequent upon successive additions to the size of the furnace. In the supplementary paper now read however, an amended calculation had been offered, by taking into account the reduced capital, that is the reduced quantity of coke in the larger furnaces, upon which the percentage of saring had to be estimated; so that the same percentage of saving, out of a total consumption which was diminished by each successive addition to the capacity of the furnace, represented a less and less absolute saving as the size of the furnace was increased. In this way, considering only the question of abstracting the heat from the escaping gas, the result now arrired at had been that 17.9 cwts. of coke per ton of iron was the limit of minimum consumption that could be attained by simply adding to the height of the furnace. No account however had been taken of the chemical work that had to be constantly performed within the blast furnace; and moreover the additional quantity of heat that could be taken up from the gas by merely adding more material in the furnace top would be found, he considered, to be a very small amount. For although he had shown that, by means of the regenerative system, with a quantity of cooling material relatively very much smaller than was contained in a blast-furnace top, it was quite practicable to take up the heat from the outgoing current down to within $20^{\circ}$ or $30^{\circ}$ of the incoming draught, yet this was only the case so long as the two opposite currents were equal in the amount of their total capacity for heat; but if the current passing in one direction through the regenerator had a different total capacity for heat from that passing in the opposite direction, then whatever extent 
was given to the cooling material or regenerator, equilibrium would never be established, and it would not be possible to cool down the escaping current to the temperature of the entering draught; or, applying this argument to the case of the blast furnace, it would not be possible to cool down the escaping gas to the temperature at which the fresh materials were charged into the furnace, owing to the inferior total capacity for heat of the latter.

With regard to the amount of chemical work which was required to be performed in a blast furnace for smelting a ton of iron, he had made a calculation, the results of which it might be interesting to compare with those that had been arrived at by adapting to the Cleveland furnaces the investigations of the foreign writers referred to, whose researches upon the subject he had not previously been acquainted with. In the case of Cleveland ironstone containing 40 per cent. of metallic iron in the calcined ore, the iron being in the state of peroxide had 17 per cent. of oxygen combined with it, and the remaining 43 per cent. of the ore would be silica. To fuse this 43 per cent. of silica, which was equal to $21 \frac{1}{2}$ cwts. per ton of iron made, 7 cwts. of calcined limestone would theoretically be required, but in reality he believed 8 or 9 cwts. of limestone was the quantity generally added in the Cleveland district; these would take up about $2 \frac{1}{2}$ per cent. of iron, giving a total of about 31 cwts. of cinder per ton of iron made. The 17 per cent. of oxygen combined with the 40 per cent. of iron in the ore was equivalent to $8.50 \mathrm{cwts}$. of oxygen per ton of iron, and this would require 5.31 cwts. of carbon to produce the mixture of $\frac{4}{5}$ ths carbonic oxide and $\frac{1}{5}$ th carbonic acid which he believed actually resulted from the chemical reactions in the furnace; for although it had been calculated in the paper that the proportions in which these two gases passed off at the furnace top were about $\frac{2}{3}$ rds carbonic oxide to $\frac{1}{3}$ rd carbonic acid, he thought the difference should be allowed for the amount of carbonic acid evolved from the limestone, and that there would therefore be no material error in assuming the result of the combustion to be $\frac{4}{5}$ ths carbonic oxide and $\frac{1}{5}$ th carbonic acid.

The heat necessary to be produced in the blast furnace was therefore that required for performing the three distinct operations of melting the iron itself, melting the cinder accompanying 
the iron, and generating into a gaseous form the fixed oxygen in the ore and the fixed carbon in the coke, so as to allow of their chemical combination taking place. Considering first the heat required for melting the iron-taking the total heat developed in forming carbonic oxide as 4000 Fahr. units, and in forming carbonic acid 14,000 units - the combustion of $1 \mathrm{lb}$. of carbon into the mixture of $\frac{4}{3}$ ths carbonic oxide and $\frac{1}{5}$ th carbonic acid would develope 6000 Fahr. units of heat; and therefore-taking the specific heat of iron at 0.12 in comparison with water, and assuming the temperature to which the melted metal was heated (including its latent heat) to amount to $4000^{\circ} \mathrm{Fahr}$.- it would be found that to melt 1 toll of iron required $\frac{20 \times 4000 \times 0.12}{6000}=1.60$ cwts. of carbon. This estimate was evidently on the safe side, as no account was taken in it of the further heat necessary for keeping the iron melted in the hearth till casting time, which would hare raised the quantity of carbon nearer to the estimate of $2 \cdot 70$ cwts. giren by Mr. Bell. The $1.60 \mathrm{cwts}$, received a satisfactory confirmation from actual results which he had obtained in the working of cupolas, showing that the calculation was substantially correct. Next with regard to the cinder, taking its specific heat at $0 \cdot 20$, which he believed was below the mark, and assuming the total heat for melting it to be the same as that for iron, namely $4000^{\circ}$ Fahr., it would be found that the melting of $31 \mathrm{crts}$. of cinder per ton of iron made would require $\frac{31 \times 4000 \times 0 \cdot 20}{6000}=4.13 \mathrm{cwts}$. of carbon. In reference to the third supply of heat required in the blast furnace-for transforming into a gaseous state the fixed oxygen in the ore and the fixed carbon in the coke-it must not be overlooked that in the combination of carbon with oxygen, heat was only evolved in consequence of a reduction of volume occurring, and in proportion to the extent of that reduction of volume. But this could only take place when both bodies were already in a gaseous state; and accordingly by the combination of solid carbon with gaseous oxygen in the proportion of one equivalent of each, producing carbonic oxide, the amount of sensible heat evolved (4000 units) was less than half of that (10,000 units) which was further developed when a second equivalent of oxygen entered into com- 
bination with the gaseous carbonic oxide so as to form carbonic acid; because more than half of the total heat developed in the formation of the carbonic oxide (6000 out of 10,000 units) was rendered latent by the solid carbon having first to be volatilised before it could combine with the oxygen. The absorption of latent heat was necessarily still greater when the fixed oxygen in the ore had to be made to enter into combination with the fixed carbon in the coke, because a supply of heat had first to be absorbed sufficient for volatilising both the fixed oxygen and the solid carbon; and he had found practically that, where a mixture of ore and carbon was exposed in a close retort to the heat of a furnace, it was necessary to supply a large amount of heat in order to bring about a combination of the elements. In the combination of the $8.50 \mathrm{cwts}$. of oxygen of the ore in the blast furnace with the $5.31 \mathrm{cwts}$. of carbon of the fuel, two processes of opposite effect had to take place : on the one hand, the combustion of the carbon into the final mixture of $\frac{4}{5}$ ths carbonic oxide and $\frac{1}{5}$ th carbonic acid, developing 6000 Fahr. units of heat per lb. of carbon, would give a total of $5 \cdot 31 \times 112 \times 6000=3, \tilde{3} 68,320$ units of heat developed; but on the other hand, the volatilisation and separation from the iron of the fixed oxygen of the ore required the absorption as latent heat of, he believed, not less than 6000 Fahr. units of heat per lb. of oxygen, and the total absorption of heat thus occasioned would amount to $8.50 \times 112 \times 6000=5,712,000$ units of heat absorbed. The difference $2,143,680$ units, being an excess of heat absorbed, required therefore to be compensated by an extra consumption of $\frac{2,143,680}{6000}=357 \mathrm{lbs}$. or $3 \cdot 19 \mathrm{cwts}$. of carbon.

These three amounts added together gave $1 \cdot 60+4 \cdot 13+3 \cdot 19=$ 8.92 cwts. of ' carbon, to which had to be added the 7.43 cwts. required for chemical combination with the oxygen in the ore and for carbonising the pig metal, making $16 \cdot 35 \mathrm{cwts}$. of pure carbon. A further addition was required of 10 per cent. or 1.63 cwts. for ashes and water in the coke actually employed in the blast furnaces; and also another 10 per cent. or $1.63 \mathrm{cwts}$. for effecting the calcination of the limestone and completing that of the ore, and to allow for vaporising the moisture in the materials and for loss by radiation. The total amount was thus brought up to $19^{\circ} 61$ cwts. as the theoretical minimum consumption of coke 
necessary for the smelting of ons ton of iron. The complets consumption was therefore as follows :-

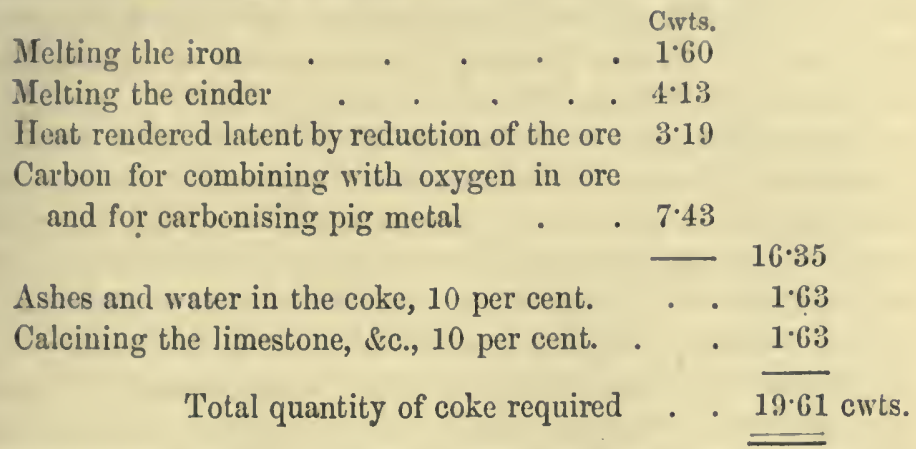

In this calculation he had left out of consideration on the one hand the heat that was carried off from the furnace by the escaping gas, and on the other hand the heat brought into the furnace by the hot blast entering at $1000^{\circ} \mathrm{Fahr}$; ; but on comparing these two quantities of heat it would be found that they balanced each other very nearly indeed. For the $8.92 \mathrm{cwts}$. of carbon made up by the first three items in the foregoing estimate would require, in order to produce blast-furnace gas consisting of $\frac{4}{5}$ ths carbonic oxide and $\frac{2}{3}$ th carbonic acid, $14 \cdot 27$ cwts. of oxygen, which would be contained in 62.04 cwts. of atmospheric air entering as hot blast; while on the other hand the gas escaping at the furnace top would contain the whole of these $8.92 \mathrm{cwts}$. of carbon and 62.04 cwts. of air, together with the $8.50 \mathrm{cwts}$. of oxygen existing in the ore and the $5.31 \mathrm{crts}$. of carbon supplied into the furnace to combine with it, making altogether $84.77 \mathrm{cwts}$. of gas, to which had to be added about 10 per cent. or $8.47 \mathrm{cwts}$. of carbonic acid and rapour of water generated from the limestone and other materials, thus making up a total weight of $93 \cdot 24 \mathrm{cwts}$. of gas escaping from the furnace top, in the form of carbonic oxide, carbonic acid, and nitrogen mixed together. Assuming the temperature of this escaping gas to be $600^{\circ} \mathrm{Fahr}$. and the specific heat of the mixture to be the same as that of air or 0.267 , the total quantity of heat thus carried off from the furnace would be $93.24 \times 112 \times 600 \times 0 \cdot 267=1,672,949$ units of heat per ton of iron made; and at the same time the heat brought into the furnace 
by the 62.04 cwts. of hot blast at $1000^{\circ}$ Fahr. would be $62.04 \times$ $112 \times 1000 \times 0.267=1,855,244$ units of heat, learing a small excess of 182,295 units of heat brought in by the blast per ton of iron made, which was probably not. more than would corer the loss of heat by radiation from the furnace.

The actual work done in one of the Cleveland blast furnaces represented therefore a consumption of between 19 and $20 \mathrm{cwts}$. of coke per ton of iron made, supposing the ironstone to contain only 40 per cent. of iron when calcined, and the blast to be delivered into the furnace at a temperature not exceeding $1000^{\circ}$; and under these conditions he believed no blast furnace could be constructed to work with less than that quantity of coke, although with richer ores and higher temperatures of blast there would of course be a considerable margin for further economy in consumption of coke. Practically speaking he thought that 22 cwts. of coke per ton of iron made would be the best result that would be obtained under these circumstances; and this would be independent of the capacity of the furnace, which might be increased indefinitely without improving upon this estimated minimum consumption.

In the discussion of the Paper

"ON THE DEVELOPMENT OF HEAT, AND ITS APPROPRIATION IN BLAST FURNACES OF DIFFERENT DIMENSIONS," by I. LowthiaN BeLL,

Mr. C. W. Siemers, ${ }^{*}$ who was receired with applause, said: I have listened with great interest to this paper, which, founded on practical information, deals with blast furnaces as an economical question. I think, in all operations, we should endeavour to look at the ultimate results we might possibly obtain, and

* Excerpt Journal of the Iron and Steel Institute, 1869-70, pp. 124-125 and 220-222. 
then try, in practice, to approach these results by the best means we can think of. The question of the chemical economy of the blast furnace was discussed, as Mr. Bell will remember, at Birmingham, some time ago ; and, in arguing the point, I disagreed witl some of the spenkers on the great results which might be expected from the mere increase of capacity. I could not see that this capacity, when it had attained a certain limit, could be beneficial as a mere absorber of heat in order to increase materially the economy of the furnace. I am glad to see Mr. Bell's elaborate investigations on the subject have caused him to take the view he has explained to us. At the discussion in Birmingham I rentured to state the minimum consumption of coke in a blast furnace in dealing with ore of a certain chemical composition. Mr. Bell, in giving the results of his investigations, based partly upon theoretical grounds, comes to a conclusion-and although the two investigations are totally distinct, for we view the question from different points of view-the results we arrive at are the same within a fraction. I came to the conclusion that the minimum quantity in smelting Cle reland ore would be $21 \mathrm{cwts.}$, and Mr. Bell's calculation comes to within $1 \mathrm{cwt}$. of that figure. This coincidence of result is, I think, the best proof that can be brought forward of the correctness of that view of the case. At this meeting we have had the whole question much more thoroughly bronght before us, and I think the paper will remain a standard paper on the subject. Mr. Bell made one very valuable suggestion with regard to the carbonization of iron in the blast furnace. He has discovered that iron ore absorbs carbon, and the amount of absorption probably rules the "number" of the pig metal produced. That is a new view of the question and a very interesting one. I, myself, have great belief in that view; it will serve to explain many apparent anomalies. The next question-that of hot blast-I am not so well prepared to agree with him. No doubt Mr. Bell has viewed the question very maturely, and I hesitate to differ from him with regard to results. But still, in viewing the question from a different point, I would come to a conclusion different from that of Mr. Bell, and probably, on comparing the ways, the result that we will arrive at may, perhaps, in some degree modify the figures placed before us at this meeting. Mr. Bell shows that by increasing the blast beyond the ordinary limits of $600^{\circ}$, it 
affects the economy in a very slight degree. My view is, that it would affect it very nearly in the same degree as an increase from $60^{\circ}$ to $600^{\circ}$ would affect it. I come to this conclusion for this reason. I view the general result of combustion in the blast furnace, and compare it with the general result of combustion in the heating stove. In the heating stove, you burn fuel into carbonic acid, and for every pound you burn, 13000 Fahr. units are evolved. This amount of heat absorbed by the air is carried into the blast furnace. Now, the action of the blast furnace-the combustion carried on there-is accomplished in a very different way. The quantity of heat imported into the blast furnace counts for more than double that expended in the heating stove. Considering that the capacity and the specific heat of the air at the higher and lower temperature is the same within a fractional amount, for every degree Fahr. by which the temperature of blast is increased, a proportionate amount of stone ought to be taken into the blast furnace. As Mr. Bell admits that by increasing the temperature of the blast he gets a higher proportion of carbonic acid at the top of his blast furnace, he admits that the effect will be an increase in ratio. In the measure in which jou increase the temperature of the blast, the amount of carbonic acid at the top of the blast furnace will augment, and the gas at the top of the blast furnace will diminish in volume. I am satisfied that an increase in the temperature of the blast must be highly economical in the results of the furnace.

\section{In the aljourned discussion of the same Paper}

Mr. C. W. Siemexs said: With regard to the question raised by Mr. Cochrane, I think I may be able to throw some light upon it by putting it in this way. If Mr. Cochrane finds the gases escape at $700^{\circ}$ at the top, and if he was then to throw in a load of ironstone, he would, no doubt, effect a temporary reduction of that temperature; but long before a corresponding amount of ore was smelted to make room for a further charge, the temperature of the escaping gases would have risen again to $700^{\circ}$ or rather more. In order to arrive at real temperature of issue, the ore should be fed, or supposed to be fed, in a continuous manner ; although, for the purpose of experiment, you can put in a heavy charge 
suddenly and effect a temporary reduction of temperature in that manner.

With regard to that point of your paper, sir, on which I took the liberty of differing from you at the last meeting, I must say that I still liold that the increase of temperature in the blast would produce a beneficial result, and the beneficial result would rise fully in the proportion of the increase of temperature. I think the chief point of difference between us on that occasion was, that you, Mr. Chairman, referred the result to a unit quantity of ore, whereas, I referred it to a unit quantity of blast; and I cannot help thinking that the latter is the correct way of taking it. The quantity of heat supplied depends upon the temperature to which we heat the blast; and if I can show that, for every unit of heat added to the blast, you produce an equal saving of heat in the blast furnace, then, I think, it is proved that increase of temperature benefits you to an unlimited extent. But I would go farther, and say that the benefit goes on in an increasing ratio; and I think we can show it fiom the facts which you have brought before us in so complete a manner. Your own figures prove that the higher the temperature of the blast, the lower is the temperature at which the gases issue from the top of the furnace. Therefore, this is no longer a question of a certain bank of heat which you can draw upon to the extent of its debit and no more ; but your bank of heat is an increasing one, because, in the first place, the gases escape at a lower degree of temperature, and, in the second place, the higher the temperature of the blast, the greater is the proportion of carbonic acid escaping from the furnace; which signifies that more heat is generated within the blast furnace, inasmuch as every pound of fuel burnt into carbonic acid produces, roughly speaking, three times the number of units than is the case when carbonic oxide is produced. These are two reasons, therefore, why the bulk of heat is very much increased by raising the temperature of the blast.

The Chairman. You are now referring to the Consett furnaces. Mr. Siemens. Yes, and to the other examples that have been given to the same effect. With regard to the rery ingenious argument which you put before us just now, regarding the negatire effect of increased temperature at the boshes, I am disposed to admit it fully in the abstract, and I am pleased to see such clear proportions 
established, regarding the chemical balance of affinities between carbonic oxide and carbonic acid, in contact with metallic iron at different temperatures. I am willing to admit these facts, which are new to me, to the fullest extent, but I would draw from them different conclusions, inasmuch as I cannot admit that the temperature in the blast furnace increases necessarily with the temperature of the blast. I believe the temperature of the blast furnace will, on the contrary, be practically the same, whether higher or lower temperature of blast is employed, and the renson why I come to that conclusion is as follows:- If blast of very high temperature is employed, the oxygen it contains takes up carbon very readily and is converted into carbonic oxide. Whereas, if a lower tempelature of blast is employed, there will be at once a large proportion of carbonic acid gas produced. The carbonic oxide gas would not nearly represent such an augmentation of heat as would be represented by the mixture of the two gases together, hence the reduced iron would, in the one case, be surrounded by an atmosphere of carbonic oxide with nitrogen only ; and in the other case, with a mixture, containing carbonic acid in variable quantity, but the very chemical balance just pointed out to us would tend to equalize the temperature in both cases. These conditions would, therefore, not alter the working of the furnace below, but the result of the higher temperature of the blast would make itself felt in the upper portion of the furnace where finally a higher proportion of carbonic acid gas, is realised when blast of high temperature is used. When these favourable circumstances are taken into account, we may expect, I submit, a continuance of the very beneficial result already realized by further raising the temperature of the blast, notwithstanding the interesting circumstances that you have brought before us. 


\section{In the discussion of the Paper}

\section{"ON THE STRENGTH OF IRON AND STEEL, AND ON THE DESIGN OF PARTS OF STRUCTURES \\ WHICH CONSIST OF THOSE MATERIALS,"}

\section{By George Berkiey, M. Inst. C.E.}

Mr. C. W. Sremexs* obserred that the paper contained a great deal of valuable practical information ; but he considered enough had not been said, on the one important question which had been raised, viz., whether or not there was a definite limit of elasticity in metals. It was stated in the paper, that a bar of iron 1 inch square would elongate with a strain of 3 tons to the inch, and would, on the load being gradually increased, continue to elongate up to a strain of 9 tons or 10 tons to the inch, beyond which point it was known that a more rapid rate of elongation commenced. These results seemed to imply that there was no definite limit where permanent elongation was produced, but in following up this argument the evident conclusion was, that the bar of metal of 1 square inch, if exposed for a great length of time to the moderate strain of 3 tons, must continue to yield, in the same ray as though its elastic limit was really exceeded, and must ultimately yield to that force. But all experience went directly against such a supposition. One of the most perfect experiments that could be tried on that point might be found in the old cathedrals of Italy, where heavy chandeliers weighing $\frac{1}{2}$ a ton, or more, had been suspended for hundreass of years, by long rods of not more than $\frac{3}{4}$ of an inch in diameter. If any permanent injury was produced by such a load, it would nu longer be safe to go into these buildings; and the heavy chandelier in the Pisa cathedral, which swung suggestively above the head of Galileo Galilei, must inevitably hare long since fallen to the ground. He thought practically that no one had any belief in any such action of time, but he was not disposed, on the other hand, to condemn such experiments as

- Excerpt Mlinutes of Proceedings of the Institntion of Civil Engineers, Vol. XXX. Session 1869-70, pp. 268-209. 
those of Hodgkinson and Fairbairn. Possibly it might be the case that, in subjecting a bar for the first time to a strain, elongation did take place, which might be explained in this way : it was conceded that in the manufacturc of a bar of iron internal strains must arise, owing to the different action of the rollers upon different portions of the material, and such "virgin" bar might be regarded as consisting of a number of aggregate fibres of metal strained one against the other, the internal metal, which had been the hottest, being permanently in tension, and the external metal in compression. In subjecting such a bar to a moderate strain, only the internal fibres would be permanently elongated, while the external metal would be simply released from compressivc strain, after which all parts of the bar would bear the strain equally, and this equalising of the active forces must necessarily be accompanied by a moderate stretch. Therefore, in order to ascertain the true limit of elasticity of a material, the first experiment upon a virgin bar should not be taken, but the strain should be continued till it had reached a certain moderate limit, when it should be reduced, and then the same series should be gone through again. In proceeding thus he thought it would be found that there was no permanent elongation till the true limit of elasticity was reached. This true limit of elasticity he regarded as being a very important point. Mr. Phipps had justly remarked that, in the long series of experiments on breaking strains, published by various authors, a conclusion was arrived at, more by guess than by scientific reasoning, to the effect that a load might be applied to, say, one-fourth of the breaking strain, with tolerablc safety, without any distinction being made regarding the limit of elasticity of the particular material under examination. It would be found, however, that two bars of metal, which might break at nearly the same point, and which miglit consist, chemically speaking, of nearly the same materials, would be capable of bearing with safety a very different load. The one might begin to elongate with less than one-half the breaking strain, and the othcr would not begin to elongate till two-thirds of the breaking strain had been reached. He had made some experiments with cast steel, which, being the most refincd and uniform metal, was best adapted for such experiments, proving these discrepancies according to the mode of its production; and he had no doubt 
that similar resnlts wonld be obtained with iron, thongh it might not be so easy always to obtain the same degree of regularity with that material. He thonght that the limit of elasticity of a materia! was of much greater practical importance to engineers than its ultimate breaking strain ; because a structure was safe if no part of it was loaded past the point of limit of elasticity, but must nltimately fail if that limit was exceeded.

\section{In the discussion of the Paper}

\section{"ON THE TESTING OF RAILS; WITH A DESCRIP-}

\section{TION OF A MACHINE FOR THE PURPOSE,"}

By James Price, M. Inst. C.E.

Mr. C. W. Siemexs* said that having lately made some experiments with steel rails and iron rails, he could bear out the author's remarks, confirmed already by Mr. Bramwell, as to the great susceptibility of steel to break under the influence of a shock. The paper which Mr. Bramwell read before the British Association $\dagger$ pointed out the reasons why it was so. In the case of an iron rail there were innumerable fibres capable of yielding indiridually to take a greater strain when necessary. Now in the case of steel which was homogeneous, no swch independent fibrons action could take place, and if one part of the line of strength was broken an indefinite amount of tearing strain was thrown upon the adjoining part. In trying steel rails under a blow, he found that where an entire rail would stand the impact of a ton weight falling 20 feet, in the case of a rail being supported rigidly between 3 feet bearings, a blow from a fall of only 4 feet of the same weight would break it at the place where the hole was drilled through the web of the rail. It followed from this experiment that in drilling or

* Excerpt Minutes of Proceedings of the Institution of Civil Engincers, Yol. XXXII. Session 1870-71, pp. 206-208.

+ Vide Report of British Association, 1859, p. 422. 
punching a number of holes through a rail the strength of that rail was diminished to less than one-fourth, as measured by a falling weight; and this fact should lead to the preference being given to a mode of fastening in which no such holes were made. It was true that in ordinary use no such working strain as the weight of a ton falling through a number of feet was put upon a rail ; but engineers liked to err upon the right side in a question of safety, and were justified, he thought, in giving the preference to steel rails of mild or ductile quality; for if the steel was not of tough quality, there was danger of its being hardened by accidental exposure to cold during manufacture. Steel containing more than $\frac{3}{10}$ per cent. of carbon would become very brittle if by accident it was thrown into water when red hot; and such a rail might break with a very slight shock. In France it was the habit to make steel rails containing $\frac{8}{10}$ per cent. of carbon, and as far as wearing qualities were concerned French engineers were right; but there was some danger in using such rails, particularly if the continuity of the rail was broken by holes. Therefore he did not agree with the author in his assertion that the test by blows was altogether inadmissible : he thought it a desirable test to apply along with others. The particular test which the author proposed was valuable in so far as it proved the fair wearing quality of the material; but he did not consider it sufficient as a test for the wearing quality of rails under the most trying circumstances. Mr. Bramwell had pointed out one of the reasons why it was not sufficient, inasmuch as it did not provide for the propelling action of the driving-wheels on the rail. But, he might have added, it did not provide for the sliding action of the wheels. Upon inclines the wear and tear of rails was much greater than on a level road; and that was owing, not to any increase of weight, but to the different mode in which that weight passed along the surface of the rails. If the load merely rolled over the surface, the effect upon the rails was very different to what it was if the same weight slid over it, burnishing or trying to dislodge every particle from its neighbour. The machine therefore appeared to him to be incomplete, unless some means of testing that sliding action upon the rail were provided in addition to the rolling action. If stopping the rotation of the wheels would not lead to the expenditure of too much power, it would provide a means of subjecting 
rails in a short space of time to a test which, in the ordinary working of a railway, would only be obtained after some months, or eren years, of trial. But if any railway company were publicminded enough to devote a length of their main line, where there was a steep gradient or a terminal station for experimental purposes, placing the same at the disposal of engineers to put down their rails, such a trial would be as valuable, perhaps, as any that could be desired.

In the discussion of the Paper

"DESCRIPTION OF TWO BLAST FURNACES ERECTED IN 1870 AT NEWPORT, NEAR MIDDLESBROUGH,"

\author{
By Berminard Sajuelison, M.P., M. Inst. C. E.,
}

Mr. C. W. Siemexs * observed that the information contained in the paper and elicited by the discussion went far to show that, by carrying out a chemical operation on a large scale, the utmost results which theory indicated could be almost realised. Two years ago, when the question of large furnaces was first mooted, he made a calculation of the work done in a blast furnace, and of the heat that was developed in that blast furnace. By taking into account, on the one hand, the ore to be heated and reduced, the pig to be melted, the slag to be melted, and the heat and composition of the escaping gases at the temperature at which they were carried away; and, on the other hand, the temperature of the blast and the heat due to its combustion with coke, in producing the gascous mixture escaping from the top of the blast furnace, he found that $20 \mathrm{crt}$. of ordinary coke should suffice theoretically to smelt a ton of pig iron from Cleveland ironstone containing 40 per cent. of metallic iron, and that $21 \mathrm{cwt}$. per ton of iron was a result that might be practically realised. Assuming

* Excerpt Minutes of Proceedings of the Institution of Civil Fngineers, Vol. XXXII. Session 1870-71, pp. 361-364.

YOL. I. 
the temperature of the blast at $1000^{\circ}$, the best results at that time were about 26 cwt., but it struck him that Mr. Samuelson had obtained the calculated minimum result almost completely; his consumption being $20 \frac{1}{2}$ cwt., and the temperature of blast about $1100^{\circ}$. Mr. Bell arrived at nearly the same figures by another mode of reasoning, and had followed up this subject very minutely, by examining into the particular stages of the chemical operation carried on in the blast furnace, deducing very valuable data for the metallurgist.

Nevertheless, he would not recommend others to follow Mr. Samuelson under all circumstances in the construction of a blast furnace. He was at that moment constructing some blast furnaces of very different dimensions ; they would only have a cubical capacity of 10,000 feet instead of 30,000 feet ; for he believed it would be inexpedient in this case to adopt such extreme dimensions. It would require the peculiar conditions of the Cleveland iron district in order to do so with advantage ; namely, an excellent hard coke and an ironstone rather strong and comparatively poor. For richer ore and tender coke he believed the size of blast furnace such as Mr. Samuelson had described would be inapplicable.

With regard to the effect of extreme capacity, he agreed with Mr. Bramwell's views, while at the same time he admitted that Mr. Forbes's remarks were perfectly correct. But Mr. Bramwell spoke of the mechanical absorption of heat-the regenerative action within the blast furnace; - on the other hand Mr. Forbes spoke of the chemical action between the gases of the blast furnace and the ores; and both these actions were subject rery much to the same laws. To get from the fuel a maximum of effect in a steam boiler plenty of heating surface was given, as in the case of the Cornish boilers ; and it was reasonable to suppose that more surface would give superior results, simply because the difference of temperature between the heat-transmitting current and the heatreceiving surfaces was brought down to a minimum. Where a current of gas flamed rapidly among a mass of solid matter, there must be a considerable difference of temperature between each particle of the fluid and the solid receiving that heat: whereas, if the mass was greater, and the current relatively slower, there must be a more perfect adjustment between the two temperatures, 
giving rise to a more economical result. In the same way the chemical action wonld be more perfect if a gas containing a certain proportion of carbonic oxide (mixed with carbonic acid and nitrogen) had plenty of time to communicate its carbon to the piece of ore which was ready to take it in yielding up its oxygen. If the quantity of material present were infinite a perfect adjustment between these conditions would arise, depending upon the temperature and the proportional amonnt of carbonic oxide present; but such a condition of equilibrium could never be obtained. It was therefore necessary in practice to consider how much would suffice for the purpose, because other considerations entered into the subject. If a blast furnace was very large in proportion to the quantity of work that was to be performed in it, a greater economy would be attained by a relative increase of first cost. 'This was the case in Mr. Samuelson's blast furnaces, where 30,000 cubic feet capacity produced only 500 tons of pig metal per week; whereas a furnace with a capacity of 10,000 or 11,000 cubic feet would produce 300 tons. It was therefore clear that these large furnaces produced approximately only about one-half the amount of work per cubic foot of capacity that the smaller furnace did. The question arose how far was it judicious to expend more capital to obtain additional saving, if other means might be resorted to of arriving at the same, or even a greater increase of economy. This point had not been touched upon in the course of the discussion. Mr. Bramwell had shown that where there was a greater outgoing current than a heat-absorbing material to meet it, an unstable condition or waste of heat must ensue ; and Mr. Forbes has argued in the same way on chemical grounds. In the blast furnace the object was to waste as little heat as possible, and to bring out the gases at the top as cool and as thoroughly deprived of their chemical or reducing power as was practicable. Both these objects were obtained by diminishing the relatire quantity of gases. If, for instance, the relative amount of gases for a given amount of incoming material could be reduced by one-half, and if the chemical conditions were the same, it was clear that the smaller quantity would be more thoroughly deprived of its heat; but the smaller quantity would have had time to divest itself more thoroughly of its chemical action also : there would be a larger relative amount of carbonic acid gas produced, 
and the coke would be consumed in the furnace to greater advantage. This could be accomplished by a blast of high temperature; and in this respect his opinion differed very much from the theory of Mr. Bell, to the effect that there was a theoretical as well as a practical limit to the beneficial heat of hot blast. He believed, on the contrary, the blast could not be made too hot for economical purposes, and that real progress in iron smelting must henceforth be looked for chiefly in that direction.

\title{
In the discussion of the Paper
}

"ON THE CONDITIONS WHICH FAVOUR, AND THOSE WHICH LIMIT, THE ECONOMY OF FUEL IN THE BLAST FURNACE FOR SMELTING IRON,"

\author{
By Isaac Lowthian Bell, Assoc. Inst. C. E.,
}

Mr. Siemens* said that Mr. Bell had watched blast furnaces more carefully than almost any other metallurgist. Some of the facts brought out in this paper were extremely interesting; amongst others the proof that the reduction of iron ore was a source of heat instead of, as was more generally supposed, the cause of loss of heat; and that reduction was effected at so low a temperature as $420^{\circ}$ Fahr. Mr. Bell had endeavoured to show that in the blast furnace the different operations, constituting the process of smelting, might be carried on in such a way as virtually to complete one process before the other commenced; and from this the somewhat astounding conclusion was arrived at, that nearly all the advantages derived from the hot-air blast might be realised by simply increasing the size of the furnaces. The argument was not pushed to the practical conclusion, that the capacity of the furnace should be increased to the point of realising all the

* Excerpt Minutes of Proceedings of the Institution of Civil Engineers, Vol. XXXIV. Session 1871-72, pp. 133-136. 
advantages of the hot blast, but the permissible temperature was limited to $960^{\circ}$ Fahr., at which point it was considered that the maximum effect could be had with a furnace of limited capacity. 'This argument was based upon the supposition that iron ore was reduced at $420^{\circ}$ Falr. ; and that the second action, which was that of carbonic acid splitting up in contact with carbon, could only be accomplished at a higher temperature. If, therefore, the carbonic acid had all been split up in contact with carbon, and a zone had now been reached at which no more unburning of carbonic acid took place, the whole remaining capacity of the furnace would be reserved for the final action-that of the reduction of the ore to the metallic condition, and the production of a large proportion of carbonic acid gas in the gases leaving the furnace. He thought, however, that iron ores, as a rule, were not reducible at the extremely low temperature of $420^{\circ} \mathrm{Fahr}$., which was really below that of incandescence. In dealing with calcined Cleveland ore he had no wish to doubt the fact, but if it was considered what this ore consisted of, it would be seen why its reduction and carbonization took place at that low temperature. In calcining Cleveland ore 25 per cent. of volatilised matter was evolved; therefore the calcined ore must be regarded as a sponge, consisting of extremely divided particles of iron ore. This sponge being brought into contact with the reducing gas, the carbonic oxide was mechanically absorbed in large quantities, and the reduction of the ore facilitated. The sponge into which Cleveland ore was converted by calcination might in effect be compared to platinum sponge, which, when a current of hydrogen gas was directed upon it, absorbed that gas so violently as to produce ignition. Again, when a solid bar of iron was exposed to a dry atmosphere, no appreciable oxidation would take place in one hundred or eren in one thousand years. There were iron bars which, in o.u' Roman buildings, had been exposed to the atmosphere for two thousand years and were not oxidised; but the same iron in a pulverulent condition would take fire instantly in a room, showing that the same material would behare differently under similar circum. stances, according to its aggregate conditions.

He had paid considerable attention to the reduction of iron ores, and he had found that, whereas hydrated ores or spathose ores were reducible at a low temperature, the peroxides required a 
higher temperature; whilst there were certain ores which were not reducible at a temperature below $1500^{\circ}$ or $2000^{\circ}$ Fahr. Those were the dense magnetic oxides which had no gases to give out, but were perfectly dense, like a piece of glass. Such compact ores, he believed, were not reduced in the upper part of the blast furnace in the way supposed-viz., by a current of carbonic acid, but only in a lower part of the furnace after they had become liquid. Certain ores, such as Ilmenite or Marbella ore, had been known to pass through the blast furnace and to come out unchanged with the slag, notwithstanding the heat through which they had passed. He thought if such pieces of ore could tell a tale, they would speak of actions and reactions going on in the blast furnace which did not altogether tally with the heautiful stratifications Mr. Bell had shown. The author's conclusion, that the hot blast could not be beneficial beyond a certain point, was mainly based upon the argument, that with the temperature of the blast the heat towards the top of the furnace was also increased. But the temperature of the blast affected the temperature at the top of the furnace in the contrary way to what Mr. Bell had in his argument supposed. If the temperature of the blast were suddenly raised, then indeed a rise would be perceptible throughout the furnaces, and the gases would escape at a somewhat higher temperature. In that case the same amount of oxygen would be introduced, and the same amount of carbon accompanied the charge ; therefore there must be the same proportion of carbonic oxide and of carbonic acid issuing at the top, with an increase of temperature resulting from the greater importation of free heat with the blast. But if at the same moment when the temperature of the blast was raised, the relative quantity of coke in the furnace could be diminished, to the point of producing not more than the requisite amount of heat, then a diminished quantity of products of combustion would have to impart its heat to the same quantity of ore; and inasmuch as the relative quantity of matter to be heated and smelted would be increased, it followed that the temperature of the escaping gases must be less than before, and that there must be advantage in raising the temperature of the blast.

As to the effect of the increased temperature of the blast upon the temperature of the crucible of the blast furnace, he had 
explained his views very fully on a former occrsion, when the nuthor of the present paper argued on the other side of the question.* He might now state that, in advocating high temperature of blast, he did not look for any great increase of heat in the zone of fusion. He looked for the advantages of hot blast to the greater importation of heat into the whole economy of the blast furnace, resulting, he believed, necessarily, in great saving of fuel.

In the statements of results which were frequently put forward, certain elements were generally wanting; and the most important of these was the relative quantity of blast used. If the temperature of the blast was increased without its being stated whether the same quantity was injected relatively to the amount of carbon in the charge, no positive conclusion could be arrived at ; but these discussions would assurne a more definite character, if the amount of blast was in all cases stated, and if the working of the furnace was only taken after it had been readjusted after a change of temperature to a minimum percentage of carbon with the charge. It could be easily conceived that with too much carbon the blast would produce an excess of carbonic oxide, and this would issue at the top of the furnace at a very moderate temperature. It might be argued, in that case, that the hot blast produced unfavourable results; but if an increasing quantity of ore had been mixed with the coke, and the proportion gradually increased with increased temperature of blast till a positive minimum, to insure fusion of the mass, had been reached, the result would have been much more favourable. The general basis which he went upon was, that if free heat was imported into the furnace with the blast, that heat was produced economically in burning fuel into carbonic acid; whereas the blast furnace could at most produce carbonic oxide, with a proportion of, say, $\frac{2}{5}$ th or $\frac{1}{4}$ th of carbonic acid. The author had clearly shown that, in producing carbonic oxide, only about th the amount of heat was produced from a given quantity of coal as when carbonic acid was formed. Therefore every unit of heat applied to the blast outside the furnace represented really 3 units of heat produced by the combustion of coke within. ante.

* Vide The Iron and Steel Institute-Transactions, Vol. I. P. 222 ; see p. 264, 
In the discussion of the Paper

"ON THE PRACTICAL WORKING OF DANKS'S ROTARY PUDDLING MACHINE,"

By Mr, JoHN Iisster, Wolverhampton,

Mr. Simmexs * said he congratulated the members of the Iron and Steel Institute on the very able reports which they had received on the subject of Danks's rotary puddling furnace. He had listened to these reports with great interest, and it seemed as though the facts brought out conclusively proved the value of the apparatus that had been brought before them. That was not the first attempt at a rotating puddling apparatus, as they well knew. $\mathrm{He}$ had, many years ago, seen the apparatus, erected, at Dowlais Works, by Mr. Menelaus, and he looked with regret at the difficulty which prevented its practical success. That difficulty had, to all appearance, been overcome by Mr. Danks, by the introduction of a judicious fettling material. In the report mention was made of one or two points which called for remark on his part. In one of them, by Mr. Jones, a paper "On Puddling Iron" was mentioned, which he (the speaker) read some years ago before the British Association, setting forth a theory of puddling which had been much criticised by practical ironmasters, but which was very fully confirmed by the results obtained in the Danks furnace. The reports in question expressed some surprise at the greater yields realised in puddling grey iron than in puddling white iron. Now, he would submit that his paper furnished a complete explanation of that result. He there endeavoured to prove that puddling was, strictly speaking, a chemical reaction between fluid cinder and fluid cast-iron, and he showed that for every pound of carbon in the metal, 3.5 pounds of metallic iron have necessarily to be reduced and added to the charge. In like manner, for every pound of silicon in the metal 2.8 pounds of metallic iron had to be produced. If, therefore, his theory was

* Excerpt Proceedings of the Iron and Steel Institute, 1872, pp. 293-295 and 314-315. 
correct, it followed that a pig metal, rich in carbon and in silicon, would give greater yields than a metal containing those foreign substances in smaller proportion, or that grey pig metal would produce larger yields than white iron. The report also made Inention of the possible application of this furnace to what was called the "Siemens-Martin" process. He could not fall in with that view. It would be very difficult to realise such a temperature in a rotating furnace as was required for carrying out a process in which they had five or six tons of almost pure iron in a fluid condition-iron containing about one-tenth per cent. of carbon. Another fatal circumstance would be that the lining of the Danks furnace was composed of oxides of metal, and in the presence of oxides of metal they could not have fluid mild steel. The steel would immediately part with its small percentage of carbon, and become wrought metal. Therefore, it could not be applied, he felt certain, to carrying out that process. But he might remark that some years ago his attention had been directed towards a rotating apparatus, not for puddling, but for accomplishing just the reverse operation - that of reducing oxides into the metallic condition. He had steadily followed out those experiments, and before long he might have the pleasure of bringing them before the Institution. Before sitting down he wished to express that he was entirely satisfied with the able, and evidently strictly impartial, reports which they had received.

Mr. I. Lowthian Bell said he should like to put one question to Mr. Siemens, who mentioned that the richer the pig iron was in silicon, the better the yields. That, he supposed, he ascribed to the action of silicon upon the oxide of iron. But he (the speaker) believed a very general impression prevailed amongst puddlers that that could only be true to a moderate extent; because the silicon, by taking the oxygen, was changed into silica, and that, not being able to exist in a puddling furnace in its uncombined state, combined with oxide of iron, and was thereby a source of waste.

$M r$. Siemens in reply stated that with regard to the carbon, the result had been proved in the most conclusive manner, by experiments which he himself had made in the regenerative gaspuddling furnace. The richer the pig iron was in carbon, the greater was the yield of wrought metal produced. The same 
chemical reason and the same practical result applied to silicon, although he would quite admit certain drawbacks, which Mr. Bell had alluded to, to the presence of much silicon in the pig metal. The silicon in the pig metal had to be combined with oxide of iron to form a tribasic slag, and this oxide of iron had to be supplied by the fettling. Therefore, if they puddled an iron coutaining much silicon they would require an extra amount of fettling to dissolve the silicon afterwards in the slag, and in the absence of this extra supply of fettling the operation would not progress favourably; but the chemical reasoning still held good. They could obtain from pig metal rich in silicon a larger yield than from the same pig metal containing no silicon, the simple reason being that the atomic weight of silicon was considerably less than the atomic weight of iron. In his paper read before the British Association he had shown that in puddling ordinary forge pig iron the theoretical increase of weight was about 8 per cent., and that he had already obtained weight for weight in practical puddling-taking the average result of six months' workingwithout using more fettling ore than was necessary under all circumstances to accomplish the operation.

Mr. Sreurens said he had certainly misunderstood the remarks made by Mr. Jones on the previous day, perhaps it was because he had not explained them fully. $\mathrm{He}$ had understood that Mr. Jones thought it possible that the Siemens-Martin process of making steel could be carried out in the Danks furnace. If the question was one of puddling Cleveland pig so as to make it suitable for this process, he would not say a word against it, except that he must see the analysis of the puddled material before he made up his mind as to its merits. If that analysis were shown to him he would be able to say at once whether the metal was suitable or not for the Siemens-Martin process, because he knew exactly how much phosphorus and how much sulphur he could do with; and if in the first instance Mr. Samuelson had put clearly to him the question whether he would be able to make steel from Cleveland pig, he (the speaker) would most decidedly have told him that he did not believe he could. He thought it could not be done unless they could show him that they could remove phosphorus to a much greater extent than the ordinary puddling 
furnace had yet accomplished. With regard to the yield he agreed entirely with the views that had fallen from Mr. Snelus, and which were in couformity with the cliemical reasoning the speaker had advanced in his paper on puddling iron. He had showed on that occasion that he could gain 8 per cent. in puddling Cleveland pig in a theoretically perfect manner, and he fclt glad to see that results so near perfection had been realised with the Danks furnace. Hc accorded with Mr. Danks's view that it was not at the expense of the fettling ore that they obtained the increase. In the ordinary furnace it happens that although they had much silicon in the pig metal, a portion of that silicon was burnt off by the direct action of the flame, but in a furnace where therc was but little oxidation by flame, very little of the silicon was burnt, and the great bulk of it was oxidised by chcmical re-action with the oxides of iron present; but they must have the oxides present, no matter whether they intended to make iron of them or not, and the difference between economical and wasteful puddling was due to whether they retained the iron from these oxides, or whether they wasted it after getting it. In Mr. Danks's furnace, and also in a regenerative gas furnace, if properly conducted and worked, they need not wastc the iron, and they could then at least get "weight for reight."

\title{
ON SMELTING IRON AND STEEL.
}

\author{
By C. Willitar Silmess, D.C.L. (Oxon.), F.R.S.*
}

[A Lecture delivered before the Chemical Society, Bfarch 20th, 1873.]

ON the 7 th of May, 1868, I had the honour of addressing you on the subject of " the regcnerative gas furnace $\dagger$ as applicd to the manufacture of cast steel," my object being at that time to point to the important part which that furnace was likely to play in such metallurgical processes where intense heat is required. At that time I described a method of producing cast steel upon the open hearth of a regenerative gas furnace by the dissolution either

* Excerpt Journal of the Chemical Society, 1873, pp. 661-678.

+ The joint invention of C. William and F. Siemens. 
of scrap iron or of ores in a more or less reduced state in a bath of intensely heated pig metal. These processes have now received very considerable practical development at the works of the Landore Siemens-Steel Company, of Messrs. Vickers and Company of Sheffield, and at several other works. Two processes are employed at these works, the Siemens-Martin process, which consists in dissolving scrap metal or steel in a bath of pig metal to which spiegeleisen is finally added, and the ore-reducing process in which pig metal and ore in a more or less reduced condition are employed.

The process chiefly employed at the Landore works consists of introducing on the bed of an intensely heated regenerative gas furnace, as shown in Plates 43 and 44, about six tons of pig metal, which may be No. 3 or 4 hematite pig. When a fluid bath has been formed, oxide of iron (which should by preference have been melted beforehand with such proportions of lime or other fluxing materials as to form with the silica in the ore and in the pig metal a fusible slag) is added, or natural ores may be used in their raw condition if they contain lime and manganese, as, for example, the African Mokta ore. When about $30 \mathrm{cwt}$. of this ore have been dissolved (with ebullition) in the metallic bath, it is found that a

- sample taken from it contains only about 0.1 per cent. of carbon; a point which can easily be detected by the eye of the workmen owing to a peculiar bright appearance of the sample when chilled in water and broken by the hammer.

In order not to pass beyond this point, samples are taken out from time to time during the latter part of the operation, and such a series of samples, which have been kindly supplied to me by Messrs. Vickers and Co., together with samples of steel made by the process, are now placed before you. The requisite point of decarburisation being reached, the supply of ore must be stopped, and from 8 to 10 per cent. of ferro-manganese or spiegeleisen added to the bath. When this has been well incorporated by stirring, the metal is ready to be tapped into a ladle mounted upon wheels, which is afterwards propelled into the foundry, and discharged either into ingot moulds, to be hammered and rolled, or into dried clay moulds for the production of steel castings.

Considerable difficulty was experienced to find a material to resist the excessive heats necessary for carrying out this process ; ordinary Dinas bricks, which are considered the most refractory 
material in general use, would be rapidly melted, but a brick, specially prepared by crushing pure quartz rock, and mixing it with not more than 2 per cent. of quicklime to give cohesion, answers well. The hearth of the furnace is made of white sand with a small admixture of more fusible fine sand, which mixture sets exceedingly hard at a steel-melting heat, and possesses the advantage of combining into a solid mass with fresh materials introdnced between the charges to make up for wear and tear. The hearth and the furnnce-roof, if of the materials just specified, are rery little attacked when the Siemens-Martin process is used, although the heat must be sufficient to maintain wrought iron containing only a trace of carbon, in a perfectly fluid condition. If pig metal and ore (previously fused with the necessary anount of flux) are used, the furnace also stands well, but the use of raw ore entails the disadvantage of a more rapid destruction of the furnace; even magnetic oxide of the purest description necessitates the addition of raw lime for the formation of a fusible slag, and the dust arising from the lime and through the decrepitation of the ore causes the silica bricks to melt away rapidly, so that after perhaps two months' usage, the 9-inch arch of the furnace is reduced to the thickness of from 1 to 2 inches. It is evident that silica is chemically speaking an objectionable material to be used in the construction of these furnaces, because it prevents the formation of basic slags, and that a furnace bed constructed of pure alumina or lime would be preferable. My friend M. Le Chatelier, Inspecteur-Général des Mines, whose valuable labours for the advancement of iron metallurgy are well known, suggested to me years ago the use of Bauxite (from Baux in France, where it was first discovered), a mineral consisting chiefly of alumina, for making the furnace-bed, but I was not able to succeed with this owing to the great contraction of the mass when intensely heated, and non-cohesion with the same material introduced for the purpose of repair. In attempting to construct the sides and roof of the furnace of Bauxite bricks, these were not found to be equal in heat-resisting power to silica bricks, which latter are indeed unobjectionable, except when raw ore and limestone are used.

If good pig metal, such as is used in the Bessemer process, is employed, a metal of high quality is the result, equalling in most respects the steel produced by melting Swedish bars in pots by the old Sheffield process. 
There is manifestly an analogy between this and the Bessemer process, both of them being processes of decarburisation of pig metal; yet there are very important differences, both as regards the nature of the chemical reactions and of the metal produced. In the Bessemer process the silicon and carbon are fully oxidised by the action of the blast, whereas sulphur and phosphorus are known to remain unoxidised. Manganese is oxidised in the Bessemer process only to a certain extent, and therefore it is not necessary to add spiegeleisen at the end of the operation, when the pig metal employed contains a moderate amount of metallic manganese, as is the case in Sweden and in Styria. Mr. W. Hackney, the manager, and Mr. A. Willis, the resident chemist at the Landore Steel Works, have analysed Bessemer metals made without the final addition of spiegel, and found them to contain no less than 0.3 per cent. of manganese. Notwithstanding the non-oxidation of manganese, from 8 to 10 per cent. of iron is oxidised in the Bessemer process, although iron has waturally less affinity to oxygen than manganese. The oxidation of this amount of iron in the Bessemer converter is, in so far, a fortunate circumstance, as without it the amount of heat necessary to liquefy the resulting malleable iron could not be produced, and the metal would necessarily set in the converter. In the ore-reducing process above described a totally different result ensues, as is shown by the following experiment.

A manganiferous pig was melted, and ore charged in the usual manner. After the pig was completely melted, it contained the ingredients stated in the first line of the following table, from which it will be seen that silicon and manganese were eliminated first, and then very little change took place in the carbon until the two other constituents were completely removed :-

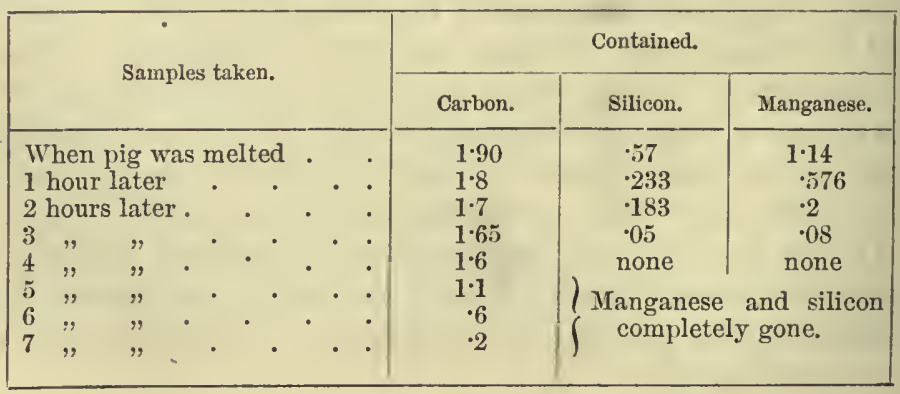


The sulphur and phosphorus are oxidised to a considerable extent; a circumstance which enables us to use pig metal containing a certain small perecntage of these admixtures, which are not absolutely objectionable unless they occur in excessive proportions, the quantity admissible of both phosphorus and sulphur being about $\cdot 08$ per cent.

The decarburising agent employed being ferric oxide, no castiron can possibly be oxidised, and a ton of pig metal with its quota of spiegel, containing from 9 to 10 per cent. of foreign substances, yields fully 21 cwt. of steel ingots. In this process the addition of spiegeleisen at the end of the operation is an absolute necessity, however much manganese may have been contained in the pig metal employed, because the manganese is rapidly oxidised, as can be seen from the foregoing table.

The reason of the different reaction in the Bessemer process is, in my opinion, that the silica liberated from the beginning of the operation requires a base for its saturation, and that its great affinity to protoxide of iron determines the oxidation of this metal (free oxygen from the blast being present) in preference to manganese.

A characteristic difference between the two metals, in their fluid condition, is that Bessemer metal on cooling in the moulds sets up a violent ebullition, probably resulting from a reaction between occluded oxygen and carbon, which is counteracted by stoppering the moulds. The ore process metal, if it has been made with care, on the contrary, contains no occluded oxygen, and sinks in the moulds on cooling in the same way as "dead melted" steel does, produced by the old Sheffield process.

It has been an open question between metallurgical chemists whether manganese is really required to be present in malleable steel, some maintaining that its beneficial action is confined to the elimination of sulphur during the process of production. Sucl, however, is not the case, as may be seen from the following extract from Messrs. Hackney and Willis's report :-

"Our observation, based on five years' experience, is that no chemical reaction takes place between the mauganese of the spiegeleisen and the other elements of the steel, but that it acts simply as an alloy. With regard to manganese not removing any sulphur in a bath of stecl, it is a curious fact that the reverse 
takes place in a blast furnace. As the percentage of manganese in the pig increases, so does the sulphur decrease; for instance, if to ore and coke, which in the ordinary way will produce a pig containing from 2 per cent. to 3 per cent. of sulphur, manganiferous ore is added so as to put 2 per cent. of manganese into the pig, the sulphur will be reduced to ${ }^{\circ} 05$ or $\cdot 08$ per cent. ; but when 3 per cent. of manganese is found in the pig it never contains more than a slight trace of sulphur. We have had occasion lately to analyse several hundreds of samples of pig iron made under these conditions, and can vouch for the accuracy of this statement, and we think it a fact well worth the attention of ironmasters who are troubled with an excess of sulphur either in their ores or fuel.

"Every one must have noticed the absence of sulphur in all analyses of spiegeleisen, although much of it is made from coke, and most of the ores used contain a considerable quantity of pyrites.

"That the manganese acts by its actual presence, and not by any chemical reaction, is, we think, proved by the fact that, if through any accident or carelessness of the workmen, the charge is left in the furnace for more than twenty minutes after the spiegeleisen is fairly melted the steel is invariably bad, owing to the oxidation of the manganese, and therefore if such delay occurs, a small addition of spiegeleisen is made, and no bad results follow."

About the impurities of steel the same gentlemen report :-

"The presence of sulphur, it is well known, makes steel redshort, and the only question is, how much may it contain without injury? Our experience is, that up to 0.08 per cent. will do no harm, provided there is also present 0.3 per cent. of manganese, and we have even found $\cdot 112$ per cent. without having any complaint from the hammermen.

"Phosphorus does not appear to affect either the rolling or hammering of steel, even if 0.2 per cent. is present, but if it exceeds 0.08 per cent., the rails become so cold-short that they will not stand the severe test to which they are subjected.

"The presence of arsenic and phosphorus increases the hardness of steel at the expense of its toughness.

"The effect of copper is not yet understood; according to Percy it renders steel red-short to a greater extent even than the same amount of sulphur. 
"From the nature of the process, as a rule, very little if any silicon is found in Siemens steel. The carbon and silicon appear to be eliminated equally when manganese is not present, and, as the carbon is generally in excess of the silicon, none remains when the carbon is reduced to 0.2 per cent. The small amount found in the steel is derived from the spiegeleisen."

At the Landore Works upwards of 1,000 tons of cast steel are produced weekly by these processes, and other works, such as Vickers and Company, Krupp, of Essen, etc., are using the sume for the production of steel of high quality.

Both in the ore-reducing and in the Siemens-Martin or scrap process, pig metal forms the principal basis, being used either as such, or as puddled iron or Bessemer scrap-metal, resulting from the conversion of pig metal by a previous process.

In my former lecture I expressed my belief that the direct conversion of ores into iron or steel would ultimately be accomplished, and, having since been actively engaged on the problem, it is now my chief object to lay before you the results I have up to this time attained.

I am aware that, on the one hand, the direct conversion of iron ores into wrought iron or steel is no novelty, inasmuch as the ancient Indians and Romans produced their iron by a direct process from the ore; and that, on the other hand, the blast furnace offers immense facilities for the wholesale extraction of metal from the ore, by the side of which the puny efforts of the ancients producing half a cwt. of metal intermixed with half-fused cinder by a day's toil, and with the expenditure of large quantities of rich ore and charcoal, sink into utter insignificance.

Mr. Riley says, in his able lecture "On the Manufacture of Steel and Iron," read before this Society on May 22, 1872 :-

"The great improvement lately introduced in the manufacture of pig iron, the enormously increased production at a diminished cost of what may be considered to be the raw material from which we start in the manufacture of iron and steel, are, I think, sufficient to convince not only practical men, but scientific men also, that in any improvement in iron manufacture we must commence with the pig, and consider that our starting point."

Mr. Riley here gives expression to the prevailing opinion amongst metallurgists ; but still I do not despair of being able to

VoL. I. 
prove to you that upon theoretical grounds the blast furnace is open to very grave objections, inasmuch as it produces iron combined with nearly all the objectionable substances contained in the materials used, that only expensive fuel, such as coke, can be employed, and that its combustion is necessarily imperfect.

Plate 45 shows the distribution of temperature in the blast furnace, as given by Mr. Lowthian Bell in a paper read by him before the Institution of Civil Engineers, in 1872.

It shows that the reduction of the metallic oxides to spongy iron is accomplished within the first 20 feet of their descent in the furnace, and at a comparatively low temperature. This upper zone is followed by one where the limestone is decomposed and the carburisation of the spongy metal is commenced. Between this second zone and the zone of fusion in the boshes of the furnace a zone of great magnitude intervenes, where apparently no other change is effected than an increase of temperature of the spongy metal, but where in reality a very powerful reducing action is accomplished of substances which had much better not be joined to the iron. It is well known that almost all the phosphorus contained in the iron-stone, the lime-stone, and the coke is here incorporated with the spongy iron. The silica is reduced to its metallic condition, and, together with sulphur, arsenic, and other bases which may be present, combines with the iron. The final action in the blast furnace consists only in fusing those reduced substances and forming the slags which enrelop and protect the fused metal.

As regards the fuel question, it will be observed that the result of the combustion in the blast furnace is for the most part carbonic oxide, and that the heat dereloped in this combustion amounts to only 2,400 heat units per pound of pure coke consumed, whereas a perfect combustion (to carbonic acid) of the same coke would be attended by the development of 8,000 heat units. It is practically impossible to obtain more than one-fifth of carbonic acid to the carbonic oxide issuing from the top of the blast furnace, and taking also into account that the gases leare the top of the blast furnace at $350^{\circ} \mathrm{C}$., it may fairly be asserted that only one-third of the heat-producing power residing in the coke is utilised. A portion of the heat thus left undereloped may be used, it is true, in burning the gases for the generation of 
steam or for heating the air blown into the blast furnaces; but this utilization represents only a small proportion of the value of the coke or charcoal charged with the ore into the furnace; whereas a much cheaper material might be employed for the purposes just named. The introduction of hot blast was unquestionably a rery great improvement in blast furnace economy, because the heat thus introduced is obtained by means of the perfect combustion of fuel, and, in reducing the combustion necessary within the furnace, the quantity of products of combustion as compared to a unit quantity of ore is greatly reduced, the effect being that the incoming ores have a relatively greater capacity for absorbing the sensible heat from the products of combustion, which latter must therefore issue from the top of the furnace at a lower temperature.

Relying upon this argument, I am inclined to beliere that the consumption of coke in a blast furnace must materially diminish with increased temperature of blast without limitation of degree, and in this respect I venture to differ from my friend Mr. Lowthian Bell, who maintains that mere increase of capacity of furnace up to a certain limit produces the same effect as increase of temperature of blast, and that no beneficial effect can be obtained by increasing the temperature of blast beyond $515^{\circ} \mathrm{C}$. In taking however, the best examples of blast furnaces, the products of combustion escaping from the top, four parts out of five, as $\mathrm{CO}$ without counting the $\mathrm{N}$, and at not less than $350^{\circ} \mathrm{C}$. of sensible heat, carry with them fully two-thirds of the heat they would be capable of producing, if they were burnt to carbonic acid.

In my former lecture I described a plan of reducing iron oxides by feeding them, mixed with carbonaceous materials, into a reverberatory furnace through inverted hopper's of firc-clay, the intention being to effect the reduction of the iron ores into spongy metal during their descent, and the fusion of the spongy metal so produced on the open hearth of the furnace, pig metal being used to facilitate the fusion. It was found, howerer, that the quantity of heat that had to be transmitted through the sides of the fireclay hopper was so great that the process of reduction proceeded very slowly, and the hoppers themselves were rapidly destroyed by the intense heat of the furnace. The reduction of the metallic iron in closed chambers of this or any other form which I have tried 
cannot be effected in less than about 36 hours, and that at a great expenditure of fuel for heating the chamber externally.

This unsatisfactory result directed my thoughts to another method of producing spongy iron by means of a rotative furnace. This furnace consisted of a long cylindrical tube of iron about 8 feet diameter, mounted upon antifriction rollers; the brick lining of it was provided with longitudinal passages for heating currents of air and gas prior to their combustion at the one extremity of the rotating chamber. The flame produced passed thence to the opposite or chimney end, where a mixture of crushed ore and carbonaceous material was introduced. By the slow rotation of this furnace the mixture advanced continually to the hotter end of the chamber, and was gradually reduced to spongy iron. This dropped through a passage constructed of refractory material on to the hearth of a steel-melting furnace, where a bath of fluid pig metal had been provided. The supply of reduced ore was continued till the carbon in the mixture was reduced to the minimum point before indicated. The rotation was then arrested to prevent further descent of reduced ore ; spiegel was added; and the contents of the melting furnace tapped into a ladle and thence into ingots, as before described.

This rotary furnace was erected by me at the Landore Works in 1869 , and it was so far successful, that the reduction of the ore was accomplished in a comparatively short time. A difficulty, however, presented itself, which led to its immediate abandonment ; it was found that the spongy metal produced, absorbed sulphur from the heating gases, and was rendered unfit for the production of steel ; the spongy iron moreover, upon its introduction into the steel-melting furnace, floated upon the metallic bath without being readily absorbed into it, and was in great part reoxidised and converted into slag by the action of the flame in the furnace.

These experiments convinced me that the successful application of reduced ores could not be accomplished through their conversion into spongy metal, and fully explained to me the want of success which has attended the previous efforts of Clay, Chenôt, Yates, and others, to produce iron directly from the ore. On the other band, I had observed that in melting iron ores no sulphur was absorbed from the flame; and it occurred to me that by melting ores mixed with fluxing materials in a furnace so arranged as to 
accomplish its fusion in a continuous manner, and on a large scale, the fused ore might be acted upun by solid carbonaceous matter, so as to separate the metallic iron in a more compact form, while the earthy constituents of the ore would form a fusible slag with the fluxing material. Experiments proved that this reduction by precipitation of the iron could be accomplished only at an intense heat, exceeding the welding heat of iron, but that the iron so produced was almost chemically pure, although the ores and the fuel used might contain a very considerable percentage of sulphur and phosphorus. The specimens of iron which I exhibit were made in this manner from ores of various descriptions, and the following tables give the analysis of the ores and the iron, as also the yield of iron obtained from a ton of ore :-

Results of Precipitation Process at LANDore.

\begin{tabular}{|c|c|c|c|c|c|c|}
\hline & & & & & & \\
\hline$=$ & Ure3? & & & Total. & $\begin{array}{l}\text { Coal charged } \\
\text { in furnace. }\end{array}$ & Yield. \\
\hline $\begin{array}{l}\text { Mokta orc } \\
\text { Scale }\end{array}$ & . & $\begin{array}{r}12 \\
. \quad 8\end{array}$ & wt. $\}$ & $20 \mathrm{cwt}$. & $6 \mathrm{cwt}$. & $1 \pm \mathrm{cwt}$. \\
\hline $\begin{array}{l}\text { Mokta ore } \\
\text { Scale }\end{array}$ & $\cdot$ & $\begin{array}{r}.10 \\
. \quad 8\end{array}$ & $" \Rightarrow$ & $18 "$ & 4, & 14 cwt. 2 qrs. \\
\hline $\begin{array}{l}\text { Mokta ore } \\
\text { Scale }\end{array}$ & · & $\begin{array}{r}12 \\
. \quad 8\end{array}$ & $"\}$, & 20 & $6 \%$ & $11,2 "$ \\
\hline $\begin{array}{l}\text { Mokta ore } \\
\text { Scale }\end{array}$ & • & . 6 & $"\}$, & 10 & 2 & $12 "$ \\
\hline $\begin{array}{l}\text { Mokta ore } \\
\text { Scalc }\end{array}$ & . & $\begin{array}{r}10 \\
.10\end{array}$ & $" \Rightarrow$ & 20 & 6, & $15 \%$ \\
\hline $\begin{array}{l}\text { Mokta ore } \\
\text { Scalc }\end{array}$ & $\cdot$ & $\begin{array}{l}.14 \\
.12\end{array}$ & $", \quad\}$ & 26 & $6 \%$ & $18 "$ \\
\hline Total & . & . & . . & 114 cwt. & 30, & $85, \quad 2$, \\
\hline
\end{tabular}

RESULTS OF ROTATOR.

\begin{tabular}{|c|c|c|c|c|c|c|}
\hline & & & Ore. & Lime. & Coal. & Iron. \\
\hline Vickers & , Shefticld & . . & 984 & 48 & 216 & 492 \\
\hline , & Birmingham & . & 784 & 40 & 176 & 258 \\
\hline
\end{tabular}


Results of Precipitation Process at Blochairn.

\begin{tabular}{|c|c|c|c|c|c|c|c|}
\hline & & Charge. & & & & & Analysis of iron. \\
\hline No. & Ores. & Lbs. & Total. & Lime. & Coal. & or iron. & Impurities. \\
\hline 1\{ & $\begin{array}{l}\text { Purple . : } \\
\text { Red }\end{array}$ & $\left.\begin{array}{l}450 \\
150\end{array}\right\}$ & 600 & 56 & 356 & 137\{ & $\begin{array}{l}\mathrm{S}=\cdot 055 \text { per cent. } \\
\mathrm{P}=\cdot 114 \quad, \\
\mathrm{Si}=\cdot 13 \quad,\end{array}$ \\
\hline 2\{ & $\begin{array}{l}\text { Purple . } \\
\text { Red . }\end{array}$ & $\left.\begin{array}{r}168 \\
56\end{array}\right\}$ & 224 & 12 & 170 & 165 & \\
\hline 3\{ & $\begin{array}{l}\text { Melted } \\
\text { Coke (powder) }\end{array}$ & $\left.\begin{array}{l}350 \\
210\end{array}\right\}$ & 560 & $\ldots$ & $\cdots$ & 160 & \\
\hline 4\{ & $\begin{array}{l}\text { Purple } \\
\text { Blackband : }\end{array}$ & $\left.\begin{array}{l}300 \\
600\end{array}\right\}$ & 900 & 90 & 390 & 210 & \\
\hline 5\{ & $\begin{array}{l}\text { Blackband : } \\
\text { Clayband } \\
\text { Purple }\end{array}$ & $\left.\begin{array}{l}600 \\
600 \\
300\end{array}\right\}$ & 1500 & 150 & 420 & 210 & 2 \\
\hline 6\{ & $\begin{array}{l}\text { Blackband : } \\
\text { Clayband . : } \\
\text { Purplc . }\end{array}$ & $\left.\begin{array}{l}300 \\
300 \\
300\end{array}\right\}$ & 900 & 90 & 145 & 202 & \\
\hline 7\{ & $\begin{array}{l}\text { Cleveland . . } \\
\text { Purple . }\end{array}$ & $\left.\begin{array}{l}900 \\
300\end{array}\right\}$ & 1200 & 120 & 290 & 268\{ & $\begin{array}{l}\mathrm{S}=\cdot 0+1 \text { per cent. } \\
\mathrm{P}=\cdot 150 \quad, \\
\mathrm{Si}=\cdot 173\end{array}$ \\
\hline
\end{tabular}

Working Results of the Cascade FurNace at Landore.

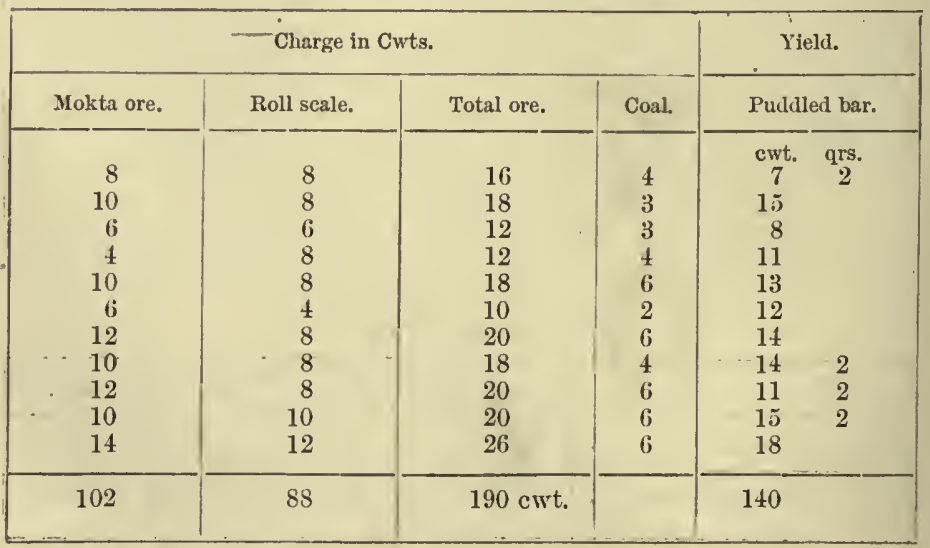


The ore employcd mas Mokta ore, of the following description :-

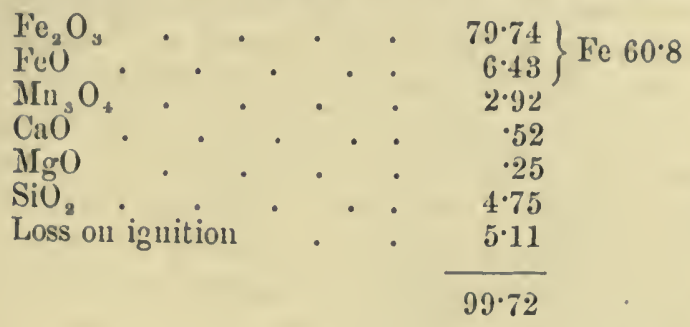

32 charges, $14,338 \mathrm{lbs}$. ore Yield in slabs.

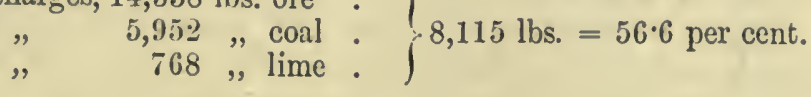

Other specimens of steel shown are produced by fusion of the iron thus obtained on the open hearth of a regenerative gas furnace, which are undoubtedly of superior quality.

The furnace used for carrying out this process of fusion and precipitation consists of a reverberatory gas furnace having two beds formed by the ore itself; on the upper bed a lake of fused ore is formed which can be let off into the lower bed by piercing the intervening bank of unfused ore; the lower bed is divided into two compartments, used alternately, each provided with a working door. The dense carbonaceous material, such as anthracite or hard coke, to be used for the precipitation of the iron in the lower bed, is reduced to a state of powder and mixed with about an equal weight of pulverulent ore. This mixture is spread over the bottom surface of the working bed, and the fluid ore is let in upon it. By stirring with a rabble it is transformed into a pasty and foaming mass, which in the course of from 40 to 50 minutes is shaped into a metallic ball in a bath of fluid cinder, which may be shingled in the usual manner and formed into bar iron or transferred to the pig-iron bath of a steel-melting furnace, where it readily dissolves. The accomplishment of this process involres, however, a certain degree of manual labour and skill, as, if it be carelessly conducted, the yield of iron will be unsatisfactory ; the analysis of the slags shows a variable percentage of iron amounting rarely to less than 15 per cent., but reaching occasionally up to 40 per cent. 
It was evident that if iron and steel were to be produced largely by direct process, that process must be a self-acting or mechanical one, and here my attention again reverted to the rotating furnace above-mentioned. If $\mathrm{I}$ could succeed in furnishing such a rotating furnace with a lining capable of resisting the high degree of heat requisite for the precipitation of the iron, and at the same time capable of resisting the chemical action, I felt confident that this mode of conducting the process must succeed. My attention here reverted to M. Le Chatelier's former suggestion of the use of Bauxite, which possesses the requisite qualities, if only it can be put into a compact form and rendered sufficiently infusible.

A series of experiments to form solid lumps by using different binding materials have shown that 3 per cent. of argillaceous clay suffice to bind the Bauxite powder previously calcined. To this mixture about 6 per cent. of plumbago powder is added, which renders the mass practically infusible, because it reduces the peroxide of iron contained in the Bauxite to the metallic state. Instead of plastic clay as the binding agent, waterglass or silicate of soda may be used, which has the advantage of setting into a hard mass at such a comparatively low temperature as not to consume the plumbago in the act of burning the brick. When the lining is completed, the interior surface of the bricks is preserved against corrosion by fluid cinder, added to bind them together, which also prevents contact with the flame. A Bauxite lining of this description resists both heat and fluid cinder in a very remarkable degree, as I have proved by lining a rotative furnace at my Sample Steel Works at Birmingham, partly with Bauxite and partly with carefully-selected plumbago bricks. After a fortnight's working the brick lining was reduced from 6 inches to less than half an inch; whereas the Bauxite lining was still 5 inches thick and perfectly compact. It is also important to observe that Bauxite when exposed to intense heat is converted into a solid mass of emery of such extreme hardness, that it can hardly be touched by steel tools, and is capable of resisting mechanical as well as the calorific and chemical actions to which it is exposed. The Bauxite used for this lining was of the following composition :-

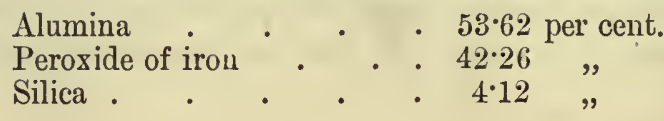


Other Bauxites which I bave had occasion to analyse were composed as follows :-

ANALYSES OF VARIOUS BAUXITES.

Frexch Bauxites.-First Group.

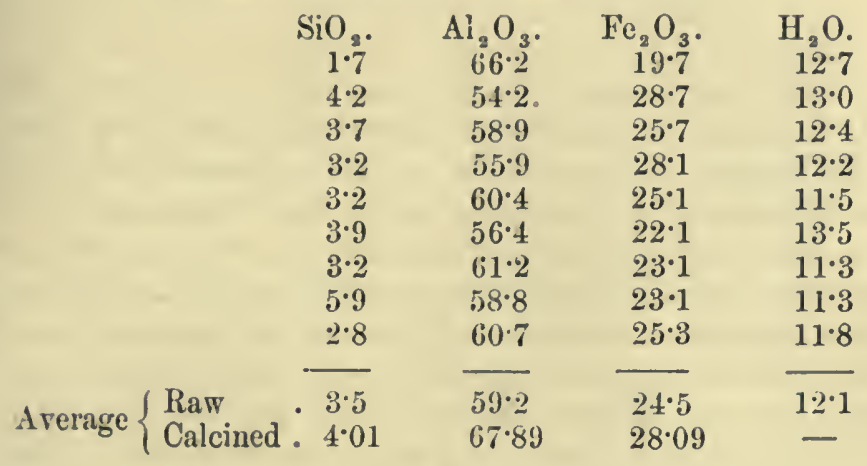

Second. Group.

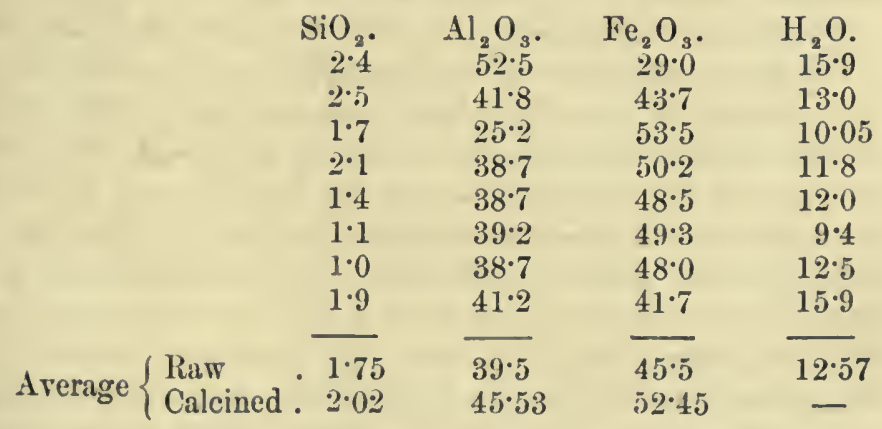

Austrian Bauxite.-Wocheinile (Carniola.)

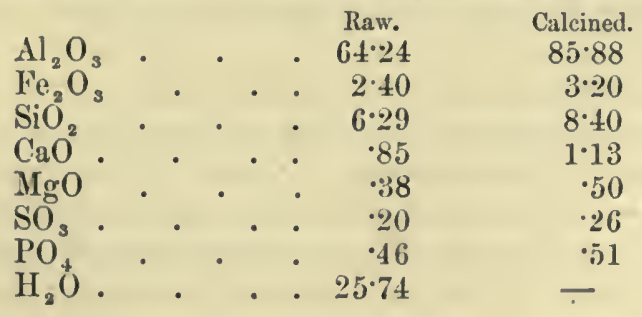




\section{IRISH BAUXITE.}

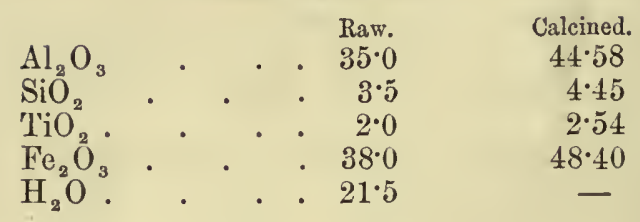

The complete rotary furnace, such as is now in use at Messrs. Vickers and Co.'s, at Sheffield, and at my Sample Steel Works at Birmingham, consists of a set of four regenerators of the usual construction with reversing valres and gas-producers. The rotative chamber is constructed of iron, and rests upon four antifriction rollers. Wheel-gearing is applied by which either a very slow rotative velocity of from four to five revolutions per hour can be imparted to the chamber, or a more rapid relocity of about 60 to 80 revolutions per liour. The chamber is about $7^{\prime} 6^{\prime \prime}$ in diameter and $9^{\prime} 0^{\prime \prime}$ long, and is provided with a Bauxite lining about $7^{\prime \prime}$ thick. A tap-hole is on the working side for discharging the slag into the cave below, where it is received in vessels mounted on wheels. At the two extremities of the cylindrical rotative chamber with its truncated ends, are large orifices, one of which, on the side of the regenerators, serves for the introduction of the heated gas and air as well as for the exit of the products of combustion, and the other facing the working platform is closed by a stationary door hung before it in the usual manner. Although the passage for the introduction of the gases in combustion is separated only by a vertical partition wall from the passage through which the products of combustion are led away, the chamber is heated very perfectly, care only being taken that the gases enter the chamber with a certain relocity, which sends them forward towards the door and makes them reach the exit passage only after having traversed the rotative chamber to and fro.

This rotative furnace is worked as follows :-

The ore to be smelted is broken up into fragments not exceeding the size of peas or beans ; to it is added lime or other fluxing material in such a proportion that the gangue contained in the ore and flux combines with only a little protoxide of iron into basic and fluid slag. If the ore is hematite, or contains silica, I prefer 
to add alumina in the shape of aluminous iron ore; manganiferous iron ore may also be added with advantage. A charge of say 20 cwt. of ore is put into the furnace when fully heated, while it is slowly revolving. In about forty minutes this charge of ore and fluxing material will lave been leated to bright redness, aud at this time from 5 cwt. to 6 cwt. of small coal of uniform size (not larger than nuts) are added to the charge, whilst the rotative velocity is increased for a short time in order to accelerate the mixture of coal and ore. A rapid reaction is the result: the peroxide of iron being reduced to magnetic oxide begins to fuse, and at the same time metallic iron is precipitated by each piece of carbon, while the fluxing materials form a fluid slag with the siliceous gangue of the ore. The slow rotative action is again resorted to, whereby the mass is turned over and over, presenting continually new surfaces to the heated lining and to the flame within the rotator.

During the time of this reaction, carbonic oxide gas is evolred from the mixture of ore and carbon, and heated air only is introduced from the regenerator, to effect its combustion within the rotating chamber. The gas from the gas-producers is entirely, or almost entirely, shut off during this portion of the process. When the reduction of the iron ore is thus nearly completed, the rotator is stopped in the proper position for tapping off the fluid cinder ; after this the quick speed is imparted to the rotator, whereby the loose masses of iron contained in it are rapidly collected into two or three metallic balls. These are taken out and shingled in the usual way of consolidating puddled balls; the furnace is tapped again and is ready to receive another charge of ore. The time occupied in working one charge rarely exceeds two hours; and supposing that $10 \mathrm{cwt}$. of metallic iron is got out per charge, the apparatus is capable of turning out at least 5 tons of puddled bar per 24 hours. If anthracite or hard coke is available for effecting the reduction of the ore, it should be crushed much finer than when coal or brown coal is used, the idea being that each particle of the reducing agent should be fully consumed during the period of chemical reaction. If wood is used, it has to be charged for the same reason in still larger pieces.

If it is not intended to make iron, but cast steel, the balls may be transferred from. the rotator to the bath of a steel-melting 
furnace in their heated condition, and without subjecting them to previous consolidation under a hammer or shingling machine.

It is feasible, however, to push the operation within the rotator to the point of obtaining cast steel. If this is intended, the relative amount of carbonaceous matter is somewhat increased in the first instance, so that the ball, if shingled, would be of the nature of puddled steel, or contain even some carbon mechanically enclosed.

If now, after removing the cinder by tapping, from 10 to 1 i) per cent. of ferro-manganese or spiegeleisen is thrown in, and the heat within the rotator is rapidly raised by urging the influx of heated gas and air from the regenerator, the metallic balls will soon be seen to diminish, and presently a metallic bath only will be found in the furnace, which may be tapped into moulds anil hammered and rolled into steel blooms or bars in the usual manner. Experience alone can determine which mode of working will ultimately prove the best; but it is probable that for the production of cast steel on a large scale it will always be more profitable to transfer the metallic balls to a separate melting furnace, a series of rotating furnaces working in concert with a series of steel-melting furnaces, so as to produce charges of 5 or 6 tons of fluid steel.

In comparing upon theoretical grounds this method of producing metallic iron with the operation of the blast furnace, it will be at once perceived that, whereas in the blast furnace the products of combustion consist chiefly of carbonic oxide, and issue from the top of the furnace at a temperature exceeding $350^{\circ} \mathrm{C}$., the result of combustion in the rotative furnace is carbonic acid, which issues from the regenerative furnace into the chimney at a temperature rarely exceeding $175^{\circ} \mathrm{C}$. This proves at once a great possible saving of fuel in farour of the proposed method, and to this saving has to be added the fuel required for converting pig metal into wrought iron by the puddling process.

It may however be asked, why the rotating surface should admit of the complete combustion of carbon, whereas in the blast furnace such complete combustion is, as is well known, not possible, because each atom of carbonic acid formed would immediately split up into two atoms of carbonic oxide, by taking up another equivalent of carbon from the coke present. The following explanation will serve to elucidate this point : 
In the rotative furnace streams of carbonic oxide are set up within the mass under renction; and this carbonic oxide on reaching the surface meets the currcnt of intensely heatcd air proceeding from the regenerators, and completes with it perfect combustion within the free space of the chamber. The carbonic acid thus generated comes in no further contact with carbon or metal, consequently it cannot split up, but is drawn away unchanged into the chimney, while the evolved heat is taken up by the sides of the chamber and transmitted by reverberation and conduction to the mixture of ore, fluxes, and coal.

In this process wc have, therefore, to accomplish two things, viz., the deoxidation of the ore, and the fusion of the earthy mattcr mixed with it. If we take (say) hematite ore, consisting of peroxide of iron with 10 per cent. of silica, we shall determine the quantity of carbon necessary for its reduction from the formula $\mathrm{Fe}_{2} \mathrm{O}_{3}+3 \mathrm{C}$, which gives $2 \mathrm{Fe}+3 \mathrm{CO}$; and according to which the consumption of carbon (taking its atomic weight at 12 and that of iron at 56) amounts to $\frac{3 \times 12}{2 \times 56}=.32 \mathrm{lbs}$. per lb. of iron reduced.

The heat absorbed in this reaction amounts, according to Dr. Debus, to 892 units * per lb. of iron produced, but on the other hand the further combustion of $.32 \mathrm{lb}$. of carbon from the condition of carbonic oxide to carbonic acid $\left(\mathrm{CO}\right.$ to $\left.\mathrm{CO}_{2}\right)$, by means of the free oxygen introduced into the rotative chamber from the regenerator yields $\cdot 32 \times 5600=1792$ units of heat, leaving 1792 $892=900$ units available for heating the materials and for melting the slag.

The quantity of materials to be heated per lb. of iron produced would amount to ore, $1 \cdot 59$; lime or other fluxing materials, $\cdot 16$; making a total of 1.75 ; and taking the specific heat of $\mathrm{Fe}_{2} \mathrm{O}_{3}$ at .154 as determined by Herman Kopp, and the temperature to which the materials have to be raised at $1500^{\circ} \mathrm{C}$., the heat requirce for this purpose would not excecd $1.75 \times 154 \times 1500$ $=404.25$ units. To this consumption would have to be added thc latent heat absorbed in liquefying the slag. The slag would amount to $\cdot 16 \mathrm{lb}$. silica $+\cdot 16 \mathrm{lb}$. lime $=\cdot 32 \mathrm{lb}$. per pound of iron

* Dr. A. W. Williamson gives $885 \cdot 3$ units as the result of his ealculation, which two figures agree sufficiently for my present purpose. 
produced, and, although we have no precise data from which we could ascertain the latent heat absorbed in liquefaction, we can hardly estimate it at more than 150 units per lb., or at $\cdot 32 \times 150$ $=48$ units, which, with the above $404 \cdot 25$, makes $452 \cdot 25$ units, whereas 900 heat-units are available, as resulting from the calculation above given, proving that $32 \mathrm{lb}$. of pure carbon wonld, theoretically speaking, amply suffice to produce $1 \mathrm{lb}$. of puddled bar from ordinary hematite ore, without counting, however, losses of heat by radiation and from other causes.

In the production of cast stcel, three operations are essentially involved, viz., the deoxidation of the iron, the fusion of the slags, and the fusion of the metal itself with such proportion of carbon and manganese as is necessary to constitute steel of the temper required.

The theoretical quantity of fuel required to accomplish these operations would exceed that of making wrought iron by the fusion of heated metal, which may be estimated at, say, 1000 units, or at $\frac{1000}{8000}=\cdot 125 \mathrm{lb}$. of carbon per $\mathrm{lb}$. of steel produced, which have to be added to the $32 \mathrm{lb}$. used in reduction.

- In fine, a ton of iron ought to be producible from hematite ore with $6.4 \mathrm{cwt}$. of carbonaceous matter, or say $8 \mathrm{cwt}$. of common coal, and a ton of cast steel with 8.90 crt. of carbon, or say 11 cwt. of coal. In giving these figures, I do not wish to imply that they will ever be completely realised, but I maintain that, in all our operations, we should fix our eyes upon the ultimate result which theory indicates, which, owing to the imperfect means at our command, we shall never completely reach, but should constantly endeavour to approach.

In taking incidental losses by radiation through imperfect combustion and through imperfect absorption of heat into account, we find that the actual consumption exceeds the theoretical limits about three times, or that a ton of iron can practically be produced with a consumption of 25 crt. of coal, and a ton of cast steel with $40 \mathrm{cwt}$. of coal, which consumption represents a great reduction as compared with other methods of production. 


\section{In the discussion of his Paper}

\section{" ON THE MANUFACTURE OF IRON AND STEEL}

\section{BY A DIRECT PROCESS."}

[Noty on Mr. Siemexs's Paper."-The Paperf "On the Manufacture of Iron and Steel by a Direct Process," was prepared under severe pressure of business, with the view of being amplitiel and correeted after deiivery. Unfortunately, however, the rough paper, with marginal remarks having referenee only to the reading, was handed to the printer without my having had an opportunity of revising and amplifying it, as I should have wished.-C. W. S.]

Dr. Siemens $\ddagger$ said, amongst the obserrations which had been made, he would notice only those that required an answer from him. Some of them had been answered fully or partly by other speakers, and need not therefore be referred to by him again, because their time was naturally valuable. The first speaker was Mr. Snelus, and he had spoken very much in favour of reducing iron from the fluid condition, and had referred to a method, which he had informed them was in course of being tried at Middlesbrough, of forcing, he supposed, carbonic oxide gas through fluid ores. Nor, he had tried that method of proceeding and he certainly had not succeeded. Carbonic oxide, or any other poor description of gas, was so near the point of saturation with carbon that, if it took up any oxygen from the ore which it contained, it soon arrived at the point where it took no more, and there the reaction would stop. The result would be that a vast amount of gas had to be driren through the fluid ore in order to produce a given amount of reducing work, but that large amount of gas had the disadvantage upon the fluid ore that it cooled it, and thereby checked the reaction that was going on. It was upon those results becoming apparent, which, howerer, he (Dr. Siemens) partly expected, that that mode of proceeding was given up and solid

- Excerpt Journal of the Iron and Steel Institute, Vol. I. 1873, p. 253.

$\dagger$ As both the paper "On Smelting Iron and Steel," see p. 283, antc, and this ono cover the same ground, the former has been reprinted, with the above discussion on the latter.

‡ Excerpt Journal of the Iron and Steel Institute, Vol. I. 1873, pp. 84-90. 
fuel resorted to in all cases. With regard to the elimination of sulphur and phosphorus, he had to draw a particular line of distinction between the ore-reducing process carried on at Landore and the process which he now had only partially substituted in aid of it. In the furnace, such as was worked at Landore, and at several other places, it was possible that the elimination of phosphorus and sulphur proceeded only at the same ratio in which it would proceed in the Bessemer converter, but there was this difference that the operation took eight hours, whereas the Bessemer process was completed in a quarter of an hour ; therefore, it was probable that a larger proportion of sulphur and phosphorus was evolved in the ore reducing process, and that, he believed, was the case in actual practice. In drawing a distinction between the two processes, he did so without the least intention of depreciating the Bessemer process, which, in many ways, he admired excessively, but as drawing attention to an essential difference between the two processes. With regard to the price of bauxite, he could hardly speak with confidence as yet. . The mineral was found in large quantities in the south of France, in Austria, and also in Ireland; and as there was no present use for it, the probability was that it would be obtained cheaply, and the process of converting it into material for the lining was certainly not an expensive one-not more expensive than that of fire-brick making. He had not been aware that Mr. Snelus had turned his attention to lime for linings; in the paper, allusion had been made to lime also, and they had, especially in the ore-reducing process, used lime bottoms to some extent. Hitherto he had not been able to obtain lime in such a form as to resist permanently the effects of scoriæ, but it was quite possible ; and he might say that he was now engaged upon a course of experiments at Birmingham, with a view to substitute lime, in some cases at any rate, for bauxite in forming a lining. Mr. Snelus had also alluded to a point in the furnace which certainly required explanation-whether the parts of the furnace throat, where it entered out into the rotating chamber, were not very rapidly attacked? He (Mr. S.) had some little misgivings on that, but he found that experience proved decidedly more favourable than anticipation; those parts (pointing to some on drawing) had now stood for five or six weeks of working, and they certainly were none the worse for it. It had to be borne in mind 
that the bauxite lining did not actually touch the silica brickirork, but was perhaps an inch apart from it, and that the flame in making a turn through the furnace did not carry with it so much dust ontward as might be the case if it swept across a furnace. He found also in the puddling furuace a very great difference in farour of the return current; it seemed as though the dust were swept out of the flane and little ashes were deposited in the passages. They could get any amount of heat, even coming up to full steel melting heat, inside the rotating furnace without artificial blast. With regard to manganese and its necessary presence in steel, he thought that Mr. Riley was perfectly right in saying that tool steel was found without more than a trace of manganese, but they must remember that such steel contained one per cent. of carbon, and generally was very free from sulphur; but it had been established in a rery absolute manner at Landore, that mild steel containing sulphur must necessarily also contain manganese in a given proportion to the amout of sulphur present, and that this proportion increased with the mildness or the relative absence of carbon in the metal. Thus, if the metal contained 08 per cent. of sulphur, they considered it not safe to have less than three-tenths per cent. of manganese in the metal, and whenever, through accidental causes, the manganese in the metal was less, the steel did not work so well, nor did it do so well when cold. He (Mr. Siemens) was much impressed by the kind observations made by Mr. Bessemer. Mr. Bessemer had been an early labourer in that field, and the great successes which he had attained were vividly before them. It was no small compliment to him (Mr. Siemens), he considered, that Mr. Bessemer had some years since been thinking of extending his labours in the direction which he (Mr. Siemens) had taken, and if circumstances had not prevented him (Mr. Bessemer), he doubted not would ultimately hare arrived at the same, if not superior results, but he (Mr. Siemens) had given attention to this question, not a few years, but many years; and if results of a practical kind had been obtained, Mr. Bessemer, he was glad to think, would be the last man in the world to dispute or discredit them. Mrr. Parks referred to the analysis of a bar of iron (which had been produced at Birmingham) containing one-third per cent. of copper. Now it was an undoubted fact that the process under discussion fetched all the copper out of the ore, and, therefore, if voL. I. 
the ore contained copper, the iron would contain it no doubt also ; but in the particular instance referred to, the presence of copper was accounted for by a previous charge which was made with ore containing about a half per cent. of copper, and some of the charge having remained attached to the sides of the furnace, it worked into the succeeding charge. Some other speakers had spoken with regard to the effect of copper on iron, and he could fully confirm the observations made by Mr. Fothergill, that a very small percentage of copper entirely prevented the iron from coming together; instead of forming balls, it remained separate, and would not hold together. Dr. Wright was the first speaker to touch upon the fuel question, which question had been very fully taken up by the President, and carried somewhat against the conclusions arrived at by himself. Now, with regard to that question, he wished to explain his views concisely, but more fully than he had done in the paper. He must say that the furnace in Birmingham was no criterion with regard to the economy of the process, because that furnace was of comparatively small dimensions, and was erected simply for the sake of experiments, the object being to see the effect produced on the lining by different treatment, and on the quality of the iron produced by rarious mixtures and fluxes. Lately, he put in a lining which had not been baked beforehand, and the result was that the balls would not hang well together; the bauxite came off in small filaments from the lining, and acted, as he might say, like soap between the nodules of iron, preventing their cohesion. That difficulty was removed after exposing the lining to two days' intense heat, and now the results were better, as might be seen by the two balls sent up, which were then in the yard at the back of the building, and had been produced in that little furnace. They were balls of nearly $600 \mathrm{lbs}$. each from charges of a thousand pounds; one of blackband and the other of Acadian ore. The normal way of working the rotary furnace was as follows:-The furnace was charged with say a ton of pulverized ore, and the slow rotation went on until the mass was heated through and through to full redness. Then the carbon was introduced and mixed with the charge in giving a rapid rotation to the apparatus. The consequence was that reaction and fusion set in immediately, and it was very important that at that point the action should be very 
energetic in order to weld the particles of iron togrether, while at the same time the earthy material with the ore was fused and formed a slag with the fluxing material employed. If that operation was normally carried out, the iron formed collected in what he might call a grisly condition-small masses hanging together and slightly rolling over each other-whereas a lake of perfectly liquid cinder formed at the bottom, and after that liquid cinder had been tapped off, more rapid rotation was given, and the mass formed readily into one or several balls of metallic iron. In that process the two actions of the formation of the metallic iron and of the fusion of constituents of the ore were carried on simultaneously, and that was an essential condition to the making of good and clean balls, and in this the process differed essentially from the processes of Chenot and others, in which spongy iron enveloping earthy matter was first formed which absorbed sulphur, and could not, therefore, yicld pure metal. Now, with regard to the fuel question, he had certainly appeared to be very bold to prognosticate such results as he had done, but the action in the furnace had hardly been fully understood, or his results could hardly have been questioned. They had there the ore and the carbon mixed together in a state of reaction; that reaction produced currents of carbonic oxide which rose to the surface, where complete combustion took place, and the whole of the carbonic oxide was consumed under the most favourable circumstances possible, because it was consumed at the moment of its generation without being first taken through a cooling tube or exposed to loss of any kind, and it was burnt by a current of intensely hot air by oxygen heated to at least 2,000 degrees Fahrenheit, perhaps 3,000 degrees Fahrenheit. Therefore, the carbonic oxide thus formed by chemical reaction which was lost in the blast furnace was consumed under the most favourable conditions of the furnace, and the heat thus developed accounted fully for all the heat that was necessary for bringing up the material to the state of heating required, and for melting the slag, the regenerators acting as flywheels for taking up an excess of heat at one part of the process, and yielding it at another. Theoretically speaking, '32 cwt. of carbon would be necessary for the production of a hundredweight of metallic iron, but, the result which he had to put forward as being practically attainable and virtually attained by himself, 
was one and a-quarter ton of fuel per ton of iron. Now, in dividing the one with the other, it would be found that he claimed only 25 per cent. of the theoretical result. Mr. Krantz, in his investigation of his regenerative gas furnace, gave him credit for utilizing from 15 to 20 per cent. of the theoretical heat residing in fuel in heating iron, but he ( $\mathrm{Mr}$. Siemens) claimed 25 per cent. in the rotative furnace, because fully one-half of the work was done by reaction of the heated oxygen upon the car-. bonic oxide produced there and then in the furnace, and upon that portion there was no sensible loss by refrigeration in cooling tubes or through leakage. Mr. Bell, when he visited his (Mr. Siemens's) little works at Birmingham, had seen the reaction within the rotator going on for a considerable time without any gas being admitted from the gas-producers, showing that the carbonic oxide generated withiu the mass sufficed to produce the requisite amount of heat to support the process. He (Mr. S.) therefore believed that he should be borne out by practical experience when he asserted that one ton and a-quarter of fuel would suffice for producing a ton of iron. With regard to the quality of that iron, he had already stated in the paper, that it was excellent material for being transferred to the melting furnaces in order to produce steel, being almost entirely free from sulphur and phosphorus, and although the material produced had not yet been practically proved for iron-making, he felt pretty confident of ultimate success in this direction also. The reason why sulphur and phosphorous did not combine with the iron was that they were in an oxidised condition in the ore and combined with other substances, and that the reducing action of the apparatus was insufficient to move them. If the reaction was insufficient for their reduction, then there was no reason why they should be present at all in the iron, and in that respect the direct process claimed an advantage over the blast furnace, where the reducing action was so energetic that everything reducible was brought into combination with the iron. He thought he had now touched upon all the points referred to in the discussion, and had only to thank them for the patient hearing they had given him. 


\section{In the discussion of}

\section{'THE PRESIDENT'S (MR. I. LOWTHIAN BELL)}

\section{ADDRESS,}

Dr. Siemens * said he had not thought of making any remarks of his own, but the President in delivering his address had, as usual, given them a good deal to think about, and he was rather sorry that the discussion had turned only upon one of his remarks, though indeed to discuss all the points raised would fill up the whole time of their meeting. With regard to one question that had been touched upon, Sir John Alleyne had already mentioned that he had tried, with tolerably successful results, the furnace for puddling that he (Dr. Siemens) had brought before the Institution last year. The chief features of that application were, that the regenerative gas furnace was used, and that the products of combustion left at the same side of the heating chamber as that at which the flame entered. Puddling furnaces, similar in arrangement, but not rotative, were now largely used. He mentioned in his paper last year the works of Messrs. Nettlefold and Chamberlain, who had then 10 furnaces at work upon that plan, and they had now 20 ; these were working very successfully, and producing excellent iron and good weight. Of course the question of fettling was the important one as regards the rotative furnace, and whatevery they might do, it would be a difficult and delicate question to make good fettling, unless they had a large supply of very pure oxides. At Butterley, they were particularly badly off in that respect, as their ores were of a poor description, though in the end they made good iron. Still, however, they were very poor ores, and their quality was not nearly sufficient to supply pure oxide, or even pure enough to use for fettling their furnaces. This difficulty was less formidable in working ores in the manner he had proposed to do last year. That process, although not yet carried out on a commercial scale, was progressing towards practical results. His sample works at Birmingham were steadily working

- Excerpt Journal of the Iron and Steel Institute, 1874, pp. 49-50. 
experimentally at the details of the process, and several applications had been made of it at other works, but they were hardly sufficiently advanced in practice to give any working results. With regard to the President's observation concerning his ore process, he must admit that it was a legitimate criticism, namely, whether in the rotary furnace, carbonic acid could be kept away from the metal as it was forming. He (Dr. Siemens) still maintained the argument he used last year, that the carbonic acid remained separate from the ore, and that in this respect he had an advantage over the blast furnace. Of course, there was no absolute separation of the carbonic acid formed from the ore, and practice alone could show whether the reduced metal was effectually protected against re-oxidation under these circumstances. The results he had obtained showed that they could get about 80 per cent. of the iron from the ore, which did not seem a good result as contrasted with the blast furnace practice, but if they compared it with the working of a blast furnace and the subsequent puddling furnace combined, it was by no means a bad result, and he (Dr. Siemens) claimed to be judged by that standard. His advantage consisted, however, chiefly in economy of fuel. $\mathrm{He}$ was glad that the President had alluded to a project which had found vent in the public press, of using chalk instead of coal. He thought that, on the whole, the President had dealt too leniently with that project. They should remember that chalk was the result of a double combustion - a combustion of calcium and a combustion of carbon-both combustions being perfect in themselves, leading to a further combustion of the two combined together, and, therefore, if the originator of that scheme had looked all the world over, he could not have found a more thorough cinder. 


\section{In the discussion of the Paper}

"ON THE MANUFACTURE AND USE OF SPIEGLLEISEN,"

By Mr. Geo. J. Srelus,

Dr. Sremexs* said the Landore Works being producers of spiegeleisen, he could, from his experience there, bear ont nearly all that had been said by the anthor of the paper. He agreed with him that there was no great difficulty in producing spiegel, as, indeed, all things were simple if they knew how to deal with them, though up to that point they were difficult. At first there had been a difficulty in getting the slag right, and according to their experience the slag must be as basic matter as possible. They had succeeded in making spiegel containing as much as from 18 to 20 per cent. of manganese, and they could vary it so as to make it from 10 to 12 per cent., which was what was preferred for common use, the richer spiegel being reserved for producing extra mild steel. There was one point upon which he would like to ask Mr. Riley to give a little more information, that was, why did spiegeleisen never contain even a trace of sulphur? As he understood the paper, it was owing to the manganiferous slag having a greater capacity for sulphur, but he (Dr. Siemens) thought that that explanation was hardly sufficient for the extraordinary fact that they did not find even a trace of sulphur in spiegeleisen. As regarded phosphorus, it had been contended that it acted as a substitute for carbon, and was rather a desirable constituent in spiegeleisen, but he would much rather be without it, and not risk the bencficial effect of phosphorus on the steel. Another interesting point with respect to the use of spiegcleisen, was the nature of its effect upon the steel; was it that the manganese simply deoxidised the iron, or was it that the manganese must be present in a metallic state, in order to produce malleable steel? He inclined to the latter hypothesis, because his observations went to prove that manganese was necessary in malleable steel, especially if sulphur was present. Manganese seemed, in fact, to hare a

- Excerpt Journal of the Iron and Steel Institute, 1874, pp. 84-\$6. 
specific action in neutralizing the effect of sulphur, and no chemical explanation, that he was aware of, had ever been even given of that fact. On the other hand, he (Dr. Siemens) did not think that the deoxidising action of the manganese was the essential effect of that substance in the process with which his name had been connected, because they could regulate the oxidising action on the bath to such a degree, that the absorption of oxygen by the bath had not commenced before the spiegel was added, and yet the addition of spiegel was necessary. If the operation of decarburisation was carried on to the point at which oxygen was absorbed from the atmosphere, that is, until the carbon was reduced to below 1 per cent., it was very difficult to get rid of the oxygen. After spiegeleisen had been added, and the bath had become perfectly quiescent, they would find the steel, when poured into the moulds, set up a violent ebullition. Now, that ebullition proved that oxygen existed in the fluid metal and probably in combination with carbon, which was liberated suddenly after the steel had been lowered in temperature to near the point of solidification, but which the manganese had not been capable of removing. He was aware that, in the Bessemer process, when spiegeleisen was added, a powerful ebullition was set up; but that was not the case in his process, in which ore was used as the decarburising agent, and the steel when poured into the ingot moulds, or moulds for casting purposes, showed no sign of ebullition, if carefully prepared ; on the contrary, the steel contracted, or what was technically called piped, but if the operation had been carried too far, it seemed to acquire an extraordinary affinity for oxygen, and that oxygen at very high temperatures did not seem to go out again, notwithstanding the addition of manganese, but remained associated with the metal until it had cooled down near to the point of solidification. He would like to have that important point cleared up in this discussion. 


\section{In the discussion of the Paper}

\section{" ON IRON AND STEEL FOR SHIP-BUILDING,"}

\section{By Mr. N. Baryaby,}

Dr. Sicmexs * said, there can be no doubt that steel is a metal which is worthy of the highest consideration of ship-builders, engineers, boiler-makers, and all persons, in fact, engaged in construction of that kind. One thing is necessary, namely, that those who use that material should know what it is. We hear of comparative results of steel and puddled iron as produced in one furnace and another furnace; and one would naturally come to the conclusion that steel was a definite compound varying only as regards quality. What is that compound may I ask? Steel in the form of a needle, an edge tool, or of a punch, is of a hardness approaching that of the diamond; steel in the form of a spring is of an elasticity unequalled by any other metal, or any other substance in nature. Then, again, steel in the form of a milled plate is, with few exceptions, the toughest material in existence, tougher than copper or wrought iron. It can be moulded into almost any shape in a cold condition. Therefore, we ought first to understand what we mean by steel before we consider its merits or demerits for structural purposes. You may say that the hardness depends upon the proportion of carbon in the metal. Does it? I have lately experimented with steel containing four-tenths per cent. of carbon. That steel, if treated in a certain way, would make an excellent punching or cutting tool. If treated in another way and annealed carefully, it is so tough that you conld work it into the form of your hat. Then, again, drawn into wire and annealed in another way - that is to say, heated in a certain way and then put into oil-it assumes a tensile strength of nearly 100 tons per square inch ; whereas, in the other form just before mentioned, when annealed carefully its tensile strength would not exceed 35 or 36 tons. Now, if the mere fact of after-treatment

* Fxcerpt Transactions of the Institute of Naval Architects, Vol. XVI. 1875, p. 140 . 
can produce such enormous changes in the behaviour of steel, how important it must be to give to steel the nature which we desire for structural purposes. Now, if you take a plate and throw it down in a wet court-yard, and then punch it and use it for the manufacture of a boiler, there can be very little satisfaction in the result obtained from the material. Very likely in the same plate, if you could cut out pieces, you would find very different qualities, and some of these qualities would be raluable in one place and would be destructive to the plate in another. It may be laid down as a general rule, that a higher material and a higher process require higher intelligence to deal with them. If you ride a common cart-horse you may go to sleep on him, but if you ride a fine spirited horse all your wits must be about jou, or else you may be landed in a ditch. So with steel, you hare to understand first of all what quality of steel you have to produce, how much carbon, and how much manganese should be mixed with the material, and how little sulphur and phosphorus you can put up with. Until you have done that, you do not know what you are speaking of. It is a material belonging to a group varying between the hardness of the diamond and the toughness of copper; and it is also of the highest importance that the manufacture throughout, and the construction throughout, should be carried on with superior intelligence. Now, should we shrink from using a material, because intelligence is required in working and using it? Surely that would be a very poor compliment to this age of progress. We should have no difficulty in finding what are the conditions necessary to produce steel of such and such a quality, and should see to it that we obtain this quality and obtain it always. With regard to the question of obtaining it always, I maintain that we have a greater power in our hands than with regard to iron; iron, as we know, is produced in small quantities; the puddler produces sometimes a ball which is rather young, and at other times produces it overheated; and this material is piled again, put through the rollers, and in the end we get a sort of average between the qualities of the different balls. In making steel we formerly dealt with it in small quantities also by melting it in pots, but Mr. Bessemer has shown us how to deal with it in large quantities in his converter. I have had considerable experience in dealing with it in large quantities in the open hearth 
furnace. There I know that we can produce six, eight or ten tons of steel of perfectly uniform quality. We can take out samples before pouring that steel to assure ourselves of having the quality desired. This metal is thoroughly mixed-it is a perfectly fluid mass - and, therefore, there can be no reason why there should be a difference in the behaviour of one part of this metal from the behaviour of another part. Now, I have lately seen steel of very mild quality produced which is eminently suitable for structural purposes. This steel contains hardly any carbon at all, perhaps one-tenth per cent. only; but it contains manganese in a larger proportion than has been given to it hitherto. It is possessed of a toughness which is unapproached by any other kind of metal; and before it breaks it yields cven to 50 per cent. Now, if such a material can be produced, and if such a material will resist say 30 tons, which is quite enough for all purposes, I think it is the very best material for structural requirements.

In the discussion of the Papers

"ON THE MANUFACTURE OF STEEL," by WiLliaM Hackney, B.Sc., Assoc. Inst. C.E., and

"ON BESSEMER STEEL RAILS," by Josiah Trmis SMIth, M. Inst. C.E.,

Dr. Siexiexs * said that he regarded Mr. Hackney's Paper as so comprehensive that it offered room for observations on many different branches of the subject. His remarks would be confined to the first two portions into which the subject was divided, namely, the chemical and the manufacturing. The author had, perhaps, dwelt too much upon the question of name, and had proposed to change the prevailing denominations of mild steel,

* Excerpt Minutes of Proceedings of the Institution of Civil Engincers, Vol. XLII. Session 1874-1875, pp. 91-95. 
hard steel, spring steel, and so forth, and to call "steel" all malleable iron which had passed through the fluid condition. This definition would exclude, however, natural, blister, and puddled steel, and was therefore in his opinion inadmissible. On the other hand, Dr. Siemens considered it would be difficult, if not impossible, to define steel by its mechanical qualities. Steel was almost the hardest substance in nature, if treated in a certain way; treated in another way it was the most elastic of metals, if not the most elastic substance in nature; and treated in another way it was nearly the most ductile of metals. It was decidedly the strongest substance in nature. Dr. Percy had said he considered steel a metal in which iron was the chief constituent, and which would harden. If that definition were adopted, a limit would be arrived at where it would be uncertain whether a substance was steel or iron. One rail delivered by a manufacturer would come under the definition of steel, and another rail delivered in the same contract would come under the definition of iron, simply because one had rather less carbon than the other; and after all, the mildest steel, and iron itself, would admit of tempering. Dr. Percy had said that molten iron, according to Mr. Hackney's definition, ought to be called steel ; but it had been already remarked that such iron could not be treated mechanically; it would not stand rolling and hammering, and therefore it was not steel. He thought, however, a definition might be found which would answer all requirements, namely, that steel was a compound of iron with any other substance which tended to give it superior strength. This definition would embrace the different kinds of steel, from the hardest tool steel down to the mildest, and would embrace those compounds in which manganese, tungsten, chromium, phosphorus, or sulphur, replaced the carbon of ordinary steel. It had been objected that steel was uncertain in its nature ; that it sometimes was very ductile and very strong, and at other times would break short and was not be trusted. Mr. Walker had said that, on that account, he preferred iron to steel for structural purposes. Steel was a material of a much higher nature than iron. It was much stronger, and could be made to possess nearly any degree of strength, hardness, and ductility, between wide limits, that it was desired to give it ; but it was only natural that such a material should require greater 
care than iron. If extreme toughness was required, care inust be taken that the material was not put partially through a process of hardening or chilling, and that its chemical constitution was uniform. The higher inaterial required a higher intelligence to deal with it, and it was not sufficient that the chemist, or the manufacturer, should possess a knowledge of its characters under different treatments. The engincer, also, had to be thoroughly conversant with its properties, and in giving his orders for a supply of the material should make out a proper specification, defining its chemical constitution and its temper. Sir Joseph Whitworth had proposed a method of defining steel according to its two principal qualities, toughness and strength ; he had one number signifying strength, and another toughness, and combining these two expressed the quality of the steel. That was a rule which furnished a fair standard of comparison, and might be worked out with great advantage. He had repeatedly heard it stated, that mild steel, such as was used for engineering purposes, ought to be rejected if it had an absolute strength exceeding 27 or 30 tons. Such a limit was, he thought, objectionable because it stopped the road to improvement. He considered it quite possible that steel might be extremely tough, and at the same time possess very great tensile strength. As an instance of this he would mention wire, which had undergone the process of annealing in oil at a certain temperature. He had lately had occasion to experiment on some steel containing 0.4 per cent. of carbon, which, if properly annealed, was extremely strong and yet sufficiently ductile ; if hardened, it would take such a temper that it could be put into the form of a punch ; and if drawn into wire, and annealed by passing it at a certain temperature through oil, its strength rose from 35 tons per square inch to about 100 tons per square inch. That was an instance of one material presenting itself under very different aspects, in consequence of slightly different modes of treatment. It was necessary that the engineer, in dealing with steel, should inquire into these different conditions, and should insist upon the utmost care being taken in order to bring the material really into the condition which he required. Cast steel was produced in the Bessemer conrerter, or in the open hearth of a regenerative gas furnace, in masses of from 5 to 10 tons ; and absolute uniformity could be obtained if all conditions were properly carried out. 
Mr. Hackney, after paying the high compliment which was due to Mr. Bessemer for the introduction of his process, had referred to one process with which Dr. Siemens's name had been associated. That process might perhaps be appropriately called the chemical process, or the cooking process, to use a more vulgar expression; because, given a hot receptacle, such materials were put into that receptacle as would, when melted together, produce steel of the quality required. The beginning of the operation must be a fluid bath, and the material natural for such purpose was pig metal. To this pig metal, when heated to a temperature exceeding $2,000^{\circ}$ centigrade, either scrap iron, scrap steel, puddled blooms, or iron sponge might be added, and thus a bath might be obtained, which would gradually come to contain less and less carbon, until it was reduced to the condition of fluid iron. It then received such additions as would give it the necessary manganese, carbon, or other substances, to make steel of the required quality. This process had the adrantage that samples could be taken out, from time to time, in order to make sure that the operation was going on properly, and that the chemical and physical qualities of the material were such as might be desired. The essential condition for carrying out such a process was a very high temperature ; it was perhaps the highest temperature used in the arts, excepting only the fusion of platinum. Considerable difficulty had existed, at first, in obtaining a vessel to withstand such heat, continuously, and the only substance capable of doing so was silica, containing only from 1 to 2 per cent. of binding material. He noticed diagrams of the furnaces in which the processes were carried out; and one diagram of a modified form of the furnace, by M. Pernot, which was certainly ingenious. The bath was circular, and was rotated on an inclined axis ; and the pig metal flowing round and round in that vessel would wash over any solid substance put into it. He however doubted very much whether such a vessel would resist the high temperature which was necessary for the production of mild steel by that process. He understood it was used at St. Etienne, in France, where engineers were content to have steel rails containing 0.8 per cent. of carbon, which melted at a much lower temperature than the mild steel required in this country. Nor would it probably work out altogether satisfactorily for the process of producing steel from pig metal and ore ; because, in that 
process, considerable ebullition ensued, and he should be afraid that the boiling mass would go between the rotating lip of the vessel and the standing part of the furnace, and cause it to stop. Mr. Hackuey had alluded to experiments carried on in America by Mr. Blair, who appeared to have found that, if the ore and carbon were heated to a sufficient temperature, and left to themselves, the heat retained in the mass would be sufficient to complete the reduction of the ore. Dr. Siemens maintained that that was an entire fallacy. Although the ore might be hot enough for the reaction to commence, a very large influx of heat would be required, during the operation, to make the whole of the oxygen contained in it combine with carbon. Mr. Lowthian Bell had already proved the fallacy of the assumption that ore, under such circumstances, would combine with carbon and form itself into spongy metal. He had himself paid considerable attention to the reduction of ore, in order to obtain material for the bath, and he had experienced great difficulty in reducing ore into spongy metal. The iron, in that spongy condition, took up sulphur very readily, and sulphur vitiated the steel produced from it. These failures and difficulties induced him to resort to another mode of obtaining metallic iron from the ore, by passing the ore, in a heated condition, through a rotating chamber, and there treating it with reducing material, not at a temperature to produce sponge, but at a melting temperature at which cohesive wrought metal was at once produced. That part of the process was as yet in an experimental stage, and he could not at present reply to Mr. Williams's inquiries regarding it; but before long it would be at work on a complete scale, and he would then be in a better position to speak definitely regarding it. The chemical process of making steel might be varied almost ad libitum, and that variety was undoubtedly the best which, from impure ore or impure pig metal, would produce material of comparatively high quality. Hitherto phosphorus and sulphur had been regarded as the enemies of steel, but recent experience had shown that they might be innocent constituents under certain conditions. If phosphorus was contained in the metal used for steel-making, it was necessary that the metal should contain very little carbon; in fact, the carbon should be reduced to a mere trace ; and manganese should be introduced in order to produce a malleable metal. This was being carried out very successfully in 
France and in this country, and the results were very satisfactory. Years ago the use of rich ferro-manganese had been found to afford great assistance, but manufacturers had not succeeded in producing a soft and tough metal containing so large a proportion of phosphorus as had been produced latterly, more particularly at 'Terrenoire, in France, in using the Siemens-Martin process. $\mathrm{He}$ had very few observations to offer with regard to the working of steel. In solidifying from the melted state it had a natural tendency to become honeycombed, either through the generation of gases, or through mere contraction of the semi-fluid mass, and it was necessary to close these cavities as thoroughly as possible, because steel, unlike iron, did not weld; and if a hollow space existed in an ingot, that hollow space would remain a break of continuity, no matter through what process it was put afterwards. Probably hammering was the most efficacious of those contrivances which had hitherto been adopted for closing those bubbles; but Sir Joseph Whitworth had elaborated a plan for remedying the evil at the proper moment. He compressed the steel while it was still in a fluid or semi-fluid condition; Dr. Siemens expected great results from that system. He was not prepared to say whether it would ever supersede hammering and rolling, for ordinary rail-making, but for such purposes as gun-making, he considered that Sir Joseph Whitworth's plan commended itself as one of great importance.

In the discussion of the Paper

"ON FLUID COMPRESSED STEEL AND GUNS,"

By Sir Joseph Whitworth, Bart., D.C.I., F.R.S.,

Mr. C. W. Siemens * observed that the paper now read was remarkable on account of the very striking results which had

* Excerpt Minutes of Proceedings of the Institution of Mechanical Engineers, 1875, pp. 285-288. 
been unived at, and which the members would have an opportnuity of witnessing at the autlor's works. But perhaps the most remarkable feature of the subject was the systematic manner in which those results had been arrived at. The question of gunnery had been taken up by Sir Joseph Whitworth in 1854 in eonnection with the rifle, and in 1868 in connection with the construction of steel guns ; and on the oecasion of his reading a paper before the British Assoeiation in 1869 on the penetration of armour plates by long shells fired obliquely, the remark had been made by himself (Mr. Siemens), as President of the mechanieal seetion, that "Mr. Whitworth having taken up the question of gunnery has viewed it from a mechanical point of view, and has arrived at purely meehanical results in this problem. His solution commends itself to all who have gone into the question; and it is natural there should be some diversity of opinion under such eircumstanees." The solution at that time arrived at by Sir Joseph Whitworth in connection with the question of construeting guns had referenee to the method of rifling that he proposed; and it appeared to be conclusive. Nothing was more natural than that his attention should next be directed to the production of the material from which the gun was to be constructed; and having perserered in thoroughly inrestigating this portion of the subject, he had succeeded in arriving at the remarkable results brought forward in the present paper.

In the plan now carried out, the steel after it had been produeed was dealt with under a method entirely different from those kefore adopted, being here eompressed while in a fluid or semi-fluid state. He had at first felt eonsiderable doubt as to the effeet of the $n \in w$ method. It was said that in applying hydraulic pressure upon fluid steel the gases contained in the fluid metal would be driven out; but he could not see how that was to be done by mere pressure. For in applying pressure to a fluid, the pressure aeted in all direetions equally ; and why a particle of gas held in suspension in the fluid should go in one direetion rather than another, and should get away from the pressure to whieh it was subjeeted, it seemed diffieult to conceive. The facts howerer spoke for themselves; and these being ascertained, it was more easy to find an explanation of syhat took place. The result he suggested might be aceounted for by the circumstance that the fluid steel eongeal- 
ing first on the outside of the mould offered more resistance there to the motion of the plunger, and the outside thus became comparatively speaking porous, while the fluid portion in the centre receiced a larger amount of compression than the outside which had more power of resisting the pressure. The particles of gas entangled within the fluid mass would therefore encounter rather less resistance towards the outside than towards the inside, the full hydraulic pressure being transmitted to the centre of the fluid mass. In that way the expulsion of the gases from the fluid metal might perhaps be accounted for ; and he should be glad if Sir Joseph Whitworth would give his explanation of the matter. The fact being admitted, it was clear that the steel prodnced by that mode of treatment must possess many great advantages over metal treated in the ordinary way by hammering; for it was hardly to be supposed that hammering would be capable of driving out the gases.

With regard to the mode in which these gases entered the metal, he did not think they were merely entrapped inechanically at the time of pouring out the metal into the mould; because in working melted steel in the open hearth of a regeneratice furnace he had found that the metal could be made at any moment to evolve gases in great quantities by simply plunging a cold bar of iron to the bottom of the fluid mass. The fluid metal evidently absorbed carbonic oxide to a very great extent; and it was due to the partial congelation of the metal that the gases were suddenly set free. Similarly in the Bessemer process a great ebullition took place on pouring the fluid metal out of the converting ressel into the iron rnoulds, and the top of the moulds had to be closed by a stopper to prevent the metal being thrown out by the ebullition. It was clear therefore that the metal contained a large quantity of gas occluded within itself ; and if this was retained in the metal it became a source of weakness. However small the bubbles of gas might be, their presence would have the same effect as the presence of particles of foreign matter between the particles of metal, and must necessarily weaken it.

In reference to the proposal to designate as steel any metal bearing a tensile strain of 28 tons per square inch, he thought it would be wise on the whole to fix a limit of strength, but some further limitation seemed also to be needed. For instance, a 
metal produced in the puddling furnace, with or without being converted into steel by the ordinary cementation process of making blister steel and shear steel, would have the required amount of tensile strength, and would therefore pass as a steel. But he considered a broad distinction should always be made between steel which had passed through the fluid condition and that produced by other processes, hecause the latter was deficient in one essential quality which was always sought for, namely, uniformity of strength. He would therefore willingly accept the suggested definition of steel and iron according to tensile strength and ductility, if it were confined to metal that had passed through the fluid condition.

It would appear from the paper that it was immaterial by what process the steel was produced, provided it had been produced from pure materials and would bear the required tensile strain. But however true it might be that the quality of the steel was due to its chemical nature, yet this chemical nature could only be obtained in a uniform and regular manner if the process of manufacture was in conformity with the conditions necessary to produce the desired result. Such steel, he believed, it would never be possible to produce by the old processes of puddling aud cementation; and this led him to suggest that the demand for the qualities generally associated with steel should be confined to what was known as cast steel. The results of the experiments in testing small cylinders with gunpowder, as shown in the table accompanying the paper, were most instructive, and appeared to leave very little room for doubt that mild steel must be the proper material for the production of guns. Whether guns made of one block of steel' like the old cast-iron guns, or those having an inner core hooped with steel rings, were the best, was a question for gunmakers to solve, and must depend mainly upon the dimensions of the structure. But the results now arrived at sufficiently showed what extraordinary strength and ductility combined might be obtained in constructing guns of a solid block of steel ; and be hoped the Admiralty and the War Office would soon see their way to affording this system a thorough trial. 


\section{In the discussion of the Paper}

\section{"ON PRICE'S PATENT RETORT FURNACE,"}

\section{By Mr. I. Lowthian BeLL, M.P., F.R.S., Middlesborough,}

Dr. Simurens * said, that when he first saw the paper on that furnace, he could hardly think it was Mr. Isaac Lowthian Bell who had written it, because they all knew that Mr. Bell was thoroughly conversant with the phenomena of heat and the chemical actions that occurred in the combustion of fuel. Yet he found in that paper, prominently put forward, a comparison of Price's furnace with his regenerative gas furnace, in which it was stated that there was an absolute loss of 30 per cent., arising from the action of the gas-producer in dealing with the carbonaceous matter while reducing it to the state of carbonic oxide, before it passed into the furnace. Seeing this statement in Engineering, he took the opportunity of calling attention to the fact that the gas-producer had several duties to perform. 'The carbonaceous matter contained in the coal was burnt to carbonic oxide, but in addition to that, all the hydrocarbons were developed from the coal, and besides a quantity of vapour of water being decomposed into its elementary substances, and thus a considerable amount of the heat that would otherwise be lost, was simply transferred from the state of sensible heat to that of latent heat, in order to be re-developed in the furnace. Considered from this point of view, it would be found that the loss in the gas-producer was not 30 per cent. as stated, but about 12 ; it was a subject that could be thoroughly cleared up by theoretical argument, and by measuring the temperature of the gases as they came from the gas-producer. He was glad to find Mr. Bell admitting that he was wrong in his calculation, but still he did not seem disposed to accord to the regenerative gas furnace the reputation for economy which it has acquired. The regenerative gas furnace was sufficiently well known, and its economy was proved in various applications, and he would not take up the time of the meeting by reasserting its

\footnotetext{
* Excerpt Journal of the Iron and Steel Institute, 1875, pp. 496, 497.
} 
merit. In his letter, he did not make comparisons between the two furnaces, he merely endeavoured to correct an error which $\mathrm{Mr}$. Bell had incidentally fallen into. Regarding Price's retort furnace, he might observe, that at one time he had retorts in connection with his own gas-producers when he found that he could not get them gas-tight, and also that if, as in Price's furnace, the coal passed through the retort, surrounded by the spent gases on their way to the chimney, the spent gas would speedily take up all the gas that leaked through the joints, and make away with it unconsumed; moreover, it was very difficult to construct a vertical retort in such a way, and to heat it to that nicety that the coal would part with its hydrocarbons, and would not adhere to the sides. The probability was that if they gave that furnace into the hands of an ordinary fireman, the retort would soon be choked, the bricks get overheated, and the whole thing come to grief. How such accidents were prevented in Price's furnace did not appear; probably at Woolwich, where extreme care was bestowed upon it under the author's own eyes, and where any failure could readily be put right, without counting much the cost of doing it, it might answer for a certain time, but judging by his own experience, he should be apprehensive of a considerable amount of difficulty if such a furnace were put into ordinary hands. The furnace, while working, would no doubt give a fair result, and develop a considerable amount of temperature.

In the discussion of the Paper

"NO'TE ON THE MANUFACTURE OF ANTHRACITE COKE IN SOUTH WALES,"

By Mr. W. Hackney,

Dr. Sirmexs * said, he could fully substantiate the results which Mr. Hackney had stated in his paper as having been

* lixcerpt Journal of the Iron and Steel Institute, 1875, pp. 530-532. 
obtained at Landore; but it must be remembered that the coke which had been used hitherto there was very weak coke, and it would be unfair, perhaps, to expect the same difference of results if that anthracite coke were tried, for instance, in the Durham district where coke of a much harder kind was obtained by direct distillation of coal. It would be admitted by the author that the process of making artificial coke from anthracite and binding material was, of course, not new. He (Dr. Siemens), had first seen it in operation many years before at the Creusot Works, and he had then formed a very favourable opinion of the coke produced; and when about seven years ago he had been requested by the Landore Siemens Steel Company to design two blast furnaces, he designed them with the idea that such coke would be used. The question which had then most occupied his mind was what height he ought to give to those furnaces. It was at a time when the general opinion of iron-masters was very much in favour of high furnaces. Some had suggested 70 or 80 feet furnaces. Others had said that 60 feet was the least height that should be employed. His idea had been to make the furnace only 52 feet high, as being the height most suitable to the fuel at his command in the locality; but he had added another 2 feet, and the first furnace was made 54 feet high. Nothing had been changed since in the proportions of the furnaces. The blowing engines worked splendidly, and the Cowper stoves had given no trouble, and yet the result had not been such as he had anticipated. That was due entirely to the weak coke that had been employed, and though before they started those furnaces all the machinery had been ordered for making anthracite coke, their erection had been postponed, as coke of that description was at the time not well known in this country. It had been a very fortunate circumstance, therefore, that Messrs. Penrose and Richards had taken up the question of making anthracite coke. They seemed to have come to the conclusion that to make hard anthracite coke, besides binding coal, a high binding material, such as pitch, was required; and he (Dr. Siemens), willingly admitted that pitch was necessary, in addition to binding coal, if it was their intention to make coke very rich in anthracite; but he was not quite so certain, notwithstanding the results which they had recorded, that it was desirable in all cases to have coke. containing quite so much anthracite as 60 per cent. He 
looked upon the blast furnace as requiring a fuel which would live down to the crucible, and there perish. If they were to charge graplite, they would get it all into the crucible, and have to tap it ont with the slag, unconsumed; and what Professor Williamson had just said showed the great resistance of hard coke to combustion, and its great advantages in certain respects ; but they might have too much hardness and so make the coke imperishable in the furnace. He had therefore propised that before deciding upon the proportion of anthracite, comparative trials should be made, using coke containing a very large per centage of anthracite, formed with pitch, and weaker coke containing only from 25 to 30 per cent. of anthracite, made without pitch. He had with him a piece of coke containing 25 per cent. of anthracite and no pitch, which appeared to him probably hard enough for their height of furnace and their blast ; but he might be mistaken. It might be that the harder coke gave still better results; but he must say that if the hardness excecded a certain limit, he expected that a large amount of carbonaceous matter would come out with the slag, and in fact, their experiments already showed that evil to exist to some extent, but they had hardly been carried on for a sufficient length of time to say definitely to what extent. 'I'here could be no doubt whatever that the production of coke of such hardness that it would resist the action of hot carbonic acid in the upper portion of the furnace and furnish carbonizing material down to the very bottom of the furnace, was a matter of very great importance. One resnlt which had been observed and which Mr. Hackney had not stated, as far as he could gather from his paper, was this, that while they were troubled with sulphur in using their ordinary coke, which contained a good deal of sulphur, the sulphur disappeared as by magic the moment the anthracite coke came down to the bottom of the furnace, producing, in fact, No. 1 pig metal with only a trace of sulphur, instead of No. 4 pig, containing a very large proportion of that objectionable ingredient. The coke now brought before them had been produced in the horizontal coke oven, commonly used in South Wales, but he thought that i still denser quality would be produced in rertical retorts of the Appold type, and in making his designs for the Landore Compauy, this had been the form of coke-oren he, had specified; 
his reason having been that the powdery material of which anthracite coke was constituted, required a certain degree of compression to bring the particles into contact, and that the absence of this pressure caused the coke to be more or less spongy near the upper surface of the mass.

In the discussion of the Paper

\section{"ON A METHOD OF PRODUCING PURE CHARCOAL} STEEL DIRECTLY FROM THE ORE,"

\section{By Henry Larkin,*}

Dr. Siemens, F.R.S.,* said the old Sheffield method of making cast steel might be called a method by error. They took the ore and smelted it in a blast furnace, turning out a product which consisted of iron mixed with slag, and a great deal of carbon, all the carbon that could be gathered from the ingredients put into the furnace. All that foreign matter had then to be removed, and so it was puddled. The result was iron mixed with slag, but without any trace of carbon, or at any rate in no definite combination therewith. This was not what was wanted, which was iroll combined with carbon, or steel, and so it was again subjected to a very different process, termed cementation, whereby it was kept heated for a fortnight in a furnace, packed with charcoal. This gave a metal which was certainly steel, but it was mixed with slag and full of blisters, so that it was not yet fit to be used. After some years they adopted the method of fusing it in pots, and so produced cast steel such as was used in Sheffield to the present day. Any means of producing this material by a short process must be of great importance to the country, since steel was becoming more essential every day. Several methods of producing steel direct from the ore had been mentioned, but others had been omitted. He him-

* Excerpt Journal of the Society of Arts, Vol. XXIV. 1875-1876, p. 93. 
self introduced the system of reduction by a rotator in 1868 , and might state the results he obtained. The cheapest and most direct method of reducing iron ore was in a rotary furnace; the ircn ore and the carbonaceous material were introduced at one end of a large rotating cylinder, and brought out in the condition of spongy iron continuously at tie other end ; nothing could be simpler or cheaper, but still he saw reason to abandon it. First, because the spongy iron thus obtained absorbed in the very process a good deal of sulphur, and this could not be remedied unless you could prevent its contact with the sulphurous acid produced in the combustion of the coal. Then, again, it was not easily dissolved in the bath of metal, even if that were sufficient, because it floated on the top, and rapidly oxidised under the influence of the flame of the furnace. Moreover, unless you used such materials as could not practically be employed on a large scale, the spongy iron becaine enclosed in the gangue of the ore, and would not melt in the metallic bath, the gangue forming a screen which prevented intimate contact between the fluid and the solid sponge. $\mathrm{He}$ therefore modified the process without abandoning the principle of the rotary furnace, and now raised the heat to the point of melting, not the ore but the gangue contained in it, and thus effected the reduction. The result was a metallic ball enveloped in scoria, which did not absorb sulphur, and which could be hammered out into bars, or transferred to the open hearth furnace and melted down into steel. He believed that would be found the cheapest and most direct method. He alluded chiefly to the production of mild steel in large quantities; with regard to tool steel he was not sure if the presence of a little foreign matter, such as silicon and sulphur, should be entirely avoided. The famous hard steel of India contained a considerable proportion of these elements, and generally compounds of iron were harder than the pure metal. 
In the discussion of the Paper.

"ON SOME RECENT METALLURGICAL PROCESSES,"

$$
\text { By J. A. Phillits, }
$$

Tue Chair was taken by Mr. C. W. Sinmens, ${ }^{*}$ who in closing said: The process which Mr. Phillips had brought before them was one of many which distinguished the metallurgy of the present day. Ancient methods were always found to be very wasteful, both in fuel and materials, because it never occurred to the ancient metallurgist to separate the silver or gold from the copper, or to make use of the iron as a secondary process. He selected his ore for the one purpose he had in view, whether it was copper, silver, or iron, and used his fuel very wastefully in extracting it. This process was conducted at the expense of the iodide, which had only lately come into use mostly through photography, and at first sight he had been struck by the apparently great expense attaching to it. The discussion, however, had shown that this was really of very little importance, because, though iodine was relatively expensive, the process was so perfect that it was used over and over again. This reminded him of another process lately come into use for the production of soda, where another expensive material, ammonia, was used over and over again to produce carbonate of soda directly from common salt, without the intermediate stages of soda ash, soda cake, and so forth. The question had been asked whether the extraction of silver deteriorated the value of the copper, and the answer was that it did not, but rather enhanced its value, and he could fully believe that. Lord Palmerston once defined dirt as "matter in the wrong place," and certainly silver in the copper must be reckoned as dirt, and those who dealt with copper as a metallic conductor of electricity regarded it as dirt of a very objectionable character, for a very slight admixture of silver or any other foreign matter in the copper would reduce its conductivity to perhaps one-fourth of the proper amount. There could be no question, therefore, that

* Excerpt Journal of the Society of Arts, Vol. XXIV. 1875-1876, p. 291. 
it was advantageous to produce the metals separately and in their utmost purity. With regard to the use of the residue in the blast furnace, with all respect to Mr. Riley's opinion, he still thought copper was an objectionable element in wrought iron ; for if any considerable amount of copper, say $\frac{1}{2}$ per cent., got into a puddled bar, it did not behave well under the hammer, and therefore the copper must be classed in that case with Lord Palmerston's dirt. He had had these residues examined repeatedly for sulphur and for copper, and found they yielded on the average 3 per cent., which was equal to 1 per cent. of the metallic iron contained in the ore. Therefore, although this material might be extremely useful in the blast furnace to assist in producing quantity, it ought to be used with great caution, in order not to increase unduly the proportion of copper or sulphur. With regard to the extraction of silver, he only hoped, for the benefit of this process, that the late discoveries in California, which it is said would reduce the price of silver to an almost nominal amount, would not interfere with its financial development. He concluded by proposing a vote of thanks to Mr. Phillips, which was carried unanimously, and the proceedings terminated.

In the discussion of the subject

“THE USE OF MOLTEN IRON DIRECT FROM THE BLAS'T-FURNACE FOR BESSEMER PURPOSES,"

Introduced by Mr. J. T. Sмiтh,

Dr. Simarens * said he hoped the two processes would live side by side and help each other, instead of being considered antagonistic. He should not have troubled them with any remarks of his own, except for the remarks which had fallen from Mr. Hackney. When the works at Landore were contemplated, he (Dr. Siemens) was

- Excerpt Journal of the Iron and Steel Institute, 1876, pp. 33, 34. 
asked to prepare plans. One arrangement proposed was to run the metal from the blast furnaces that were intended to be erected, directly into an open hearth furnace. Those furnaces were to have been worked with anthracite coke-coke similar to what was used at Creusot-and he had no doubt that if coke of that description had been employed at the time, instead of that made from the coal available at the works, pig of sufficient purity to be run at once into the steel-melting furnaces would have been produced. $\mathrm{He}$ believed that with weak impure coke it would be impossible to obtain regularity and such freedom from sulphur in the pig as would give satisfactory results, and it appeared to him that the success of that-invention he would not call it, because it was contemplated by Mr. Bessemer, and it must have occurred to most of them as a possibility-that the success of that addition or improvement in the Bessemer process, or the process with which his own name was connected, must depend upon the working of the blast furnace, and if they could get such results as had been produced at Seraing, at Creusot, and as no doubt were produced now in this country, there was a clear margin of benefit; but in order to attain success, it would be necessary to work the blast-furnaces with greater care than was usually exercised. At the time when he contemplated using pig metal from the blast-furnace, he thought it preferable to work with an open top; in fact the blast-furnace specified was almost identical with what Mr. Whitwell had just stated was now used at Seraing. The open top was preferred, because it gare them greater power of regulating the charge, and he would throw out the suggestion to those eminent iron and steel makers who were there present, whether it would not be worth while to make a comparative trial between the open top and the close top furnaces. No one would be able to give them sounder advice on this subject than his friend Mr. Bell. A good metal could no doubt be produced with a close as well as by an open top, but it appeared to him (Dr. Siemens) there was a greater margin of safety in working with the open top. With regard to the experiment which Mr. Hackney had tried in using pig metal remelted with impure coke in a cupola, he did not wonder at the want of success that had attended it for two reasous : first, the molten metal would contain a great deal more sulphur than there was in the pig charged, especially if No. 3 or 4 pig metal was 
used, as was the case at Landore, and secondly, it would be produced at a comparatively low temperature. Much also would depend upon the condition of the steel melting furnace at the time when the fluid metal was run into it; if the furnace was in a comparatively cool condition (for instance, if the bottom had just been made up with cold material, and the comparatively cold pigmetal from the cupola was run in), then considerable time must be lost before both the furnace and the fluid pig metal were brought up to the temperature at which the raw ore would act upon the latter, and this time might be quite equal to that required for fusing pig iron in the melting-furnace ; but if the furnace was heated to full steel melting heat before the molten pig iron was run in, and if the metal was taken direct from the blast-furnace at the highest temperature attainable, he had no doubt that an adrantage would be realised analogous to that which had been obtained by the Bessemer process.

In the discussion of the Paper

\section{"ON THE CASSON-DORMOY PUDDLING-FURNACE,"}

By Mr. E. Fisher Suith,

Dr. Siemexs * said Mr. Scattergood had given them a somewhat amusing account of the great precautions he used in making his expcriments. He trusted to nobody but himself ; but it struck him (Dr. Siemens), in listening to his obserrations, that in one or two particulars perhaps he had been over-cautious. He was not satisfied with puddling the Earl of Dudley's iron, but took iron of his own-pig metal of a rery inferior kind-with a view of putting the furnace upon its trial ; but it appeared to him (Dr. Siemens) not improbable that that very circumstance might hare contributed to the superior results which he reported, viz., the shortness of time which it took to bring his iron to nature, and to the com-

* Excerpt Journal of the Iron and Steel Institute, 1876, pp. 134-135. 
paratively small consumption of coal. Inferior irons were often puddled much more rapidly.

Mr. Scattergood said it was not white iron, but grey common iron.

Dr. Siemens, continuing, said that even then it depended very much upon the constitution of that iron, upon the silicon it contained, and the way in which carbon was combined with iron; but as regarded the time necessary to bring pig-metal to nature, another observation which the same speaker made struck him as being contrary to generally accepted views. Mr. Scattergood said that less fettling was required than in the ordinary furnace, because there was less surface, and he went on to say that if the furnace could be constructed without any sides, no fettling would be required. That perhaps was a slip only, because they all knew without fettling they could not carry out the puddling process; they must have oxide of iron in order to oxidise the carbon and silicon in the pig and bring it down to the condition of wrought iron. He wished to make a few observations on the paper itself. Mr. Smith very fairly stated that the furnace contained no striking element of novelty. Of course the dandy was a wellknown thing; it had often been tried in this country, and it had never found farour with the men. On the Continent it was used almost universally, and it produced no doubt very considerable economy. Blast under the grate was used, moreover, to a very large extent, and the points of novelty in the furnace before them seemed to reduce themselves to the round form of the puddling chamber and the mode in which that chamber was cooled. Now, with regard to the cooling of the chamber, he might observe that he had once tried a similar arrangement without success. He had placed under the puddling chamber an open vessel containing water very similar to what had been shown, but he had had to give it up very soon, because it was found that the vapour rising from the water found its way through the joints into the puddling chamber and affected the iron prejudicially. He should like to hear Mr. Smith's observations on that point, and whether or not he found any inconvenience on that score; also with regard to the inclined side of the puddling chamber, whether it had been found that the side held the fettling as well as the vertical side, his (Dr. Siemens's) own observation being that on the sloping side the 
fettling-unless it was of a very strong nature, that is to say of a very pure oxide-slipped down and did not stand up so well to its work as on the vertical side.

\section{In the discussion of the Paper}

\section{"ON IMPROVED CASTING ARRANGEMENTS FOR THE SIEMENS-MARTIN PROCESS,"}

By Mr. Michale Scott,

Dr. Siemers * said the paper referred to a subject which was one of considerable practical interest. At present they usually tapped the metal into moulds, as they were aware, which were stoppered at the top, and there was a good deal of uncertainty as to the amount of metal which they filled into these moulds. The metal, if it was at all frothy, boiled and gave only uncertain indications of its height in the moulds, which made it difficult for the workmen to stop the flow of fluid steel at the right moment. There was another effect resulting from the mode of filling at the top, viz., atmospheric air was carried in and mixed with the steel, to be liberated again at the moment of solidification, and thus giving rise to spongy metal. It was well known in ordinary practice that gases were set free at the moment of congelation in the moulds; the steel seemed to take up air, which was, he thought, combined with iron, forming a sub-oxide, which oxide of iron appeared to be dissolved throughout the mass, without combining with the carbon contained in the steel at the high temperature. 'The temperature of steel being in excess of the point at which carbon and oxygen combined, such metal might be kept for any length of time in a fluid condition, at that temperature, without getting rid of the free oxygen which was evolred at a lower temperature in the moulds. It had been the endeavour of several gentlemen, both in this 168.

* Excerpt Journal of the Iron and Steel Institute, 1876, pp. 161-163, 165- 
country and abroad, to overcome these difficulties by filling the mould from below, amongst which he would only mention Pinks's process, which had received a considerable amount of public attention, and realised to some extent the advantages of not exposing the metal to the oxygen of the atmosphere, and of getting the ingots of definite size and shape. There had been several difficulties met with, however, in the attempts made to realise those advantages, and Mr. Scott, who had had a considerable amount of experience in the matter, had devised a mode of overcoming those difficulties by running his metal through refractory material, which could be easily heated up beforehand, and which was surrounded by a non-conducting substance, namely, sand, and he had thus overcome one of the difficulties, that of the metal setting in the gits, and of not filling moulds right up to the top. Another part of the arrangement which Mr. Scott brought forward was to have the moulds divided longitudinally instead of casting them solid. That really was going back to the old Sheffield plan of making the moulds, and a very good plan it was. The difficulty connected with it, in using such large moulds, was to fit the two parts well together, and that Mr. Scott proposed to do by an elastic clamp, which would bring the surfaces home, one against the other with a great degree of certainty. He (Dr. Siemens) did not know that the plan in its entirety had yet been tried, but he learnt, and in fact knew, that it had been partially tried, and with, he believed, very encouraging results. In fact, there could be no doubt that the arrangement would work, and it was only by continued practical experience that the exact amount of saving and convenience, as compared with present modes of working, could be ascertained, but, as far as he could see, these advantages would be largely in excess of any corresponding drawback arising out of the method of arranging the ingots as Mr. Scott had shown.

$D r$. Siemens asked Mr. Snelus whether he considered that dead melting depended upon manganese, as if so, it was certainly quite a new principle to him. He had looked for the cause of dead nelting in quite another direction, and might mention, in support of his view, that the Sheffield pot steel contained comparatively little manganese, at all events much less than Bessemer metal, which he mentioned, not with a view to disparage it, but as the metal with which they were most familiar. His view regarding 
lead melting was, that it was chiefly a question of temperature, and the result of maintaining the steel for a considerable time in a fluid condition at a comparatively low temperature, at which the (x)ygen which was chemically combined with iron would leave the irun and go to the carbon, and escape as carbonic oxide, gradually before the metal was poured. If $\mathrm{Mr}$. Snelus had any other decided view on that subject, it would be important, he thought, that it shonld be brought forward.

IIr. Snelus finished his reply with the words:-If they put plenty of manganese into the steel, he believed the temperature at which the metal could occlude the gas was raised, and therefore the whole of the gas came off. The alloy with manganese appeared to have a less power of holding those gases in solution than the ulloy without it. That was his idea upon the subject.

Dr. Siemens said he should like to be allowed to express his views on that point. They all knew Mr. Snelus liad great ability is a chemist, and his view on such a subject was entitled to the ntmost consideration; at the same time, on a parely scientific point, each man was entitled to his own opinion until he saw sufficient reason to change it, and his view was in effect that the amount of gas held by liquids in solution decreased generally with the increase of temperature-for instance, they drore carbonic acid out of soda water when they heated it, and their champagne got flat when it had not been kept cool before it was poured out. In the same way he should argue that if it was simply a question of occlusion of carbonic oxide gas in the fluid steel, that the gas would be driven out in a greater measure at the high temperature in the Bessemer converter than it was at a much lower temperature just before the metal was going to congeal in the mould; and a further point which he would mention in favour of his view was, that in Sheffield it was the practice to lower the temperature of the pot furnace during the latter portion of the operation of melting, and that that lowering of the temperature produced the effect of dead melting. After all, the effect would be similar if Mr. Snelns's view conld be proved by absolute chemical test. It would simply show that occlusion in steel took place to a greater extent at a higher temperature than at the lower; whereas, according to his (I)r. Siemens's) view, the oxygen at the high temperature was combined with iron, and its combination with carbon was due to 
a somewhat lower temperature. Now, Mr. Snelus said, in opposition to that view, that they could never finish a Bessemer blow under those circumstances. He did not quite agree with him. there. In finishing a Bessemer blow, the carbon first went out, because the temperature was comparatively low, and towards the end of the blow he expected very little carbon combined with oxygen, when iron was chiefly acted upon, producing intense heat, a fusible silicate which in its turn would react upon the carbon to a certain extent. They all knew that carbon, which might exist in a proportion, say, of $\frac{2}{10}$ ths per cent. in pure metal at that temperature, wonld not be able to exist in the same percentage in the presence of oxide of iron, and it was all a question of how much oxide of iron was necessary to push out the carbon. According to this view, the amount of carbon remaining in the Bessemer metal after the blow would depend upon the amount of oxidation of the iron which had taken place, but he should be much surprised to learn that the Bessemer metal at the end of the blow was entirely without carbon.

In the discussion of the Paper

\section{"ON THE PERMANENT IVAY OF RAILWAYS,"}

\section{By R. Price Williams, M. Inst. C.E.,}

Dr. Siemers * said there seemed to be a great divergence of opinion with regard to the quality of steel composed of different percentages of carbon. Mr. Riley, who had given considerable atiention to these questions, no doubt could have supplemented the information by further chemical details, which perhaps he did not like to do because there was at present doubt as to the specific effect produced by other materials, such as phosphorus, sulphur, silicon, \&c. Dr. Siemens might perhaps be able to supply some

* Excerpt Minutes of Proceedings of the Institution of Civil Engineers, Vol. XLVI. Session 1875-1876, pp. 203-205. 
data regarding steels in which the proportions of different materials reached their limits on the one side or on the other. It had been said that steel containing a considerable percentage of carbon, $11^{\circ}+$ per cent., was very soft. That might be partly owing to the tempering, for if the steel had been slowly cooled it would be soft, but it might also be owing to the manner in which the carbou was combined. Carbon was not always chemically combined even in steel. In the process of mixing spiegeleisen with the blown metal at the last moment in the Bessemer process there was hardly time to form a chemical combination, and hence metal might be produced which contained a considerable proportion of carbon, and yet was essentially soft metal because the carbon was not chemically combined. He had observed, in boring a large cylinder of steel cast from metal of that description, that at one point the boring tool went deeply into the metal, and at another point there was a resistance as though the metal were hard. In such a case no effect of temperature, of sudden cooling, was involved, because of the particular form of the metal. The phenomena showed clearly that steel was not always homogeneous unless special care had been used to make the mixture perfect. Mr. Cowper had attributed to manganese the quality of making the metal tougb, whereas carbon made it hard. That was not universally the case. In the case of steel containing as much as 0.4 or 0.5 per cent. of carbon, little manganese was desirable or necessary to make the metal forge properly; but in the case of very soft metal, and metal containing phosphorus, the manganese was an essential condition. For instance, $0 \cdot 2$ per cent. of phosphorus, which was about the maximum amount admissible, necessitated about 0.4 per cent. of manganese to make the metal at all workable and to prevent its extreme brittleness when hard; but in metal containing hardly any carbon, less than 0.1 per cent. manganese was of the utmost importance, and without it the metal could not be got to work or stand against the grinding axle. The manganese seemed to bind the particles of metal together, and to make it more homogeneous. Mr. Riley had mentioned the difficulty of determining such a slight amount of carbon by the ordinary colour test. No doubt the difficulty was great, but Mr. Willis, of the Landore Works, had introduced a test for determining a very slight proportion of carbon, sufficiently accurate for all practical purposes, by dissolving the 
metal in nitric acid and observing the effect of colour on the solution. The nitric acid did not act upon the carbon, and it produced a brown tinge of sufficient intensity to be distinctly observable, even though the proportion of carbon should be considerably below $0 \cdot 1$ per cent. This test would enable manufacturers to produce steel of extreme mildness, such as was now used largely for engineering purposes. It was impossible to estimate so slight a difference in carbon as 0.05 or $0^{\cdot} 1$ per cent. by any mechanical test; but by a ready chemical test of that kind the manufacturer was enabled to bring the metal down to an exact point considerably below $0 \cdot 1$ per cent. No doubt these questions were at present only partially understood, and much work was still required in order to arrive at certain conclusions regarding the conditions necessary to produce steels of definite qualities. If steel was produced from pure iron, such as was found in Sweden, a metal could be made containing hardly any manganese, and only a trace of carbon, and no appreciable percentage of phosphorus or silicon; and metal of that description, which was as nearly as possible of pure iron, was perhaps the toughest that could be made, exceeding in toughness copper or even silver. A further advantage of such metal was that it was less liable to rust. Experiments lately made in France showed a percentage of rust, as compared with wrought and cast iron, in the proportion of 0.4 to 1.4 , being much in favour of a pure metal such as a very mild steel-a quality of great value for shipbuilding and purposes of that kind.

SOME FURTHER REMARKS REGARDING THE PRODUCTION OF IRON AND STEEL BY DIRECT PROCESS.

By Mr. C. William Siemens, D.C.L., F.R.S.*

IN mixing comparatively rich iron ore in powder, with about 25 per cent. of its weight of pounded coal, and in exposing this mixture for some hours to the heat of a common stove or of a smith's

* Excerpt Journal of the Iron and Steel Institute, 1877, pp. 345-359. 
fire, metallic iron is formed, which, on being heated to the welding point, on tlie same smith's liearth, may be forged into a horseshoe of excellent quality. The admixture with the ore of some fluxing materials, such as lime or clay, will, in most cases, be of advantage to rid the iron of adherent slag.

'The simplicity of this process is such that it naturally preceded the elaborate processes now in use for the production of iron and steel upon a gigantic scale, nor can it surprise us to find that attempts have been made from time to time, down to the present day, to revert to the ancient and more simple method. It can be shown that iron produced by direct process is almost chemically pure, although the ores and reducing agent employed may have contained a considerable percentage of phosphorus, sulphur, and silicon, and that, if freed from its adherent slag, it furnishes a material superior in quality and commercial value to the ordinary iron of commerce.

The practical objections to the direct process, as practised in former days, and as still used, to a limited extent, in the United States of America and in some European countries, are that-

1. Very rich ores only are applicable, of which about one-half is converted into iron, the remainder being lost in forming slag.

2. The fuel used is charcoal, of which between three aud four tons are used in producing one ton of hammered blooms.

3. Expenditure of labour is great, being at the rate of $33 \mathrm{men}$, working twelve hours, in producing one ton of metal (see Percy). Iron produced by direct process in the Catalan forge is therefore expensive iron, and could not compete with iron produced by modern processes except for special purposes, such as furnishing melting material for the tool steel maker.

But, it may be asked, could not the advantages of the direct process be combiued with those of modern appliances for the production of pure and intense heats, and for dealing with materials in large masses, without expenditure of manual labour, and cannot chemistry help us to obtain larger yields and facilitate the using of comparatively poor and impure ores?

A careful consideration of these questions led me to the conclusion, some years ago, that here was a promising field for the experimental metallurgist, and that I possessed some adrantage over others in the use of the regenerative gas furnace as a means 
of producing the requisite quality of heat without the use of charcoal and blowing apparatus. I engaged, accordingly, upon a series of experimental researches at my sample steel works, at Birmingham, and, in 1873 , I had the honour of submitting the first fruits of these enquiries to the Iron and Steel Institute, in a paper entitled "On the Manufacture of Iron and Steel by a Direct Process." Encouraged by the results I had then obtained, I ventured with others upon some larger applications, the principal one of which has been made at Towcester, in Northamptonshire.

If viewed by the light of present experience, it would have been wiser to hare fixed upon another locality with fuel, skilled labour, and better ores within easy reach ; but in extenuation of the error committed, it may be urged that the site was fixed by force of circumstances rather than by selection, the chief temptation being an ample supply of small Northamptonshire ore at a very low cost. It was, however, soon discovered that this ore, although capable of producing iron of good quality, was too poor and irregular in quality to yield commercial results unless it was mixed with an equal weight of rich ore, such as pottery mine, Spanish ore, or Roll-scale, all of which, as well as the fuel, are expensive at Towcester, owing to high rates of carriage. It is in consequence of these untoward circumstances that the works at Towcester have not been completed by the addition of rolling mills, the intention being to transfer the special machinery ultimately to existing ironworks when the process has been sufficiently matured for that purpose.

The Towcester Works were visited, in the autumn of last year, by two eminent metallurgists, Professors Von Tunner, of Leoben, and Åkermann, of Sweden, who have published the results of their observations in separate reports.* The results noted down by Mr. Von Tunner are referred to by our past-president, Mr. I. Lowthian Bell, in his paper on the "Separation of Carbon, \&c.," which was read in March last, and will be discussed at the Newcastle meeting. The criticisms contained in these publications are conceived in the fairest possible spirit, and form indeed a most valuable record of the progress achieved up to that time, but they furnish me with an inducement to break silence sooner than I had intended, regarding the further progress which has been effected,

* Das Eisenhüttenwesen von L. Ritter von Tunner, Wien, 1876. 
and the conclusions I am disposed to draw, from past experience, rergarding the direct process of the future.

'The leading idea which guided me in these researches was to operate upon such mixtures of ores, fluxes, and reducing agents as would, under the influence of intense heat, resolve themselves forthwith into metallic iron and a fluid cinder, differing essentially froin the methods pursued by Chenot, Gurlt, Blair, and others, who prepared spongy metal in the first place, by a slow process, which is condensed into malleable iron or steel by after processes, but assimilating to some extent to the process first proposed by Mr. Wm. Clay. In my paper of 1873 , I described two modes of effecting my purpose, the one by means of a stationary, and the other by means of a rotative furnace chamber, the former being applicable chiefly where comparatively rich ores are available, and the latter for such poorer ores as occur near Towcester.

At the Towcester works, three rotative furnaces have been erected, two of them with working drums $7 \mathrm{ft}$. in diameter, and 9) $\mathrm{ft}$. in length, and the third of smaller dimensions. The gas flame both enters and passes away from the back end of the furnace, leaving the front end available for the furnace door, which is stationary. The ends of the furnace chamber are lined with Bauxite bricks, and the circumference with iron oxides, resulting from a mixture of furnace cinder enriched with roll-scale, or calcined blackband in lumps. About $30 \mathrm{cwts}$. of ore mixed with about 9 cwts. of small coal having been charged into the furnace, it is made to rotate slowly for about $2 \frac{1}{2}$ hours, by which time the reduction of the metal should be completed, and a fluxed slag be formed containing the earthy constituents and a considerable percentage of ferrous oxide. The slag having been tapped, the heat of the furnace and the speed of rotation are increased to facilitate the formation of balls, which are, in due course, taken and treated in the manner to be presently described.

These balls contain on an average 70 per cent. metallic iron and 30 per cent. of cinder, and upon careful analysis it is found that the particles of iron, if entirely separated from the slag, are pure metal, although the slag may contain as much as 6 per cent. and more of phosphoric acid, and from 1 to 2 per cent. of sulphur. In shingling those balls in the usual manner, the bulk of the cinder is remored, but a sufficient residue remains to impart to the 
fractured surface a dark appearance without sign of crystallisation. Upon being worked, the metal shows what appears to be redshortness, but what should be termed slag-shortness. In re-piling and re-heating this iron several times this defective appearance is gradually removed, and crystalline iron of great purity and toughness is produced. But a more ready mode of treatment was suggested by Mr. Samuel Lloyd, one of my co-Directors in the Towcester Company, in reverting to the ancient refinery or charcoal hearth. The balls as they come from the rotator, are placed under the shingling hammer and beaten out into flat cakes not exceeding an inch in thickness. These are cut by shears into pieces of suitable size and formed into blooms of about 2 cwts. each, which are consolidated under a shingling hammer and rolled into bars.

The bars have been sold in Staffordshire and Sheffield at prices varying from $£ 7$ to $£ 9$ per ton, being deemed equal to Swedish bar as regards toughness and purity.

It may therefore be asserted, as a matter of fact, that iron and steel of very high quality can be produced from ores not superior to Cleveland ironstone by direct process, but the question remains -at what cost can this conversion be effected? The experimental works at Towcester are unfortunately not sufficiently complete to furnish more than the elements upon which the question of cost may be determined, the principal reasons being that the one re-heating furuace and a 30 cwt. hammer at the works are not sufficient to deal with the iron produced by the three rotators, that the iron has to be finished at a rolling mill elsewhere, and that transport weighs heavily upon the cost of production. The principal factor in the calculation of cost is unquestionably the rotator, and Table I, furnishes the working result of eighteen consecutive charges as taken from the charge book. The mixture of ores consisted for each charge of 12 cwts. of Towcester ore (containing about 38 per cent. metallic ir $3 n$ ), $8 \mathrm{cwts}$. of calcined Great Fenton ore, 1 cwt. of tap cinder, 1 cwt. of limestone, and $6 \frac{1}{2}$ cwts. of small coal. The time occupied for each charge was about $4 \frac{1}{4}$ hours, and the yield of hammered blooms was, on an average, 6 cwts. 2 qr. 13 lb., whereas the metal contained in each charge, amounted (by estimate) to $8.2 \mathrm{cwts}$., showing a loss of 19.3 per cent. This loss is, however, partially recovered in using 
a portion of the cinder again in succeeding charges, but the proportion of cinder that may be so used with impunity, depends upon the amount of phosphorus, sulphur, and alumina contained in the ore.* The coal used in the producers amounted to 2 tons per ton of hammered blooins produced, and in pricing the materials used and labour engaged upon the work, the table-prepared by the manager at the Works-gives $£ 38$ s. as the cost per toll of hammered blooms. To this amount must be added repairs and general expenses, and the cost of rolling the hammered blooms into bars, which in the case of Towcester practice are very heavy, but of which an experienced ironmaster would form his own estimate. The cost of working the metal in the hollow fires is also not included, and this may be taken to add from $25 \mathrm{~s}$. to $30 \mathrm{~s}$. to the ton. The refined iron so produced will, therefore, cost from $£ 5$ s. to £5 10s. per ton.

Tables II. and III. give the analyses of irons produced from various descriptions of ores, and Tables IV. and V. give Kirkaldy's tests of the mechanical properties of the iron; but it should be understood that these tests were taken with a view to ascertain the influence of different methods of manipulation rather than to show high results. Only a small proportion of the samples had been subjected to the refinery process, and the variable percentage of phosphorus may be taken really as indicative of the extent to which the cinder had been removed from the metal.

Table VI. gives the analyses of slags produced in the process. These are no doubt rich in iron, but it must be remembered that in the case of comparatively pure ore they can be used almost entirely in succeeding charges, and that in the case of ores conltaining much sulphur and phosphorus they are the recipients of those impurities-in the same way as the puddling cinder carries off the same impurities in the puddling furnace-and thus serve a useful end.

If rich ores, such as hematites, are available, it is more advantageous to use a stationary furnace, and to modify the process as follows.

* Since this paper was prepared, further experience has shown the possibility of obtaining greater yields of iron from the ores employed, and of making, at the same time, a greater number of charges per 24 hours; some of these results are recorded in Tables VII. and VIII., which may be considered as appendices to this jexper. 
A mixture is prepared of pulrerulent ores combined with fluxing materials and reducing agents in suitable proportions, and of this 4 to 5 tons are charged from a platform into the heated chamber to the depth of some 12 or 15 inches. But, before charging the mixture, some coke dust or anthracite powder is spread ovis the bottom and sides of the chamber for the protection of its silica lining. The heat of the furnace is thereupon raised to a full welding heat, care being taken that the flame is as little oxidising as possible. The result is a powerful superficial action upon the mixture or batch, causing simultaneous reduction of the ore and fusion of the earthy constituents. In the course of two hours a thick skin of malleable iron is formed all over the surface of the mixture, which, on being withdrawn by means of hooks, is consolidated and cleared of cinder under a hammer, and rolled out in the same heat into rough sheets or bars, to be cut up and finished in the refinery furnace or charcoal hearth. ()ne skin being removed, the furnace is closed again, and in the course of $1 \frac{1}{2}$ hours another skin is formed, which, in its turn, is removed and shingled, and so on, until after three or four removals, the furnace charge is nearly exhausted. A fresh charge is then added, and the same operation repeated. Once every 12 hours the furnace should, however, be cleared entirely, and the furnace lining be repaired all round.

The shingled metal, so produced, forms an excellent melting material for the open-hearth or Siemens-Martin process; but if ores, both rich and free from sulphur and phosphorus are used, together with roll and hammer scale, which form an admirable admixture, I simplify the process still further in causing the fusion to take place in the reducing furnace.

The furnace having been charged with say five tons of batch, the heat is allowed to play on it for four or five hours, when about two tons of hematite pig iron are charged upon the surface, by preference in a heated condition. The pig metal on melting constitutes a bath on the surface of the thick metallic skin previously formed, and gradually dissolves it on the surface while it is forming afresh below, and in the course of from three to four hours the whole of the materials charged are rendered fluid, consisting of a metallic bath, with a small percentage of carbon, covered with a glassy slag containing about 15 per cent. only of metallic iron. The carbon of the bath is thereupon brought down to the desired 
point, of only about 1 per cent. of carbon, and spiegeleisen or ferromanganese is added, and the metal tapped in the usual manner. By these means the direct process of making cast steel is carried to a further limit than I have been able to accomplish before, and no difliculty has presented itself in carrying it into effect. The steel so produced is equal in quality to that produced by the open bearth process as now practised. If light scrap, such as iron and steel turnings or shearings are arailable, these may be mixed with adrantage, with the batch to increase the yield of metal.

These are, in short, the more recent improvements in the direct process of producing iron and steel which I have been able to effect, and which I should have been glad to lay before the Iron and Steel Institute in a more complete form than I am able to do at the present time.

TABLE I.

Chatges in "A" Furnace a" Towcester.

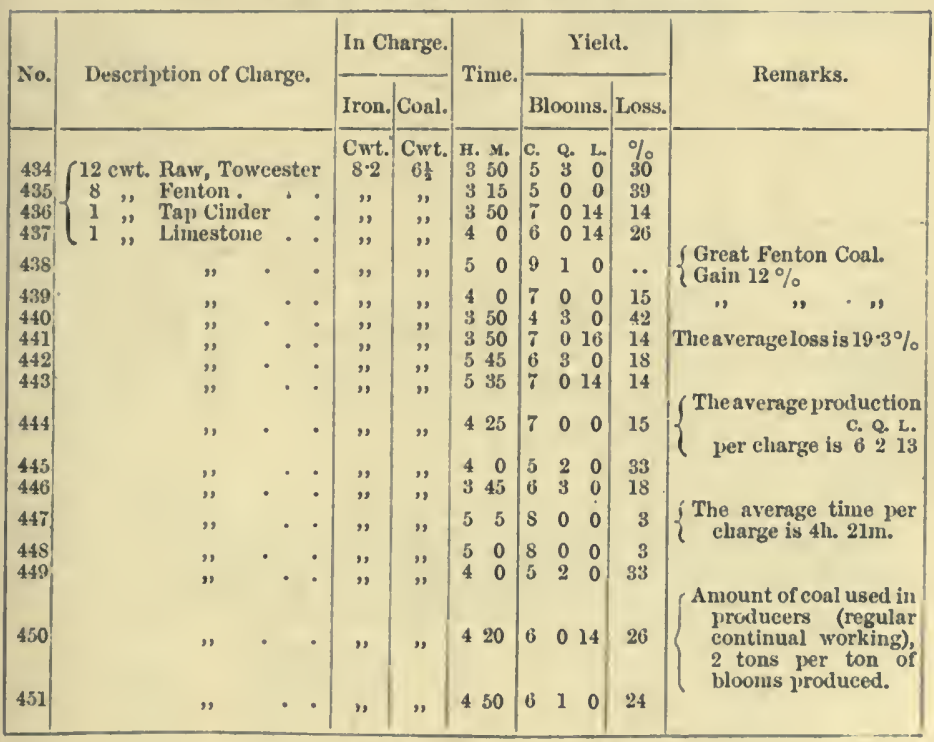

Estimate for the Production of 1 tos Blooss.

Ores, 3 tons (including fluxes), at the average price of $10 s^{\circ}$ per ton $\quad \begin{aligned} & f \\ & \text { is }\end{aligned}$ Coals, 1 ton for reducing at 8 . . . . . . . . . 0880 2 tons for heating at 4s. . . . . . . . 080 Hammering 


\section{TABLE II.}

ANALyses OF IRON.

\begin{tabular}{|c|c|c|c|c|c|c|c|c|c|c|}
\hline & 1 & 2 & 3 & 4 & 5 & 6 & 7 & 8 & 9 & 10 \\
\hline $\begin{array}{l}\text { Iron } \\
\text { Silicon } \\
\text { C. Carbon } \\
\text { Phospliorus } \\
\text { Sulphur } \\
\text { Manganese. }\end{array}$ & $\begin{array}{c}98 \cdot 30 \\
\cdot 745 \\
\because 0.080 \\
.065 \\
\cdot 144\end{array}$ & $\begin{array}{c}98 \cdot 73 \\
\cdot 243 \\
.032 \\
.071 \\
\cdot 101\end{array} \mid$ & $\begin{array}{c}99.45 \\
.643 \\
\because 030 \\
\text { trace } \\
\text { traces }\end{array}$ & $\begin{array}{c}98 \cdot 97 \\
.565 \\
\cdot 235 \\
.019 \\
.085 \\
.126 \\
\text { traces } \\
\text { of } \mathrm{Ca} \mathrm{O} \\
\text { and } \\
\mathbf{A I}_{\mathbf{2}} \mathrm{O}_{\mathbf{2}}\end{array}$ & $\begin{array}{r}98 \cdot 909 \\
\cdot 582 \\
-225 \\
\cdot 020 \\
\cdot 106 \\
\cdot 158 \\
\text { traces } \\
\text { of } \mathrm{Ca} \mathrm{O} \\
\text { and } \\
\mathrm{Al}_{2} \mathrm{O}_{3}\end{array}$ & $\begin{array}{l}\cdot 15 \\
.090\end{array}$ & $\begin{array}{r}99.907 \\
.640 \\
\cdot 100 \\
.128 \\
.035 \\
\text { traces }\end{array}$ & $\mid \begin{array}{c}99 \cdot 128 \\
717 \\
\text { trace } \\
\cdot 125 \\
.03 \\
\cdot 228\end{array}$ & $\mid \begin{array}{c}98 \cdot 728 \\
\cdot 932 \\
\text { traces } \\
\text { traces } \\
\text { traces } \\
\cdot 34\end{array}$ & $.024 \& 172$ \\
\hline & $99 \cdot 334$ & $99 \cdot 17$ & $100 \cdot 123$ & $100 \cdot 000$ & $100 \cdot 000$ & & $100 \cdot 000$ & & & \\
\hline
\end{tabular}

1. Iron hammered from Charge 60 A.-Aug. 9th, 1875 .

2. Iron made from Canadian ore.-Aug. 18 th, 1875 .

3. "Towcester ore.-Aug. 25 th, 1875

4. Towcester iron, rolled fairly at Darlaston-Sept. 15th, 1875.

5. " " h" badly " "

7. Charge 94 A." Chatterley, -Oet. 13th, 1875.

8. Toweester iron, rolled at Dariaston. Charge 94 A to $102 \mathrm{~A}, 717$ Si corresponds to $1.54 \% \mathrm{Si} \mathrm{O}_{2}$.

9. Indian iron. Charge $132 \mathrm{~A}$. - Nov., 1875. $932 \mathrm{Si}$ corresponds to $2 \%$ Si O,

10. Phosphorus in Toweester iron.

TABLE III.

No. 3.-ANALYSES OF IRON.

\begin{tabular}{|c|c|c|c|c|c|c|c|c|c|}
\hline & & 1 & 2 & 3 & 4 & 5 & 6 & 7 & 8 \\
\hline $\begin{array}{l}\text { Iron } \\
\text { Silicon } \\
\text { C. Carbon . } \\
\text { Phosphorus } \\
\text { Sulphur } \\
\text { Manganese }\end{array}$ & $\begin{array}{l}\cdot \\
\text {. } \\
\text {. } \\
\text { : }\end{array}$ & $\begin{array}{c}99 \cdot 711 \\
.065 \\
\cdot 12 \\
.077 \\
.027 \\
\text { trace }\end{array}$ & $\begin{array}{c}99 \cdot 278 \\
\cdot 316 \\
\cdot 12 \\
\cdot 073 \\
\text { trace } \\
\cdot 213\end{array}$ & $\begin{array}{c}99 \cdot 1988 \\
\cdot 400 \\
\cdot 150 \\
\cdot 0502 \\
\text { trace } \\
\cdot 201\end{array}$ & $\begin{array}{c}\because \\
\because 316 \\
\text { trace } \\
\cdot 019 \\
\text { trace } \\
\text { trace }\end{array}$ & $\begin{array}{l}\because 155 \\
\text { trace } \\
046 \\
\text { trace } \\
\text { trace }\end{array}$ & $\begin{array}{c}\because 230 \\
\text { trace } \\
.083 \\
.060 \\
\text { trace }\end{array}$ & $\begin{array}{l}\because 026 \\
.10 \\
.090 \\
.021 \\
\text { trace }\end{array}$ & $\begin{array}{l}\because 027 \\
\cdot 10 \\
093 \\
\because . \\
\because .\end{array}$ \\
\hline & & $100 \cdot 000$ & $100 \cdot 000$ & 100.0000 & & & & & \\
\hline
\end{tabular}

1. Hoinogeneous iron, made from Towcester iron, at Dariaston, June, 1876.

2. Toweester iron, rolled at Darlaston, August, 1876 .

3. Toweester iron, rolled at Nortlampton, August, 1876. Charges $95 \mathbf{A}$ and $98 \mathbf{A}$.

4. Towcester iron bloom, February, 1877, contained 3.17 per cent. slag.

5. Broken iron bloom $25 \mathrm{C}$. fracture crystalline. Slag- $1 \cdot 58$ per cent.

$6 . "$ " " " fibrous and dirty. Slag-2.61 per cent. 7 and 8 . Iron from blowing fire"s.

Iron from Blowing Fires.

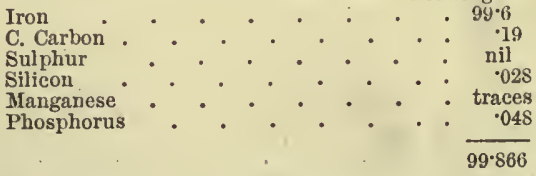

(C.)-Iron made from mixture of Crewe-Scale, and Somorróstro; and afterwards passed through the blowing fires. 
SIR WILLIAMI SIEMENS, F.R.S.

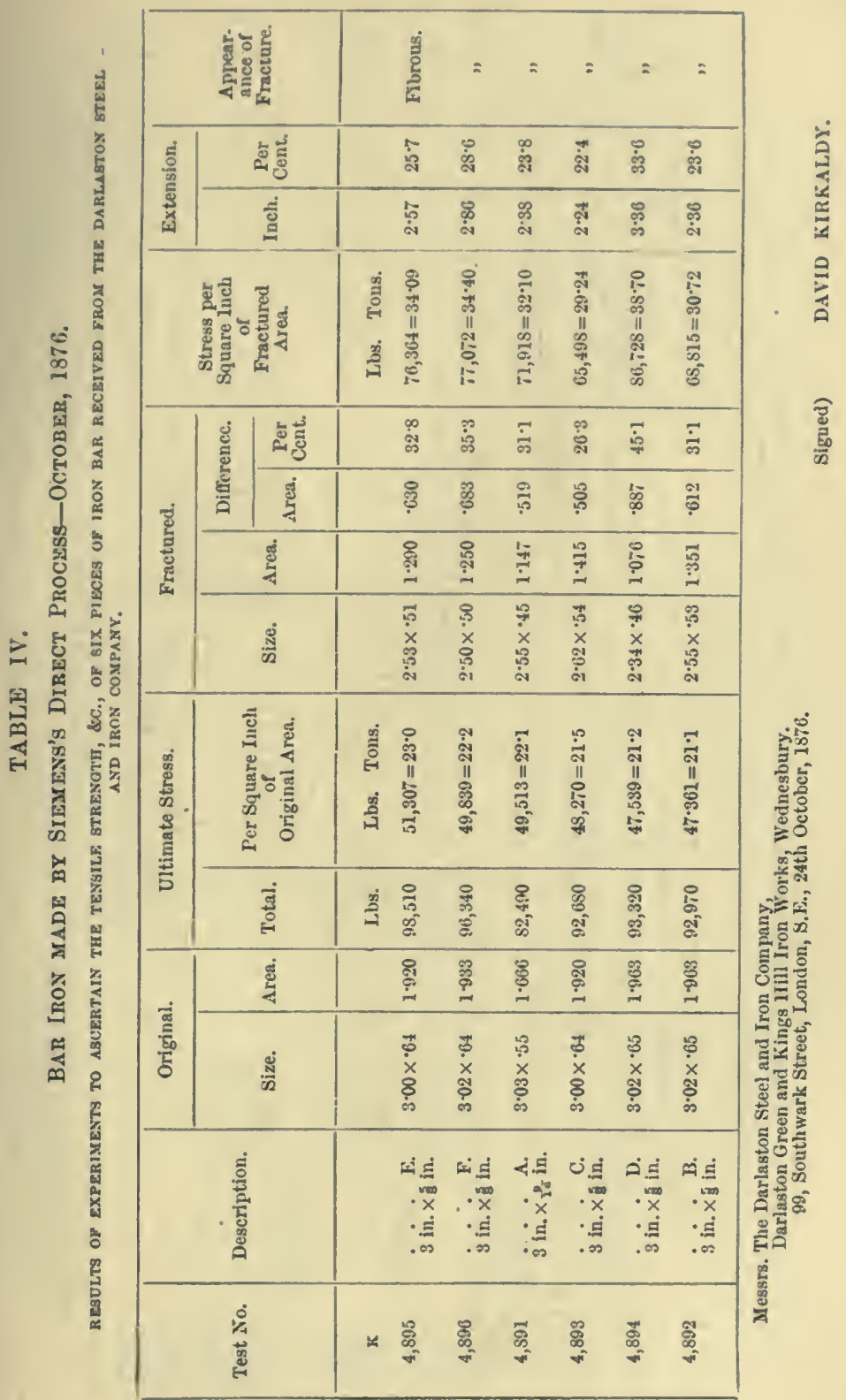




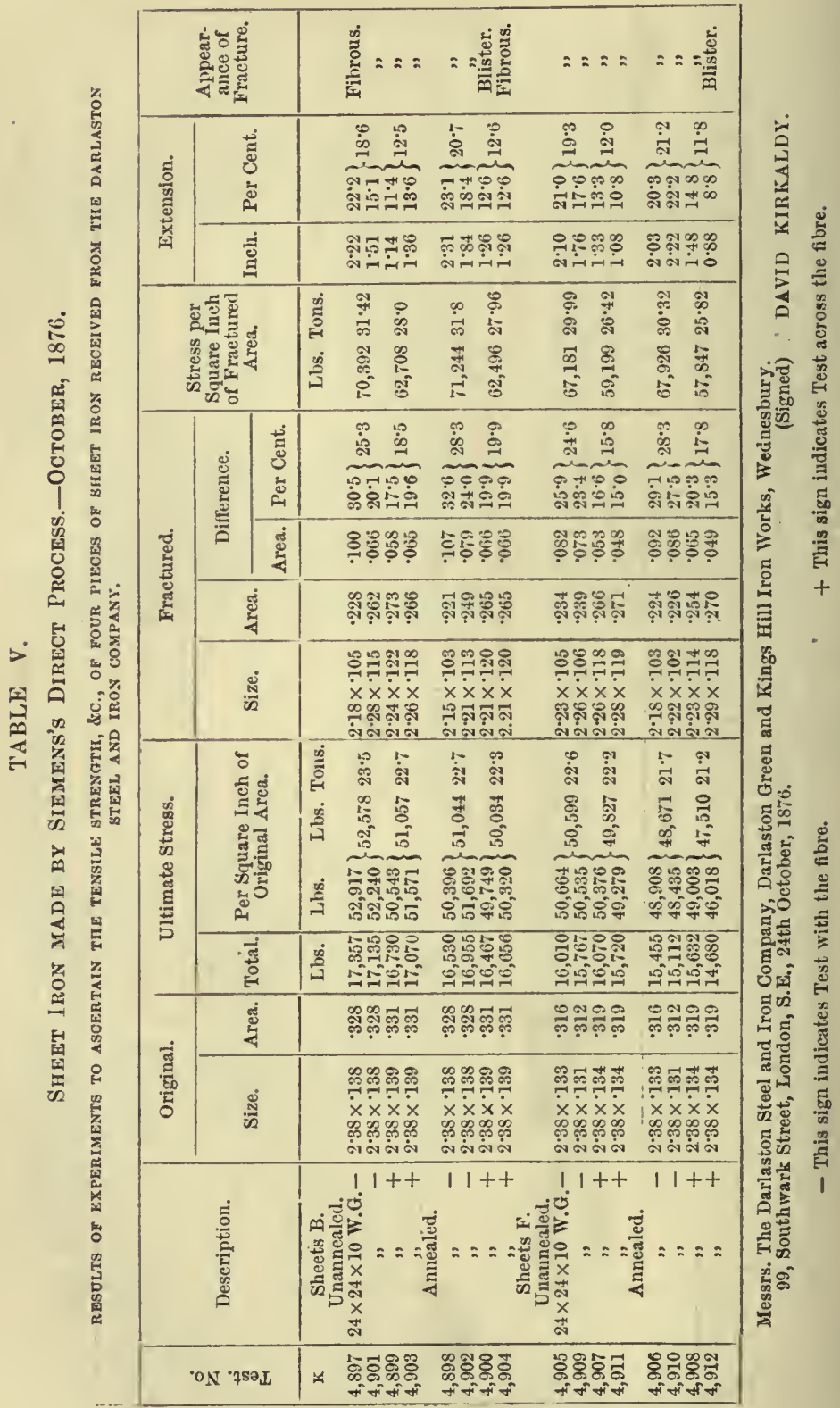




\section{TABLE VI,}

Axalyses of Slatis proa Rotalr Fursace.

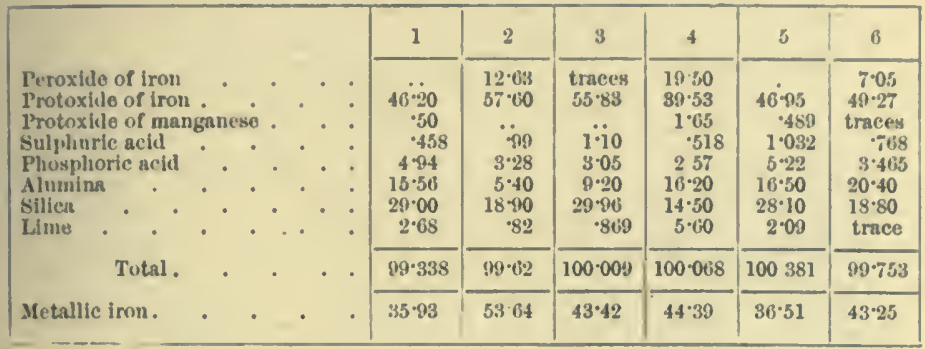

No. 5 tirst tapping.

No. 6 second tapping.

TABLE VII.

Charges made in "C" Fursace at Towcestelk

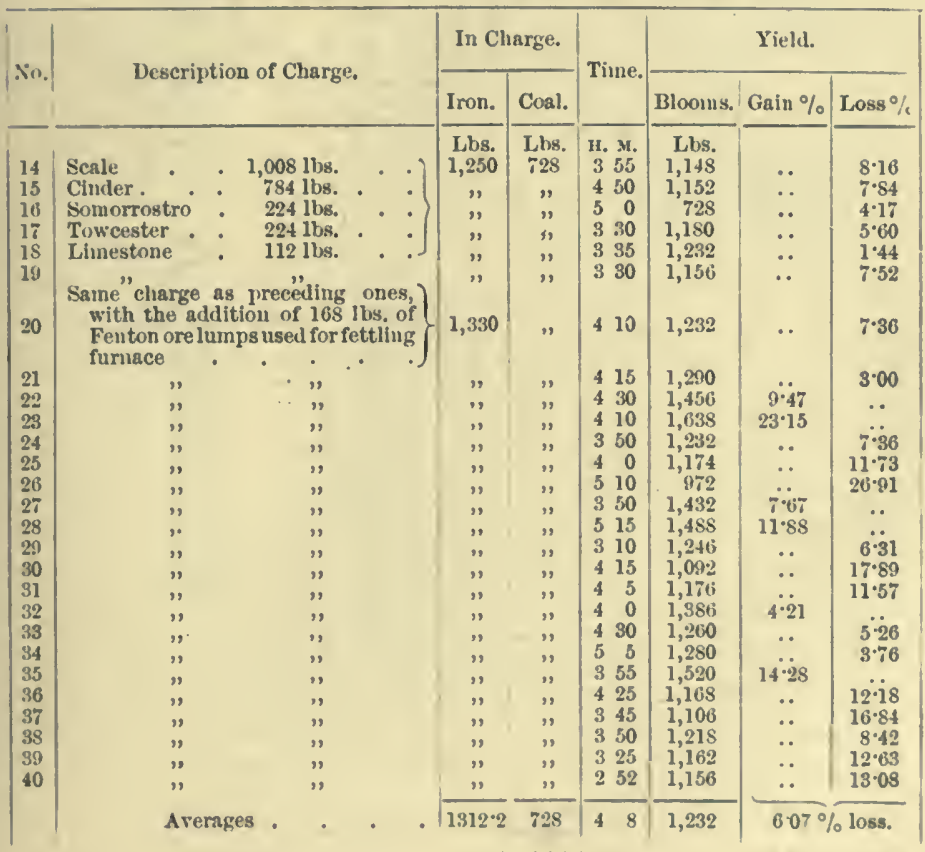


TABLE VIII.

Charges MADE IN "C" FuRXACE AT TowCester.

\begin{tabular}{|c|c|c|c|c|c|c|c|c|}
\hline \multirow{2}{*}{ No. } & \multirow{2}{*}{$\begin{array}{l}\text { Description of } \\
\text { Charge. }\end{array}$} & \multicolumn{2}{|c|}{ In Charge. } & \multirow{2}{*}{ Time. } & \multicolumn{3}{|c|}{ Yield. } & \multirow{2}{*}{ Remarks. } \\
\hline & & Iron. & Coal. & & Blooms. & Gain $\%$ & Loss $\%$ & \\
\hline 1 & $\left\{\begin{array}{l}\text { Same as charges } \\
\text { Nos. } 2 \text { to } 13 \text { follow- } \\
\text { ing, but without } \\
\text { Fenton lumps, } \\
\text { and with only } \\
784 \text { lbs. seale }\end{array}\right.$ & Lbs. & Lbs. & 40 & Lbs. & . & $12 \cdot 18$ & \multirow[t]{42}{*}{$\begin{array}{l}\text { Small charge } \\
\text { to clear fur- } \\
\text { nace of ac- } \\
\text { cumulations } \\
\text { on lining. }\end{array}$} \\
\hline 2 & $\begin{array}{l}\text { Scale : 1,00slbs. } \\
\text { Cinder }\end{array}$ & 1,310 & 728 & 410 & 1,248 & .. & $4 \cdot 65$ & \\
\hline 3 & Cinder $\quad 7841 \mathrm{lbs}$. & , & ", & 40 & 1,153 & .. & $11 \cdot 90$ & \\
\hline 4 & $\begin{array}{l}\text { Somorrostro } 2241 \mathrm{bs} \text {. } \\
\text { Towcester }\end{array}$ & 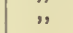 & $"$ & 335 & 1,309 & $\ddot{0}$ & 0.00 & \\
\hline $\begin{array}{l}5 \\
6\end{array}$ & Fenton lumps $112 \mathrm{lbs}$. & $"$ & ", & $\begin{array}{ll}3 & 50 \\
3 & 20\end{array}$ & $\begin{array}{l}1,360 \\
1,195\end{array}$ & $3 \cdot 89$ & $8 \ddot{7} 0$ & \\
\hline 7 & \multirow{2}{*}{$\begin{array}{l}\text { Limestone. } 56 \mathrm{lbs} . \\
\text { Coal . } \quad 728 \text { lbs. }\end{array}$} & $"$ & ", & 330 & 1,288 & $\ddot{0}$ & $1 \cdot 68$ & \\
\hline 8 & &, & $"$ & 350 & 1,090 & .. & $17 \cdot 55$ & \\
\hline 9 & , & ", & $"$ & 340 & 1,153 & .. & 11.91 & \\
\hline 10 & $"$ & $"$ & $"$ & 345 & 1,097 & .. & $16 \cdot 18$ & \\
\hline 11 & ", & $"$, & $"$ & 325 & 1,283 & .. & $1 \cdot 98$ & \\
\hline 12 & " & ", & $"$ & 340 & 1,092 & $\cdots$ & $16 \cdot 64$ & \\
\hline 13 & \multirow{4}{*}{$\begin{array}{c}\text { Same as charges } \\
\text { Nos. } 2 \text { to } 13 \text {, witl } \\
\text { the limestone in- } \\
\text { creased from } \\
561 \text { bs. to } 1121 \text { bs. }\end{array}$} & $"$ & $"$ & 340 & 1,103 & .. & 15.57 & \\
\hline 14 & & $"$ " & $"$ & 35 & 1,029 & $\cdots$ & $21 \cdot 45$ & \\
\hline 15 & & $"$ & , & 325 & 1,032 & .. & $21 \cdot 22$ & \\
\hline 16 & & $"$ & ,. & 335 & 1,005 & $\cdots$ & $23 \cdot 20$ & \\
\hline 17 & \multirow{2}{*}{ ", } & " & " & 30 & 1,059 & .. & $20 \cdot 68$ & \\
\hline 18 & & " & $"$ & 35 & 1,069 & .. & $18 \cdot 31$ & \\
\hline 19 & ", & $"$ & $"$ & 35 & 1,122 & .. & $14: 27$ & \\
\hline \multirow{2}{*}{21} & . " " & $"$ & ", & $\begin{array}{ll}3 & 0 \\
& 15\end{array}$ & 1,019 & . & $22 \cdot 14$ & \\
\hline & \multirow{3}{*}{$\begin{array}{l}\text { Same as" charges } \\
\text { Nos. } 14 \text { to } 21 \text {, Fen- } \\
\text { ton lumps being } \\
\text { omitted }\end{array}$} & ", & ", & 315 & 1,044 & .. & $20 \cdot 22$ & \\
\hline 22 & & 1,250 & $"$ & 315 & 963 & .. & $22 \cdot 88$ & \\
\hline 23 & & " & $"$ & 315 & 951 & .. & $23 \cdot 84$ & \\
\hline 24 & ", & $"$ & " & 30 & 1,123 & .. & $10 \cdot 88$ & \\
\hline 25 & $"$, & " & $"$ & $\begin{array}{ll}30 \\
3\end{array}$ & 1,156 & .. & $7 \cdot 52$ & \\
\hline 26 & $"$, & $"$ & " & 320 & 1,106 & .. & $11 \cdot 36$ & \\
\hline 27 & $"$ & $"$ & $"$ & $\begin{array}{l}320 \\
250\end{array}$ & $\begin{array}{l}1,004 \\
1,021\end{array}$ & $\ddot{*}$ & $\begin{array}{l}1800 \\
18 * 24\end{array}$ & \\
\hline $\begin{array}{l}28 \\
29\end{array}$ & $"$, & ,", & $"$ & 310 & $\begin{array}{l}1,021 \\
1,091\end{array}$ & $\ddot{. .}$ & $\begin{array}{l}18 \cdot 44 \\
12 \cdot 48\end{array}$ & \\
\hline 30 & ", & $"$ & ", & 310 & 1,003 & .. & $19 \cdot 68$ & \\
\hline 31 & ", & $"$ & ", & 255 & 1,126 & .. & $9 \cdot 84$ & \\
\hline 32 & ", & ", & ," & 315 & 900 & .. & 28.00 & \\
\hline 33 & $"$ & $"$ & $"$ & 30 & 1,128 & .. & $9 \cdot 68$ & \\
\hline 34 & ", & $"$, & ," & 240 & 1,121 & .. & $10-80$ & \\
\hline 35 & $"$ & $"$ & $"$ " & 250 & 1,178 & .. & $5 \cdot 60$ & \\
\hline 36 & ", & " & $"$ & .. & 1,205 & .. & $4 \cdot 32$ & \\
\hline 37 & ", & $"$ & ", & 35 & 1,223 & .. & 2.08 & \\
\hline 38 & " & & $"$ & 245 & 934 & .. & $25 \cdot 20$ & \\
\hline 39 & ", & $"$ & $"$ & $\begin{array}{ll}3 & 0\end{array}$ & 1,159 & .. & 7.04 & \\
\hline 40 & ", & " & ", & $\begin{array}{ll}3 & 0\end{array}$ & 1,031 & .. & $17 \cdot 22$ & \\
\hline 41 & ", & $"$ & ", & 255 & 1,100 & & $11 \cdot 92$ & \\
\hline 42 & $"$ & ", & $"$ & $\begin{array}{lr}3 & 0 \\
9 & 45\end{array}$ & 1,310 & $\begin{array}{l}4.80 \\
5.68\end{array}$ & . & \\
\hline 43 & $"$ & $"$ & $"$ & 245 & 1,313 & 5.28 & .. & \\
\hline & Averages & $1,274 \cdot 4$ & 728 & 312 & $1 \cdot 113$ & $12^{\circ} 6^{\circ}$ & $\%$ loss. & \\
\hline
\end{tabular}




\section{In the discussion of the Paper}

"ON THE SEPARATION OF CARBON, SILICON, SULPHUR, AND PHOSPHORUS in the REFINIYG and Pudduisg Furvaces and in the Bessener Cosverter; with some Remarks on the MLAxufacture axd Durability of Railway Bars," by Mrr. I. Lowthlax Beli, M.P., F.R.S.,

\section{and some further remarks regarding}

“THE PRODUCTION OF IRON AND STEEL BY DIRECT PROCESS," by Mr. C. Williay Siemeas, D.C.L., F.R.S.

The President * (Mr. C. W. Sremexs) said that perhaps he might be permitted to explain a point to which Professor Williamson had referred, as it might save time hereafter.

Professor Williamson wished to know how it was that in a rotative furnace the phosphorus did not go back to the metal, seeing that the temperature must be as high as in a puddling furnace. This question would gire him the opportunity of explaining the action as it took place in a rotative furnace. Thirty hundredweight of material was introduced into the furnace ; and heat was applied-intense heat, if they liked-to work upon this mixture. At first the temperature of the mixture did not rise, because the work that had to be done was carried on, as it were, at its own temperature-that of the reducing point of iron ore. But as the deoxidation of the iron proceeded, the temperature would rise, and a point would be attained where metal would become malleable; but at this point the fluxing materials, which had been mixed with the ore, would have commenced to be fluid, and would form fusible slag which, immediately upon fusion, would run away from the mass, sinking to the bottom of the rotative drum; whereas the solid material formed on one side, and rolled about until it went into balls. Hence, although the flame that

* Excerpt Journal of the Iron and Stẹel Institute, 1877, pp. 389-395. VOL. 1. 
was brought into the furnace would produce a full welding heat if it was continued, yet the essential work done was accomplished at its own temperature, just as water would be evaporated at its own temperature in a boiler, whatever might be the intensity of the heat applied outside. Probably to this circumstance was attributable the fact that the iron when taken out of the furnace was really free from phosphoric acid. But he attributed in large part this freedom from phosphoric acid in the iron to the circumstance that the phosphorus was combined in the ore-very often combined - with oxygen and lime as phosphate of lime, and to the fact that it would take a greater heat to disturb this compound which already existed than would suffice to retain the phosphorus in combination with metallic iron after having been combined with that metal in the blast furnace. This argument rould lose its force probably if the time allowed for these reactions was unlimited, and it must further be borne in mind that the final chemical reaction in both the puddling and direct process did not probably exceed a quarter of an hour, during which dephosphorization would go on in the one and phosphorization in the other process to a limited extent. No one would be better able to judge than Prof. Williamson to what extent this question of time might be expected to influence the final result in the two processes.

Before proposing a vote of thanks to Mr. Bell for his valuable communication, he would reply very shortly to some of the remarks that had been made with reference to the paper he had had the honour to bring before the Institution. Mr. Ridley wished him to explain how it was that in dealing with an ore containing much phosphorms he should be able to get an iron free from phosphorus, whereas in the puddling furnace a cinder containing 5 or 6 per cent. of phosphoric acid would readily communicate that phosphorus, or a portion of that phosphorus, to the iron. In dealing with chemical processes they had, of course, to take into account all the circumstances of temperature, and the relative proportion in which the substances liable to act upon one another existed. Now, he explained yesterday that in treating poor ores, and poor ores containing a great deal of phosphoric acid, in a rotatory furnace, such as the one erected at Towcester, care was taken that a very fluid cinder was the immediate result of the heat acting upon the mixture. The first action of the leat upon 
the mixture was no doubt the reduction of the iron, but as the reduction got more and more completed the fusion of the earthy constituents immediately set in, and it set in practically before the reduction was completed. The moment fusion took place, which was necessarily at the ininimum temperature, the cinder drained away from the iron, accumulated at the bottom of the rotating vessel, whereas the iron separated more and more from it, and as soon as the cinder had accumulated in any considerable quantity it was tapped from the vessel. The result was that the first cinder coming from the vessel contained a considerable quantity (he had seen and tested it even up to 8 per cent.) of phosphoric acid. At that time the temperature of the ressel was not sufficient to re-act upon the phosphate of lime or other chemical combination in which the phosphorus was held in the slag so as to bring it back to the metal. If the temperature was now pushed forward in the rotative vessel, that action, which had been so ably described by Mr. Bell in reference to the puddling process, no doubt would set in there also. 'The iron would gradually but slowly take up the phosphorus again, but, in order to break up the combination in which the phosphorus was by that time comfortably settled, time was required; and in that process, although the total duration of each operation was between three and four hours, yet the time during which the metal was in contact with the fluid cinder was very short indeed, in fact, the ball was brought out as soon as the metal would hang together, and it was purposely brought out at as low a temperature as possible, in dealing with impure ore, and the cinder squeezed out as he had described in the paper, not by squeezing it or hammering it in large masses, but by either hammering it flat out or rolling it into thin sheets, squeezing the cinder out, and dealing then with the bar metal either in the ordinary way in the re-heating furnace, or, what was better, in a hollow fire, where the cinder was more thoroughly washed out from the metal, without increasing the temperature very rapidly, to such an extent as to make the phosphorus go back to the iron. 'Therefore, he thought there was nothing contradictory in those results if all those circumstances were taken into account, and at any rate the analysis showed that iron was produced from very impure ores practically free from phosphorus, and what was very curious, sometimes charges from ore containing a great deal of phosphorus 
were almost entirely free from that ingredient, whereas other charges made of richer and better ore, contained phosphorus in somewhat more tangible proportion, owing no doubt to the presence of cinder which had not been sufficiently removed before the iron was consolidated. Mr. Bell, in criticising the process which he (the President) had submitted-and criticising it very fairly, and contrasting it with the method of treating iron rich in phosphorus which he (Mr. Bell) proposed-observed that, in dealing with Towcester iron, he (Dr. Siemens) found it necessary to mix richer oxides with it, and that that would put the process altogether out of consideration in dealing with similar ores in the blast furnace, but it must be remembered that Towcester ore could not be smelted in the blast furnace by itself either. It was a very valuable ore as an admixture with other ores, on account of the large proportion of alumina which it contained, but all attempts to smelt it by itself in a blast furnace had hitherto practically failed, and, therefore, it was but reasonable that they should find it necessary to mix other ores with the Towcester ore. Then his friend, Mr. Bell, said that he (Dr. Siemens) required forty-two rotators to produce the metal yielded by one of his great blast furnaces. That was very true, and if the two apparatus produeed the same results he would say at once the blast furnace had the advantage ; but it must be remembered that the blast furnace produeed pig metal, whereas the rotator produced wrought metal, and that probably torty-two puddling furnaces were required, in addition to the blast furnace, in order to produce the same result ; therefore he, at any rate, had the advantage of one.

Mr. I. L. Bell, M.P., remarked that he had been talking of steel.

The President said he would come to that presently. Therefore, as far as wrought iron was concerned, the number of apparatus required was certainly not greater, and it must be remembered that the results which he had placed before the meeting were by no means final results (that they were tentative results, and that they hoped io do a great deal better), whereas with the blast furnaee, after the powerful mind of his friend Mr. Bell had been given to it for so long a time, he supposed they had very nearly reached finality. Then, his friend found fault with his consumption of coal, three tons being required to produce a ton of 
malleable iron. Well, that was higher than he wished to see it, but Mr. Bell admitted it was no higher than his consumption in smelting and pudaling iron.

ML. I. L. Bell, MI.P. : No ; smelting and making into steel.

The President: I am now speaking of iroll.

IIr. I. L. Bell, M.P. : Pardon me, Mr. President, for interrupting you. I was contrasting the conversion of iron from the ore into steel by the two methods, considering the fact that we have steel to look forward to.

The President: Mr. Bell says he wishes to compare my iron with his steel, but in the description which he gives of his process I do not see a trace of steel. He describes a method of purifying the pig metal of its phosphorus and then transferring it-remelting it, it appears, before he can puddle it, and then he says this puddled iron may be converted into steel in an open hearth furnace; but he fails entirely to bring forward auy proof that by his method he produces steel in one operation.

Mr. I. L. Bell, MI.P.: You must let me explain, please. I am quite willing, sir, to admit that if you can make bar iron by your process from a poorer ore containing phosphorus, it is obvious that there are certain advantages in doing so ; but if you inform us that you require richer ores free from phosphorus, this is a totally different matter. I did not intend to compare your process with the one I had previously described, and I hope nothing. I said induced the meeting to imagine that such was my intention. All I wished to draw attention to was that portion of your charge which consisted of hematite, and the question I raised was whether such ore was most economically treated by being made into malleable iron, and then converted into steel, than by being smelted in the blast furnace, and the pig iron then treated in the Bessemer converter or in the open hearth for the purpose of obtaining steel.

The President said he wished, first of all, to reply to the obserrations with regard to the production of iron, considering iron as the goal to which they tended. If he had rich ores, and wanted to convert these rich ores into steel, he modified the process entirely; and, indeed, he described the modus operandi which he adopted in that case. If he had rich ores and wanted to make steel, he put five or six tons of a misture of that rich ore with fluxing material and carbonaceous matter on the bed of an open 
bearth furnace-a regenerativc gas furnace-and he applied heat to it for several hours, until a thick crust of metallic iron was formed all over the surface. He then added, on the surface of that, pig iron, perhaps in the proportion of about 25 to 30 per cent. to the amount of iron contained in the ore, and that pig metal as it melted acted upon the crust of metallic iron formed in the furnace, melting it gradually, and constituting with it a bath of steel, which, after being adjusted and mixed with the requisite amount of manganiferous material, was tapped into ingots and worked in the usual manner. In that case he did not touch the ore from the time he charged it into the furnace to the time of tapping it from the furnace as liquid steel, and he believed a more direct process could not well be conceived. But that process of converting rich ore into steel was not applicable to poor ores and to ores containing a great deal of such materials as phosphorus and sulphur, which would undoubtedly go into the ingot metal if they were left in contact with it at a high temperature. Therefore, they must draw a broad line of distinction between the process of making iron and that of making stcel. In dealing with poor and impure ores they could still make steel from them, but, in that case, they must eliminate the earthy matter, the sulphur, and the phosphorus, at a low temperature, and then re-melt the material at a high temperature. That was an extra operation, which ought to be paid for by the differcnce in the cost of the ore. In that case, if they dealt with those impure ores, they had to go so far on the road of making wrought iron as to take the metal out of the furnace and squeeze it or roll it in order to get rid of the cinder. Then it was in a proper condition to transfer it, either to the re-heating furnace to be worked up iuto wrought iron, or into the bath or open hearth furnace to be converted into steel. With regard to his friend's process (and he supposed he would allow him now, on his side, to make some objections), his objection to it was that it was an additional process, which necessarily would cost money to accomplish, and he doubted very much whether the iron resulting from his refinery furnace would work in a Bessemer converter.

Mr. I. L. Bell, M.P. : I said this was doubtful.

The President: Mr. Bell admits it; therefore, it had to be treated and used as iron, or that iron would be melting material 
for the open liearth process, but sti.l in that case they would bare to compare his results with those obtained by simple puddling. He (the President) had lately made some experiments at the request of Messrs. Hopkins, Gilkes, and Cn., which proved in a very satisfactory manner that Cleveland pig metal, when puddled curefully in a rotative furnace, and then melted on the open hearth furiace, produced a very good steel. He believed Mr. Hopkıns had exhibited some of the steel upstairs which ras so produced, and Mr. Crampton had given them proofs long before that time of the suitability of Cleveland pig to produce steel if treated in his (Mr. Crampton's) puddling furnace, and subsequently in his (Dr. Siemens's) open hearth furnace; therefore, in that case they would hare to compare the results obtained by the refinery process proposed by Mr. Bell with those of ordinary puddling done in the most careful manner. In other respects he was ready to compliment Mr. Bell upon his very valuable communication. He had placed before them experimental facts which he (Dr. Siemens) believed were entirely reliable, and which in themselves constituted most valuable information. Whether or not the particular process which he had lately followed would lead to practical results or not, was a matter which perhaps did not interest even Mr. Bell very much, because he was searching for information at present, and in those researches he was powerfully assisted by the North Eastern Railway Company, who-acting very differently to railway companies in general-encouraged research instead of rather throwing impediments in the way of those who proposed any new method of manufacture. His (the President's) experience had been that even when they had got a result it was very difficult to make people take the trouble to test that result, and it was a very refresling sign that here a great railway company not only encouraged research, but found large means for carrying that research into effect. One of the implements proposed to be used in carrying out those researches was a very large hydraulic squeezer. That machine had been constructed by Sir William Armstrong \& Co., and they would have an opportunity of seeing it to-morrow.

A rote of thanks having been passed to Mr. Bell for his valuable paper,

Mr. Menelaus said the President could not very well include 
his own name in that vote of thanks, but he (Mr. M.) would ask them to pass a hearty vote of thanks to their friend, Dr. Siemens, for the paper he read yesterday, and on which, with Mr. Bell's they had had such an interesting discussion, although the two were opposed to each other on certain points. He was quite sure that if his (Mr. B.'s) process was to be successful, he must go hand-in-hand with Dr. Siemens, and use his open hearth for converting the material which he was modest enough to say he was purifying for the purpose of using it in the shape of iron. He was quite sure that his (Mrr. Bell's) meaning was to make steel, and, if he was going to make steel, he must go hand-in-hand with Dr. Siemens and use his open-hearth furnace.

A vote of thanks was accorded to the President by acclamation.

On the presentation of

\section{THE BESSEMER MEDAL}

To Professor von TunNer,

The President * (Mr. C. W. Siemexs) observed that, thanks to the liberal prorision of our past President, Mr. Bessemer, it was the pleasurable duty of the President of the Iron and Steel Institute, at the beginning of each year of office, to present this medal to any gentleman who, in the opinion of the Council, had highly distinguished himself in that branch of science which the Institute specially cultivated.

The choice of the Council had this year fallen on a gentleman who, all would agree, was fully entitled to the distinction. Members of the Institution all knew Professor Tunner by repute, and those who did not know him personally would also be pleased to learn that this compliment was paid to a gentleman who, although drawing towards the close of the average period of active life, yet retained all the energy and all the active interest in his work that made it still productive of useful results-a gentleman

* Excerpt Journal of the Iron and Steel Institute, 1878, pp. 8-10. 
who, by his amiable, modest manner, impressed ercry onc very much in his favour. It was, however, not his personal qualities which the Institute had to look to. Professor 'Tunner was, it might be said, at the head of a very ancient iron district. Styria had produced for centuries iron of very high quality. The cutler of Damascus had for centuries forged his blades of Styrian ironat any rate, Styrian iron had cntered largely into the composition of the material of which those blades werc made; and he remembered that when, in 1851 , the Intcrnational Jury made certain expcriments upon the scythes sent from Styria, they were perfectly surprised to find that the keen edge of those implements would cut off the head of a nail without being injured by the operation. Nature had been very kind to the ironmaster of Styria in providing him with a spathose ore of extraordinary purity, and with a fuel in abundance of the highest quality in the form of enormous and beautiful forests. Still, with all those adrantages, results such as we heard of could not be realized without skill and the application of scientific knowledge. In this country, we were very proud of our achievements in blast furnaces, but the Styrian furnace, although a different thing from the blast furnace of this country, was one of peculiar merits, and the economical results which had been obtained from it werc very surprising. He learnt that $a$ ton of iron was smelted with something like thirteen cwt. of charcoal. That result was a remarkable one, although, of course, it could not be fairly compared with the results obtained from coke and the inferior ironstones of this country. Professor Tunner might be said to be the leading spirit in that centre of industry. It was unnecessary to enlarge upon his literary works, which were well known to members, and which were largely quoted in our excellent "Metallurgy" by Pcrcy ; but Professor Tunner had for many years becn active in educating young metallurgists who had done good work in Austria, and who liad also given us indirectly some benefit. We were now receiving from the district of Styria a large supply of ferro-manganese, a material which we could not produce from substances of our own. Professor Tunner had bcen active on many commissions, in which his practical sense, and his thorough mode of investigation, going to the very foundation of every matter that came before him, had left a remarkable impress on inquiries into metallurgical subjects. I therefore think (the 
President concluded), that members will approve the action of the Council in giving our annual award of the Bessemer Medal to Professor Tunner. I have great pleasure, Mr. Bell, in presenting this medal to you, as representing Professor Tunner on this occasion, and I hope you will convey to him the high appreciation in which he and his works are held amongst us.

In the discussion of the Paper

"ON THE SEPARATION OF PHOSPHORUS FROM PIG IRON,"

By J. Lowthian BeLI, M.P., F.R.S., \&c.,

The President * (Mr. C. W. Siemens) remarked that Mr. Bell had contributed some valuable facts on a subject which interested many members.

Mr. Bell had found that he could, by treating Cleveland pig metal in a rotating furnace (such as was to be seen at the Clarence Works), reduce the phosphorus to the extent of from $\frac{3}{10}$ ths to $\frac{4}{10}$ ths per cent. ; but other results had been given, showing that the phosphorus had been reduced below $\frac{1}{10}$ th per cent., while the slag produced gave 6 and a fraction per cent. of phosphoric acid. 'These figures relating to phosphorus in the slag and in the metal, agreed well with the results which he himself had found in treating the subject in another way. At Towcester, in the rotary furnace, according to figures given by him at the Newcastle meeting, the slag was generally found to contain from 6 to 7 , and sometimes 8 per cent. of phosphoric acid; but the metal produced in that process had been brought to a rery low percentage indeed. So far, therefore, we might consider it an accomplished fact that, whether they dealt with pig iron or with ores containing a large percentage of phosphorus, that phosphorus could be eliminated to

* Excerpt Journal of the Iron and Stcel Institute, 1878, pp. 41-44. 
such su extent as to make the metal perfectly applicable to the production of steel. The question as to the relative merit of the two nodes of doing it was one of expense, and on that subject they were still without sufficient information. Mr. Bell had given certain data which commenced with Cleveland pig metal. He subjected the material to a refining process, and in that operation he used 10 crit. of oxide of iron to the ton of metal. Now without desiring in any way to discourage Mr. Bell and his friends, he thought they would have to modify that process before they could tempt steel manufacturers to use it practically. The employment of $10 \mathrm{cwt}$. of rich oxide of iron, which could not be valued at less probably than $10 \mathrm{~s}$., would form an item of expense altogether out of proportion to what was now practically admissible. Adding to that, the cost of the operation itself, and the fuel used, he thought there would be no margin in favour of using the cheaper Cleveland as compared with the dearer Cumberland metal. But, as Professor Williamson had said, some bases might be found to take the place of oxide of iron ; and Mr. Snelus had brought forward a scheme, which he had been working out, to employ lime for lining. For his own part, he could not look with mucl favour on that proposal. At his experimental works at Birmingham, he had made an experiment with a lining of that description. 'The difficulty he found was that the lining was not sufficiently hard to resist the action of the charges. He thought that as much heat was applied as the material could stand, but the limestone employed contained a percentage of magnesia, which rendered it fusible to some extent, and probably prevented satisfactory results from being obtained. With regard to the extent of phosphorus allowable in the steel, he might speak with some confidence, having made a great many experiments, and having seen the results on a large scale in a process of making steel from materials containing a considerable percentage of phosphorus. There was no difficulty, for instance, in converting old iron rails -which might be to a great extent Cleveland rails-into steel rails of such quality as would satisfy all the mechanical tests that engineers insisted on. The limit he would assign to phospliorus in such a material was $\frac{1}{4}$ per cent. In increasing the amount of phosphorus in steel beyond $\frac{1}{4}$ per cent., there was great danger of making the steel brittle-that was to say, of making it liable to 
fail under the test of a falling weight. That difficulty increased very much with the reduction of temperature. On a hot summer's day such a rail might resist the test, but on a cold winter's day it would not. Another very essential condition was that the steel rail containing $\frac{1}{4}$ per cent. of phosphorus should contain certainly less than $\frac{2}{10}$ ths per cent. of carbon, and considerably less in order to withstand the falling weight test, and it must contain not less than $\frac{7}{10}$ ths per cent. of manganese. Such metal would stand almost any ordinary mechanical test that could be applied to it. He could quite believe the result which had been given by $\mathrm{Mr}$. Price, that he had produced a metal containing $\frac{2}{10}$ ths per cent. of phosphorus, and $\frac{2}{10}$ ths per cent. of carbon, which would stand the Admiralty test, but he could not go with Mr. Price further than that. It might be said that manganese was to the steel maker what charity was to religion : it covered a multitude of sins, and these were of a lucifer kind-phosphorus and sulphur. If you gave him the worst class of iron, and wished him to make steel of it that would stand the Admiralty test, he would undertake to do it ; but such steel, nevertheless, should not be used in such applications as were now contemplated of mild steel-no boiler should be made of it, no forging should be made of it, and he thought also no ship should be made of it. Steel of that description depended for its mechanical qualities on the larger dose of manganese which it contained. Now every practical steel maker knew that manganese was a somewhat treacherous element in steel. Its distribution was never so uniform as to make a homogeneous compound: Then, in the working of a plate containing a large amount of manganese, the manganese was apt to be burnt out, and in attempting to flange it, although sometimes it would stand the test, at other times it would break. That was a question to which the users of steel should direct particular attention in order to present failure in the application of a comparatively new material. Good mild steel, such as could be safely recommended to the boiler maker, should contain only mere traces of manganese; $\frac{x}{10}$ th per cent. was about the limit which he considered such steel could contain with entire safety, when the material had to undergo certain preparations in order to put it into its definite shape. Then, again, we heard a good deal about the liability of mild steel to corrode, and some results which had lately 
come to light seemed to throw great doubt upon the desirability of using mild steel, especially in the Navy. He believed that a tendency to corrode was also the result of excessive manganese, and some experiments which he had himself mado went certainly in confirmation of that view-that as the manganese in mild steel was incrensed, so its liability to corrosion increased. He quite agreed with the suggestion of Mr. Fox that the subject of the quality and treatment of mild steel should be carefully inquired into. The Committee of Lloyd's Register were collecting experimental data regarding it, and the Board of Trade had also turned their attention to it recently; but whether individually or collectively, the Iron and Steel Institute should not be indifferent to a subject so important.

\section{In the discussion of the Paper}

\section{"ON SOMLE RECENT IMPROVEMENTS IN THE MANUFACTURE OF IRON SPONGE BY THE BLAIR PROCESS," by Mr. J. Ireland,}

The President * (Mr. C. W. Siemers) said the converting of ore into spongy iron was not new. It was first proposed by Mr. Clay, many years ago. We had also heard much of the Chenot process, and after that there had been many other attempts to produce spongy iron. He himself gave very considerable attention to the subject at one time, and he had produced spongy iron by methods somewhat analogous to that which had been brought before the meeting. He did not think, therefore, that any particular name could be attached to the process of making iron sponge for the purpose of utilising that spongy metal in the after-process for the production of iron and steel. The difficulties which made him desist from his endeavours to arrive at a practical solution of the

* Excerpt Journal of the Iron and Steel Institute, 1878, pp. 57-58. 
problem in that way were sereral. The iron sponge locked up in it all the earthy materials of the ore, and if you threw it in the open hearth furnace these materials prevented liquefaction of that sponge in the metal. Another great difficulty was that the iron sponge absorbed sulphur at a most extraordinary rate from flame. In fact, he would deprecate any process of making the sponge or using the sponge afterwards, which brought it into contact with coke gas of any kind, as even the purest coke gas might give so much sulphur to the sponge as practically to make it unfit for steel. Mr. Ireland proposed a novelty which consisted in melting the sponge in a cupola furnace, and then puddling or otherwise treating the liquid pig metal so produced. He altogether failed to see the advantage of these processes. We had an apparatus which made spongy iron better than any other, and that was the blast furnace. Take a blast furnace at a certain heat, and you had your spongy iron produced at the lowest possible cost and in a heated condition. Why cool it, and then melt it in a cupola? There it was, perfect sponge, in the lower part of the blast furnace, heated and ready to be melted. He quite failed to see what advantage you could gain by dividing the process into two. Altogether, the difficulties connected with spongy iron were very great indeed, and were such as had induced him, at any rate, to abandon that mode of proceeding entirely, and to endeavour rather to treat the iron ore in such a way, that while the iron was reduced to the metallic condition, the earthy matter contained in the ore was at the same time fused and combined with the fluxing material. The product had been obtained by a method which inrolved but one instead of two intermediate processes, and which produced iron at once in a perfect metallic condition. He was sorry to be obliged to speak thus discouragingly of a paper brought before the meeting, but, as $\mathrm{Mr}$. Bell had said, it was much kinder to point out plainly and clearly the objections one felt because it could not be to the advantage of the inventor or patentee to be encouraged in a direction which was open to objection. If $\mathrm{Mr}$. Ireland could show that these objections were inapplicable to the process he brought forward, he should certainly be most happy to congratulate Mr. Ireland on having overcome difficulties which had made himself desist. 


\section{In the discussion of the Paper}

\section{"ON STEEL FOR ShIPBUILI)ING," by B. Marterd,}

Dr. Cirartaes W. Siemexs * said, with reference to the observation that fell from Mr. Reed, as to the difficulty of rolling steel plates to dimensions that would present a reduction of weight equal to 20 per cent., I would mention that when the material for the Iris and the Mercury were ordered from the Landore Company, a wish was expressed by the authorities that the weights of the plates should in no case exceed those specified, but that it would bo desirable to make those plates perhaps 2 per cent. less in weight than would follow from the calculation. I believe the Iandore Company acted strictly up to that, and that the total weight of the material supplied was just 2 per cent. below that calculated, showing that there really is no difficulty in working by weight instead of dimensions. I would suggest that it would be a far more rational thing to order the plates by weight per square foot, rather than by vulgar fractions of an inch thickness. With regard to rireting, I, for one, would strongly adrocate steel rivets in preference to iron. It is true that at Pembroke the experiments tend rather to show that no material advantage would be gained by the employment of steel rivets, but at that time the question was hardly sufficiently understood. Now steel has been produced which I think answers its purpose perfectly, and reduces the risk of riret heads falling off to a minimum. I may mention that at another Institution, Mr. Boyd, the engineer of the Slipway Company, wilk read a paper to-day giving the result of the construction of sereral steel boilers in which steel rirets were employed, and he states in that paper that not a single rivet gare way or gave any trouble whaterer in the manipulation, showing that with a little care difficulties that have been complained of, such as orerheating, may be overcome. The adrantage of steel riveting over iron is not only in the rivet itself, but it is in a great measure in the plate, which has to be cut away to a nuch less extent, and thus

* Excerpt Transastions of the Institute of Naval Architects, Vol. XIX. 1878, p. 29 . 
leaves a larger nett area of metal to resist the strain. Then again, if the rivets are put the same distance apart as they would be put in an iron plate 20 per cent. thicker, it is natural that these rivets stand too far apart for this reduced thickness of the plate, and thus throws a buckling strain on the plate. I would suggest that in riveting steel plates together, the distance between rivet and rivet should be the same as that which would be adopted if a thin iron plate were used-in fact; the reduction should be proportionate. The moment you use one material for the plate and another material for stitching the plate together, there is a disproportion between the two elements introduced which naturally must tend to weaken the whole. Perhaps I may be allowed to say one word before I sit down with regard to corrosion. Certain laboratory experiments which have been tried seem to show that steel corrodes faster than iron, whereas most of the working results that have come to my knowledge seem to show the contrary, and that steel wears longer. We have heard to-day of steel ships from Mr. Martell himself, that have stood wear and tear exceedingly well. But I have no doubt that some steel may be introduced which is liable to corrode at a greater rate than iron would; and although I perhaps have no right to speak absolutely and definitely on the subject, I believe it is the result of an excess of manganese in that steel, and it would perhaps be well for steel users to turn their attention to that subject. Manganese is an exceedingly convenient agent in order to give to steel, or homogeneous iron, the high degree of ductility which is desirable; but it is by no means a necessary element, because at least the same ductility, and the same strength, may be obtained without an appreciable percentage of manganese in the material ; and my experience, which is somewhat limited as to the wearing quality and resistance to corrosion of the two materials, goes distinctly to prove that with an increase of manganese beyond a very narrow limit the steel becomes more corrosive, does not weld with the same facility, and is not so absoIutely uniform as when a little manganese is used. 


\section{In the discussion of the Paper}

"ON THE USE OF STEEI, FOR MARINE BOILERS AND SOME RECENT IMPROVEMENTS IN THEIR CONSTRUCTION," by W. Parker,

Dr. Srexexs* sxid, I think this paper of Mr. Parker's has brought bəfore us some very important matter, and the questions arising upon it have been so well discussed already that I feel it is almost unnecessary for me to say anything.

The Chairman. There is a question upon which you can give us some important information, namely, whether the thing called steel and the thing called iron exist any more as separate existences?

Dr. Siemens. Chemically the only difference is, that what we call mild steel is pure iron-it is more essentially iron than what is sold as such; but as regards the physical properties of the material, it differs in many points from iron and ought not to be confounded with it, because if we were to call it iron and confound it with iron, we should think it right to treat it in the same manner, whereas it requires in many respects different treatment. In fact, Mr. Parker has given you one or two instances. I had occasion to allude at another place to one point which was brought before my notice very forcibly with regard to the steel boilers which Mr. Boyd has constructed. After testing samples of the plates that were supplied by the manufacturers the rumour was spread that the material was wholly uureliable-that instead of breaking through the riveted seam, through a narrow strip of metal, it broke through a line of 50 per cent. greater extension rather than through the narrow place; and as iron would not have given way in that manuer, and as the experience of engineers has been derived from iron, it was at first concluded that the new material was not reliable; but it was soon discorered upon further investigation that the method of riveting employed had been such

* Excerpt Transactions of the Institute of Naval Architects, Vol XIX. 1878, pp. 188-190.

VOL. I. 
as to be unsafe for this mild steel. Two large rivets had been put in a forward position and other rivets to make up the holding strength between the piece under test, and the shackles yielding were put back. In dealing with a material like this mild steel, the strain comes entirely upon the forward rivets, whereas the backward rivets being, as it were, the elongation of a much larger picce of metal, do not feel the strain at all. As it appears to me these two forward rivcts were near the edge of the metal, and they set up a tearing action. Now, it was remarked that although the sample was expected to elongate 25 per cent. before rupture took place, it did not elongate at all, but broke in the manner already alluded to. In further testing this metal it was found to be perfectly homogeneous and capable of an amount of elongation of 25 or 28 per cent. before breaking.

If you take a strip of india-rubber you may elongate it to several times its length, but if you make the least nick in the edge of the india-rubber, and try to elongate it, it will tear readily. In the same way, if you gire this mild steel a chance of tearing it will tear. In that case no elongation will take place, because in tearing the strain is confined to an infinitcsimal amount of area, and its course in fracture will be the result not of the total amount of resisting area, but of the direction the tearing action may choose to take. With regard to rireting, Mr. Parker states, and perfectly correctly I need hardly say, that in punching a plate such as is used in the construction of large boilers, the metal in the act of punching is reduced 30 per cent. in strength. Mr. Kirk has already offered an explanation which is similar to the explanation I should give; but with your permission I will draw attention, perhaps a little more, to the precise action that I conceive takes place in punching a thick plate of this material. Suppose the plate is being punched, the punch being above and the supporting die below it. As the punch penetrates into the metal, the latter does not immediately sever ; it will first yield by compression, and it will, as it were, be forced laterally into the mass of metal surrounding the punch, where it will create a zone of highly compressed metal all round the hole that is being punched. The metal beyond the zone of compression will be to a certain extent under tension. If the piece punched out is afterwards examined it will be found to be about 10 per cent. thinner than the uriginal thickness of 
the plate, and that diminution in thickness is accounted for by these forces of compression and cxtension set up within the metal. If the metal is now subjected to a tearing strain, it has to resist besides this, the abnormal states of strain into which it has been thrown by the punching action, and is therefore destroyed by a force consilembly less than that it can resist in the original condition, as the paper shows. Now, if this plate after the punching has taken place is subjected to annealing, then this strain between metal and metal will be rclieved and the platc will regain its full strength; or if the strained metal be rimed away, and the holc be enlarged, the platc will have its full strength. But I have the results of some cxperiments which were made by Mr. Riley at the Iandore Works, near Swansea, proving that punching docs not weaken the plate, but increases the strength of it. His cxperiments were not confined to one or two cases, but comprised a whole series that, strange as it may appear, went to prove that the punching absolutely increased the bearing strain of the punched plates, without annealing, to something beyond the strength of the plate per square inch before it was punched. I should first say he used the precaution to make the die larger, to perhaps a greater cxtent than is usually done, and the result was, to my inind, that the mass of metal under compression of which I have spoken was not formed, and that the plate was thus relieved from the abnormal strains generally produced in punching. Under these circumstances I can understand that a slight increasc of strength should take place, for the samc reason that when you subject a bar of metal of any form to strain, its strength will be increased. It is a subject, perhaps, not sufficiently understood, but I have had an opportunity of observing very extraordinary results in that way. Take a bar of iron or steel and subject it to a strain exceeding the elastic limit, and allow this strain to be activc for some time, in testing the same bar again you will find not only the elastic limit has bcen raised, but that the ultimate breaking strain is considerably increased. In that way whatever strain you put upon a piece of metal you increase its strength, unless the strain is applied in such a way as to set up contending forces within the metal. Mr. Parker has alluded to two forms of construction with regard to marine boilers. The one is the admirable furnace of corrugated form which is represented by the drawings, and which 
I quite believe is a step in the right direction. The other is an experiment of construction which I had occasion to make, and which, by Mr. Parker's request, I have put before the meeting. I was asked to design a ressel that could resist the pressure of at least $1,000 \mathrm{lbs}$. per square inch, and with a capacity of not less than $100^{\circ}$ cubic feet. The mode in which such high pressure airvessels have been hitherto constructed has been in making them multitubular, but in resorting to that construction you get many joints and you have also a voluminous structure. It occurred to me that a better result would be gained by rolling cylindrical bands of metal from solid steel ingots-cylinders of 1 foot in depth and 44 inches in diameter. In rolling metal in this fashion you get the whole strength of the metal in the right form for resisting a bursting strain. The difficulty was to make joints between the cylinders, and this was accomplished by turning in the face of each a V groove of about $\frac{1}{4}$ inch deep, rings of copper wire of $\frac{3}{8}$ inch thickness are thereupon placed between groove and groove, and the whole set of cylinders are screwed up and bolted together by sixteen or twenty long bolts made of steel of great elasticity containing about $\frac{1}{2}$ per cent. carbon, with a resisting power of about 50 tons to the square inch on the ends of the vessel. After screwing down these bolts hydraulic pressure was applied, and the vessel stood 1,300 lbs. to the square inch without a leak, but at that point a great many joints began to weep. The bolts were then drawn up $\frac{1}{8}$ th of a turn, when the vessel was found to be perfectly tight at the pressure of $1,300 \mathrm{lbs}$, but the joints began to weep again at 1,400 pounds. We might have continued the operation of drawing up and have reached a higher limit of pressure, and seen whether all the parts of the vessel were not strong enough to resist 2,000 lbs. to the inch, but inasmuch as the vessel in use was only to resist a pressure of $1,000 \mathrm{lbs}$. to the square inch, it was thought sufficient to tighten these bolts to the limit of $1,400 \mathrm{lbs}$. because we felt that if ever the pressure should reach that point the bolts would yield owing to thcir elastic property, and allow the fluid within to escape, thus avoiding the risk of an explosion taking place. In that way vessels I believe can be constructed which are perfectly safe and capable of resisting a very high pressure. I may mention that in this form steel will bear a pressure of 45 tons to the inch with perfect ease and 
safety. It occurred to me, therefore, that marine boilers might be constructed on the same principle, by rolling a number of rings in this fashion and placing them one behind the other, with these copper rings inserted, and bolting the whole down. In that way we should have at any rate a boiler-shell capable of resisting 200 or $300 \mathrm{lbs}$. pressure without the least risk of an explosion, whereas in riveting rery heavy boiler plates of an inch in thickness there is always some difficulty in treating the material.

\section{In the discussion of the Papers}

"ON THE MECHANICAL AND OTHER PROPERTIES OF IRON AND MILD STEEL," by DANIEL ADAMSON, C.E., Manchester ; and

"ON CERTAIN MATTERS AFFECTING THE USE OF STEEL," by M. ERNest Marché, Paris,

The President * (Mr. C. W. Siemexs) said he would proceed to make a few observations upon the papers before them, commencing with Mr. Adamson's, which he thought was one of great practical merit.

He agreed with Mr. Adamson both in his objection to short specimens and in his reason for such objection, but regretted that he had adopted a 10-inch specimen instead of the standard length of 8 inches; for the 8-inch standard, or the length of 200 millimetres, had found its way into very large practice. It had been adopted first of all by the French Admiralty, and afterwards by the English Admiralty and by Lloyds, and it was of very great importance to have uniformity. There was, of course, no a priori objection to Mr. Adamson's standard, but it would render comparison of bis results with those obtained by the Admiralty standard less easy,

- Excerpt Journal of the Iron and Steel Institute, 1878, pp. 424-427 and $457-458$. 
and this was the more to be regretted as, in his opinion, $\mathrm{Mr}$. Adamson's paper would be largely referred to hereafter regarding the mechanical properties of steel.

With regard to weldings, he would observe that all the speeimens which Mr. Adamson had brought before them were rery beautiful indeed, and he had sueceeded in welding up an angleiron ring in a very perfect manner; but he (the President) objected altogether to welded rings. Why not roll them at once as they would roll a tire? This had been done already to some extent in England, and he thought it was a rery exeellent practiee. The results which Mr. Adamson had plaeed before them regarding eorrosion were very interesting. This question of corrosion, as they were aware, had oecupied the attention of the English Admiralty, and had been diseussed on several oeeasions. The results which Mr. Adamson now brought before the members of the Institute made steel come out much better than they conld have hoped after the results that had been brought before them by the Admiralty Committee; and he must say he could not see why a really pure metal like melted irou should corrode more than an impure metal where different substances were at war one against another.

The reason why some speeimens of mild steel had given such unfavourable results was in his opinion (and he simply repeated the opinion now) due to an excessive quantity of manganese. Manganese was a highlly oxidisable metal, and if eaten out of the mixture, there remained only a sponge, which was easily destroyed. Altogether he fully maintained the view he expressed that mangauese was only a eloak to hide imperfeetions in steel, and when they wanted a really high-class metal, they should hare it as pure as possible, eontaining a little earbon in order to give strength, but as little of other materials as they could possibly do with. Manganese, no doubt, was a good metal for the maker. It ellabled him to push stuff through the rolls, whaterer it might be made of ; but now that they spoke of really high-class metal, he thought manganese was one of its worst impurities. Mr. Adamson had also alluded to steel higher in carbon than the mild steel which was now used for engineering purposes. He thoroughly agreed with $\mathrm{Mr}$. Adamson that it was absurd, in a bridge where they wanted any moderate extensibility and great streugth, to 
ennploy a metal that would bear without breaking a tensile strain below 30 tous, when they might have for the sane money and with the same ease n metul that would resist 40 or 45 tons. 'The practical difficulty to the ndoption of the higher metal would be found in oflicial circles. The Board of 'Trade lind, after a grent deal of argument and a great deal of endenvour on the part of engineers and steel-makers to induce them to recognise steel at all, consented to allow steel to be used in engineering constructions, but they would only credit it with $6 \frac{1}{2}$ tons per square inch, and so long as that rule was maintained, the engineer was powerless to adopt material of a higher cluss; but tho hindrunce, no loubt, must be removed by the force of fact, and Mr. Adanson's paper would do raluable service in furnishing further data for them to consider and to act npon.

With regard to Professor Akerman's paper, it was a valuable communication on the exhibits of steel slown nt the Lixhibition, but they could expect only a very high-class paper from one of Professor Akerman's well-known attninments and position. 'There were, however, some observations as to which he must beg to differ from that gentleman. Professor $\Lambda$ kerman said- "No proper difference between Bessemer and Siemens-Martin plates could be discorered in the course of these experiments, which comprehend both complete analyses and tension tests," \&c. Now he (I)r. Siemens) had always avoided comparisons between the open-hearth and the Bessemer metal. He had been always a grent admirer of the Bessemer process and a great friend of Mr. Bessemer, but he thought Mr. Bessemer himself would probably take exception to that sentence. Was it probable, he would ask, that if they commenced with the same pig metal, put $n$ portion of it into a Bessemer converter, and another portion into an openhearth furnnce, treating the one by blowing nir through it, diminishing its quantity by 15 per cent., and treating the other with rich ore such as they used for the reduction of the carbon in pig metal on the open hearth, that the results would be the same? He could not see liow the results could possibly be the same. It might be better in the Bessemer process than in the open-hearth for aught he knew, but it could not be the sane. If absolutely pure pig iron were used, such as is found in Sweden, then the analysis might show no difference in the amount of phosphorus 
and sulphur in the final result, because taking the half of nothing, it was again nothing. But if they had an impure pig metal to deal with, the simple diminution in weight must, as it was well known it did, increase the percentage of phosphorus and sulphur in the Bessemer metal, whereas the ore in acting upon the bath not only substituted for every pound of carbon and silicon it took away a pound of pure iron, but the slag took away at least a small portion of the impurities from the metal, especially if lime were used in the process. One of the essential differences between the two metals was this (and it was well known in practice at those works where the open-hearth furnace was carried on), that if they wanted a certain ductility, they must put $\frac{1}{10}$ th per cent. more carbon into the open-hearth metal than they would require in the Bessemer metal. That was common practice. It was alluded to in Mr. Akerman's paper, but with a doubt thrown upon it. $\mathrm{He}$ could inform them that it was a positive fact, and it was a significant fact also ; because if for the attainment of a certain degree of ductility they could put in $\frac{1}{10}$ th per cent. more carbon, it meant that they had the extra strength due to the $\frac{1}{10}$ th per cent. of carbon in their metal, and for that reason he believed that the open-hearth metal would have its own special application, in which it would take the first position, whereas the Bessemer metal was very excellent indeed for perhaps the majority of purposes. He thought it was but right that he should call attention to this difference without wishing in any way to detract from the value of the paper. Mr. Barnaby, the Chief Constrnctor of the British Navy, was, he believed, in the room, and as he was a very large user of steel and iron, they would be glad to hear his views.

\section{In closing the Discussion,}

The President said he only wished to refer to two points in the discussion. One was an obserration by Mr. Kitson, to the effect that steel did not stand heating and cooling as well as iron. Now, he had received from Messrs. Easton and Anderson, only the previous day, a statement of some very interesting experiments which they had made with steel boilers. The cylindrical bodies were heated to redness, then plunged into cold water, and again reheated and flanged. In other experiments they were flanged 
while in a state of reduess, and then plunged into water. Without going into the details of those experinents he would, with the permission of the Meeting, hand them to the Secretary, in order that they might appear in their "Transactions." He had the misfortme, though he very highly esteemed Mr. Bell, and put great store upon his views, of often differing from him, but in this instance he believed $\mathrm{Mr}$. Bell had been perhaps too severe upon him. He certainly took the view that if they wanted to make a ligh-class steel, such as Mr. Adamson had brought before them, they must cxclude from that material foreign substances, not only phosphorus and sulphur, but also manganese. He knew from his own experimental facts, and from long experience, that they could not produce a rery high-class material unless they made it exceedingly pure; and with all deference to Mr. Bell, he thought there was a broad line of difference between carbon and manganese. Carbon, they knew, associated itself with the iron, and for every 1uth per cent. of carbon they got a definite increase of tensile strength, therefore when they wanted tensile strength they put in carbon, but that was not the case with manganese. They did not put $1 \frac{1}{2}$ per cent. of manganese into their rails in order that they might resist the action of corrosion better, or in order that they inight stand the test better to which they were subjected, but it was well known that they used that amount of manganese in order that the stuff might roll better, and, as regards rails, he had not much to say against it ; on the contrary, he locked upon the steel which had latterly been brought forward so much by the TerreNoire Company as a feather in the cap of the open-hearth process, and therefore he had no reason to find fault with it; but he saw great danger in the indiscriminate use of manganese for the production of the higher classes of steel. When they heard such extraordinary results as Mr. Kitson had alluded to, when they heard from an authority like M. Frémy such results announced to thein as that, under certain circumstances, steel utterly failed, he believed that if the case were to be examined chemically it would be found that the steel was, as it were, forced into a condition of mechanical aptitude for its purpose by the addition of silicon, which was another of those substances which, he thought, under the circumstances, ought to be strictly excluded from high-class stecl. Mr. Adamson had called iron a "concrete " of "slag" and 
" iron." He (the President) thought the same appellation applied to a material containing $1 \frac{1}{2}$ per cent. of manganese, besides an ample allowance of phosphorus and sulphur, and, howerer perfect the material might be for such a purpose as rail-making, he was quite certain it would not stand the higher tests required of a material such as Mr. Adamson had brought before them, and when they wanted to melt it and heat it rapidly and cool it to stand the tests alluded to by Mr. Kitson, or when they wanted to expose it for a length of time to corrosive action, they would find out the difference.

\section{ON THE PRODUCTION OF STEEL, AND ITS APPLI-}

\section{CATION TO MILITARY PURPOSES.}

By C. W. Siemens, Esq..* D.C.I., LL.D., F.R.S., \&c.

The Chairman, Lieut.-General Sir Henry Lefroy, K.C.M.G., R.A., F.R.S., said, It is scarcely necessary for me to remind you that you have before you one of the most distinguished physical philosophers of the present day. We have to do to-night, not with the distinguished electrician, with the constructor of the Faraday, with the inventor of the bathometer, with the fertile inventor whose range has gone over subjects as various as the setting of type, and the measure of the depth of the ocean, but with one of the most scientific metallurgists of England, the inventor of inany remarkable processes in that art, and particularly of one which I daresay he will allude to for the direct extraction of steel and iron from the ore, and of whom it may be very safely said that he has touched no subject which he has not adorned.

$D r$. Siemens. The subject-matter regarding which I propose to engage your attention this evening is not new. Steel was known to the ancients, and is still produced by semi-barbarians in a similar manner to what we find described in ancient records.

* Excerpt Journal of the Royal United Service Institution, Vol. XXIII., 1879, pp. 536-553. 
Rich ferruginous ores were placed upon ignited charcoal in a carity formed in the side of a hill, and as the result of a day's hard labour in activating goat-skin bellows, a lump of metal mixed with charcoal and slag was produced, which after being subsequently forged, would prove sometimes of a comparatively soft nature, when it was called iron, and at other times harder, when it was denominated steel. This shows that the two metals iron and steel are substantially the same, and that they are distinguishable ouly by difference of physical qualities which are the result of very small chemical admixtures.

The steel produced by the ancients was of rery high quality, remarkable for its great hardness, and for its, power to resist abrasion. Who lias not heard of the blades of Damascus, and at a somewhat later period of those of Toledo, and of the remarkable swords that were made by the Norsemen? So much value indeed did the Norsemen place upon the production of cutting edges of great hardness coupled with tenacity to resist chipping, that those who could produce a blade of unequalled edge were highly esteemed and in one or two instances even rewarded with the purple of royalty in being elected sea-kings.

Notwithstanding the antiquity of the metal called steel, its production and its application have taken a new and very remarkable stride within our recollection. It was, however, as early as the year 1722, that Reaumur, the distinguished French philosopher, proposed to produce steel on a large scale by fusing cast or pig metal with wrought inetal or scrap. He put these ingredients into a crucible, and melting them together produced a metal partaking of the nature of steel. The difficulty he encountered, however, was insufficiency of heat. As far as we can make out, Reaumur's suggestion amounted to little more than a proposal, and it was not until 1820 that steel melting was introduced into commerce in a successful manner by Huntsman of Sheffield, using coke in a furnace actuated by intense draught, such as we know at present as an air furnace. Huntsman succeeded in melting steel in considerable quantity in pots, and from that date steel has become of great value in commerce for various applications.

Steel has variable properties depending upon very slight differences in chemical composition. Thus one steel when hardened will be next to diamond in its power to resist abrasion, and in its 
suitability to cut other metals, or when drawn out it will show a permanent elasticity not equalled by any other substance; it is susceptible of retaining magnetism, and will become what is called a permanent magnet, which property is shared with it to an inferior degree by only two other metals-nickel and cobalt. It is now produced in another condition known as mild steel, in which it manifests a quality of a totally different kind, a ductility not equal only but superior to that of copper and silver.

I hold in my hand a vase that has been wrought from a bar of this mild steel by an ordinary blacksmith, or I should rather say by an extraordinary blacksmith, because upon examination the workmanship displayed in the production of this vase is found to be really astonishing. The rase is hollow throughout, and not more than $\frac{1}{3^{2}}$ of an inch in thickness and perfectly sound, without weld or soldering. For this work of art I am indebted to my esteemed friend Mr. Henri Schneider, of the celebrated Creusot works in France, who has forwarded it to me as a sample of what he had produced by the open hearth process of stcel making, of which process I shall have occasion to speak further on.

It was not, however, until the year 1856, that a means was proposed of producing steel at a cheap rate. This was the year when Mr. Henry Bessemer read his famous paper at the meeting of the British Association at Cheltenham. His paper was entitled "The manufacture of malleable iron and steel without fuel," and it naturally created the greatest possible interest throughout the country. Mr. Bessemer, however, did not immediately succeed in producing by his process such steel as could be used. It was not until the year 1862, the time of the Universal Exhibition in London, that Bessemer steel attained a decided position in commerce. But, in speaking of this very important process, $I$ feel in justice bound to make reference to the name of Mushet, who, when he heard of the Bessemer process, thought that it would require an addition-analogous to what Heath made in the Sheffield potmelting process-that of manganese. Mushet proposed and patented a mode of adding spiegeleisen (or pig metal containing a considerable percentage of manganese) to the Bessemer metal whilst it is still in the liquid state, thereby separating from it the oxygen held in suspension in the metal in consequence of the blowing, and as we now know, adding to it some manganese which 
is essential in order to make the metal thoroughly malleable. We have here then a process that has done more than any other invention in modern times to rerolntionize, I may say, the most important industries of the land. At present not only railway machinery, but the very rails upon which we travel, are made not of iron, but of steel, and if I say that steel rails have shown a power of endurance five or six times greater than those of iron, I may add, with some regret (and I now speak not as a consumer, but as one connected with the production of steel as a manufacture) that they are unfortunately produced at a price alınost cheaper than iron or any other metal that could be named. Perhaps, howerer, the manufacturer will learn to produce them at those prices and jet clear some profit.

Almost at the same time that Mr. Bessemer made his remarkable invention experiments were instituted, at a distance of not 100 yards from this place, which have led to another process of producing steel upon a large scale. I, in conjunction with my brother, Frederick Siemens (who had previously been my pupil), erected an experimental furnace at Scotland Yard, by which we proposed to attain very high degrees of heat, and it was almost from the first that I looked upon that furnace as capable of accomplishing what Reaumur, and after him, Heath, had proposed to do, namely, to produce steel in large quantities upon the open hearth.

At first our attention was confined to melting steel in crucibles, to melting glass, and to other applications of this mode of producing intense heat ; the difficulties encountered were very great, and it was not until the year 1861 or 1862 that the prejudices in the way of the practical application of the furnace were sufficiently overcome, and that the furnace itself had assumed such a shape as to enable us to show that it could be applied with commercial advantage. And it is a curious coincidence that it took us just as long to mature this furnace as it took Mr. Bessemer to mature his process. In the year 1861, a large furnace was erected at the glass works of Messrs. Lloyd and Summerfield, near Birmingham, which has been at work up to the present time, and has realized those results that we, up to that time, had only hoped to attain. The success then achieved encouraged me to commence a series of experiments in the direction of producing steel on the open hearth, but, in order not to weary you, I will proceed to describe the 
regenerative gas furnace in the form in which it is now applied for the production of steel on the hearth, in quantities of from 5 to 10 tons at a time.

The regenerative gas furnace is so essential a part of the process of open hearth steel-making that it is indispensable to describe its principle and construction to some extent. It consists of two distinct parts-the furnace proper, with its reversing valves, regenerators, and melting chamber, and the gas-producer, in which the raw fuel (mostly small coal) is converted into gaseous fuel, which is thus separated from all the drossy and dirty constituents in the coal. It would appear, at first sight, a roundabout operation to convert fuel from the solid into the gaseous condition and then to take and burn this gas in a furnace elsewhere ; the gas, as it passes from the producer, is in a heated state, and in its transit to the furnace a great deal of that heat must necessarily be lost ; therefore, it might well be asked, why make this conversion of solid into gaseous fucl? Surely, in burning the gas less heat is obtained than if the fuel were burnt in the heating chamber of the furnace, and produced its effect there. That would be perfectly sound argument, if it was not for the regenerators of the furnace. These regenerators are by far the most important part of the whole arrangement, and, in order to understand the general principle of the furnace, I will first describe their action.

Plate 46 , represents the furnace in longitudinal section; the gas from the gas-producer passes in through a reversing valve, by means of which it is directed into the bottom part of the regenerator chamber. The gas flowing up through the mass of brickwork the chamber contains, and which is placed so as to form a large aggregate snrface, with intricate zigzag passages, will become heated, providing any heat has been accumulated therein. In the first place, there will be no heat, and the gas will pass unheated through this chamber and thence to the combustion chamber of the furnace. At the same time, a current of air is admitted through the air-reversing valce into the air regenerator chamber, which is larger than the gas chamber. The air passing up through the chequer work will reach the same point as the gas does at the entrance into the combustion chamber of the furnace. Now, since both the air and gas are cold, and as they meet for the first time at the entrance into the furnace, they will, if there ignited, 
produce a heat not certainly superior to what would be prodnced if solid fuel had been burned there instead; on the contrary, gas of the description we are dealing with is a poorer fuel than solid fuel, and the heat produced in the furnace will, therefore, be very moderate indeed. But the flame, after passing over the bed of the furnace, does not go to the chimney direct, but has to pass through two regenerative chambers, similar to those already described; the larger proportion of the heated products of combustion will pass through the air regenerator clamber, simply because it is the lurgest channel, and another portion will pass through the gas regenerator. The products of combustion pass from these chambers through the reversing valves, and are by them directed into the passage leading to the chimney.

The operation, therefore, is simply this, that the air and combustible gas pass up into the furnace through the one pair of chambers, and pass away, after combustion, towards the chimney through the other pair. But in passing through the second pair, the heat of the products of combustion is given up to the brickwork. The upper portions of this brickwork take up the first, and, therefore, the highest degree of heat, and, as the burnt gases are passed downwards through the regenerators, they are, by degrees, very completely deprived of their heat, and reach the bottom of the chambers and the chimney comparatively cold. After this action has been going on, say, for an hour, the reversing valves are turned over. They are simple flaps, acting like a fourway cock, and, by throwing over the levers which work them, the direction of the currents is reversed. The gas and air will enter now through the second pair of chambers, and the air passing up one regenerator and the gas passing up the other, will take up heat from the bricks previously heated by the descending current. The gases so heated, say, to $1000^{\circ} \mathrm{Fahr}$., will enter into combustion, and if the heat produced at the former operation was $1000^{\circ}$, it ought this time to be $2000^{\circ}$, because the initial point of temperature is $1000^{\circ}$ higher. The products of combustion will also escape at $2000^{\circ}$, and passing through the chequer work of the first pair of regenerators, its uppermost ranges will be lieated to very nearly $2000^{\circ}$. The temperature will diminish by degrees in descending till the gaseous currents have again reached the bottom nearly cold. Again reversing the process, after another hour or half-hour, 
as the case may be, the gas will take up the heat to the extent of nearly $2000^{\circ}$, and since another $1000^{\circ}$ is again produced in combustion, the temperature of the furnace will this time attain $3000^{\circ}$, and in this way it might be argued that, unless work is done in the furnace, the heat developed in combustion will, step by step, increase the temperature of the furnace $1000^{\circ}$, or something less, each time the reversal of the valves takes place, till we arrive at the practical limit imposed by the melting point of the most refractory substance we can find (pure silica, in the form of Dinas brick), of which the melting chamber is usually formed. This high temperature is obtained by a gradual process of accumulation, and without any such current as would be likely to destroy, by oxidation, the metal in the bath, or cut away the sides and roof of the melting chamber.

There is, however, a theoretical as well as a practical limit to the degree of heat obtainable in combustion, which was first pointed out by M. H. St. Claire Deville, namely, the point of dissociation at which carbonic acid would be converted back into its constituents, carbon and oxygen. If carbonic oxide or any other combustible gas and air enter the furnace at a temperature very nearly equal to the point of dissociation, it is evident that association or combustion cannot take place, and thus nature fortunately steps in to restrict the increase of heat by accumulation, within comparatively safe limits. In a furnace fully heated up to the melting point of iron, this action of dissociation can be very clearly observed. At first, when the gas and air are comparatively cold, combustion takes place sluggishly, the gases will flow through the furnace and produce only a dark-red flame; the next time the valves are reversed a whitish flame is produced; the next time a short white flame; and after having reached a full white heat, exceeding the welding point of iron, the flame will again become a long one, but this time not red, and of little apparent power, but bluish white, and flowing in clouds. This indicates the near attainment of the point of dissociation; combustion can no longer take place, except in the measure of the heat being dispersed to surrounding objects, or to the metal in the furnace, and that is about the degree of heat required for the process of making steel on the open hearth.

Before I leave the question of the furnace, I must refer back to 
the apparatus in which the solid is converted into gaseous fuel. This is a very simple apparatus, consisting of a cubical brick chamber of about 8 feet side, one side of which is cut off in a slanting direction. Fuel descends on this inclined plane, to the grate at the bottom where combustion takes place. 'The result of this combustion is carbonic acid at a high degree of temperature, and if this product of combustion was allowed to pass up the gascollecting channel, and through the overhead tube to the furnace, there would be nothing to burn; and the only result we should probably observe would be that the iron tube would very soon become red hot, and be melted down. But the carbonic acid as it is formed near the grate, encounters a further layer of fuel descending from above, which is also incandescent, but which cannot be consumed on the same terms, because there is no longer aly free oxygen present. The first result of combustion being carbonic acid, a compound of one atom of carbon and two of oxygen, this carbonic acid in passing through the subsequent layers of incandescent fuel is broken up, and a second molecule of carbon is added to the first, thereby producing carbonic oxide, which is a combustible gas. But coal is not simply carbon, it consists also of volatile matters, hydro-carbons, water, and the constituents of ammonia, and the hot carbonic oxide in passing through a further thickness of the fuel which contains these gaseous constituents, acts upon them in the same manner as heat does upon the coal in a gas retort. This action absorbs a portion of the free heat in the carbonic oxide, and the result is a gas consisting of carbonic oxide, hydrogen, hydro-carbons, aqueous vapours, and nitrogen, which latter, being a constituent of atmospheric air, necessarily passes with it through the fuel, and dilutes the combustible gas produced to the extent of about 50 per cent. of the total volume. This combined gas leaves the producer not at $3,000^{\circ}$, the temperature of direct combustion, but at about $700^{\circ} \mathrm{F}$. only. This remaining heat is thrown away and purposely so, and many criticisms have been made in consequence of this apparent waste of heat in the regenerative gas furnace, but I think I can prove that although there is loss of heat, no waste is incurred.

The gases passing from the gas-producer could be forced to the furnace by mechanical means, but this would be very troublesome VoL. I. 
and costly, and the duty performed by the $700^{\circ}$ of heat is to give them onward motion in the direction of the furnace. The hot gases rising in the uptake represent a column of heated gas at a temperature of $700^{\circ}$, at which its density will be about half the density at ordinary temperature. From the uptake they pass through a long tube of sheet iron or steel, and on their journey through this horizontal tube they part with most of their heat, so that when they reach the downtake their temperature has probably fallen from $700^{\circ}$ to $200^{\circ}$, having parted with $500^{\circ}$ of heat by radiation from the tube. The consequence is that the descending column will be of about twice the specific weight of the ascending column, and therefore a continual flow of the gas will take place, ascending on the one side, and descending on the other in forcing its way towards the gas furnace; by this means the heat apparently lost in the gas is utilized to produce useful mechanical effect.

But suppose that the gas passed from the producer to the furnace without being allowed to cool, what would be the result? The gas would enter the regenerative chamber at a temperature not of $200^{\circ}$ but of $700^{\circ}$; it would, in ascending, take up more heat and enter the heating chamber at the temperature previously imparted to the upper ranges of the chequer work by the descending current or product of combustion. The same temperature would be attained by the gas if it entered at $200^{\circ}$, the only difference being that the regenerator in the case of the cooled gas would work through a greater range of temperature by $500^{\circ}$. But a regenerator will work with the same economy through a greater range as through a less range; therefore, this heat, if it could be saved, would be of no benefit whatever to the gas furnace. The only difference in result would be that the gases would get less cooled in descending on their way towards the chimney, and that we should have a hot chimney instead of a comparatively cool one. Therefore, no loss to the furnace is incurred in cooling the gas on its way to the regenerative chambers, and the temperature of the gas is utilized to produce the very essential mechanical effect of urging the gas from the producer to the furnace.

The economical action of the furnace depends upon the circumstance that the products of combustion reach the chimney, not at 
the temperature of the heating chamber, as is the case when ordinary furnaces are employed, but at a temperature not exceeding $300^{\circ}$ or $400^{\circ} \mathbf{F}$., thus reudering nearly all the hent produced in actual combustion available for accomplishing useful work. It will be readily perceived that the economy of this system must be greatest in melting steel or in accomplishing operations of melting or heating at very high temperatures, whereas for the attainment of low temperatures, such as the heating of boilers, the economy would be comparatively small. Its practical economical result for high temperatures is well illustrated by the fact that in melting steel in pots in the ordinary air furnace at Sheffield, 3 tons of Durham coke are required to melt a ton of steel, whereas a ton of small coal suffices to melt a ton of steel in the same pots when the regenerative gas furnace is employed. In melting steel in bulk upon the open hearth, the consumption of fuel is further reduced, and does not exceed 12 cwt. of coal for the production of a ton of steel. In re-heating iron, the practical economy effected in the regenerative gas furnace over the ordinary furnace amounts to from 40 to 50 per cent., owing to the inferior degree of temperature required. When applying the system to inferior temperatures, there is advantage in suppressing the cooling tube and gas regenerator, and in approaching the gas-producers to the furnace, to consume the gas at its initial temperature.

At large works such as are now erected for carrying out the open-hearth steel process, a cluster of producers are put up outside the works; and the fuel is delivered from the railway at an elevated point in order to be put into the producers in which it is gradually consumed, and flows as a gas through the large overhead tubes into the works, where a number of furnaces are supplied for the production of steel. I think these observations may suffice to describe the furnace which plays a most important part in the process to which I shall presently refer.

I have already stated that one of the chief objects I had in view in maturing this furnace was the production of steel on the open hearth, but, as usual, in introducing a new process, great difficulty was encountered in first attempting to carry that idea. The question arose whether steel could be melted and maintained as steel upon the open hearth of a furnace at a temperature exceeding the melting point of most fire-bricks. The general opinion of 
practical men was entirely opposed to the idea of accomplishing: the object, and it is, therefore, perhaps natural that its realization was a question of time. The first attempt to make steel on the open hearth of a regenerative furnace was made by Mr. Charles Atwood, of Tow Law, who, in 1862, agreed to erect such a furnace -a small one, it is true-to my design; but although he was partially successful, he abandoned the attempt because he was afraid that the steel so produced would not be of the proper quality. In the following year, another attempt was made in France. A large furnace was erected at the Montluçon Works, and my colleague in the experiment was a very celebrated French metallurgist, the late M. le Chatellier, Inspecteur-Général des Mines. The experimental results were on the whole satisiactory. We obtained some charges of metal that was decidedly steel, but unfortunately, the roof of the furnace soon melted down, and the company who had undertaken the erection of this furnace were so much disheartened, that they, for the time at least, abandoned the idea of following up the trials. After two or three very similar disappointments, I decided to erect experimental works at Birmingham, where the processes of producing steel on the open hearth have been gradually matured, until they were sufficiently advanced to entrust them into the hands of others. But another French manufacturer, MIM. Martin of Sereuil, undertook to erect a regenerative gas furnace that could be used for making steel on the open hearth, but which, in the first place, was to be used as a furnace for heating wrought iron. While I was engaged at Birmingham with experiments to produce steel of good quality by my process, MM. Martin also succeeded in obtaining results with the furnace $I$ had designed for them. At the time of the French Exhibition, in 1867, MM. Martin brought forward their excellent exhibits, for which they soon got a considerable name. I also sent samples of steel produced by me at Birmingham, differing from those sent by MM. Martin, as regards the material used in the process; they had turned their attention to the production of steel by dissolving wrought-iron in a bath of cast iron, whereas my efforts were directed, from the first, to the use of cast iron and ore for the production of open-hearth steel.

In the process as it is now carried on at the Landore and other works, both scrap metal and ore are employed, in conjunction 
with pig metal and such other ingredients as serve finally to adjust the quality of the steel. The process may be described as follows :-The furnace having been heated up to the steel-melting point, or say, $3,500^{\circ} \mathrm{F}$., the first duty of the steel-melter is to see that the silica bottom and tapping hole are in the proper condition for work. If, in consequence of wear caused by previous charges, the surface-bed should be pitted, white sand, previously calcined, is introduced in such quantities as to fill up the inequalities, and heat is allowed to act for eight or ten minutes with the furnace doors closed, by the end of which time the silica or white sand introduced will be partially melted and consolidated with the older portion of the furnace-bed. The tapping hole is filled up with white sand mixed with powdered anthracite or coke, which serves to prevent its entire consolidation, and thus facilitates the tapping of the furmace at the end of the operation.

These preliminary operations completed, the furnace is charged with say six tons of pig metal, mixed with two tons of such iron or steel scrap, as gits, spillings of previous operations, old iron or steel rails, that may be available. The furnace doors are thereupon closed, and heat is allowed to act upon the charge for two hours and a half, when it will be found to have fused, and analysis would prove the metal to be an intermediate condition between pig iron and steel, its percentage of both carbon and silicon being greatly reduced. The subsequent work of oxidation of these ingredients consists in the introduction, at intervals of about half-an-hour, of rich ores or oxides of iron, in charges of about 5 cwt. each; the immediate effect of the introduction of cach charge is an active ebullition, through the reaction of the oxide of the ore upon the carbon of the metal, producing carbonic oxide. This gas escapes to the surface, whereas the iron contained in the ore or oxide becomes metallic, and is added to the bath. When about $25 \mathrm{cwt}$. of ore have been thus added, a sample is taken from the bath, by means of a sinall iron ladle, and subjected to a simple mechanical test, whereby the percentage of carbon remaining in the metal is readily, though somewhat roughly, ascertained. If it appears from the test that the carburization is nearly completed, no more ore is added, but 3 or 4 cwt. of limestone are thrown into the furnace, which has the effect of combining with the silicon contained in the slag, and of liberating ferrous oxide from the same, 
which latter, being thus set free from its combination with silicon, continues the action of decarburization of the metallic bath. Samples are again taken, until the steel-melter finds that, upon breaking the sample, the peculiar silky fibre is obtained which is indicative of a reduction of the carbon in the metal to 0.1 per cent. The metal is now ready for final adjustment, according to the strength or temper of the steel required.

If it is intended to produce ordinary rail metal, from 7 to $8 \mathrm{cwt}$. of spiegeleisen, containing 20 per cent. of manganese, previously heated to redness, are charged in, the bath is stirred by means of a rabble, and, after being allowed to rest for a few minutes, is tapped either into a ladle or directly into ingot moulds, arranged in groups, whilst the slag that followed the metal through the taphole is collected in a pit or mould prepared for its reception. The amount of slag produced depends chiefly upon the percentage of silicon in the pig metal used, and also upon the degree of purity of the ore employed in effecting the reduction, and amounts generally to 2 tons in an 8 -ton charge. The yield of metal should be within 1 or 2 per cent. of the total amount of pig metal and scrap (if of a solid description) charged into the furnace, because, although the pig metal would contain some 7 or 8 per cent. of carbon and silicon, which have to be expelled, this loss of weight is made up by the metallic iron given up by the ore. The lime added near the end of the operation is useful in taking up some of the other impurities, such as sulphur and phosphorus, from the metal, although the amount so taken up is only small.

After tapping; the steel-melter again inspects his furnace-bed, repairing any slight defects that may have arisen, fills up the tapping-hole, and introduces the next charge.

The time each charge occupies is from seven to nine hours, according to its character and to the heat of the furnace. When pig metal and scrap alone are used, a charge can be worked in from six to seven hours, and the proportion of pig metal employed can be reduced to from 10 to 15 per cent. of the total charge, whereas when no scrap at all is used, the amount of pig metal charged must be equal to the total amount of steel to be produced, and the reaction between the ore and pig metal extends the time of each operation by about three hours. In this respect, then, the scrap or Siemens-Martin process has an advantage over the ore 
process, which is compensated for, however, by the corresponding advantage in favour of the ore process, that it is not dependent upon the irregularities appertaining to scrap metal, and upon the purifying action produced upon the fluid metal first by the oxide and thereafter by the lime. It has been found generally that for small applications the scrap or Siemens-Martin process is the more advantageous, while for large applications the ore process has the advantage.

For the production of steel of special quality, such as is employed for boiler and ship plates and castings, the process is different only towards the end of the operation from that already described. The reduction is carried to a still lower degree than $(1 \cdot 1$ per cent. of carbon, and in order to make sure that the right degree of carburization is attained, chemical analysis of a sample is resorted to. Instead of spiegeleisen, a rich ferro-manganese is einployed, together with a small proportion of silica iron (a pig metal containing about 10 per cent. of silicon), which latter metal has the effect of taking up oxygen from the fluid iron, and thus preventing blow-holes in the casting. Another method of consolidating steel is that which has been introduced and so successfully carried out by Sir Joseph Whitworth. The steel upon which he operates is made upon the open hearth of the furnace in the manner I have described; but steel when it is poured from the ladle into the moulds shrinks, and during shrinkage little airspaces or hollows are formed, which break the continuity of the steel, although the cavity may afterwards be closed. Sir Joseph Whitworth, by applying great pressure through hydraulic agency to the steel while in the fused condition, closes up these cavities, and steel is thus produced perfectly continuous in its nature, and of such great hardness and tenacity combined, that when put, for instance, into the form of shells, some of these shells have gone three or four times through thick iron armour, and have been quite fit to go into the gun again.

The rich ferro-manganese now introduced into the market affords the steel-maker great facility for producing sound metal, notwithstanding its admixture with a considerable amount of impurities, notably of sulphur and phosphorus. By its means such inferior irons as the Cleveland can be rendered suitable for the production of steel rails, and large contracts have been carried 
into effect by some of my licensees for converting old iron rails of mixed or doubtful parentage into steel rails.

The facility thus offered to steel manufacturers introduces, however, a danger upon which the steel user will have to fix his attention. A steel rail containing from 1 to $1 \frac{1}{2}$ per cent. of manganese may look well and resist the tests for toughness and strength which are usually applied, and may yet contain more than $\frac{1}{4}$ per cent. of phosphorus or sulphur, or both these substances. It is only at temperatures below the freezing-point that the presence of phosphorus will make itself felt by symptoms of cold shortness, and it would therefore certainly not be advisable to put down rails of this description in cold climates.

For the construction of ordnance and other high class purposes, more than a trace of manganese in the metal is, in my opinion, decidedly objectionable. Manganese, though very efficacious in hiding impurities in the steel, is in itself an impurity inconsistent with high quality of the material produced. Its admixture with the metal is purely mechanical, and upon analysis of different portions of the same ingot it is found that its distribution is very irregular. Being more oxidizable than iron, a metal containing a considerable percentage of manganese cannot be re-heated without deterioration; is pitted by exposure to sea-water ; and its strength and toughness are also found to be below those of really pure metal when subjected to crucial tests. It is important, therefore, that steel for war purposes where high temper and great tensile strength is required, should be practically free from manganese, as well as from all other admixtures, with the sole exception of carbon. Extra mild steel, which is so remarkable for its extreme ductility, should contain in 100 parts 99.75 parts of metallic iron, and only 0.25 per cent. of all foreign substances put together.

It is for the production of these special qualities of steel that the open-hearth process has come into extensire use, being employed, either wholly or partially, by many of the leading works both in this country and abroad. The total production of openhearth steel (both the Siemens-Martin and Siemens variety) amounted in 1877 to 275,000 tons, since which time its production has gone on increasing, notwithstanding the extreme depression which continues to prevail in the iron and steel trades.

The French Admiralty were the first to take up the subject of 
constructing ships of very mild steel, and the British Admiralty now use it largely in naval construction, with such results as I believe will shortly be placed before another Institution by their chief constructor, Mr. Baruaby.

Although I have described the open-hearth process, as dealing with pig metal and ore-or, when it can be had, pig and scrap metalmy attention has been directed for many years to the accomplishment of a process, in which the ore used is put through a preparatory process of reduction and precipitation, and only a minimum quantity of pig metal is employed to impart fluidity to the mass in the meltingfurnace. In my early experiments in this direction I followed the lead of Chenot and others in producing what is called spongy iron, or iron deprived of its oxygen by heating it to redness, in combination with carbonaceous material. I soon convinced myself, horrerer, that no practical results could be obtained by.this means, inasmuch as the spongy iron contains, bound up with it, the gangue of the ore, which can with difficulty be separated from the metal, and afterwards encumbers the melting-furnace with excessive slag. All the hurtful impurilies contained in the ore, such as sulphur, phosphorus, arsenic, \&c., remain, moreover, in the spongy iron; and, as regards sulphur, its quantity is much increased on account of a powerful absorbing action, exercised by the spongy iron upon the sulphurous acid contained in the flame of the furnace. It was necessary, therefore, to devise some plan by which the metallic iron could be simultaneously separated both from the ore and its impurities. This object I have succeeded in accomplishing by means of a rotating furnace, which has, however, hitherto received only a limited application. The furnace, which is represented in Plate $4 \overline{7}$, consists of a gas-producer, the air-regenerator, a reversing-valve, and the revolving drum. No gas regenerators are employed in this furnace, but the gas passes from the producers through an oblong channel continuously into the rerolving chamber, where it is brought into contact with the heated current of air passing in from one or the other of the air regenerators. The flame thus produced rushes forward into the heating chamber, and after heating the material therein, passes back again towards the inlet side, whence the products of combustion pass through the second air regenerator and the reversing valre into the chimney stack. By this arrangement the front of the rotatory furnace is 
left free for access, and is provided with a charging and discharging door placed eccentrically, for the convenience of withdrawing masses or balls of iron from the furnace on a level with the lining when the furnace is stopped with the aperture in its lowest position. The lining of the furnace is made of highly aluminous or bauxite bricks covered on the inside with a certain thickness of iron oxide produced by melting hammer scale and rich ores in the furnace, which set while the furnace is kept slowly rotating. The rotation of the furnace is effected by means of a small Brotherhood or other engine, and suitable gearing.

The modus operandi is as follows :-The furnace being already lined and heated, a batch of ore mixed with fluxing and reducing materials, in a proportion depending upon the chemical constitution of the ore employed, is charged from an elevated platform in front, the rotator being stopped for this purpose with the charging orifice in its upper position. From 30 to $40 \mathrm{cwt}$. of batch is thus charged, upon which the door is closed, and the furnace chamber is made to rotate at the very slow rate of six or eight revolutions per hour. A high temperature is produced within the chamber by the combination of the gas with the highly heated air from the generator, causing the mass rapidly to become hot, whilst slowly rotating, so as to present continually new surfaces to the heat. No chemical action takes place under these circumstances until the temperature of the mass is raised to a full red heat, when reaction between the carbonaceous matter and the ore will take place, giving rise to the development of carbonic oxide, which, meeting the heated air proceeding from the regenerators, is burned, and thus adds to the heating action of the flame. When this reaction has fully set in, the supply of producer gas may be almost entirely stopped, and thus no sulphurous gas is admitted into the furnace during this critical interval. The leat now rises rapidly, and fusion of the earthy constituents of the ore occurs simultaneously with a continuance of the reducing action. In the course of an hour and a half after starting, the charge consists of metallic iron in a more or less agglomerated condition, found on analysis to be almost chemically pure, and of a liquid mass of cinder containing the earthy constituents of the ore and other foreign matter. The rotation of the furnace is now stopped with the tapping-hole in its lowest position, and the bulk of 
the cinder is discharged; the tapping-hole is thereupon closed again, and the furnace made to rotate somewhat more rapidly with a view of facilitating the agglomeration of the metallic iron; by the timely introduction of a rabble, the agglomeration of the mass can be so regulated as to induce the formation of two or three balls of convenient size for handling. The balls being formed, the furnace is stopped with the large door in its lowest position, which, upon being removed, admits of the charge being withdrawn. This is effected by the introduction of tongs supported by pulleys running upon overhead rails for transferring the balls in rapid succession from the furnace to a squeezer (which has for its purpose to expel adhering cinder), and from the squeezer to the bath of such a steel melting-furnace as already described.

The great purity of the metal thus reduced from the ore, and the rapid and comparatively inexpensive nature of the reducing process, are conditions highly favourable to the production of steel of high quality by this method at reasonable cost ; and it is my intention gradually to complete the open-hearth process of producing steel by combining with it the mode of preparing the material to be melted just described.

What I also wish on this occasion to call attention to are certain properties of steel which are of importance in considering its applicability to engineering and military construction. We know that steel varies between rery large limits in its hardness and in its ductility, but it is not so generally known that steel up to a certain point is of the same strength to resist strain when it is mild as when it is hard, and I have prepared a table of results which shows very clearly the nature of both mild steel and hard steel if compared under different strains.

Upon reference to the table it will be seen that loads from 6 to 15 tons per square inch affected all the bars equally, whether hard or soft, annealed or unannealed, and with the exception of one bar only this uniformity holds good up to 18 tons; up to this limit, the elastic elongation of all the samples was equal; but with the strain of $18 \frac{1}{2}$ tolls, the mild steel has become permanently elongated, whereas the harder steel shows a normal increase of elastic elongation. With the hard bars experiments were continued, and 21 tons to the square inch was applied, producing an elastic elongation 108 , which is entirely normal, and no permanent set is pro- 


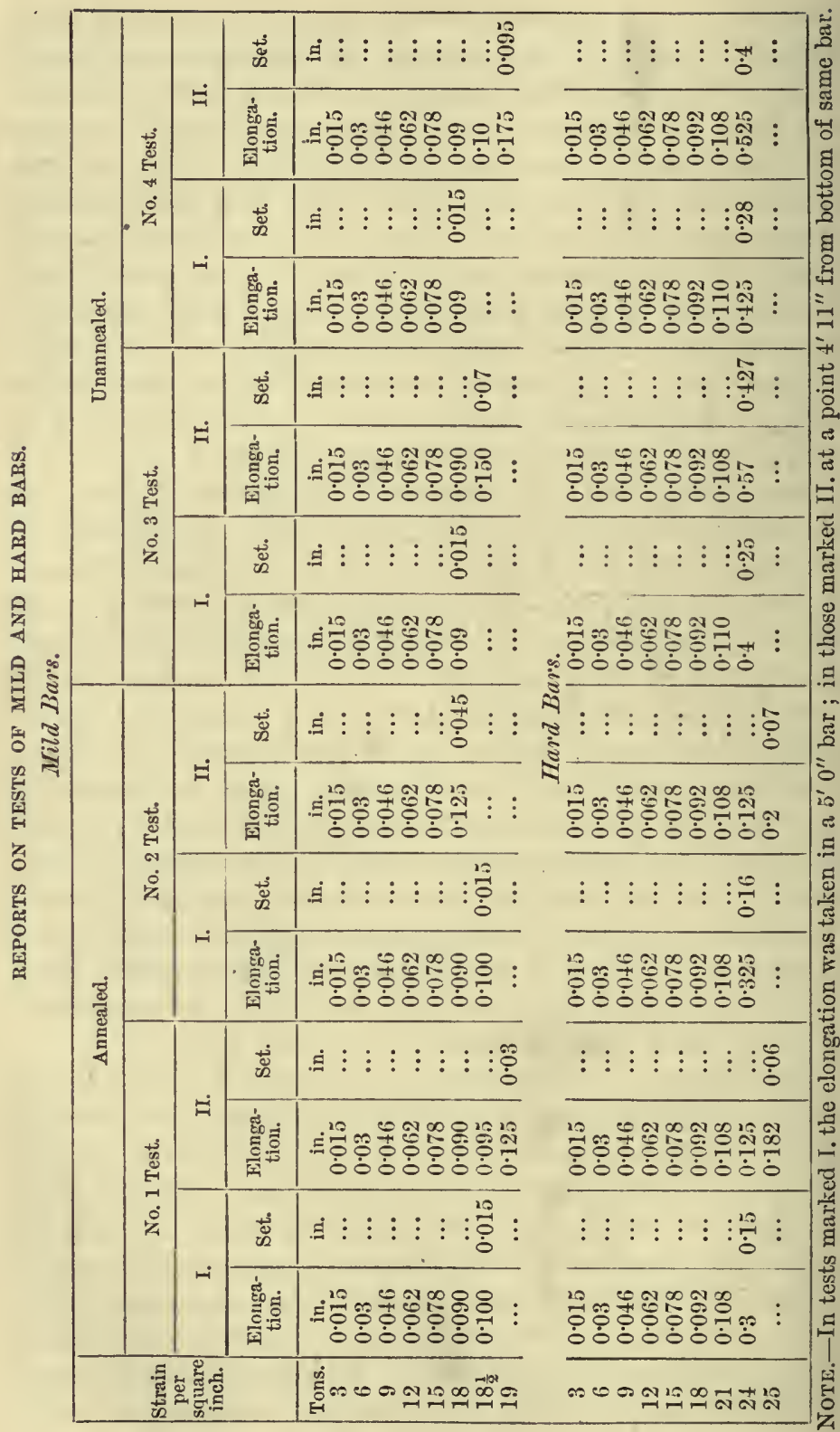


duced, but when $2 t$ tons were applied, then a permanent set occurred also in the liard bars; therefore the elastic limit of the hurd steel was 24 tons, whereas that of the milder steel was only 18 tons.

But there is a very peculiar circumstance connected with these elongations. If a bar of mild steel is taken from the rolls and subjected at once to a test of say 18 tons, it will rery likely be found to show a permanent elongation, but if the same bar is first subjected to a strain of say 17 tons, for several hours, it will then be capable of resisting perhaps 19 or 20 tons before showing any permanent elongation. One might also say the bar of steel can be taught to resist a higher strain without yielding permanently. Sir William Thomson has lately made some elaborate researches on this point, and perhaps he will favour the Meeting with some account of them.

The question of using steel for the purposes of engineering or military construction depends a great deal upon the particular application. Mild steel has the peculiar quality of yielding to an enormous extent to strain before giving signs of rupture. Bars are tested generally to 28 tons, at which mild steel, such as is used in naval construction, generally breaks after showing an elongation of 25 per cent. The steel used in the construction of boilers, which is made still milder, will stand only a total strain of 24 tons, but will show a still greater elongation before breaking. From this we can go upwards, and produce steel that will bear a breaking strain of 50 tons, with an elongation of perhaps 12 per cent. Still harder steel shows a strength of 60 tons, and an clongation of only 7 or 8 per cent. before breaking, whilst Sir Joseph Whitworth has shown that the absolute strength of steel in the form of bars, of the proper temper, may be brought up to 90 tons per square inch, by subjecting it to a process of oil hardening; such a tensile strength is hardly exceeded by carefully tempered steel wire. Therefore we have a range of strength which we can apply under different circumstances with great advantage. It must be borne in mind that the harder steel is apt to become brittle when suddenly cooled, and therein consists the great safety of using the milder description of steel for engineering and military purposes. With regard to this last matter I would say something before concluding, with reference to the construction of ordnance. 
Years ago a great advance was made in gun manufacture by Sir William Armstrong in producing his well-known mode of construction. At that time wrought iron was the strongest material practically available for the gun-maker's use, and this was put into the strongest possible form by the construction of coiled rings, which method places the fibre of the metal in the direction of the strain. The Woolwich or Fraser system of gun construction being a modification of the Armstrong system comprises the same mode of putting iron into the condition of greatest strength; but it is time I think to enquire whether, after the recent advances made in the production of mild steel, which is a material of superior strength, tenacity, and uniformity to iron, the mode of constructing ordnance should not be modified to suit these altered circumstances.

It is important then to appreciate wherein consists essentially the difference between iron and mild steel.

Mild steel is a metal consisting of $99 \cdot 75$ per cent. of the elementary substance, iron; and only a quarter per cent. of manganese, carbon, and such impurity as phosphorus and sulphur in the smallest possible quantity; whereas wrought iron of commerce generally consists of 96 to 97 per cent. of metallic iron and hetween 3 and 4 per cent. of other material, for the most part slag. Now, it seems not a rery great matter that in $100 \mathrm{lb}$. of iron there should be $3 \mathrm{lb}$. of slag, but if we represent this proportion to our eyes we see that it is not such a very inconsiderable quantity, considering that slag is both voluminous and entirely devoid of tensile strength. I hold here two cubes, one of $4 \frac{1}{2}^{\prime \prime}$ side, and the other of $1 \frac{1}{2}$ " side, representing as nearly as may be the one the metallic iron, and the other the slag which when mixed together form wrought iron. If the slag was mixed up amongst the mass of metallic iron in an irregular way, the strength of the iron would probably be very little more than is due to that of the glassy slag, because filaments of slag might go right across ; but in drawing out the iron, again and again, the little original globules of metal become elongated into strings or fibres of iron, held together by filaments of slag, and thus we get in iron a great apparent increase of strength by drawing it. But even if we draw it out to the utmost, we lose strength to the extent of the sectional area taken up by the slag, and thus get less resisting power than if the pure 
metal is scparated from the slag in subjecting it to the melting process, when we get the maximuin strength of which the metal is capable in all rlirections, and we have, in fact, metal of the greatest strength for moderate strains that can bo obtained, as we have seen, that even the hardest steel elongates as much as the mildest metal when subjected to moderate strains.

At another Institution Mr. Irongridge has severely criticised the coil system of construction, which is still followed at Woolwich, upon the ground that the stresses are not properly distributed; but whilst not agreeing with him, chiefly as regards the limits to which shrinkage can be advantageously resorted to, I cannot, on the other land, but think it is wrong in principle to use the harder and more resisting material in the inside, and the wcaker material outside the gun, as is still practised at Woolwich.

Mr. Longridge says that the inner tube of the gun should be under compression, and therefore one or several layers of rings should be shrunk on with such increasing force as to bring the metal into considerable tension, in order that when the powder gas acts expansirely upon the inside of the gun, the compression of the inner ring may be such as to resist the first part of the impact of the powder, and then after having come to its condition of neutrality take up its proper portion of the tensile strain. But, practically, I believe the shrinkage is not carried to any such cxtent, and it appears to me reasonable that it should not be, notwithstanding Mr. Longridge's argument, because if the large mass of iron he suggests to usc is put under compression to the extent indicatcd by theory, it would inevitably crush or permanently deform the inner tube. But if the inner tube is of steel and the onter portion of iron, a metal of less elastic range than steel, it follows that by repeated expansive actions, the external metal will be strained beyond the limit of elasticity before the metal of greater clastic range in the interior.

Again in firing the gun the inner metal will be expanded by the heat, which will increase the pressure exerted by the inner ring against the outer rings. This action will result in excessive strain on the outer rings tending to enlarge and loosen them, or in compressive action upon the inner tube, tending to produce the same result through crushing.

It appears, therefore, to me to be evident that, in constructing a 
gun, steel only should be used, in which the strains should, if possible, be so distributed that when the powder pressure acts, each portion should offer the same resistance to the strain. This, I think, might be effected in a very thorough manner by a process analogous to that employed by Admiral Rodman in the construction of cast-iron guns, only that cast-iron is perhaps the material least adapted for the purpose. If a steel gun or a ring forming part of the same was put into a furnace, heated up to a temperature of say $600^{\circ} \mathrm{C}$., and the inside was subjected to cooling action, while the outside was maintained at the temperature of the furnace, a distribution of stress would result which would be highly advantageous to the strength of the gun. The chilling of the inside surface of the ring or gun would cool the metal towards the inside circumference. This metal could not shrink, nor would the inner diameter of the gun diminish, because the diameter would be determined by the mass of metal still in the heated condition. The racancies produced in the cooled metal would be filled up by the inflow of metal from the heated mass outside, resulting in equilibrium of the metal at the diameter originally due to the heated mass, and the temperature will gradually vary from say $100^{\circ}$ inside to $600^{\circ}$ outside. If the gun was afterwards taken out and allowed gradually to cool, but without stopping the cooling action from within, the whole mass will cool down to the minimum temperature. If we imagine the ring to consist of a succession of concentric cylinders, each cylinder would acquire a tensile strain due to its previous temperature, which being a minimum on the inside and a maximum on the periphery, there would result a distribution of tension throughout the mass, being negative or compressive in the interior and more and more tensile towards the exterior. Then when the full pressure of powder gas was active, the strain upon each portion would be equal, and the resulting strain would be opposed by the whole elastic strength of the metal. The internal portion of the tube would, with such a mode of construction, have no other function to perform than to resist the abrasion that is necessarily going on in the gun. This question is just now very much before the scientific public, and therefore I thought it well to bring before you my own view of the matter.

Before quite concluding, I would call attention to a machine 
which has lately been sent me from America for testing pieces of steel or iron, and after the meeting is closed I will break a test bar of mild steel, that the members may see the amount of elongation of which such a bar is capable before breaking.

Dr. Sremess. With regard to an observation made by General Younghusband, I should ask permission to say one word. I do not wish to suggest for a moment that a gun, such as is now turned out at Woolwich, is not a very excellent mechanical production; and at the tims the materials that were to be used were desided upon, thos w were the very best materials that could be obtained. And with regard to iron, I admit the value of putting the strain in the direction of the fibre, but at the present time we have made a very considerable step forward, which I think should be taken advantage of in the construction of guns. If the coil is limited in its len rth, it gives, as General Younghusband says, no longitudinal strength, and the inner tube becomes a matter of much greater importance than it would necessarily be if the outside of the gun, instead of being multifarious, was solid. But there seems to be no reason why, if the outside of the gun was of steel, and the elasticity of that mass of steel was properly distributed, it should be divided, and not be of a single piece. If that was the case, the inner tube would have only one function to fulfil, that of taking the rifling; but it is most essential, I consider, that it should be as mild as is consistent with its power to resist abrasion, inasmuch as it cannot be true in principle, although it may be perfectly workable, to have the material of which the lining is composed of greater resisting power than the material surrounding this inner tube, upon which the strength of the gun depends. The lining must necessarily be subjected to very considerable expansion through the firing itself. One fact I should like to mention, viz., that a shrinkage of 1 in 1,000 produces $11 \frac{1}{2}$. to 12 tons of strain to the square inch, and an elongation of 1 in 1,000 is produced by heating the material to $130^{\circ}$ Fahr. ; therefore, if a gun is built up by shrinkage, and the inner tube afterwards heated up to $130^{\circ}$ Fahr., the amount of fight between the inside metal and the outside must be just double. If the heating should exceed that limit, as it appears to me it would be likely to do, the strain between the inside and the outside must increase in vol. I. 
the same ratio ; and this action between the two principal portions composing the gun could only be obviated if the inner tube was of such a material as to yield absolutely to the outside strain. Therefore, it was not with a view of criticising, but rather with a view of suggesting, that I ventured to make the observations I did. I thank you very much for the kind attention you have given me this evening.

In the discussion of the Papers

"ON IRON AS A MATERIAL FOR ARCHITECTURAL CONSTRUCTION," by J. Alianson Picton, F.S.A., and

"ON MILD STEEL," by A. W. B. KenNedy, M. Inst. C.E.,

Dr. C. W. Simmens, F.R.S., Hon. Associate, ${ }^{*}$ said : I am sure I cannot do less than congratulate you, Mr. President, and the Institute of Architects upon the interesting and valuable papers to which we hare listened. Mr. Picton, in surveying the whole question of the application of iron and steel to architecture, appears to have taken such a broad and enlightened view of the subject, that I hardly know what to add. Professor Kennedy has dealt more particularly with steel, the latest development of iron as it may be called, and with its preferential merits to iron ; and as my name has been connected with one of the processes now largely used for producing this material, I may be expected to offer a few remarks chiefly with reference to the properties of steel and its applicabilities for architectural purposes. Steel is a material, which, as Professor Kennedy very correctly said, has not been well defined. We call steel the material of which watch-springs and cutting tools, needles, \&c., are made, and we all know it is very remarkable for its hardness, its great elasticity or rather, I should say, its high limit of elasticicy, and also for its brittleness the moment that limit is exceeded. We call steel

* Excerpt Transactions of the Royal Institute of British Architects, 18791880, pp. $173-176$. 
the material now used largely in railway structures, both in producing wheel tyres and the rails upon which they run. This material is remarkable for great strength coupled with a sufficient decrree of toughness to resist very heavy blows, and we now call steel the material which exceeds even copper in ductility, stretching us it does 25 per cent. before breaking. Yet I am in favour of continuing the appellation of steel in speaking of all materials consisting mainly of iron, which are malleable and have been produced by a process of complete fusion. 'It is to this circumstance of complete fusion that the superior uniformity and the certainty of character of the steel of the present day are due. If we follow the production of wrought iron through all its stages we almost wonder how even such uniformity of strength and character is produced as we find it to possess. In puddling iron the workman produces abont 1 cwt. of metal that has been massed together from a semi-fluid condition, and the nature of which depends upon his skill, the temperature of the furnace, and other variable conditions. The consequence is that one ball is nerer quite similar to another. One may be what is called young irnn, and another is more matnred when it leaves the furnace. The young iron will, after consolidation by hammering and rolling, show a crystalline fracture, and the other more entirely decarburized material will possess a fibrous texture. In order to harmonize the differences in the character of the iron in successire balls, the process of re-mixing or packeting is resorted to, which consists in welding together bars produced from different charges, and rolling them anew. Thus by very careful treatment the inequalities naturally appertaining to purddled iron may be reduced, and iron of high quality, such as Yorkshire plate, may be produced; but such care is not always taken, and hence arises the uncertain character of the iron of commerce. Even the best commercial wrought iron is not pure iron, but an agglomeration of that metal with cinder (as may easily be secn by viewing a section of a bar through an ordinary magnifying glass), and not unfrequently with more hurtful substances such as sulphur and phosphorus. In producing steel, however, and particularly in producing the steel now used in engineering and architecture, a mass of some ten or twelve tons may be seen in the furnace in a state of perfect fluidity, in which state it 
is tested by means of samples both as to its chemical and mechanical condition. It is thereupon run into a ladle and from that ladle into ingot moulds, and all we have to do afterwards is to give it the particular form or shape required for our purpose. It is therefore nothing more than natural that a material so produced should be much more uniform and trustworthy than the iron of former days. There is, however, still a prejudiceI cannot call it by any other name-in the minds of many of the users of these materials, because the steel of former days was of an uncertain nature, and occasionally gave way when least expected. Professor Kennedy has sufficiently alluded to the causes of this, and I have no doubt but that very shortly this idea will be got rid of entirely, and steel will be used in lieu of iron for a great many purposes to which it has as yet been unapplied, and that it will be trusted to a higher limit of its strength than has hitherto been allowed either by the Board of Trade or by the insurance companies. The advantages of steel as a material to be used in architecture, I would consider to be the following :-For purposes where boldness and grandeur of outline are essential no material can rival steel; when we want to bridge a third of a mile in span, or to construct a roof or dome of enormous size, there is no material that can serve our purpose like steel ; if the object is simply to get tensile strength, without subjecting the material to cross strain, as is the case in the chains of a suspension bridge, the use of steel wire enables us to attain a limit of strength exceeding 100 tons per square inch, or as much as five times the tensile strength of wrought iron. The chains supporting the great American suspension bridges across the Falls of Niagara and across the Hudson River at New York are constructed of this material, and in the latter case 120 tons per square inch is the breaking strength to which the wires are tested before approval. If, instead of wire, links or bars are used in the construction of bridges subject to continuous strain, the breaking strength (which is really optional, being dependent upon the percentage of carbon admitted into the material) may be conveniently fixed at from 40 to 50 tons per square inch, or say twice the strength of wrought iron. This same material lends itself best for rolling girders to span large openings, and it will be readily conceived that, although 
the absolute strength of such steel is ouly twice as great as that of iron, the girders themselves, if of considerable length, may be reduced in section in a much greater proportion as compared with iron, because a considerable portion of the duty of a lung iron girder consists in its having to carry its own weight. By reducing that weight to a half in taking advantage of the extra strength of steel, a greater proportion of the total strength becomes available for carrying load, which latter being a fixed quantity renders a furtler diminution of scantling possible. It is in consequence of this compound effect, resulting from the use of high-class material, that its great advantage in large structures arises, and it is difficult to assign the limit of size which skilful treatment may not accomplish by its use. These, however, would be exceptional instances, and the more important question after all is : How does stecl compare with its old rivals, iron and wood, in ordinary construction? I would venture to say that the use of steel in certain portions of ordinary buildings is not only better and safer, but absolutely cheaper than the use of such a material as wood. In using steel girders instead of wooden beams in the construction, for instance, of a ceiling, what is the comparison as regards efficiency and cost? The fluoring, supported on steel girders, would be more permanent, being both fire-proof and not subject to gradual decay; it would, moreover, if made as rigid as a wooden flooring, be four to six times as strong when subjected to exceptional loads. As regards price, granting the material would be dearer, we should have to take into our calculation an element which is not at once apparent. Whereas the depth of wooden beaming of sufficient strength would be, say twelve inches, if constructed of steel a depth of seven or eight inches would amply suffice; and if we were to repeat this, say five times in a house, a total saving in height of two feet would be the result. Now comparing the cost of the cubical contents in the structure built in the trro ways, we should find that in a house of an area of thirty feet by sixty, in taking the price of construction of one cubic foot of capacity at 1s. $2 d$., without taking into consideration fittings and ornamentation, we should save $£ 210$, to be placed to the credit of the steel girders. If allowance were made for this or even half of this it would be found that the steel girder would probably be the cheaper 
construction of the two. I may mention here a case with which I had to deal in a small way a year or two ago. I have at my house in the country a terrace, and beneath that terrace a billiard room; I wanted to lower the terrace six inches and to raise the ceiling of my billiard-room at least a foot. The billiard-room had been constructed according to ordinary practice. I managed, by putting steel girders over this billiard-room (which was about serenteen feet span), by filling in between girder and girder with cement and covering it with the same sheet of lead that had formerly been used, to save the eighteen inches I required. The result was a perfectly dry room of increased loftiness, whereas before I had considerable difficulty in keeping the water out. This simply shows how, by the use of the stronger material, structural advantages, besides saving in cost, may be obtained. But it has also been reproached against iron that it is not fireproof. I have heard Captain Shaw say he liked houses with wooden beams and columns, because he knew exactly when they would give way, whilst this was not the case with iron. The remark is no doubt the result of very extensive experience, but I expect that it has arisen through the use of cast iron. Now cast iron, I should think, is a rery unsafe material to be used in architectural structures. You can never know with certainty whether the iron is sound throughout, when put in the shape of a column or girder, or whether there are not unperceived cavities within the shell that make it unsafe. Another danger is that in case of fire cast iron, when heated partially, is apt to crack, and the fire brigade would reeeive no warning as to when the building would give way. But in using steel a very different condition of things obtains. Steel is produced at the highest temperature attained in the arts, and it sets or solidifies at a temperature far exceeding that reached in a burning house. Therefore, although the structure contains this material in parts where strength and solidity are required, it would be improbable that any portion of the fabric would be heated, in case of conflagration, to a temperature sufficient to make it yield on account of that temperature. The temperature would depend upon the amount of combustible material accumulated at any one place, and by the employment of steel instead of wood in the structure the quantity of combustible material would be necessarily much diminished; it would be 
reduced in fuct to furniture and stores, and it is probable that a conflagration would remain confined within very narrow limits. If ly encentration of flume the heat should nevertheless reach a ligli point in any portion of the building, the steel when heated to redness would certainly deflect to an enormous extent before griving way, and the same indication which the fire brigade men receive in the ease of wood they would have in probably a still greater measure in dealing with steel. But an almost complete protection of the steel employed in structures would be obtained by constructing the floors of girders filled in between with plaster or cement, a method which is more largely resorted to in France and other portions of the Continent than in this country. In employing stecl in the construction of columns the metal may be conveniently rolled in the section of a cross and be enclosed in a casing of plaster or cement, which latter will in that case fulfil the double purpose of protecting the steel against accession of heat and of lending itself to such structural effect as the architect may desire to produce. In making large girders of steel, riveting has to be resorted to, and the quality of steel that should be used for such purposes differs widely from the harder and stronger description of material applicable for tie rods, rolled rafters or columns. These harder descriptions of steel would lose strength in an extraordinary degree through break of continuity such as is necessarily produced by punching and eren drilling for the introduction of rivets. Although steel is immensely stronger than iron, it is more apt to tear from a point of discontinuity, and this liability to tearing action in steel increases with its strength. By careful annealing, risk from this source may be reduced; but annealing itself is a delicate and therefore risky operation, and no work would be safe that depended upon its due accomplishinent. The steel-maker of the present day is not at a loss, horrever, to supply a material combining extraordinary toughness with a strength still greatly exceeding that of iron. This "mild steel," which has recently nearly expelled irou from naval construction, has an absolute strength of about thirty tons per square inch, but its touglness is such that if a bar of eight inches in length is subjected to increasing strains it assumes a length of ten inches before giving way. Nor is this toughness dependent upon previous annealing; on the contrary this mild steel may be heated to red- 
ness and cooled suddenly by plunging it in water, without losing its yielding property to any great extent. Although the absolute strength of this material does not much exceed that of best iron, its superiority consists in its uniformity and power of yielding before breaking, which makes it a safer material to be used when weighted even to a point nearer its elastic limit than it would be safe to go to in dealing with iron. The Board of Trade have fixed upon six tons and a half as the weight allowable per square inch of steel in bridge work, instead of five tons, the weight allowed for iron, but this rule, which makes no distinction between steel and steel, will in all probability be yet considerably modified in favour of the new material. It bas been mentioned in Mr. Picton's paper that iron, when applied to architecture, has very often been hidden in order to obtain its strength without acknowledging its use. That it could be worked into elegant shapes he proved by the productions of mediæval times, but it appears that this art of working in iron has been-if not abandoned-very much less used, and one of the reasons is probably to be found in the fact that, after the introduction of the blast furnace, wrought iron was no longer produced of its former excellent quality, and that there was a difficulty in working inferior wrought iron into those forms which are admired in old churches, gates, \&c. But in mild steel we have a material which is above all others capable of being put into perfect form. We lare in this material not only the greatest uniformity combined with the greatest strength, but we have the utmost security against accident and breakage, either when loaded in excess or in case of fire, and it is also a material capable of being wrought into the highest artistic forms. 


\section{In the discussion of the Papers}

"ON THE MECHANICAI, PROPERTIES OF IRON AND MILD STEEL," by D. ADAMSON,

"ON THE USE OF STEEL IN THE CONSTRUCTION OF BRIDGES," by A. N. MaYNaRD; and

"ON THE USE OF STEEL IN NAVAL CONSTRUCTION," by Nathanili Barnaby, C.B.,

Dr. Simmexs * said he thought he should not be entirely silent when a discussion took place on steel such as they were now engaged in. They had before them three papers dealing with the use of steel : one by Mr. Adamson, another by Mr. Mayuard, and a third by Mr. Barnaby. With regard to Mr. Adamson's paper he would like to say a few words. They had had a very admirable paper from Mr. Adamson at their Paris meeting, and he had added some very raluable information that day. He was glad to see that Mr. Adamson had arrived at a conclusion to which he (Dr. Siemens) had sometimes giren expression, namely, that in riveting steel plates together steel rivets should be used, and that those rivets should be put as close together as they could be conveniently placed. He was glad to see that Mr. Adamson had by his investigation brought this matter so clearly to light; but it was a thing which had often come before him in dealing with those very subjects that had been alluded to by Mr. Parker and others. Mysterious failures occasionally had occurred. It so liappened that the one failure which Mr. Parker mentioned had been brought to his (Dr. Siemens's) notice at the time; and the very nature of that failure proved, he thought, that the cause was only hidden below the surface, and was not beyond their ken to umravel. If a cylindrical tube was intended to fit into a flanged neck, and the tube was too small, and if, after heing punched all round or drilled, it was forced out mechanically to fit the larger diameter, it stood to reason that the metal extending from the riret holes to the edge had to be stretched considerably. This extension of the outer

- Excerpt Journal of the Iron and Steel Institute, 1879, pp. 82 and 107. 
edge would throw a corresponding tensile strain upon the metal inside the line of rivet holes. The result was, that if in any of these holes there was the slightest defect or the slightest discontinuity of the even surface a tear would begin. It was said that metal which ought to stretch 25 per cent. before breaking should not have torn under these circumstances, because they could find that it had not stretched at all. But, in arguing this point, gentlemen forget the fact that in tearing a material they did not extend it. A tear meant applying the whole of the force available upon absolutely one point of the metal. At that one point the metal might be capable of stretching even 50 per cent., but this would not save it, inasmuch as the force was confined to one point. At that point it would tear, and afterwards at another point, and so on. All the mysterious failures reported might in nearly all cases be attributed to tearing action, which was generally set up at rivet holes if the rivets at those holes took more than their due proportion of the strain. He knew of another instance where failure took place in a testing bar. It was not intended to test the strength of a riveted joint. In fastening the piece it was held by two large rivets on each side, followed up by smaller rivets. With a metal of high elasticity, such as mild steel, a great strain would be thrown upon the part most forward. The supports, which were backward, could not come into full bearing condition till the forward part had taken the proper strain. Wherever that strain exceeded certain limits, tearing action would take place from any part where the continuity was broken. One of the chief advantages of drilling over punching was that the drilling made a smoother hole, and there was less susceptibility to tearing; but, as stated by Mr. Barnaby, mild steel should not require either the particular attention or expense due to drilling, nor should it require annealing. The failures spoken of were generally attributable to some fault in the treatment. He would rather not touch upon the subject of a comparison between Bessemer metal and the metal with which his name was connected. He had more than once expressed his great admiration of the Bessemer process, and of the excellence of the metal which could be produced by it. At the same time it was not probable that he should have gone to the great labour and expense of developing another process if he had. not thought it possessed some particular merits. It would 
have been entirely waste labour, and lie might bo excused, perhaps, if he dropped in a word in favour of the latter process without in any way wishing to detract from the Bessemer process. Mr. Bessemer had brought before them very interesting specimens, showing that at the very early stages of the process excellent material was produced thereby. Therefore he might ask why was it that this material did not come for a number of years into such use as the mild steel was now put to? The answer, he thought, had been given indirectly by JIr. Bessemer himself. Mr. Bessemer lad said frankly that he did not always produce such excellent quality, and that there were irregularities which sometimes gave rise to failure. It might be added, as remarked by Mr. Snelus, that there was another cause of difficulty, and that was the chemical composition. If the Bessemer process was carried out properly, and good Swedish metal or high-class hematite was used, he did not doubt that excellent results would be produced by it; but he thought that in a process such as the open hearth, which allorred plenty of time for the taking of samples and for adjusting the composition of the metal at the end of the operation, if they started on equal ground, with equal care, there must be some advantage in farour of the uniform production of such metal as they were speaking of. Another reason he might allege was that of the chemical composition. Starting with pig metal of the same percentage of phosphorus, silicon, and sulphur, in the case of the open-hearth process, where they treated the metal with ore and limestone, they did not diminish the weight of metal ; that was to say, for a ton of pig metal put in they got out within 1 per cent. of a ton of steel. That in itself meant no reduction in the percentage of phosphorus and sulphur. Whereas in the Bessemer process there was a certain loss of weight, meaning a certain concentration within a less weight of those materials. It might be rery little ; it might be nothing if absolutely pure metal was used; but if impure metal was used it would be something. On the following day they would have a process brought before them by which Bessemer metal could be produced from Cleveland iron. He did not doubt the chemical result; but if there was merit in it, that merit might be claimed in favour of the open-hearth process as carried on hitherto, inasmuch as in the Siemens process they had always used ore and limestone as necessary additions to the 
bath. In 1863 and 1865 he had tried, moreover, many experiments with basic linings, including lime lining, in connection with the open-hearth process, but he never met with such an amount of practical success in his endeavours to render such linings permanent as to justify him in recommending their adoption to his licensees. He believed the Bessemer metal was perfectly good for nearly all the purposes to which mild steel was put, but he was equally satisfied that the open-hearth process was best suited for the production of such special qualities of steel as were now under discussion.

Dr. Siknexs remarked that with regard to the mysterious breakages which had just been alluded to by Mr. John, perhaps he (Dr. Siemens) had not expressed himself as clearly as he should have wished on the previous day, if he had said that it was owing to its great ductility that steel tore more readily than iron. What he meant to say was, that steel tore more readily because it was the more uniform and more homogeneous metal. In iron each fibre was a place at which a tear would stop. In steel, if a tear was once started, it would run alnng just as it would, for instance, with india-rubber, the most elastic of all materials. If they took a strip of india-rubber and elongated it ten times, it would return to its original length upon removal of the strain upon it. If, therefore, the edge of the india-rubber was slightly nipped with a pair of scissors, and it was again stretched to the same extent as before, the india-rubber would tear right across from the point of discontinuity produced by the incision. The same kind of tearing action was set up in mild steel, when it was treated in a way that was not suitable to it. In working mild steel drawn out in a half cold state and allowed to set, great tension arose in the mass; and unless the metal was subsequently annealed, a tear might commence at a riret hole, and that tear would run along more readily than in iron. Care should be taken to prevent mischief from this cause in dealing with mild steel. 


\section{In the discussion of the Paper}

\section{"ON THE ELIMINATION OF PHOSPHORUS," by}

Mr. Sinney G. Thomas and Mrr. Percy G. Gilcirist,

Dr. Srfmexs * said they should distinguish two things in the discussion - the proposition to use a basic lining, and the chemical results which had been brought before them. As to the first of these, he had no experience and no knowledge with regard to the Bessemer converter, but as regarded the open-hearth furnace, he had to say that the question of the advantages which would result from a basic lining had occupied his serious attention as early as sixteen years ago. In 1863 , he, in conjunction with M. le Chatelier, conceived and patented a lining for the open-hearth furnace, with which he was then experimenting for the purpose of producing steel. They had arrived, by inductive reasoning, at the conclusion that in order to carry out the process properly, a basic material ought to be adopted for the lining; and M. le Chatelier suggested bauxite (alumina with a certain proportion of peroxide of iron). They commenced experiments in France, at the Fourchambault Works, with a lining composed of bauxite, crushed and rammed into the furnace. But they did not find that they could get that lining to stand when the fluid charge came upon it. He afterwards made bricks of bauxite (at the present time he had, perhaps, 50 or 100 tons of those bricks in Birmingham), and by the use of these they had succeeded in forming a lining which would stand for a series of charges. But although the result with the use of this lining had been good, he confessed that he had no such marvellous effects to put before them as were stated in Messrs. Thomas and Gilchrist's paper. He also tried lime mixed variously with clay and other binding substances, and he found that the difficulty of getting the binding to stand increased very much in using that material. He had also used a lining made of magnesia formed into bricks, and burned at a very high temperature; a magnificent lining was thus produced, but it was expensive, and on that account not commendable. The reason

* Excerpt Journal of the Iron and Stecl Institute, 1879, pp. 153-156. 
why he did not persevere with the basic lining was, that although for a few charges it seemed to stand exceedingly well, the slag containing silica and oxide of iron acted upon it more rapidly than was desirable ; and it was subject, moreover, to the inconvenience that, unlike a silica lining, it could not be repaired. In dealing with silica they had only to put in a few shovelfuls of sand where the lining was defective, and after the application of heat for a few minutes, the new material was found to have perfectly combined with the old; whereas with a basic lining, the lining had to be taken out when defective and entirely renewed. These results discouraged him from continuing the application of these linings to the open-hearth furnace. He still continued, howerer, the use of bauxite brick lining in his rotative furnace, in the manner described in his paper before the Iron and Steel Institute in 1873. Reference to the same subject would also be found in his printed lecture, delivered to the Fellows of the Chemical Society in 1868.

With regard to the subject now brought before them, he found that there was something wanting in the papers communicated. Mr. Thomas, in his paper, stated that the amount of basic material added usually exceeded $2 \mathrm{c}$ wt. per ton of pig iron. He wished Mr. Thomas had given them, not what it exceeded, but the exact amount. They knew that basic material would absorb phosphorus, but the President in his able address had already called attention to the circle through which they seemed always to wander in developing the different processes for the manufacture of iron and steel. The puddling furnace had originally a silica lining, and only after a basic lining had been adopted were good results obtained. It was probable, therefore, that in making steel they were only now passing from the first stage to the second. The difficulty they had to contend with in this case was, however, a more serious one, inasmuch as the temperature was very much higher than in the puddling furnace, in which the oxide lining could be as easily maintained as the silica lining that was previously employed; but it was to be apprehended that the use of a basic lining in the Bessemer converter and in the open-hearth furnace would entail a good deal of difficulty and expense in the renewal of the lining-on which subject, however, he should be glad to elicit more definite information from the authors of the paper. 
The lining itself did nothing towards the remoral of phosphorus; but it was the added basic material that effected that result, and the question was how much of that basic material was requisite to remove a large amount of phosphorus from the iron. Mr. Bell had brought forward last year a system of eliminating phosphorus from iron. He (Dr. Siemens) at the time questioned whether the amount of rich oxide proposed to be employed by Mr. Bell, would not be too great to pay for the difference in cost of hematite and Cleveland pig metals. He rould only repeat the same question to Messrs. Thomas and Gilchrist. Was not the quantity of basic material necessary to absorb from the Cleveland pig the amount of phosphorus it contained, such a serious item as to make it an open question whether they had not better go on using West Country iron for steel ? They must also bear in mind the materials of which the basic linings were composed. Limestone itself was certainly cheap enough, but the question was, would limestone, unaided by more expensive reagents, carry amay the phosphorus which had to be eliminated ? The paper admitted that ferrous oxide was employed in the process, and he should wish to ask how much of that material was necessary to accomplish the effect contemplated, and how much of it was produced by oxidation in an overblown charge. In overblowing the charge they had to oxidise some of the pig metal, and that might be a conrenient way of providing the ferrous oxide, but he should like to know how much of the iron under treatment was destroyed. Hc had no reason whatever to doubt the chemical results brought before them by Messrs. Thomas and Gilchrist in their paper-results which were certainly most interesting, and which he would not have been prepared to expect. The question, therefore, seemed to him to narrow itself into one of cost, which could only be fully solved by experience. 


\section{In the discussion of the Paper}

\section{"ON THE DEPHOSPHORISATION OF IRON AND}

STEEL," by M. A. Pourcel, Terrenoire, France,

Dr. Siemens* said he wished he had had an opportunity of reading M. Pourcel's paper previous to the meeting, because there were so many points of interest attaching to it, and involving chemical complexities, that it was almost impossible to discuss such a paper without having previously perused it. He would, thercfore, confine himself to one or two matters only, in which M. Pourcel made reference to processes and experiments he (Dr. Siemens) had carried out. He was disposed to agree with Mr. Snelus in his criticisms of the three principal factors upon which M. Pourcel said the elimination of phosphorus depended, these factors being liquid basic cinder, high temperature, and, if he understood right, the absence of oxygen. He was disposed to think, however, that the presence of oxygen was an advantage in the elimination of phosphorus, for it stood to reason that as the phosphorus was removed by oxidation, oxygen could not interfere with the process. He further could not agree with the author when he said, that by the ore-reducing process only rail metal was producible, and that in order to obtain very mild metal the scrap process had to be resorted to. It was, indeed, quite the contrary; for in order to make a very mild metal, such as was now generally used in naval construction, the ore process was almost exclusively used, and scrap was only added for two objects,-the one being to get rid of the cuttings and other scrap produced in the mills, and the other to quicken the output. In working with ore and pig only, the time taken up was naturally greater than in adding at once a proportion of perhans 20 or 30 per cent. of scrap metal, which would bring down the carbon of the bath by one-third to begin with; and there was this further advantage in. it, that in dealing with a silicious pig a very considerable amount of slag was produced in using ore and pig only, which was diminished relatively

* Excerpt Journal of the Iron and Steel Institute, 1879, pp. 367-370. 
in udding refined metal. M. Poureel went on to say that an advantage miglit be obtained by tapping off the slag at a certain stage, and, after dephosphorization had taken place, adding the ferro-manganese ; and then he said, "All this is very complicated. Dr. Siemens himself will acknowledge that this is no longer his simple method. It is a mixture of the Krupp and the fornoconvertisseur processes" (p. 22). Now he (Dr. Siemens) should be sorry to interfere with the carrying out of Herr Krupp's process, but if it consisted in tapping off the slag, the misfortune was that he had done that alrealy ten years ago, and he must, therefore, pardon him for interfering with that part of the process. A very great advantage could be gained through tapping off the silicious slag at a certain stage, and then adding the final quantities of ferro-manganese and silicon iron, if the latter was used for bringing the bath into its final and proper condition. But it was difficult in actnal practice to insist upon such nice operations. The tapping off of the slag took time, and his experience was that, after having used it anywhere, and finding that it worked very nicely, the next time he came to the place he found it had been discontinued. Except for the additional trouble it involved, the tapping off of the silicious slag, in order to produce towards the end of the operation a basic slag by adding lime, was a very adrantageous mode of working, and one that he had for many ycars insisted on.

Mr. Richards had made some interesting remarks, giving the negative results of experiments he had made at Middlesborough, with a view of saring time in deoxidising the metal, by means of silicon and manganese combined, after the blow in the Bessemer converter. He (Dr. Siemens) could confirm Mr. Richards from his own experience, it being the established practice in some of the works where the open-hearth process was carried on, to add silicon iron and spiegeleisen abont twenty minutes before the final addition of ferro-manganese, this interval of time being necessary in order to effect the formation and separation of the particles of slag, formed when silicon, manganese, and the oxygen absorbed in the metal combined. This modus operandi, he believed, was first suggested by M. Gautier of the Terrenoire Works.

M. Pourcel alluded to the rotary process as carried on at Towcester, and said that there conld be little advantage in workVoL. I. 
ing that process, because the removal of phosphorus must depend on finding oxide of iron in the slag. It was quite true that it did do so, but at the same time Dr. Siemens thought that the rotary process was a most effectual and thorough one for the removal of phosphorus, or rather for the production of a metal free from phosphorus. He was much surprised at that portion of M. Pourcel's remarks, because on the preceding page he said, "In this operation only an imperfect reduction of the ore is obtained, and if the phosphate of iron can be partially reduced at a low temperature, nearly all the phosphoric acid remains in the slag, and as phosphorus was generally present in ores only in the state of phosphate of lime, it was not reduced by the ordinary reducing action of the furnace" (p. 15). He (Dr. Siemens) found, in fact, that in operating upon ore containing phosphorus, the phosphorus never went to the metal ; it remained in the oxidised condition, and he had been enabled to produce metal alınost entirely free from phosphorus from an ore containing a very considerable percentage of phosphoric acid in combination. It was necessary, in order to carry out the process properly, to tap off the first slag before the metal was brought into the form of balls. This first slag contained certainly not an excessive quantity of oxide of iron, and as much as 3 or 4 per cent. of phosphorus. If done systematically, there was no great difficulty in obtaining metal free from phosphorus without incurring great loss. The cinder must be a rich cinder in order to produce the welding quality of the ball. He could bear his testimony to the great value of M. Pourcel's paper, which opened out a very important subject for discussion.

The President asked Dr. Siemens whether he had anything to say about the last paper-that of $\mathrm{Mr}$. Bull.

Dr. Siemens said, that with regard to the last paper read, they had in it the revival of a very old friend. He had heard of the blowing in of steam into molten metal even before the days of the Bessemer process, when their friend Mr. James Nasmyth proposed and patented such a plan. Sir Henry Bessemer himself had also proposed to blow steam through the metal. There was, therefore, nothing new in the conception. At the same time, he did not doubt the chemical reaction, but, as had already been pointed out, he doubted very much its practicability, because when 
he had tried experiments of that sort he had always found a very rapid reduction of temperature. Steam acted like a wet blanket on the metal, making it pasty almost immediately, and he expected that this would be the difficulty which the author of the process would experience.

In the cliscussion of the Paper

"ON THE PROGRESS OF IRON AND STEEL AS CONSTRUCTIVE MLATERIALS,"

By J. A. Picton, F.S.A., Liverpool,

1)R. Siemexs * said he rose, as one representing the steelmakers more than the steel-users, to make a few remarks, and in answer to Mrr. West he should say, "Do not diminish your tests, but rather increase their severity." The President, in his remarks on the previous day, had said that iron, which was not perhaps first-rate, had answered well for ship-building, and why should they be so very particular with regard to steel? Now, iron and steel differed in more than one important particular. Iron always held together. It was apt to break when it got a blow, but it held to a considerable extent although it might be of poor quality; whereas steel of high quality would bend like leather, would extend, and was almost unbreakable. But the moment they left that high pedestal of perfection, they got a very treacherous material-a material of which they had heard it stated that it was rireted in the evening, and on the following morning it was found rent from end to end. They must not relax the tests with regard to steel. Then, with regard to the degree of carburisation-the mildness or the hardness of steel-Mr. Adamson had no doubt liad great experience of steel, and everything coming from him should be listened to with great attention. But in science, pure and applied, there was no infallibility, and he must differ from

* Excerpt Proceedings of the Iron and Steel Institute, 1879, pp. 408-411. 
that gentleman when he said they should have a harder steel for such purposes as ship-building, and that they should do away with the bending test.

Mr. Adamson: No, no.

Dr. Siemens, continuing, said he should strongly advocate the maintenance of that test. Mr. Adamson had alluded to the material for the Frith of Forth Bridge, and he (Dr. Siemens) agreed with him, that where the bars of such a structure as a bridge had to be subjected to a permanent strain, a comparatively hard steel was the most suitable to be employed. The question of the links for that bridge had indeed occupied his attention for some time, and when Sir Thomas Bouch, in the summer of 1878 , came to consult him as to their construction, he had an idea of riveting mild plates one-eighth of an inch thick together, but he (Dr. Siemens) strongly advised him to abandon that and to use solid links, making them of a material which would stand a breaking strain of 50 tons, and which they could load with perfect safety to the working strain of 10 tons. While it was perfectly safe to make such a structure as a chain bridge of this material, it would not be safe, and there would be no advantage, he maintained, in making a ship of it. It might be supposed that the harder material was stiffer, and that they might therefore make the plates lighter; but if they tested a bar of mild steel of a square inch sectional area, and by the side of it a bar of hard steel which would break with a strain of 50 tons to the square inch, they would find that both elongated exactly to the same extent per ton of weight put upon them, up to, say 15 tons; therefore, it would be wrong to say that the hard steel was, within that limit, more rigid than the mild steel, and this was a fact which he thought was not sufficiently known or borne in mind by engineers. If they continued their tests, increasing the weight beyond 15 tons per square inch, then only a difference became perceptible. The mild steel, when it was strained beyond that point, began to take a permanent set, whereas the hard steel, having a much greater elastic range, would return to its original length until the elastic limit of, say, 25 tons per square inch was reached.

In selecting a material for ship-building, they should put the problem to themselves in this way: Do we intend to strain this material in any direction beyond $\mathbf{1 5}$ tons per square inch? He 
said "No," as the limit for steel according to the Board of Trade rules was at present $6 \frac{1}{2}$ tons compared with 5 tons for iron; and it was not likely that this limit would be materially extended in favour of steel for riveted work, because a certain thickness of plate was necessary to prevent buckling and rapid deterioration through oxidation. There was, then, at 15 tons with mild steel all enormous margin of safety within the elastic limit, and a vessel constructed of mild steel would be just as rigid as one constructed of hard steel, using the same scantling in both cases. But occasions would arise upon which a ship was bumped, and then it would be strained far beyond 15 tons per square inch; and what would be the result? If they had a ship of mild steel, it would simply yield to that extreme strain; if they had a hard steel, it might break. It was, therefore, a question for the shipbuilder to consider. "Is my ship as a whole structure, taken as a girder, to be strained beyond 15 tons per square inch, and must I therefore make the plates strong enough to resist that strain, or shall I limit the extreme strain of the structure to within 15 tons per square inch, and have a material which, if subjected to an excessive strain or blow, will yield and not break?" He should say that it was far safer to have a material that would, under such circumstances, yield. He would, therefore, maintain comparatively low tests for absolute strength, which he would limit to perhaps 30 tons per square inch breaking strain, whilst insisting upon an elongation of at least 20 per cent. of an 8-inch bar. There were other advantages connected with mild steel which would be lost in using a hard material. A mild steel could not be injured by sudden cooling, and it need not be annealed, but a hard steel had to be annealed. If a comparatively hard steel plate was punched, its strength would be diminished to a considerable extent, whereas it was fully proved that a very mild steel might be punched without injuring its strength any more than by drilling; and at some of the Government yards, after careful consideration of the whole subject, they had given up the practice of drilling plates whenever it was found more convenient to resort to punching. These arguments were all in farour of a very mild steel. Then with regard to what fell from his friend Mr. Adamson as to the bending test not being a test of elongation but a kind of mixed test of elongation and solid flow, he thoroughly agreed 
with this observation, but he would still maintain the bending tests, after sudden cooling, as most important. If they had a material that would elongate to a certain extent, and that did not possess at the same time the quality of flowing under great compression, that material would break in the case of a sudden shock such as a ship might receive in knocking against a rock or against another ship : if it had the power of flowing, it was a much safer material. That quality of flowing came chiefly to the fore in making material for the tin-plate trade. Instead of using charcoal bar, tin-plate makers now used to a great extent a very mild steel for making tin plates, and their test was entirely a bending test. They took the tin plate, doubled it, doubled it again, and doubled it again ; put it on the anvil and hammered it quite flat with an iron hammer ; they then bent it back, and if it stood that three times, it was considered a pretty good material. Now that test would not be stood by metal which would bear almost any amount of elongation; the quality required of such a metal was a quality which he would call the power of solid flow, that was possessed only by very pure iron indeed. He would, therefore, as one representing more the manufacturer than the user of steel, say to them, do not drop your tests, but rather increase their sererity.

In the discussion of the Paper

"ON IRON AND STEEL AT LOW TEMPERATURES,"

By John James Webster, Assoc. M. Inst. C.E.,

Dr. C. W. Siemens * observed that the impression produced on his mind by the paper was that it dealt with a limited question purely for a practical purpose, and that within those limits the

* Excerpt Minutes of Proceedings of the Institution of Civil Engineers, Vol. LX. Session 1879-1880, pp. 204-207. 
results were much as might have been expected. The author had dealt with rarious metals at the limits of $5^{\circ}$ and $50^{\circ}$ Fahr. The limit was a narrow one, and it could not be expected that the results of the experiments could be such as would lead to a general conclusion regarding the effect of temperature within wider limits on materials of that description. There could be no donbt that tolerably pure material must be stronger at the lower temperature than at the ligher, because the last particles of the material were closer in contact at the lower than at the higher temperature. For a similar reason the material would resist a blow rather less at the lower temperature than at the higher. But he agreed with the observations of previous speakers that no influence was produced by those degrees of temperature on the absolute structure of the metal. It was quite out of the question to expect to change the metal from a crystalline to a fibrous condition, and back again from a fibrous to a crystalline condition, by lowering or raising the temperature a few degrees. The paper, though valuable of its kind, was suggestive chiefly of what had been omitted to be taken into consideration; for instance, the author had not in the first instance given a chemical analysis of any of the materials he had employed, thongh that omission had, he beliered, since been remedied; but at any rate he had drawn no conclusion from such analysis. Nor had be considered the elastic limit of the materials, although to an engineer the elastic limit and the condition of the material up to the elastic limit were more important than the breaking strain. Engineers did not want to break down with their materials ; but they wanted to see to what extent it was safe to use them. It would have been most interesting if the author had given the elongation due to the rate of elastic extension at different temperatures. It was $\mathrm{Mr}$. Barlow, the President, who first established by experiments that steel of rarious tempers was equally strong up to a certain linit. In other words, that if a bar of rery mild steel having a sectional area of 1 square inch pure iron, as $\mathrm{Mr}$. Adamson had correctly described it, was weighted with a ton weight, the same absolute extension would ensue as in weighting a bar of very hard steel of 1 -inch sectional area and of the same length, and so on, each ton additional weight producing the same amount of extension in both bars until the elastic limit of the mild metal was reached. These results, which he must 
confess at first appeared hardly credible to him, had since been fully confirmed by experiments of his own. It was a remarkable fact for engineers to consider that in constructing a bridge it came to the same thing whether they took mild steel that would break with 28 or 30 tons strain to the square inch and would come to its elastic limit at about 15 tons, or whether they took a material that would find its elastic limit only at 25 or 30 tons, and would break at 50 or 60 tons; therefore the advantage that would be derived from the hard and strong material would only be met with after exceeding the elastic limit of the milder steel. He was not aware of any experiments giving the influence of heat upon the coefficient of elastic extension of those materials. If it should so happen that a bar of iron or steel at the temperature of $5^{\circ}$ would follow a less rate of elastic extension than a warmer bar, a steel bridge that was ordinarily loaded to a strain of 8 tons per square inch, when it cooled down, would contract rather more than in the ratio of simple thermal contraction ; and afterwards, if the bridge changed from the one temperature to the other, it would alter its length in all its members due to the two ratios of absolute contraction and a contraction due to a different rate of extensibility. It wonld be interesting to know how the modulus of elasticity was influenced by temperature. It was often thought that metals were fatigued by strain ; and in the case of inferior classes of iron, it might be true that, if a bar were strained a little beyond its elastic limit, its fibres would be ruptured to some extent, and the material would receive an injury ; but in the case of high-class material, such as mild steel, there was an absolute advantage in straining it beyond the limit of elasticity. It was possible, by careful manipulation, to raise the breaking strain of a bar of a given sectional area to a remarkable extent by gradually accustoming it to the strain. By taking a bar of mild steel of 1 square inch sectional area and loading with a weight of, say, 15 tons, and leaving the weight on twenty-four hours, it would be found that both the elastic limit and the breaking strength of the bar were materially increased. That was a quality of high-class material which was, perhaps, not yet thoroughly understood, and which certainly gave a great factor of safety in favour of its employment. The chemical analysis, which had not been dealt with in the paper, was of great importance in reference to the object the author had in view. The 
unthor had spoken of certain brunds of material - of certain makes, for instance by a firm like Krupp's. Now, he happened to know that Krupp made steel by at least three different processes, and it was diffieult to say by what process the particular bar was produeed that liad been referred to in the paper, nor, if the proeess were known, could it be affirmed what were the materials used in its manufacture. If it was a cheap material, probably Mr. Krupp woild have put in some cheap iron, and the result might be a bar that would give a very fair absolute strength, but would give way to a bending and breaking test before its time; whereas if he knew that the inetal would be tested very sererely, he would produce something that would be capable of resisting very high impaets. Some years ago Dr. Sicmens made a series of experiments on the power of materials of particular composition to resist blows at different temperatures. His object was to see what effect phosfhorus had on mild steel with regard to that quality. From those experiments he had arrived at the conclusion that the power to resist blows in mild steel, at any rate, was dependent almost entirely on the presence or absence of phosphorus. It was well known that phosphorus might be counteracted in the steel, to a great exteut, by the addition of manganese; but let the steel be cooled down to freezing point, or below, and the metal would break short: whereas true mild steel, containing only traces of phosphorus and of manganese, would be affeeted to a very slight extent by any depression of temperature to which it might be subjected. He believed that pure metal was influeneed very little by changes of temperature, whereas metal eontaining foreign matters, and particularly phosphorus, wonld be influenced to a great extent. It would, therefore, be erroneous to draw general eonelusions from such experiments as were given in the paper. The author seemed to have attempted to find out results without the chemist; but the chemist now-a-days would put his finger into everything. If they called a thing iron, he would call it a mixture of iron, phosphorus, sulphur, silicon, carbon, and other earthy materials, and it was useless to try to do without him. They must work hand in hand with him in order to arrive at such results as would guide them safely in their practice. 
In the discussion of the Papers

"ON STEEL IN THE SHIPBUILDING YARD," by Mr. W. Denny, and

"ON STEEL FOR SHIPBUILDING," by Mr. West,

Dr. C. W. Siemens * said : My Lord and Gentlemen, we have listened to two, in my opinion, very raluable papers, one written by an eminently practical shipbuilder, and the other by a gentleman who has had great experience in the testing of a material now largely used in construction. I agree with many of the opinions advanced in both these papers. Both seem to advocate advance in the same direction; but there are certain points on which I inust, with all respect to the authors, differ from them in opinion. The all-important question which has been put forward in these papers, is the question of the absolute maximum strength to be required or accepted in mild steel. If you take a bar of comparatively hard steel-steel that will stand 50 tons to the inch-it will at the time of its breakage have elongated perhaps only 6 or 7 per cent. But take a material of 30 tons to the inch and it will have elongated 20 per cent. Now, to begin with, it is not strictly correct to say that this latter material broke under a tensile strain of 30 tons to the inch, because whatever might have been the sectional area of the original bar at the time it broke, it had bodily elongated 20 per cent. ; therefore, the strain was no longer 30 tons to the inch, but 36 tons to the inch, and I claim for the mild material at any rate this advance of strength. What, however, is the condition of things before we have reached this ultimate limit? Take one bar with a breaking strain according to the usual test of 30 tons to the inch, and another of 50 ; weight both these bars with 5 tons to the inch and you will find that these bars have elongated to exactly the same extent. Weight both these bars to the limit of 10 tons to the inch, and again it will be found that the elongation is the same. Therefore, up to that

* Excerpt Transactions of the Institute of Naval Architects, Vol. XXI. 1880, pp. 216, 217. 
point at any rate, I claim as great $\boldsymbol{a}$ strength for the mild steel as the hard. Increase that strain even to 15 tons to the inch, and elongation will still be the same. Take the load of both bars and they will botl eome back to the original lengths. Go to 20 tons and you will find a difference. The hard steel-the steel that will break at 50 tons to the inch-will again return to its original length when the load is taken off, whereas the material breaking witl 30 tons to the inch of the original seetion will show a permanent elongation. This, you will say, is a sign of weakness and condemns that bar; but I would venture to maintain that this is a sign of the strength of the latter bar. Up to the point of 15 tons to the ineh the two materials are precisely alike, and if the naval constructor takes eare that no portion of his ship, viewed as a girder, should receive a greater strain than 15 tons, both materials are able to bear the strain, and they will both deflect to precisely the same extent. But it may be said, materials may be aceidentally subjected to a higher strain, and in that case greater strength will be needed. Taking the strain of bumping a ship against a rock, or the ground, or against allother ship, the hard steel will no doubt stand a heavier blow, but there is just the possibility that when the blow eomes it will fracture, whereas the soft steel we know will lead almost to any extent to sudden impact. Therefore, as far as the safety of the structure against an aetion of that deseription is eoncerned, the soft metal is decidedly the stronger. Then again it has been put very foreibly by $\mathrm{Mr}$. Denny, that very mild steel requires no annealing; that it is very nearly as strong and as duetile annealed as unannealed; whereas if you have a harder material, a material containing more earbon, aunealing becomes necessary after bending; after punehing eertainly, and even after drilling. It beeomes a neeessity. But by annealing, you take away some 20 per eent. of the strength, and therefore $I$ say it is much better to make at once a material that requires no annealing, that does not assume a strained condition when put into a definite shape, and which maintains its strength. The mild material without annealing, is as strong, or at any rate is as ductile practically, as after annealing ; and, I believe, at some yards punehing without annealing has been resorted to without any practieal drawback. These are powerful arguments, I think, in favour of the very soft material. There is one more argument 
which I wish to adduce, that is, if the material of the low elastic limit happens to be chilled accidentally after manufacture, this chilling does not interfere with its strength to resist blows or sudden strains ; whereas with a hard material you will even come to the point of contemplating with great concern the safety of the structure when inade, I beliere it is much safer to adherc to a material which stands an extreme bending test, and to assign to it the same practical limit of load which you would to a harder material. In dealing with wrought iron the practical limit generally allowed is one quarter breaking strain, whercas in dealing with cast iron we allow onc-sixth breaking strain as the safe working limit. What I maintain is, that in dealing with mild steel the safe working limit may safely, for similar reasons, be extended to one-third the breaking strain ; and if this were agreed to, a ship constructed of mild steel need not be madc any thicker in its scantlings than one having a breaking strength of 35 tons, such as I am sorry to find is now being advocated by ship-builders. Regarding the remark made by my friend Mr. Bramwell, I am ready to agree with him in principle to this extent: that if a steel could be produced of increased ultimate sirength without in any way trespassing upon the quality of extra mild stecl, of maintaining its ductility after tempering, and after punching or bending, that material would deserve the preference; but so long as the strength has to be preserved at the expense of ductility, I must maintain my objection to an advance, or rather a retrogression, in that direction in ship-building. I may add one word of entire approval of the opinion put forward by Mr. Denny, that all plates ought to be tested at the works of the maker, in the most careful and rigorous manner possible, and not at their destination, and also that for riveting steel plates, steel rivets should be used. 


\section{In the discussion of the Paper}

\section{"ON THF STEEL-COMPRESSING ARRANGEMENTS AT THE BARROW WORKS," by Mr. AlFred Davis,}

Dr. C. W. Sibmexs * said the adrantages to be derived by compressing steel in a fluid condition had been proved by Sir Joseph Whitworth, who for a number of years had produced steel of a very higl quality, made in the open-hearth furnace, and subjected, while in a state of fluidity, to very high pressure by hydraulic pumps. Other steel makers had tried to arrive at the same result by similar means. This was perhaps the first paper that had been brought before them giving a distinct account of an attempt to obtain the same advantage by pressure exerted upon fluid steel, without resorting to the rery thorough but expensive plan adopted by Sir Joseph Whitworth. At various times he had himself tried to bring pressure, resulting from the spontaneous generation of gases within the closed ingot mould, to bear upon steel; but he had not obtained altogether satisfactory results. Accordingly, when last year the subject of steam compression was brought before the Iron and Steel Institute, he immediately offered to make an experiment; but he had found that for mild steel, such as he operated upon, a very high pressure was certainly necessary. Sir Joseph Whitworth had found that 2 tous per square inch was the pressure necessary to produce solid metal. They now heard of $100 \mathrm{lbs}$. or $150 \mathrm{lbs}$. per square inch being sufficient to produce success ; and from the photographs exhibited by Mr. Richards it was evident that a certain degree of success was obtained, although the holes in the metal were not entirely got rid of. In the case of rery mild steel they were also troubled with holes near the surface, which they called honey-combs; and it was to get rid of these that the heary pressure seemed to be necessary. The large cavities formed in the centre of the ingot would no doubt be, if not removed, very much reduced in size by sucl moderate pressure as had been mentioned; but he was quite

* Excerpt Minutes of Proceedings of the Institution of Mechanical Engineers, 1850, pp. $403-407$. 
certain that, in the case of mild steel, to get rid of the honeycombs they would have to resort to a pressure of 1 ton, if not of 2 tons, per square inch.

With regard to the interesting question raised by Mr. Richards, as to how the pressure acted upon the gases which had been occluded, he confessed that he was in the same difficulty as the President. He could not conceive how, by applying pressure to a fluid mass, they could induce one ingredient out of several to go from the centre to the outside, or from the outside to the centre. The pressure was the same throughout over the whole surface; and all he could conceive was that by that pressure the volume of say one cubic inch of gas would be reduced, if the pressure were high enough, to say one-tenth of a cubic inch; or it might be that the gases would be reabsorbed in consequence of the pressure, and thus return to their former combination with the steel. Mr. Richards had drawn a comparison between steel and soda-water. Now when the cork of the soda-water bottle was lifted, the whole contents became a froth, and might be called spongy soda-water. If the cork were pressed down again, the frothing would immediately cease, the gases being again absorbed in the liquid. Therefore it was quite conceivable that by the application of a sufficient pressure to fluid steel, although the gases were not expelled, they might remain occluded in the steel. He imagined that this wonld be the real solution of the problem. But there could be no doubt that, if the cavities could be prevented in the ingots, a great gain would be secured; and he should be glad to see that, by the application of so moderate a pressure as was mentioned in the paper, this result could be obtained.

While discussing the question of steel, he should be glad, with the permission of the President, to make a few observations upon the more general question of mild steel. Within the last week or two a great deal had been said about this steel not being reliable, and they had heard of boilers giving way mysteriously under a very moderate pressure. It so happened that he had been made cognisant of some of the circumstances regarding the failures which had been prominently alluded to ; and he might say that, although the first boiler had failed under pressure, the second was found to be rent in precisely the same manner without any pressure having been applied : clearly showing that it was not a 
case of weakness of the metal, under so very moderate a pressure as 140 lbs. per square inch; but that from one cause or another the metal had been cracked and broken previous to testing. $\mathrm{He}$ could not speak as to the cause of the metal being in that condition; and he would only say at present that mild steel, properly made and properly put together, would not burst under any pressure whaterer. If a boiler made of mild steel were subjected to an increasing pressure, it would be found impossible to burst it. And it was natural that this should be so. A material that would stretch :30 per cent. before rupture, would naturally give way first at the weakest sections, namely those through the rivet-holes; the round rivet-holes would become oblong, until sufficient water or steam leaked out to balance the amount of water pumped in or steam generated. That was not a mere hypothesis of his. He had witnessed some experiments made by Mr. Dean, the locomotire superintendent of the Great Western Railway, in the presence of Mr. Parker, the chief surveyor of Lloyd's, and described in a paper by Mr. Parker before the Institution of Naval Architects * in 1878. The leakage began at $560 \mathrm{lbs}$., and the highest pressure reached was 800 lbs. Messrs. Easton and Anderson had also tried a boiler made of mild steel; and, in order to increase the severity of the test, between each trial they put the boiler into a furnace, made it red hot, and then took it out again, caulked it where it appeared necessary to close the seams, and then again subjected it to a pressure of several hundred pounds per square inch. $\mathrm{He}$ believed that Mr. Greig had also made similar experiments. It might therefore almost be taken as an axiom that a steel boiler could not be burst ; it might be made leaky, but that was all.

Wlth regard, then, to the great question as to whether mild steel was a reliable material or not, he would answer most unhesitatingly that it was the most reliable material they knew of ; they might punch, shear, bend it, or do what they liked with it, but they would not in any way destroy its tenacity. By way of practical proof he might mention one other fact. The steamers "Iris" and "Mercury" had been constructed of mild steel about three years ago for the Admiralty : not only the shell-plates of the ressels, but the angles and the whole of the boilers were all con-

* See Transactions of the Institution of Naval Architects, 1878, p. 178. 
structed of that material ; and amongst all the plates and angles not one had been returned as defective in quality. Since then the Admiralty lad used steel for the construction of their boilers and ship plates, almost to the exclusion of iron; and although probably more than 10,000 tons had been used, he believed he was correct in saying that no plate had been returned as being cracked or unsatisfactory, except a very few from mere mechanical blemishes. There had been no case of mild steel, properly made and worked, giving way in a mysterious and treacherous manner.

The demon of cheapness, however, seemed to be abroad, and it had settled especially upon steel. The works with which he was more particularly connected had introduced tiro qualities of mild steel : one which was to compete for price in the open market; and another, called "special metal," which was vouched for as being in every way reliable. This metal was not only made of more expensive material, but it received greater attention, and was worked to a greater extent : crop ends were cut off more resolutely than one could afford to do under all circumstances; and consequently it was rather more expensive to produce than ordinary steel. But he was sorry to say there were many engineers who, for the sake of $£ 2$ or $£ 3$ per ton, preferred the unguaranteed material for the construction of their boilers; others, however, took only the special or guaranteed material. It appeared strange to him that there should be such a tendency to get cheap steel for the construction of boilers, \&c. ; because, when a good iron boiler was wanted, Yorkshire iron was used, costing from $£ 22$ to $£ 40$ a ton; whereas reliable steel plates could be obtained for $£ 14$ to $£ 16$ a ton. The special steel plates thus cost a great deal less than what engineers were willing to pay for the best Yorkshire plates; but engineers would have the cheapest steel, at perhaps $£ 11$ to $£ 18$ a ton, and took their chance. He thought it was a very dangerous policy, and one that naturally led to the dissatisfaction of which they had heard.

He might mention another form which steel now took, and which had received his special attention : he referred to the production of rivet-bars. For a long time engineers had continued to use iron rivets for riveting steel plates together. He had always considered this was like stitching a silk gown with a cotton thread, making the stitching material a weaker thing than 
the material to be stitched. Latterly a certain confidence had been created in favour of stcel for rivet-making; and great care was taken in producing rivet-steel of such a quality as would make it perfectly reliable. But what was the fact? Since rivet-steel had been brought into the market, it was not sold for so high a price as was given for the best rivet-iron. The latter cost as inuch as $£ 19$ a ton, but for rivet-steel engineers went down at once to the very cheapest quality they could get, which he might mention was steel rolled from crop-ends, and with all the defects of crop-ends about it. It was therefore unfair to criticise steel severely, unless all the circumstances regarding it were known, and abore all things unless it was known what price had been paid for it.

\section{In the discussion of the Paper}

\section{"ON HARDENING IRON ANI STEEL; ITS CAUSES}

ANI) EFFECTS," by Professor Akermax,

Dr. Sresrexs * congratulated Professor Akerman on having dealt with a subject which had puzzled all those who were practically engaged in the treatment of steel, and which had never yet been sufficiently or scientifically explained. It would be impossible at a meeting like that to discuss all the matters brought forward in the paper. 'There was, however, one leading idea running through the whole, which was to the effect that carbon existed in iron and steel, not in two conditions, as was now generally supposed, but in three conditions, and that it was to this intermediate condition that the phenomena of hardening and tempering were mostly attributable. Professor Akcrman held that this intermediate carbon travelled towards the graphitic condition when steel was gradually cooled, and that this furnished the key to the somewhat striking changes that arose if they took an ingot of steel, hardened it, and then subjected it to the processes of

* Excerpt Journal of the Iron and Steel Institute. 1880, p. 437. VOL. I. 
hammering and rolling. Dr. Siemens confessed that he had been sceptical regarding this effect until he had had light thrown upon it by Professor Akerman. If pressure was the cause why steel became stronger in manipulation than in chilling the outside of a heated ingot, greater pressure was thrown upon the interior metal, and it was easily conceived that the effect produced would be similar to that brought about by hammering and rolling. The experiments referred to in the paper seemed to prove this very clearly.

There was one point to which Professor Akerman also called attention, and which Dr. Siemens conld not allow to pass without observation. They had heard much of the extension of mild steel, and they knew that the results were of the most variable character. Some eminent steel makers and users tested bars two inches long, and obtained a marvellous elongation before rupture took place. Others, again, including the British Admiralty, used bars eight inches long, and the elongation, after fracture, was measured from the distance of the two points that were originally eight inchcs apart, after placing the fractured pieces end to end. Other experiments, especially those of Mr. Barlow and the Committee appointed by the Institution of Civil Engineers, dealt with very long bars, and the rates of elongation were consequently much less. Professor Akerman suggested they should exclude the drawn portion of the bar from the total elongation, and thus obtain the real elongation, and his suggestion deserved the greatest possible attention. But why carry the test to rupture at all ? They knew that up to a certain point the elongation continued very uniform throughout the bar, and it would be quite sufficient to carry the test to the point where partial tearing had set in. They shonld thus obtain a measure of the force which a bar was capable of resisting, because from the moment the slightest irregularity in the line of contour occurred, the result was no longer a proper test of the strength of the material, and there was a fault or error created by the continuance of the general elongation after that partial action had set in. But in whatever way the experiment was conducted, it would be far more correct to reckon the elongation of a bar of steel by excluding that portion of it which had been drawn, and therefore presented no portion of legitimate elongation of the bar. 
There were many points referred to by the Professor which lie need not observe upon. There was, howerer, the vexed question of nomenclatnre, which they would yet have to deal with. In Germany, Sweden, and Austria, the nomenclature recommended hy the committee nt Philadelphia had been adopted and carried ont. In England they had seen considerable difficulties in tlie way of adopting that nomenclature, and these had arisen from the want of indicatious as to the limit at which a material ceased to be ingot iron and commenced to be steel. It was clearly sherw in the paper that all material containing only traces of carbon was snbject to hardening; and Professor Akerman now suggested that they should select an arbitrary limit for steel, namely, the limit at which feldspar would no longer touch the hardened part of the iron. This might be a limit which would keep on one side of the boundary line the material known as mild steed, and on the other what was now generally called rail or engineering steel. Still he must say he saw difficnlties. In England some engineers used rails of a harder character, and others insisted upon metal which was softer. Then, again, there was a process by which phosphorus took the place of carbon in steel of that description, and they would, by employing phosphorus steel, obtain hardness without temper. These limits would be very difficult to draw, but they should very carefully reconsider the question, because it appeared to him that as some countries had adopted the new nomenclature, and England was adhering to the old one of calling by the name of steel all malleable metal that had passed through the fused condition, they would be in an isolated position. It would be better certainly if a uniform system could be adopted, and a meeting like the present wonld be a suitable place and occasion for doing so. Before sitting down he wished to give expression to the pleasure that all probably felt in Professor Akerman's most valuable paper, which, in his opinion, would be hereafter cited as a standard exposition of the subject. 


\title{
In the discussion of the Paper
}

\section{ON “DEPHOSPHORISING IN THE CONVERTER,"}

\author{
By J. Massanez (Hoerde), Westphalia,
}

Dr. Siemens * said, that, after the speeches they had heard regarding the economical conditions necessary for the basic process, little remained to be said. Dr. Wedding had pointed out the importance of removing the slag before the final operation took place, and he thoroughly agreed with him that that would be a most important step to take. But when experimenting in the open-hearth furnace with similar objects in view, he had found it very difficult in practice to remove this slag thoroughly from a large surface of fluid steel. The slag came away only partially; it hung about the furnace; and although in the Bessemer converter they had to deal with a smaller area than in the open-hearth furnace, yet there was delay and practical inconrenience in removing the slag, which was not of a nature, however, to stand in the way of accomplishing the end. The two causes of difficulty in the way of carrying out the process appeared to be, first, the sulphur, and secondly, the silicon. Now as regarded the elimination of the sulphur, as Professor Tünner had remarked they must depend chiefly upon the blast furnace, and in order to accomplish such a result, in dealing with poor ironstone, a difficulty arose on account of the great amount of basic material that had to be added to the ore. If the ores employed contained a considerable percentage of manganese, the difficulty regarding the sulphur would be very much diminished; but there remained that of reducing the silicon to a very low percentage, which he thought could hardly be effected with ores such as those of Cleveland, which contained a large amount of silicon in their composition. The use of hot blast would probably also have to be very much restricted, involving an increase of fuel consumption and a decrease in the output of the furnace. But he should like to ask the gentlemen connected with the Rhenish Steel Works

* Excerpt Journal of the Iron and Steel Institute, 1880, pp. 556, 55\%. 
whether he had been rightly informed the previous day that the iron treated by the basic process contained no more than one-tenth per cent. of silicon? If this were so, it slowed that they had managed to obtain a brand of iron that did not exist on the other side of the Channel, and it was rery interesting that they should know exactly the cause. Could iron be produced there containing

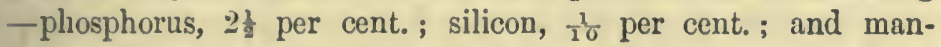
ganese, $2 \cdot 2$ per cent. ? Such iron appeared to him to be most exquisitely suited for carrying out this basic process, and it was of the greatest interest to know whether they found it necessary at the Rhenish Steel Works to obtain such a chemical composition in order to be successful in the process.

Herr Massenez, in replying to Dr. Siemens, stated that it was not at all difficult to make the iron described, in Germany. They had at Ilsede rery large quantities containing no more silicon than one-tenth per cent., and with white iron of that kind they might well work the basic process. . . . . They made iron containing just the quantity of silicon, manganese, and sulphur mentioned by Dr. Siemens; all that was necessary was to add a sufficient quantity of limestone to the ore. . . . .

\section{In the discussion of the Paper}

" ON MACHINERY FOR STEEL-MAKING BY THE BESSEMER AND THE SIEMENS PROCESSES,"

By Benjamin Walker, M. Inst. C.E.,

Dr. C. Wili.iam Siemexs * said the author had wisely confined himself to the manipulation of steel after it had been produced. If he had attempted to deal with processes, his paper would hare assumed dimensions far beyond the scope of what could be dealt with at one time, and there would also have been chemical con-

- Excerpt Minutes of Proceedings of the Institution of Civil Engineers, Vol. LXIII. Session 1880-1881, pp. 22-24. 
siderations involved which would have led beyond the usual range of the discussions. He had, however, mentioned two processes now largely used: the Bessemer process, which, by the great ruvolutions it had effected not only in the manufacture of iron and steel, but in the engineering of the world, was too well known to require any further comment; and the process with which Dr. Siemens's name was connected, which, although much less used, had been in existence nearly as long as the Bessemer process ; and which, although it had been for many years confined to comparatively few works, had lately, owing to some particular advantages it possessed under certain circumstances, attained a considerable extension. Setting aside the question of process, the paper dealt very ably with the modes by which the ingot metal should be treated in order to collvert it into such forms as were required. The author advocated economy in the construction of the steam-engine, a subject which Dr. Siemens was glad to see had been taken up at last seriously by the makers of that class of machinery. At the time when the puddling furnace and the reheating furnace sent up flames of living fire into the air, the question of economy in the engine was really a superfluous one; there was so much steam produced in using ouly a portion of the heat that would otherwise have been entirely thrown away, that the difficulty rather was how to keep it under, than to economise it. The converter, however, and the regenerative gas furnace had materially changed that condition of things. The heat was now in a great measure utilized to do its work; it was employed for producing the effect required, and there was little heat to be thrown away. If, therefore, steam was required to work the metal after it was produced, that steam had to be raised by means of special fires, and it became as important to work mill-machinery upon economical principles as it was a steam-engine on board ship. No wonder, then, that economical engines had attracted the attention of those practically engaged in working steel; and he quite agreed with the author in selecting a compound engine as the type which was perhaps the most suitable for the purpose. It distributed the load very uniformly upon the crank centre, and it carried out the system of expansion without involving a maximum strain too much above the mean strain on the working piston. The author proceeded to 
recommend a form of engine working directly on the roll, and in that respect he was obliged to differ from him. It was stated that in working the steam cylinder with the connecting-rod directly upon the axis of the roll, gearing was saved. That was true, but the gearing was saved at the expense of an enormous strain on the crank piu, an elaborate foundation, and a relatively slow working of the piston. Admitting the advantage of simplicity in convecting an engine directly to the working crank, there were the drawbacks to which he had referred, which were in fact drawbacks in regard to economical results, and also in regard to the first cost of the engine. If the gearing was properly constructed, and if the wheels and pinion were made of steel, there was, in his opinion, nothing very objectionable in it. A quick-working engine was more economical and more easily repaired than a slow-working, long-stroke engine, and the pinion and wheel were conrenient pieces of mechanism to convert the speed into the degree of reduction necessary to work a pair of rolls : he therefore thought it would be better, on the whole, to continue the system of having a quick-working reversing engine, and to reduce the circular velocity by gearing. The author had also dealt with the question of hydraulic arrangements for working the pit both with the Bessemer converter and with the openhearth furnace, and in other parts of the machinery; and the question arose, what pressure would be must suitable for such a purpose? Sir William Armstrong was quoted as an authority for fixing $700 \mathrm{lbs}$. to the square inch as the proper pressure to be used; and for such purposes as had been named he beliered it was a very convenient working pressure. It would, however, be wrong to assume that Sir William Armstrong adrocated that limited pressure under all circumstances. Dr. Siemens went to him last year and asked whether he could make a cylinder hydraulic ram of 3 feet diameter to work to 8,000 lbs. pressure per square inch. He was rather struck by the proposition, but he did not say "No." Although his first idea was to use a coil for the cylinder to give strength to it, a forged steel cylinder of 7-inch wall thickness was eventually decided on. The accumulator and other hydraulic arrangements were carried out by Sir William Armstrong, but the hydraulic cylinder was furnished by Sir Joseph Whitworth of compressed steel. He mentioned this case to show 
that there was almost no limit to the hydraulic pressure that could be called into requisition. The special object he had in view was to place telegraph cables under the equivalent of Atlantic pressure. Into the plungers cores of insulated wire were placed, and a pressure equal to the deep-sea Atlantic pressure was applied. It was of great value for such a purpose, inasmuch as it ensured the soundness of the insulating covering when it came to be subjected to the enormous pressure which it had afterwards to bear. But he thought that hydraulic arrangements of equal force would be applicable with great advantage for metallurgical purposes in pressing rather than beating steel into its definite form.

In the discussion of the Paper

" ON THE COMPARATIVE ENDURANCE OF IRON AND MILD STEEL WHEN EXPOSED TO CORROSIVE INFLUENCES," by David Philitiss, M. Inst. C.E.,

Dr. C. W. Stwarass * said, it perhaps would have been better if the discussion had been commenced by persons more interested in the use of iron and steel, than by those who, like himself, were intimately connected with their production; but in another respect it might possibly save the time of the Institution, if he took that early opportunity of referring to some conclusions in the paper with which he could not agree. The author had given the results of elaborate experiments on a subject which was of the utmost importance to engineers; and if his conclusions were to be relied upon, engineers were daily committing a grave error in using a material which gave so slight a guarantee of endurance. But while he accepted every one of the experimental facts adduced by the author, he thought he was in a position to prove, from the author's figures alone, that his conclusions were entirely erroneous. He had referred, in the first place, to a long series

* Excerpt Minutes of Proceedings of the Institution of Civil Engineers, Vol LXV. Session 1880-1881, pp. 98-101. 
of experiments made by the Admiralty, under the direction of Admiral Aynsley, and as far as the collection of facts was concerned, nothing could be more conscientious or thorough than that series of experiments; but as regards proof, they went no further than to show what every experimenter ought to avoid, and how lie ought not to conduct his experiments in the future. The author had placed before the Institution the apparatus then used. It consisted of thirty-eight tubes of iron and steel rireted in metallic contact with the shell of a boiler, and exposed partly to air and partly to hot water and solutions. Although the author had a very poor opinion of electricity and its effects, Dr. Siemens had a strong belief in electricity wherever it had a chance of acting for good or for evil, and he was convinced that the results obtained in those experiments were rendered entirely unreliable through galvanic agency. The results were most variable. Whereas one iron (common iron seemed to be the best) gave a corrosion of only 7 grains, on an average, per square foot, Bessemer steel gave 21 grains, or three times the amount during the time of exposure. The author was really most merciful when he stated that the result was only 69.3 per cent. in favour of iron, because it was really 300 per cent. in that instance. Notwithstanding these experiments, the Admiralty had adopted a mode of action which seemed strangely at variance with the conclusions to which the experiments would point. They now used steel almost to the exclusion of iron, and he hoped that some one connected with the Admiralty would state the result of more recent experiments undertaken with a better knowledge of the conditions under which they should be made. He believed the conclusions since arrived at were very different from those deduced by Admiral Aynsley some years ago. At Table VII. the author had compared Landore metal and iron, the one giving an average loss per square foot of 506.24 grains, and the other of 483.17 grains, showing a difference of only 4.8 per cent. against the steel, and that was, at any rate, a great deal better than 69 per cent. On the same page, the author stated, "The only peculiarity worth noticing in this experiment is that, while the two plates in the feed-water heater lost 381.8 and 394.2 grains, the two in the boiler fed from the heater lost only 8.0 and $3 \cdot 4$ grains respectirely." Therefore in the boiler the iron lost by corrosion about one forty- 
eighth, and the steel about one hundred and twentieth of what they respectively lost in the feed-water heater, the loss of ron in this case being about two and half times that of the steel. In Table IX., set 98, the $Y$ steel produced by the Siemens process gave a corrosion of 1,220 grains, and the DD. Yorkshire iron 1,221 grains, in each case per square foot of surface; the corrosion in those instances being practically the same. In the next set, 99, the $\mathrm{Y}$ steel gave a corrosion of 259 grains ; Staffordshire iron 269 grains, and DD. Yorkshire iron 260 grains ; showing that the steel came out best in that series. In set 102, the $\mathrm{Y}$ steel gave 109.5 grains (in rain water), and the DD. Yorkshire iron 144 grains. And yet the author followed up these facts with the conclusion that steel corroded on an average 64.8 per cent. more rapidly than iron. He entirely objected to the mode of reasoning adopted ; he contended that averages were only applicable to errors of observation. If an observer was not certain of his weighings, and he made a hundred weighings of the same piece of iron, he would be perfectly justified in taking the average. But nothing could be more unscientific or erroneous than averaging several materials, one group of which he chose to call iron, and another which he called steel. It was as if a moral philosopher wanted to find out whether fair complexioned people were more virtuous than dark complexioned people, and were to take six fair people and six dark people promiscuously; then finding that they were all very well behaved, except one of the fair people, who happened to have just escaped from gaol, and had committed six murders, he were to draw his average and say, "I find that fair people have committed, on an average, one murder each, and should therefore not be trusted." That was the kind of argument which the author appeared to have adopted. There were substances, compounds of iron, manganese, and silicon, sold for steel, which no doubt corroded very rapidly; but it was fur the consumer not only to select the proper material, but also to see that it was properly used. He believed it was in regard to the proper selection and use of the materials that the enormous discrepancies with which they had to deal would be found. The author stated that there was more cinder in iron than in steel, and therefore that there was prima facie ground for supposing that iron would corrode more than steel. There was, however, an 
('ssential difference between cinder in iron and the scale of stecl. 'The cinder in iron was a glassy substance, which was a dielectric, und therefore had no effect upon the corrosion of the metal, whereas the scale on stecl, which was produced in rolling, had a very deteriorating influence; it was a magnetic oxide, which was negative to the steel, and wherever the metal was exposed in the presence of such magnetic oxide, corrosion took place rapidly. Again, if the scale should be rolled into steel plates, as was sometimes the case, rapid corrosion ensued, for the same reason. But he need hardly say that with proper care those causes of undue corrosion could be and were prevented, and the extensive use to which steel was now put proved sufficiently that there was, at any rate in ordinary practice, 110 such destructive effect going oil. The author stated that those interested in steel had been singularly negligent in not following up the question of corrosion. Being himself much interested in steel, Dr. Siemens had for some years caused a running set of experiments to be carried out by Mr. Willis, the chemist at Landore, which told a very different story from the author's. In one series, extending over six months, made partly in a boiler supplied with salt water, and partly by exposure in a tidal river-the plates being exposed to the air for six hours, and then immersed for six hours in salt water-the result was in some instances of open exposure slightly in favour of iron, but, in the cases of boilers, always very much in favour of steel. He had just reeeived a report from Mr. Willis, in which reference was made to a point of importance, the perfect cleaningr of the surfaees. It had been found that if the surfaces were carefully cleaned of oxide by dipping the plates in the first instance in an acid solution, the corrosion was always much diminished. The evil effects of seale on steel were pointed out at the Institution of Naval Architects, * by Mr. Barnaby, on the 5th of April, 1879, when he clearly showed that the magnetic oxide scale was very deleterious in its effects. He believed that it was now the practice of the Admiralty to clean the scale ofl' before using the plates for shipbuilding. During the past week he had received a number of letters, quite unsolicited, from gentlemen interested in the use of steel, all speaking in the most

*Vide Transactions of the Institution of Naval Architects, Vol. XX. p. 225. 
definite manner in farour of steel as a metal not liable to corrode under ordinary circumstances. One of them was from the Clyde Bank Foundry, in which it was stated by Mr. Thompson that forty steel boilers had been at work for more than two years, and that their examinations had led to the conclusion that no actire corrosion was going on. He believed it would be found, from general experience, that steel under proper conditions lasted at least as well as iron. He hoped that the discussion would bring out such further facts as would put the question practically at rest. That there was, under certain conditions, a very active corrosion going. on both upon steel and iron was clearly proved by the paper, and by other experiments ; but the conclusions drawn by the author in farour of iron were, he thought, unjustified by the results of his own experiments as well as those of others.

In the discussion of the Paper

“ ON THE PECULIARITIES OF BEHAVIOUR OF STEEL PLATES SUPPLIED FOR THE BOILERS OF THE IMPERIAL RUSSIAN YACHT 'LIVADIA," by W. Parker, Esq., Chief Engineer Surveyor of Lloyd's Register,

Dr. Siemexs * said : The behaviour of the material composing the boilers of the Livadia is so extraordinary, and the results so contradictory, that it is certainly of the greatest interest to have it sifted to the very bottom. When the defective condition of these plates was first discovered, Mr. Parker kindly sent me a piece of plate broken off short by a hammer. The analysis which I had made showed that the metal was irregular in its composition, and it gare a certain percentage of an element which I do not see represented on that table, and that is silicon. The specimen

* Excerpt Transactions of the Institution of Naval Architects, Vol. XXII. 1881, pp. 27, 28. 
which I had given me contained certninly a very considerable percentage of silicon.

The President. Conld you state the percentage?

Dr. Siemens. I can give it in the notes; I think it was about - 03 per cent., but unfortunately I have not the analysis with me. Other analyses by eminent chemists have given, I am aware, different results; they have shown no silicon. But if we look upon the interesting table that has been placed before us, I think we have quite sufficient ground given us to account for these differences in the analyses. There we have in the same plate, carbon, differing in the proportion of at least one to two between the outside and the inside of the plate; we have phosphorus, a substance that is not easily oxidised, when combined with metal, distributed in the same irregular manner, and the same with regard to sulphur. Now a question arises, how can that very great difference in those constituents have arisen in the metal? Is it that the metal itself-the ingot-was not composed of the same mixture, that it was imperfectly fused, and imperfectly distributed in the ingot mould; or has the metal, after it has been rolled into plates, been subjected to treatment whereby its chemical nature has been so completely disturbed as would appear from that table? I can hardly imagine that in the same ingot-although there may be some differences of composition found between one portion and another-differences of such extraordinary magnitude could possibly have occurred. I an, therefore, forced to the conclusion that the metal has been greatly injured in the after-process to which it has been subjected. Mr. Kirk has brought before us very interesting experiments indeed, showing how steel of undoubted good quality, when heated injudiciously and heated for a length of time in a furnace containing a large excess of oxygen, can be, what we call in the trade, burnt. It would have been interesting if we could have seen another columu there, only I admit it would have been very difficult to ascertain it, showing the amount of oxygren absorbed in the metal. I think it would hare been found that the plate near the surface had absorbed a very considerable amount of oxygen, which assisted in making it the brittle, unreliable substance which it became when it was expected to stand its work. It is stated in the paper that every precaution was taken, and that when the plates after punching showed defects, 
they were taken back to the works to be annealed. I am disposed to take considerable objection to that procedure. Mild boiler steel should bear any amount of rough work in a cold condition without receiving the least injury. If by punching mild stecl you lose strength, I consider you have a clear proof that the material is not what it should be. So far from diminishing its strength, the very act of punching should increase the strength of the material. In fact, any treatment to which mild steel is subjected, straightening or punching it, or straining it in any one place, so as to alter slightly its form, the effect invariably is increase of strength, and not a slight increase of strength either. It is, therefore, a practice with which I have little sympathy, that of annealing plates after punching. I would prefer to see the metal used, after it has been punched, without being annealed, and if it is a proper metal it should not require annealing, except in case it had been partially heated in a smith's fire. If the holes are afterwards bored to make the edges smooth, that may be desirable to give more elegant work, but for the mere sake of getting strong and reliable work, I do not believe that it is necessary. Punching alone should give you the full strength of the metal when the work is put together. Therefore, what we should know, in order to judge this question more fully, is the exact mode in which the metal was treated after it had been made, what sized ingots were cast, and were those ingots hammered before they were rolled; if they were reheated, as they were undoubtedly, what kind of furnace was used, and were they allowed to remain, as sometimes happens, a night in the furnace. Then, again, Mr. Thornycroft has already alluded to the processes of annealing which are sometimes adopted: I think there is great danger in annealing steel plates; only if a steel plate has been heated in the forge fire, if it has been heated partially in order to bend it, annealing is necessary, to put it as a whole in a natural condition; but if the metal has been worked cold, I believe it would be much better to leave it unannealed. Then, again, annealing is not always done in a proper and judicious manner ; if one plate only could be put into a well-heated furnace, to take up rapidly the temperature necessary in order to put the particles to rest towards one another, and then could be taken out and allowed slowly to cool, probably no danger would arise. But plates are heaped up 
in the annealing furnace, and in order to bring the heat down to the bottommost plate, a strong flame is applied to the uppermost, and it is but natural that those plates are put in great danger. 'The probability is that some of them will be overheated and that others will be heated all round at the edges, but will not be uniformly heated. Such a process of annealing must be, at any rate, fraught with danger to the material produced. Now one word, my lord, with regard to the process used. It has been said here, that the plates last alluded to, those made at the Cumberland Works, were undoubtedly made by the Siemens process. Now, no doubt this statement has been received authentically, but was there not perhaps some little mistake, inasmuch as those works have only lately put up one furnace according to my system, and I was only told the other day by Mr. Snelus himself that it has not yet been properly put to work. I do not, of course, wish to imply that this could not hare happened with steel manufactured by one process or another.

Dr. Sremexs. Might I be allowed to say one word in explanation? There is one observation which I made which has been perhaps rather severely criticised. It concerns a matter of great importance. I do not wish to say whether plates should be punched only, and left, or whether it would be better to clean out the holes. But what I say is, that in taking a strip of mild steel (and I refer not to the somewhat harder steel used in ship building, but to the milder steel used in boilers) and punching a line of holes across a plate of this steel and subjecting it to tensile strain, the total strain that piece of metal will bear would be fully equal, or, in the case of first-class metal, about 10 per cent. superior, to the normal strength of the material multiplied into the remaining cross-section. I base that view, not upon mere theoretical grounds, but upon many experiments, which I have made and seen tried, and I should be very happy if Mr. Martell rould give me an opportunity of testing it with him. 
In the discussion of the Paper

" ON THE USE OF MILD STEEL FOR SHIP-BUILDING IN THE DOCKYARDS OF THE FRENCH NAVY,"

By M. Marc Berrier-Fontaine,

DR. Siemens* remarked : The paper that has just been read before the Institution is one of very great interest to naval architects, because it brings before us the practice developing in a neighbouring country, in which steel was used at a very early date indeed for naval construction. If I may be allowed to discuss the end of the paper first, I would refer to the remarks of the author upon the liability of steel to rust; and I would here draw attention to a very exhaustive discussion which took place only a week or more ago at the Institution of Civil Engineers. There an alarming account was presented, showing that steel rusted more rapidly than iron; but after two evenings' discussion the prevailing opinion alrived at was that with steel of a proper character this was not the case; and the facts brought before the Institution left no doubt upon the subject. Now, with regard to the French practice, I wish to mention that the open-hearth process used in the production of steel plates in France differs essentially from the process that has been more generally adopted in this country. There the Siemens-Martin process is used, and steel is made by the fusion of scrap steel or scrap iron with pig metal, and the final addition of spiegel, whereas in this country the process with which my name is more exclusively connected-whereby steel is produced by the use of ore and pig metal only-is practised by most of the large works which carry on that manufacture ; and I am disposed to consider that there is an essential difference between the two kinds of steel; for you get a more refined and homogeneous metal by employing only very little scrap and using the ore instead of the scrap process. This difference may account for the less favourable results which the French Navy appears to have

* Excerpt Transactions of the Institution of Naval Architects, Vol. XXII. 1881 , pp. $139,140$. 
obtained as regards the corrosion of their ships. I would attribute that result also in some measurs to their continuing to use iron rivets in the construction of steel hulls. The discussion already alluded to brought out the most rariable results regarding corrosion. In one case steel seemed to corrode much more quickly than iron. In other cases, in experiments continued over years, steel showed decidedly less corrosion than iron. But one thing is certain, that when different materials are brought into contact with one another, and with seawater, rapid corrosion of one or the other will ensue, and I could not too strongly urge the desirability of using in naval construction one material only, be it iron or be it steel. As I have mentioned the process with which I am most intimately connected, I wish it to be understood that I have no desire whatever to set that process before any other. I do not think that users of steel should inquire too much into the process involved. We had yesterday brought before us facts regarding certain materials that had been used, which speak for themselves; and plates, different parts of which give different analyses, are evidently materials that ought never to be employed. It is in the users' power to ascertain whether the material they propose to use, and which is supposed to be homogeneous, is so or not. I was reproached for not having gone into the causes of the failure of the material employed in the construction of the Livadia's boilers, but the facts speak for themselves. Metal that is brought into the ship-yard ought to be above all things homogeneous. I mentioned yesterday a circumstance which gave rise to great difference of opinion. I said that good mild steel should not lose strength in being punched, but should rather gain strength. My lord, I have since then looked up such experimental facts as I happened to have at my office in support of that view. I have here a report which was made by an assistant to Mr. Rendel, who wished to see what the effect of punching was, and those experiments were made in consequence of observations I made at the Institution of Civil Engineers. The result of the experiments, which are rery accurate and perfect, is as follows: In a strip which broke with $30 \frac{1}{2}$ tons to the square inch, when one hole was punched the strength diminished to 30 tons to the square inch; when two holes were punched side by side the strength increased per square inch to 31.65 tons; and when three holes were punched the strength was increased to roL. I. 
32.65 tons per square inch, showing an increase of more than 2 tons to the square inch after having been punched or disturbed in the greatest possible manner; and I hold that the most crucial, the most searching test this homogeneous metal can be put to is to punch it with several holes at close distances in a line. If it is really high-class metal it will simply flow when it is put to a great local strain, and the ultimate strength will increase, for the same reason that if a bar is stretched to a certain extent its strength per square inch is increased. But if it is metal that is not capable of perfectly solid flow it will diminish in strength. I have here, also, experiments by Professor Kennedy; these experiments will shortly be published by the Institution of Mechanical Engineers, and also go in support of the view I stated yesterday, that of good mild steel it might be said, what the old proverb attributes to "a wife and a mulberry tree," "the more you beat it the better it be."

In the discussion of the Papers

"ON THE USE OF A MECHANICAI، AGITATOR IN THE MANUFACTURE OF BESSEMER STEEL," by W.D. Allen, Sheffield ; and

"ON THE DISTRIBUTION OF ELEMENTS IN STEEL INGOTS," by G. J. SNELUS,

Dr. C. W. Siemexs * said he wished to make a few remarks on the second and third papers, which opened up questions of very great interest. They dealt with two distinct questions, one being that of mixing the metal before it was poured into the ingot mould, and the other the action that took place within the ingot mould when the steel was allowed to cool very gradually. Sir Henry Bessemer had, at a very early period, directed his attention

* Excerpt Journal of the Iron and Steel Institute, 1881, 386-388. 
to the first of these two questions, as he had to most questions regarding the production of steel in large masses by his process. He might say that he had himself occasionally given attention to it also, but he had not been bold enough to resort to the mechanical stirrer, which Sir Henry Bessemer had conceired, and which was now practically being carried out, as it appeared, with advantage. He had tried sometimes to produce agitation by resorting to what the copper-smelters called "polling," that was, putting into the ladle poles of dried wood, which made a considerable agitation without disturbing the chemical condition of the metal. No donbt all these means were very beneficial, and he was not the least surprised to hear of the good results which had been obtained. The second question was one involving greater difficulty, because the results placed before them by Mr. Snelus proved, what they had already had occasion to observe, especially with regard to the plates of the Livadia's boilers, that there was chemical change going on in the metal when it first consolidated. The portion which first solidified seemed to take with it such admixtures as manganese, phosphorus, and carbon even, often leaving the metal in the centre of a different composition. The only way to counteract such action within the ingot mould would be that of very rapid cooling. That would be attended with great difficulty, and particularly if they dealt with very large moulds. But he believed he had observed that it depended also upon the time which was allowed to the fluid metal, when thoroughly mixed, to stand before it was poured into the mould. There was such a thing as imperfect and perfect chemical admixture. To use a popular illustration, they might pump carbonic acid into water and make soda-water, but if they used it immediately after it was made, they might just as well save themselves the trouble of forcing the carbonic acid into the water, because it came out instantly. If they had a second bottle made in the same manner, and it were left for a week, they would find a better chemical combination; but if they left it for three months, they would have the carbonic acid retained by the water for a very considerable length of time after being poured out. He had obserred that considerable benefit accrued to the steel if, after it had been poured into the ladle, it were allowed to remain there under the protecting covering of slag to prevent decrease of temperature. The objection to this mode of proceeding was, that 
at this portion of the process time was valuable; but he felt sure that great practical benefit would accrue if the steel could be kept in a quiescent fluid state for a quarter of an hour before pouring. $\mathrm{He}$ considered that both papers were of great interest, as they directed the attention of steel manufacturers to points where great improvements, as regards uniformity of metal, might yet be looked for.

In the discussion of the Paper

"ON THE METALLURGY AND MANUFACTURE OF MODERN BRITISH ORDNANCE,"

By Colonel Martuand, Superintendent, R.G.F., Woolwich,

Dr. C. W. Sienens, * F.R.S., in opening the discussion, said that the observations which he proposed to address to the Institute had reference almost entirely to the first paper, that by Colonel Maitland on the practice now followed at the Royal Gun Factory. When a public department like the Ordnance brought their practice before them, it was, no doubt, with the intention of inviting criticism, and it was a duty for the Iron and Steel Institute to discuss it freely. It was satisfactory to find that the Ordnance Department had at last seen the advantage of using steel not only for the inner tube but also for the hooping of their ordnance. To that extent he was pleased to express his entire concurrence with the author. He did not, however, quite agree with him that it could have been the absence of block powder or compressed powder that was the cause of the long delay; because if steel was both stronger and tougher than iron, then whilst the more dangerous small powder was used, there must have been all the more reason to resort to it as the stronger and tougher material. It was true, as Colonel Maitland had said, that with the use of small powder the strain thrown upon the inner tube was so

* Excerpt Journal of the Iron and Steel Institute, 1881, pp. 483-488, 521, 522. 
great as to render the assistance of hooping comparatively small ; but if that was the case, surely a lighter hoop of stecl would have answered the purpose of the larger hoop of iron. It might have been urged, "Oh, but we wanted the material for recoil purposes," had not the anthor said the objects were to make the gun light, powcrful, and safe. He thought that to realise these three qualities, steel must, undoubtedly, have been better than iron. Nor could he admit that large powder was not known twenty years ago, because he held in his hand a very interesting paper that was read before the Institution of Civil Engineers, in that very room, in 1860, entitled "Our National Defences," in which Rodman's perforated cake powder was described and very fully discussed by the meeting. 'They had, therefore, during the last twenty-one years, been in posscssion, not only of large powder but of a statement of the advantages obtained by its use in the United States. Perhaps Colonel Maitland would favour them with further explanation on this point.

Another and a purely scientific point connected with the statement made by Colonel Maitland had reference to the temperature to which the hoops were heated before they were shrunk on. The anthor said that that temperature was of little importance provided it was sufficiently high. He begged to differ from him; he believed that it was of the utmost importance that the temperature to which the hoops were raised should be adjusted with the greatest nicety, and if they would allow him he would make his meaning plain. (Dr. Siemens drew upon the blackboard a hoop surrounding a tube.) He asked them to suppose that to be a hoop whiclı was bored so as to be a little smaller than the tube upon which it liad to be shrunk. Supposing they heated the hoop considerably beyond the point that would allow it just to slip on, what would be the result? When the inner surface of the hot ring came into contact, or nearly into contact, with the cold tube, it would chill all round, and form in itself an abutment against the further shrinkage of the heated ring ; and the metal behind, being still hot, would readily yield by stretching tangentially instead of contracting radially. It would be fallacious to suppose that a ring cooled internally would shrink back to its original diameter. A ring so cooled would, under no circumstances, shrink back entirely to its original diameter, although not resisted by an 
internal core, but the difference between the original and final diameter would depend upon the temperature to which it had been heated in the interval. He would undertake to take a ring of a certain diameter, and by the mere treatment of heating and internal cooling increase the diameter to an extent very considerably exceeding the external diameter of the tube upon which it was to go. Therefore, he would submit that the temperature to which the rings were heated should be adjusted to the greatest nicety, in order to ensure the condition upon which the safety of the gun depended. The subject of "Physical changes occurring in iron and steel at high temperatures "was brought before the Iron and Steel Institute by Mr. Wrightson, one of their members not long ago, ${ }^{*}$ and the conditions there referred to applied very forcibly to the case now before them.

The paper under discussion went on to describe the process followed at the Gun Factory to make the steel they used. The apparatus there employed consisted of two things, a furnace, stated to be Price's patent retort furnace, and a process called the openheartli process, but which was in reality as minute a description of the one known by his name as though it had been taken from the instructions which he was in the habit of sending out to his licensees, and in accordance with which nearly half a million tons of steel were annually produced in this country. Price's furnace, it was stated, differed from the regenerative gas furnace in having a retort gas-producer, and of that a considerable point was made. He had with him a sheet which he had taken out of a patent he had obtained as early as 1863, describing a very similar gasproducer ; and if Colonel Maitland was present he should like him to point out the essential difference, if any, between the two. Although Dr. Siemens had used the retort gas-producer for some time, he had come to the conclusion many years ago that it was not productive of the best results ; that, in order to convert coal into gas of the greatest heating power, it should be acted upon energetically, so as to attain the highest possible temperature at the point where the carbonic acid took up another equivalent of carbon to form carbonic oxide. He felt inclined to challenge the Department to make a comparative experiment, using their furnace

* "Journal," No. II. 1879, p. 418, and No. I. 1880, p. 11 et seq. 
and their open-hearth arrangement, and see what the consumptiou of fuel was, and what time was necessary for the charge as compared with the furnace constructed entirely in accordance with his plans. If it should be proved that the results were in favour of his own construction, he thought he should have a good claim upon the 1)epartment to come to him for designs before erecting further furnaces. He need hardly say that these furnaces at Woolwich had been erected and the process set to work without any communication with himself. The Department considered themselves above any such liability as patent rights, and therefore appeared bound to follow out their own detailed designs. The paper went on, moreover, to describe the unfortunate results obtained with a Siemens furnace erected nineteen years ago at the Arsenal. Any unprejudiced person, reading the paper, would think that he had gone there promising them wonderful results from his furnace, and that they, finding it a failure, had abandoned it, and resorted to devices of their own. But if such a conclusion were come to by any member, it would be a very erroneous one. The Department at that time, acting on the principle that the Government was independent of patentees, did not address themselves to him, but to a former draughtsman of his who had established himself in business as a contractor. That gentleman was permitted not only to contract for the erection of a furnace, but to furnish his own designs. Possibly the former circumstance had influenced him to some extent to put in the enormous culverts that might have answered for eight or ten such furnaces, and must have rendered the construction very costly indeed. At that period furnaces had been erected by him (Dr. Siemens) for precisely the same purposes. Sir William Armstrong had at that time not one but several of his furuaces for heating gun coils at his works, and how highly he approved them was shown by his own allusions to the matter when President of the British Association, and again as President of Section $\mathrm{G}$ of the same Association at Birmingham. Members of the Institute would recollect, moreover, that when visiting the Creusot Works, three years ago, they saw there four splendid furnaces erected by Messis. Schneider for heating large gun and other forgings. At Krupp's the same furnace was also used, particularly in connection with the Gun Factory ; and the same could be saidalso with regard to Sir Joseph Whitworth. Having all the gunmakers 
of great importance throughout the world using the regenerative furnace as designed by him, why was it that at the Royal Gun Factory, and only there, it was a failure, and was now for the first time publicly so described? The fact was, it was a failure there because it had been put up without knowledge. It was true that after the furnaee had been erected and failed, he had received a letter from the War Offiee to go and see what was the matter. $\mathrm{He}$ expressed his surprise at being called upon at so late a date to see to it, but he immediately went, and reported that, although he had not seen the furnace in operation, it was evidently constructed in a manner to prevent its proper aetion ; amougst other things there was no sufficient ventilation provided below the seat of the furnaee, although it was to work with a cinder bottom. The coil would therefore stand in the fluid cinder, and this could not be altered without pulling down the furnace, and re-erecting it in accordanee with approved designs. This was the course he recommended, and he received instructions to prepare plans, but before these were quite finished, he received another letter, stating that the estimates for the year did not contain an item for rebuilding such a furnace, and its consideration must be postponed; and it had been postponed to the present day.

He thought that the question of patents as regarded public departments should be inquired into and eleared up. He was quite sure that if the Gorernment had not elaimed immunity from such liability, they would have come to him in the first instance, and they would have had the benefit of all the experience which he had gained at that time. A good furnace would have been ereeted for much less money than they had paid, eren if they had ineluded some few hundreds for royalty and personal charges which might have been incurred. By this time they would have saved, indeed, many thousands of pounds, while he would have been richer not only by the amount of royalty he might have received, but beeause the reputed failure in question had stood in his way for years and years in the introduction of his furnace. He had felt aggrieved regarding this for the last eighteen years, but now was the first opportunity that had been given him for publicly relating the circumstances of the ease.

Before sitting down, he would say only a few words regarding the very eareful and practically valuable paper of Mr. Butter. 
Mr. Bntter incidentally described hydraulic compression for checking the recoil of gun carriages, but without reference to its origiu. Here, again, he considered himself aggrieved to a certain extent, because hydraulic compression had been adopted by the Department on his recommendation. He had been called down to Woolwich to advise whether electricity could not be employed for checking the recoil of gun carriages. At that time he knew too much of the weakness of electricity, and then and there suggested the plan of hydraulic compression, which, modified and improred no doubt by the Department, had been generally adopted throughout the service. He must add, in justification of Colonel (now General) Clarke, who was then chief superindent, that he gracefully ackuowledged his claim regarding this improvement in a paper read by that officer before Section $G$ of the British Association at Exeter; but as regards the Department, he never received so much as a line of acknowledgment for either the suggestion or the time he had deroted to the matter.

Dr. C. Wildiam Siemexs, F.R.S., said that before the discussion closed he would like to say a few words in explanation of his observations of the prerious day. From what had fallen from Mr. Markham, he was almost afraid that he had conveyed the idea to the members that he wished to make a personal attack, either upon the gallant Colonel who had brought the paper before them, or upon other gentlemen connected with Woolwich; but he meant no reflection either upon their honourable disposition or their skill. In fact, nothing was further from his thoughts. He found fault with Colonel Maitland when he presented himself before the Institute as a historian, and he thought it his duty to correct an erroneous impression. His attack was not directed towards individuals, but towards the system. No one had a right to complain if it were understood that the Government were resolved not to recognise patent rights. He had never preferred a claim against the Department, and therefore he had no right to complain in that respect; but he considered that a patentee was the guardian of his invention while it was in its infancy. It was interfering very much with his interests if a Government Department took up his invention without consulting him, and then, perhaps, through an oversight of the essential conditions, brought about a failure which 
acted very detrimentally to the introduction of that invention. It was with regard to such unauthorised applications of inventions that he felt rather strongly, and he therefore wished to say something on that subject.

In the discussion of the Paper

"ON STEEL FOR STRUCTURES,"

By Mr. E. Matheson,

Dr. Siemexs* said, he thought the author had brought forward one of the vexed questions of the day, viz., to what extent steel should be trusted for engineering structures. In consequence of rules which had hitherto been followed by the Board of Trade with regard to steel, that material had not come unto use for engineering purposes except under special circumstances; and although he believed that at the present time the officers of the Board of Trade were anxious to study the material, and gain from their own observation the experience necessary to give contidence, the public were still without the result of their labours in that direction. Steel differed very materially from iron in regard to the variety of strength and other qualities which it was able to assume. There was steel which resisted a tensile strain of nearly 80 tons, and whose elastic limit exceeded 40 tons; with a rery slight modification of its composition, it would assume an ultimate strength of only 27 tons; but on the other hand it would have acquired a power of elongation amounting to nearly 25 per cent. before breaking took place. It was, therefore, an important question, which of the endless varieties of steel between those limits was the best for engineering purposes. He thought it would be impossible to give one satisfactory answer to a question of such scope. It required a careful study of the

* Excerpt Minutes of Proceedings of the Institution of Civil Engineers, Vol. LXIX. 1882, pp. 36-39 and 58. 
precise purpose for which the material was required. If it wis wanted to make a chain-bridge, steel of 80 tons breaking strain per square inch was the proper material; if, on the other hand, a suspension link bridge were constructed, the links could hardly be made of steel of such hardness, and the engineer would have to be content with a tensile strength of from 35 to 40 tons. The reason why it would not be safe to take steel of a higher ultimate strengtl was that its elongation would be insufficient to give a sufficient factor of safety; in case of unequal strains between the parts, accidents might arise, whereas in dealing with steel of from 35 to 40 tons per square inch, there would be an elongation of something like 10 per cent. before breakage could occur, and within that range the unequal strains could adjust themselves. Again, if it were intended to put steel under a compressive strain, a high limit of elasticity was the chief desideratum, and it was possible in that material to vary the limit of elasticity without interfering with the ultimate strength. Two bars of steel, both with an ultimate strength of 35 tons to the square inch, might have different elastic limits, but within those elastic limits the ductility would be influenced. It might appear that, owing to the great variety of conditions that were attainable, steel was an uncertain material, but that was not the case; whereas, in the manufacture of iron a good deal depended upon the personal skill of the worker, in steel it was rather a chemical test which determined the qualities; and it was quite possible to ensure a uniformity in steel such as could not be approached in iron, only it was necessary that the engineer should understand clearly what was the quality of steel required for certain purposes, and then it was for the manufacturer to produce that quality uniformly and regularly. If, then, structures like links of a chain should have a tensile strain of, say 38 tons per square inch, to what extent might such a material be trusted ? In the case of wrought iron, engineers thought it generally safe to trust a structure to one-fourth of the breaking strain, and the same rule might still hold good for steel of that description, because the elongation before rupture would be very much the same as in the case of iron. But in considering the case of very mild steel the same rule should no longer hold. If they constructed a bridge of cast iron they would consider it unsafe to load it to more than one-sixth or even 
one-eighth of its breaking strain, whereas, in the case of wroughtiron, it was thought safe to go to one-fourth. Why was this the case? Because wrought iron would elongate before it broke; but in dealing with mild steel, an elongation to more than double that in the case of wrought-iron took place before fracture, and therefore the same reason that would make an engineer trust wroughtiron to a higher proportion of its ultimate strength than cast-iron, would lead him to trust steel to a still higher limit as compared with its own breaking strain. T'here was another reason why mild steel could be trusted to a limit exceeding half the elastic limit, namely, that in riveting or punching, its strength was not diminished in anything like the same extent as in the case of wrought iron or of harder steel. He had caused a great many experiments to be made with mild steel, and had found that the strength per square inch of the remaining section of material, after a line of holes had been punched in it, was nearly equal, and in some cases, even superior, to the original strength of the bar per square inch of section. That seemed strange but it was perfectly consistent. Taking a bar of this material, and putting it under tensile strain nearly equal to the elastic limit, for a length of time, it wonld be found that not only was the elastic limit raised, but that the ultimate strength was raised, and that very materially. It was possible to teach a bar to carry at least 10 per cent. more than it did on the first trial, by simply keeping it under strain for a length of time. In the same way in subjecting the material to a kind of solid flow-any kind of strain-its ultimate strength and its elastic limit would be raised ; and the reason why punching or ill-treatment of any kınd did not injure such material was that it obeyed the law of solid flow; whereas, an inferior material, would not in its entirety, obey that law, but would be liable to rupture in its ultimate parts. He, therefore, submitted, that in using steel for rireted structures only the mild kind should be employed. It might be said that in that case it would be necessary to give up the strength of the material and approach the ultimate strength of iron; and what was the use of the material if no more could be done than that with it? His answer would be that it was a safer material when put together than the stronger steel, and much safer than iron (although its ultimate strength was not much greater,) for the simple reason that there was a 
ruliable strength in erery part of it, eren in the lines of riveting, that a material of that sort would stretch more than 20 per cent. before it broke, and that for that reason the unequal strain originally set up in the structure would be set right by straining it. In fact, he could see no reason why one-third of the breaking strain should be considered as the limit to which mild steel could be safely trusted. If the shell of a boiler could be rolled in one piece without riveting he would advocate the use of a much stronger steel, of from 35 to 40 tons, but so long as riveting was resorted to he would give the preference to the milder steel, and notwithstanding its mildness, would trust it to the limit of onethird of its breaking strain, or, say, 8 tons per square inch, which he thought, would be a safe limit. He hoped the discussion would materially contribute to the obtaining of a safe but progressire rule which would enable engineers to use steel not only to the same extent to which it had already been applied in other countries, but to a still greater extent.

Dr. Siemexs, in explanation, said the strength of the steel before punching, alluded to by Mr. Parker, was rather high for the quality. The weakening by punching was very great indeed. It had brought the tensile strength of the remaining metal down to 17 tons per square inch, whereas the bar, after being annealed, had a tensile strength of 24 tous per square inch; but even that was apparently 6 tons below the original strength of the bar. As Mr. Campbell had remarked, punching was an art, and ought to be done properly; but he felt satisfied that, in punching mild steel properly, engineers need not look for a reduction in tensile strength of 24 per cent., such as the results referred to indicated. He had the particulars of experiments showing that the strength of mild steel was not materially influenced either way by punching without annealing. In one experiment communicated to him by $\mathrm{Mr}$. Rendel, tluree bars were prepared from the same plate and in the same manner. The first one was not punched at all, and it broke at a tensile strain of $31 \frac{1}{2}$ tons per square inch. When one hole was punched in the middle of it, the tensile strength was reduced to 30 tons per square inch. On punching two holes side by side, whereby the remaining metal was more equally strained, the strain was again brought up to 31.65 tons per square inch, and similar 
results were obtained by Professor Kennedy and by himself over and over again in testing good mild steel. Of course the stretching was ever so much less after the bar was punched through the middle, because it did not matter how long the bar was, the strain fell only in the line of least sectional area. In the first bar there was a stretch of 2 inches, in the second $\frac{3}{4}$ inch, and in the third $\frac{1}{2}$ inch.

In the discussion of the Paper

"ON THE INFLUENCE OF THE BOARD OF TRADE RULES FOR BOILERS UPON THE COMMERCIAL MaRINE," by J. T. Mrlton, Esq.,

Sir Williayr Siexexs * said :-My Lord, when gods fall out, mortals suffer, and I present myself to-day as one of those sufferers, in the character of a shipowner. Nine years ago I had a ship constructed for cable purposes-the "Faraday." I took great care myself of all the arrangements necessary to make that ship efficient for laying and picking up cables, but as regards boilers and engines I relied entirely upon the Board of Trade Rules and Lloyd's Rules as they then existed, my instruction being simply, "Make the boilers as safe and the engines as efficient as they can be made." The result was undoubtedly a success. That ship never failed to do its arduous duties, being out on the Atlantic sometimes in the winter months for weeks together, engaged in rery rough work. But in the course of a few years the Board of Trade Rules were altered, and it was intimated that these boilers were really no longer sufficient under the new Rules laid down. We had the boilers carefully inspected after each voyage, and they were pronounced both by the Board of Trade surveyors and Lloyd's surveyors to be in perfect condi-

* Excerpt Transactions of the Institntion of Naval Architects, Vol. XXIV. 1883 , p. 88 . 
tion. Nevertleless, in order to induce us to fall ill witl the new Rule, the pressure was reduced after each royage $5 \mathrm{lbs}$., and we should very soon have been in the lappy condition of depending upon our sails. The operations that have to be carried on on board this ship are so important, that I decided to have steel boilers put in, at an expense of $£ 10,000$, although the inspection of the boilers proved that they were in perfect condition. Now, this is a hard case to me as a slipowner, because if the two authorities had been agreed regarding the Rules, I should not have been pnt to this expense, and have had to sell good boilers second-hand, which have gone into other ships not requiring to be under the rules of the Board of Trade. As an engineer, and one interested in the manufacture of materials, I should say that the Board of Trade Rules give us excessive thicknesses, especially in cases where first-class material is used. I see on page 79 that certain strengths of iron are assumed, not according to the tests this iron can stand, but it is taken to be equal to $47,000 \mathrm{lbs}$. per square inch in the one direction and 40,000 lbs. in the other. Now this seems to involve a condition of things which does not exist - that of all materials being equally good. I would rather say, have each plate, whether it be steel or irou, tested, and if it does not stand an elongation of 20 per cent. in a bar 8 inches long, it ought to be considered unfit for being put into a boiler. Mr. MacFarlane Gray has given us his reasons why the Board of Trade insist upon a thickness of plate exceeding, as he admits, the necessities of the case. He has giren us an instance where, at a pressure of only $17 \mathrm{lbs}$., a plate had cracked all along the seam, although the boiler was expected to stand $70 \mathrm{lbs}$. But I fail to follow Mr. MacFarlane Gray in his argument. The forces that come to bear (viz., the strains) upon the material through expanslon by heat increase enormously with the resisting power of that material, and therefore the very fact which Mr. MacFarlane Gray has brought before us, appears to me to tend rather in the direction of aroiding excess of thickness, because with excess of thickness you get always, whaterer be the nature of the material you employ, an inferior plate. But, I say, have sufficient thickness, and be more careful regarding the quality of the material which is employed. If the material of which that boiler was constructed had been such as would elongate 20 or 30 per cent. before break- 
Ing, I am quite certain that the strain put upon it by expansion would have had for its results simply a local elongation, but there would have been accommodation; whereas rigid material has no accommodation, but must yield when, through local action at any one point, the strain put upon it exceeds its absolute strength. This, therefore, appears to me to furnish a very powerful argument in favour of a material of high ductility, and the fault I would find with all these rules is, that the factor of ductility is not introduced as part of the factor of safety. Now, Sir Joseph Whitworth, who has given much attention to this subject, has laid it down as a rule that the value of a material is composed of the sum of its ultimate strength and of its yielding power under strain. I believe that this is a very excellent rule. Therefore if the factor of safety of 5 is none too much for a material that would break when extended 10 per cent., if it could be made to extend 20 per cent., the factor 5 ought to come down to the factor 4 ; and you would get with that factor at least as much safety as you would get with the factor 5 , and the lower extensibility of the material. This is a question which I hope will be very fully and carefully discussed, and I trust that it will lead to a Rule in which both the Board of Trade and Illoyd's surveyors concur, in order to prevent the recurrence of such incidents as I have given you.

In the discussion of the Paper

"ON THE USE OF STEEL CASTINGS IN LIEU OF IRON AND STEEL FORGINGS FOR SHIP ANI) MARINE ENGINE CONSTRUCTION," by Mr. William PARKER, Chief Engineer Surreyor of Lloyd's Register of Shipping,

Sir Wirmitam Siemens* said he thought the Institute should accord their most hearty thanks to Mr. Parker for his rery prac-

* Excerpt Journal of the Iron and Steel Institute, 1883, pp. 89-90. 
tical paper. As an official referee of Iloyd's it would have been much easier for Mr. Parker to continue on the old lines, which would have saved him a great deal of trouble and a great deal of responsibility ; and he (Sir William Siemens) thought it was a most welcome thing to find a gentleman in Mr. Parker's position coming forward and asserting the advantages in favour of a new mode of practice. There could be no doubt that a steel casting, if made without blow-holes, and if properly annealed, was more reliable than $n$ forging, if the form was at all of a complicated kind. It had already been shown to them in forgings of large shafts, and especially where a large shaft was suddenly contracted down to a narrow throat or changed its direction in order to form a crank, that the act of forging was productive of a very great evil. A blow could not be struck sufficient to penetrate the whole of the mass, and a light blow must necessarily have the effect of extending the surface and thereby producing cavities in the interior where strength was wanted. On the other hand, if a casting be cooled in the mould, it must contract unequally, and must have within itself the germs of destruction; and it must therefore be most advantageous to cool it right down, whereby these differences of tension would be brought to a maximum and very likely cause an evil that was preventable. In order to anneal the casting to the best advantage, it should be remored from the mould to the annealing stove without allowing it to cool ; they would thus give time for the different parts, while at a uniform temperature, to adjust themselves to one another.

Oil hardening had been alluded to, and very remarkable results had been obtained through it which had never been satisfactorily explained. Why steel should be increased in its ultimate strength without losing its ductility was a matter requiring further investigation. The oil did not seem to enter chemically into the process at all; the result could only be due to that degree of surface cooling, which, while it did not amount to cracking or injuring the surface of the metal, produced the effect of compression on the inner portions of it, a compression which they knew was favourable to a dense structure of the metal such as they found suited best for resisting great strains. Nor could he agree quite vor. I. 
with his friend Mr. Walker that the same result would be obtained by fluid compression.

There was one more point which he might allude to. Mr. Parker had shown on a table that the best results, as regards wear and tear, were produced from a comparatively mild steel. He thought it should be borne in mind that for all working parts of machinery the ultimate strain which the metal had to endure did not exceed two or three, or at most four tons to the square inch, for it was inconceivable for a shaft, while it did its regular work, to be strained in any part above four tons to the square inch. If the steel was of the mildest description, the limit of elasticity would be about fifteen tons. There was no object to be gained in raising that limit up to twenty tons, and the ultimate strength to forty tons, if they lost thereby that most valuable of all qualities in all metals, that of ductility, or yielding before fracture took place. All moving parts of machinery, such as shafts and cranks, he thought should be made of steel of the mildest description. 


\section{INDEX TO VOLUME I.}

\section{HEAT.}

AERO-STEAM ENGINE.

Atro-steam engine, Warsop's, 136. Air-engine, 36 ; eomparison of, an essential differenee between steam. engine and, 39, 46, 138 ; diffieulty with joints of, 162 ; drawbacks in, 164; (Ericsson's, 26, 36 ; action of, 26 ; compared with steam. engine, 49 ; description of, 42 ; economy of, estimate of, 43 , and means of improving, 27 ; experiments on, 59 ; failure of, eause of, 58 ; friction great in, 44 ; heated eylinder of, drawback of, 44 ; heating surface too small in, 28,44 ; imperfeetions of, 44,163 ; indieated horse-power of, 45 ; practical arrangement of, 28 ; pressure effective in, 43; radiating surfaecs large of, 44 ; regenerator applied to, 42 ; theoretical diagram of, 42 ; theoretical result impossible in, 28 ; weight and bulk of, 44); expansive, thcorctical superiority and practical inferiority of, 38,39 ; important for small power, 164; joints of, ecment for, 162 ; regenerative prineiple applied to, 161 ; regencrator in, misconeeption of use of, 163 ; (Stirling's, 36, 39 ; advantages of, 39 ; and Cornish engine eompared, 41 ; deseription of, 40 ; failure of, eause of, 41 ; and perfect engine compared, 41 ; praetical defect of, 42 ; pressure, working of, 40 ; real effect of, 41 ; theorctical diagram of, 40 ;
BLAST.

theoretically inferior but actually equal to Eriesson's, 46).

Air expansion. See Expansion of air. Air injected into steam, 136 ; action taking place when, 137 ; preventing sediment and priming in boilcr, 136, 137 ; work increased when, 136, 138.

Allen governor, 159 ; essential differenee between Siemens's liquid governor and, 160 ; mode of aetion of, 159 ; simplicity of, 159 ; throttle valve essential to, 161.

Anthracite eoke, 100.

Appold oven, 100.

Atmosphere, elosencss of in dwellings heated by steam, 192.

Auxiliary propulsion, 124.

BIDDER, S. P., coal working and brcaking, machines for, discus. sion of paper by, 128-130.

Black, expcriments of, on latent hcat of steam, 18.

Blast furnace, chemical action in, 133 ; fuel, minimum for smclting in, 134 ; limit of economy in, 134 ; opinions of iron-masters regarding, 134, 135.

Blast furnace gas, application of, 182 . Blast of high tempcrature, 132 ; duties to be performed by, 134; question considered, 133 : reduction in quantity of required, 135 ; temperature of, 135 . 


\section{BLOOMING FURNACES.}

Blooming furnaces, application of regenerative gas furnace to, 93.

Boiler of Watt's engine, 51.

Boilers, application of Landore mild steel to, 170 ; bursting steel, impossibility of, 173 ; encrustation, how formed in, 136 ; iron riveting injurious in steel, 171 ; riveting plates of steel in, mode of, 170 .

Boiler feeding, 78,80 .

Boulton and Watt's condensing engine compared with expansive air-engine, 38 .

Boyd, W., steam-boilers, experiments relative to, discussion of paper by, 170-173; steel, failure of in boilers, experiments on, 170 .

Brix, experiments on quantity of heat in steam, 19.

Bunsen on dissociation, reference to, 204.

Bye-products from illuminating gas, 186.

CALORIC engine, 28; theoretical consumption of, 28.

Carbonic oxide and carbonic acid, relative heating powers of, 133.

Carnot on heat, reference to, 32 .

Carnot's theory, 59.

Carendish Society, publication of Regnault's experiments by, 20.

Chance's glass-works, application of rcgenerative gas-furnace at, $\mathbf{8 9}$.

Chemical energy, production and application of, 177 .

Cheverton, B., heated air, use of as motive power, discussion of paper by, 26-28.

Chronometric governor. See Governor, Chronometric.

Chubb, C. J., coal-getting machinery, discussion of paper by, 128-130.

Circuit system of pneumatic trans. mission, 147 ; advantages of, 155.

Clapeyron on heat, reference to, 32 .

\section{COMBINED VAPOUR ENGINE.}

Clausius on conversion of heat into mechanical effect, 59 ; on steam condensation, 33,34 .

Clerk, D., gas-engine, theory of, discussion of paper by, 203-206.

Cleveland ironstonc, reduction of, in blast-furnace, 134.

Clock regulated by liquid in rotation, 115 ; action of, 116 ; description of, 116 ; formula to determine relocity of cup with continuous overflow, 118 ; table of comparison of with chronometer, 119.

Coal, casualties in getting, 128 ; cost of per horse-power per annum, 52 ; economy in use of, 52 ; expenditure and possible saving per annum of steam, 52; getting, force expended in, 128; machines for working and breaking down, 12S; wedging and blasting, $12 \mathrm{~S}$.

Coke, advantage of, as fuel, 181 ; making treated too lightly, 101.

Coke ovens, 99 ; Appold, 100 ; conversion of ordinary into close, 99 ; for production of heating and il. Inminating gases, 101 ; primitive, 99 ; quality of coke in, 99 ; regenerative, 100 ; semi-cylindrical horizontal, 100.

Coleman, J. J., air refrigerating machinery and its applications discussion of paper by, 192-203.

Combined steam, 76 ; adrantage of, 77

Combined steam and ether engine, 45; additional effect of, how otherwise attainable, 45 ; description of, 45 ; practical difficulties of, 45 .

Combined vapour engine, 69 ; advantages of, 71 ; causes influencing result in, 70 ; comparison of, with expansive steam-engine, $70,71,72$; disadvantages of, 71 ; extra power of, obtained by expansive work- 


\section{COMBUSTION.}

ing, 72 ; thcoretical considerntions of, 70 .

Combustion, complete, 204 ; partial, 204 ; perfect in regenerative gasfurnace, 96.

Combustion of regetable substances, 168 ; eontinuous, systematic and equal feeding in Head's, J., system, 169 ; Garrett's, F., system, 169.

Combustion, waste products of, used in, regenerative gas furnace, 81 .

Condensation, depends on, 3 ; duc to development of power, 74 ; how effected, 3 ; perfeet, 3 ; prevented by mixing air with stcam, 138 ; surface, 69 ; Dr. Ure's experiment on, 14.

Condenser, advantages of effective surface, 12 ; Hall's, 12 ; historic sketch of, 11 ; Hornblower's surfaec, 12 ; for land and other steamengines, 1 ; loss of mechanieal effeet in, 52; (Mc Carter, 167, compared with ordinary, 167 ; compensating, advantage of, 167 ; worked on Newcomen prineiple, 167); Neweomen's, 11 ; object of, 3 ; regenerative, sce Regenerative condenser ; surfaee, 12 ; water required for, 7 ; Watt's, 12, 51 .

Condensing water, required for ordinary condenser, 7 ; required for regenerative condenser, 2,6 ; temperature of, 4.

Conical pendulum, principle of, 107.

Contre-vapeur system, Le Chatclier's, 165.

Convertibility of physical forces. See Physical forees.

Cooke, C. W., Wenham's heated airengine, discussion of paper by, 161-164.

Copper, great heat-conducting power of, 14 ; thiek pan of evaporates more quickly than thin, 14.

\section{EJECTOR-CONDENSER.}

Cornish engine, action of, 68 ; reason of ceonomy of, 68 ; supcrheated steam used in, 24.

Cowper, E. A., expansive steam. engines, cxperiments on, 24 ; horizontal pumping-engines, deseription of, discussion of paper by, 68, 69 ; hot-blast stoves, applieation of regenerative system to, 94 ; regenerative hot-blast furnaees, reeent improvements in, diseussion of paper by, 132-135; steam, suggestions as to experiments on, 18.

Cylinder, steam, of Watt's cngine, 51 ; uneovered, loss by condensation in, 138.

DALTox on expansion, 21.

Davy, heat, material theory of, disproved by, 30 .

Dean, experiments to burst steamboilers, 173.

Desprez, quantity of heat in stcam, 19.

Diagram of gas production in gasretort, 185 ; theoretieal of Ericsson's, 42 ; and of Stirling's engine, 40.

Disassociation, 179, 204 ; Bunsen on, 179,204 ; Ste.-Claire Deville on, 179, 204; temperature of, 204.

Dulong. See Expansion of air.

Dynamical curve, 36 .

Dynamical theory. See Heat.

EAtox,R.,Warsop aëro-steam engine, diseussion of paper on, 136-139.

Ebelmen's, blast-furnace gases, researches on, 182.

Efficieney of mechanical . contrivances, how adjudged, 133.

Ejector - Condenser, 157; annular water-jet in, 158 ; increasing eondensing surface of, 157, 158. 
ELASTIC MEDIUM.

Elastic medium in perfect heat engine, theoretically and practically considered, 59, 60 .

Electric arc for high temperatures, 181.

Ellissen. See Gas retorts.

Engines. Sec Air, Caloric, Combined vapour, Cornish, Gas, Heat, Perfect, Pumping, Regenerative steam, Steam, Steam-steering.

England, J., Giffard injector, discussion of paper by, 101-106.

Ericsson. Sce Air-engine, Regenerator.

Ether-engine, advantages and disadvantages of, 70 ; and steamengine compared, 70 .

Evaporation of sugar, 150 ; high temperature in, ill effects of, 151 ; steam-jet exhauster applied to, 151 ; vacuum pan for, 151.

Expansion of air and gases by heat, 21 ; curve of, 22, 162 (Determinations by Dalton, 21; Dulong and Petit, 21 ; Gay Lussac, 21) ; Siemens's, C. W., views regarding, 22.

Expansion of steam. See Steam.

Expansive steam-cngine. See Steamengine.

Expansive valve-gear, Joy's, theoretically and practically superior to old link motion, 174.

FARADAY's gas-burners, reference to, 190.

Fire-syringe for converting force into heat, 54 .

Flame, regulation of in regcnerative gas furnace, 96 .

Flint-glass melting in closed pots in regenerative gas furnace, $\mathbf{9 2}$.

Formula for liquid in rotation, 111 , 112 ; for power of heat-engine, 37.

Foucault, governor of, 110.

Fox-Henderson, regenerative steamengine manufactured by, 16 .
GAS-PRODUCER.

Franklin Institute, experiments on iron of, 58.

Freezing, operation of, differs esscntially from power producing, 195, 197.

Frost on expansion of isolated steam, 21.

Fuel. See Coke, Gaseous fuel, Liquid fuel, Peat, Regenerative furnace, Regenerative gas furnace.

Fuel, evaporative power of, Rankine on, 126; heat energy in, 178 ; saving of, by rcgenerative gas furnace, 65 ; wastcd, 62.

Furnace. See Regenerative furnace, Regenerative gas furnace.

GAIGNARD DE LA TOUR's state of vapour, 54.

Galton, Capt. D., steam-hcating for towns and villages, combination system of, discussion of paper by, 190-192.

Garrett, F., on combustion of vegctable substances, 169.

Gas-engincs, 203 ; mechanical arrangements of, 203 ; modern, 205 ; Siemens's, of 1860,205 ; smaller, 206 ; theory of, 203 ; three types of, 204.

Gas fire. See Regenerative gas fire.

Gas from blast-furnace, application of, 182 .

Gas furnace. See Regenerative gas furnace.

Gas, illuminating. See Illuminating gas.

Gas lamp. Sec Regenerative gas lamp.

Gas-produccr, action of, 87 ; carbonic acid changed into carbonic oxide in, 87 ; description of, 86 ; evolution of hydro-carbons in, 88 ; excess of pressure in, how effected, 88,89 ; fuel used in, 86 ; gases proceeding from, $87,91,95$; hori- 
GAS-PRODUCERS.

zontal cooling tubo in, 89 ; pre. vention of sulphuring due to chemical transfcrmation in, 92 ; (Siemens's, $C$. W., new form of, description of, 183 ; high temperature in centre of mass of, 183 ; modus opcrandi, 183 ; water de. composed to cnrich gascs from, 183) ; suceessful use of, 86 ; underground usc of, suggested, 95 ; uniform quality of gas from, 88 ; water decomposed in, 87.

Gas-producers, 175 ; coneentrating lient in, 175 ; historical reeord of, 175 ; Lürmann's, 175 ; Pricc's similar to Siemens's old form. of, 175 ; retort action too slow for, 177 ; Siemens's, C. W., patents of 1863 and 1864 for, 176 ; Siemens's, $86,182,183$.

Gas-retorts, method of producing .separatc heating and illuminating gas iu, 185, 186; M. Ellissen's and M. Regnault's experiments on, 185 ; variation of quality and quantity of gas from at different periods of operation, $185,186$.

Gasworks, regencrative gas furnace applied at, 94 .

Gascous fuel, 177, 184 ; advantages of, 178,179 ; arrangement to produce from retorts with illuminating gas, 185 ; for distant supply, 184 ; heating power of, 178 ; prevention of smoke by use of, 179 ; producers for, 86,182 ; reason of heat-energy of, 178 ; retorts for, 181 ; Siemens's ncw producer for, 183 ; Siemens's producer for, 86, 182.

Gay Iussac, cxpansion of air, 21.

Gay Lussac and Clement, steam, quantity of heat in, 19.

Giffarl injector, 78, 101 ; action of, 102,103 ; action of, how paralyzed, 103 ; advantageously used when water has to be heatcd and raised, 106 ; (application as an cleratur,

\section{GOVERNOR.}

79 ; economy in, reason for want of, 80 ; inferior to a pump in, 80 ); boiler feeding, economical for, 80 ; eomparison of theory and practice in, 79, 104, 105 ; entire condensation of stcam jet neecssary in, 103 ; failurc, eause of partial, 105 ; jets of water and steam, relative areas of, 104; marinc engincs, applicability to, 104 ; motor, inapplieability of, as, 104, 106 ; quantity of water which may bc forced into boilcr by, 103 ; reference to, 143; and steam jet, differenee of action betwecn, 144 ; thcorctical considerations regarding, 102; water, increased tem. pcrature of, passing through, 78, 103 , with higher pressurc of steam in, 79 .

Glass-mclting in regencrative gas furnace, $89,90,91$.

Gorrie, Dr. See Refrigerating machincry.

Governor (Chronometric, 108; application to astronomical and chronographical instruments, 109 ; eross-armcd, good action of, 140 ; instantancousand rcgular aetion of, 109,110 ; leading idea in and how realizcd, 109; uniform rotation obtained by, 109) ; Foucault's, 110; (Gyrometric, description of, 120, 121 ; formula for speed of cup of, 122 ; rapidity of readjustment of, 123 ; uniform velocity of engine governcd by, 123); (Watt's centrifugal, 107; action of, 107; defect of, 108 ; depends on permanent ehange of speed, 108; improved suspension of, 10S; throttlc valve, how worked by, 108).

Governor for steam engine, 139 ; advantage of addition of spiral spring to, 140 ; chronometric action of, 139. Sec Allen. 
GRAY, J. MACFARLANE.

Gray, J. McFarlane, steam-steering engine for Great Eastern, discussion of paper by, 124, 125.

Gyrometer, liquid, 112 ; action of, 113 ; applications of, 115 ; automatic dip of cup in, 114 ; correction for lower orifice of cup of, 117 ; description of, 113 ; power absorbed in, 114 ; range of power in, 115 ; rotation of liquid in outer vessel, how prevented, 113 ; uniform rotation produced by, 114; velocity of, excess of calculated over actual, 118; relocity of, formula to compute, 118 ; vertical position indifferent to, 120 .

Gyrometric governor. See Governor, gyrometric.

HALL, condenser of, 12.

Head, Jeremiah, steam-engine governor, with nearly perfect action, discussion of paper by, 139-141.

Head, John, combustion of refuse vegetable substances under steamboilers, discussion of paper by, 168-170.

Heat, Carnot on, 32 ; Clapeyron on, 32 ; consumption of, in expansion, 28 ; conversion of, into mechanical effect, 29 ; curve of equal, 33 ; (dynamical theary of, 30,62 ; Helmholtz, Mayer, Rankine,'Thomson on, rcference to, 32 ; practical application of, 52 ; Regnault's experimental proof of, 54); economical application of, 62 ; (cngine, formula to express power of, 37 ; Holtzman on, 32 ; relative economy of, 38) ; identity of, and dynamical effect, 53 ; lost, 62 ; (material theory of, 29, 30; disproved by Davy, Dulong, Joule, 30 ; how explained, 30) ; scientific application of, 62 ; specific, proportionate to expansion, 34 ; theoretical views
JOY, $\mathbf{D}$.

regarding, 29 ; undulatory theory of, 29 ; (unit of, 31, 53; Joule's, 31, 74 ; results by different observers, 32 ; unaffected by matcrial, 31 ).

Heating by steam. See Steam, Heating by.

Heating furnaces, application of regenerators to, 93 .

Helmholtz on heat, reference to, 32 . High pressure engines, reference to, 4 . See Regenerative Condenser for.

Holtzman on heat, reference to, 32 .

Hornblower, surface condenser of, 12.

Hot-blast stores. See Regenerative hot-blast stoves.

IlLOMTNATIXG gas, 181 ; first employed in 1792,181 ; illuminating power of increased by drawing from bottom of retort, 100, 101 ; value of bye-products from, 186 .

Injection condenser. See Regenerative condenser.

Injector. See Giffard injector.

Interchanger of temperaturc, Siemens's, C. W., for refrigerating machincry, 193, 194, 201.

Iron, temperature of maximum strength of, 58.

Irvine, latent heat, experiments on, 18.

Isolatcd steam. See Steam.

JAMESON, J. W., combined vapourengine and expansive engine, discussion of paper by, 69-72.

Jet. Sec Steam jet.

Jones's coal-getting machine, 129.

Joule, material theory of heat disproved by, 30 .

Joule's unit of heat, 31,74 ; views regarding elastic pressure, 31.

Joy, D., reversing and expansive valve-gear, discussion of paper by, $173,174$. 


\section{KILNB.}

KILss, brick and pottery, application of regencrative gas furnaee to, 94.

Kitson, F. W., Allen governor and throttle-valve for steam-engines, discussion of paper by, 159-161.

LAMCPADIU', gas investigations of, 181.

Lechatelicr, his method of freeing steam from water, 80 ; invention of Contre.vapeur system, 165; referenec to labours of, 165 .

Link motion doomed, 174.

Liquid fuel, 125 ; arguments in favour of, 126 ; combustion perfect with, 131 ; distilled from coal, 127 ; cvaporative power of, 126 ; grates for, 131 ; practical and theoretical results with, 125 ; priee of, 127 ; progress of, 130 ; sourees of supply of, 131 ; superiority of, to solid, 131.

Liquid gyrometer. Sce Gyrometer, liquid.

Liquid in rotation, 111 ; curve formed independent of specific gravity, 111 ; equations of, 112 ; formula for curve formed by, 111; paraboloid produeed by, 111 .

Lloyd and Summerfield's applieation of regenerative gas-furnace, $170_{-}$ 177.

Low-pressure engines, See Regenerative eondenser for.

Lürmann, gas-generating furnaees, discussion of paper by, 175-177; gas-producers criticised, 175, 177.

MarshalL, W. P., suggestions as to experiments on steam, 18.

Material theory. See Heat.

Mayer on heat, reference to, 32.

McCarter condenser, eriticism of, 167.

Meadows, J. MeC., peat fuel ma.
PERFECT RNGINE.

chinery, discussion of paper by, 166-167.

Mild steel. See Steel, mild.

Morin, Gen., experiments with regenerative steam-engine, 162.

Morton, A., cjector eondenscr for steam-engines dispensing with air-pump, discussion of paper by, $157,158$.

Motion, heat manifestation of, 30 .

Murdoch, J., illuminating gas produeed by, in 1792, 181.

Newall \& Co.'s trial of regencrative steam-engine, 61 .

Neweomen's condenser, 11, 167.

Newton. See Refrigcrating machinery.

Non-condensing steam-engines, 4 .

OPEN fireplace, method of heating by, 191 ; regenerator applied to, $18 \mathrm{~S}$; ventilation by, 191.

PAMBOUR's expansion curve of steam, based on Watt's law, 24.

Parker, W., experiments to burst stcel boiler, 173.

Paul, B. H., liquid fuel, discussion of paper by, 125-127.

Peat, application of, 166 ; charcoal from, 166 ; conversion of into gas, 166 ; drying of, 166 ; fuel, importance of, 167 ; use of, in loeomotives, 166.

Perfect cngine, 47, 54, 162; and actual enginc compared, 38 ; eharacteristics of, 46,54 ; cylinder, capaeity of working for, 55 ; difficulty, pretical, of, 71 ; expansion, infinite in, 47,55 ; impractical nature of, reason of, 55 ; losses of hcat in, reduction of, 47 ; regenerator, application of, to, 47 ; theoretical 
PERKINS.

minimum consumption of fucl in, 163.

Perkins, steam-guns, experiments on, 35.

Pernolct, coal distillation, coke manufacture, utilization of bye products, discussion of paper by, 99-101.

Petit, expansion of air, 21.

Physical forces, conservation of, 53 (convertibility of, 53 ; illustrations of, viz., falling weight, 53 ; hammer striking anvil, 53; fire syringc, 54).

Plate-glass melting, application of regenerative gas-furnace to, 89,90 .

I'neumatic dispatch, circuit system, Siemens's, 146 ; coal consumption in, 147 ; speed of carriers in, 147 ; vacuum in, 147

Pneumatic despatch tubes, details of, 15ั3. Sce Steam-jet, Siemens's.

Pole, W., Cornish engine, treatise on, reference to, 34 ; expansive steam-engine, experiments on, 34 .

Power of heat-cnginc, formula for, 37.

Preston, F., McCarter condenser for steam-engines without air-pumps, discussion of paper by, 167-168.

Price's gas-producers, 175 .

Priming in boilers prevented, by injecting hot air into water, 136.

Producers. See Gas-producers.

Puddling. See Regenerative furnacc, Regenerative gas furnace.

Pumping, 68 ; Cornish engine, economy of, for high lifts in, 68 ; crank and fly-wheel, employment of, for low lifts in, 68 .

Pumping-cngine, theoretical effect of, 80.

Punch, helical, 172.

Punching, 171 ; experiments on, by Riley, J., 172 ; by Sharp, H., 172 ; tension in metal produced by, 172 . Pyrometer, copper or platinum ball
REGENERATIVE CONDENSER.

application of, 97 ; description of, 97 ; measuring high temperatures by, 97 .

QUANTITY of heat, 18 ; in steam, 18.

RAISING water. See Steam-jet, Siemens's.

Rankine, dynamical theory of heat, 32 ; fuel, evaporative power of, 126 ; steam, expansion of, 33 ; steam-jet, investigations on, 144.

Refrigerating machinery, 192 ; power-producing machinery and, cssential difference between, 195 ; Siemens's interchanger of temperature for, 193, 194, 201, cost of ditto, 202 ; (Dr. Gorrie's or Newton's, 193 ; action of, 194 ; conception of, crror in, 194 ; description of, 195 ; engine power, expenditure of, examination of and report on, 195 ; cxpanding apparatus in, inquiry into cause opcrating against performance of, 199 ; experiments madc with, 196 ; theory of, 197 ; trial of, 193).

Regenerative coke-ovens, 100 ; no secondary products with, 101.

Regenerative condenser, action of, $1,3,6$; addition of, to injector condenser, 5 ; applications of, 2, 8, 16 ; (for High-pressure engines, 4 ; action of, 5 ; advantages of, 7 ; applications of, 8,16 ; description of, 4 ; dimensions of, 8 ; indicator diagram of, 6 ; saving of fuel with, 8 ;) (Injection, 15 ; present form of, 15 ;) for locomotives, $9,16,17$; (for Low-pressure cngines, 11 ; advantages of, 11 ; description of, 11 ) ; Society of Arts' Gold Medal awarded to, 2; (Surface, 13 ; description of, 13,15 ; esscntial features of, 13,15 ; rationale of, 13) ; water required for, 2,6 . 
REGENFRATIVE FURNACE.

liegenerative furnaee, 62 ; action of, 6t; alternating prineiple of, 66 , 83 ; applieable for intense heat, (i2, 6t, 66 ; briekwurk of, durability of, 605 ; deseription of, 63 ; difficulty in comnection with, 83 ; economy greatest in, 67 ; gaseous fuel, first use of, in, 84 ; heat in, aecumulation of, 64 ; invention of 1. Siemens, 63 ; smokeless, 65 (puldling iron with, 65; advantage of, 66 ; experienee limited with, 67 ; hent retained long in, 67 ; quality of iron improved in, 65 ; temperature high in, 67 ; time employed in, 66 ; yield large in, 66).

liegenerative gas fire for ordinary grates, 188 ; cost of, 189 ; deseription of, 188.

Regenerative gas furnaee, 81 ; advantages of, 93 ; applications of, 81 ; (application to puddling and welding iron, 92,96 ; plate-glass melting, 89 ; round flint glass furnaee, 91; stcel melting, 94); eost of construetion of, 98 ; essential features of, 95 ; flame, regulation of, in, 96 ; fuel employed in, 81 ; gas and air heated by waste produets of eombustion in, 81 ; gas-produeer, separate, for, 85,86 ; gasifieation of solid fuel for use in, 82,85 ; heat, effect produeed by, 81 ; heat, transfer of, in, 82 ; pots, open, used in, 92 ; principle of, 82 ; siege kept eool in, 89 ; temperature of regenerators of, 91,97 .

Regenerative gas lamp, deseription of, 189 ; intense light of, 189.

Regenerative hot-blast stoves, 132 ; differ from ordinary hot-blast stoves, 132 ; reason for economy of, 132 ; save heat in blast furnace, 134 ; temperature, high, attainable with, 132.
ROBINSON, J.

Regenerative prineiple, 62 ; universal applieability of, 63.

legenerative steam engine, 50 ; applieations of, 61 ; eylinder, regenerative, description and objeet of, 55 ; essential parts of, viz., furnaee and working and regenerative eylinders, 55 ; essentials of heating vessel in, 58; respirator, use of, in, 56 ; similarity to Stirling's and Eriesson's engines only apparent, 59; working of, 55, 56.

Regenerator, 27, 47; aetion of, 49 ; eonflieting opinions regarding, 42 , 48 ; discovery of prineiple by Stirling, $39,57,82$; employment of for high temperatures suggested by F. Siemens, 82 ; Eriesson's views regarding, 27 ; experimental investigations by siemens, C. W., on action of, 47 ; heating surfaee insufficient in Eriesson's, 49 ; suspieions regarding, 49,57 ; useful application of, 49 .

Regenerators, eomposed of, 83,84 ; reversing valves in, 84,93 ; simplicity and permaneney of, 63 .

Regnault, disapproval of Watt's law by, 17, 19; (experiments of, 32 ; Cavendish Soeicty published, 20); quantity of heat in steam, 19. S'e Dynamieal theory, Gas retorts, Watt's law.

Respirator, 48, 57. And see Regenerator.

Retorts. See Gas retorts, Gaseous fuel.

Riley, J., on punching, experiments by, 172 .

Riveting. See Boilers.

Robinson, J., Giffard injeetor for feeding steam-boilers, diseussion of paper by, 78-79; modern locomotives, designed with a view to eeonomy, durability, and facility of repair, diseussion of paper by, 165. 
RUMFORD.
Rumford, steam, quantity of heat in, 19.

Ruthven, re-action propeller, reference to, 124.

Ryder, J. N., superheated steam, application of, discussion of paper by, 72-75.

ST. HELEx's Glass Works, application of regenerative gas furnace at, 89.

Saltley Works, experiments on regenerative condenser at, 16.

Saturated Steam. See Stcam, saturated.

Selwyn, Captain J., liquid fuel, progress of, discussion of paper by, 130-131.

Sharp, H., punching experiments by, 172 .

Siemens, C. W. See Expansion of air, Gas-engincs, Gas-producers, Gaseous fuel, (Governor's, Chronometric, Gyrometric), Gyrometer ; papers by, 1-2, 3-17, 17-26, 29-50, $50-61,62-65,81-95,107-123,141-$ 153, 177-190; Refrigerating machinery (Regenerative Condenser, furnace, gas fire, gas furnace, gas lamp, steam engine), Regenerator, Steam, Steam-jet ; suggested coalgetting machine, 129.

Siemens, F., regenerative furnace, invention of, 63 .

Southern, latent heat of stcam, 19.

Society of Arts' Gold Medal awarded to regenerative condenser, 2.

Specific heat of elastic fluid proportionate to rate of expansion by heat, 34 .

Speeds, alternation of, affecting steam governors, 140.

Steam, ancient knowledge regarding, 50 ; combined, 76 ; conducting power of, 61 ; expanded is superheated, 24; (expansion of behind

\section{STEAM ENGINE.}

piston, causes condensation, 33, 34 ; Clausius, Rankine, referred to, 33); (expansion of isolated, 21; Frost's experiments on, 21 ; Siemens's apparatus for determining, 21 ; and law of, 21 ; and curve of, 22 ; and expcriments on, 22 ; and table of, 25); (expansion of saturated, 23 ; agrecs with that of air, 23 ; curve of, 33 ; variation of pressure and density of, 23); heat of, increased with density, 60 ; (heating by, 190; closeness of atmosphere with, 192 ; criticism of system of, 191; gas preferable to, 191 ; large pipes necessary for, 191 ; objections to, 191); high prcssure, cooling effect of expansion of, how explained, 24 ; high pressure contains excess of heat whicl superhcats expanded, 20, 24 ; latent heat of, observed by Black, 18 ; mixcd with air, 136 ; quantity of heat ill, 18,19 ; preferable to other elastic mediums for caloric engines, reasons why, 60 ; rise of temperature with pressure of, 78; saturated, great capacity for heat of, 76 ; specific gravity of, 60 ; (superheated, advantages attained with, viz., complete eva. poration, 73, condensation prevcnted, 73, 74, 77, and increased bulk, 73 ; trial of, 72,73 ; considerations in experimenting with, 73 ; economy by use of, not great, 76 ; heat advantageously applied in, 74 ; joints for, difficulty with, and cement for, 75 ; regenerative steam, versus, 75 ; saving by use of, 75); (total lieat of, 17 ; Siemens's, C. W., apparatus and experiments for determining, 20, 26 ; Watt's law for, 19).

Steam engine, air engine, comparison and essential difference between, $39,46,138$; application of, recent, 
STEAM-EXGINE GOVIRNOR.

50 ; efticiency of Watt condensing, 23 ; (expansive, 24 ; condensation, effeets not shewn in dingrams of, 34 ; condensing, example of, and indiented horse-power of, 37 ; when theoretically perfeet, but impracticable, 35 ) ; first suggested use of, 50 ; high pressure, loss in, 4 ; low-pressure condensing, diagram of, 35 ; power of, depends on, 29 ; prineiple of, laid down by Watt, 50; (Watt's, 50 ; improvements, recent, of, 51 ; organic parts of, viz., furnace, boiler, cylinder, and condenser, 51).

Steam-engine governor. See Governor.

Steam jacket, 69 ; advantage of, 69 ; cundensation in eylinder prevented by, 72; cylinder, sides and end require, 69,138 ; Watt's engine supplied with, 72.

Stean jet, 141; air delivery by, dependent on surface contact between air and steam, 143, 154; air delivery in inverse ratio to weight of air acted on, 143 ; air pressure, limit of, attainable with given pressure of steam, 143; elnstic force changed into onward motion in, 153 ; investigations regarding, by Rankine, 144, and Zeuner, 144 ; parts, judicious arrangement of, 141 ; principle of action of, 143 ; simplicity of, 141 .

Steam jet, Siemens's, 142 ; air delivered proportionate to surface contact in, 154; annular jet of steam in, 142, 143, 156 ; applications of (to evaporation of sugar, 150 ; costly apparatus saved by, usc of, in, 151 ; description of arrangement of, 151; successful experiments with, 152) ; (to GasProducers, 152; advantages of, 153; description of, 152); (to Pneumatic Dispatch Tubes, 146 ;

\section{SUP PRIEATED STEAX.}

description of, 147 ; intercepting apparatus for, 147, 148); (to raising water, 148; apparatus, description and action of, 149 ; lift attainable with, 150 ; preliminary results with, 150); compression or exhaustion proportionate to steam pressure in, 143, 154 ; con. clusions derived from experiments with, 143 ; delivery tube in, parabolic curve, best form of, 143,155 ; description of, 142; details of, considered, 156 ; exhauster exhibited in action, 155 ; (experiments with as blower, 146 ; as exhauster, 145); rationale of, 142 ; steam orifice, inercase of area of, with increase of compression or vacuum, 157 ; and Zeuner's apparatus com. pared, 144, 145.

Steam steering engine, 124 ; auxiliary propulsion, useful for, 124 ; submarine tclegraph ships, impor. tant for, 125 .

Steel boilers. See Boilers.

Stecl melting. Sce Regenerative gas furnace.

Stecl, mild, application to boilers, 170 ; homogeneity of, 171 ; punching plates of, 172 ; tearing of, 171 ; yiclding property of, 170 .

Stirling, regenerator or respirator, invention of, 57.

Stirling's engine. See Air engine, Stirling's.

Straw, analysis of, 169 ; ash in, 169 ; heating power of, 169 ; water in, 169.

Stc.-Claire Deville, dissociation, reference to, 204.

Submarine telegraph ships, difficulty of mancuvring, 125 ; steam steering apparatus for, 125.

Sugar, evaporation of. See Steam. jet, Siemens's.

Supcrhcatcd steam. See Steam, supcrherted. 
SURFACE CONDENSER.

Surface condenser. See Condenser, Condensation, Regenerative condenser.

TABLE of comparative merits of steam and air engines, 46; (of experiments on expansion of isolated atmospheric stcam, 25 ; with steam jet as a blower, 146, and as an exhauster, 145); of quantity of heat in steam, 18, 19.

Tempcrature of combustion limited, 179,203 ; of condensing water, 4 ; of regenerative furnace, 67 ; of regenerative gas furnacc, 91,96 , $97,180$.

Thomson on heat, reference to, 32 .

Total heat of steam. See Stcam.

Tresca, experiments with regenerative steam engine, 162 .

UNIFORM rotation, 107 ; liquid in rotation applicable to production of, 112 ; obtained by Chronometric Governor, 109.

Unit of heat. See Heat, Joule.

Ure's experiments on condensation, 14 ; on quantity of heat in steam, 19.

\section{ZEUNER.}

VALVE gear, Joy's reversing and expansire, 173 ; best expansive, 174 ; perfect cut-off with, 174.

Vegetable substances, combustion of, 168.

Vena contracta, for steam jet, 156 .

WARDLE, C. W., Giffard injector, as elevator for colliery drainage, discussion of paper by, 79-81.

Water, absorption of heat, slow, by, 14 ; condensing, temperature of, 4 ; conductive power low of, 14 ; specific, heat of, high, 14 .

Water gas, rcference to, 133.

Water raising. See Steam-jet, Siemens's.

Watt's condenscr, 3,12 ; governor, $107,108,140$; law of total hcat of steam, 19 ; steam cngine, 50,51 ; steam jacket, 72.

Welding. See Regenerative gas furnace.

Wenham's hcated air-engine, 161.

Wethered, J., combined stcam, discussion of paper by, 76, 77 .

ZEUNER'S experiments on steamjets, form of apparatus, 144. 


\section{METALLURGY.}

\section{ABSORPTION.}

A Bsorption of carbon by iron rules "number" of pig-metal, 265 ; of heat in blast furnace by traus. fer of oxygen of ore to carbon of eoke, 262.

Actual consumption of fuel to smclt a ton of iron, 264.

Adamson, D., iron and mild stecl, mechanical and other properties of, discussion of papers by, 373$378,409-412$.

Adamson's test picce, objection to, 373.

Additional height of blast furnace: 256 ; consumption of fucl, reasons why theoretical, not attainable by, $256,257,267$; fails to produce economy beyond ncutral point, 257.

Advantages of open top to blast furnace, 332.

Akerman, Prof, hardening iron and stecl ; its causes and effects, diseussion of paper by, 433-435.

Åkerman, Prof., rotary furnacc, report on, 342 ; on steel, 375.

Allen, IV. D., Bessemer stecl, usc of mechanical agitator in manuture of, discussion of paper by, $450-452$.

Ammonia uscd in making soda, 330 .

Analysis of cinder from puddling furnace, 241 ; of puddled bar, illustrating separation of impurities in puddling, 244; of paddling furnace contents, by Messrs. Calvert and Johnson, 238.

Ancient metallurgical methods wasteful of fuel and material, 330 .

Ancient sleel, hardness of, 379 ; high quality of, 379 ; process, deseription of, 378,379 .
BASIO LINING.

Anncaled stcel reduced in strength, 427.

Anncaling, irregular heating in, 447 ; overheating in, 447 ; proeess eritieised, 446 ; after punching, 371 ; of stcel, 407 ; of stcel castings, 465.

Annealing hard stcel, nccessity of, $421,427$.

Anthracitc coke, 325 ; Appold ovens for, 327 ; binding material for, 326 ; in blast furnace improves quality of pig-iron, 332 ; height of blast furnaces for, 326 ; in horizontal coke ovens, 327 ; Landore blast furnaces designed for, 326 ; manufacture of, at Creusot, 326 ; proportions of material in, 327 ; sulphur disappears with use of, 327.

Architectural purposes, steel for, 404.

Armstrong system of ordnance, 398 .

Attwood, C., attempt to make steel on hearth of regenerative furnace, 388.

Averages, applicable to errors of observation, 442 ; illustrations of, 442.

BALLING, iron prevented from, by copper, 306, 331.

Barnaby, N., naval construction, use of steel in, 409-412; shipbuild. ing, iron and steel for, 313-315, discussion of papers by.

Basic lining, transition from siliea lining to, in Bessemer, puddling and open-bearth steel furnaces, 414. 


\section{BASIC PROCESS,}

Basic process, 436 ; pig-metal suitable for, 437 ; sulphur should be removed in blast furnace for, 436 ; tapping slag in, 436 .

Bauxite, analysis of, 217, 297, 298 ; converted into emery by intense heat, 296 ; infusibility of, 296 ; Le Chatelier's proposal to use, 217 ; lining of calcined, and plumbago powder, 296 ; resists fluid cinder, 296 ; supply of, 304.

Beam of steel $v$. beam of wood, 405 .

Bell, I. L., address of, discussion of, 309-310.

Bell, I. L., blast furnaces of different dimensions, development and ap. propriation of heat in, 264-268; blast furnaces, economy of fucl in, conditions of, 276-279; Price's retort furmacc, 324-325 ; separation of impurities from iron in different processes, 353-360 ; separation of phosphorus from pigiron, 362-365, discussion of papers by.

Bell, I. L., on blast furnace, 264 ; diagram of, on distribution of temperature in blast furnace, 290; discussion with Siemens,C.W., on blast furnacc, 358,359 ; process of dephosphorization, 362 ; standard paper on blast furnace, 265 ; views on hot blast for and capacity of blast furnace, 276 .

Bending test for steel, maintenance of, 420.

Berkley, G., iron and steel, strength of, \&c., discussion of paper by, 269-271.

Berrier-Fontaine, M., shipbuilding, steel for, discussion of paper by, 448-450.

Bessemer, H., reference to, 375 ; reference to remarks by, 305 .

Bessemer converter and opcn-hearth steel furnace compared, 375 .

Bessemer medal, presentation of

\section{BLAST FURNACE.}

to Prof. von Tunner, 360 ; remarks on occasion of, 360 .

Bessemcr steel, early, 411 ; for general purposes, 376 ; pouring of, ebullition in, 322.

Bessemer stcel process, 215, 438; application extended, of steel due to, 215 ; chcap steel produced by, 215,380 ; difference between ore process and, 287 ; difficulty of rcmoving sulphur and silicon in, 436 ; ferro-manganese or spiegelcisen in, 212; high qualityof steel not always producible with, 411 ; high temperature of fusion produced by oxidation of iron in, 286 ; im. purities concentrated in diminished weight in, 376,411 ; industries revolutionized by, 381 ; first introduction of: 380 ; Mushct's addition of spiegeleisen to, 212, 380 ; occlusion of oxygen in metal made by, 287 ; oxidation of carbon and silicon in, slight oxidation of manganese in, non-oxidation of phosphorus and sulphur in, 286 ; results of, 381 .

Birmingham Sample Steel Works, advantage of, 218.

Blair's process, criticism of, 319 ; spongy iron by, 365 .

Blast furnace, additional height of, $256,257,266$; Bcll's, I.L., a standard paper on, 265 ; boshes of, increased temperature at, 267 ; capacity of, considerations determining, 274, 275 ; capital expenditure $v$. other means of saving in, 275 ; charging hopper of, advantage and economy by closing, 256 ; equality of heat brought in by hot blast, and carried away by escaping gases from, 263,264 ; equality of ore charged and smelted in, 257 ; amount of gases, $\mathrm{CO}$ and $\mathrm{CO}_{2}$, passing from, 260 ; gases issue at reduced temperature from, with increased tem- 
BLISTER BTEEL.

perature of hot blast, 267 ; temperature of, unaffected by temperature of hot blast, 268.

Blister steel, 328.

Board of Trade limit of strength for mild steel, $375,408$.

Boilers, enreful inspeetion of, 462 ; mild steel for, 367 ; steel not elongating $20 \%$ in $8^{\prime \prime}$ unfit for, 463 ; testing of, 462 ; thiekness of plates for, exeessive, 463 ; Trade, Board of, rules for, 462 .

Bridges, American suspension, made of steel, 404.

Brittleness of hard steel rails eaused by cold, 272.

CALCULATION of heat necessary in blast furnace to melt cinder, 261 ; to melt iron, 261.

Caleulation of iron oxide required in puddling, 243.

Calculation of metal produced from cinder in puddling furnace, 241, 242.

Capacity of blast furnace, 291 ; considerations determining, 274, 275 ; depends on nature of eoke and ore, 274 ; economical heating due to large, 275; gaseous flow slow with large, 274 ; time for chemical reaction due to large, 275 ; work done in relation to, 275.

Capital expenditure $v$. other means of saving in blast furnace, 275 .

Carbon, ehemical tests of, in steel, 340 ; ehemieally eombined in hard steel, 339 ; combination of, in steel, mode of, 339 ; mechanicaily mixed in soft steel, 339 ; phosphorus and sulphur in puddling furnace, order of removal of, 238 ; in puddling removed with ebullition, and evolution of carbonic oxide, $\mathrm{239}$; in steel, pereentage of, 210 ;

vor. I.

\section{CH ENOT'A PROCESS.}

table of, in erst and wrought iron and stecl, 253.

Carbonic oxide, absorbed by fluid stcel, 322 ; heat rendered latent in formation of, 262.

Carburization of stecl, degree of, 419.

Caron on steel, 211.

Casson Dormoy puddling furnaee, 333; eireular puddling ehamber in, 334; eooling puddling ehamber of, mode of, 334 ; dandy in, use of, 334 ; experiments with, 333 ; fettling in, 334 ; time required to bring iron to nature in, 334 .

Cast iron, danger of, for buildings, 406 ; tables of earbon and silieon in, 253.

Cast stecl, manufacture of, 209 ; by Shefficld proeess, 211.

Casting, moulds divided longitudinally for, 336 ; moulds filled from below for, 336 ; oxidation of metal in, 335; running metal through refractory material in, 336 ; Sicmens-Martin proeess, arrangements for, in, 335.

Catalan forge, 214.

Cementation stecl process, 214, 328 .

Chalk, a thorough cinder, 310 ; result of double eombustion of ealeium and earbon, 310.

Charging hopper of blast furnace, advantages and economy by elosing, 256.

Cheap eonstruetive material, steel as, 405.

Cheapness injuring stecl, 432.

Chemical admixture, perfeet and imperfeet, 451 ; analysis of steel, importanee of, 424 ; problems in puddling, 238 ; work required to smelt ironstone, calculation of amount of, 260.

Chemistry, value of, 209.

Chenot's process of manufacturing spongy iron, 365 . 


\section{CHILliNg.}

Chilling effects similar to those of rolling and hammering, 434.

Cinder, in blast furnace, heat necessary to melt, 261 ; from puddling furnace, analysis of, 241 ; in puddling furnace proteets metal, 243.

Clay's experiments with spongy metal, 292, 365 .

Cleveland pig, difficulty of climinating phosphorus in puddling, 283 ; unsuitable for steel-making, 282.

Coal pits, gas-produeer at bottom of, 224.

Cochrane, C., blast furnaces, wastc gas from, and inereased capacity of, diseussion of paper by, 255 264.

Coke in blast furnace produces only bुrd heat-producing power, 290.

Cold affects steel, 364,428 .

Cold-shortness in steel, 212, 288.

Columns of steel, 407.

Combining oxygen of ore with earbon of fuel, ealculation of heat required for, 262.

Combustion, in blast furnace of fuel into $\frac{4}{5} \mathrm{CO}$ and $\frac{1}{5} \mathrm{CO}_{2}, 260,262$; in blast furnace and hot-blast stove compared, 279,290 ; hindered by dissociation, 384 ; theoretical and praetical limit to temperature of, 384.

Compressed metal, zone of in punching steel, 370 .

Compressed steel, Whitworth's fluid, $320,321,429$.

Compression of steel, 429 ; by gas pressure, 429 ; honeycombed structure redueed or removed by, 429 , 430 ; by Whitworth's process, 429.

Conductivity of metals affected by foreign ingredients, 330 .

Conflagration, ordinary temperature of, below that of fused steel, 406 .
DAVIS, A.

Consumption of fuel in blast furnace, diminution of by hot blast, 291 ; in blast furnace, regarding, $256,257,267$; to smelt a ton of iron, 263,264 ; in steel production, 302.

Cooling steel gradually in ingot, 450 . Cooling tube for gas-producer, 222, 245,386 .

Copper, blast furnace yield increased by, 331 ; contaminated by silver, 330 ; eliminated by direct process, 305 ; iron prevented from balling by intermixture of, 306,331 .

Cornish boilers, economy due to large heating surfacc of, 274.

Corrosion, 449 ; Admiralty early experiments on, 441 ; cinder in iron affects, 443 ; diminished by removing oxide, 443 ; experiments on, at Landore, 443 ; galvanic aetion affeets, 441 ; recent experiments on, 441 ; relative, of iron and steel, 440 ; scale in steel affeets, 443 ; variable opinions regarding, 441.

Corrosion of steel, 374 ; compared with that of iron, 440 ; due to manganese, 365, 368, 392 ; general expericnce on, 444 ; by riveting steel plates with iron rivets, 449 .

Creusot, manufaeture of anthraeite eokc at, 326.

Crucibles, fusion of steel in, 229 ; in regenerative gas furnaee, 229 , 381.

DAMAscus steel, 379.

Danks's rotary puddling furnace, difficulty of puddling overcome in, 280 ; lined with metallic oxides, 281 ; inapplicable to SiemensMartin process, 281 ; yield in, 283.

Davis, A., steel-compression, discussion of paper by, 429-433. 
DEAD MELTING.

Dent melting, eusused by oxygen in iron going to carbon, 337 ; caused by retaining steel in fluid condition at comparatively low tempcrature, 337 ; illustration of, from completing Bessemer blow, 338; shefticld prnetice for, 337 ; Snelus's view of, criticism of, 337 .

Decarburization stcel process, 214.

Definition of stecl, eriticisms of, 316 , 317 ; Hackney's, as malleable fused iron, 316 ; Pcrey's, as iron capable of hardening, 31 l; ; Siemens's, C. W., as iron eompounded to possess supcrior strength, 316 , 323 ; want of good, 402 ; Whitworth's, by its strength and toughness, 317.

Denny, W., shipbuilding, stecl for, diseussion of paper by, 426-428.

Dephosphorization, 413; bauxite bricks for, 413 ; Bell's, I. L., process for, 362 ; eaused by basic material added to the bath, 415 ; of Clevcland pig, by rich iron oxide, 363 ; eost of, by Bell's, I. I., proccss, 363 ; depended on basic einder, high temperature, and oxygen, 416; expcriments by Siemens, C. W., in 1863 on, 413 ; ferrous oxide used in, 415 ; iron destroyed in, 415 ; Le Chatelier's bauxite lining for, 413 ; lime lining for, 363 ; magnesia lining for, 413 ; in open-hearth proeess by addition of silicon-iron and spiegeleisen, 417 ; in rotator, 362 ; by tapping off first slag before balling in rotator, 418 ; Thomas and Gilehrist's paper on their prosess of, 413 ; Williamson, Prof., suggests use of other bases than iron oxides for, 363 .

Dic should be larger than punch in punching mild stecl, 371 .

Direct process, advantagcs of, combined with pare and intense heat,

\section{lixgiNT.}

341 ; copper eliminated by, 305; for iron and stcel mnnufacture, 303, 340 ; prnctical objections to, viz. rich ores, pure fuel, and much labour, 341 ; pure iron by, 341 ; for redueing iron by foreing earbonic oxide into it, 303 ; simplicity of, $3+1$.

Direct stecl process, 289.

Direet wrought-iron proeess, 289.

Dirt, Yalmerston's definition of, 330.

Dissuciation hinders combustion. 384 .

Distillation of eoal in gas-producer, $221,245,385$.

Drilling and punching compared, 410.

Ductility of stecl, 459 ; of steel castings, 466 .

ECONoMICAL and wastcful puddling compared, 283.

Economy of blast furnace affectcd by use of hot blast, 276 ; of fuel in regencrative gas furnacc, 224 , $225,247$.

Elasticity, ealcalating, experiments for, 270 ; definitc limit of, in metals, 269 ; limit of, no elongation by strain within, 269, 270 ; limit of, more important than ultimate strength, 271,423 ; of metals not affected by time, 269 ; of stecl, 420,459 ; of stecl, experiments wanting on influcnee of tcmperature on, 424 .

Elimination of carbon, manganese and silicon in ore-redueing process, 286 ; of sulphur and phosphorus in ore-reducing process eompared with Bessemer steel process, 304.

lilongation tests must exelude drawn portion, 434.

Eugine working directly on rolls, criticism of, 439 . 


\section{ENGINEERING "STRUCTURES.}

Engineering structures, steel for, 375.

Equality of heat carried away from blast furnace by escaping gases, and brought in by hot blast, 263 , 264.

Equality of ore charged and smelted in blast furnace, 257.

Errors of observation, averages applicable to, 442.

Experiments on puddling by Price and Nicholson, 238.

FACTOR of safety, calculated erroneously in terms of ultimate strength, 271 ; ductility as affecting, 464 ; for steel, $428,459,460$.

Failure of Chenot, Clay and Renton to puddle spongy iron, 242.

Failure of steel, causes of, 409 ; due to faults in treatment, 410 ; due to silicon, 377 .

Falling weight test of steel, 271.

Faraday described regcnerative gas furnace in 1862, 210.

Final action in blast furnace, 290.

Fluid steel, carbonic oxide absorbed by, 322.

Forth bridge, steel for, 420 .

Frémy on steel, 211.

Fuel, in blast furnace, should live down to crucible, 327 ; availablc for gas-producer, $219,245$.

Fuel consumption in blast furnace, minimum $7 \frac{1}{2} \mathrm{cwt}$., error in calculating, 256, 257 ; minimum, recapitulation of arguments regarding, 259.

Fuel, theoretical minimum, in production of steel, 302 .

Fused steel and other steel, distinction between, 323 .

Fusion of steel, importance of, 403 .

Fusion of steel in crucibles, 229 ; (in regenerative gas furnace, 229 , 381 ; bed of coke-dust for, 229 ;

\section{GASES،}

saving and arrangement of crucibles in, 229 ; reduction of cost of, 229 ; melting chamber for, 229 ; saving of fuel in, 229.)

Fusion of steel processes, 215 ; in crucibles, 229 ; Hindoo, recently revived by Heath, Price \& Nicholson, Gentle Brown, and Atwood, 216 ; Huntsman's, 215 ; openhearth, q. v. ; Réaumur in 1722 used, 215 ; regenerative openhearth, $q . v$; Uchatius's, 216.

GAS-producer, 219, 385 ; air, how admitted to, 220, 245; aqueous vapour, utilization of, in, 221 : charging arrangement for, 219 , 385 ; $\mathrm{CO}_{2}$, how reduced to $\mathrm{CO}$, in, $220,245,385$; coal pits, bottom of, for, 224; composition of gases from, 219 ; cooling gas from, advantage of, 223, 386 ; cooling tube elevated, for, $222,245,386$; damper, sliding, for, 245 ; description of, 219,245 ; distillation of tar and hydrocarbons in, 221, 245, 385 ; any fuel available for volatilization in, 219, 245; gas, low heat of combustion of, 220 ; grate of, 220 ; grouping of, and leading gas from into main flue, 224, 246, 387 ; indraughts into, how prevented, 221 ; losses in, consideration of, 324 ; objections to, refuted, 223 ; plenum of pressure within, how maintained, $222,223,245$; retorts for, 325,454 ; steam decomposed in, 221 ; surplus heat of, how utilized, 221 ; syphon arrangement of, $222,246,386$; temperature of gas rising from, 222 , 385 ; total loss in, 12 per cent., 324 ; waste heat of, how utilized, 221.

Gases set free in moulds in congclation, 335. 


\section{GENTLE BROWN.}

Gentle Brown, revival of Hindoo steel process by, 216.

Gilehrist, P. G., phosphorus, elimination of, discussion of paper by, 413-415.

Girders of steel, 407.

Goverument tests of inventions without patentec's co-operation an interference with his rights, 457.

Graphite uneonsumed in blast furnnce, 327.

Guns, effeet of gunpowder on, 453 ; interual chilling and subsequent gradual cooling proposed to equalise strain in, 400; steel better than iron for, 453 ; use of steel ensures lightness and strength in, 453 ; temperature, necessary adjustment of, for shrinking hoops on, 453,454 .

HACKxEY's definition of steel, 316.

Hackney, W., anthracite coke, manufacture of, $325-328$; steel, manufacture of, $315-320$, discussion of papers by.

Hard coke comes out with slag from blast furnace, 327 .

Hard and mild steel equally strong within limits, $395,420,423,424$.

Hard steel rails, brittleness of, from cold, 272.

Hard steel rails used in France, 318.

Hard untempered steel, 435.

Hardness of steel, 313.

Heat, absorption of in blast furnace, 262 ; application of, 209 (of combustion of coke in the blast furnace, 290 ; of gas-produeer, low, $220)$; evolution of, in relation to volume, 261; generation of in. tenae, 209 ; rendered latent in formation of earbonic oxide, 262 ; (to melt einder in the blast furnace, ealculation of, 261; iron in the blast furuace, calculation of, 261 ;

\section{IMPURITIES.}

iron in cupolas, 261 ;) in smelting operations, viz., melting iron, melting ore, and transferring oxygen of ore to carbon of coke, $260,261$.

Heated steel, deflects before failing, 407.

Heaton and Hargreaves' steel process, 215.

Heath, applieation of manganese due to, 212,380 ; Hindoo steel proeess, revival of, by, 216 ; patents of, contested, 212.

High elass steel, purity of, 377 , 378.

High pressure, multitubular boilers unsuitable for, 372 (vessel to resist, deseription of, 372 ; joints of, 372 ; risk of explosion aroided in, 372 ; system applicable to steam boilers, 373).

Honeyeombed strueture reduced by compression, 429, 430.

Hot blast, 265 ; blast furnace economy affected by, 276 ; blast furnace gases affected by, 267 ; stoves, combustion in, eontrasted with that in blast furnace, 279 , 290 ; increases bulk of heat in blast furnace, 267 ; increased temperature of, improves economy of blast furnace, 266,267 ; increased temperature of, causes reduction in temperature of waste blast furnace gases, 267.

Hot-blast stoves, regencrators for, 258.

Huntsman's steel process, 215.

Hydraulic arrangements in steelmaking, 439.

Hydraulic eylinder of compressed steel, 439.

IMPURITIES, added to pig iron in blast furnace, 290 (in steel, 211 ; effect of, 338 ; experiments on, diffic ulties of, 214). 
INCREASED TEMPERATURE.

Inereased temperature at boshes of blast furnaee, negative effeet of, 267.

Indian Wootz made by steel fusion proeess, 215.

Ingots of steel, non-homogeneity of, 339.

Intelligenee required in using and working steel, 314 .

Iodine used in silver extraetion, 330 .

Ireland, J., iron sponge, reeent improvements in manufaeture of by Blair proeess, diseussion of paper by, 365-366.

Iron, in blast furnaee, heat necessary to melt, 261 ; slow oxidation of, in dry atmosphere, 277.

Iron ores, temperature of reduetion in blast furnaee, high for peroxide, magnetic and dense, 277 ; low for hydrated and spathose, 277 ; not high enough for Ilmenite and Marbella, 278.

Iron oxide, required in puddling, ealeulation of, 243.

KFNNEDY, A. W. B., mild steel, diseussion of paper on, 402-408.

LANDORE open hearth steel proeess, 388 ; bath, final adjustment of, in, 389 ; eharging pig metal and serap in, 390 ; ferro-manganese used in, 391 ; furnaee bed, Le Chatelier's mixture for, 231 ; limestone added to, 389 ; oré, advantages of, in, 391 ; oxidation with ebullition of gas in, 389 ; preliminary operations in, 389 ; sampling bath in, 389 ; serap, use in, advantages of, 391 ; slag from, 390 ; modifieation of, for speeial quality of steel, 391 ; stirring bath and tapping, 390; temperature requisite for, 389 ; time oeeupied in, 390 ; yield by, 390 .

\section{MANGANESE.}

Larkin, H., steel direet from ore, manufacture of, diseussion of paper by, 328-329.

Le Chatelier's proposal to use bauxite: 217.

Lefroy, Sir H., remarks by, regarding Siemens, C.W.: 378.

Lester, J., Danks's rotary puddling maehine, diseussion of paper by, 280-283.

Lime for furnaee linings, 304 ; and magnesia linings, Siemens, C. W.'s, experiments on, 305 ; used in oreredueing proeess, 304 .

Lime lining, dephosphorization by, 363 ; used in ore-redueing proeess, 304.

Limestone added to open hearth steel process, 411

Limit of elastieity in metals, 269, $270,271,423,424,459$.

Lining, basie,used in open-hearth steel proeess, 412 ; of ealeined bauxite, and plumbago powder, 296.

Livadia's steel plates, 444 ; burnt, 445 ; earbon varying in, 445 ; chemieal nature of, 445 ; irregular eomposition of, 444,445 ; silieon in, 445 .

Longridge, J., views on ordnanee eritieised, 399.

MACHINERY for steel-making, 437 ; eompound engine for, 438 ; eeonomy in steam engine for, neeessity of, 438 ; hydraulie arrangements in, 439 ; quiek-working reversing engine best for, 439 .

Magnesia lining, diffieulty of repairing, 413, 414 .

Maitland, Col., British Ordnanee, metallurgy and manufaeture of, diseussion of paper by, 452-458.

Manganese, aetion of, non-ehemical, 288 ; in blast furnaee removes sulphur from ore and fuel, 288 ; 
MANGANLSE IN BTELL.

oxidises out of steel, 364 ; red-shortness prevented by, 232; ill Sicuens process, retion of, 312 ; traees only of, in good steel, 364 .

Manganese in stecl, 212 ; action of, 339 ; aets as an alloy, 287 ; advantages of, 212 ; applieation of, due to Heath, 212, 380; when beneficial effect of eeases, 213 ; chemical action of, doubtful, 212 ; corrosion duc to, 365,392 ; dangerous ingredient, 374 ; distribution of, not uniform, 364 ; effect of, due to, 213 ; heterogeneity caused by, 368 ; neutralises sulphur, 312 ; Parry on, 213 ; phosphorus counteracted by, 339,364 ; report on by Hackney and Willis, 287 ; stcel remelted without, 213 ; rolling assisted by, $368,374,377$; sulphur counteracted by, 212 ; treacherous ingredient, 364, 392 .

Manufacture of east steel, 209.

Manufacture of stecl, advance, recent, in, 379 ; by Bessemer process, $q . \tau$; compared with that of wrought iron, 403 ; by fusion, 209 ; by Huntsman's process, 379 ; liquefaction neessary in, 214; Réaumur's proposal for, 379 ; by Martin's steel process, 218, 388 ; by ore or Siemens process, 284, 448 ; by serap or Siemens-Martin process, 284, 448; Swedish ore used for, 212.

Marché, E., steel, use of, matterz affecting, diseussion of paper by, 373-378.

Martell, B., shipbuilding, stecl for, discussion of paper by, 367-368.

Martin, open-hearth steel process, 218,388 ; gold medal awarded at French exhibițion, 218, 388 ; at Sireuil Works, 218.

Massanez, J., dephosphorizing in the converter, discussion of paper by, $436-+37$.

\section{MILI) STEEL.}

Material in blast furnace not eomparable with regenerators of hotblast stoves as heat absorber, 258.

Matheson, E., steel for structures, discussion of paper by, 458-462.

Mnynard, A. N., bridges, steel in construction of, discussion of paper by, 409-412.

Melting, ealculation of heat necessary for, cinder in blast furuace, 261 ; iron in blast furnace, 261 ; iron in eupolas, 261.

Metallic iron, in stcel, 398 ; in wrought iron, 398.

Metals, conduetivity of, 330 .

Mild steel, 407 ; annealing not required for, 427 ; arguments in favour of, 421, 427; Board of Trade limit of strength for, 375 , 408 ; for boilers, 397 ; boilers of, eannot burst, 431 ; careful manufacture and working of, 432 ; eastings, 464; ehemically pure iron, 369 ; compared with hard as regards strength and ductility, 428 ; compared with wrouglit iron, 398 ; contains $99 \cdot 75$ per cent. of metallic iron, 398 ; differs physically from iron, 369 ; duetility of, 421 ; for gun-making, 323 ; and hard steel equally strong within limits, 395 , $420,423,424$; and hard steel, tables of tests of, 396 ; homogeneity of, 449 ; not injured by sudden eooling, 421; Iris and Mercury buiit of, 431 ; mainly made by ore process, 416 ; by ore process, 448 ; plates, relative cost of, and Yorkshire plates, 432 ; punching action in, 370 ; punching or straining, strength inereased by, $371,397,446,447,449,460,461$; rails, preference for, 272 ; reliability of, 430 ; rivet bars of, 432 ; for riveted structures, 460 ; riveting plates of, 369 ; for shipbuilding, 397, 448; by siemens. 
MILTON, J. L.

Martin process, 448; solid flow a quality of, $422,450,460$; special, 432 ; steel rivets for plates of, 409 ; for structural purposes, 315 ; containing sulphur must contain manganese, 305; tearing of, due to its homogeneity and uniformity, 412; tears casily, 370 ; tests of, for tin plates, 422 ; uniform in quality in large masses, 315 ; working of, 408.

Milton, J. T., commercial marine, influence of Board of Trade rules for boilers on, discussion of paper by, 462-464.

Mushet's addition of spiegeleisen to Bessemer steel process, 212, $\$ 80$.

NATURE of steel, 210.

Nitrogen in steel, 211.

Nomenclature of steel, 435 ; various views regarding, 435 .

OBJECTIONS to blast furnace, theoretical and practical, 290.

Objections to gas-producer refuted, 223.

Occluded gases in steel, action of pressure on, 430.

Occlusion of gas, diminished with increasing temperature, 337 ; in steel, 337, 338.

Open-hearth furnace and Bessemer converter compared, 375 .

Open-hcarth steel, chemical composition of, 411 ; for special applications, 376.

Open-hearth steel process, 216 ; basic lining used in, in 1863 and 1865, 412 ; capability of regenerative gas furnace to produce steel by, 382 ; a chemical or cooking process, 318 ; description of, 318 ; dephosphorization by, 417; difficulties
ORE.

of, 217 ; Heath's, 216 ; limestone added in, 411 ; Martin's, q.v.; refractory material required in furnace for, 318 ; regcnerative, $q . v$; report on, by Ste.-Claire Deville, Bcauclerc, and Caron, 216 ; Siemens's, $q . v$.; Sudré's experiments on, under patronage of Emperor Napoleon III., 216 ; temperature, high, required in, 318 ; time for sample-taking and adjusting com. position in, 411.

Open top to blast furnace, advantages of, 332.

Ordnance, Armstrung system of, 398 ; hard material outside, weak inside, wrong system of constructing, 399, 401 ; Longridge, J., views regarding criticised, 399 ; mode of construction of, to suit mild steel, 398 , 401; stcel for inner tube, of, 400 ; strains, distribution of, in manufacture of, 400 ; Woolwich system of, 398.

Ore charged into blast furnace limited in quantity and capacity for heat, $256,257$.

Ore-reducing stcel process, 284; bath of fluid pig metal in, 284; bauxite objectionable for, 285 ; compared with Bessemer steel process, 286, 287 ; metal " dead melted" in, 287; decarburizing agent in, 287; disadvantage of raw ores for, 285 ; elimination early of manganese and silicon, and late of carbon in, 286 ; climination of sulphur and phosphorus in, 304; manganese, oxidation of in, 286, 287; mild steel made by, 416 ; output quickened by use of scrap in, 416 ; refractory material suitablc for, 285 ; and scrap process, difference between, 448 ; silica chemically objectionable in, 285 ; special or prepared ores for, 284 ; spiegeleisen, necessity for addition of in, 


\section{OXIDATIOX.}

257 ; steel of high quality produeed by, 285 ; sulphur and phosphorus cxidation of in, 287.

Oxidation of silicon and carbon, slight of manganese, and nonoxidation of phosphorus and sulphur in Bessemer steel process, 286.

PARKER, W., marine boilers, steel for, 369-373; steel plates of Livadia, 444-447; use of steel eastings in lieu of iron and steel forgings, 464-466, discussion of papers by.

Parry on manganese in steel, 213.

Patentec, guardian of his invention, 457.

Patentee's rights, and Government departments; 450 ; interferenee with, 457.

Perey, Prof, on puddling, suggestion that sulphur and phosphorus are remored by liquation in, 243 ; puddling, conelusions of on experiments ir, 238 ; steel, definition of, by, 316 ; on steel processes, 214.

Perfect steel should be aimed at, 419 .

Pernot's cireular furnace, eriticism of, 318,319 .

Phillips, D., iron and steel, comparative corrosion of, 440-444; J. A., reeent metallurgical proeesses, 330-331, discussion of papers by.

Phosphorus, difficulty of eliminating from Cleveland pig, 283.

Phosphorus in stcel, 211, 212, 288, 320 ; amount of permissible, 363 ; causes brittleness or eold short. ness, $212,288,363,425$; counteracted by manganese, 339,364 .

Phosphorus and sulphur innoeuous in steel under eertain conditions, 319.

Pieton, J. A., architectural construetion, iron as a material for, 402 408 ; construetive materials, pro-

\section{PUDDLING.}

gress of iron and steel as, 419422 , diseussion of papers by.

l'ig-iron, improvement in steel dependent on improvement in, 289 ; improvement in quality of by use of anthracite coke in blast furnaec, 332 ; "number" of ruled by absorption of earbon by iron, 265 .

Pinks's proeess of casting, 336.

Piping of steel in moulds, 312 .

Platinum, variation of electric conduetivity in east and welded, 236.

Poureel, A., dephosphorization of iron and steel, discussion of paper by, 416-419.

Pouring steel, agitation before, 450 , 451 ; ebullition in, 312; kept quieseent at high temperature, 452 ; stopping moulds in, 322 .

Precipitation process, bed for, 295 ; experiments proving suecessful reduction of iron by, 293, 295; furnace for, deseription of, 295 ; at Landore, table of results of, 293, 294; Mokta ore used in, analysis of, 295 ; manual labour and skill involved in, 295; rationale of, 293 ; results at Blochairn by, 294; slags from, analyses of, reference to, 295 .

Prejudice against steel, 404.

Price, J., testing rails, discussion of paper by, 271-273.

Priee's retort furnace, 324; and regencrative gas furnace, eriticism of Bell's, I. L., comparison of, 324 ; used at Woolwich, 325.

Price and Nicholson, revival of Hindoo steel process by, 216.

Properties of steel due to ehemical admixture, 379 .

Puddled bar, analysis of, 244 ; theoretical consumption of fuel in production of, eompared with aetual, 301, 302.

Puddling, chemical problems in, 238 ; economical and wasteful 
PUDDLING.

compared, 283 ; important branch of metallurgy, 237 ; Siemens's, C. W., views regarding, 239, 241, and confirmation of, $2 \varepsilon 0$; silicon removed in, 239; waste due to oxidation in, 242.

Puddling furnace, action in, popular views of, 239; analysis of contents of, 238; cooling puddling chamber of, by open vessel, 334 ; order of removal of carbon, sulphur, and phosphorus in, 238 ; yicld from, actual and theoretical, 242.

Puddling process, usually wasteful, laborious and incomplete, 244.

Punching, annealing after, 371 ; die should be larger than punch in, 371 ; and drilling compared, 410 ; or straining increases stcngth of mild steel, $371,397,446,447,449$, $460,461$.

Punching of steel, 460 ; action in, 370.

Purc steel, little influenced by temperature variations, 425 ; production of, 340 .

QUALITIES of steel, affected by treatment, 316, 317 ; determined by chemical test, 459 ; have to be studied, 314 ; various, 340.

Quantity of blast required in blast furnace, 279.

RAILS, actual test of on railway line important, 272 ; testing machine for, 272 ; wearing quality of, test of, 272 ; wheels on, propelling and sliding action of, 272.

Réaumur made steel by fusion, 215.

Recoil of gun carriages, checking by hydraulic compression, 457; (Siemens, C. W.'s, suggestion for, referred to by Col. Clarke at

\section{REGENERATIVE GAS FURNACE.}

Exetcr meeting of British Association, 457 ; used without acknowledgment by Government, 457).

lied shortness in steel, 211 ; prevented by manganese, 232 .

Ricduction of temperature of gases from blast furnace, how effected, 278.

Regenerative gas furnace, 209, 455 ; Sir Wm. Armstrong's allusion to, 455 ; arrangement of for lower temperatures, 387 ; cool chimney in, 224, 247 ; description of, applicable to ore and scrap open-hearth processes, 219, 382 ; most economical for high temperature, 387 ; cconomy of fuel in, 224, 225, 247 ; cconomy of steel melting in, 387 ; failure of at Royal Gun Factory, cause of, 455,456 ; failure of early Sheffield experiments, cause of, 217; Faraday described in 1862, 210 ; (flame in, conccntration of, 227 ; regulation of length of, 227) ; fusion of steel in crucibles, 229,381 ; gas and air separately heated in, 224 ; gas in, advantages of using, 227 ; heat accumulation in, 226, 247 ; heat, action of, in, illustrations of, 226 ; heat ample in, 218; heat of combustion, almost entirely available in, 387 ; heat below temperature of work utilized in, 224, 225, 247; heat nearly all retained in, 224, 225, 247 ; high temperature, effect of, in, 236 ; invented jointly by Sicmens, C. W. and F., 210 ; outward pressure in, advantages of, 228 ; gas-producer for, 245 , and see Gas-producer; rate of combustion of gas in, regulation of, 227 ; refractory material for, 226 , 236 ; regenerators for, 224,246 ; regulation of, by chimney-damper, 229 ; retorts formerly used with,

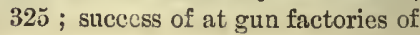


RLGENERATIVE GAS I'UDILING.

Armstrong, Krupp, Schneider and Whitworth, 45.5; tempernture in, practical limit of, 384 ; visible apyearnnce of flame in, depending on temperature, 384 ; Woolwich Arsenal type of, 455,456 .

liegenerative gas puddling furnace, 244 ; advantages of, detaited, 248 ; applications of, 252,309 ; nuxiliary henting chamber for, 248 ; bel of, with water bridges, 248 ; best iron from, 2.51 ; cost of, 254 ; criticisms on, reply to, 254,255 ; description of, 244, 246 ; flame in, command of temperature and quality of, 247,333 ; gas and air regulating valves in, 247 ; heat not wasted in, 254 ; heats increased in number with, 250 ; improvement of iron in, to what duc, 255 ; and ordinary puddling furnace, tables of comparisonl of, 249,250 ; power of, tested with inferior pig metal, 255 ; puddler's labour redueed in, 252 ; rabble applied to, 252; saving of fuel in, 251 ; water bridges in, consumption of fuel saved by, 252; workmen well disposed to, 254 ; yield of puddled bar, exceeds charge of pig metal into, 251.

legenerative open hearth ore process, 233 ; apparatus for, present form of, 233 ; charging in, manner of, 234 ; experiments over several years with, 233; Grand Prix at French Exhibition for, 233 ; heated gas forced among ore in, 234; qualities of ore for, 235 ; reduction of ore into sponge and dissolution in bath in, 234 ; ores used in, steel dependent on, 235 ; testing of metal in, 235.

Regenerative open hearth stecl process, 217, 389 ; Attwood's experiments, 217, 388 ; bauxite used il,

\section{EQENERATORS.}

217, 218, 388 ; Boigue, Rambour and Co.'s experiments at Montluçon with, 217 ; bottom repair of in, 389 ; eharging materials, 231, 389 ; experiments on, at Birming. ham Sample Stecl Works, 218, 388; experiments with, incomplete, 233 ; high temperature in, method of maintaining, 231; ferro-manganese used in, 391 ; Le Chatelier's experiments on, 217,388; Martin's, 218, 388 ; Martin's, French Exhibition gold medal awarded to produce by, 218,388 ; ores charged in, 389 ; rail metal by, 390 ; reagents employed in, 233 ; running metal from blast furnace in, 332,333 ; sand used in, 218 ; spiegcleisen added in, 232,281 ; steel of special quality by, 391 ; tapping furnace in, 231, 389 ; testing samples from metallie bath in, 232, 284; time available for ehemical reaction in, 232 ; time required to melt eharge in, $232,390$. liegenerators, aetion of, 224,383 ; air, 224,382 ; bricks for, arrangement and size of, 228 ; brickwork actually required in, ealeulation of quantity of, 227 ; chambers of loose firebricks, 224, 246, 382 ; cooling of, 224,383 ; current in, advantages of regular reversal of, $224,225,247$; detailed deseription of action in, 247,383 ; gas, 224,382 ; experiments by Siemens, C. W., on, referenee to, 228 ; how heated, 224,383 ; heated from above downwards, 228 ; hot gas supplied to, produces hot chimney, 386 ; opposite currents passing through, should have equal eapacity for heat, 259; placed below heating chamber, 228 ; reversing valres in, action of, 246 , 247,383 ; tempeinture of, 224 , 383 ; temperature constant in, 225 ; temperature range in, 386 ; vertical, advantages of, $22 \mathrm{~s}$; waste 
REMOVAI OF IMPURITIES. products of combustion passing through, 224, 383.

Removal of impurities in puddling depends on high temperature, 244.

Research, encouragement of, 359.

Reversing valves for regenerators, $246,247,383$.

Rise of tempcrature of blast furnace gases, cause of, 258, 260.

Riveting of steel, 460 .

Rolling of steel, assisted by manganese, 368, 374, 377 ; tires, 374 .

Rotary furnace, Siemens's,C.W., 292, 304 , 393 ; abandonment of, in connection with steel-melting furnace, 292 ; advantage of over blast furnace, 308 ; analysis of iron, 348 ; analysis of slag, 351 ; anthracite in, 299 ; apparatus and process, description of, at Towcester, 343 ; balling in, 299, 395 ; bauxitc used in, see Bauxite; and blast furnace compared on theoretical grounds, 300 ; cast steel obtainable in, 300 ; charges from, working results of, at Towcester, 347 ; charging of, 299 ; Cleveland pig carefully puddled in and melted on open hearth made good stcel, 359 ; carbonic oxide consumed at moment of generation in, 307 ; carbonic oxide developed in, 394 ; comparison of results with those from blast furnace and puddling furnace combined, 310 , 356 ; complete combustion in, explanation of, 301 ; consumption of coal in, at Towcester, 345 ; consumption of fuel in, theoretical and actual, 302 ; cost of hammered blooms from, 345 ; cost of process, 344 ; deoxidation of ore and fusion of earthy matter in, 301 ; description of, 298, 393 ; discussion between Bell, I. L., and Siemens, C. W., on, $35 \%, 357$; economy of fuel in, 310 ;
SAMUELSON, B.

energetic action in, necessity for, 307 ; experimental furnace no criterion of economy of, 306 ; cxperiments with at Sample Stecl Works, Birmingham, 309 ; fettling for, 309 ; fuel in, 306 ; heat absorbed in, 301 ; heat of high temperature attainable in, 305 ; heated gas and air introduced into, 298 ; iron dephosphorized in, 354 ; lining for, 306 ; loss in, 344 ; material from, suitable for steel-making, 308 ; mechanical tests of iron from, 349,350 ; modus operandi in, 394 ; process in, 301 ; production of $\mathrm{CO}$ and $\mathrm{CO}_{2}$, within, 301, 307 ; products of combustion withdrawn from, 298; purity of iron from, 343,395 ; reaction in, $299,301,354$, 355 ; reaction and fusion combined in, 307,319 ; reports on, by Profes. sors Åkerman and von Tunner, 342 ; rotation of, 292 ; saving of fuel in, 300 ; sulphur and phosphorus not added to iron in, 308 ; tapping of, 299 ; temperature high in, 394 ; theoretical consumption of fuel for production of metallic iron in, 307 ; throat of not attached, 304; time occupied in working chảrge in, 299, 344 ; variation of process with different ores, 358 ; wood in, 299 ; working of, 298,306 ; working for a time without gas, 299, 308 ; yield from, 344. Rotary puddling furnace, 280 ; Danks's, 280 ; steel-melting temperature not attainable in, 281 .

Running metal direct from blast furnace for steel manufacture, 332 .

Ste.-Claire Deville, report on open-hearth steel process, 216.

Samuelson, B., blast furnaces, discussion of paper by, 273-276. 
SCIRNCE.

Scienee, sign of advancement of,209.

Scientific attention paid to puddling, slight, 233.

Scott, M., casting arrangements for Siemens-Martin process, discussion of paper by, 335-338.

Scrap and ore process, difference between, 448.

Sernp proeess in regenerative gas furnace, 230.

Sheflield steel process, 214, 328 .

Shipbuilding, iron and steel for, 313 ; steel for, $313,367,420$.

Shoeks, influenee of, on steel, 271.

Short test pieces, objection to, 373 .

Shrinking hoops on guns, action taking place in, 453 ; temperature of, 453,454 .

Sicmens, C. W., definition of steel, 316,323 ; gas-producers, q. v., lime and magnesia linings, experiments on, 363 ; mild steel, q. v. ; open-hearth steel process, q. $v$.; ore-reducing proeess, $q . v$. ; papers by, 209-237 ; 237-255 ; 283-302 ; $303-308$; 3.10-352 ; 378-401 ; precipitation process, $q . v$. ; views on puddling, that earbon and silicon are replaced by iron from fluid oxide of iron, 239,241 ; views on puddling confirmed by experiment at Sample Steel Works, Birmingham, 240, 280, and results in Danks's furnace, 280 ; regenerative gas furnace, $q . v$; regenerative gas puddling furnace, $q . v$.; regenerative open hearth ore process, $q$. $v$. ; regenerative open hearth steel proecss, $q . v$.; regenerators, $q . v$. ; rotary furnace, $q . v$.

Siemens-Martin steel process, 284 ; casting arrangements for, 335 .

Siemens steel, weekly production of, 289.

Siemens, Werner, researehes on tungsten in steel, 213.

\section{PONGY IRON.}

Silica iron, 391.

Silicon, non-absorption of by fluid cast metal in eontact with silica or silicates, 240 ; removal in puddling by reducing flame of low tempernture, 239 ; in steel, effect of, 213 ; table of, in cast and wrought iron and steel, 253.

Slag, mode of mixing with iron, 398. Smelting ironstone, chemical work in, 260.

Smelting operations, heat necessary in, 260, 261.

Smith, E. F., Casson-Dormoy puddling furnace, discussion of paper by, 333-335.

Smith, J. T., Bessemer steel rails, 315-320; use of molten metal direet from blast furnaces for Bessemer purposes, 331-333, diseussion of papers by.

Snelus, G. J., spiegelcisen, manufacture and use of, 311-312; steel ingots, distribution of elements in, $450-452$, discussion of papers by.

Snelus, view of dead melting, eriticism of, 337.

Soda, ammonia used in making, 330 .

Solid flow, a quality of mild steel, $422,450,460$.

Solidifaction of steel, chemical change during, 451.

Spiegeleisen, addition of, to openhearth process, 232, 284; manganese, pereentage of, in, 311 ; manufacture of, 311 ; on steel, effect of, 311; sulphur, why not found in, 311.

Spongy iron produced in blast furnace, 290,366 ; by Blair's process, 365 ; Chenot's process of manufacturing, 365 ; difficulties in conneetion with, 366 ; failure to puddle, 242 ; by Ireland's proeess, 365 ; sulphur absorbed by, 366 ; trials of Chenot, Clay, and Yates with, 292. 


\section{STEAM.}

Steam blown into molten metal, 418 . Steel, ancient, $q . v$. ; annealing, $q$. $v$. ; Bessemer, q. $v$.; boilers, q. $v$. boilers riveted with steel rivets, 367 ; carbon in, q.v.; (castings, free from blow-holes, 465 ; in lieu of forgings, 464 ;) chemical analysis of, importance of, 425 ; a cheap construetive material, 405 ; cold, effect of, on, 364,428 ; compared with iron and wood for structures, 405 ; compressed, q. v. ; compressed in eentre eauses porosity towards outside through which gases escape, 322 ; compression of, by Whitworth's proeess, q.v., 391 ; corrosion of, $q . v$; crucible, $q . v$. ; definition of, q. $v$.; ductility of, 459,466 , and $q . v$. ; elasticity of, $q . v$; for cnginecring struetures, 375 ; factor of safety of, $q . v$.; failure of, 377, 410, and $q$. $v$.; forgings, unequal strength of complieated, 465 ; fusion of, $q . v$. ; gases cannot be driven out of, by pressure, 321 ; guns, q. $v$.; (hardening; Åkcrman's views regarding, 433 ; due to carbon in intermediate eondition, 433 ; with oil, 397, 465) ; impurities, q. v. ; and iron, comparison of methods of producing, 314; machinery, $q . v$. ; making, Cleveland pig unsuitable for, 282 ; manganese, $q . v$; manufacture, $q$. $v$. ; mild, $q . v$. ; open-hearth process, q. $v$.; ore-redueing process, $q . v$; phosphorus in, q.v. ; (plates, scale rolled into, causes corrosion, 443 ; steel rivets for, 367); pouring, $q . v . ;$ ( proeesses, Bessemer, q. v. ; Catalan forge, 214 ; cementation, 214, 328 ; deearburization, 214 ; fusion, $q . v$. ; Heaton and Hargreaves, 215 ; open hearth, $q . v$. ; ore-reducing, $q . v$. ; Percy on, 214 ; precipitation process, $q . \imath$.; regene-
TABLE.

rative open hearth, q. $v$; Shefficld, 214,328 ; Siemens, $q . v$.; SiemensMartin, 284, 448; Styrian, 214); produetion of, operations involved in, 302 ; properties of, 317 ; punching, q.v. ; rails, 378 ; red shortness of, 211 ; rivets of, advantages of, 367 ; for shipbuilding, $313,367,420$; silieon in, effect of, 213 ; specification of chemical constitution and temper of, 317 ; spicgeleisen affects, 311 ; (strength of, varies, 313 ; versus duetility, 428 ; limit of, for different purposes, 459); strengthened by straining, 42t; supply of, by weight instead of dimensions, 367 ; tires, rolling of, 374 ; toughness and tensile strength of, 317 ; uncertainty of, 316 ; varies in strength and quality, 459: weakened by occlusion of gases, 322 ; what is, 313 ; worked hot and eold, experiments on, 376 .

Stoppered moulds, uneertainty of filling, 335.

Strains produeed in manufacture, how equalized, 270.

Stretching and tearing, difference between, 410 .

Styrian, ferro-manganese, 361 ; furnace, 361 ; iron, 361 ; ore, 361 ; steel process, 214.

Sulphur, disappearance of, with anthracite coke, 327 ; (in steel, 211,212 ; counteracted by manganese, 212 ; when advantageous, 212).

TABLE, of carbon in east and wrought iron and steel, 253 ; of carbon in steel, 210, 211; of comparison of regenerative gas puddling furnace and ordinary puddling furnace, 249 , 250 ; of results of precipitation 
TAPPINC.

proeess, 293, 29t; of silicon and carbon in east iron and steel, 253 ; of Sicmens's direet process results, $347-352$; of tests of unild and hard steel bars, 396 .

Tapping siliecous slag with addition of lime, 417.

Tearing of steel, $370,407,412$.

Tearing strain in homogeneous material, 271.

Temper of steel, 210.

Temperature, of combustion, theoretical and practical limit to, 384 ; diagram of distribution of, in blast furnaee, 290 ; of gases from blast furnace as affeeted by temperature of blast, 278 ; high, of hot blast, improves blast furnace economy, 266, 267 ; high, required in open-hearth steel proeess, 318 ; low, of reduetion of Cleveland ore in blast furnaee, 277 ; of reduetion of ores in blast furnaee, 277 ; steel affected by variations of, 423 ; steel unaffected by, as regards absolute structure, 423.

Terre Noire steel, 377.

Test, falling weight, of steel, 271 ; of iron from rotary furnace, 349,350 .

Test pieees, D. Adamson's ten-inch, objeetions to, 373 ; standard eightinch, 373 ; objections to short, 373.

Tests for steel should not be diminished, 419.

Testing machine, 401.

Thomas, S. G., phosphorus, elimination of, diseussion of paper by, 413-415.

Thomas and Gilehrist on dephosphorization, 413.

Titanium in stecl, effeet of, 213.

Tool steel without manganese, 305 .

Toughness of steel, 313 .

Toweester, application of rotary furnaee at, 342. See Rotary Furnace.

Treatment of steel affeets its applications, 313.

\section{WELDING BTEEL,}

'Trinl of closed versus open tops in blast furnaee, 332 .

Tungsten in steel, effeets of, 213 , 214 ; Siemens, Dr. IVerner, researehes on, 213.

Tungsten steel, experiments on increased'magnetie retaining power of, 213.

Tunuer, Professor von, Bessemer medal, presentation of to, 360 ; literary works of, 361 ; metallurgieal researehes of, 361 ; personal qualities of, 361 ; report of on regenerative furnaee, 342 .

UCHATIUs's steel fusion process, 216.

Ultimate strength, test of, not neeessary, 434 .

Utilizing heating and ehemical power of gases in blast furnaee, 275.

VARIETIES of steel, 403.

Variety of steel for different struetures, 420.

Vessel to resist high pressure, 372 , 373.

Volatilisation and separation of oxygen from ore in blast furnaee, 257 , 262 .

WALKER, B., steel-making maehinery, diseussion of paper by, $437-440$.

Waste due to oxidation in pudaling after metal brought "to nature" by removal of earbon, 242.

Water bridges, expenditure of heat due to, 252.

Webster, J. J., iron and steel at low temperatures, diseussion of paper by, 422-425.

Weight of strueture, reduetion of, by use of steel, 405.

Welding steel, 374 . 
WELSH DINAS SILICA BRICK.

Welsh Dinas silica brick, analysis of, 226.

West, J., shipbuilding, steel for, discussion of paper by, 426-428.

Wheels, action of, on rails, 272.

Whitworth, Sir J., fluid compressed steel and guns, discussion of paper by, 320-323.

Whitworth, Sir J., 321 ; definition of steel, 517 ; rifling, mechanical gunnery, gun material considered by, 321 ; process for compression of steel, 321.

Williams, R. P., permanent way of railways, discussion of paper by, 338-340.

Williamson, Prof,, regarding dephosphorization, 363 .
YIELD FROM PUDDLING FURNACE.

Woolwich system of ordnance, 398.

Work done and heat dereloped in blast furnace, 273.

Wrought iron contains only 96 or 97 per cent. of metallic iron, 398 ; what it is, 403 .

Wrought iron and steel, table of carbon and silicon in, 253.

Wrought steel from Creusot, 380 .

YATES's trials with spongy metal, 292.

Yield from blast furnace increased by copper, 331 .

Yield from puddling furnace, actual, 241,282 ; differencc between actual and theoretical, 242.

END OF VOLUME I. 


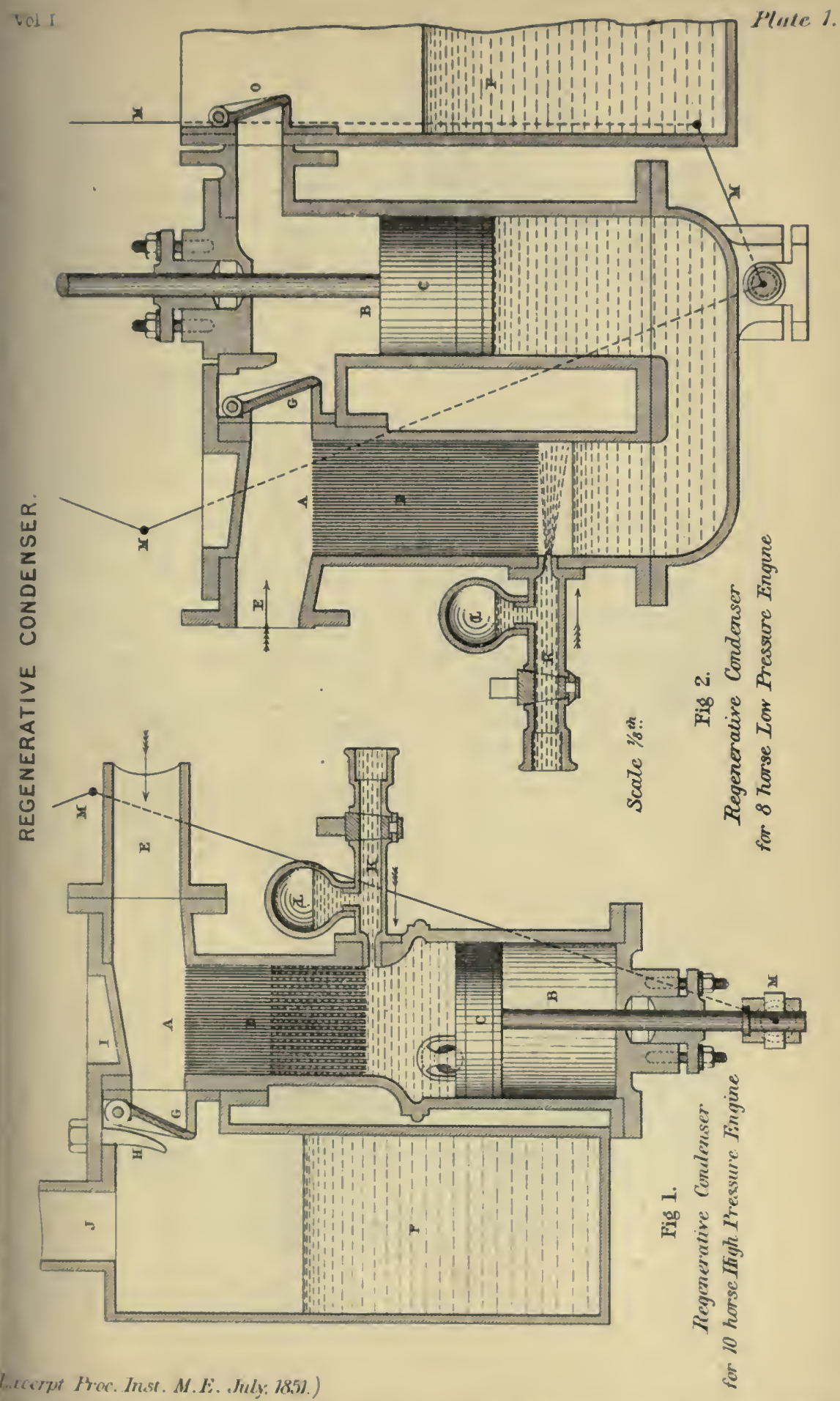





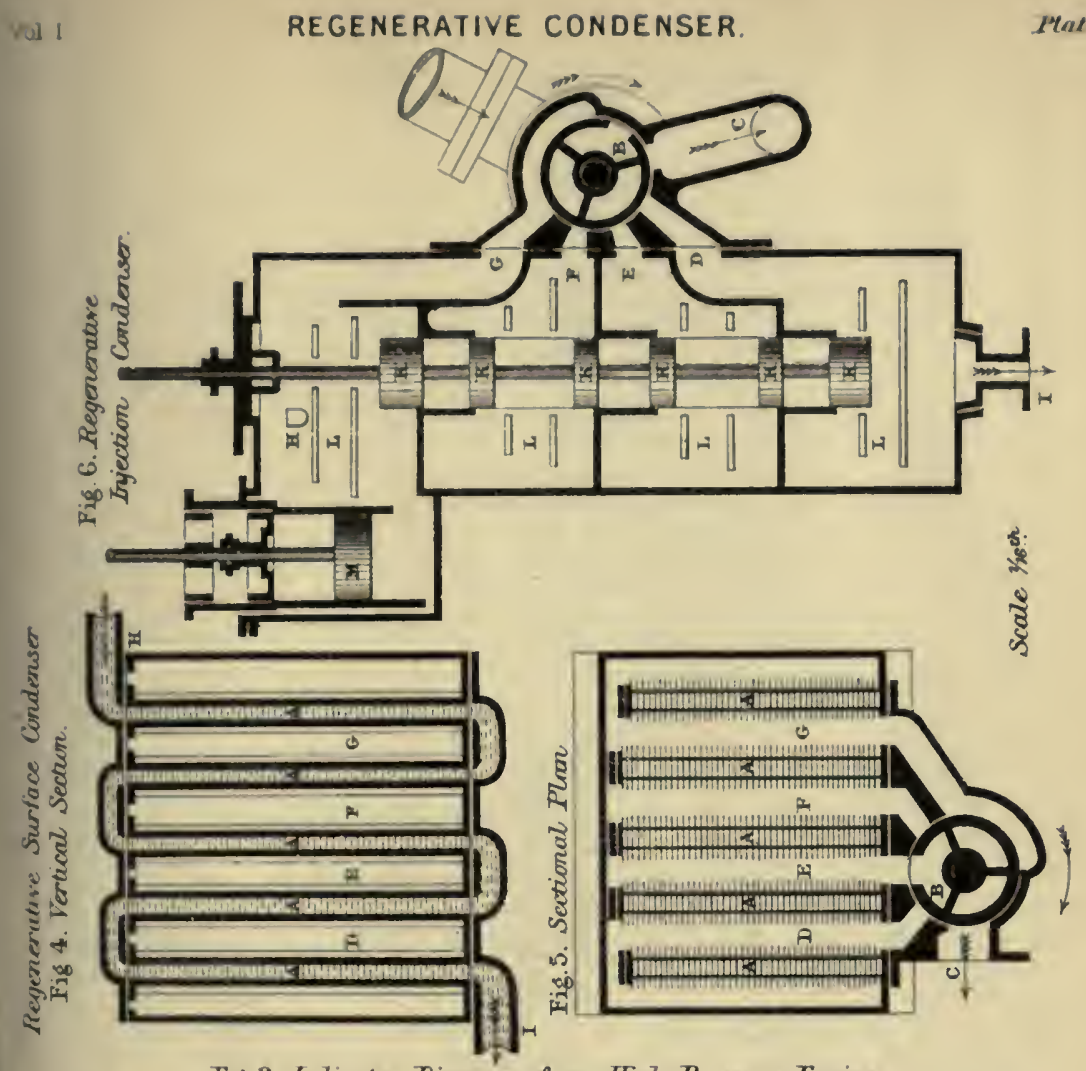

Fig. 3. Indicator Diagram from High Pressure Engine

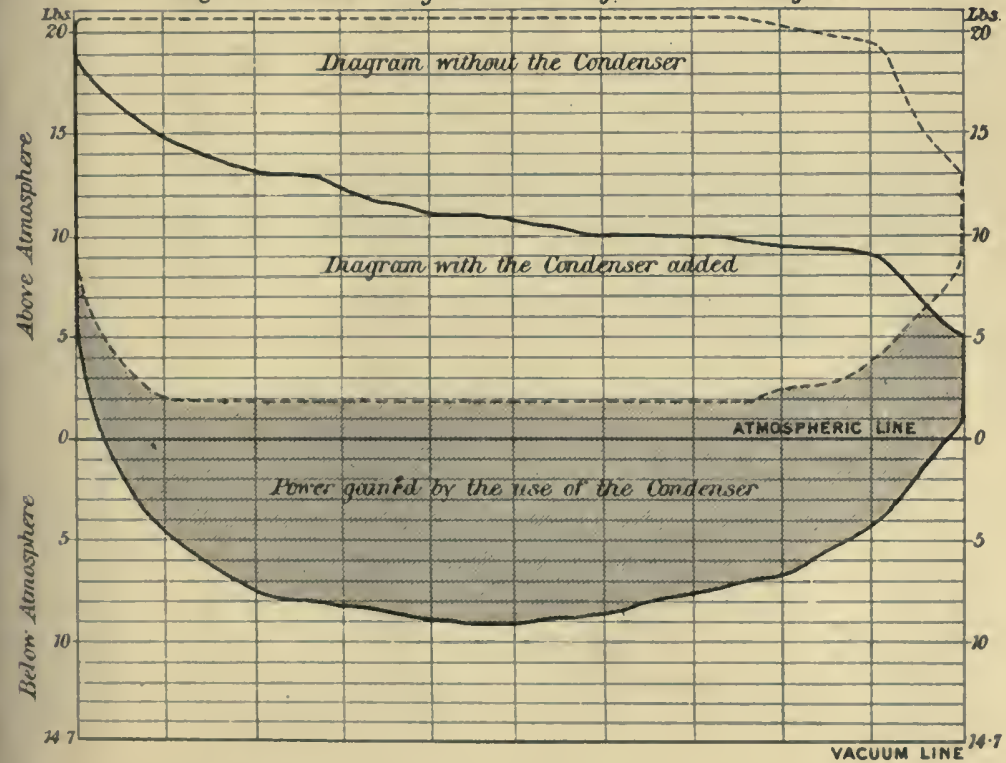

"ixcerpt Proc. Inst. M.E. July, 1851.) 



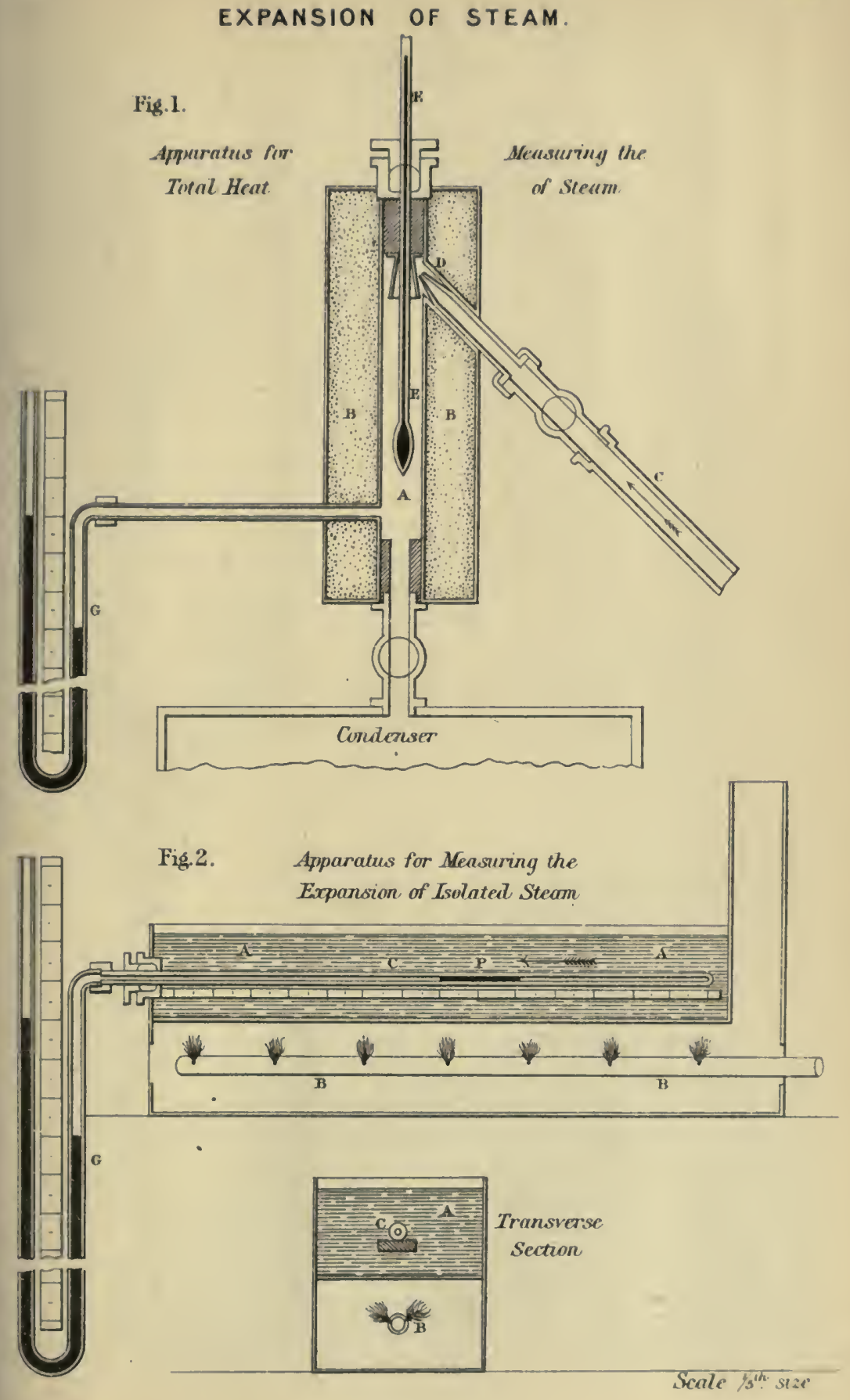



Expanstom of Lsoluted, Steurn, by IIeal,

at constaul Almaspheric Pressure

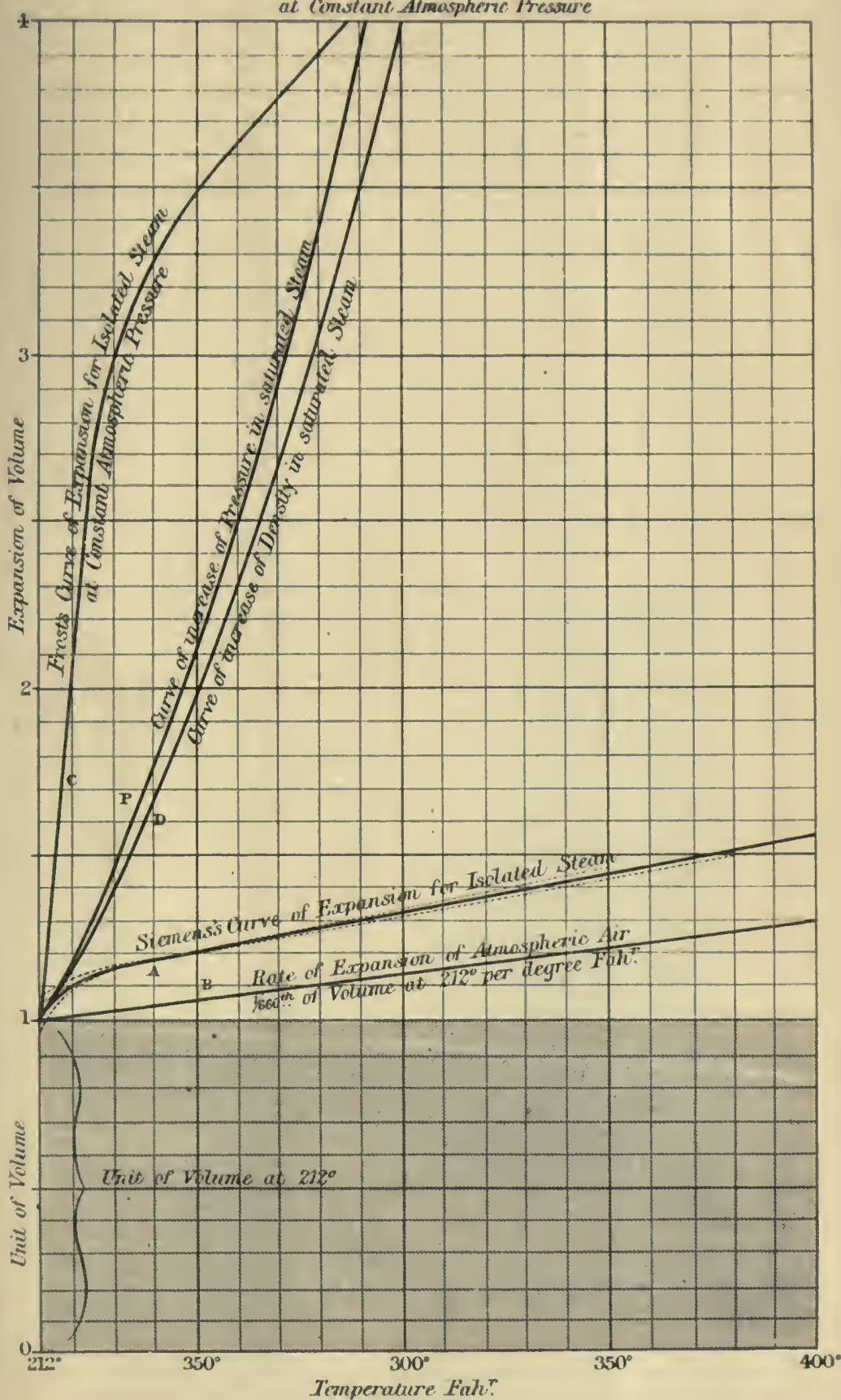

(Excerpt, Iroc. Inst. M.E. 1852.) 

Al. EFIFlich

Plute 5.

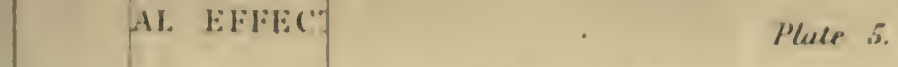

STIRLINC'S ENGINE.

Fig 5.

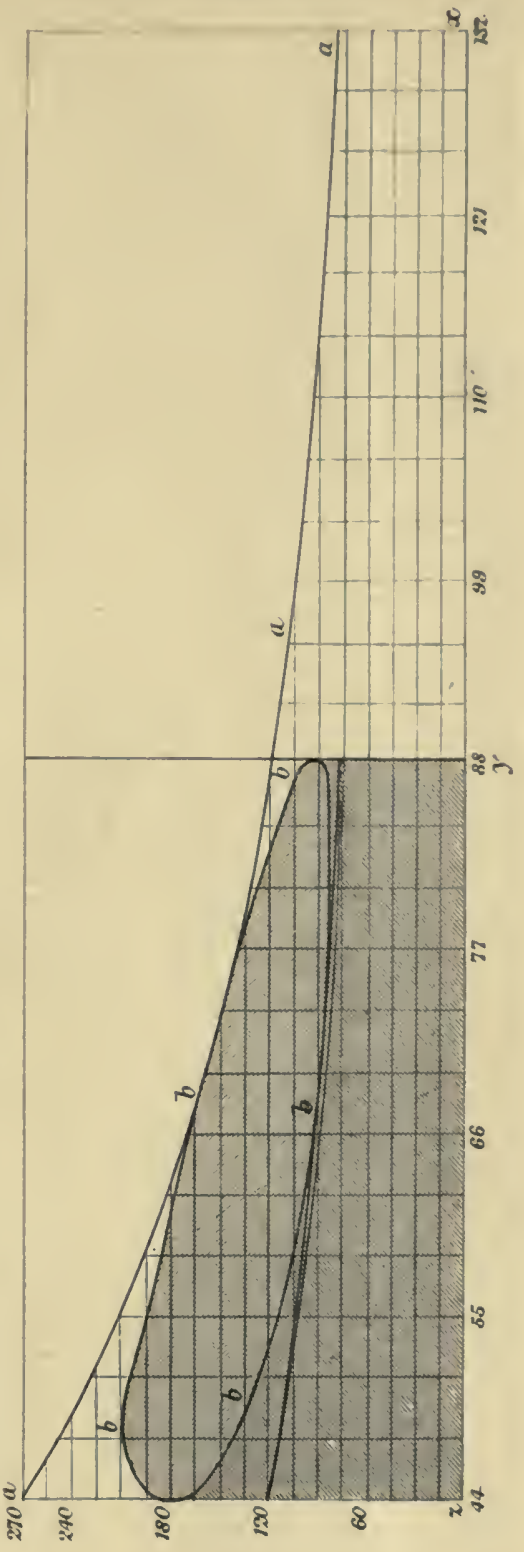

8:F.

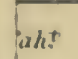

$130^{\circ}$

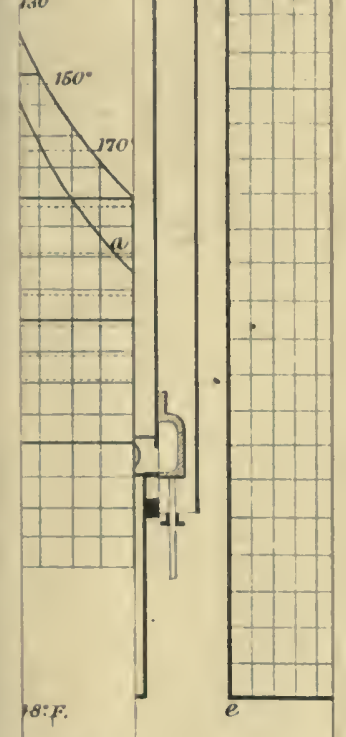

130. $\mathrm{C}$

$1+1+19$ 



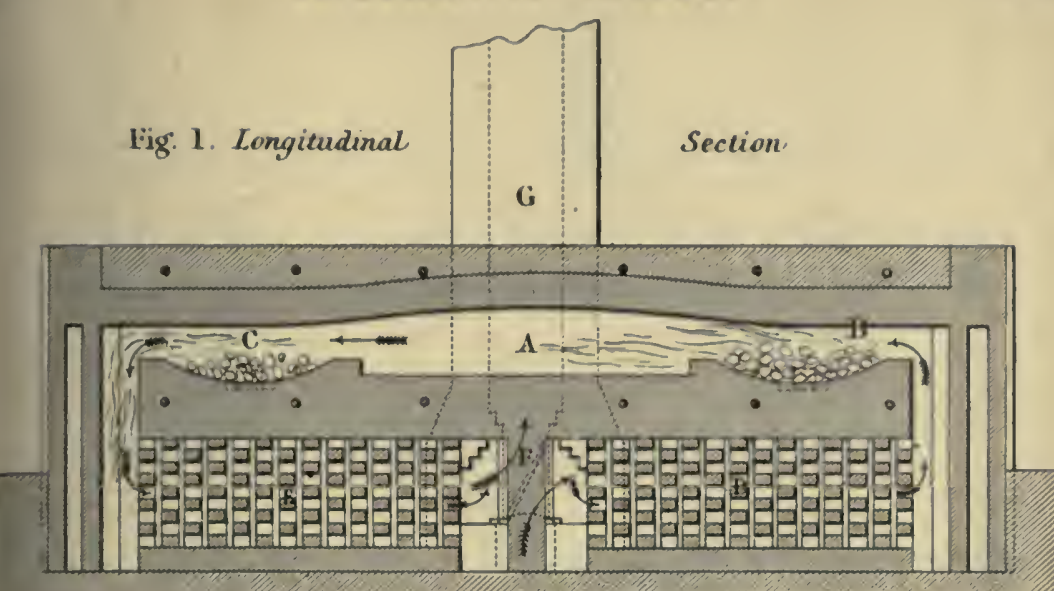

Fig. 2. Sectional Plan.
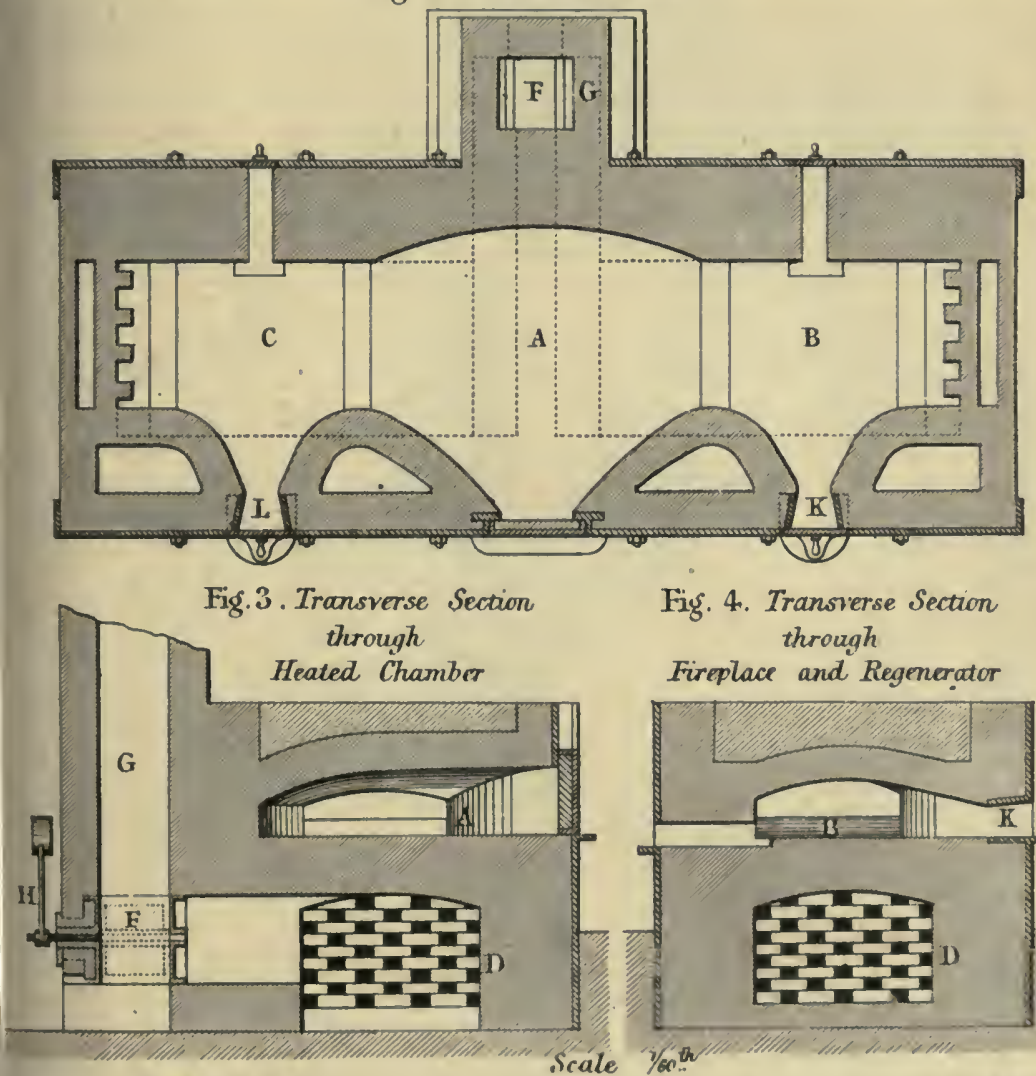

Fis. 4. Transierse Section Fireplace and Regenerator

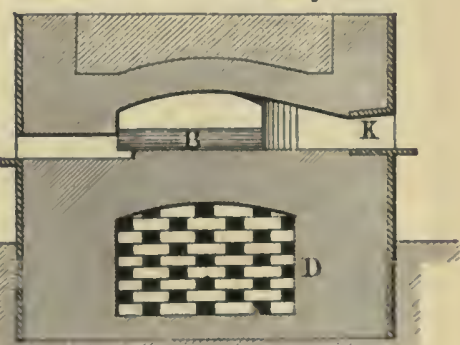

Irches 1260

6

10

scerpt Proc. Frot: AY.E. 1857 Page 104) 


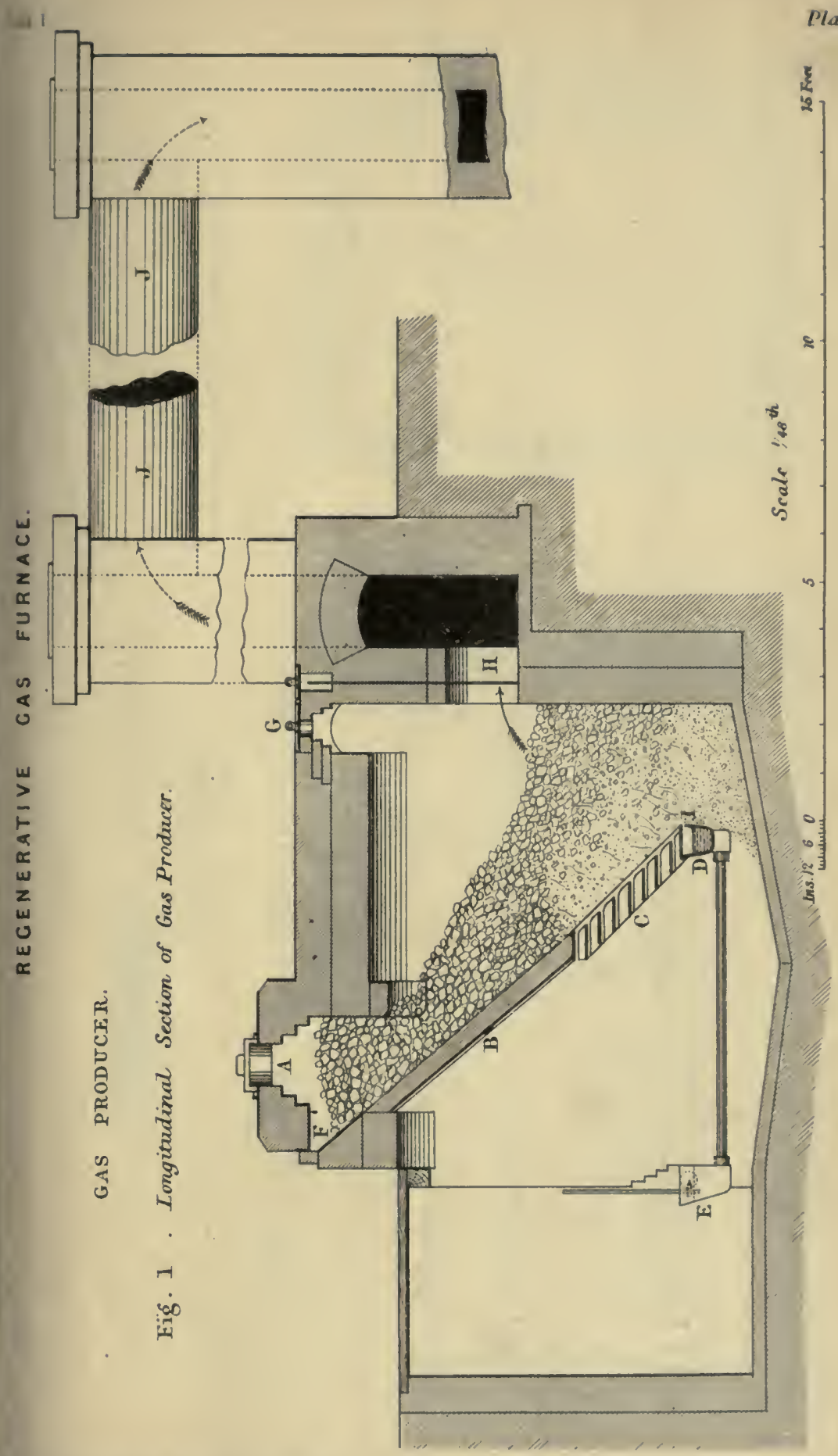

Erreerp Thr. Hust. M.E. 1862, Page 21) 

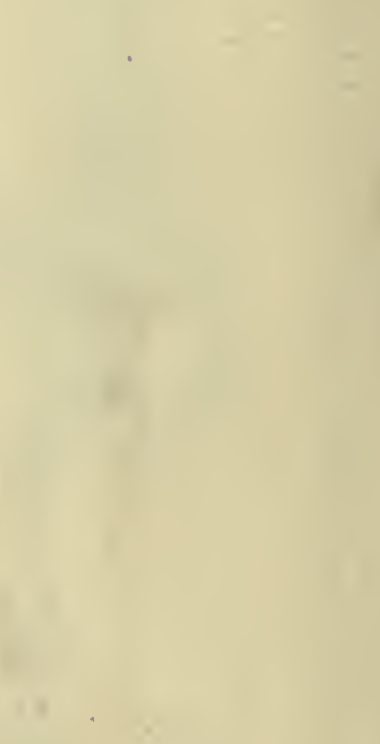
Vol I.

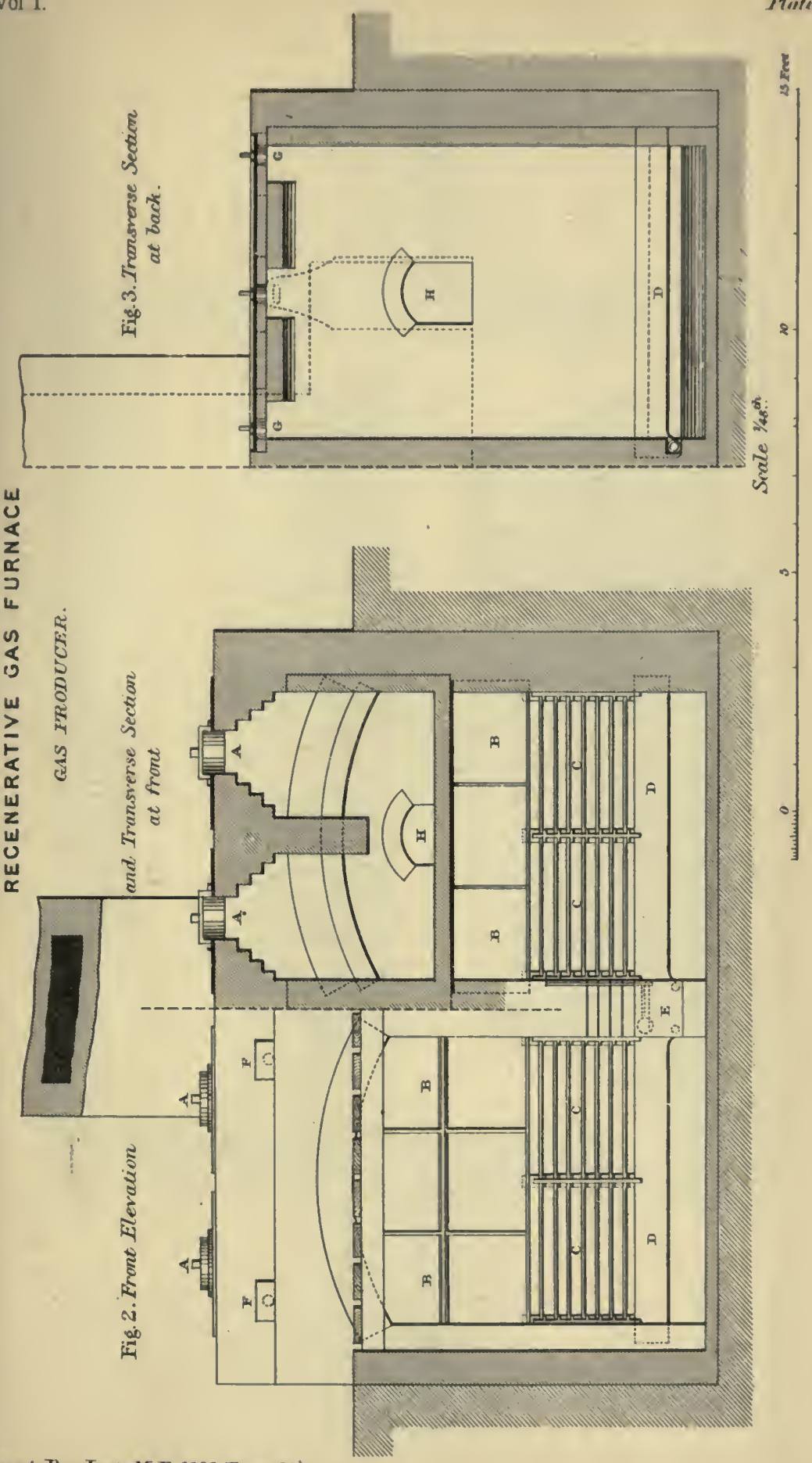




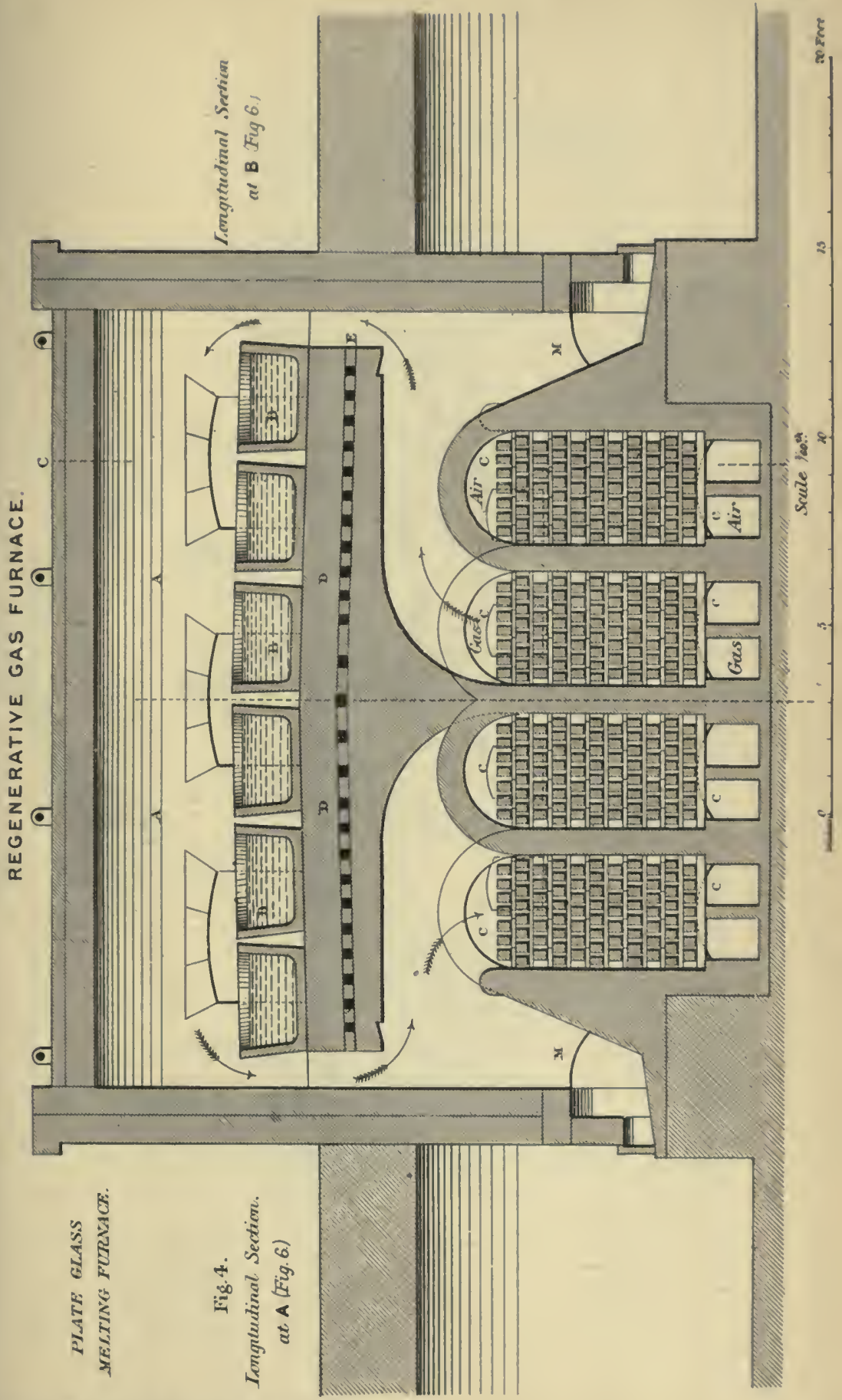

(Exceryt Brr. Trast M.E. 1862. Puge 21.) 




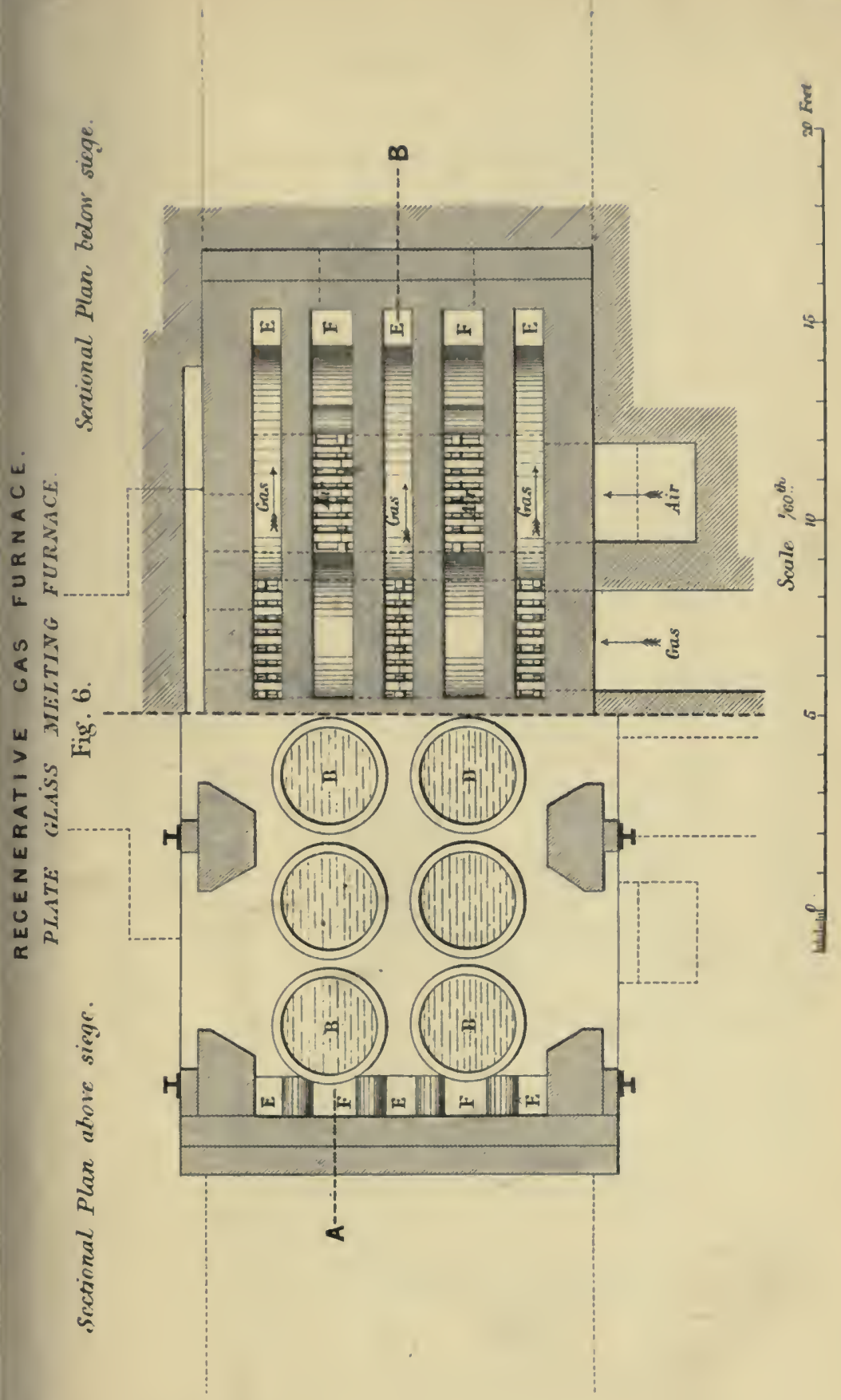




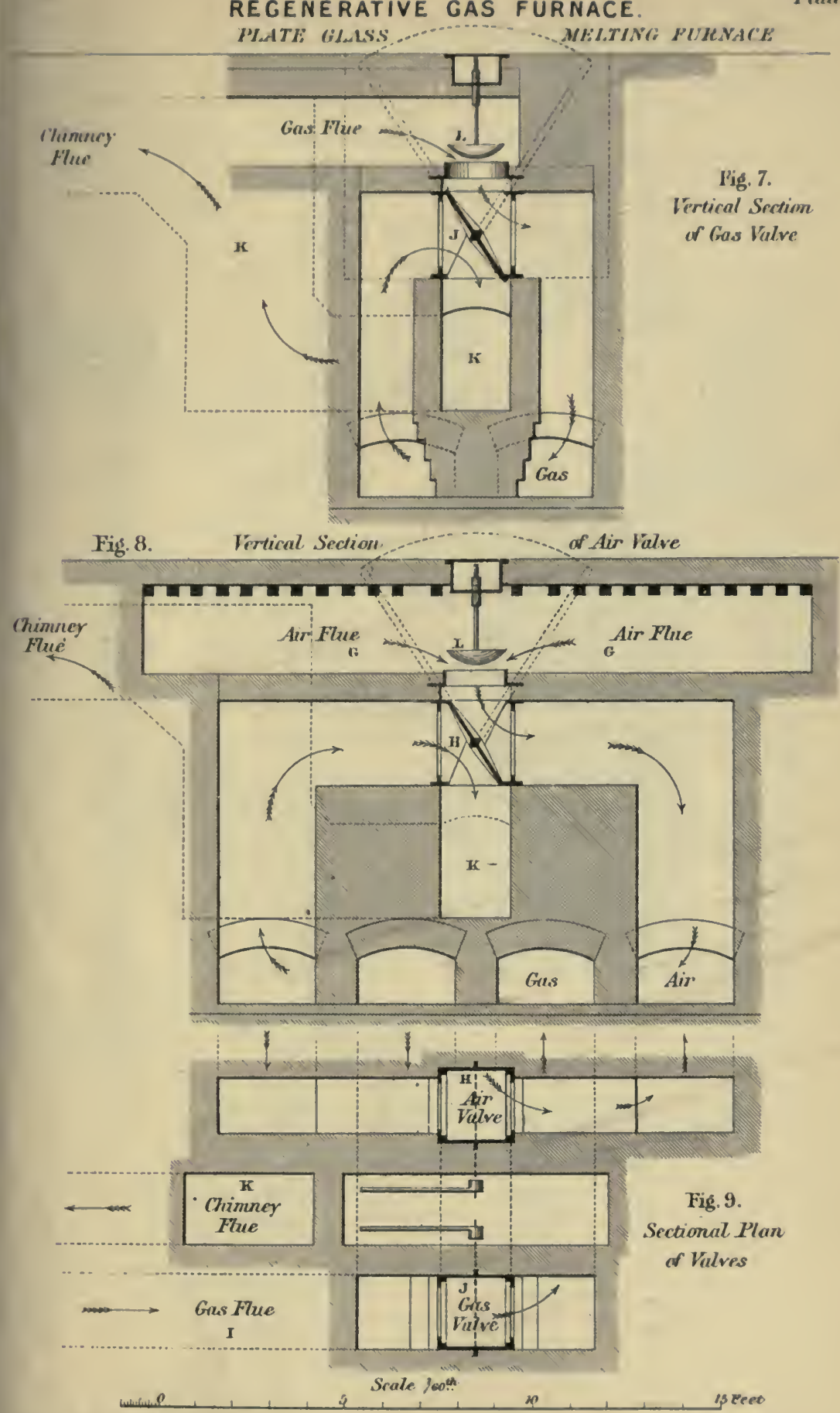

Illate. 23.

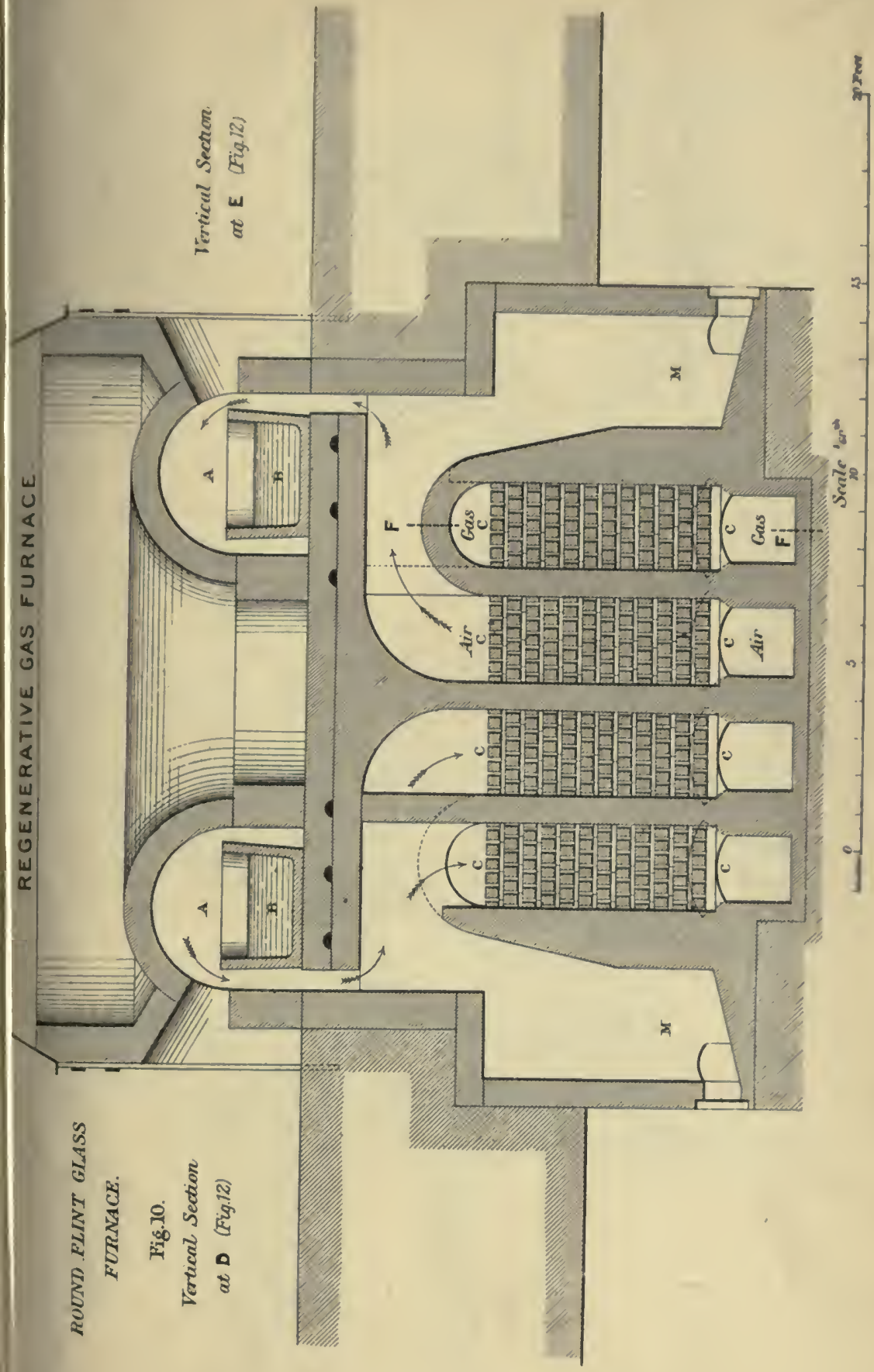





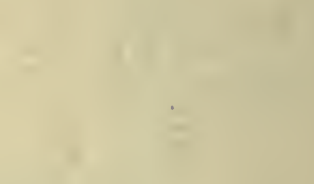

18 


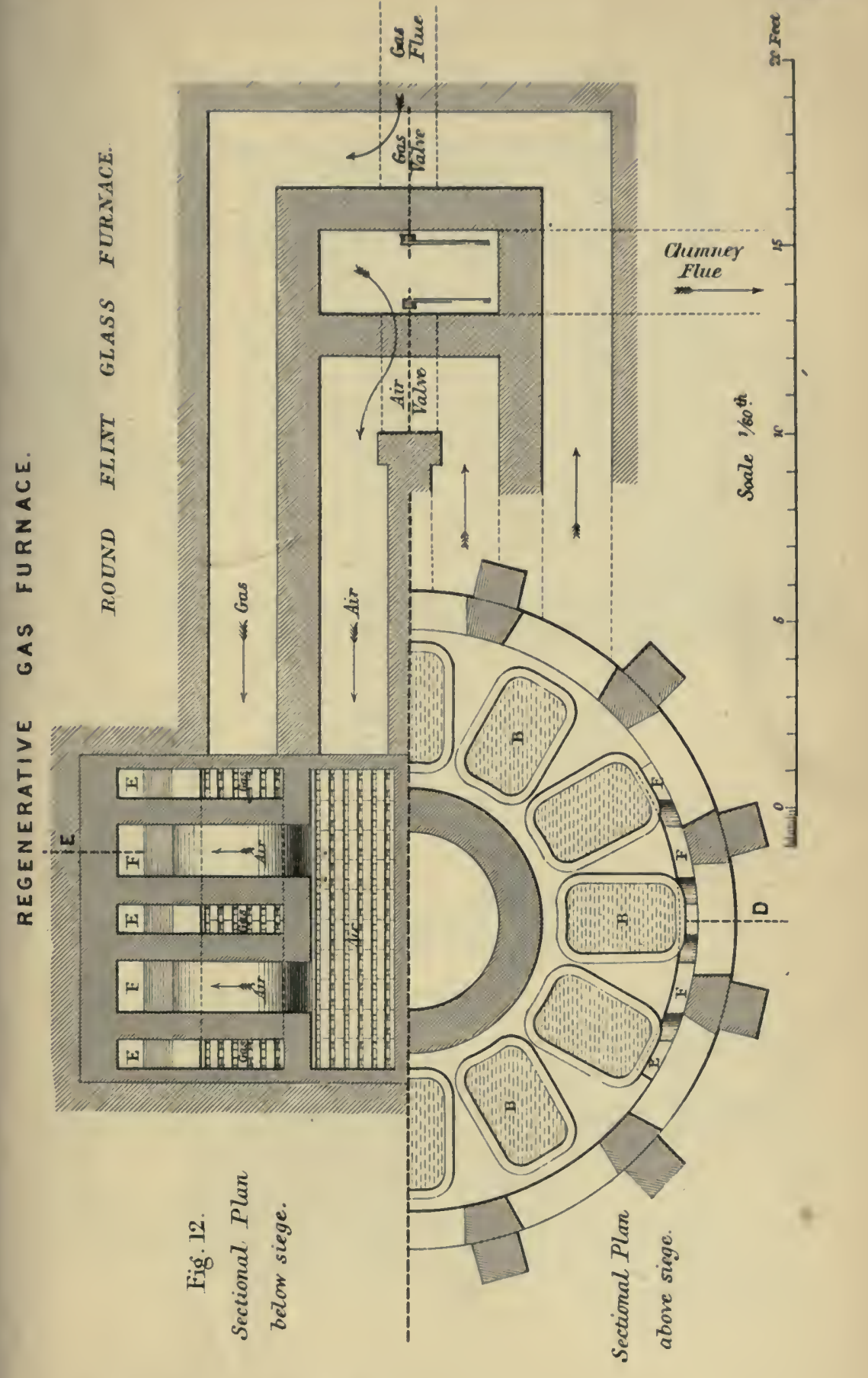



REGENERATIVE GAS FURNACE.

PUIDISINE PURNACE.

Fig. 13. Lannglualinat. Scatiom.

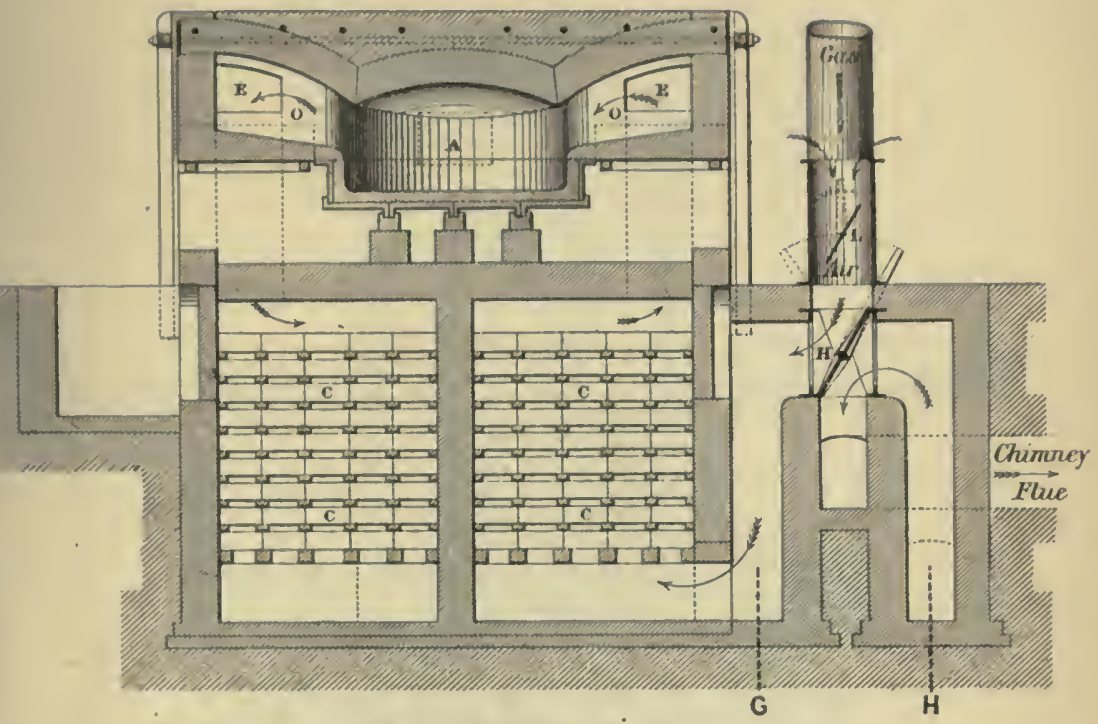

Fig.14. Sectional Plan of Prudilling Chumber.

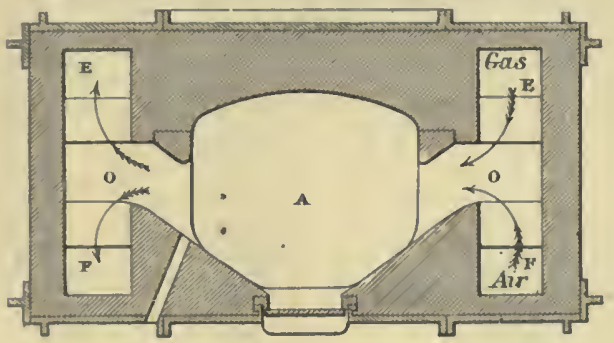

Fig 15. Sertional Plan helow Pulding Chamber.

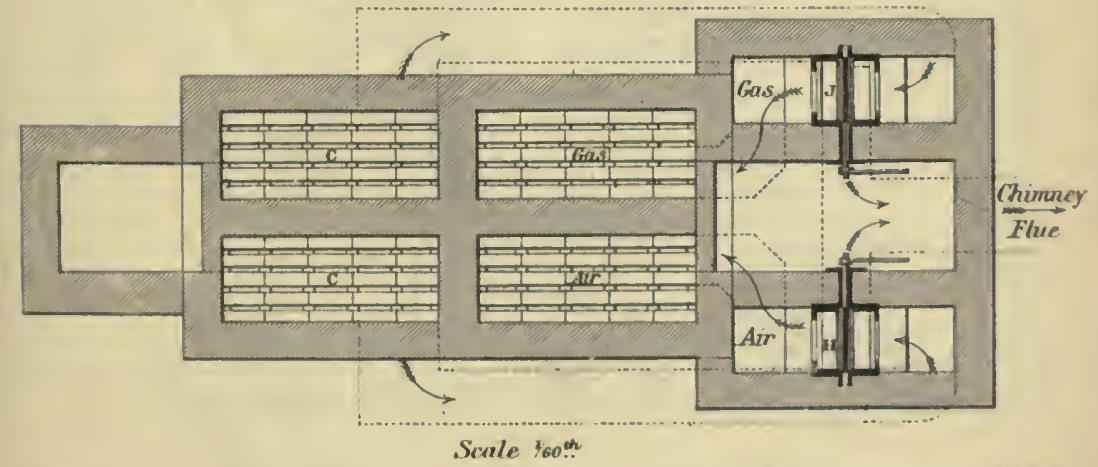

o

9

10

15 



\section{REGENERATIVE GAS FURNACE.}

PUIJDIING FUTRACE.

Fig. 16. Tranurverse Section through, mixing charmber ().

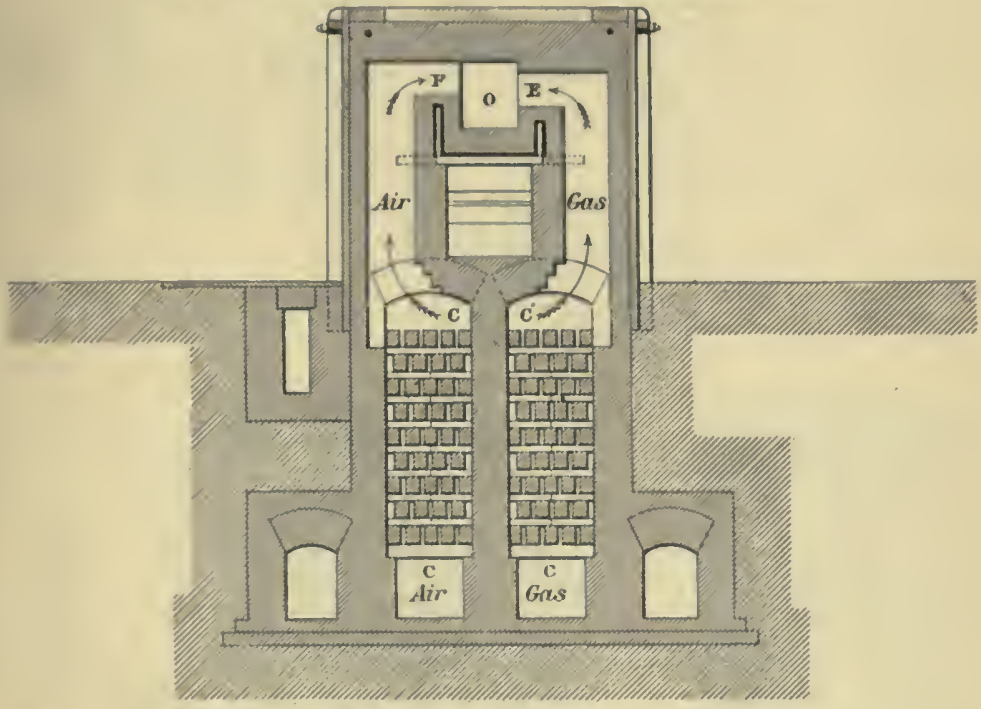

Fig.17.

Vertioul Section at G (Fig.13)

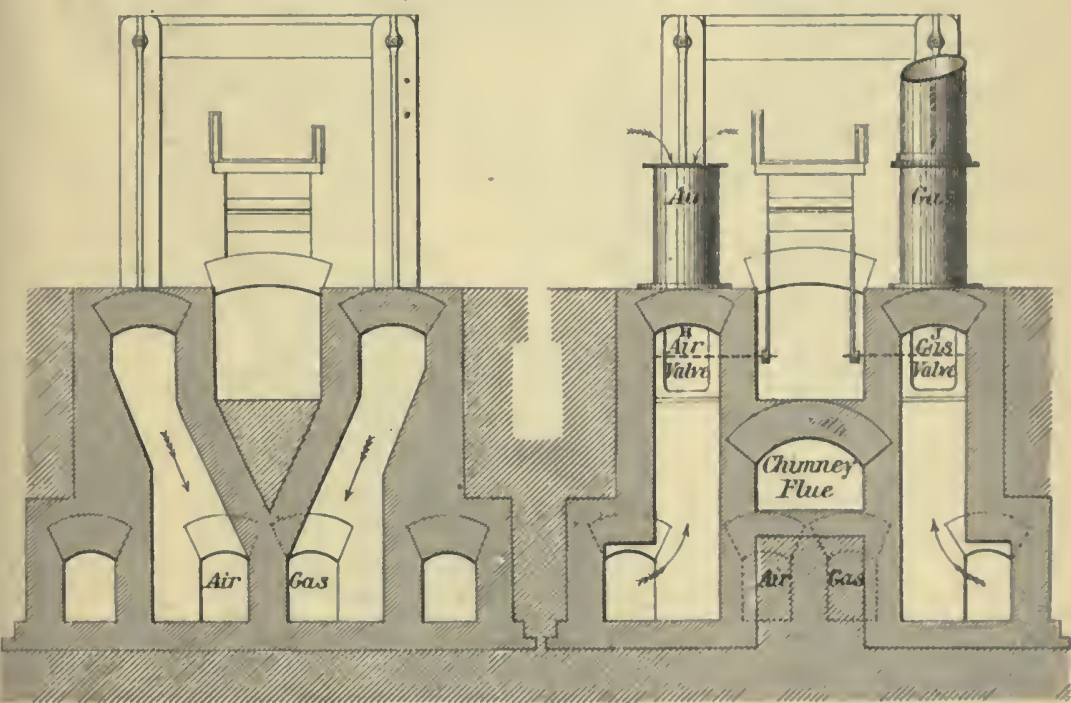

Fig.18.

Verticul, Sertion, at, H (Fugl3) 

Vol L

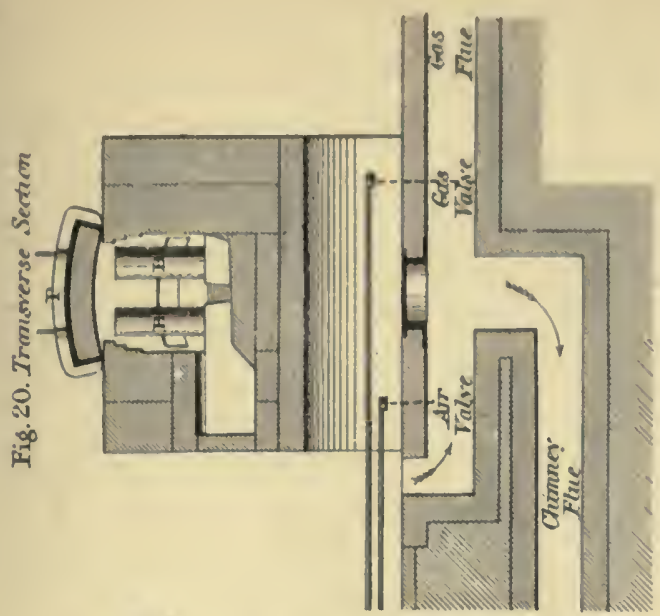

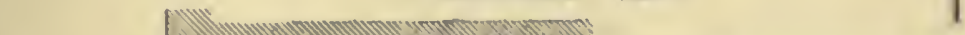
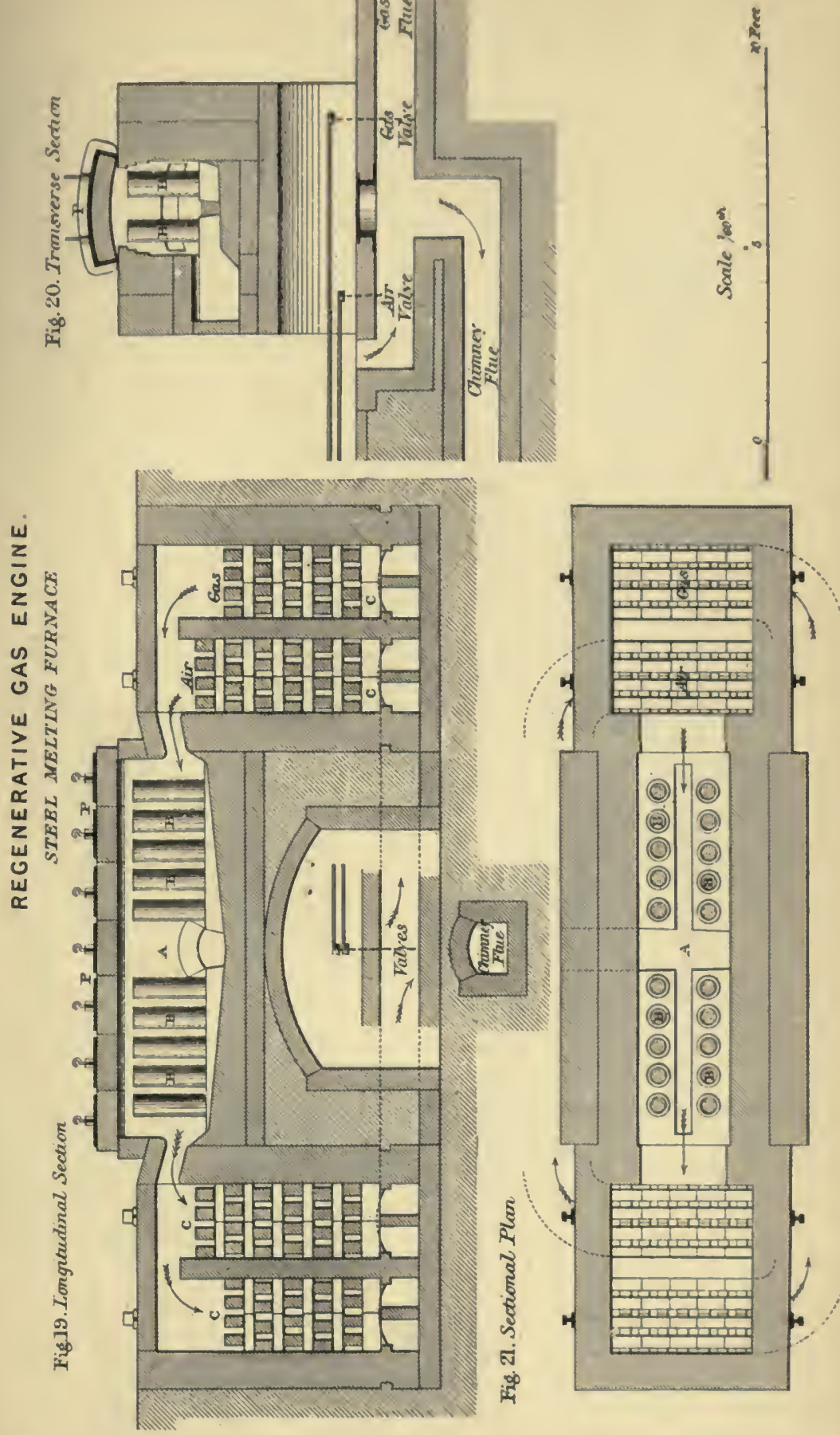
Vol.I.

\section{UNIFORM ROTATION.}

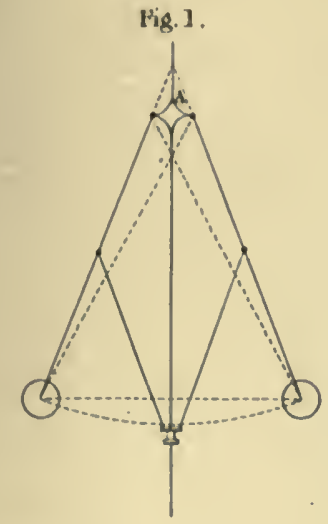

Fig.3.
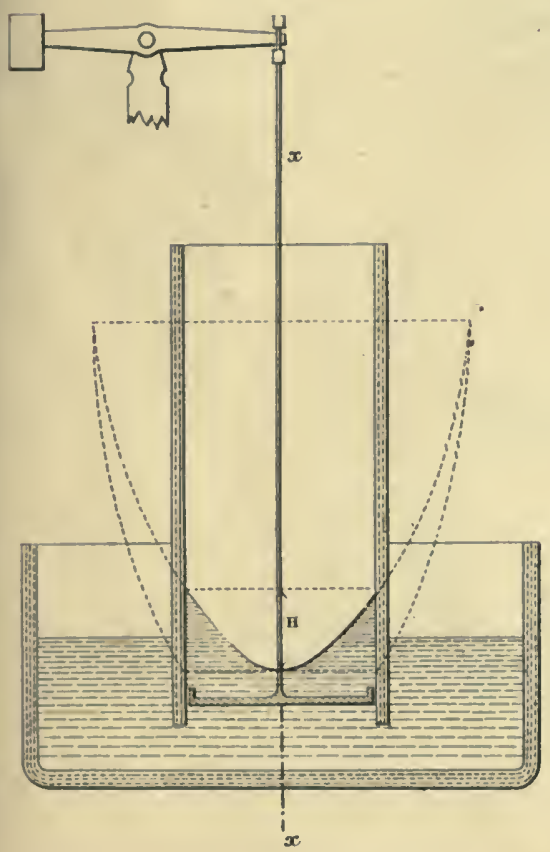

Iig. 2.

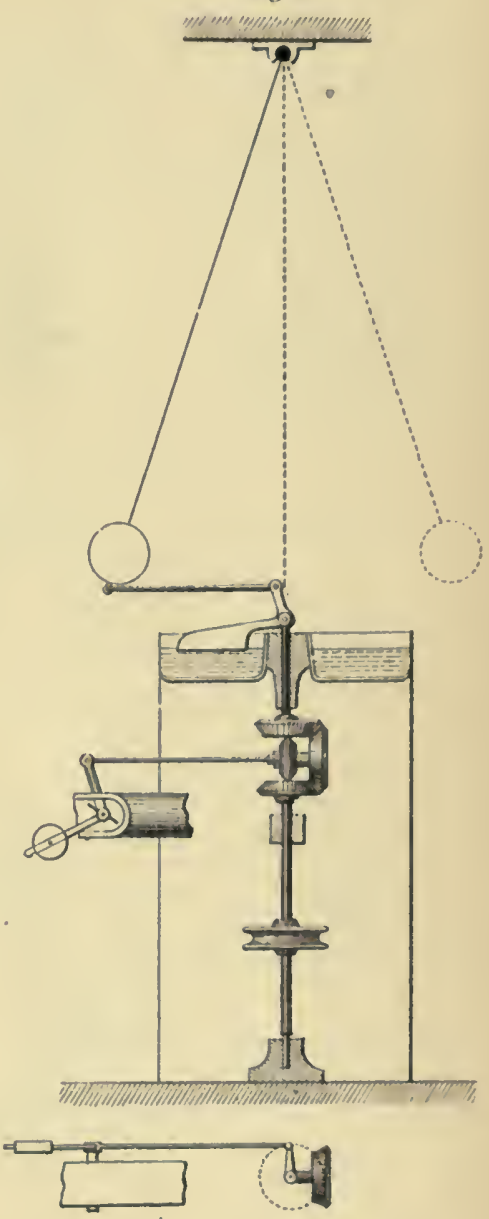



GYROMETRIC GOVERNOR

FOR STEAM ENCINES

Fig. 2 .

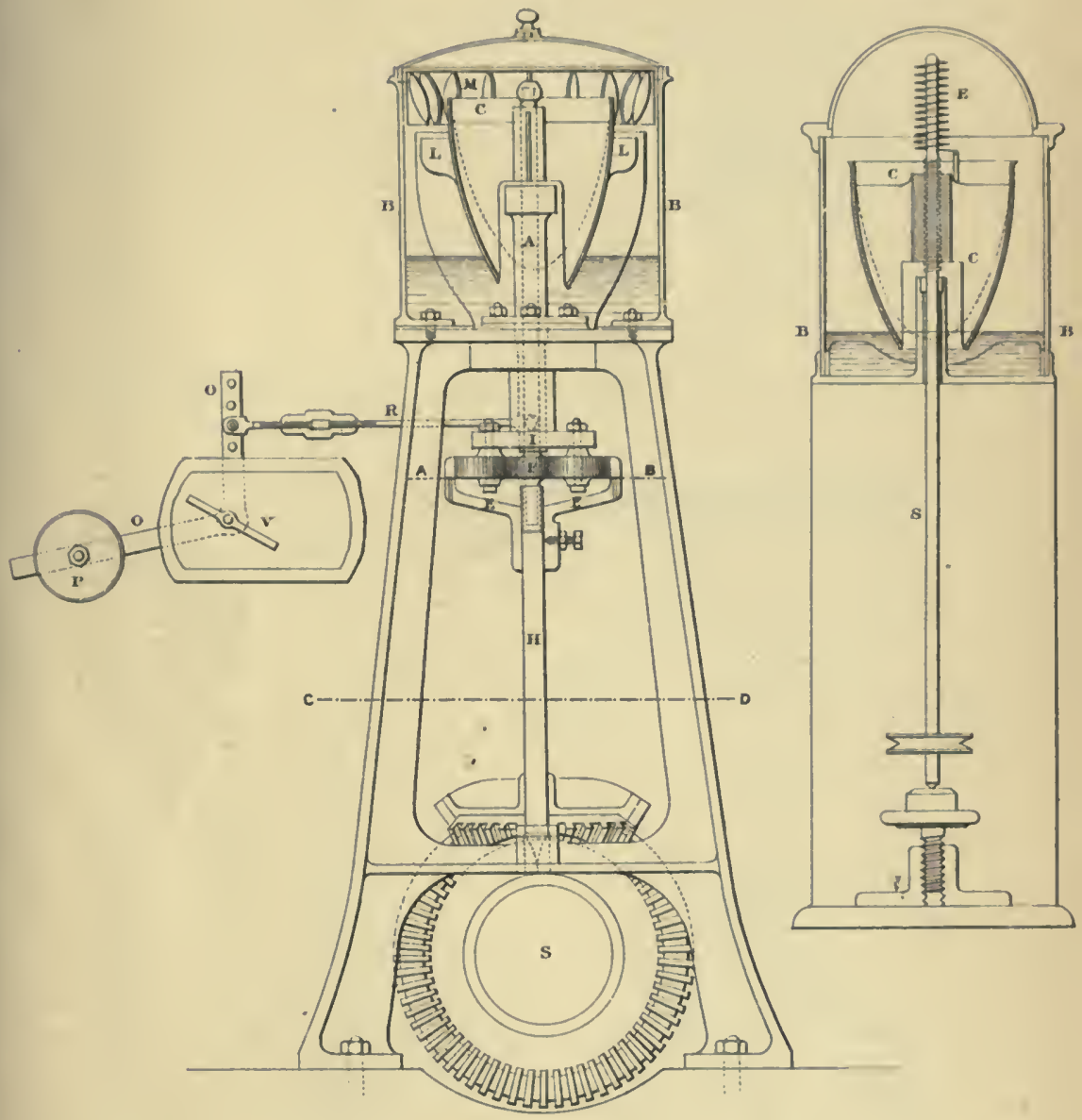

Pig..1.

s 3 
$=$ 


\section{GYROMETRIC GOVERNOR.}

FOR STEAM ENGINES

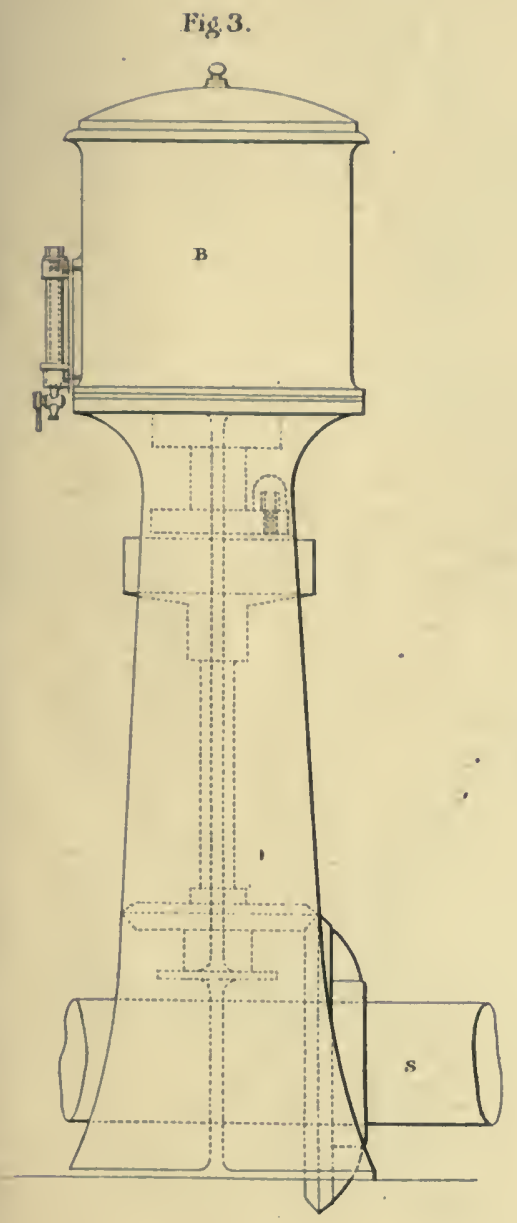

Fig. 4.

Phen of disferentual

liesrung al A.B.

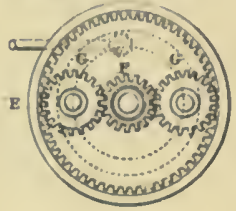

Fig.5.

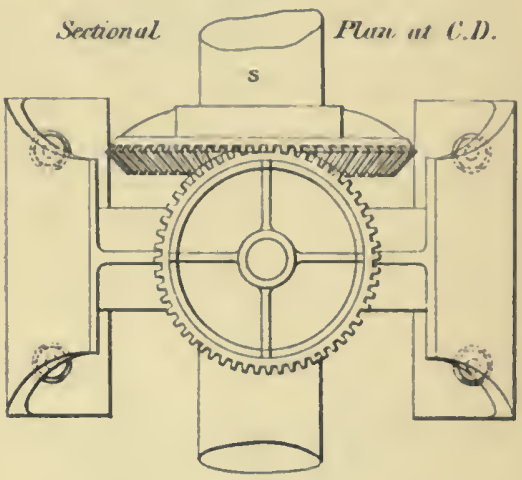

Fig. 6.

Plin wilh cever oft shering Gup

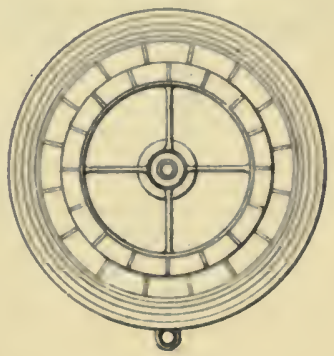

Scale of Inches

15 20 


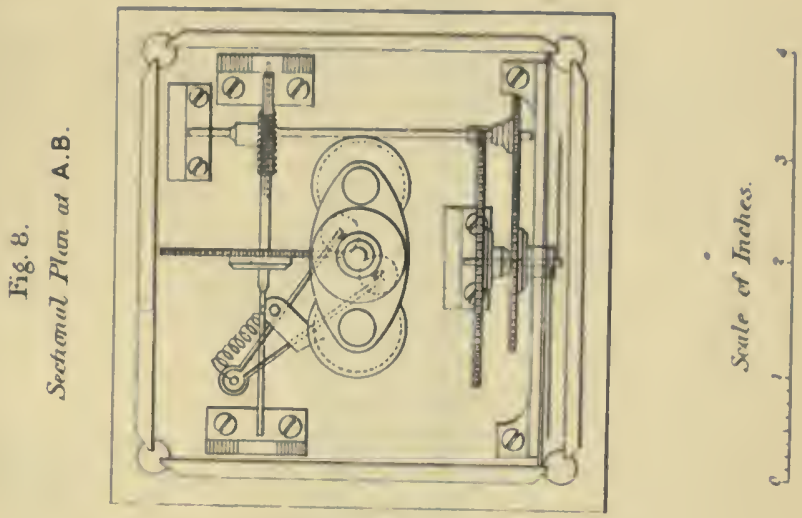

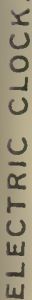

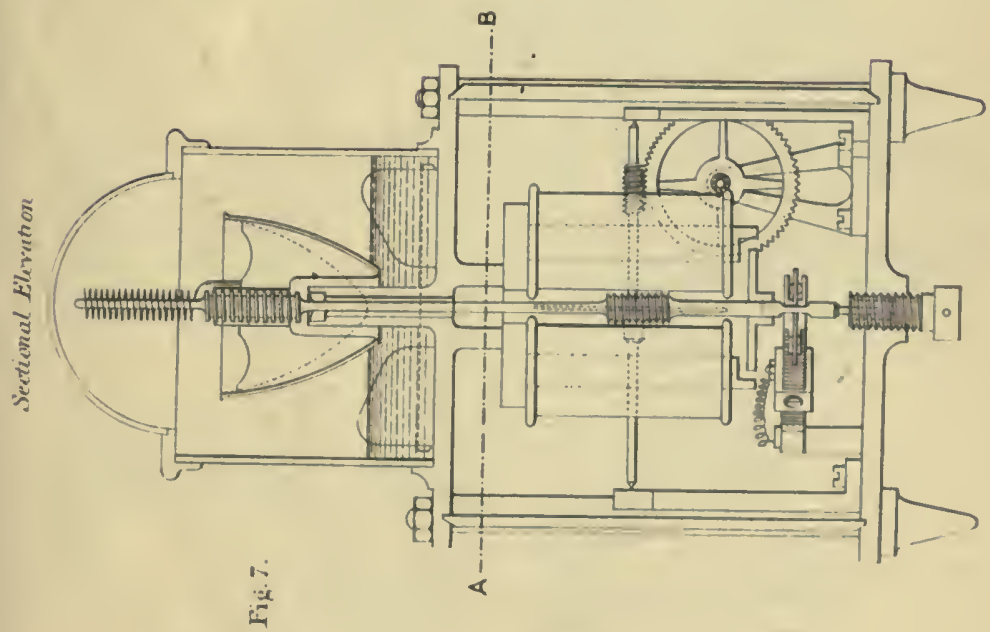



Vol 1.

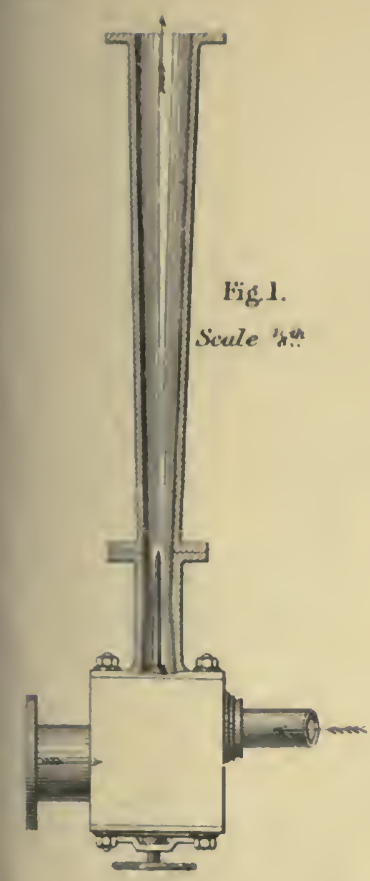

STEAM JET.

Steame. Jet Lixhluaster or Blewer.

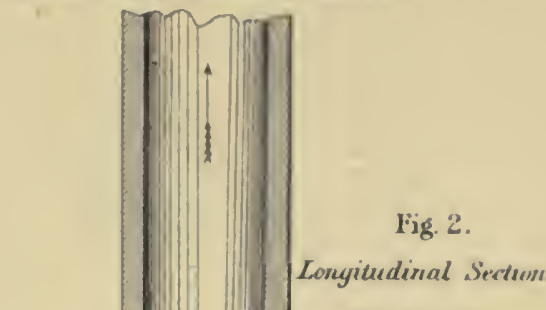

Iurlf fill size. 

STEAM JET
Sceum Jet Exherister or Blemer

Fig 3. Trunsverse Section at XX.

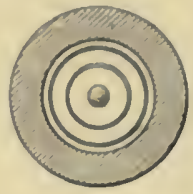

Fig. 4. Transwerse Secten at YY.

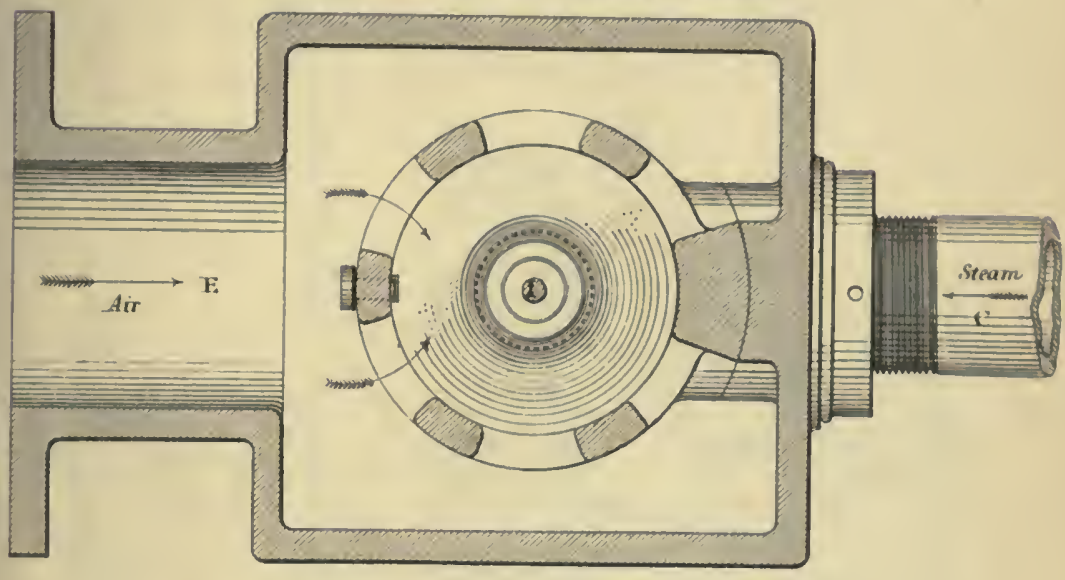

Fig. 5. Tranusverse Section at ZZL.

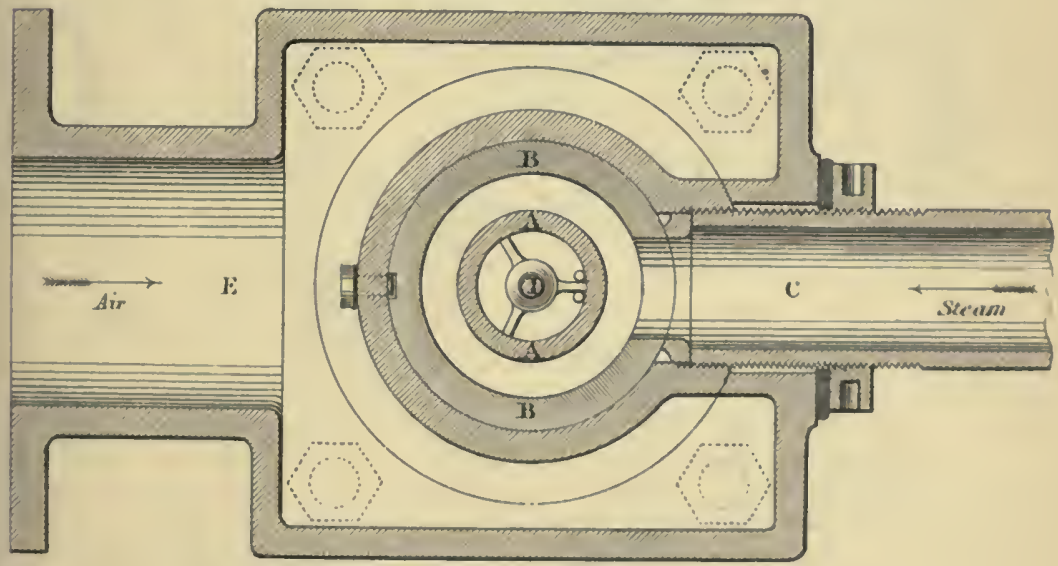

Herlf linll siar. 


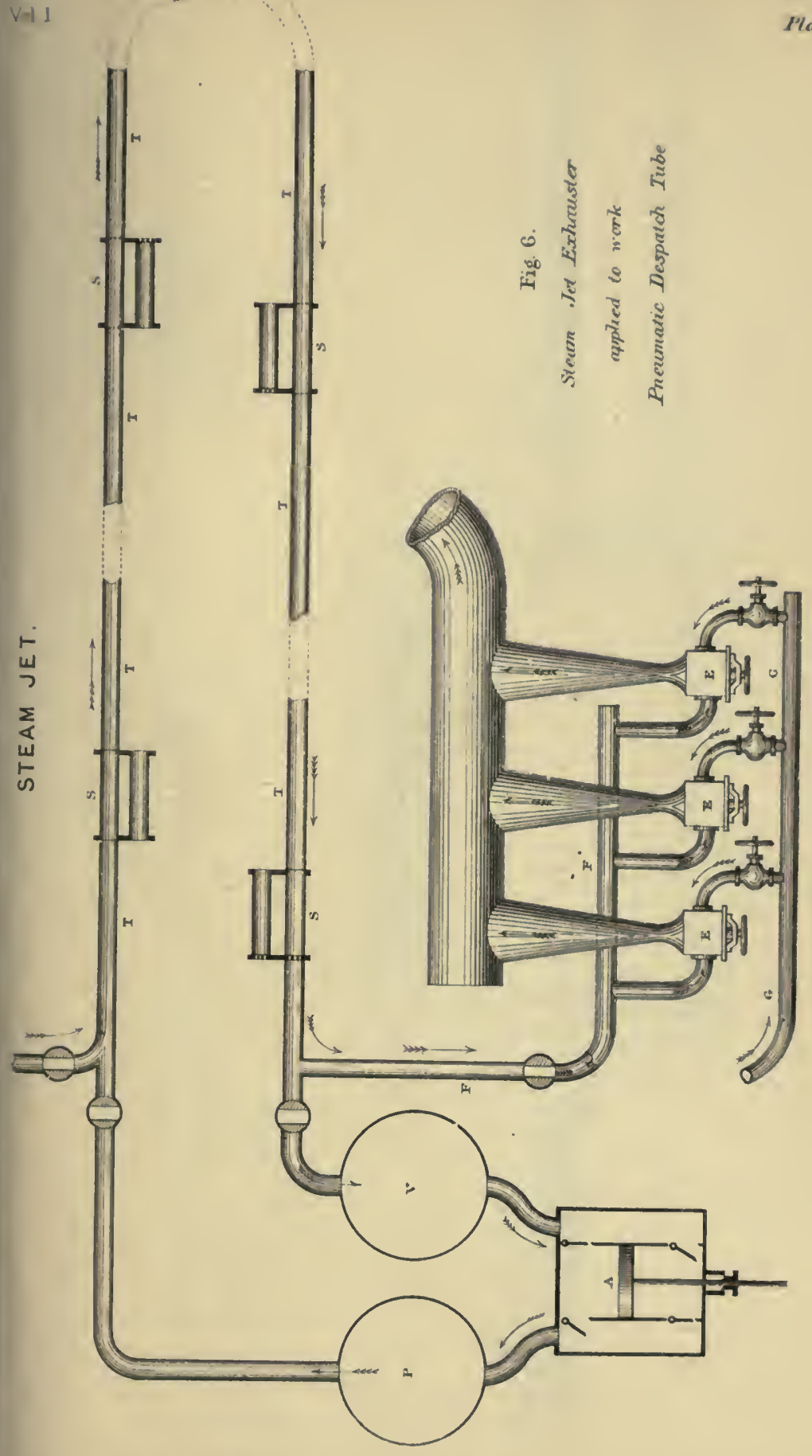

Plate :.5. 

Vol I.
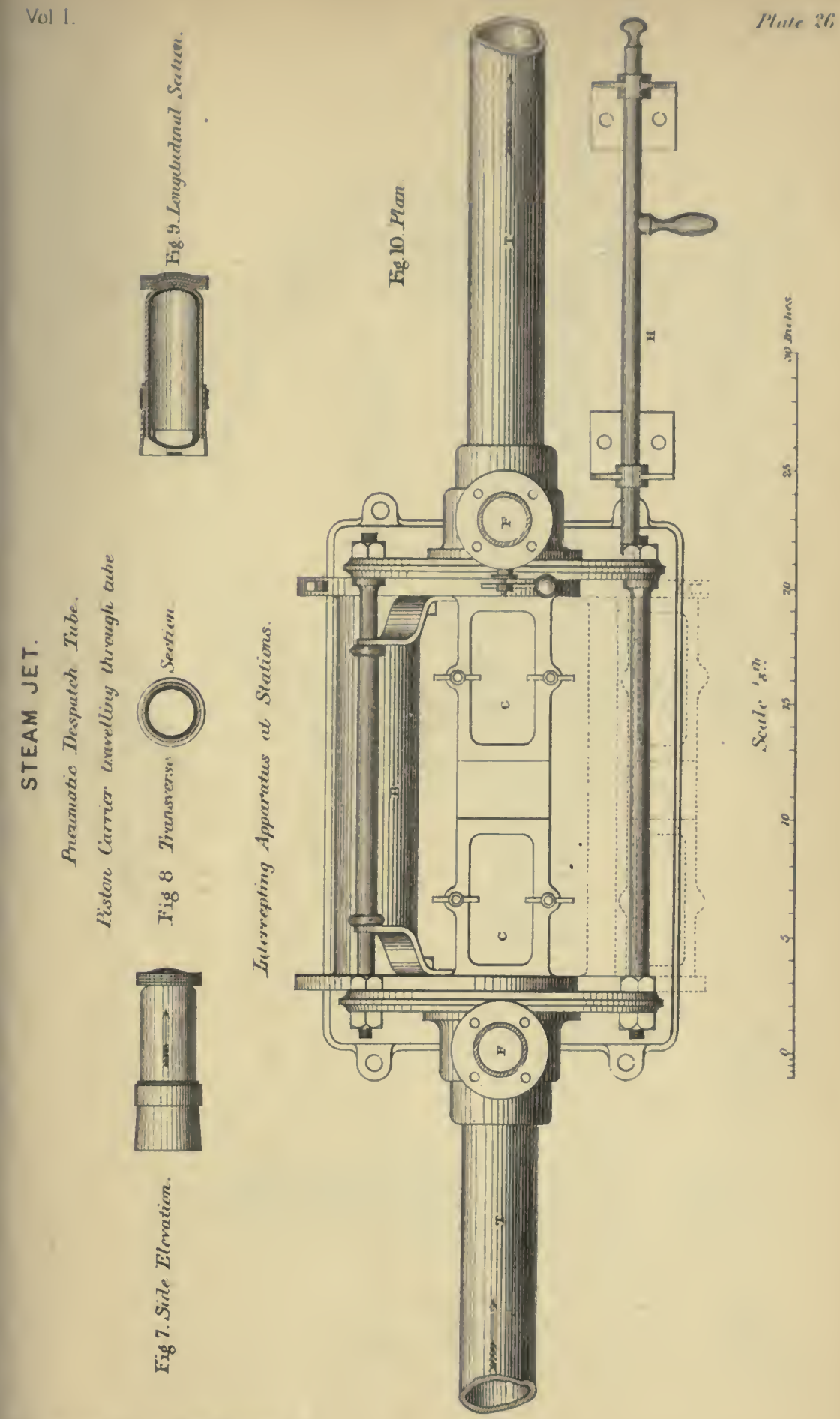


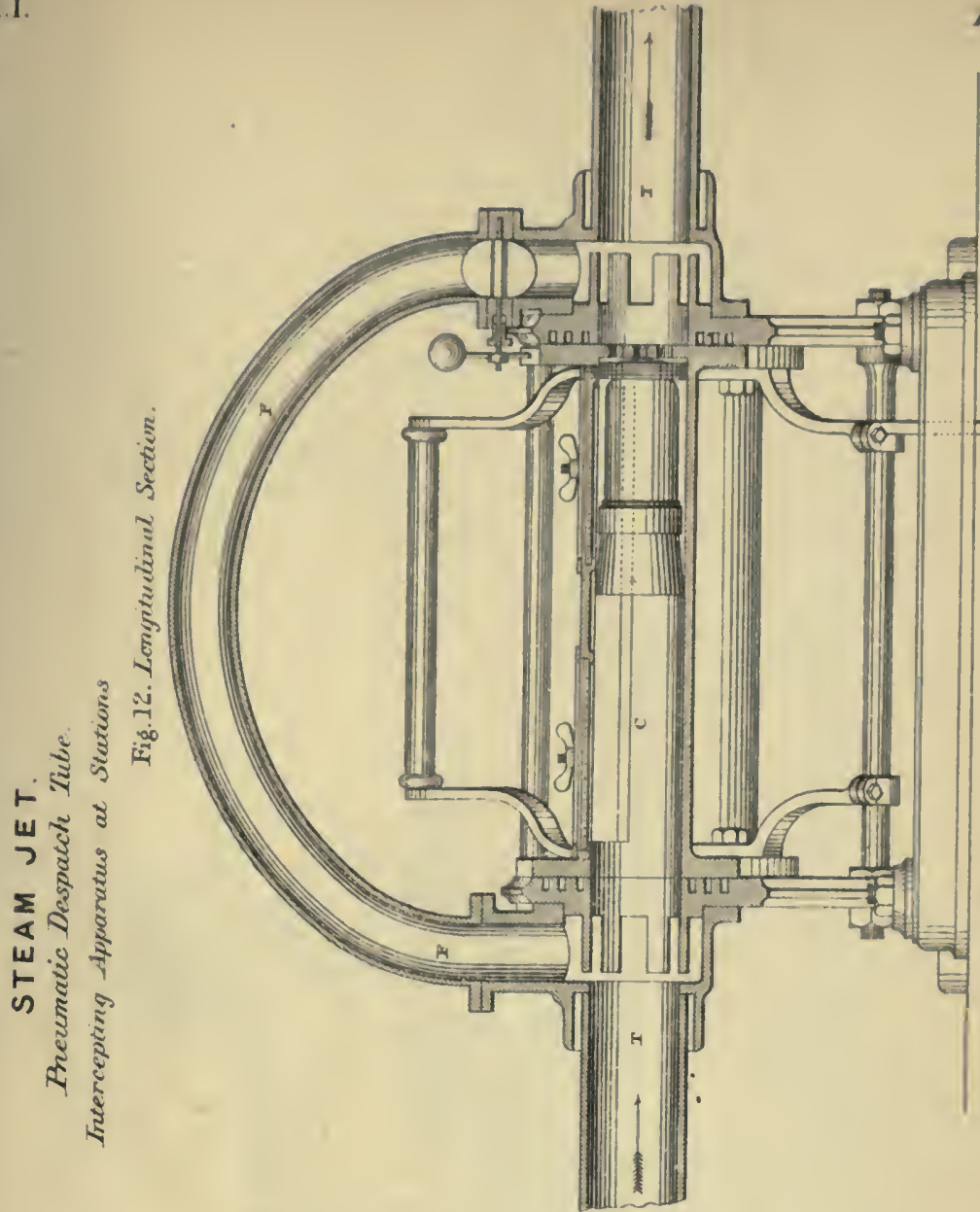

ए है 
Vol.1.

Iluse ix
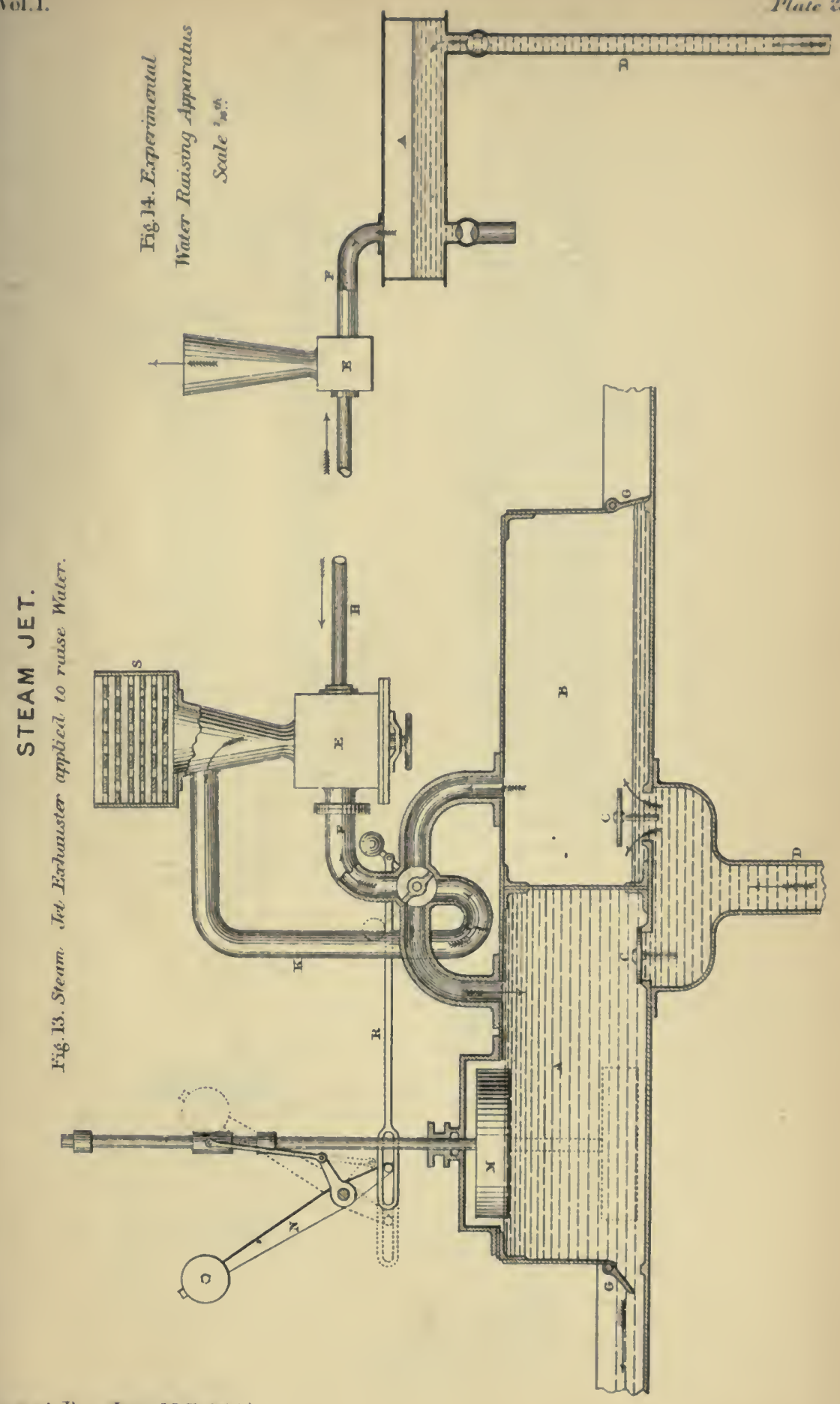


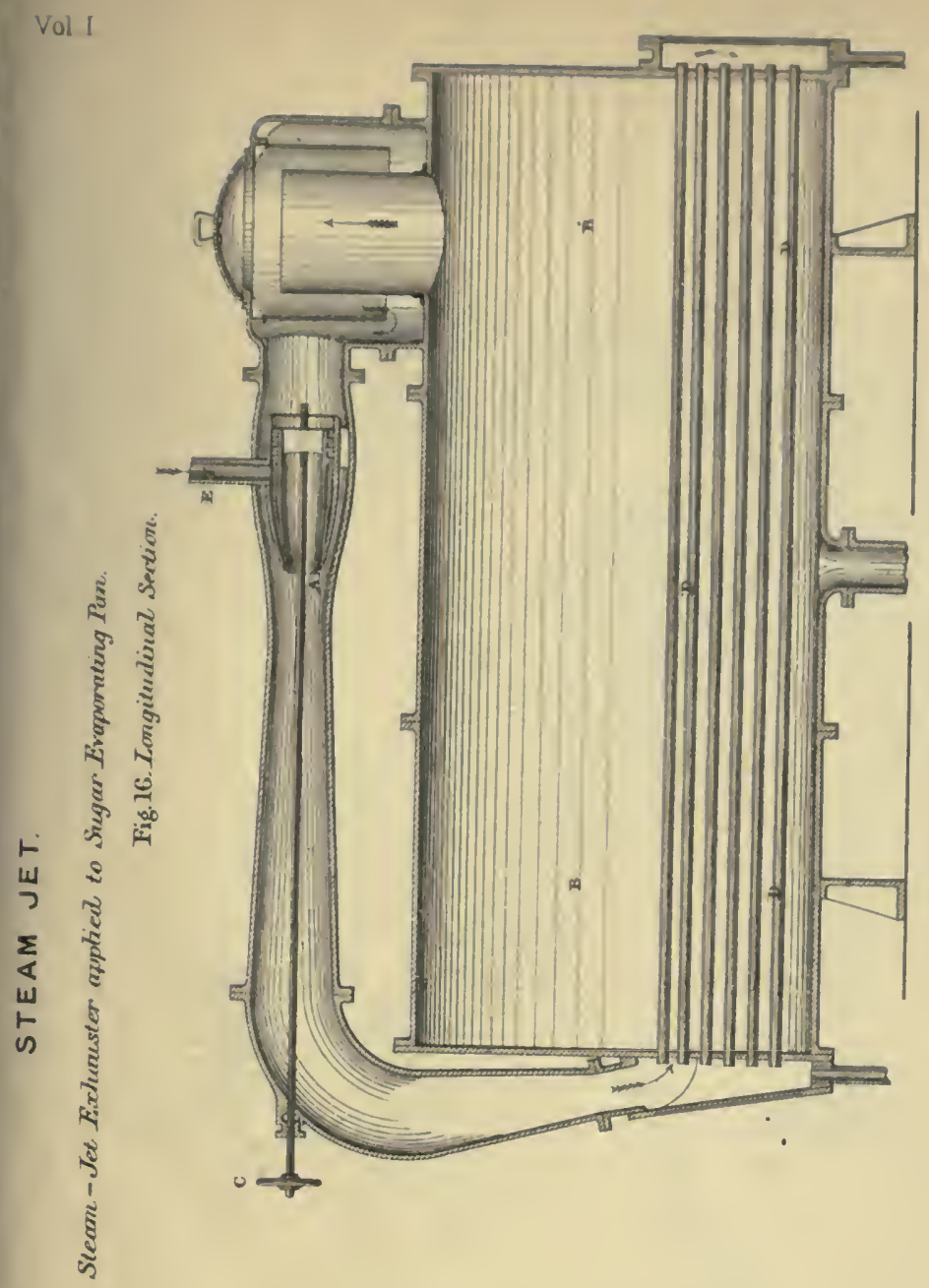

Itute ay

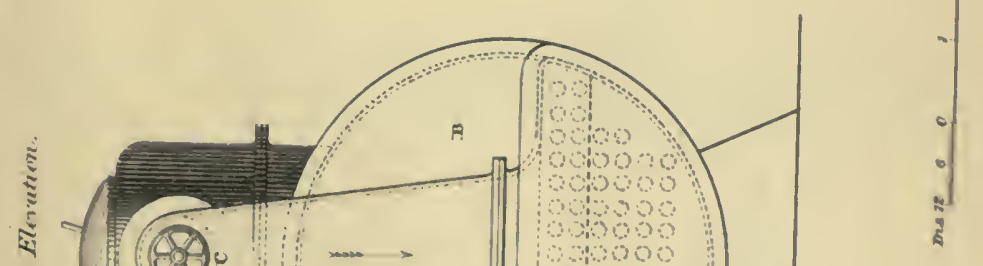


,

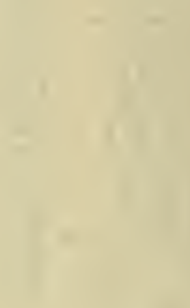


Fig. 17. Sterom . Let HIrwors

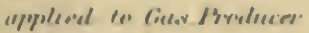
Sirule sw?
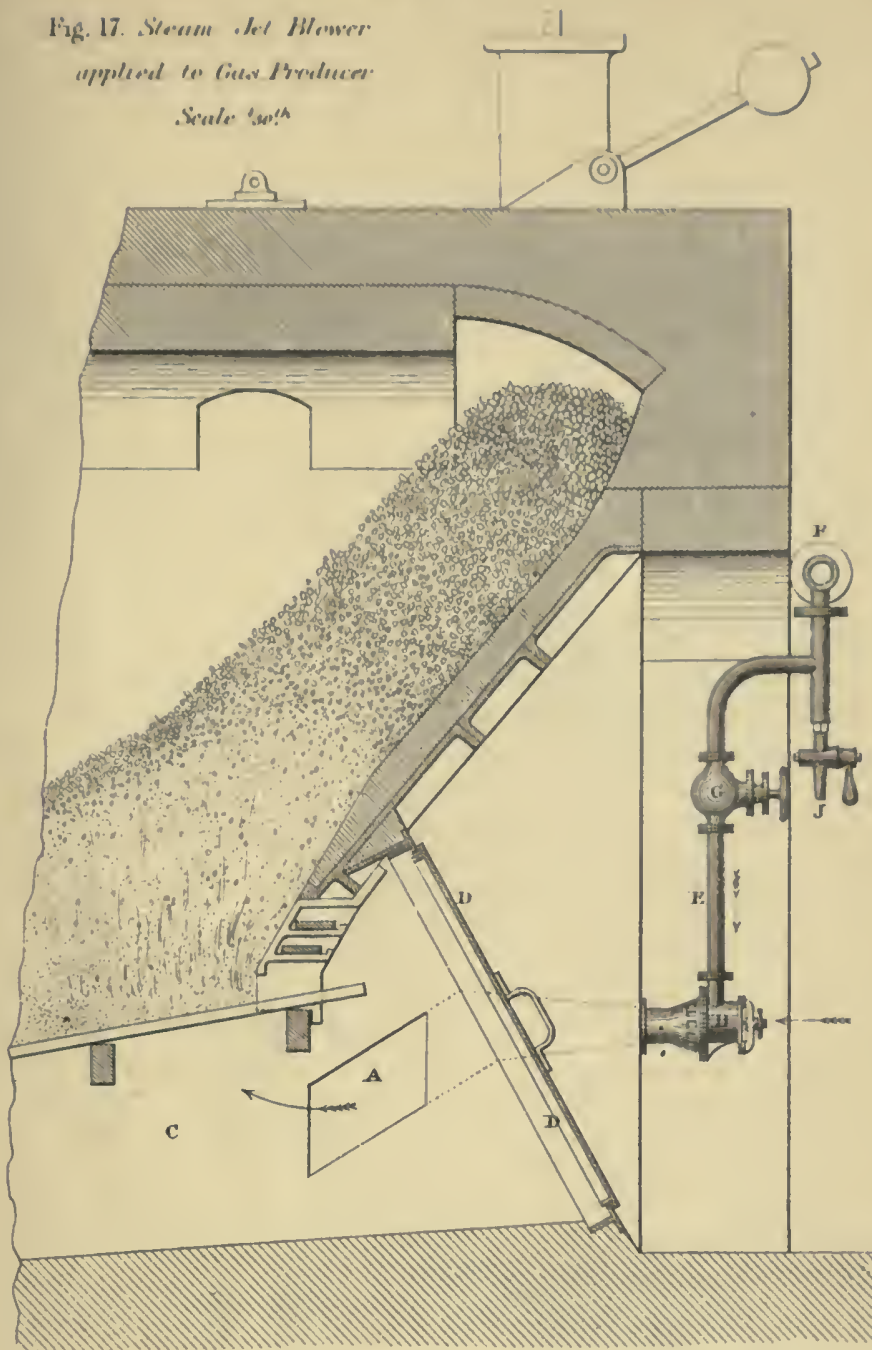

Fis 1.

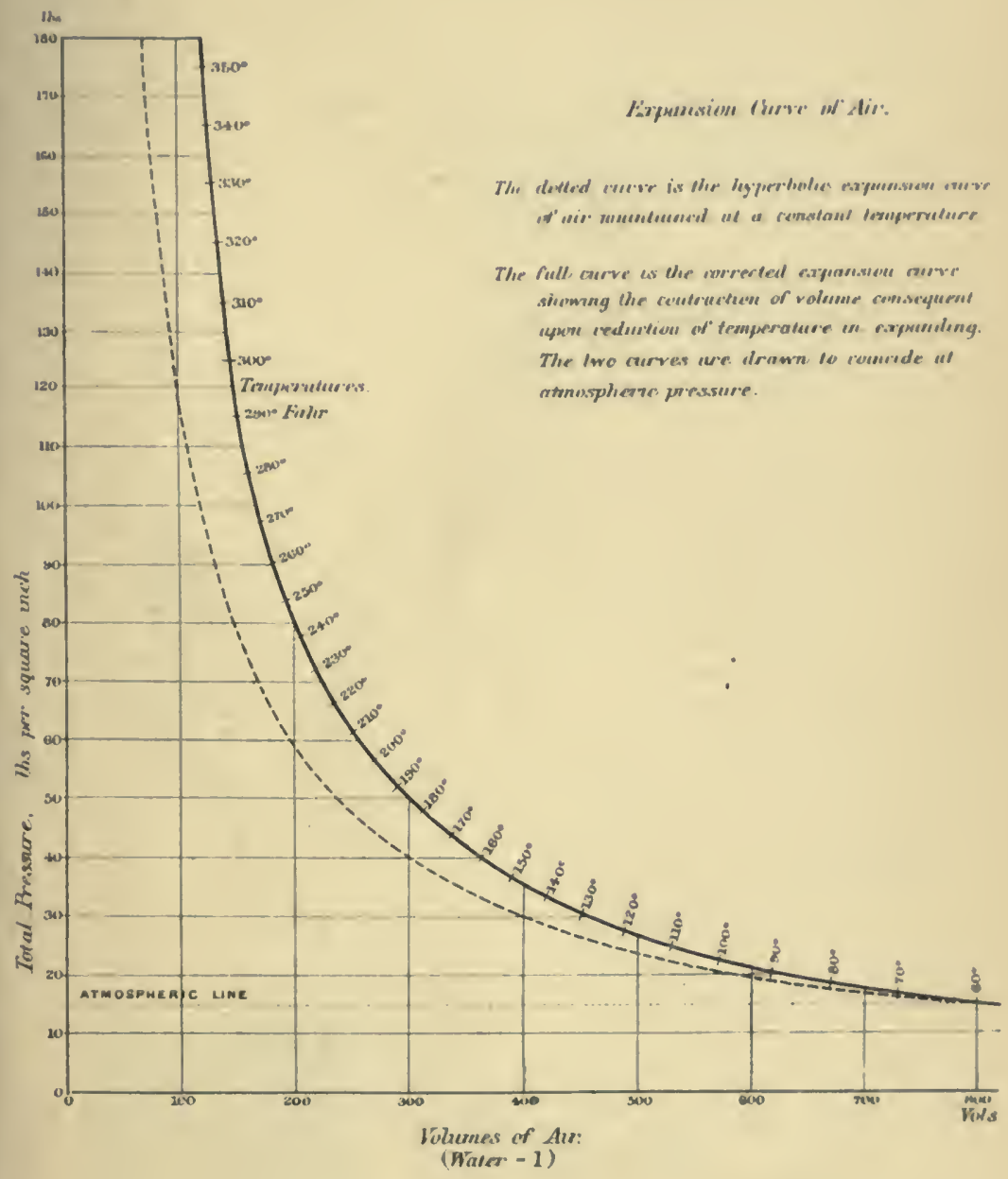




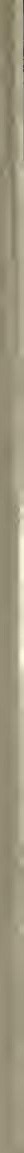




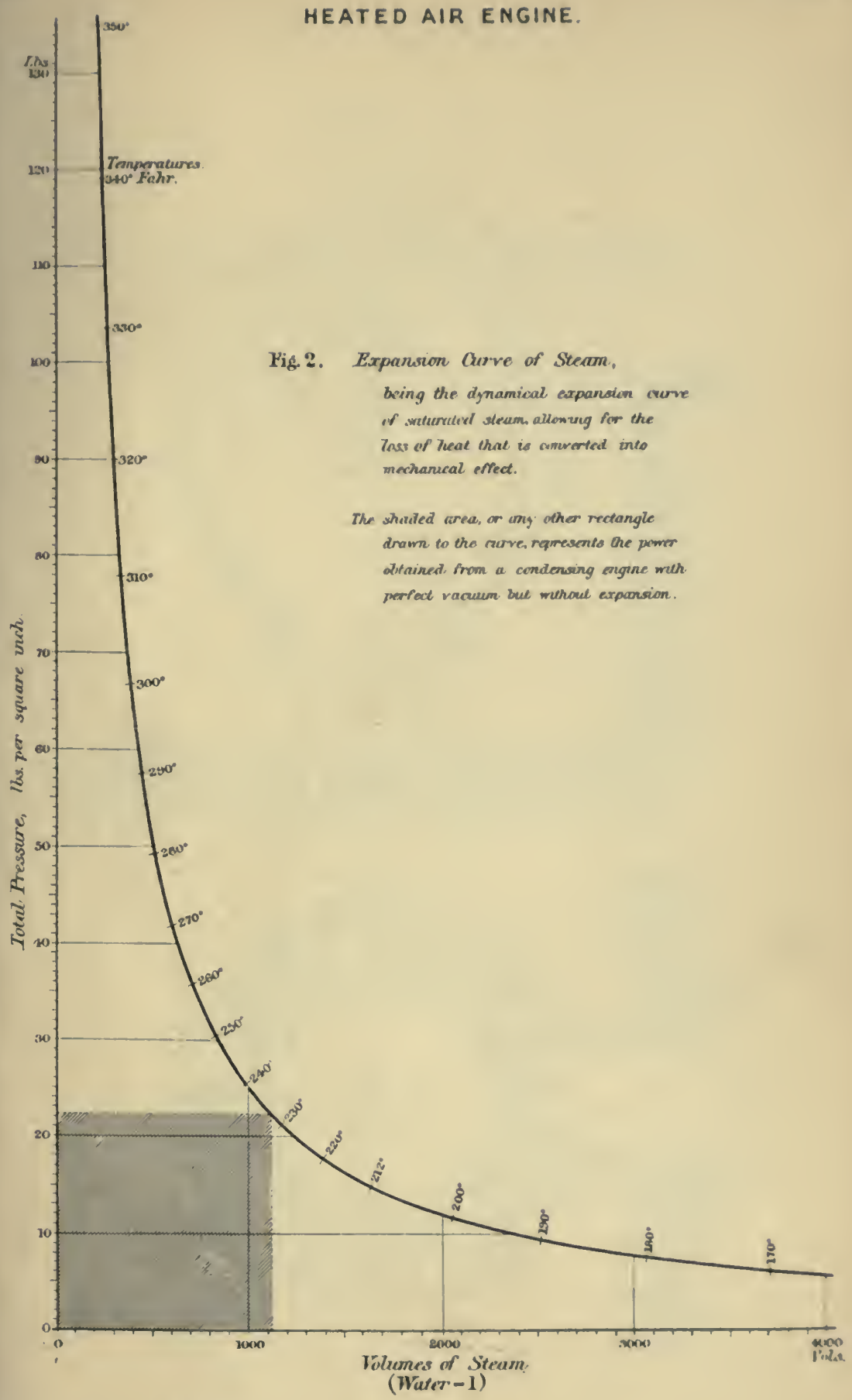

Faxcerpt. Proc. Inst. M. SE. 1873) 

CIRCULAR GAS PRODUCER.

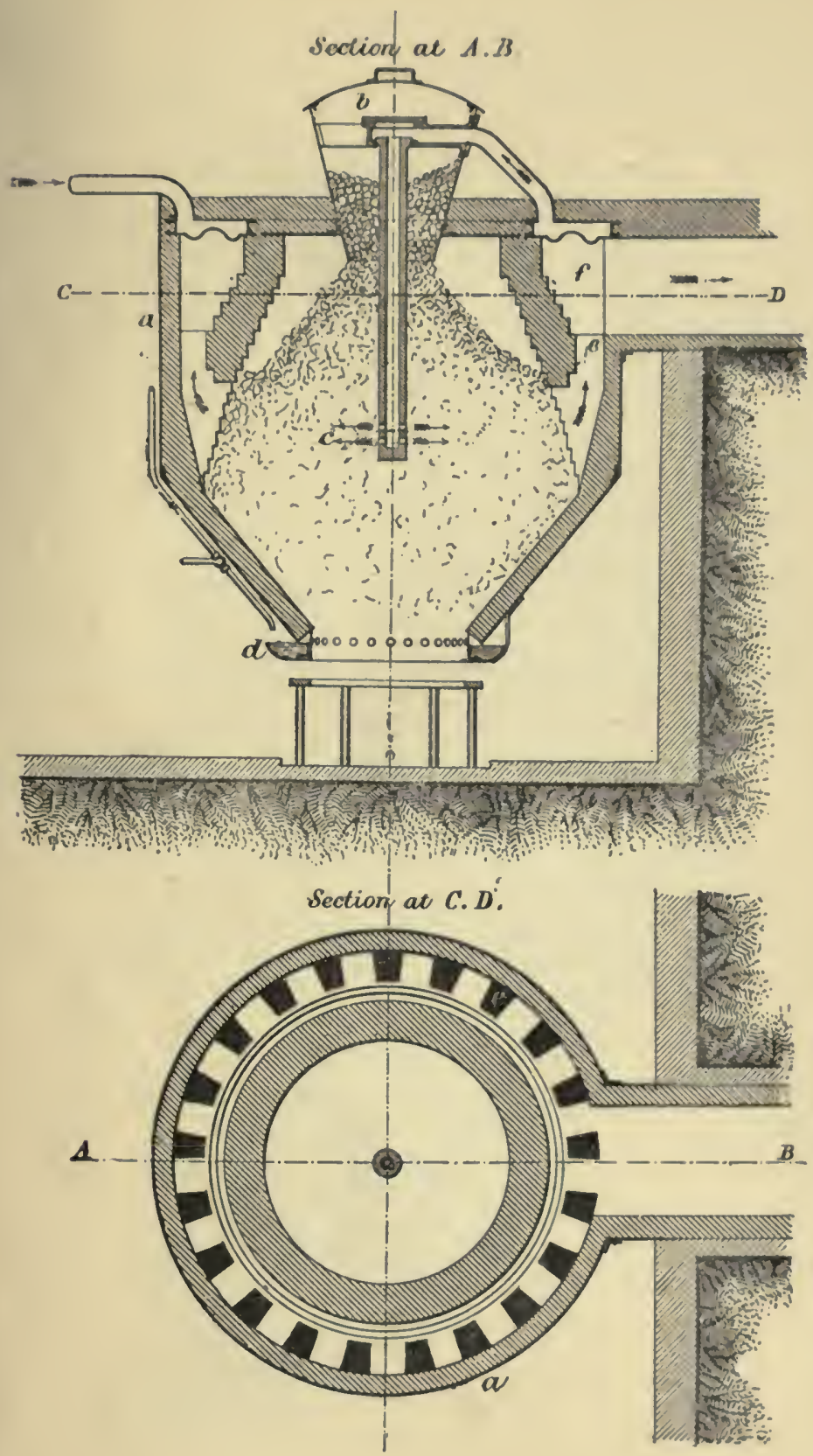

(Excerpt Jour. Soc. Chem. Indv. 1881.) 


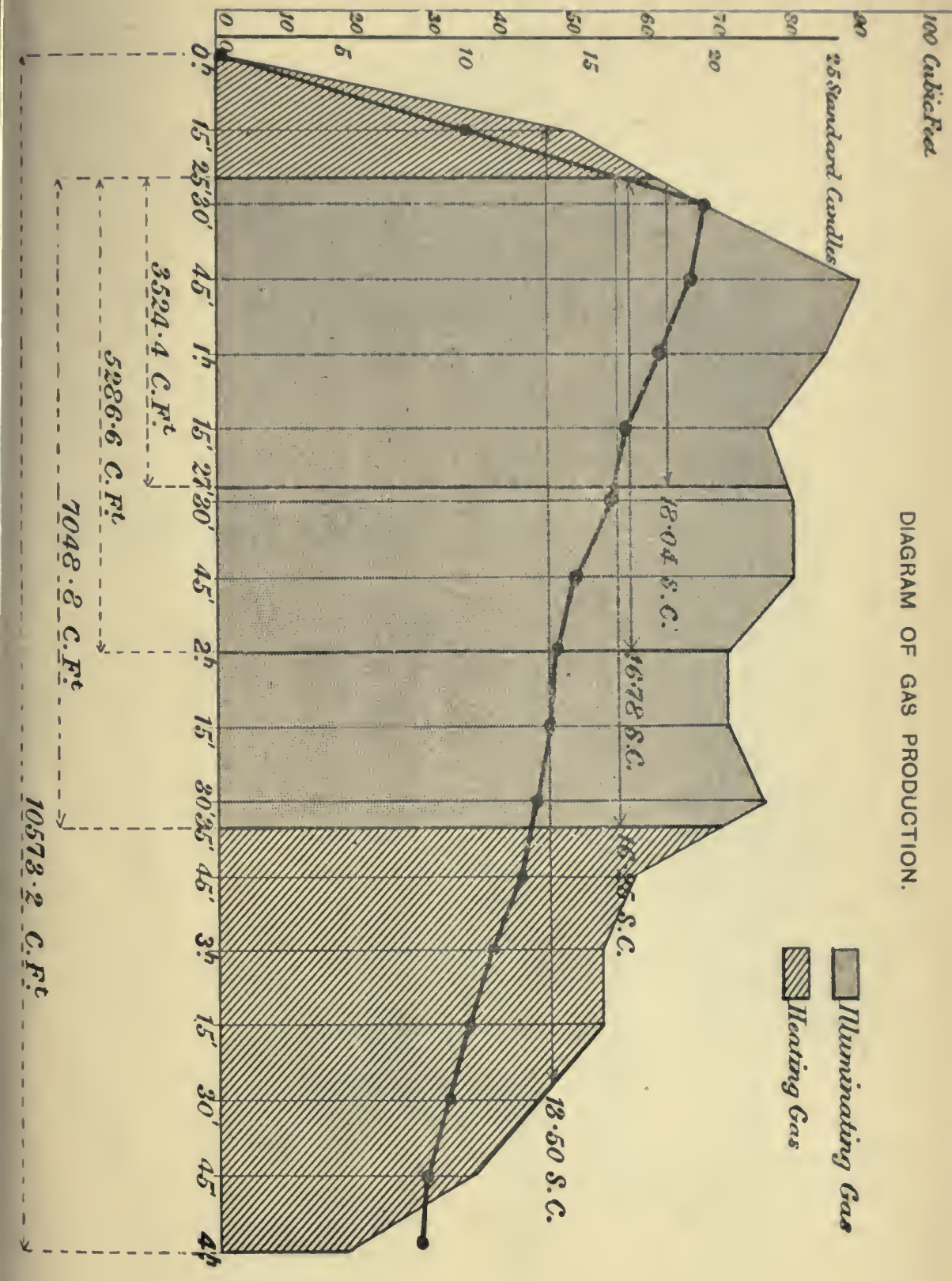

(Excerpt Jour. Soc. Chem, Inly., 1881.) 

REGENERATIVE GAS FIRE AND GAS LAMP.
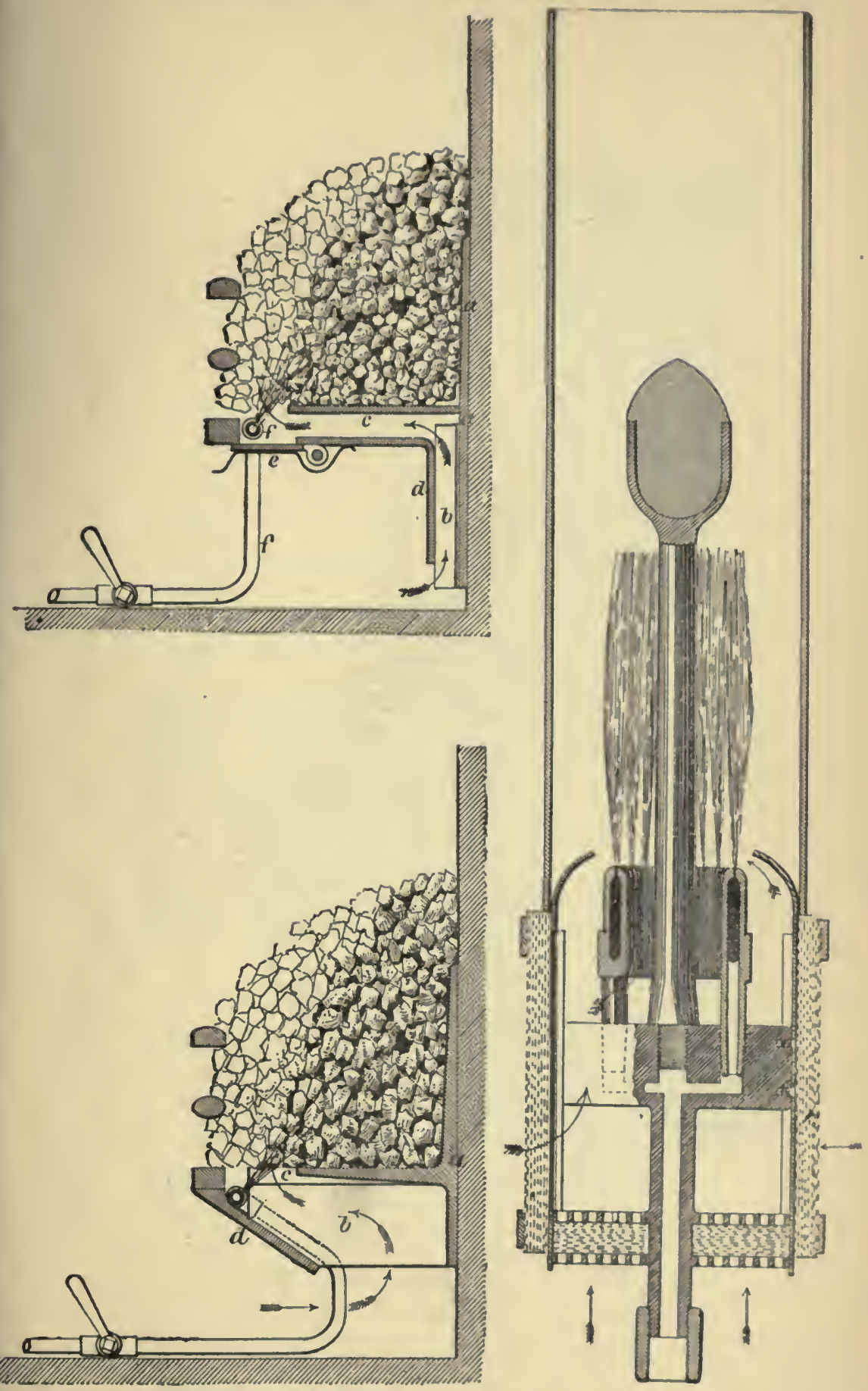

(Excerpt Jour. Soc. Cliem. Indy., 1881.) 


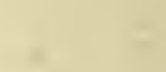




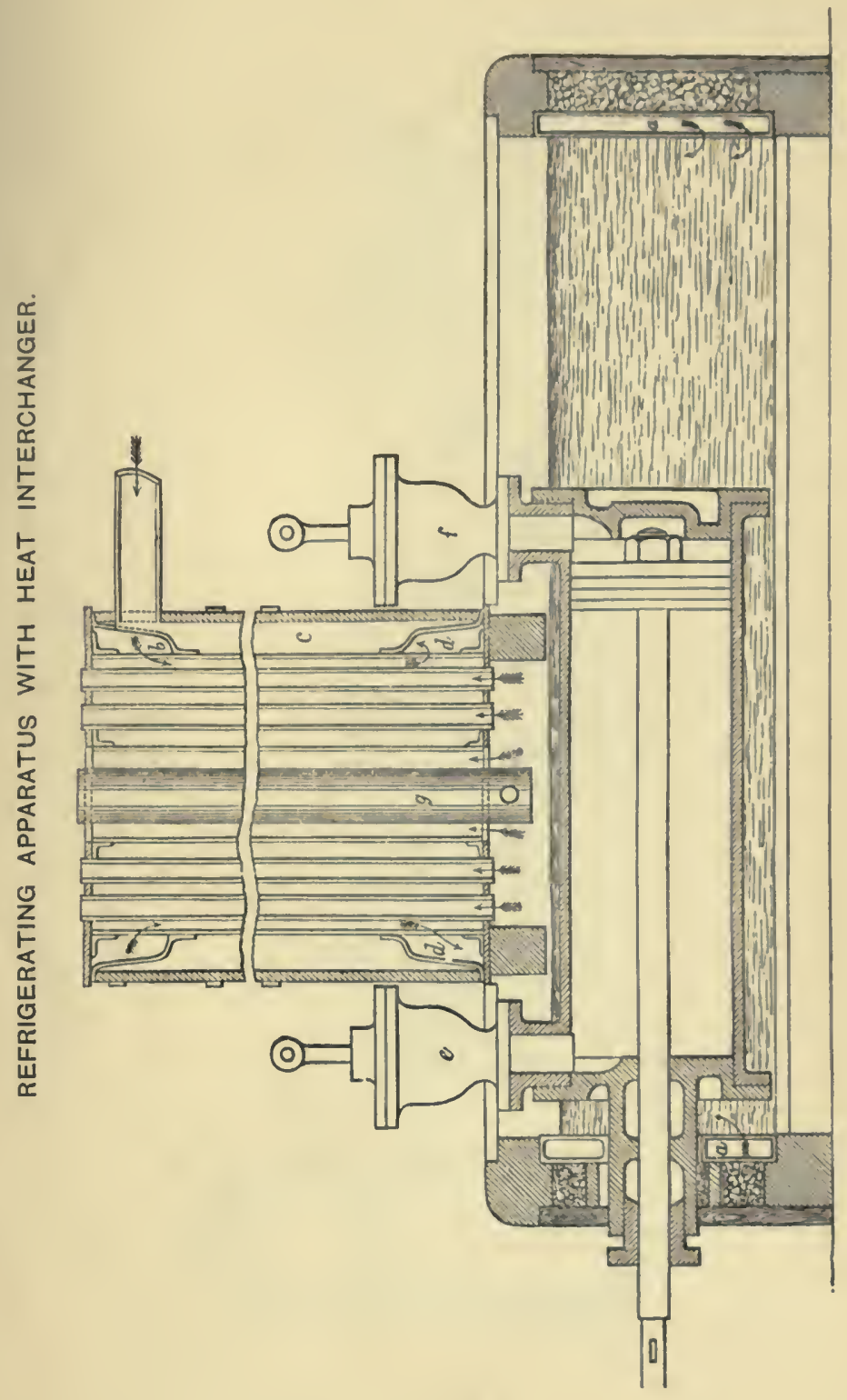

(Excerpt Pric. Inst., C.E., 1881-82. Vol. LXVIII.) 



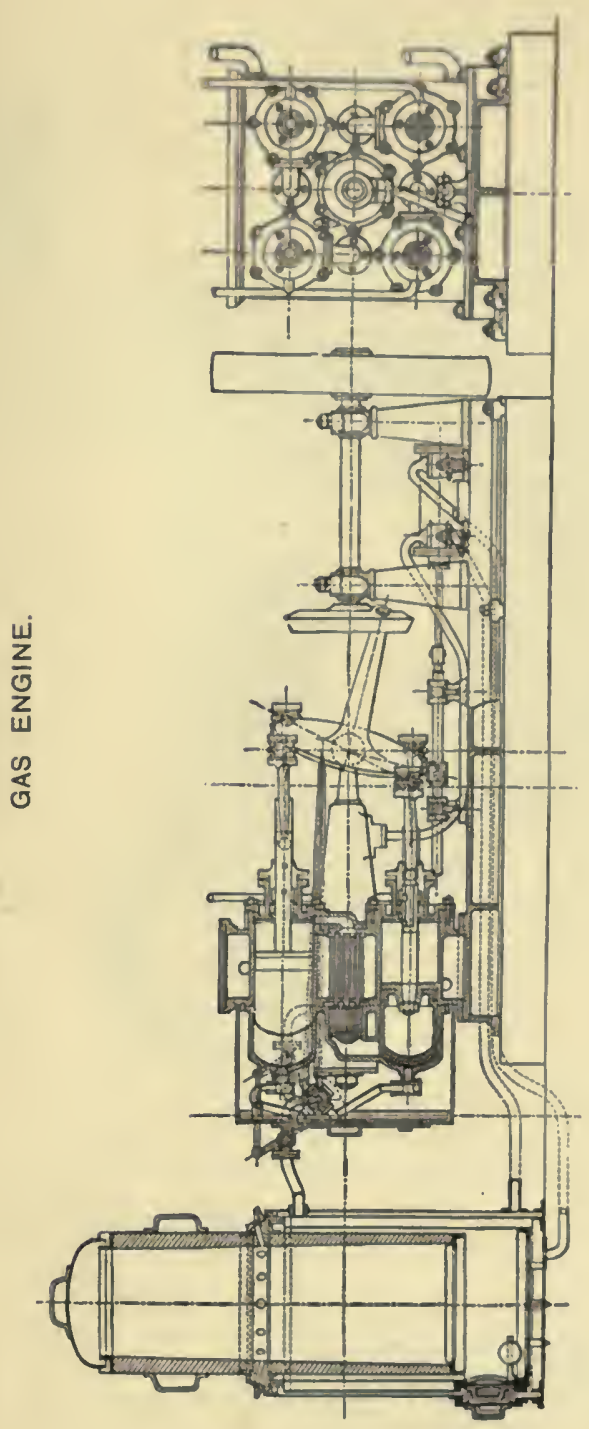


Vol. I.

Jlate 38.

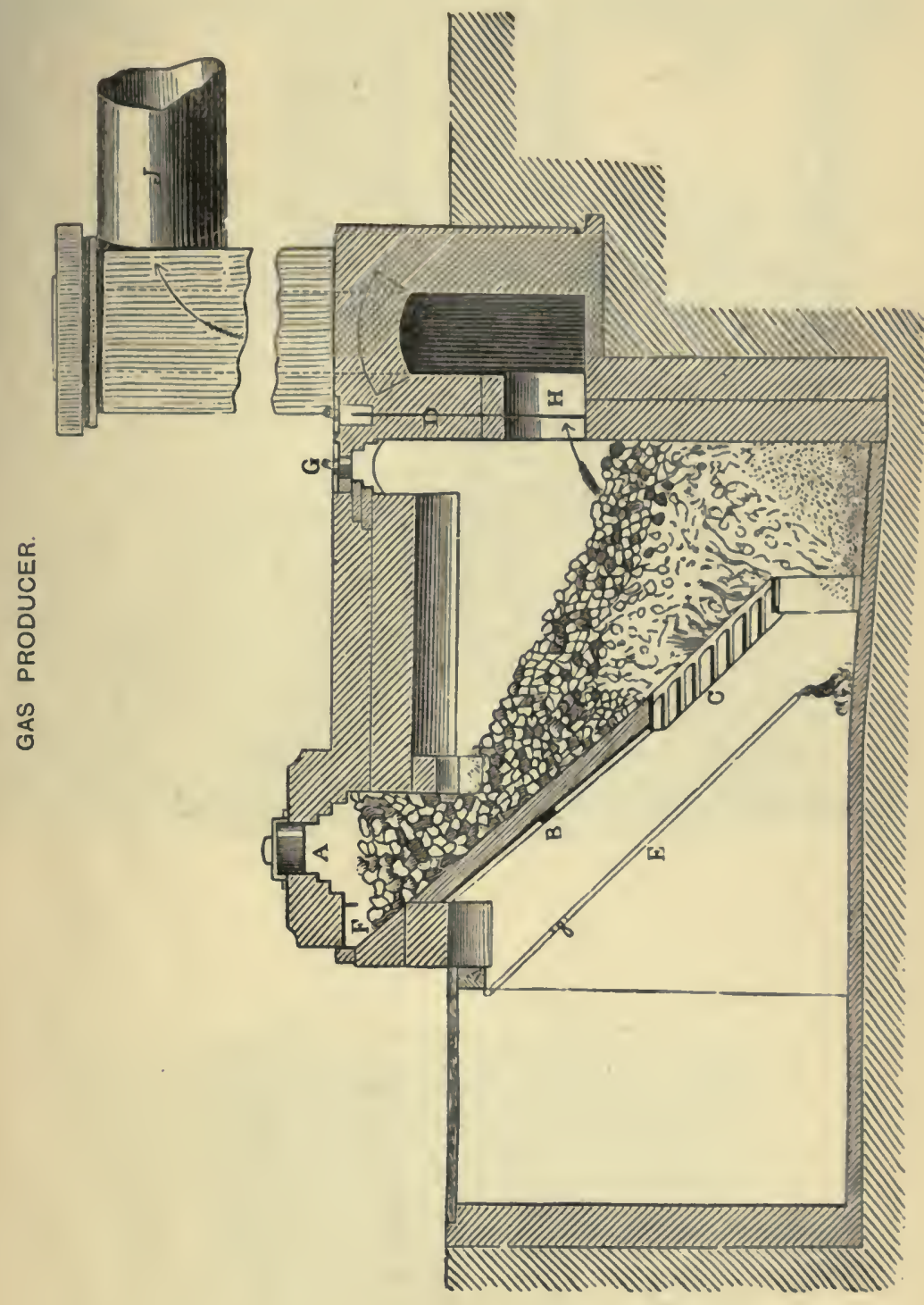

(Excerpt Jour. Chirm. Sike, 1868.) 

STEEL MELTING FURNACE.
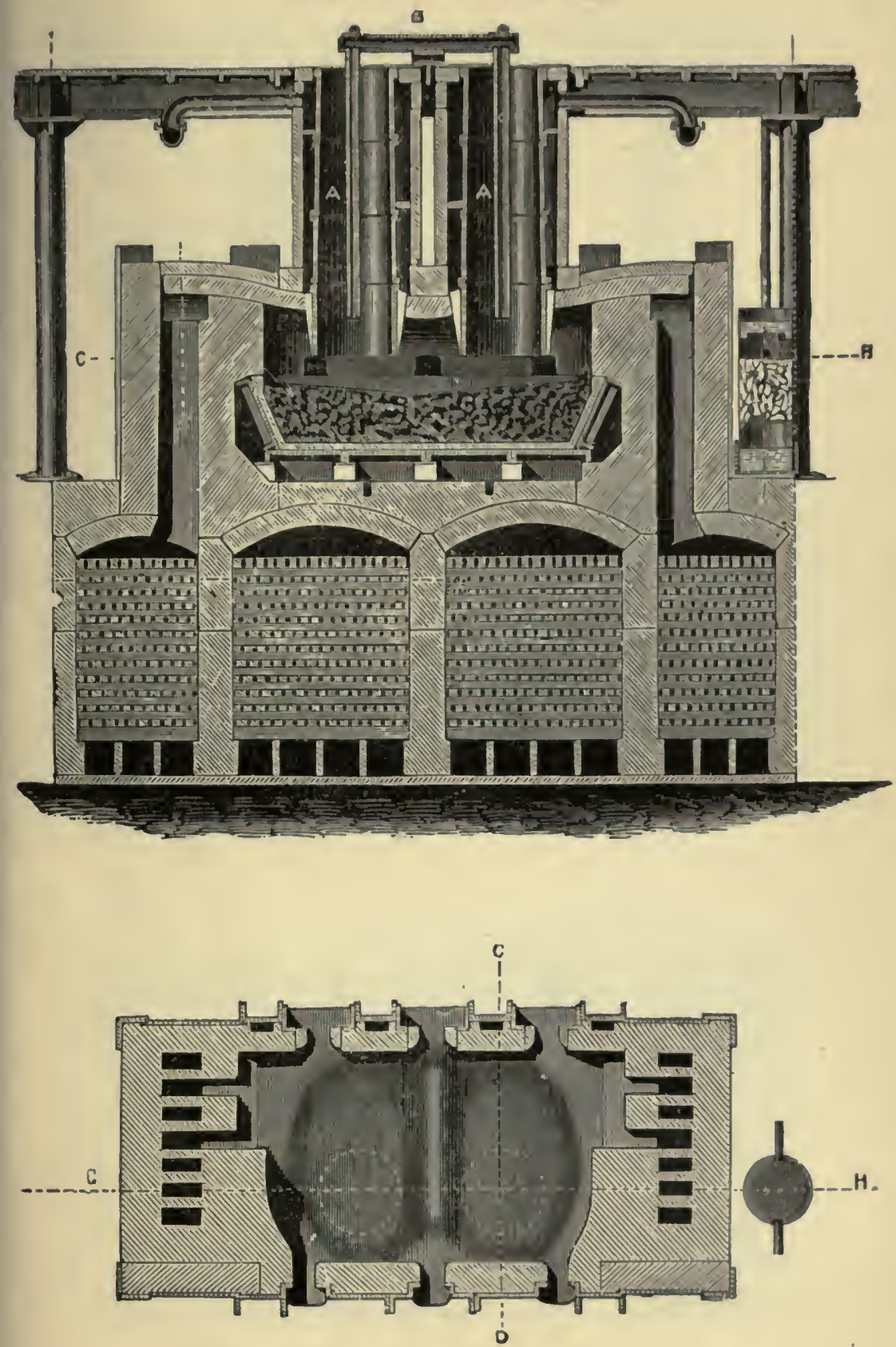

STEEL MELTING FURNACE.
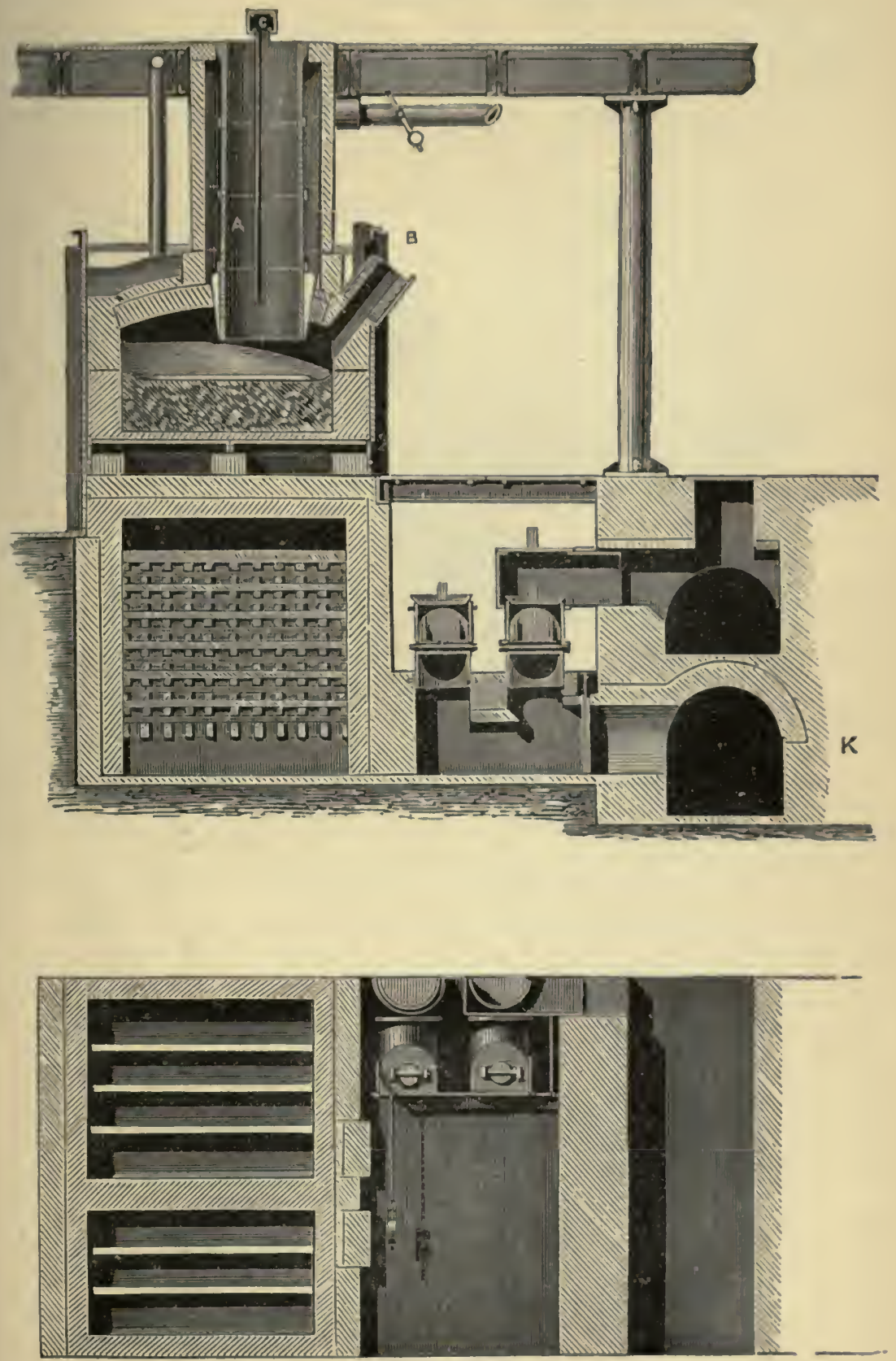


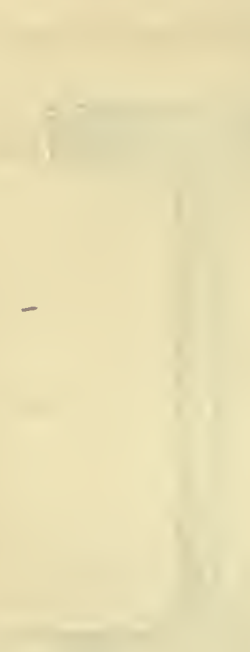


GAS PRODUCER.
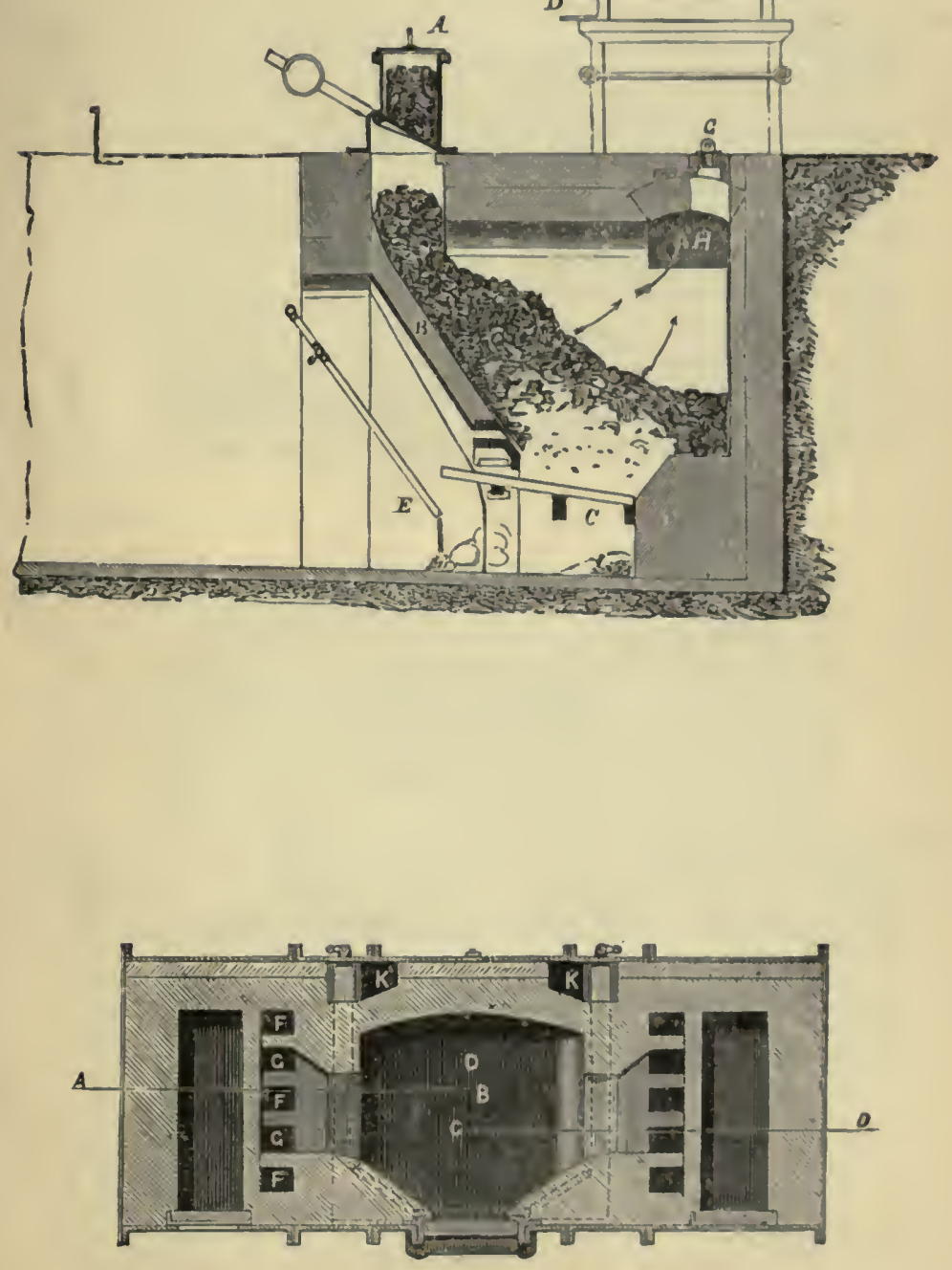


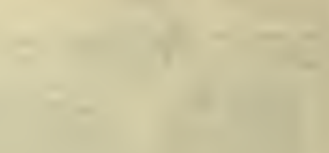


PUDDLING FURNACE.
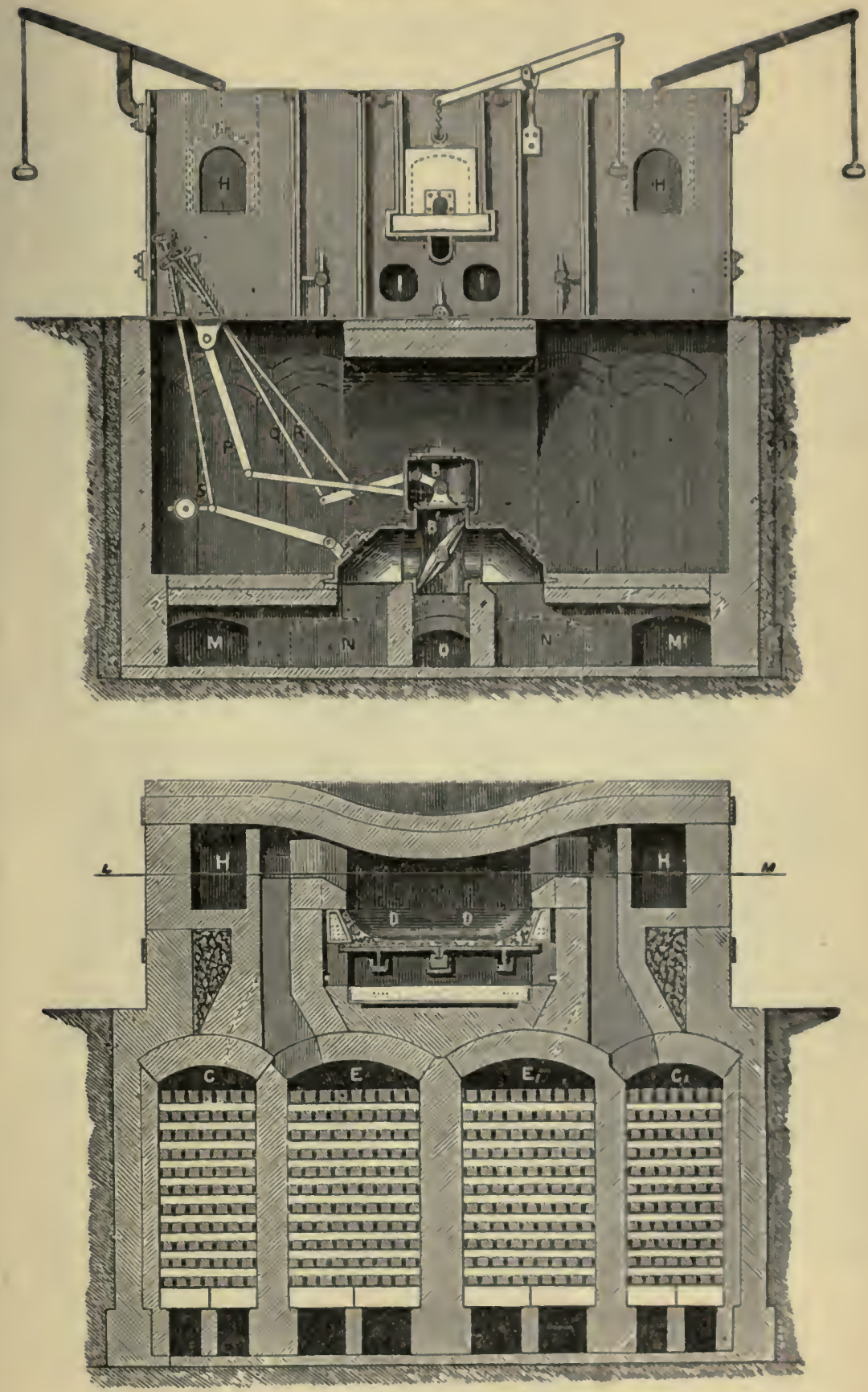

(Excerpt Jour. Brit. Assoc. 1868.) 

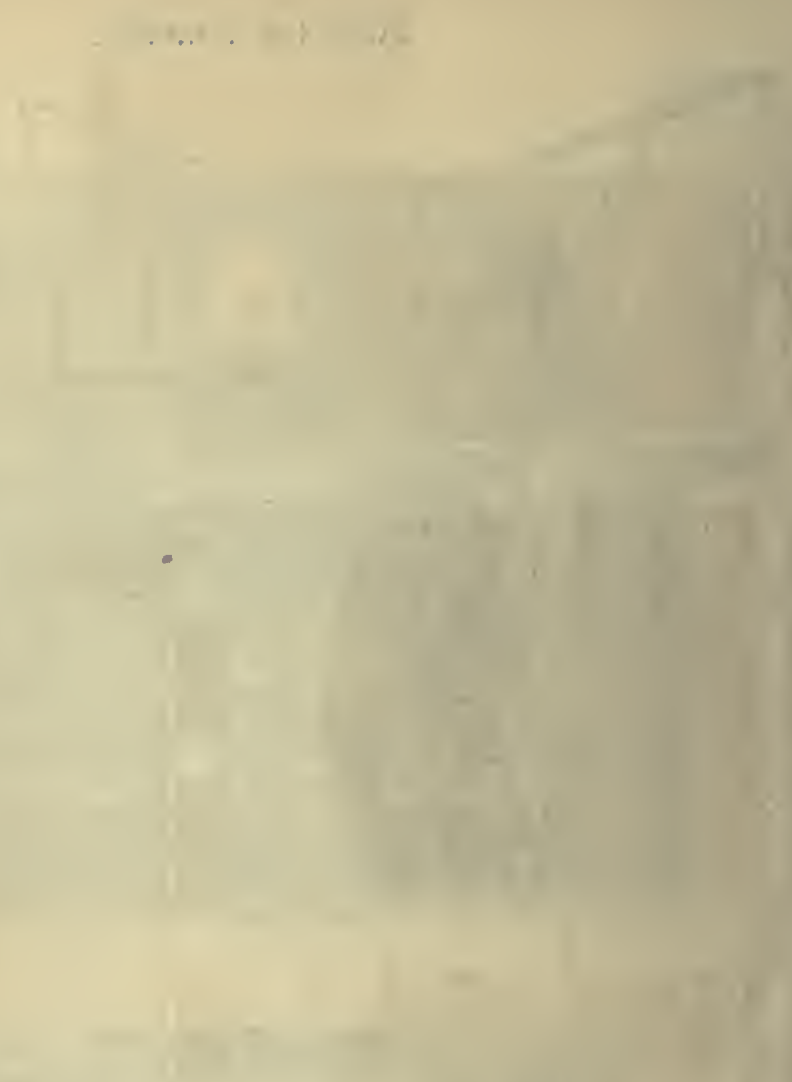

(n)
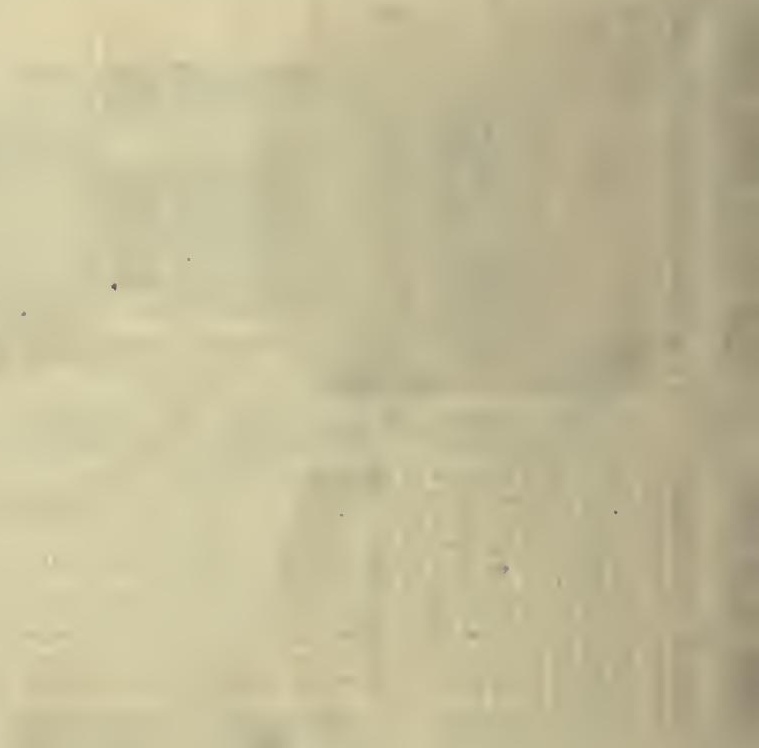

( 


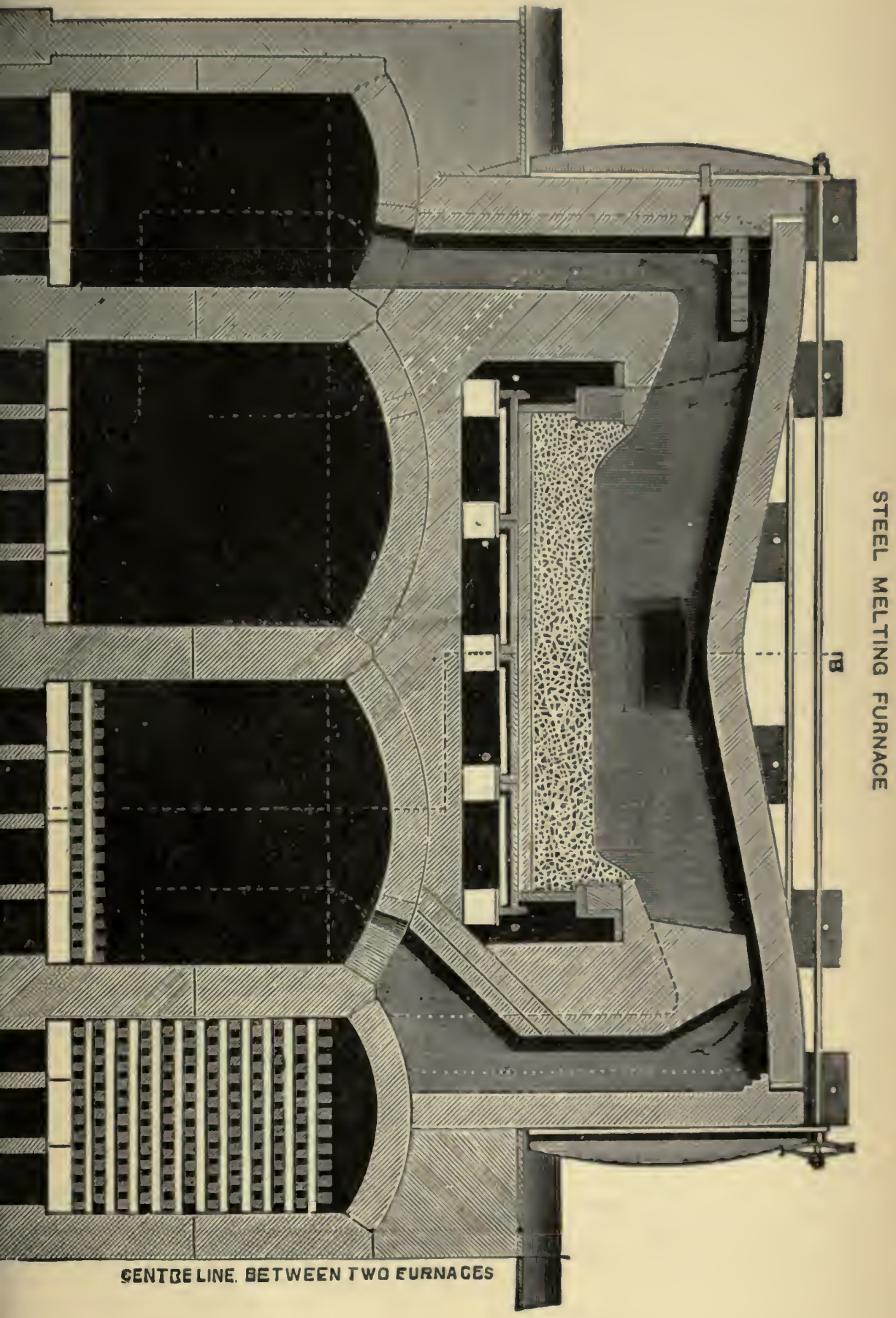





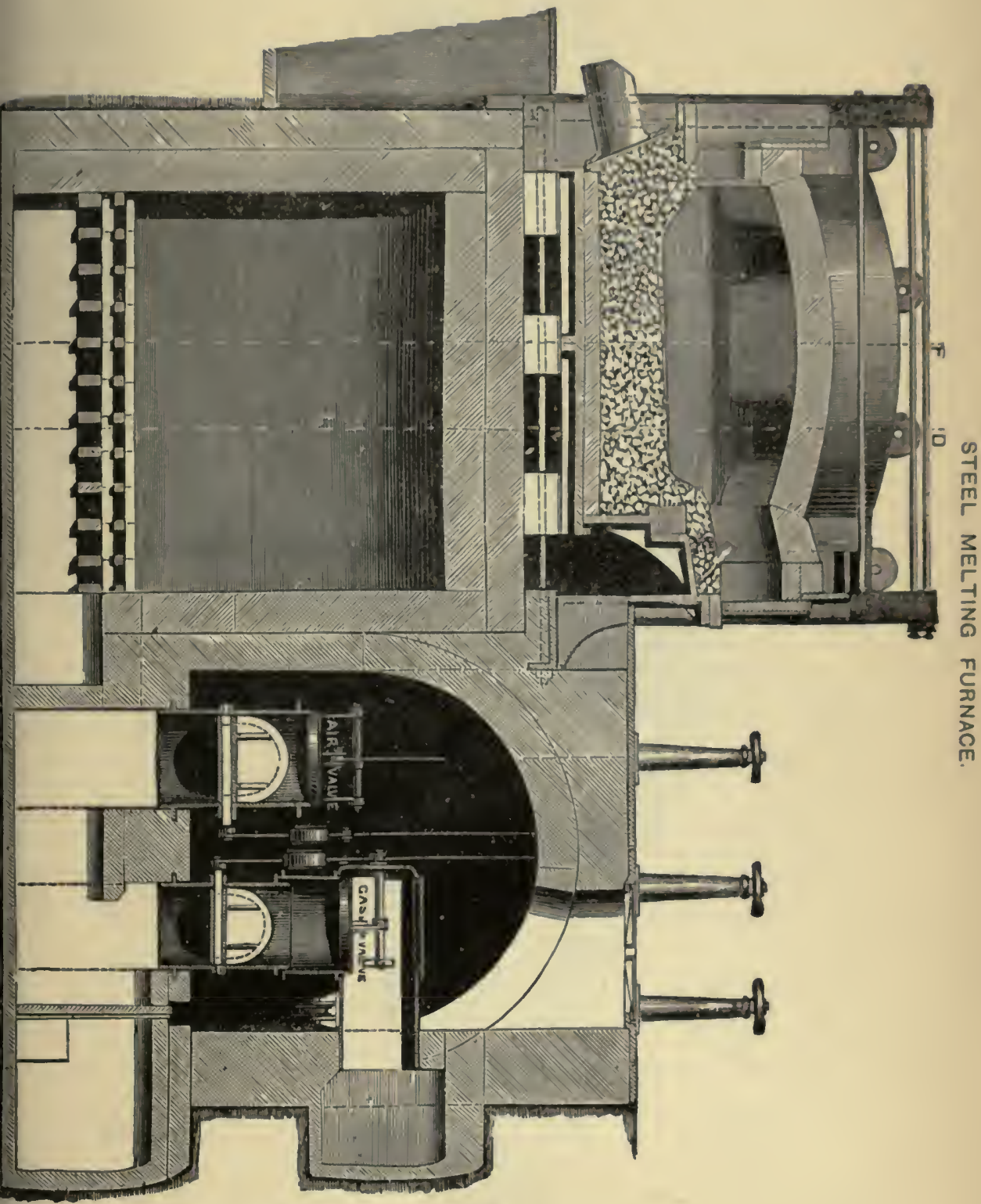

(Excerpt Jour Chem. Soc., 1873.) 

BLAST FURNACE DIAGRAM.

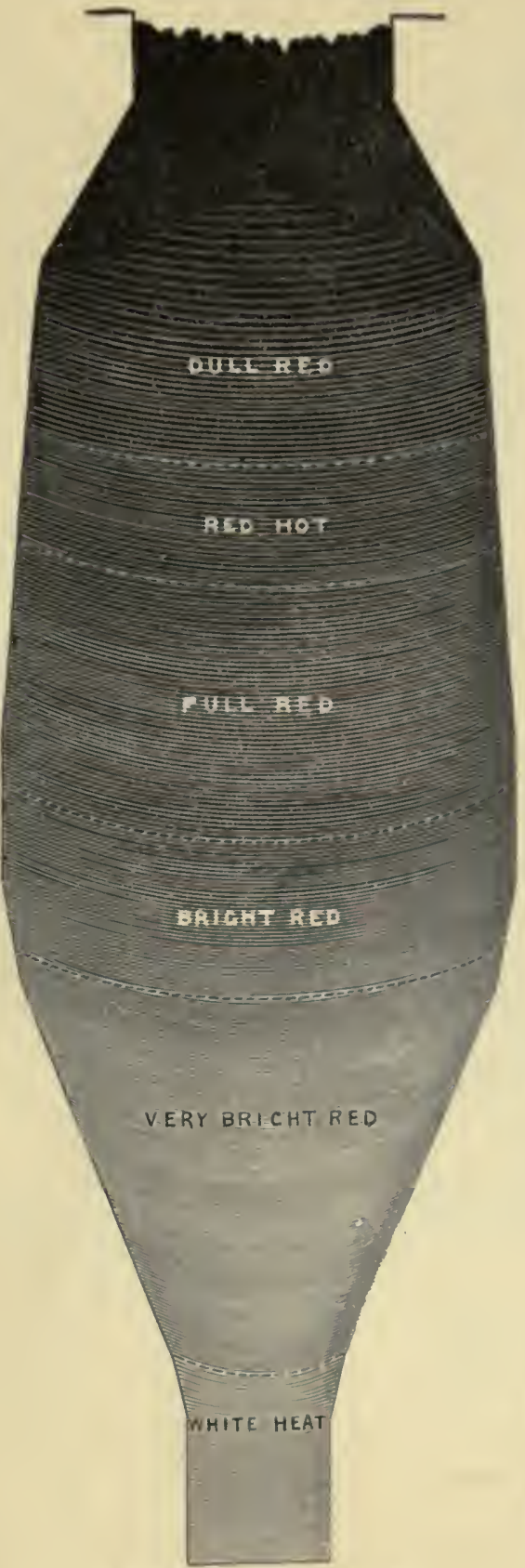

Henting.

Reduction.

Iimestonc.

Decomprosed.

Absorption.

Ditto.

Eusion.

Fluid Slag.

Fluid Pig Metal.

Ero. 2.-BLast FursacF.

Excerpt Jour. Chem. Soc., 1873.) 


Vol..1.

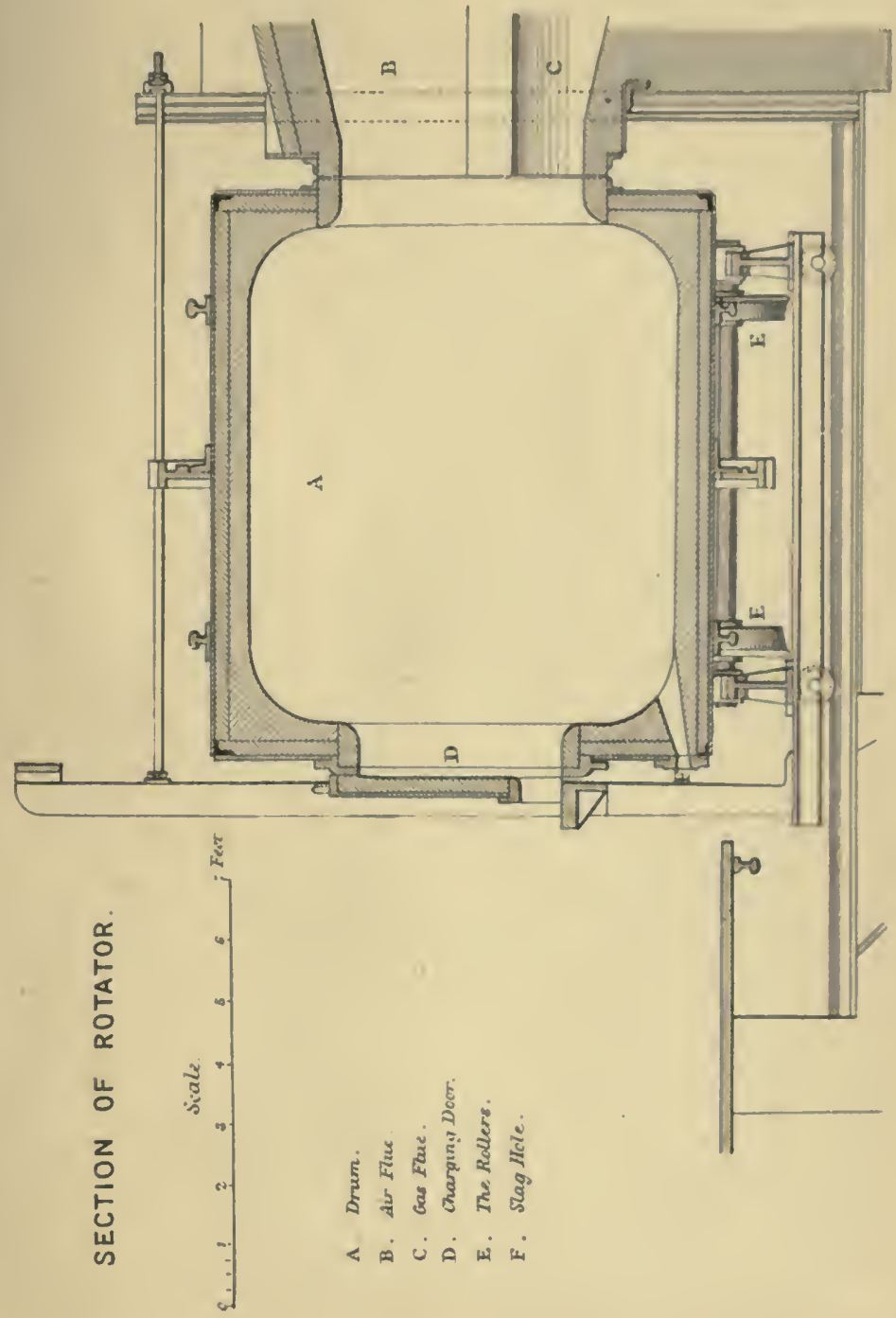






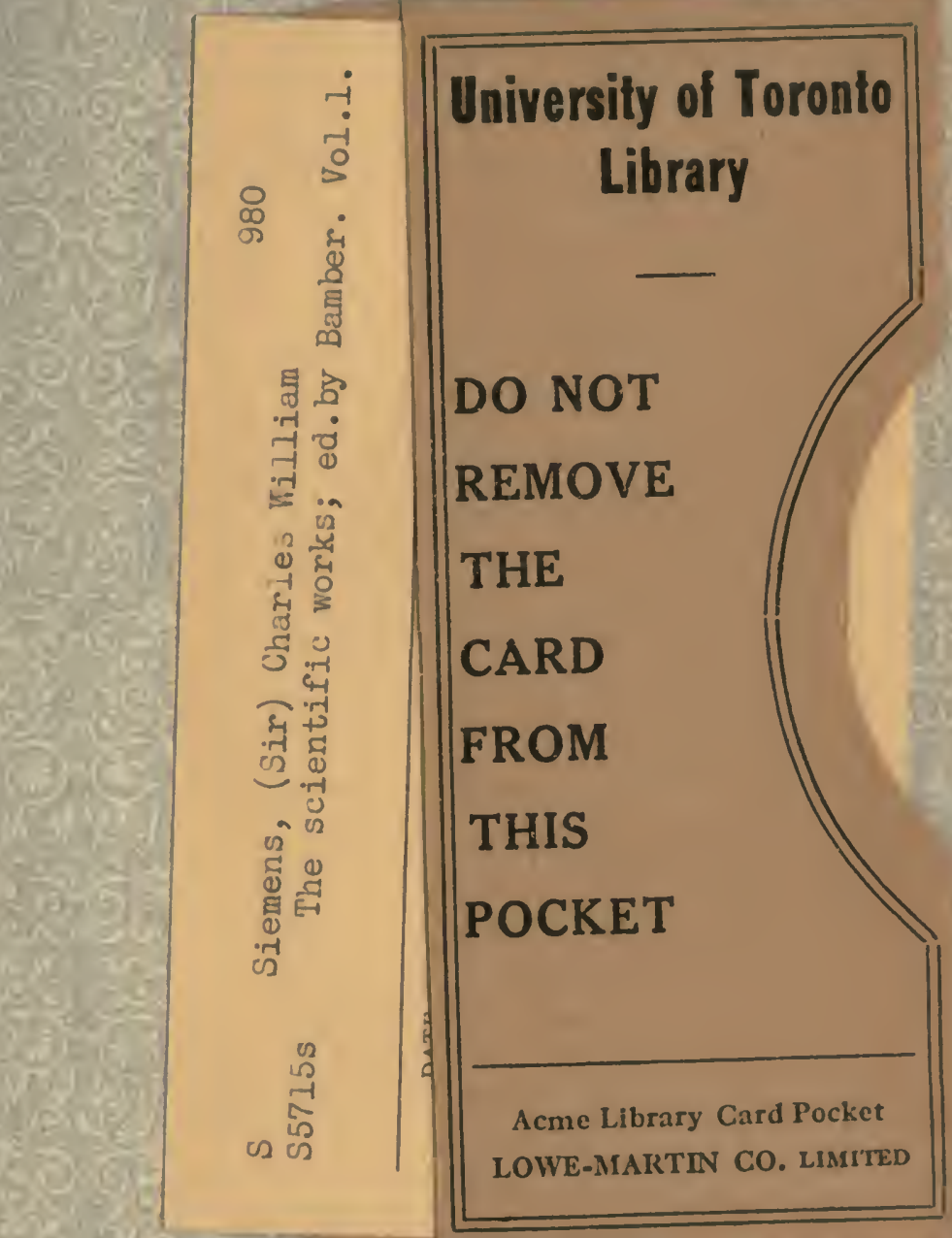


